\title{
End Use Energy Consumption Data Base: Transportation Sector
}

February 1980

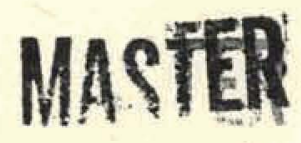

Prepared for:

U.S. Department of Energy

Energy Information Administration

Assistant Administrator for Program Development

Under Contract No. W-7405-eng-26

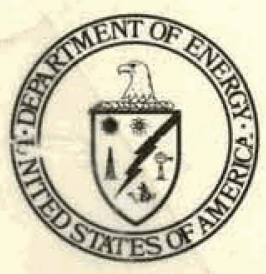




\section{DISCLAIMER}

This report was prepared as an account of work sponsored by an agency of the United States Government. Neither the United States Government nor any agency Thereof, nor any of their employees, makes any warranty, express or implied, or assumes any legal liability or responsibility for the accuracy, completeness, or usefulness of any information, apparatus, product, or process disclosed, or represents that its use would not infringe privately owned rights. Reference herein to any specific commercial product, process, or service by trade name, trademark, manufacturer, or otherwise does not necessarily constitute or imply its endorsement, recommendation, or favoring by the United States Government or any agency thereof. The views and opinions of authors expressed herein do not necessarily state or reflect those of the United States Government or any agency thereof. 


\section{DISCLAIMER}

Portions of this document may be illegible in electronic image products. Images are produced from the best available original document. 
Companion products to this study include the following magnetic tapes:

End Use Energy Consumption Data Base: Transportation Sector. Data Tape, EIA Format (DOE/EIA/CR-7405-01(MT)1)

End Use Energy Consumption Data Base: Transportation Sector. Data Tape, ORNL Format (DOE/EIA/CR-7405-07(MT)2)

End Use Energy Consumption Data Base: Transportation Sector. Retrieval Programs Tape (DOE/EIA/CR-7405-01(MT)3)

These tapes will be available for sale from:

National Technical Information Service

U.S. Department of Commerce

5285 Port Royal 1 Road

Springfield, VA 22141

$$
6.061-003-00120-3 \quad \$ 8.50
$$




\section{End Use Energy Consumption Data Base: Transportation Sector}

February 1980

Prepared by: John N. Hooker

Axel B. Rose

David L. Greene

Oak Ridge National Laboratory

Oak Ridge, Tennessee 37830

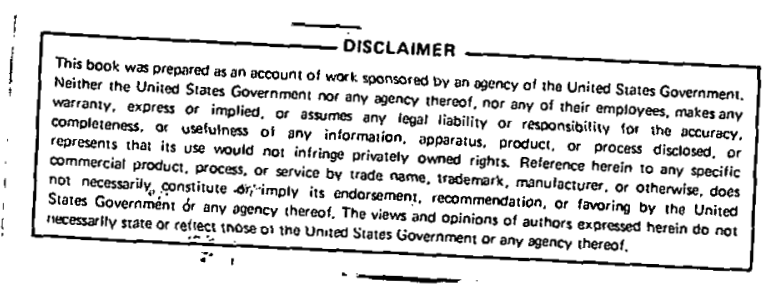

Prepared for:

U.S. Department of Energy

Energy Information Administration

Assistant Administrator for Program Development

Office of the Consumption Data System

Washington, D.C.

Under Contract No. W-7405-eng-26

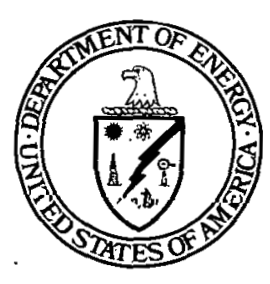


Released for Printing: June 16, 1980. 
The project described in this report forms the Transportation Sector of the End Use Energy Consumption Data Base of the Office of the Consumption Data System, organized under the Assistant Administrator for Program Development, Energy Information Administrätion.

Work documented here was performed by Oak Ridge National Laboratory (ORNL) under contract to the Department of Energy. Within the sponsoring office, the project was completed under the general supervision of Kenneth $A$. Vagts with data base management assistance from Michael J. Maloney. Overall direction was provided by Leigh Carleton, the technical project officer.

The work performed by Oak Ridge National Laboratory was a collaborative effort of several persons, most of whom during this period were members of the ORNL Data Management and Analysis Group, headed by Andrew S. Loeb1.

John Hooker devised the estimation method for the plpeline mode and, with the assistance of Ben Elliot and David T. Johnson, wrote computer programs implementing $1 t$ and the estimation methods for the highway modes and military fuel use. He wrote computer programs'for aggregating estimates and generating tables and data tapes. He also wrote the report and prepared the other materials submitted to the Department of Energy.

Axel Rose with the assistance of Ken Reed devised the estimation methods and carried out the necessary calculations for the rail and marine modes. Mr. Rose developed the estimation, methods for the air mode and assisted Sam Holmes in their implementation.

David Greene was reponsible for devising the methods of est1mating energy use in all of the highway modes: auto, bus, truck and motorcycle. He wishes to acknowledge Gwen Walton's contribution of the intercity and commuter auto estimation methods, as well as the assistance of Gretchen Kulp and Jennifer Hill.

The authors wish to acknowledge the technical services of Betsy Horwedel and Mary L. Johnson and the secretarlal services of Carolyn P. Boggess and Stephanie B. Davison.

The retrieval system used in the course of this project was written by Niket Patwardhan and Danny Johnson, under the direction of Derrell Foster at Vanderbilt University.

Questions, suggestions or criticisms concerning this report or the results of this project may be addressed to:

John Hooker

Transportation Energy Group

Oak Ridge National Laboratory, Ma11 Stop G-22

P.0. Box X, Oak Ridge, Tennessee 37830

(615) 574-5967; FTS 624-5967 
TABLE OF CONTENTS

$\underline{\text { Page }}$

Foreword . . . . . . . . . . . . . . . . . . . . . . . . i

List of Tables . . . . . . . . . . . . . . . . . . . vi v

Chapter I. Introduction . . . . . . . . . . . . . . . . . 1-1

1.1 How to Use this Report . . . . . . . . . . . . . . 1-2

1.2 What Is End Use Energy Consumption?........... . 1-4

1.3 What Is Transportation Energy? . . . . . . . . . . 1-7

References . . . . . . . . . . . . . . . . 1-10

Chapter 2, Types of Data Provided . . . . . . . . . . . 2-1

2.1 Fuel and Energy Consumption . . . . . . . . . . 2-2

2.2 Data Qua1ity Numbers ............... 2-4

Chapter 3. The Classification of Energy Use . . . . . . . . . 3-1

3.1 The Breakdown by Year . . . . . . . . . . . . . 3-4

3.2 The Breakdown by Mode of Transport . . . . . . . . 3-4

3.3 The Breakdown by Sector . . . . . . . . . . . . . 3-5

3.4 The Breakdown by Use . . . . . . . . . . . . . . 3-6

3.5 The Breakdown by Range .. . . . . . . . . . . . 3-7

3.6 The Breakdown by Carrier . . . . . . . . . . . . 3-8

3.7 The Breakdown by Region and State . . . . . . . . . . 3-8

3.8 The Breakdown by Income . . . . . . . . . . . . . . 3-8

3.9 Aggregate Data . . . . . . . . . . . . . . . . 3-9

3.10 Retrieval of Data by Category. . . . . . . . . 3-10

Chapter 4. Tables of Transport Energy Consumption... . . . . 4-1

See the List of Tables:

Chapter 5. Methods of Estimation ............... 5-1

Method 100. Air . . . . . . . . . . . . . . . 5-5

101. Certificated air carrier fuel use, 1970-77, by fue 1 by range by use by aircraft type by state . . 5-8

102. U.S. supplemental air carrier jet fuel use, by range, 1974-77................ 5-13

103. Foreign flag air carrier jet fuel use, 1973-77, by state....... .. ......... . 5-14

104. General aviation use of aviation gasoline, 1974-77, by fuel by stato........... 5-15

105. Aggregations ................ . 5-17 
Input Data Files . . . . . . . . . . . . . . 5-18

Data Quality Numbers .. . . . . . . . . . 5-20

References ................ . . 5-21

Method 200. Rail . . . . . . . . . . . . . . 5-22

201. Rail transit electricity use, by weight (light/

heavy) by state, 1968-77 ............ 5-23

202. Commuter rail fuel use, by fuel by state, 1967-78 . 5-25

203. Intercity passenger rail fuel use, by fuel by

state, 1967-78 ................. 5-27

204. Freight rail fuel use, by fuel by state, 1968-77. 5-29

Input Data Files . . . . . . . . . . . . . 5-30

Lata Uuality Numbers .. . . . . . . . . . . . 5-31

Refercnces ................ . 5-32

Method 310. Auto ................ . . 5-33

311. Commercial sector gasoline use (excluding

taxicabs) 1967-76, by state .......... . 5-34

312. Taxicab gasoline use, 1967-76, by state... . . 5-36

313. Federal government civilian gasoline use, by state, 1967-76 ................ 5-37

314. Household and state and local government gasoline use, 1967-76, by state .. . . . . . . . . 5-38

315. Intercity household gasoline use, by use by income (1972\& $\& 6)$, by income by region (1972 \& 76), and by use by state $(1972-76)$. . . . . . 5-40

316. Gasoline used for commuting to work, 1975, by state................. . 544

Inipul Dala Flles . . . . . . . . . . . . . . . 5-47

Data Quality Numhers . . . . . . . . . . . . . 5-53

References ..... . . . . . . . . . . 5-55

Method 320. Bus .. . . ... . . . . . . . . . 5-57

321. School bus gasoline use, by state, 1967-76 . . . 5-58

322. Federal civilian buo gasolinc use, hy state, 1967-76 . . . . . . . . . . . . . . . 5-60

323. Ttallsll bus luel use, narionally $196 /-/ 6$, diesel fuel use by state for 1976 . . . . . . . . 5-61

324. Intercity common carriers fuel use, 1967-76, by trip purpose by income clas., $1.967,72,76$. . . 5-63

325. Private carrier fuel use (no data) . . . . . 5-66

Input Data Files . . . . . . . . . . . . . 5-66

Data Quality Numbers . . . . . . . . . . . 5-70

References ... . . . . . . . . . . . 5-71

Method 330. Truck . . . . . . . . . . . . . . . 5-72

1. Household commercial sectors, Methods 331-35 . . 5-74

331. Household and-commercial truck fuel use nationwide, by sector by fuel by weight by body type by range of operation, 1967-76...... . 5-76 
332. Local household and commercial truck fuel use, by sector by fuel by state, 1967-72 . . . . . . . 5-79

333. Intercity household and commercial truck diesel fuel use, by state, 1967-76... : . . . . . 5-79

334. Intercity household and commercial truck gasoline use, by state by sector by weight class, 1967-76 . . . . . . . . . . . . . . 5-81

335. Intercity household and commercial truck fuel use nationwide, by sector by use by fuel by weight class, 1967-76 . . . . . . . . . . 5-82

336. Federal government civilian truck fuel use, by state, 1967-76... . . . . . . . 5-83

Input Data Files . . . . . . . . . . . . . . 5-84

Data Quality Numbers .. . . . . . . . . . 5-88

References . . . . . . . . . . . . . . 5-89

Method 340. Motorcycle . . . . . . . . . . . . 5-90

341. Household motorcycle fuel use, 1967-76, by state, and by use, 1974-76............ 5-91

342. Government motorcycle fuel use (no data) . . . 5-95

Input Data Files . . . . . . . . . . . . . . 5-95

Data Quality Numbers . . . . . . . . . . . . . 5-98

References . . . . . . . . . . . . . . . . 5-99

Method 400. Marine ... . . . . . . . . . . 5-100

401. Recreation boat fuel use, by fuel by state, 1967-78 . . . . . . . . . . . . . . . 5-100

402. Commercial ship fuel use, by fuel by state, 1967-78................ . 5-103

Input Data Files . . . . . . . . . . . . . 5-104

Data Quality Numbers .............. 5-105

References ................. 5-106

Method 510. Natural Gas Pipeline . . . . . . . . 5-107

1. Consumption of natural gas, by year by state . 5-107

2. Consumption of all fuels, by year by state . . 5-108

3. Consumption of electricity, by year by state . . 5-110

4. Consumption of other fuels ......... . 5-110

Input Data Files ... . . . . . . . . . . 5-110

Data Quality Numbers .............. 5-111

References ................... 5-112

Method 520. Liquids pipeline . . . . . . . . . 5-113

Data Quality. Numbers ....... . . . . . 5-114

Reference .................. 5-115

Method 600. Military Fue1 . . . . . . . . . . 5-116

Input Data Files . . . . . . . . . . . . . 5-118

Daca Qual1ty Numbers :. ............. . 5-119

References ............... . 5-120 
Method 900. Aggregations ............... 5-121 Data Quality Numbers .. . . . . . . . . . 5-121

Units of Measurement . . . . . . . . . . 5-129

Chapter 6. Technical Articles .............. . 6-1

6.1 Estimating the Number of Aggregate Data . . . . . 6-1

6.2 Adding Aggregate Data to the Data Base . . . . . 6-4

6.3 Flagging llie Absemle of Dala . . . . . . . . . . 6-11

Chapter 7. The Retrieval Program "DBRS" . . . . . . . . . 7-1

7.1 How to Use It . . . . . . . . . . . . . 7-1

7.2 How to Insta11 It . . . . . . . . . . 7-6

Chapter 8. The Tape Formats ............... . $8-1$

8.1 The EIA Tape .. . . . . . . . . . . . . . 8-2

8.2 The ORNL Tape.................. . 8-6 


\section{LIST OF TABLES}

All tables appear in Chapter 4.

1. Summary tables.

1.1 Summary of transport energy use, by mode and type of transport, 1967-76

1.2 Summary of transport energy use, by mode and fuel type, 1967-76

2. Table of categories for which data are provided.

2.1 Summary of categories of transport energy use for which estimates are provided

3. Air tables.

3.1 Total aircraft fuel and energy use, by fuel by sector, $1972-77$

3.2 U.S. certificated aircraft fuel and energy use, by fuel by aircraft type, 1972-77

3.3 U.S. certificated passenger aircraft fuel and energy use, by fuel by aircraft type, 1972-77

3.4 U.S. certificated freight aircraft fuel and energy use, by fuel by aircraft type, 1972-77

3.5 U.S. certificated aircraft fuel and energy use, by fuel by state, 1972-77

3.6 U.S. certificated passenger aircraft fuel and energy use, by fuel by state, 1972-77

3.7 U.S. certificated freight aircraft fuel and energy use, by fuel by state, 1972-77

3.8 U.S. supplemental and foreign-flag air carrier jet fuel and energy use, by range, 1972-77

3.9 Foreign-flag air carrier jet fuel and energy use, by state, 1974-77

3.10 General aviation use of aviation gasoline, by state, 1974-77

3.11 Total consumption of aviation fuels, by fuel by state, $1974-77$

4. Rail tables.

4.1. Total rail fuel and energy use, by fuel by type of operation, 1967-78

4.2 Rail transit electricity and energy use, by state, 1967-78

4.3 Commuter rail fuel and energy use, by fuel by state, 1967-78 
4.4 Intercity passenger rail fuel and energy use, by fuel by state, 1967-78

4.5 Freight rail fuel and energy use, by fuel by state, 1967-78

5. Auto tables.

5.1 Total civilian auto gasoline and energy use, by sector, 1967-76

5.2 Commorcial auto gasoline and energy use (excluding taxicabs), by state, 1967-76

5.3 Taxicat gasoline and cnorgy use, by state, 1967-76

5.4 Federal auto gasoline and energy use, by state, 1967-76

5.5 Household auto gasoline and energy use, by state, 1967-76

5.6 Intercity household auto gasoline and energy use, by state, 1972-76

5.7 Intercity household auto gasoline and energy use, by use by state, 1976

5.8 Intercity household auto gasoline and energy use, by use by income, 1972 and 1976

5.9 Intercity household auto gasoline and energy use, by family income by census region, 1972 and 1976

5.10 Huuseliold auto gasoline and cncrgy use for commuting to wurk, by state, 1975

6. Bus tables.

6.1 Total civilian bus fuel and energy use, by bus type by fucl, 106776

6.2 School bus gasoline and ellergy use, by statc, 196776

6.3 Federal civilian bus gasoline and energy use, by state, 1967-76

6.4 Intercity bus diesel fuel and energy use, by family income, 1967, 72, 76

6.5 Transit bus fuel and energy use, by fuel, 1967-77

6.6 Transit bus diesel fuel use, by state, 1976

7. Truck tables.

7.1 Total civilian truck fuel and energy use, by sector by fue1, 1967-76

7.2 Nongovernment truck fuel and energy use, by fuel by sector by weight, 1967-76

7.3 Nongovernment truck fuel and energy use, by fuel by range by body type, 1967-76 
7.4 Local household truck energy use, by state, 1967-76

7.5 Local commercial truck energy use, by state, 1967-76

7.6 Local nongovernment truck gasoline and equivalent energy use, by state, 1967-76

7.7 Local nongovernment truck diesel fuel and equivalent energy use, by state, 1967-76

7.8 Intercity nongovernment truck diesel fuel and equivalent energy use, by state, 1967-76

7.9 Intercity nongovernment truck gasoline and equivalent energy use, by state, 1967-76

7.10 Intercity nongovernment truck energy use, by sector by use by weight, 1967-76

7.11 Federal civilian truck fuel and energy use, by weight, 1967-76

7.12 Federal civilian truck fuel and energy use, by state, 1967-76

8. Motorcycle tables.

8.1 Household motorcycle gasoline and energy use, by state, 1974-76

8.2 Household motorcycle gasoline and energy use (registered motorcycles only), 1967-73

8.3 Household motorcycle gasoline and energy use, by use, $1974-76$

9. Marine tables.

9.1 Total civilian marine fuel and energy use, by fuel by sector, 1967-77

9.2 Recreational boat gasoline and equivalent energy use, by state, 1967-77

9.3 Commercial ship fuel and energy use, by fuel by state, $1967-77$

10. Pipeline tables.

10.1 Natural gas pipeline fuel and energy use, by fuel, 1967-77

10.2 Natural gas pipeline energy use, by state, 1967-77

10.3 Liquids pipelines fuel and energy use (order-ofmagnitude estimates), by fuel by type of pipeline, 1967-77

11. Military tables.

11.1 Military highway fuel and energy use, by mode, .1967-77 
11.2 Military transport fuel and energy use (aircraft fuel excluded), by fuel by state, 1975-77

11.3 Military consumption of jet fuel, by type of fuel, 1975-77 


\section{CHAPTER 1. INTRODUCTION}

This report documents the transportation fuel and energy use estimates developed at Oak Ridge National Laboratory (ORNL) for the End Use Energy Consumption Data Base.) This data base contains estimates of energy use in the United States broken down into many categories within all sectors of the economy: agriculture, mining, construction, manufacturing, commerce, the household, electric utilities, and of course, transportation. The transportation data ORNL has provided generally cover each of the ten years 1967-1976 (ocassionally 1977 and 1978), with omissions in some modes. The estimates are broken down by mode of transport, by fuel, by region and State, by the sector of the econnmy providing the transportatinn and by the use to which it is put, and in the case of automobile and bus travel by the income of the traveler. The mode, fuel, sector and use categories themselves subsume one, two, or three levels of subcategories, resulting in a very detailed categorization of energy use. The aim has been to furnish the Energy Department with the definitive accounting of transportation energy use in the United States.

t.

The report contains both methods and results. There are a few-dozen tables displaying a fraction of the data that have been submitted to the Energy Department on computer tapes. There are also detailed and precise descriptions of the methods by which the data were generated. Besides these, there are an explanation of the scheme of categories, a description of tape formats and retrieval programs, and miscellaneous essays, some of technical and some of general. interest. Section 1.1 offers advice as to how to use the report.

In total, the materials that comprise ORNL's contribution to the End Use Energy Consumption Data Base are the following. The section of this report dealing with each is mentioned.

+ this report (Section 1.1 )

+ two computer tapes, containing the same consumption estimates but recorded in different formats (Chapter 8)

+ a computer tape containing all input data sets, other than survey tapes, used in generating the energy estimates, as we:11 as, the programs described here. (9 track, $1600 \mathrm{bpi}$, IBM standard label tape - Fortran programs, dataset name: ENDUSE. TRNSPORT.ORNL. FORTRAN.FEB80. and dataset. name: ENDUSE. TRNSPORT . ORNL. INPUT . FEB80).

+ a computer tape containing the Fortran retrieval program described below. ( 9 track, 1600 bpi, IBM standard label tape, - dataset name:ENDUSE.TRNSPORT.ORNL.RETRIEVE. FEB80)

i a series of Fortran routines used to compute and record the est1mates (the methods implemented by these routines are described in Chapter 5) 
t: a FORTRAN retrieval program, DBRS, used for on-line retrieval of the consumption data at ORNL (Chap. 7), and a separately bound guide to its use

+ a FORTRAN program, KEYSUM, used to compute all possible aggregate data, given any combination of aggregate and disaggregate data as input (Method 900 in Chap. 5; Chap. 6)

+ numerous smaller FORTRAN programs used to generate tables, prepare data for tables, produce documented listings of input data, etc.

\subsection{How to Use this Report}

This report is intended for use by persons having any of several purposes in mind. Below, advice for using the report is addressed separately to each type of reader. The previous section, however, should be read first.

For those consulting the tables of energy and fuel consumption:

+ Chapter 4 contains the tables.

+ The introduction of Chap. 4 contains some important caveats.

+ Chapter 5 explains how the numbers in these tables were arrived at. The method number at the bottom of each table refers to a corresponding method description in Chap. 5.

+ The introduction to Chap. 5 explains the method numbering scheme and offers tips on. how to read the method descriptions.

+ The data quality numbers at the bottom of each table are defined in Sec. 2.2 .

+ The categories by which energy use is classified are defined in Chap. 3. They are summarized in a chart in Sec. 3.10.

For those who wish to retrieve data, or have data retrieved, from the data tapes:

+ The introduction to Chap. 2 lists the sorts of data recorded on the tapes. Oniy a portion of the data on these tapes is displayed in the tables in Chap. 4. 
+ Section 3.10 explains generally how the data are retrieved and provides a chart of the categories used to classify energy use. Consultation of this chart is necessary for intelligent retrieval of the data.

+ Chapter 3 as a whole defines the categories that appear on the chart. The introduction of the chapter should be read first.

+ Section 7.1 provides simple instructions for how to use DBRS, a retrieval program developed for the purpose of retrieving these energy use data.

For those who wish to install retrieval capability on a local computer :

t Chapter 8 details the tape formats.

+ Section 7.2 provides instructions for Installing DBRS.

+ Chapter 3 explains the scheme by which the data are classified.

For those who have a general interest in the estimation and analysis of energy use data:

+ Section 1.2 analyses the concept of end use energy consumption.

+ Section 1.3 distinguishes transportation energy use from the use of energy for other purposes.

+. Section 2.1 introduces the reader to the British Thermal Unit:

+ Section 2.2 discusses at length the problem of assessing the accuracy of an energy use estimate.

For those who have a professional interest in how the estimates were generated:

+ Chapter 5 presents the estimation methods in explicit detail, cites the sources, and discusses problems that arise in estimation.

+ Section 2.2 discusses at length the problem of assessing the accuracy of an energy use estimate.

For those who have a technical interest in the recording and aggregation of data: 
+ Section 3.9 introduces some of the problems encountered in the aggregation of the data whose generation is documented in Chap. 5 .

+ Sections 6.1 and 6.2 discuss, in a technical idiom, the problem of generating aggregate data and the algorithm used to do so.

+ Section 6.3 discusses the techniques used to flag missing data in order to prevent the generation of incomplete aggregations.

Lists of references occur at the end of each chapter containing references, with the exception that each Method Description in Chap. 5 has its own list of references.

\subsection{What Is End Use Energy Consumption?}

An energy end use is a use of energy that is not used again. That is, it is a use of energy that is not merely passed along, perhaps in another form, to another user. Accordingly the end use energy consumption of an operation is the net amount of energy it consumes. For instance, suppose a coal-fired power plant consumes 30 billion Btu each day in the form of coal energy in order to generate 10 billion Btu in the form of electrical energy. The difference, 20 billion Btu, represents the plant's end use energy consumption. On the other hand, the end use.consumption of an electric razor is simply all the energy that reaches it through, the cord, since the razor obviously delivers no energy for use elsewhere.

The End Use Energy Consumption Data Base, as the name says, accounts for end uses of energy. Consequently when coal:or oil is burned to generate electricity, most (usually about two-thirds) of the energy released is dissipated as waste heat and is charged against the power plant. The remaining third of the energy is converted to electricity. A small fraction of this electricity never reaches the consumer, but is lost in transmission. This loss might reasonably be classified as consumption by the transportation sector, but in the End Use Data Base it is not. The rest of the electricity is charged against the consumers to whom it is transmitted.

Ail this means that while, say, a diesel locomotive's consumption is taken to be the full energy content of the oil it burns, an electric locomotive's measured consumption is the energy content of only about a third of the oil or coal burned to supply the electricity. This discrepancy must be kept in mind when the energy use of electrical devices is compared with that of other devices.. (A locomotive's consumption of hydroelectricity, on the other hand, does not incur an overhead at the power plant, since the Data Base assigns hydroelectric plants a net consumption of zero.) 
Although this is not the place to discourse at length on the concept of energy consumption, a notion as misleading as this one warrants some brief remarks. It is misleading because consumers of energy do not, in a literal sense, consume energy. They do not use it up, as one uses up a tank of gasoline. The reason, of course, is that outside of nuclear reactions, energy is neither created or destroyed, but only transformed. Indeed, consumers of nuclear-generated electricity are responsible for increasing the energy in the world, since nuclear fission converts a small amount of matter into energy.

It is better to say that to consume energy is to decrease the usefulness or availability of energy. Energy need not occur in a useful form, after all. Useless energy occurs as an undifferentiated pool of heat. The air that fills an empty supertanker, for instance, contains heat that, if it could somehow be used to fuel an auto, would take one from New York to Los Angeles and back. But energy in this state is useless.

Useful or available energy occurs in several forms. An obvious form is mechanical energy, such as that had by flowing water. There are various. kinds of potential energy, such as that gained by water as it is pumped to the top of Raccoon Mountain in Tennessee in order to be chuted through turbines during periods of peak demand for electricity. Potential energy is also stored in the bonds of hydrocarbon molecules, such as those of gasoline or coal. And, even though heat is not useful per se, temperature differences make the heat available for use, as does the temperature difference between hot underground rocks and the chilly interior of a house to be heated geothermally.

One "consumes" energy when he allows a reservoir of useful energy to degrade into one that is less useful. When one heats his house geothermally, or harnesses the temperature gradient of the ocean, he narrows a temperature gap and hence reduces the utility of the heat reservoir he is tapping. One who grinds corn with water power transforms the useful mechanical energy of falling water to less useful heat in the millstone and the grist. Heat is always less useful than its equivalent in mechanical or potential energy because energy converted to heat can never be fully recovered as mechanical energy; the laws of thermodynamics dictate how much is theoretically recoverable. Most consumers of potential or mechanical energy not only reduce it to heat, of course, but then allow the heat to dissipate, thus reducing the utility of the energy to nought. So it is in the case of the auto, which not only converts gasoline energy to heat but allows the heat to escape and dissipate through the radiator and exhaust pipe. Even the 10 or $20 \%$ of the gasoline energy that is delivered to the drive wheels is quickly dissipated, as friction and air drag heat up the tires, brake drums and car body.

One subtlety in the notion of energy consumption is that, contrary to what was said above, it is in certain circumstances possible to consume energy that is not made less available as it is consumed. For instance, the potential energy an auto gains by driving to the top of a mountain is 
energy that is still available, and that will in fact be used when the car rolls back downhill. Yet since fuel was burned to supply this energy, and since the energy will sooner or later be dissipated by friction and its availability destroyed, we speak of the energy as consumed on the way up. An exception to this principle occurs when the energy whose dissipation is delayed is used again during its dissipation. When water makes it return trip down Raccoon Mountain, for example, the potential energy converted to electricity should not be counted as consumed by the Raccoon Mountain operation, since that energy is to be consumed elsewhere. It is on the same principle that the electrical energy produced by a power plant should not be counted against the plant's consumption. Rather; only that portion of the energy which is not delivered for consumption elsewhere is counted. In other words, only the end use energy consumption is counted. The notion of end use energy consumption, then, is simply the proper way to conceive of energy consumption in general.

An interesting consequence of the foregoing line of thought is that the energy consumed in the production and use of hydroelectricity should not be equated with that consumed in the production and use of the same amount of coal or oil-generated electricity, even if this is a common practice. Rather, the energy required to produce hydroelectricity is the energy lost by the water as it passes through the reservoir and through or over the dam. This only reasonable, since a leaky dam should be regarded as consuming more of nature's energy (per kilowatt produced) than a tight dam with efficient turbines.

The End Use Data Base, due to its emphasis on end uses, does not follow the practice of equating the energy cost of hydroelectricity with that of coal-generated electricity. It would be ludicrous, after all, to report that a hydroelectric dam consumes twice as much energy as it delivers to the electric grid. The Data Base policy, as noted earlier, is to put the dam's net consumption at zero. This practice is entirely reasonable in view of the facts that: (a) no one knows just how much water power is consumed by hydroelectric plants; and (b) if it were known, the figure would probably be only 20 or $30 \%$ above the energy content of the electricity generated, as compared to a $200 \%$ overhead in the case of fossil-fuel plants.

The reader may have noticed an affinity between energy consumption, as conceived here, and the physicist's concept of entropy. The connection is indeed close, but far from straightforward. A more rigorous discussion of this matter and a defense of the analysis suggested above is presented in Ref. 1, which is a spinoff of work on the transportation sector of the End Use Data Base. 


\subsection{What Is Transportation Energy?}

There are a number of reasonable ways to distinguish energy used for transportation from energy used for other purposes, and they issue in consumption estimates of substantially different sizes. The transportation data in the End Use Energy Consumption Data Base adhere as consistently as possible to the following definition:

Transportation energy (i.e., energy used for the purpose of transportation) is considered to be the energy content of the fuel burned by transportation engines. (Electricity is counted as a fuel.) A transportation engine is an engine that has some part in achieving and controlling the motion of the objects transported.

The reader should be alerted that within particular categories of transportation energy use, this definition must be refined and occasionally modified in order to make the resulting comsumption figures useful or estimable. The precise definition used for any category is presented at the beginning of the method description(s) for that category.

Still, it is possible to say generally how the definition applies to the various modes. To begin with, the energy content of oil, gasoline or natural gas is the heating value of the fuel - that is, the energy. equivalent of the heat released upon its combustion. The energy content of electricity is equated with the kilowatt-hours delivered. The energy used by autos, trucks, aircraft, watercraft and nonelectric locomotives* is considered to be the energy content of the fuel pumped into their fuel tanks. Electric locomotives are charged with the kilowatt-hours they receive from the catenary or third rail. The pipeline fuel counted is that which powers the transmission and storage pumps. In all cases, the reader is admonished to consult the method description for definitions and any other important details before he begins drawing inferences from any number he finds in. the data base:

The implications of the above definition, as well as the reasons for its choice and its precise meaning, can be better understood if some alternative definitions, each having its own merit, are examined. The definitions to follow begin with the narrowest and become successively broader.

*The traction of a "diesel-electric" locomotive is provided by electric motors, but the motors use electricity generated by diesel engines on board the locomotive; consequently the locomotive's energy use is taken to be the energy content of the diesel oil it burns. 
1. Transportation energy can most strictly be defined as the mechanical work actually done by the transportation engine(s) to achieve and control motion, such as the work done by the drive wheels and steering mechanism of an auto. The idea here is that the rest of the energy involved is either wasted as heat or used for some such purpose as running an air conditioner, and so it does not end up actually being used to transport things. It was noted earlier, for instance, that only 10 to $20 \%$ of the energy used by an auto (depending on the speed) is delivered to the drive wheels (Ref. 2, pp. 4-5). Recall that a transportation engine is an engine that has some part in achieving and controlling motion; the driver of an auto, no less than the engine under the hood, would be one. It is necessary to consider the energy used to control motion, since otherwise a helicopter, say, would be regarded as using no transportation energy at all while hovering. True, the application of brakes also results in work which controls motion, but the energy brakes consume is presumably not counted because brakes are not transportation engines, and in general, transportation engines should not be identified in such a way as to count some energy as consumed twice by the same vehicle, as would be the case with braking energy.

This definition, far stricter than the one adopted for the End Use Data Base, is perhaps of little practical value and certainly makes estimation on a national scale difficult or impossible. But it lays a conceptual foundation for more useful definitions, such as the one to follow.

2. Transportation energy can be more usefully defined as the energy content of that portion of the fuel used by the transportation engine(s) to do the work described in definition 1, such as that portion of an auto's gasoline burned to drive the drive train, valve mechanism, oil and water pumps, power steering, alternator (in part), and so on. The fuel cost of an air conditioner, lights, radio or other accessories would be excluded. Many of these accessories use negligible energy; but an air conditioner typically increases a car's fuel use some 13\% (Rcf. 2, pp. 4-7). The caloric content of that portion of the driver's diet that allows him to steer the car should theoretically be counted, but it is, perhaps regrettably, far too slight to be significant in relation to the gasoline energy that is consumed.

This definition has the virtue of fonusing on fuel concumption, which is our principal worry anyway. It differs from the End Use Data Base definition only in that it overlooks that portion of a. vehicle's fuel consumption that powers accessories. Comparison of transport energy consumption reckoned in these two ways can give us an idea of what potential savings a reduction of accessories could effect. But a good many accessories are indispensible, and their energy consumption is difficult to estimate. Perhaps the best course is to compute transportation energy according to the slightly broader End Use Data Base definition and then to consider the energy advantages of removing particular accessories. In any case, the narrower definition is out of the question 
for the data base, since the data base taxonomy provides no category for this accessory energy use other than the transportation category.

3. Transportation energy can be still more broadly defined as operational energy, which is that covered by the data base definition, plus the indirect energy consumption of transportation - that is, the energy consumed in order to build and maintain the vehicles, plus that consumed in order to build, maintain and operate supporting facilities. In the case of the auto this would include the energy used to build and maintain autos and auto plants, highways, bridges, etc., amortized in a reasonable way over their lifetimes. By one estimate, the operational energy consumed by all transportation in 1977 was 20 quadrilition Btu's, whereas the addition of indirect energy consumption raises this figure to 28.4 quadrillion Btu's, a jump of $42 \%$ (Ref. 3).

This definition is an excellent one for questions of long-range policy, since indirect energy costs are substantial. For instance, if one is interested in the energy advantages of a conmuter rail system, he must consider that a good deal of energy is required to build the system - a quantity that, when properly amortized, is of the same order of magnitude as the operational energy (Ref. 4). Also when one is counting up the energy savings of small cars, he must consider the fact that small cars have shorter lifetimes than big cars (Ref. 5), so that the energy used to make more small cars may partially offset their operational energy advantage. A grave difficulty, however, is that estimates of transportation energy in this sense are as yet of limited reliability. Furthermore, even if one knew accurately the average indirect energy costs of, say, a commuter rail system, his knowledge is likely to be of little value in estimating the energy cost of a particular system in a particular city, which could differ enormously from the average. As for the End Use Data Base, it cannot provide estimates of transportation energy use in this sense because the indirect energy costs are accounted for elsewhere as consumpliun in the induatrial and construction sectors.

4. Finally, the foregoing definitions are in a way unfair to the highway modes, since the installation of rail and air routes entails an additional expenditure of energy in the cars, taxis and buses that must shuttle people to the airport or rail depot. Transportation energy, then, might be yet more broadly defined as the energy described in definition 3 plus the energy consumed (in any of these senses) by any other transportation mode necessary to make the mode in question usable. 


\section{References}

1. J. N. Hooker, "Some Problems of Definition Raised by a Transportation Energy Use Data Base," in Rocco Fazzolare \& Craig B. Smith, eds., Changing Energy Use Futures, vol. I, Pergamon Press, 1979, pp. 286-93.

2. A. B. Rose, Energy Intensity and Related Parometers of Selected Transportation Modes: Passenger Movements, ORNL-5506, Jan 1979.

3. Energy Information Administration, Dept. of Energy, End Use Energy Consumption Data Base: Series I TahTes.s, Tune 1978, p. 23.

4. Conversation with David Boyce, Dept. of Civil Engineering, University of Illinois, Urbana-Champaign, April 6, 1979.

5. Philip D. Patterson, "An Initial Estimation of Automobile Differential Average Lifetimes and Scrappage Rates," mimeographed by Data Analysis Branch, Transportation Programs, Conservation and Solar Applications, Dept. of Energy, March 23, 1979. 
CHAPTER 2. TYPES OF DATA PROVIDED

.. A11 of the fuel and energy consumption estimates documented in this report, as well as all possible aggregations of them, are recorded on two computer tapes (Chap. 8). A portion of these data appear in a set of tables in Chap. 4 of this report. The two computer tapes contain the same data classified in the same way; only the formats differ.

Each of the many thousand fuel and energy use estimates provided represents consumption within a particular category of transportation energy use. For each of these categories the computer tapes contain:

+ a figure showing the quantity of fuèl used, in appropriate units (Sec. 2.1 explains the units used)

+ a figure showing the energy content of this quantity of fuel, expressed in billions of Btu (Sec. 2.1 explains what a Btu is and how fuel quantities are converted to energy quantities)

+ a series of codes identifying the category in which the consumption figure falls (Chap. 3 describes how energy use figures are classified and Chap. 8 sets out the codes representing the categories)

+ a 3-digit number identifying the method, described in this report, by which the figure was calculated (the method descriptions appear in Chap. 5, and the introduction to that chapter explains how the method numbering works)

+ a single digit indicating roughly the reliability of the estimate (Sec. 2.2 discusses the problem of grading the reliability of an estimate and explains the data quality codes used)

+ codes indicating the units in which the energy consumption (always in billions of Btu) and fuel consumption are expressed (see Sec. 2.1)

Chapter 8 lays out the format of the two tapes in detail.

Each energy use estimate is recorded with its own uniquely idenlifylng category codes in order to ease its retrieval. These data can be retrieved "on-line," at a computer terminal by plying an interactive computer program written for the

purpose. ORNL uses retrieval program, DBRS, to retrieve 
the transportation data, and it is described in Chap. 7 of this report. DBRS was written as part of ORNL's End Use Data Base project and is available to those who wish to install it on a local computer.

\subsection{Fuel and Energy Consumption}

Fuel consumption is reported in the following units:

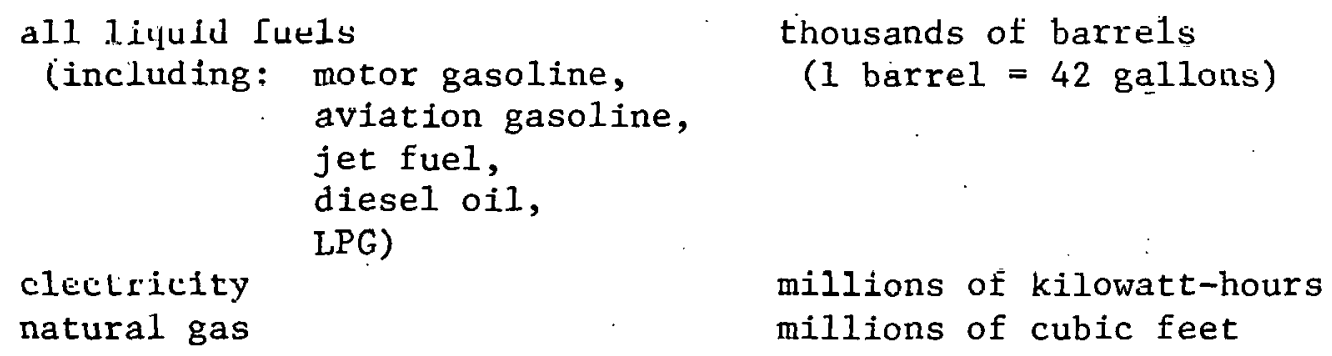

Each fuel consumption figure is accompanied by a figure showing the energy content of that amount of fuel, expressed in billions of British thermal units (Btu). Except in the case of electricity, the energy content is computed simply by multiplying the fuel quantity by the heating value of a single unit of that fuel. Since the heating value of a quantity of fuel is the amount of energy released on its combustion, these energy figures by no stretch represent the amount of energy that is actually put to use. They represent the amount of heat that is released when the fuel is burned, much of which is wasted (see Sec. 1.3). As for plertririty, its energy content is of course identical to its quantity expressed in kilowatt-hours, but for comparison the kilowatt-hours are converted to Btu.

It should be understood that the heating value of petrolcum fuel.s can vary a few percent from the average, depending on the type of crude oil from which they are derived and the process by which it is refined. Perhaps most variable, however, is the heating value of natural gas, which depends nn how "wet" the gas is: that i3, on the fraction of propane, butane, etc., mixed in with the predominant methane. For this reason the state-by-state breakdown of natural gas consumption by gas pipelines is multiplied by the average heating values of gas delivered in the respective states, a quantity that is fortunately kept track of by gas companies for contractual purposes. In the case of the remaining fuels, however, regional variations are not known, and there is no reason to believe they are significant. Consequently the following average values are consistently used:

Motor gasoline aviation gasoline
$125,000 \mathrm{Btu} / \mathrm{ga} 1$

$124,000 \mathrm{Btu} / \mathrm{ga} 1$ 


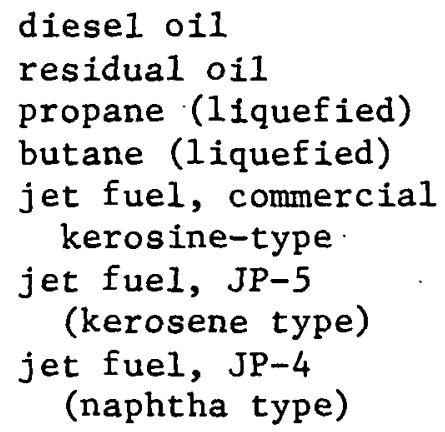

One kilowatt-hour is equivalent to 3412.1416 Btu.

Unfortunately most people do not have a working familiarity with the British thermal unit, which is the amount of energy that, when converted to heat, will raise the temperature of a pound of water one degree Fahrenheit. The following comparisons may help convey the relative size of a.Btu:

- one Btu is equivalent to 778 foot-pounds, 1.41 horsepower-seconds, 0.293 watt-hours, and 1055 joules

- a 100 watt bulb burns about 341 Btu each hour

- a one-horsepower motor provides about 2544 Btu of mechanical energy each hour

- a typical daily diet providing 2000 calories provides about $8000 \mathrm{Btu}$

- an average auto travelling at $55 \mathrm{mph}$ uses about $8000 \mathrm{Btu}$ per mile

- a gailon of fuel oil provides the household furnace about $150,000 \mathrm{Btu}$

- a monthly electric bill of $\$ 75$, which typically buys about 1500 kilowatt-hours of electricity, buys about five million Btu

- a ton of coal, when burned, supplies about 25 million Btu

- a 100 megawatt power plant produces, at full capacity, about 340 million Btu an hour

- the same power plant produces about 3 trillion Btu a year

- the USA consumed about 70 quadrillion Btu (70 quads) in 1974

The End Use Energy Consumption Data Base reports energy in billions of Btu, as noted earlier. Onc thougand billinn Rtu, i.e., one trillion Btu, is the energy content of about: 
one billion cubic feet of natural gas

200,000 barrels of gasoline

300 million kilowatt-hours of electricity

40,000 tons of coal

\subsection{Data Quality Numbers}

Al1 fuel and energy use estimates documented in this report have been assigned a data quality code that is meant to convey roughly the rellability of the estimates. The codes are:

$$
\begin{aligned}
& 1 \text { - probably less than } 10 \% \text { error (in either direction) } \\
& 2 \text { - probably less than } 25 \% \text { error } \\
& 3 \text { - probably less than } 50 \% \text { error. } \\
& 4 \text { - reliability unknown }
\end{aligned}
$$

These codes are recorded on the computer tapes containing the estimates and are indicated at the bottom of the tables in Chap. 4 of this report. They are also summarized at the end of each of the method descriptions in Chap. 5. Aggregate data (i.e., data that are got merely by summing figures whose generation is described herein) are assigned computed quality numbers based on the quality of the addends. The formula used for this computation is given and derived in Method 900 of Chap. 5.

The word "probably" in the quality code definitions above is meant to suggest that these data quality codes indirate crude confidence intervals in the statistician's sense. The quality code 1 , for instance, indicates that one can be 80 or $90 \%$ confident (not $100 \%$ confident) that the true value lies within $\pm 10 \%$ of the estimate. The level of confidence is as high as 80 or $90 \%$ only because the data quality numbers were chosen rather conservatively, with care not to overestimate the quality of an estimate.

The reader who is distressed by the fact that most of the estimates have a quality number other than 1 should keep several things in mind.

(a) It is very difficult to obtain accurate estimates of energy consumption. In this report, the inherent unreliability of such estimates is honestly acknowledged.

(b) A large percentage error in one of the more highly disaggregated estimates represents a relatively small absolute error, and it is these estimates that generally are rated lowest in quality. 
(c) For many purposes it is useful even to have an estimate that is accurate to within a factor of 5 or 10 . It would be useful to know, for instance, whether recreational boats and motorcycles, say, consume $10 \%, 1 \%$, or $0.1 \%$ of our gasoline. The estimates provided here are of course more accurate than this.

(d) The errors are generally more systematic than random. This means that one can compare consumption figures from one year to another, or from one subcategory to another within a given mode, with considerably greater confidence than he can estimate the absolute value of a given consumption figure. The data quality numbers of course reflect the accuracy of estimates as absolute values.

(e) The estimates provided herein are almost entirely derived from data that had already been collected by government, trade associations, survey firms, etc. An improvement in the quality of the data would require that more primary data be gathered directly from the users of energy. The imposition of more data-gathering. not only is a nuisance to those who are asked to comply, but a single data-gathering instrument can easily cost many millions of dollars to administer.

The remainder of this section deals with problems that arise in the determination and definition of data quality numbers.

It was found impossible to assign confidence intervals to estimates in any systematic or defensible way. There are too many variables, many of them doubtless unknown, that affect the accuracy of an estimate. The assignments made represent judgment and guesswork on the part of the persons preparing the estimates. These are intended only to put the user on guard when there are reasons to suspect a number's reliability. The user, if uneasy about the quality number assigned an estimate, should read the description of how the estimate was derived and make up his own mind as to its reliability.

Two specific remarks should be made about the choice of data quality numbers. One is that figures obtained from primary sources, such as figures routinely reported to the government or to trade associations, are given the benefit of the doubt. They are presumed to be probably accurate to within $\pm 10 \%$ unless there is some specific reason to doubt their verisimilitude. Secondly, when a large number of estimates, calculated by the same method, are assigned a single quality number, this is not meant to imply that every one of the estimates is believed to be probably within the stated interval. It implies that the great majority of them are so regarded, but that here and there an estimate, especially one of the smaller numbers, may well be likely to show greater error.

No less troublesome than the choice and defense of a confidence interva1. is the matter of understanding just what it means to say that an estimate is "probably" within $\pm x \%$ of the true value. Furthermore, 
the fourth data quality number ("reliability unknown") is puzzling. If a data quality number indicates the interval within which one can place the true value with confidence, why not simply replace the "reliability unknown" description with an interval so wide that one can be sure that the true value lies within it? That is, what is the difference between "reliability unknown" and a sufficiently wide confidence interval?

Such questions are puzzling in part because the notion of probability can be understood in two entirely different ways that are often confused. The1r confusion is in fact evident in nearly every application of probabilistic notions, and the concept of a data quality rating cannot be clarlfled uncil the contusion is dispelled. In one sense when nne. says. that an event is "probable" or "improbable," he says something about the physical process responsible for it. To say that heads and tails aro equally probable when a coin is tossed is to say something about the symmetry of a coin and of physical. forces affecting it. One who believes that heads and tails are equally probable should also expect them to occur with more or less equal frequency when a coin is tossed repeatedly (but more on this later). This type of probability might be called "objective" probability. In another sense, to say an event is "probable" or "improbable" is to say something about how sure one is that it will happen, or about the strength of his reasons for believing it will happen. In this sense probability is really not probability at all and perhaps should not be called such; it is rather a judgment about the state of one's mind or one's evidence. It might be called "doxastic" probability if. it reflects the strength of one's belief, or "epistemic" probability if it reflects the strength of his evidence. A meteorologist who says that there is a $90 \%$ probability of rain tomorrow, for instance, may mean it epistemically: he may mean that he has good reason to believe it will rain. On the other hand, he may have in mind an objective probability; perhaps the coming cold front dumps rain. on $90 \%$ of the area it passes over, so that there is presumably a $90 \%$ (objective) probability that a given reader of the weather forecast will be in one of the wet areas. This latter judgment need not (although it llsually does) imply that the weatherman has good reason to believe it will rain on a given reader, since he may have little or no evidence to back up his assignment of probability!

It is clear that if a data quality number were to 1ndicare the interval within which it is epistemically or doxastically probable the true value lies, it would indeed be odd to recognize a "reliability unknown" assignment of confidence. Although it is possible that one be unaware of the strength of one's evidence or belief, it generally is not difficult to become aware of it. There would be no good reason, then, for indicating that one does not know what his degree of certainty is by assigning the quality number 4 to an estimate.

The data quality numbers, however, do not indicate degrees of certainty, except in an indirect sense to be explained shortly. They 
indicate intervals within which the true values probably, in an objective sense, lie. Yet even once this is made clear, the notion of a confidence interval is not a straightforward one. Statisticians hasten to concede that to say that an interval extending $25 \%$ on either side of a given estimate is a $90 \%$ confidence interval is not to say that there is a $90 \%$ chance the true value lies within that particular range of numbers. Rather, it is to say that if many estimates were made, about $90 \%$ of them would lie within $25 \%$ of the true value. This obviously implies that it makes sense to speak of a probability distribution of estimates.

The notion of a probability distribution of estimates was conceived in a mathematical context in which an estimate is based directly on a random sampling from a fixed population. But these ideas often become problematic when one attempts to apply them to a real-world estimation. For one thing, it is difficult in principle to tell whether a sampling procedure is random, due to the fact that our only clean definitions of randomness merely state the mathematical properties of random variables. It is usually question-begging to judge a sampling procedure to be random on the grounds the resulting estimates exhibit these properties, since careful examination usually reveals that it is as unclear whether these properties obtain as it is whether the sampling is random. But more pertinent here is the fact that even if the idea of randomness were clarified, it is difficult to conceive of energy consumption estimates as statistically distributed in some way, because it is difficult to conceive of them as based on sampled observations. One might be inclined to characterize the difficulty by saying it is impossible in principle to learn the shape of such a distribution. For, one could attempt to learn its shape only by taking a random sample of estimates, and different estimates of the same quantity would necessarily, it seems, be made under conditions too different to allow the estimates to be regarded as samplings from a single distribution. But it is not from this that the obscurity of the idea of a probability distribution of estimates actually stems. Upon close analysis objective probability appears to be best conceived not as definitionally connected with the observed frequency of occurrence in experiment in the first place. Rather, it should be seen as an idea that must be made an integral part of the physical theory describing the phenomenon in question. The connection between probability and frequency of occurrence is apparently only epistemic. That is, when an event described as improbable by a physical theory is observed to happen over and over again it becomes irrational to continue to believe the theory. The frequency of occurrence provides a test of the warrantability of belief of a probability claim and of a theory from which it is derived, but it does not enter into the definition of the probability claim. (It still may be correct to define an objectively probable event as one that would happen frequently in experiment, but only with the understanding that the subjunctive "would" can be ultimately analyzed only as a statement about the physical theory governing the event's occurrence, and not as a statement about the frequency with which the event will actually occur.) 
The natural question at this point is: how does one define objective probability in terms of a physical theory? It is precisely because this question is difficult to answer in general that the idea of objective probability is problematic. Since objective probability receives its meaning from its role in a physical theory, its precise sense varies from one application to another. Often probabilities derive from a stipulation that certain events are equiprobable due to a symmetry or isomorphism they and their causes have. The number of raindrops that will land in any one of a row of identical buckets, for example, may be said to have a Poisson probability distribution because, at any instant, all of the buckets have equal probability of being hit next, and because a Poisson distribution is the mathematical result of this equiprobability. In this case the assignment of a certain probability to that event consisting of the collection of, say, 3584 drops in a given bucket might ultimately be understood as a statement about the lack of relevant differences in the situation of the buckets. But each such application of probability has its own peculiarities, and any satisfactory understanding of objective probability requires examination of particular applications. (Perhaps most bizarre is the application of probability to quantum mechanics, wherein it receives no definition at a11; it is a primitive notion in whose terms the rest of the theory is expressed.)

The lesson to be learned here is that if talk about the probability of arriving at this estimate rather than that one is to make sense, it must be understood in reference to the natural laws governing the process by which the estimates come about. Since this process involves judgment and ratiocination on the part of data analysts, we are generally ignorant of these laws, and all the more ignorant of what interpretation probability statements might receive. This fact alone would doom any attempt to arrive systematically at defensible confidence intervals.

It need not doom attempts to guess at confidence intervals, however. Objective probability, though it in the end receives its meaning in the context of particular physical theories, has vague but recognizable general features that tend to recur from one context to the next. (Otherwise, no one would know how to apply probability to a new theoretical context.) Consequently if one has some familiarity with an imperfectly understood phenomenon, such as the production of an accurate estimate, he may be able to anticipate roughly what its probability of occurrence would turn out to be if the meaning of probability in that context were made clear. He might do this through a combination of looking at the frequency of similar phenomena and of considering the factors that seem to bear on its occurrence. In the area of data estimation, one might recall the accuracy of past estimates that were later compared with better data and consider such conditioning factors as possible deliberate bias in the primary data, ways that underreporting might occur, assumptions in the estimation method that would tend to under- or overestimate some quantity, and so on. Yet it all must be judgmental because there can be no cogent and specific defense of a probability statement whose meaning is still unclear. 
This, then, is the nature of the confidence intervals assigned in this report to energy use estimates. A $\pm 10 \%$ confidence interval (data quality 1), for instance, represents someone's guess that the natural laws governing the process issuing in the estimate make it probable, in a sense that can be made clear only once these laws are understood, that the estimate is within $10 \%$ of truth. Note that, on this analysis, it makes perfectly good sense to distinguish a "reliability unknown" judgment from the assignment of a sufficiently wide confidence interval.

"Reliability unknown" means that the analyst is prepared to make no objective probability judgments whatever, presumably because he knows too little about the process that led to the estimate in question. A wide confidence interval, on the other hand, implies a judgment that the (objective) probability that the estimate will lie close to the true value is low.

An illustration may help. Suppose one estimates energy use by tossing an odd-shaped die he is not allowed to examine first. (Be assured that the authors of this report have not used such a method.) Suppose further that he knows that a right answer is possible: that at least one side of the die bears the true value. He is of course unable to estimate the objective probability that his estimate is right to within a stated tolerance. It could be as high as one (if all sides bore the correct answer) or as low as, say, 0.001 (if only one in a thousand sides bore the correct answer). Consequently he will designate his estimate as "reliability unknown." The epistemic probability he is right is of course quite low, and it would be low even if the objective probability were one, since he has no idea of what is on the faces of the die. On the other hand, suppose he is allowed to examine the die before tossing. Then since he knows that at least one side bears the correct answer, he can easily assign a confidence interval to his estimate. If it happens that the objective probability that he is close to the right answer is low, then the epistemic probability that he is close is again low. But this time he would judge it to be low on the basis of his knowledge of the objective probability, rather than on his ignorance of it, as in the first case. This, at least in theory, is the difference between "reliability unknown" and a wide confidence interval.

In a complete accounting of data quality one could provide a data quality number for his data quality number, a third quality number for the second, and so on through an infinite regress. These second-order data quality judgments might reflect epistemic, doxastic or objective probability. But for present purposes the objective probability that a given data quality number is correct is regarded as inestimable. Furthermore, the epistemic and doxastic probability it is correct is assumed to be at least as high as the objective probability the energy use estimate itself is correct (or within the stated tolerance). That is, if an estimate is assigned data quality 3 , then the analyst may have had little confidence in this assignment. But if an estimate is assigned a $l$, then it can be assumed that the analyst had good reason to believe 
the assignment is correct and consequently that the estimate itself is a good approximation. (If the analyst had been very unsure of the quality judgment, then he would have been equally unsure of the estimate, even though he assigned it a quality of 1.) This is why it was remarked earlier that a data quality number, even though it reflects objective probability, indicates indirectly the epistemic or doxastic probability that an estimate is close to the true value. 


\section{CHAPTER 3. THE CLASSIFICATION OF ENERGY USE}

Aside from making everything conveniently. available in one place, probably the main contribution of the End Use Data Base is that it breaks energy use down into categories more finely than is ordinarily done. Consequently the invention of a logical and well-defined taxonomy of . energy use is crucial to the success of the data base. In this section the transportation categories used in this report are set out and explained. For the user's convenience they are also summarized in a category chart appearing in Sec. 3.10. The categories and intersections of categories for which estimates are actually provided are summarized in Table 2.1 of Chap. 4.

The taxonomy breaks energy use down in nine major ways:

1. by year - the year in which the energy was used

2. by mode - the mode of transport that used the energy

3. by sector - the sector of the economy in which the vehicles using the energy were operated

4. by range - whether the energy was used for local or intercity transport

5. by fuel - the form in which the energy was consumed

6. by use - the particular use to which the energy was put in transporting people or things

7. by carrier - whether the vehicile using the energy was a common carrier or not..

8. by region and state - the region or state in which the energy was used

9. by income - the income class into which the travelers (if any) transported by the energy fall

Several of these categories, especially those in the breakdowns by mode and use, are further subdivided, as depicted by the chart in Sec. 3.10. This same chart governs the classification of fuel use as well as energy 11 se.

The power of a taxonomy with multiple breakdowns lies in the possibility of allowing categories to intersect. A certain quantity of expended energy, for instance, might be classified as falling simultaneously under the auto category, the Kentucky category and the 1972 category. This would of course be the energy used by cars in Kentucky in 1972. Or there is the energy used by intercity diesel-powered dump 
trucks operated in Ohio in 1976, which lies in an intersection of five categories. Although the possibilities are practically limitless (they number in the hundreds of millions), figures can be provided for no more than a few hundred thousand intersections of categories: As it happens the two quantities just mentioned are available, but in general one should check the breakdown charts at the beginning of each method description to learn for which categories data are provided (see the introduction to Chap. 5).

It may be helpful to conceive the data as scattered through a large array of many dimensions. For the sake of illustration suppose the data are classified only by three modes (highway, rail and air), two uses (passenger and freight) and three fuels (gasoline, diesel, jet fuel). Then these data can be conceived as arranged in the cells of the $3 \times 2 \times 3$ box pictured in Fig. 1. Each datum (each cell in the box) lies in the intersection of three categories, and there are $3 \cdot 2 \cdot 3=18$ such intersections. In addition the data can be aggregated in numerous ways. They can be summed over one breakdown: the energy used by highway passenger vehicles, which represents a sum of that used by gasoline-burning and that by diesel-burning vehicles, is a sum over the fuel breakdown. Or they can be summed over two breakdowns, as is the total energy used by all passenger vehicles (all modes and all fuels). It turns out that when all aggregate data are taken into account, the number of data increases from 18 to $4 \cdot 3 \cdot 4=48$ (see Sec. 6.1 for the theory behind this).

'The point is that the entire End Use Data Base can be conceived as such an array, except that each cell in the array lies in the intersection of many categories rather than only three. Granted, such a multidimensional array is impossible to visualize, but it is yet a helpful device when conceived in analogy with a three-dimensional array like the one just described. In particular, aggregate data can be computed by summing over cells in a similar way, except that now there are many possible types of aggregations - sums over five breakdowns, over 10, and more. The energy used by gasoline-burning California autos in 1976 represents a sum over all breakdowns but these four, and the total transportation energy used nationwide in 1974 is a sum over all breakdowns but one.

The following nine sections elaborate on each of the nine major breakdowns. They are intended to convey the motivation behind the taxonomy and a feeling for how to use it as well as the particulars of its definition. Afterwards there is a brief discussion of the kinds of aggregate data that are included in the data base. 
FIG. 1 IF THERE ARE THREE BREAKDOWNS, THE DATA FORM A 3-DIMENSIONAL ARRAY, PERHAPS :

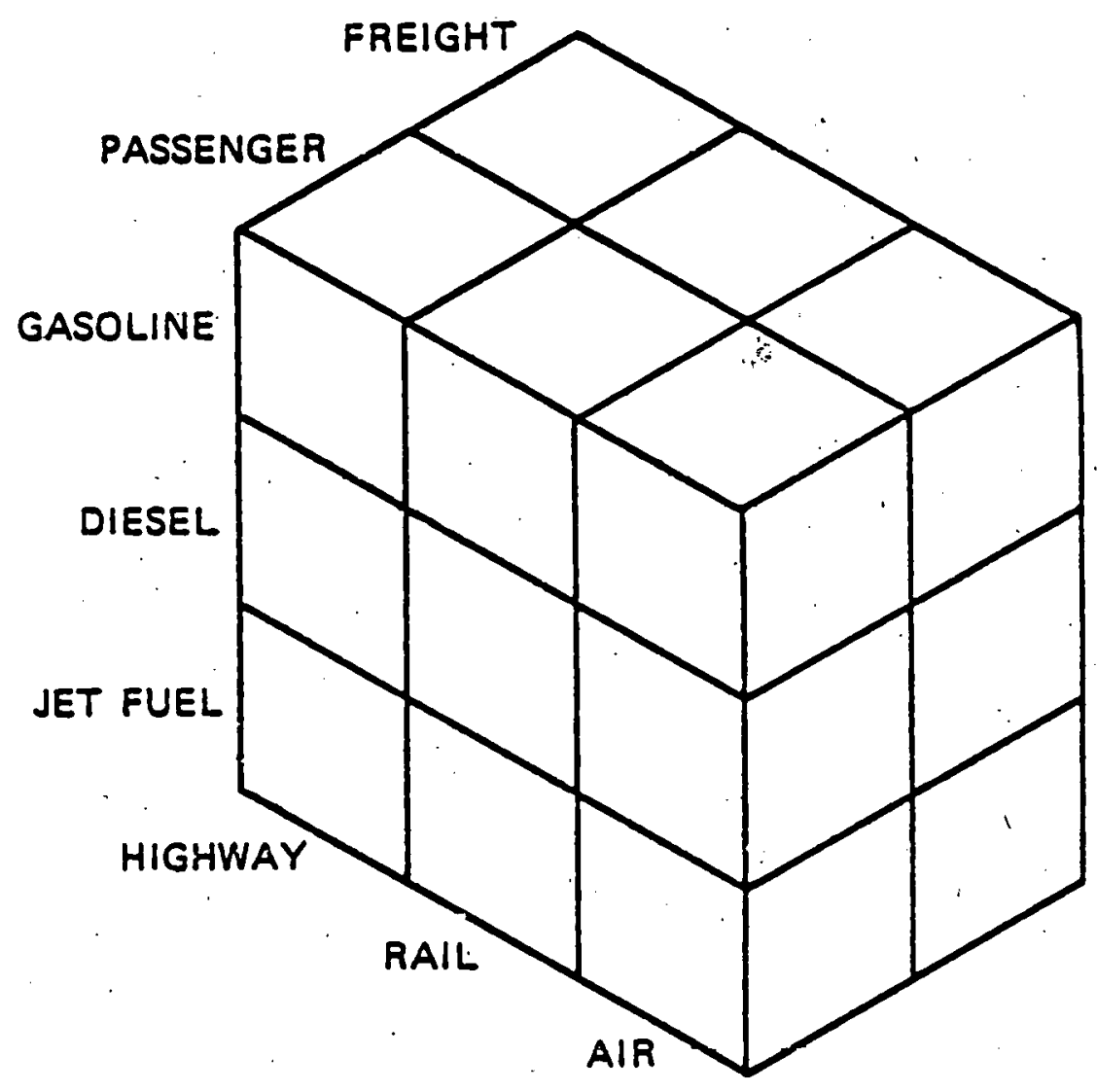

HERE THERE ARE 18 CELLS, WITH 30 POSSIBLE MARGINAL SUMS (AGGREGATIONS). 


\subsection{The Breakdown by Year}

The development of the transportation portion of the End Use Data Base was undertaken with the understanding that data would be provided for the calendar years $1967,71,74,75$ and 76 whenever possible. In fact every effort was made to supply data for the intervening years as well, and occasionally 1977 and 1978 data are provided. But there are gaps in many categories; see the individual method descriptions for details. No seasonal breakdowns were attempted.

\subsection{The Breakdown by Mode of Transport}

The different modes of transport are conceived solely as different types of transportation hardware. Whereas transit rail cars and transit buses are counted as separate modes, transit buses and intercity Greyhound buses are counted as the same mode, since the hardware is practically the same. Likewise taxis and private autos represent the same mode. The taxonomy distinguishes transit buses from Greyhound buses by way of the range breakdown: one is local and the other intercity. It distinguishes taxis from private autos by way of the carrier breakdown: one is a common carrier and the other is not.

'The major modal divisions are based on the surface (if any) on which the transportation hardware operates - air, rail, highway, marine and pipeline. The air mode is broken down into wide-body and narrow-body craft and by the engine configuration. The rail mode is divided into heavy rail, which denotes trains pulled by locomotives (overland and subway), and light rail, which denotes rail coaches individually equipped with engines, such as rail trolley cars. The highway mode, which devours the bulk of the energy, splits into autos, buses, trucks and motorcycles. It is convenient to regard school buses as representing a different mode than other buses. All highway vehicles except buses, trucks and motorcycles are classified as automobiles. This includes jeeps, station wagons, hearses, and motor homes. The marine mode is divided among commercial and recreational craft. In theory commercial (or recreational) craft are not identical with craft used for commercial (or recreational) purposes, since the former refers to the type of boat and the latter to the use to which the boat is put, but for practical purposes the two breakdowns coincide. Finally, pipelines are classified as liquids or gas pipelines, since the equipment differs substantially between the two cases. The distinction between crude oil, oil product, coal slurry and water pipelines is made in the breakdown by use. Further definition of the mode categories, when necessary, is provided in the individual method descriptions. 


\subsection{The Breakdown by Sector}

A breakdown by sector of the economy is unexpectedly effective at permitting categories within the other breakdowns to fall neatly into place. This household/commercial/government breakdown also corresponds to the three major avenues by which public policy can influence transportation. The sector under which a given quantity of transportation energy is classified is conceived as the sector of the economy served by the vehicles using the energy. Vehicles in the household sector are taken to be private vehicles, in the sense of vehicles that are not owned by or under the economic control of a business or government. Data constraints, however, have required that all autos other than taxis and cars in fleets of four or more be counted as household autos. Some of the auto fuel consumption attributed to the household section, then, is likely to be consumption by autos owned or controlled by businesses. As for trucks, all trucks whose owners indicated their trucks were used primarily for. personal transportation have been counted as trucks in the household sector. Since a few of the trucks so described are rather large, it is possible that a few of the trucks classified as household are owned or controlled by businesses. Boats put into the household sector are recreational boats.

It is important to distinguish the sector of the economy to which a vehicle belongs from the use to which it is put. Both the energy used by autos in the business sector and the energy used by autos for business purposes can be estimated, but they are classified differently. The former is found under the commercial category of the sector breakdown, and the latter is found under the personal transport subcategory of the use breakdown. The energy used to transport a vacationer in a bus is classified as consumption in the commercial sector, since the bus is operated by a commercial enterprise, even though its use classification is that of personal transport.

By way of summary, the household/commercial breakdown of passenger vehicles is as follows:

\section{household sector}

autos (i.e., all nongovernment highway vehicles besides buses, trucks, cycles) other than taxis and other than cars in fleets of four or more

trucks and vans used primarily

for personal transportation

recreational boats

private aircraft (the data,

\section{commercial sector}

taxis

other autos in fleets of four or more

buses (except government and school buses)

commercial aircraft (the data, however, do not permit identification of commercial all fuel use other than that of certificated, supplemental 


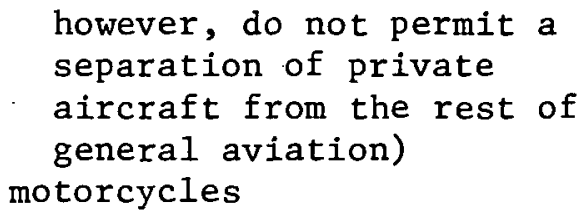

and foreign-flag air carriers) rail cars and trains

pipelines

As for government vehicles, they are generally those owned or operated by some government. All school buses are considered to be part of the government sector, since no data are available on fuel use by buses operated exclusively by private schools. A public transit bus or rail system is counted as part of the commercial sector regardless nf its degree of public support.or ownership. Transport systems in government receivership, such as Amtrak, or those getting government subsidies are placed in the commercial sector, on the theory that public outlays in these cases are instances of largesse calculated to ransom a commercial enterprise rather than expenditures of the controlling entity.

Each of the three sections is given two subcategories in the End Use Data Base taxonomy: civilian and military. This is done, despite the fact the household and commercial sectors have no military subcategory, in order to facilitate the computation of aggregate data. The difficulty is that the civilian branch of the government sector is much more highly disaggregated than the military branch, so that data for all the government sector cannot be as highly disaggregated as the civilian data. If the highly disaggregated household and commercial sector data are specifically indicated in the data base as civilian data, then crosssectional sums with the highly disaggregate civilian military data, ylelding totals for all civilian transport, are possible. Otherwise most of these summations are missed, because only the totals for all the government sector could then serve as addends.

\section{4 'l'he Breakdown by Use}

The use categories represent the purposes for which trancportation energy is expended. The major division is into passenger and nnnpassenger uses, and these are subdivided, subdivided again, and in one instance subdivided still again. Three caveats are in order with respect to this breakdown. One is that energy consumed in driving, say, autos for "personal" uses is not the same as energy consumed in driving personal (i.e., household) autos; this point is covered in Sec. 3.3. $\Lambda$ sccond is that the distinction between freight and services, the major subdivisions of the nonpassenger category, is ill defined. A utility truck or mealson-wheels van, for instance, seems to fall into either category. In practice, all nonpassenger transport is presumed to be freight transport except that fraction of truck transport that is identified by the Truck Inventory and Use Survey as providing "services" (see Method 330). 
A third caveat is more serious. When bus or aircraft fuel use is broken down by trip purpose, the matter is complicated by the fact that a bus or plane carries passengers traveling for different purposes. A bus or plane's energy use has, with reluctance, been allotted to each trip purpose in proportion to the number of people aboard that are traveling for that purpose. This is extremely misleading because the user of these consumption figures is likely to infer that if, say, vacationers riding the bus were to stay home instead, total bus fuel use would decrease by the amount that had been allotted to the vacationers. This is of course a mistake because it is easily possible that as many buses would run as before, or nearly as many, and because the subtracted passenger weight reduces the bus's fuel use only slightly. Also there is the fact that the cargo carried in the bottom of a bus or in the belly of a passenger plane gets, in this allocation, an energy-free ride. For these reasons bus and plane breakdowns by use should be interpreted with caution. This particular method of allocation was chosen only because it. is relatively simple and because no other method seems preferable from either a practical or a theoretical point of view.

\subsection{The Breakdown by Range}

When possible, transportation energy is broken down into that used for local transport and that used for intercity transport. A third range category, "regional" travel, is useful for the air and rail modes, and estimates for "foreign" travel are available for the air mode.

No air travel is classified as 1ocal. Travel over airlines other than the major carriers, over supplemental (i.e., chartered) carriers, and over all carriers other than common carriers is classified as regional travel. Domestic travel over the major U.S. carriers (United, Delta, etc.) is called intercity, and all flights leaving the U.S. for foreign countries are considered to provide foreign transport.

Rail transport on subways and local elevated lines is classified as local. Travel over commuter lines, such as the Long Island Railroad, as well as that portion of travel over intercity lines (e.g., Amtrak) that is identifiable as commutation, is classified as regional travel. The rest is intercity.

In the auto and bus modes, intercity travel encompasses trips to a destination at least 100 miles away, a definition imposed by the National Travel Survey. All other auto and bus travel is local. Intercity truck travel is that designated "short-haul" or "long-haul" by the Truck Inventory and Use Survey, and it includes the travel of all trucks whose trips are primarily "over the road." Trucking that is "mostly in the local area (in or around the city and suburbs, or within a short distance 
of the farm, factory, mine, or place vehicle is stationed)" is counted local. As for the marine mode, all recreational boating is classified as local, and all commercial shipping as intercity. An unknown fraction of the fuel used for intercity shipping is fuel burned on trips to foreign countries. Finally, all pipelining is considered to be intercity.

\subsection{The Breakdown by Carrier}

This breakdown allows the identification of energy used by common carriers. As remarked earlier it distinguishes energy used by taxis from that used by autos, otherwisc undistinguished (except by the numbers of the methods used to calculate them). In similar fashion it distinguishes energy used by corporate aircraft from that used by commercial airlines, and it distinguishes energy used by company-owned tractor-trailer rigs from that used by operator-owned tractors. In neither of the last two cases, however, did the data permit a breakdown by carrier.

\subsection{The Breakdown by Region and state}

The breakdown by state and Census region would seem to be straightforward, but sometimes it is not. For most purposes the amount of fuel consumed in New York is best conceived as the amount of fuel burned within. its borders, even if in many cases this must be interpreted as the amount of fuel sold within its borders. But it would make little sense to allot the energy used during a transcontinental flight to the states flown over, presumably in proportion to the amount of fuel burned while over each state, even if this were possible. Instead, the energy used by aircraft during a given leg of its flight (i,e, , between one takeoff and the next landing) has been allotted wholly to the state from which the plane took off. A similar convention has been adopted for marine transport. The reader is referred to the individual method descriptions for explicit information on how energy use was broken down by region and state within each mode of transport.

\subsection{The Breakdown by Income}

The National Travel Survey permitted a breakdown of intercity auto and intercity bu; energy use by the income class of the traveller. The 
income categories, however, change enormously from one year to another. For this reason no single range of categories has been set up, and the user must consult Methods 315 and 324 for category definitions. There are statistical techniques that allow one to fit the data into a single income breakdown, but since they require several assumptions about income distributions, it was thought best to provide the original categories and let the user perform whatever transformations he wishes.

\subsection{Aggregate Data}

Great care has been taken to provide, on the data tape containing : the consumption estimates documented herein, all aggregate data that can be computed from the other data. (See the introduction to Chap. 3 for a definition of aggregate data, and Sec. 6.1 for a technical description of how they are computed.) The tapes, then, contain not only the data that would result from doing all the computations described in this report, but in addition all the totals that can be computed by summing these data over one or more breakdowns. Certain types of aggregate data, however, are never to be found on the tapes, usually because some of the addends that would be summed to complete these totals were unknown. It may be helpful to 1ist these types of missing aggregate data. They do not include all the aggregations that are missing, but all those enumerated below are missing.

1. No sum covering more than one year is provided, since there seems to be no point in providing it. For instance, the total gasoline use in 1967 is provided, but the total over the 1967-76 period is not.

2. No sum is broken down by income category, since different modes use different income breakdowns (see Sec. 3.8). The only data so broken down are those whose generation is documented in Methods 315 and 324 . For instance, the 1967 auto fuel use by people in income category 1 is provided, but the 1967 fuel use over all modes by people in income category 1 is not provided.

3. It turns out that no sum representing all modes, or even all highway modes, is broken down other than by YEAR, SECTOR, FUEL and USE. In other words, a sum classified under some category besides these four w111 also be classified by MODE, and by MODEl as well if it represents one of the highway modes. This is the case because no data more finely broken down are consistently available across all the modes or across all the highway modes. Perhaps some examples will make this clear.

a. The dicsel fucl consumption of common-carrier buses in 1976 is $\therefore$ provided, but the diesel fuel consumption of all common carriers 
in 1976 is not provided. This last figure is not supplied because it is broken down by CARRIER and does not specify a particular mode.

b. The gasoline used for transporting persons by all modes is provided, but the gasoline used for transporting persons for business purposes is not provided (because this' sum would be broken down by USE1 but not by mode).

c. The gasoline used for transporting persons over the highway for business is not provided, because this sum would be broken down hy IISFi. and does not specify a particular highway mode.

All other aggregate data not found in the tape are those that could not be computed due to missing data.

The foregoing remarks are intended to give the user prior notice that certain types of aggregations are never to be found. The best and often the easiest way to tell whether a given aggregation is provided, however, is simply to try to retrieve it from the data tape and see whether it is there.

\subsection{Retrieval of Data by Category}

This section explains how in principle fuel and energy use estimates can be retrieved from the data tapes containing them. It also provides a chart of categories that can serve as a guide to retrieval. This chart should also be useful to those who merely wish to consult tables in this report.

'l'his section does not instruct onc in how tó opcracc any part1cular retrieval system or program. Most such systems are in principle very similar, however, and the remarks to follow should apply to them. Chapter 7 discusses DBRS and Sec. 7.1 tells how to use DBRS, a program developed expressly for the retrieval of the data documented in this report.

As remarked in Chap. 1, the data tapes consist of many thousands of records, each of which contains the following data:

a fuel use estimate, with a code showing the units in which it is expressed

a corresponding energy use estimate, with a code showing the units in which it is expressed (always billions of Btu) 
a data quality number

a method number

a series of codes indicating the category to which the estimates on this record correspond

Chapter 8 explains that there is a choice of two tapes, an "EIA tape" and an "ORNL tape," which contain exactly the same data. They differ in format, however, in that the EIA tape puts several fuel and energy use estimates on each record, covering several years, whereas the ORNL tape devotes a separate record to each year within each category. The EIA tape also uses different codes for the categories, and the repercussions of this difference for retrieval will be discussed shortly. The details of format can be found in Chap. 8 .

Each datum on a record can be referred to as an "attribute" of that record. The attributes of records in the End Use Data Base are the data items listed above. The series of category codes, listed last, is actually a series of 18 attributes, corresponding to 18 breakdowns by which the data are classified.' (On1y 17 are indicated on the EIA tape, omitting the YEAR breakdown, since all years are represented on a single record.) The value of one of these attributes indicates the category in the corresponding breakdown under which the estimates on that record fall. For instance, if the estimates on a particular record are for rail energy in 1976, then the YEAR attribute on that record will have the value 76 , and the MODE attribute will be a code that stands for RAIL. If these estimates do not happen to correspond to any particular USE, but represent a sum over all uses, then the USE attribute will be a code that stands for a total over that breakdown (viz., a zero). The combination of values had by all 18 category attributes serves uniquely to identify the data on that record.

Generally a retrieval program operates by allowing the user to specify a desired value for some or all of the attributes. The program then retrieves all the records whose attributes have the specified values and permits the user to examine any part of these records he wishes. It is important to realize that if only a few attribute values are specified, the number of records retrieved may be very large. One who specifies only that the year is 76 , for instance, may find himself retrieving 50,000 records. If one wants, however, to retrieve only the total energy use in 1976, he has two options. One is to specify the value ALL.for the other breakdowns, indicating that the total over all those other breakdowns is desired. The other is to use a retrieval system so designed that when an attribute's value is not specified, it is assumed to be ALL. (The retrieval system DBRS makes no such assumption.) In the meantime, one should bear in mind that a given specification of categories may retrieve nothing at all. Only a fraction of the possible combinations of attribute values appear on the tape. Mnst nf these in fact make no senee, ac ic the case with the energy use of pipelines for passenger transport. 
Although data are generally retrieved by category, they can be . accessed by specifying or limiting the values of other attributes. One might, for instance, specify the method to be Method 102 and the quality number to be 1 , in order to retrieve all estimates generated by Method 102 having the data quality 1.

The chart that appears with this section presents the entire scheme by which transport energy use is classified. Recommended abbreviations for each breakdown name and each category name are typed in capital letters. Users of DBRS should refer to breakdowns and categories with these abbreviations, and it is suggested that any other retrieval system bc set up to recognize the same abbreviations.

Note that categories in some breakdowns are subcategories of categories in other breakdowns. For Instance, some of the MUDE categories subsume MODE1 categories, some of which subsume MODE2 categories, some of which in turn subsume MODE3 categories. Other hierarchies of breakdowns are USE-USE1-USE2-USE3, SECTOR-CIVMIL and FUEL-FUEL1. ("USE1," then, is not a category in the USE breakdown, but is an entirely distinct breakdown, whose categories are subsumed by categories in the USE breakdown.)

The difference of coding between the EIA and ORNL tapes, mentioned earlier, require that these hierarchies be treated somewhat differently. Users of the EIA tape should proceed as follows. When one wishes to specify the value of any but the highest attribute in a hierarchy, such as MODE2, he assigns that value not to MODE2 but to the highest attribute, MODE. One interested in light trucks, for instance, would specify that the MODE is LIGHT. It is not necessary to say that the MODE is TRUCK and HIGHWAY as well, since these are implied by saying that the MODE is LIGHT; HIGHWAY and TRUCR are the only categories that subsume LIGHT. The aircraft engine-type categories under MODE2, however, are subsumed by both the WIDE and NARROW categories under MODEl. For this reason, users of the EIA tape interested in 4-engine wide-body jet aircraft should specify some value that indicates both WIDE and 4-JET for the MODE attribute. To retrieve the figure for all wide-body jets, he need only specify MODE = WIDE. No figure for all 4-engine jets (both wide- and narrow-body) is recorded, since the body categories subsume the engine categories. The truck body types under MODE3 are similarly subsumed by multiple categories (the four weight classes) under MODE2.

The EIA tape also has its own way of delivering aggregate data classified within a hierarchy of categories. If one specifies that the USE is PERSONAL (a value of USE1), he does not get all records on which USE1 has the value PERSONAL. He gets only records on which USE1 is PERSONAL and on which all breakdowns lower in the hierarchy (USE2, USE3) have the value ALL. In other words, he gets only records showing a total over all PERSONAL uses. This holds even if the retrieval program is not designed to assume that all unmentioned attributes are to have the value ALL. 
- Users of the ORNL tape must view hierarchies differently. The values of MODE1, USE1, etc., are assigned directly to MODE1, USE1, etc., rather ,.. than to the subsuming breakdown (MODE, USE, etc.). It is still true, however, that implied subsuming categories need not be specified; once one says that MODE2 is LIGHT, he need not say that MODE1 is TRUCK and MODE is HIGHWAY. Specifications of aircraft engine type of truck body type must again be accompanied by a specification of the immediately subsuming category (if one wants to specify the immediately subsuming category). Yet whereas the EIA tape requires that one who wants a figure for 4-engine jets specify a value of MODE that implies a body type as well, the ORNL tape requires that he say separately that MODE2 $=4-\mathrm{JET}$ and MODE1 = WIDE. The ORNL tape has the advantage, however, that a figure for a particular engine type, such as 4-JET, representing a total over both body types (WIDE and NARROW), can be obtained by specifying MODE2 = 4-JET and MODE1 = ALL. Such a sum over subsuming categories, where a subsumed category is specified, cannot be obtained from the EIA tape.

Aggregate data within hierarchies are also retrieved differently from the ORNL tape. Whereas the EIA tape delivers only a total over all personal uses when one specifies USE = PERSONAL, specification of USE1 = PERSONAL fetches from the ORNL tape all records on which USEl has the value PERSONAL. This includes records on which USE2 is COMMUTE, OUTDOOR, etc. (This of course does not hold if the retrieval program assigns all unmentioned attributes the value ALL.)

A final difference in the two tapes has to do with the specification of a desired year. Users of the ORNL tape who want fuel or energy use data for 1976 will retrieve FUELUSE or ENERGY while assigning YEAR the value 76. But since the EIA tape places all the years on one record, its users should retrieve, say, FUEL76 and ENERGY76 without attempting to specify the value of the YEAR attribute (which does not occur on the EIA tape). Data quality numbers for the different years are similarly retrieved by asking for QUAL67, QUAL68, etc. 
In addition to a category within each of the 18 breakdowns listed in the next chart, the following data occur on each record of the data tapes and can be retrieved.

Recómmended abbreviations of the data names are typed in capital letters. See Sec: 3.10 for instructions in using this table.

FUELUSE, or fuel consumption (use FUEL67, FUEL68, .., FUEL77 for $\therefore: .:$ retrieval from the EIA tape)

FUNIT, or the units in which the fuel use estimate is expressed

ENERGY, or energy consumption (use ENERGY67, ENERGY68, ..., ENERGY77 for retrieval from the EIA tape)

EUNIT, or the units in which the energy use estimate is expressed (always billions of Btu)

QUALITY of the data, as explained in Sec. 2.2 (use QUAL67, ..., QUAL77 for retrieval from the EIA tape)

METHOD, which is the number of the method used to derive the estimates, as explained in the'introduction to Chap. 5 .

The reader is reminded that only the first two or so of the recorded digits are significant. The rest are recorded only for the purpose of computing sums over breakdowns without accumulating roundoff error. 
Recommended abbreviations of breakdown and category names are typed in capital letters.

An arrangement like this

A....... indicates that $B$ and $C$ are

D subcategories of $A$ but not of $D$

An arrangement like this

A...... indicates that $B$ and $C$ are

D C subcategories of $A$ and subcategories of $D$ as well

See Sec. 3.10 for instructions in using this chart. 
MODE categories.

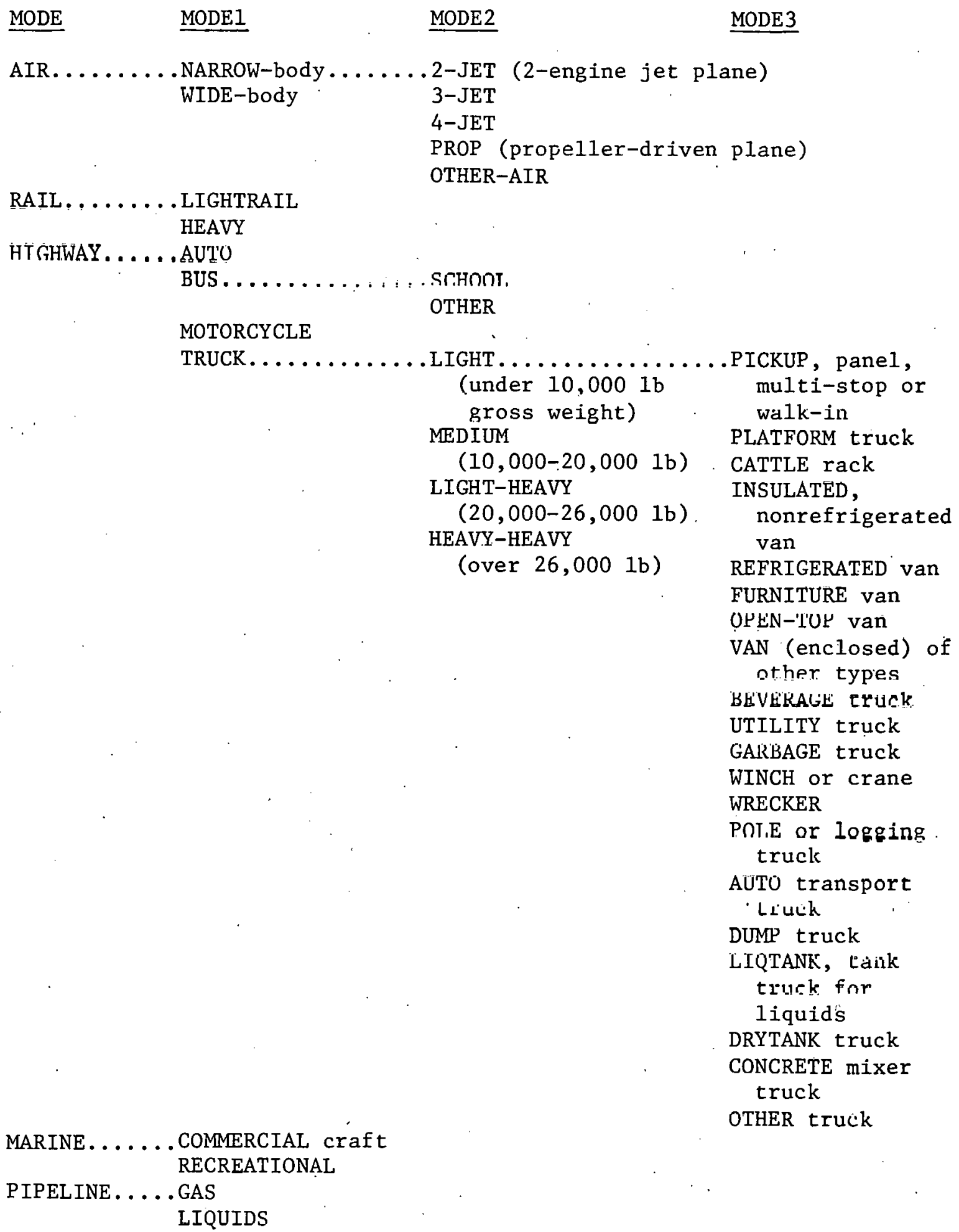


$\begin{array}{ll}\text { SECTOR categories. } & \text { SECTOR } \\ \text { HOUSEHOLD........ CIVILIAN } \\ \text { COMMERCIAL } \\ \text { GOVERNMENT } \\ \text { RANGE categories. } & \begin{array}{l}\text { LOCAL } \\ \text { REGIONAL (for AIR mode only) } \\ \text { INTERCITY. } \\ \text { FOREIGN (for AIR mode only) }\end{array} \\ \text { CARRIER categories. } & \begin{array}{l}\text { COMMON carrier } \\ \text { PRIVATE carrier (i.e., other than a common carrier) }\end{array}\end{array}$

USE categories.

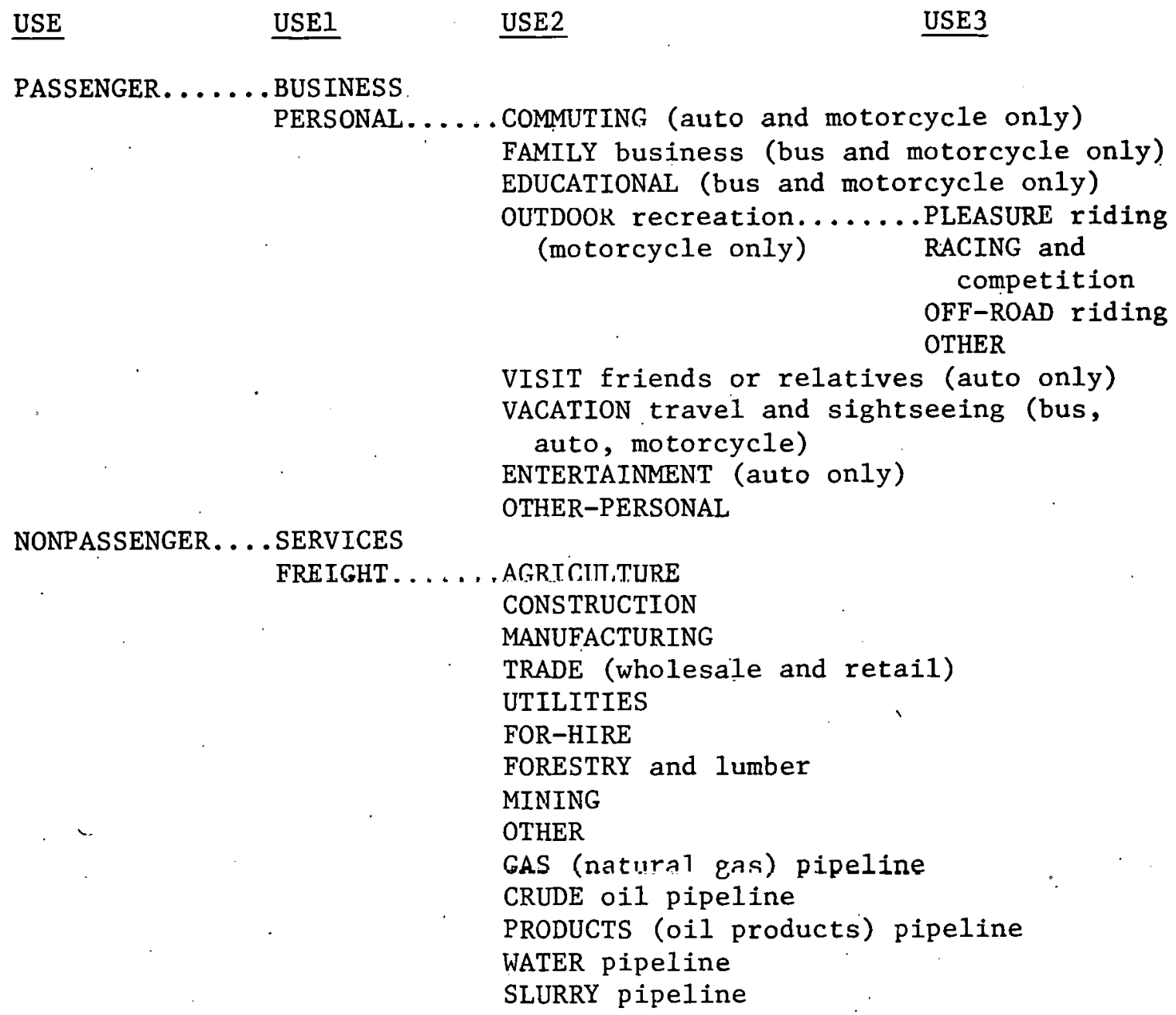




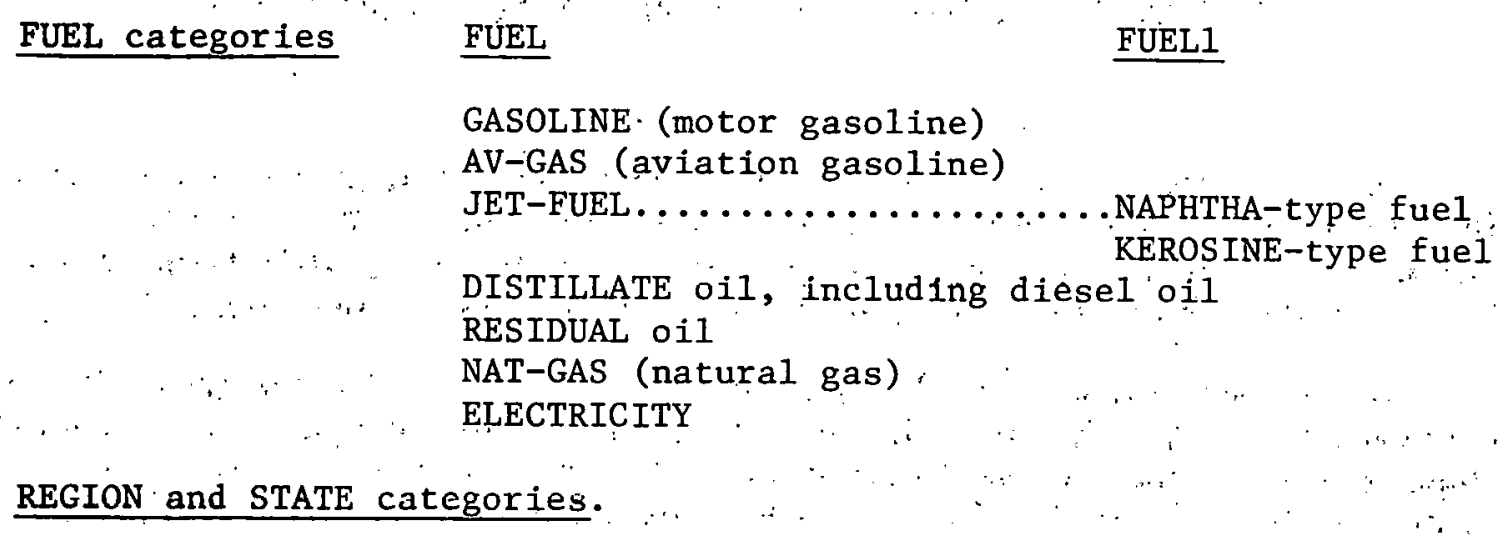

$\underline{\text { REGION. . . . }}$

NE (Northeast) ............ NT

ME RI

MA VT

MA (Mid-Atlant1c)...........NJ PA

NY

SA (South Atlantic)........DE NC

DC SC

FL VA

GA WV

MD

ENC (East North Central)......IL OH

IN WI

MI

EEC (East Boull Ceulral) .... AT, MS

. KY TN

WNC (West North Centra1).....IO NE

KS ND

MN SD

WSC (West South Centra1)....AAR OK

LA TX

MTN (Mounta1n)..........AZ NV

CO NM

ID UT

MT WY

PAC (Pacific)............... OR

CA WA

$\mathrm{HA}$

CERTIFICATE categories (used for the air mode only).

YES (i.e., travel over certificated air carriers)

NO (i.e., all other air trave1)

(see Method 100 for an explanation) 


\section{CHAPTER 4. TABLES OF TRANSPORT ENERGY CONSUMPTION}

This chapter consists of tables of transport energy use estimates. They contain only a fraction of the estimates made by the methods described in Chap. 5. The rest of the estimates, generally those more finely broken down, must be got from computer tapes (see Chap. 8).

The reader is cautioned that only the first two digits or so in' an estimate are significant. The others are retained only because they are necessary to reduce accumulated round-off error in totals and to serve as a precise record of the figures generated by the methods of chap. 5 .

Note that the scaling of the figures in the summary tables (Tables 1.1 and 1.2) differs from that of the figures in the remaining tables by a factor of 1000 . 
CHAPTER 5. METHODS OF ESTIMATION

The pages to follow contain documentation of the methods by which the energy consumption of the several modes of transport is estimated. The documentation is divided into eleven self-contained essays, corresponding to the air, rail, auto, bus, truck, motorcycle, marine and two pipeline modes, and to military fuel use and aggregations. Every estimate provided in this report or on the data tape is explicitly documented in this way.

The method descriptions are referenced in this report and on the data tape by three-digit numbers. A method number divisible by 10 is understood to refer to one of the eleven self-contained descriptions, as follows :

$$
\begin{aligned}
& 100 \text { - air } \\
& 200 \text { - rail } \\
& 310 \text { - auto } \\
& 320 \text { - bus } \\
& 330 \text { - truck } \\
& 340 \text { - motorcycle } \\
& 400 \text { - marine } \\
& 510 \text { - gas pipeline } \\
& 520 \text { - liquids pipeline } \\
& 600 \text { - military fuel use } \\
& 900 \text { - aggregations }
\end{aligned}
$$

other method numbers refer to headings within a particular method description. For instance, Method 310 is the complete auto description, while Method 312 is the portion of that description dealing with taxicabs. The distinction is important because whereas Method 310 is self-contained, Method 312 should not be read in isolation from the rest of Method 310 . Aggregate data on the data tape are footnoted Method 900, which is a description of how the aggregate data are generated. (Here, an "aggregate" datum is one whose estimation is not explicitly documented but can be obtained by summing documented estimates over one or more breakdowns; see - Sec. 3.9.) Method 600 has been set aside for military fuel use because the military's use of fuel can be broken down by mode only. in a very limited fashion.

The method descriptions follow generally the same format. Each component of a description is outlined below, along with some pointers as to how to interpret it.

I. The categories used. The list of categories, which heads every method description, is designed to permit the reader to infer precisely which data are generated by the method that follows. A simple hypothetical example should clarify how the inference can be made: 
categories used:

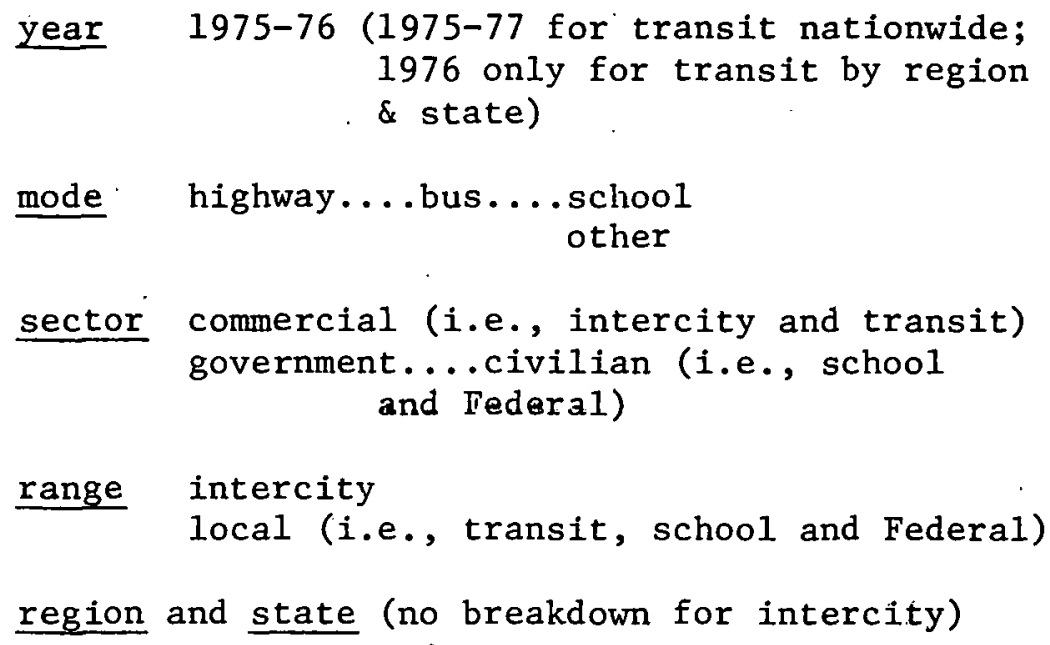

Note that this breakdown is a simplification of the one actually used for buses, Method 320. Let us simplify matters further by supposing that there are only two states, Connecticut (CT) and Massachusetts (MA), both of which lie in the Northeast Census region (NE).

The convention for reading this sort of schematic is that all possible intersections of the categories mentioned, and no others, are provided consumption estimates, except where omissions and additions are explicitly noted. That is, for any choice of categorics from those 1isted, taking one from each hreakslown 1 isted, the energy use that falls in all these categories simultanenusly is estimated, except where otherwise noted. For instance, the consumption in 1975 by school buses in the civilian government sector operating locally in Connecticut is estimated. When annotations speciflcally exclude a certain intersection of categories, then the intersection of these same categories except for the ones excluded is yet provided an estimate. For example, the 1975 energy consumption by Connecticut's transit buses (i.e., its local buses in the commercial sector) is not estimated, because transit energy use is not broken down by. state for the year 1975 . Yet the 1975 nationwide transit consumption (omitting the breakdown by state) is estimated. A complete list of the category intersections for which data would be provided, in this illustration, follows. 


\begin{tabular}{|c|c|c|c|c|c|}
\hline Year & Mode* & Sector & $\underline{\text { Range }}$ & Region & State \\
\hline 75 & school & government...civilian & loca1 & $\mathrm{NE}$ & CT \\
\hline 75 & school & government. . civilian & local & $\mathrm{NE}$ & MA \\
\hline 75 & other & commercial & intercity & all & al1 \\
\hline 75 & other & commercial & local & al1 & al1 \\
\hline 75 & other & government. . civilian & local & $\mathrm{NE}$ & $\mathrm{CT}$ \\
\hline 75 & other & government...civilian & local & $\mathrm{NE}$ & MA \\
\hline 76 & school & 'government. ..civilian & local & $\mathrm{NE}$ & CT \\
\hline 76 & school & government. . .civilian & local & $\mathrm{NE}$ & MA \\
\hline 76 & other & commercial & intercity & aII & al.1. \\
\hline 76 & other & commercial & local & $\mathrm{NE}$ & $\mathrm{CT}$ \\
\hline 76 & other & commercial & local & $\mathrm{NE}$ & MA \\
\hline 76 & other & government...civilian & local & NE & CT \\
\hline 76 & other & government. ..civilian & local & NE & MA \\
\hline 77 & other & commercial & local & al1 & all \\
\hline
\end{tabular}

*The categories "school" and "other" both fall under the category highway.... bus.

Note that some of the annotations, those beginning "i.e.,...," provide additional information as to what sorts of buses fall into a category. Sometimes such notes reveal when a category does not cover all the energy it should; the civilian government category, for example, includes only the energy used by Federal buses in the illustration above, whereas it would ordinarily include state and local government energy. All such irregularities are noted either in the list of categories or immediately following, in the second component of the method description.

In addition to the data categorized in the list above, a11 possible aggregations of these data would be provided. For example, transit bus consumption nationwide, total commercial bus consumption, and consumption by all buses would appear. Missing data rule out some totals, however. There would be no figure for the total bus consumption in Connecticut in 1975 because the transit and intercity bus portions of this total are missing.

A more schematic but serviceable accounting of the categories provided appears as Table 2.1 in Chap. 4.

II. Important notes. This portion of the write-up consists of a few sentences warning the user of irregularities in the data or of other caveats that should get prominent billing. These notes are sufficiently important that a user who did not read them could misinterpret the data seriously. 
III. Instructions for estimating energy use, normally under several headings. The pattern is to follow a general discussion with formulas that provide explicit instructions for calculating the estimates. Each symbol in the formulas is defined, and when the value of a symbol must be retrieved from a data file, the number of the file contalning that value is mentioned.

IV. Data quality numbers. The data quality numbers are detailed here (see Sec. 2.2 for an explanation of what these are).

V. Input data files. $\Lambda 11$ tho input data filca eltcd in the symbol definilluns art Lliuroughly documented in this section. 'l'he references from which the data were extracted are cited by number. Documented printouts ot any ot these files, as well as card decks containing them, are available upon request; they should be requested by the file name (e.g., BUSES.320). given at the beginning of each file description.

VI. References. Each method description has its own reference list. 
Method 100

AIR

Categories used:

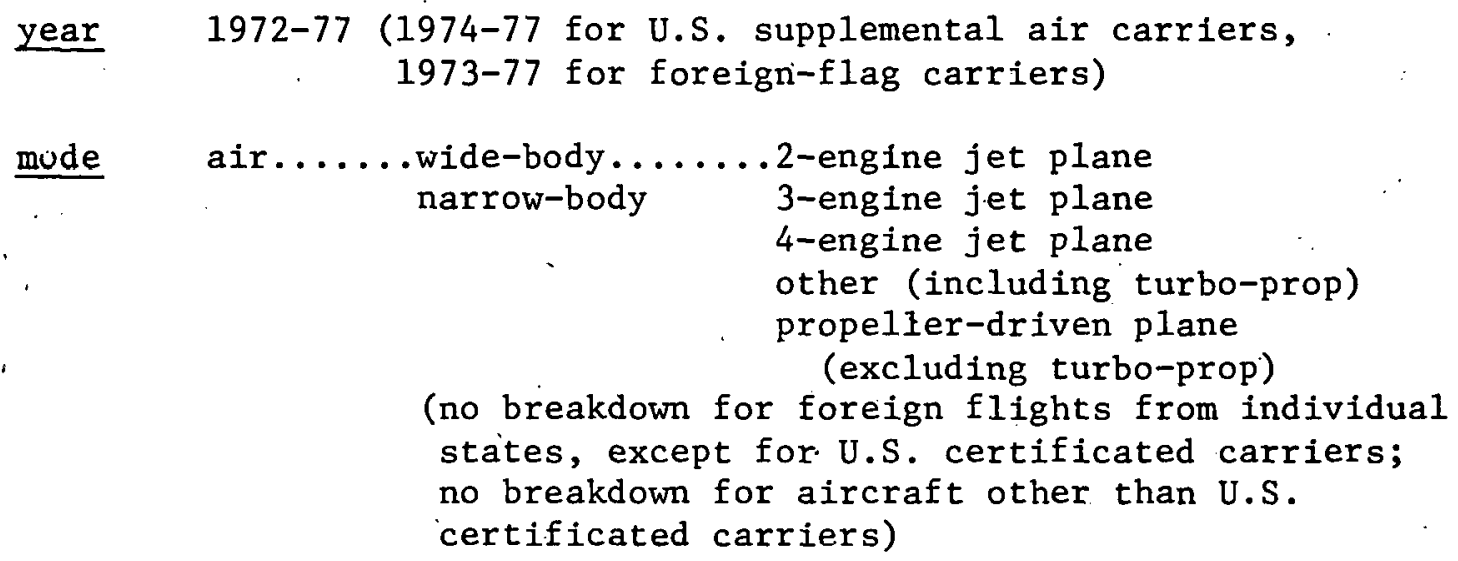

sector commercial (i.e., all common carriers; no breakdown for aircraft other than common carriers)

range regional (i.e., all flights of aircraft other than common carriers, and all flights of airlines other than the major ones and of supplemental carriers)

intercity (i.e., flights of major U.S. and of foreign-flag airlines)

foreign (i.e., flights departing the U.S. for other countries)

fuel aviation gasoline

jet fuel........kerosene type

residual oil (i.e., lubricating oil for certificated carriers)

use passenger (i.e., all passenger aịcraft, including those that carry belly freight)

nonpassenger.......freight (i.e., all freight aircraft)

(breakdown for U.S. certificated carriers only)

carrier common (i.e., all commercial airlines; air taxis and commuter aircraft excluded)

private (i.e., all general aviation, plus air taxis and commuter aircraft)

certificate certificated U.S. air carriers

everything else

(see below for an explanation of this breakdown) 
region and state (no breakdown for U.S. supplemental air carriers or for jet fuel use by general aviation)

N.B. Estimates of jet fuel use by common carriers providing service to other countries (except for certificated carriers), when broken down by state, omit all fuel used by noncertificated domestic (i.e., supplemental) carriers. Estimates not so broken down omit nothing.

Energy use reported for aircraft other than common carriers includes that used by commuter aircraft and by air taxis, since their consumption could not be separated (see Method 104).

The fuel or energy use attributed to a state is that used by aircraft in flights that depart from that state. Finergy usp altributed to forelgn tlights is that of planes leaving the U.S. for foreign countries.

Estimates of certificated carrier jet fuel use in some states exceed the recorded total use of jet fuel in those states. This is because the latter figure represents sales, which need not occur in the states where the fuel is actually burned (as determined in the way just described). This is discussed further in Method 104.

Estimates of fuel used for air freight includes consumption by freight aircraft only. Freight in the bellies of passenger aircraft is accorded an energy-free ride. See Method 101 for treatment of mixed passenger-freight aircraft (i.e., craft having a vertical partition separating passengers and freight).

The computation of energy use by certificated carriers required a series of data sets, each the result of calculations on the last, beginning with the Civil Aeronautics Board tapes and ending with the air section of the End Use Data Base tapes described in Chap. 8. The "Input Data F1les" section documents only the penultimate data sets, those from which the data for the tapes were derived directly. Because of its complexity, complete documentation of the intermediate data sets has been submitted in a separate packet and is available on request. And as always, the computer programs that made the calculations have been turned over to the Energy Department and are available. Meanwhile, the method by which the final figures were arrived at is completely documented here.

The energy consumption of an aircraft is defined to be the energy content of the fuel burned to power its engines.

The air mode presents a peculiar problem to one who would estimate energy use, in that the operations of one group of aircraft, the certificated air carriers, are monitored in detail by the Civil Aeronautics Board, whereas little can be inferred about the energy use of the rest. This contrast is slightly exasperating because the division between certificated and other aircraft corresponds to no division that can be 
consistently delineated within the nine major end use breakdowns (mode, year, sector, range, fuel, carrier, use, income, state). So, to avoid wasting the wealth of data from the certificated carriers, an extra breakdown has been created expressly to solve this problem: the "certificate" breakdown, which classifies transportation energy as that used by certificated air carriers or as that used by anything else. Aircraft energy estimates that fall into the certificated category tend to be accurate and highly disaggregated, whereas the remaining estimates do not.

Once energy use by certificated carriers is estimated, energy use by supplemental carriers, foreign-flag carriers and general aviation can be estimated separately for each. Supplemental air carriers normally provide charter service, usually for civilian organizations but often for the military. All supplemental carrier energy use is classified in the commercial sector, however, since the chartered planes are under the economic control of the business sector. In fact, no military aircraft energy can be estimated (see Method 600). Foreign-flag carriers are carriers registered in other countries and that connect U.S. airports with cities abroad. General aviation is everything not mentioned so far, including private aircraft and corporate planes. Although the category is distinguished by classifying these aircraft as other than common carriers, they unavoidably include commuter aircraft and air taxis as well. Unfortunately it is impossible to distinguish those general aviation craft belonging to the commercial sector from those belonging to the household sector.

The breakdowns provided for each of the four classes of aircraft are as follows.

(a) Certificated carriers - U.S. certificated commercial common-carrier fuel use, broken down by year (1972-77), type of aircraft (e.g., 3-engine jet), type of fuel (aviation gasoline/jet fuel), range (foreign/intercity/regional), use (passenger/freight), and state.

(b) Supplemental carriers - U.S. noncertificated commercial common-carrier jet fuel use, broken down by range (foreign/regional). (Fuel use classified as foreign includes the national totals for foreign-flag air carriers.) There is no breakdown by state.

(c) Foreign-flag carriers - Foreign noncertificated (i.e., by the U.S.) commercial common carrier jet fuel use for flights departing from the U.S., broken down by year (1970-77) and state. There is no breakdown by type of aircraft or use.

(d) General aviation - U.S. noncertificated aircraft fuel use, classified as other than common carrier and as providing "regional" service, broken down by year (1970-77) and state, except that jet fuel is not broken down by state. There is no breakdown by type of aircraft. 
A discussion of the somewhat awkward range breakdown can be found in Sec. 3.5. The energy use within the above four classes is estimated respectively in Methods 101-104.

Part of the jet fuel used by noncertificated common carriers providing service to other countries is included among the supplemental carrier estimates, and the rest is included among the foreign-flag carrier estimates. Method 105 explains how these are added together to arrive at the correct total.

101. Certificated air carrier fuel use, 1970-77, by fuel by range by use by aircraft type by state

The detailed accounting of certificated air travel provided on computer tapes by the Civil Aeronautics Board enables fairly accurate estimates of energy use, even when broken down rather finely by state, range and type of aircraft. Schedule T3 (Ref. 1) catalogs the number of all scheduled and nonscheduled departures by carrier.(e.g., United), aircraft make and model (e.g., Boeing 707), cabin configuration (passenger, cargo, mixed), airport and quarter. The total tons of cargo loaded and the number of passengers embarking and disembarking before departure are recorded along with the number of departures. Schedule T2 (Ref. 2) provides, among many other data, the fuel and oil use nationwide for each certificated air carrier. Practically the only estimation necessary is that of fuel use by state, and this is done with considerable accuracy below.

These data permit a breakdown of energy use by year (1970-77), type of aircraft (e.g., three-engine jet), type of fuel, range, use (passenger/ freight), and state. The type of fuel is easily inferred from the type of aircraft: propeller engines (except for turboprop engines) burn aviation gasoline, and the remaining engines in commercial use burn the kerosene type of jet fuel. The range categories used are intercity, regional and foreign. The large airlines connecting major cities (United, PanAm, etc.) are classified as making intercity and possibly foreign flights;

Schedule T3 permits the distinction of flights to foreign countries from domestic flights. The smaller airlines connecting large cities with lesser cities are classified as making regional flights. The fuel used by passenger aircraft is charged wholly against consumption for passenger transport; the energy cost of the luggage and cargo in the belly of the plane is regarded as part of the cost of transporting people. Cargo aircraft fuel use is counted as consumption for freight transport. About 2 or $3 \%$ of certificated aircraft fuel is used by mixed passenger-cargo planes, which are popular in Alaska. The fuel use of these is allotted to passenger and cargo consumption in proportion to the weight of the passengers and the cargo aboard the plane. 
Estimation begins with a determination of some highly disaggregated energy intensities. The extra fuel required to carry each extra ton of payload a mile has been estimated in Ref. 3 for each aircraft type. The fuel required to carry an empty plane a mile is calculated from this figure and the fuel required to carry the loaded planes:

$$
\text { EI }_{\text {fcrmn }}^{\text {empty }}=\frac{F_{\text {fcrmng }}-\mathrm{TM}_{\text {fcrmng }} \mathrm{EI}_{\mathrm{ft}(\mathrm{m})}^{\text {tons }}}{\mathrm{VMT}_{\text {fcrmn }}}
$$

where

$$
\begin{aligned}
& \mathrm{EI}_{\text {fcrmnq }}^{\text {empty }} \text { average gallons per mile of fuel } \mathrm{f} \text { required by carrier } \\
& c \text { to fly an empty p.lane of make and model } \mathrm{m} \text { and cabin } \\
& \text { configuration } n \text { over a range } r \text { during quarter } q \\
& \mathrm{~F}_{\text {fcrmng }}=\text { total fuel of type } \mathrm{f} \text { used by planes of make and model } \mathrm{m} \\
& \mathrm{EI}_{\mathrm{fa}(\mathrm{m})}^{\text {tons }}=\text { average extra gallons of fuel } \mathrm{f} \text { per mile required to }
\end{aligned}
$$

This calculation of energy intensities permits the fuel use by each carrier to be broken down into that used by scheduled revenue flights, nonscheduled revenue flights and nonrevenue flights. And this breakdown by type of service will later permit a more accurate allocation of fuel use to the states. So, we have:

$$
\begin{aligned}
& F_{\text {fcrmnq }}^{s, r}=E I_{f c r m n q}^{\text {empty }} \mathrm{VMT}_{f \text { crmn }}^{s, r}+E_{f t(m)}^{\text {tons }} \mathrm{TM}_{\text {fcrmnq }}^{s, r} \\
& F_{\text {fcrmnq }}^{\mathrm{ns}, \mathrm{r}}=\mathrm{EI}_{\text {fcrminq }}^{\text {empty }} \mathrm{VMT}_{\text {ferinnq }}^{\mathrm{ns}, \mathrm{r}}+\mathrm{ET}_{\mathrm{ft}(\mathrm{m})}^{\text {tons }} \mathrm{TM}_{\text {fcrmn }}^{\mathrm{ns}, \mathrm{r}}
\end{aligned}
$$




$$
\begin{aligned}
& F_{f c r m n q}^{n r}=E_{f c r m n q}^{e m p t y} V M T_{f c r m n q}^{n r} \\
& O_{f c r m n q}^{s, r}=\left(F_{f c r m n q}^{s, r} / F_{f c r m n q}\right) \cdot O_{f c r m n q} \\
& O_{f c r m n q}^{n s, r}=\left(F_{f c r m n q}^{n s, r} / F_{f c r m n q}\right) O_{f c r m n q} \\
& O_{f c r m n q}^{n r}=\left(F_{f c r m n q}^{n r} / F_{f c r m n q}\right) O_{f c r m n q}
\end{aligned}
$$

where

$$
\begin{aligned}
& O_{\text {ferming }}=\text { tntal 1ubricating oil uocd by planes } \\
& \text { of make and model } \mathrm{m} \text { and cabin } \\
& \text {, configuration } n \text {, belonging to carrier } \\
& c \text { and flying over range } r \text { during } \\
& \text { quarter q (Ref. 2) } \\
& \mathrm{F}^{\mathrm{s}, \mathrm{r}}, \mathrm{VMI}^{\mathrm{s}}, \mathrm{r}, \mathrm{TM}^{\mathrm{s}, \mathrm{r}}, \mathrm{O}^{\varepsilon, \dot{\mathrm{r}}}=\text { fuel, plane-miles, ton-miles and oil } \\
& \text { pertaining to scheduled revenue } \\
& \text { flights (Refs. } 1 \& 2 \text { ) } \\
& F^{\mathrm{ns}, \mathrm{r}}, \mathrm{VMT}^{\mathrm{ns}, \mathrm{r}}, \mathrm{TM}^{\mathrm{ns}, \mathrm{r}}, \mathrm{O}^{\mathrm{nS}, \mathrm{r}}=\text { fuel, plane-miles, ton-miles and oil } \\
& \text { pertaining to nonscheduled revenue } \\
& \text { flights (Refs. } 1 \& 2 \text { ) } \\
& F^{\mathrm{nr}}, \mathrm{VMT}^{\mathrm{nr}}, \mathrm{TM}^{\mathrm{nr}}, \mathrm{O}^{\mathrm{nr}}=\text { fuel, plane-miles, ton-miles and of } 1 \\
& \text { pcrtaining to nonreveuue flights } \\
& \text { ( } \operatorname{Refs} .1 \& 2 \text { ) }
\end{aligned}
$$

Since the number of nonrevenue departures is not available, there is no breakdown of nonrevenue service into that which is scheduled and that which is unscheduled. The breakdown is assumed to show the same fractions as the parallel breakdown of fuel use for revenue service:

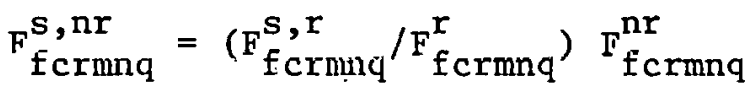

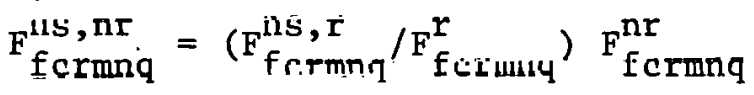

where,

$$
\begin{aligned}
F^{s, n r} & =\text { fuel use for scheduled nonrevenue flights } \\
F^{n s, n r} & =\text { fuel use for unscheduled nonrevenue flights } \\
F_{\text {fcrmnq }}^{r} & =F_{\text {fcrmnq }}^{s, r}+F_{f c r m n q}^{n s, r}
\end{aligned}
$$


Now we can add to get the fuel use for all scheduled and all unscheduled flights:

$$
\begin{aligned}
& F_{\text {fcrmnq }}^{s}=F_{\text {fcrmnq }}^{s, r}+F_{f c r m n q}^{s, n r} \\
& F_{\text {fcrmnq }}^{n s}=F_{f c r m n q}^{n s, r}+F_{f c r m n q}^{n s, n r}
\end{aligned}
$$

The lubricating oil use for all scheduled and all unscheduled flights,

$$
o_{\text {fcrmnq }}^{s}, o_{\text {fcrmnq }}^{\text {ns }}
$$

is derived from formulas (5), (6) and (7) in exactly the same way that scheduled and unscheduled fuel use is derived above from formulas (2), (3) and (4).

Each carrier's fuel and oil use can now be allotted to the states in proportion to the number of scheduled and unscheduled departures in each state. The breakdown by fuel, range, aircraft make and mode1, and quarter is maintained.

$$
\begin{aligned}
F_{\text {fcrmnsq }} & =\frac{D_{\text {fcrmnsq }}^{s}}{D_{\text {fcrmnsq }}} F_{\text {fcrmnq }}^{s}+\frac{D_{\text {fcrmnsq }}^{n s}}{D_{\text {fcrmnsq }}} F_{\text {fcrmn }}^{n s} \\
O_{\text {fcrmnsq }} & =\frac{D_{\text {fcrmnsq }}^{s}}{D_{\text {fcrmnsq }}} O_{\text {fcrmnq }}^{s}+\frac{D_{\text {fcrmnsq }}^{n s}}{D_{\text {fcrmnsq }}} O_{\text {fcrmnq }}^{n s}
\end{aligned}
$$

where

$$
\begin{aligned}
& \mathrm{F}_{\text {fcrmnsq }}=\text { fuel of type } \mathrm{f} \text { used by planes of make and model } \mathrm{m} \\
& \mathrm{F}_{\text {fcrmnq }}^{\mathrm{S}}=\text { fuel used for scheduled flights, from (10) } \\
& F_{\text {fcrmnq }}^{\text {ns }}=\text { fuel used for unscheduled flights, from (11). } \\
& o_{\text {fcrmnq }}^{s}, O_{\text {fcrmnq }}^{\text {ns }}=\underset{\text { from (12) }}{\text { oil used for scheduled and unscheduled flights, }} \\
& \begin{aligned}
\mathrm{D}_{\text {fcrmnsq }}= & \text { number of departures from points in state } \mathrm{s} \text { of } \\
& \text { planes burning fuel } \mathrm{f} \text {, of make and model } \mathrm{m} \text { and }
\end{aligned} \\
& \text { cabin configuration } n \text {, belonging to carrier } c \\
& \text { and flying over range } r \text { during quarter } q \text { (Ret. 1) }
\end{aligned}
$$




$$
\begin{aligned}
D^{S} & =\text { number of scheduled departures (Ref. 1) } \\
D^{n s} & =\text { number of unscheduled departures (Ref. 1) }
\end{aligned}
$$

Al1 that remains is properly to aggregate the figures calculated according to (13) and (14). Passenger and freight energy use are treated separately.

$$
\begin{aligned}
& \mathrm{F}_{\text {frast }}^{\mathrm{p}}=\sum_{\mathrm{c}} \sum_{\mathrm{m \varepsilon a}} \sum_{\mathrm{q} \varepsilon \mathrm{t}}\left(\mathrm{F}_{\text {fcrmsq }}^{\mathrm{p}}+\frac{\mathrm{TM}_{\text {frrmq }}^{\mathrm{p}}}{\mathrm{TM}_{\text {fermq }}} \cdot \mathrm{F}_{\text {fcrmsq }}^{\mathrm{m}}\right) \\
& \mathrm{F}_{\text {frast }}^{\mathrm{f}}=\sum \sum_{\mathrm{m} \varepsilon \mathrm{a}} \sum_{\mathrm{q} \varepsilon t}\left(\mathrm{~F}_{\text {fcrmsq }}^{\mathrm{f}}+\frac{\mathrm{TM}_{\text {fcrmq }}^{\mathrm{f}}}{\mathrm{TM}_{\text {fcrmq }}} \cdot \mathrm{r}_{\text {fcrmsq }}^{\mathrm{m}}\right)
\end{aligned}
$$

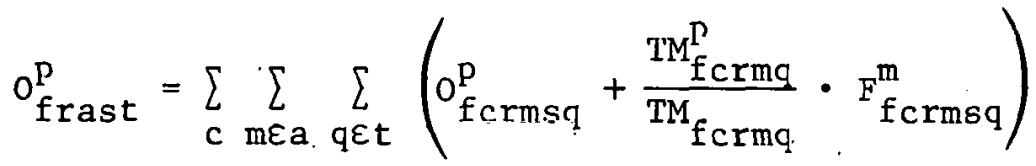

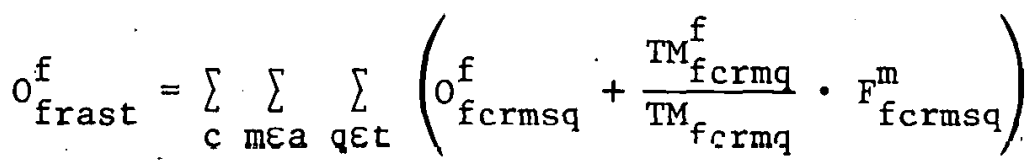

where

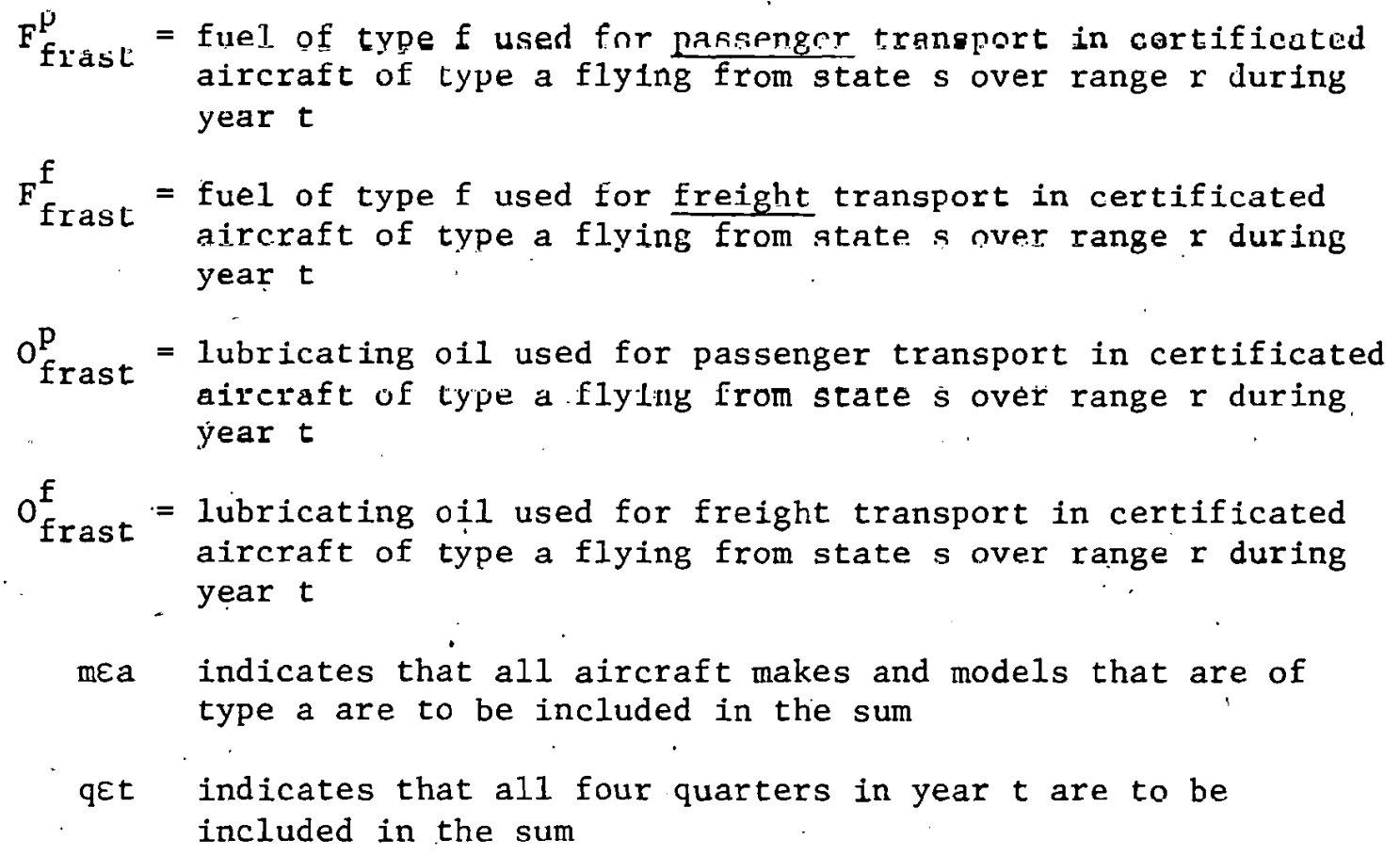




$$
\begin{aligned}
& F_{\text {fcrmsq }}^{\mathrm{P}}=\text { fuel of type } \mathrm{f} \text { used by passenger aircraft of make and } \\
& \mathrm{F}_{\text {fcrmsq }}^{\mathrm{f}}=\text { fuel of type } \mathrm{f} \text { used by cargo aircraft of make and model } \mathrm{m} \text {, }
\end{aligned}
$$
$\mathrm{TM}_{\text {fcrmq }}^{\mathrm{P}}=$ ton-miles of passengers flown by mixed passenger/cargo aircraft of make and model $\mathrm{m}$, belonging to carrier $\mathrm{c}$ and flying over range $r$ during quarter $q$ (Ref. 1)
$\mathrm{TM}_{\text {fcrmq }}^{\mathrm{f}}=$ ton-miles of cargo flown by mixed passenger/cargo aircraft . of make and model $\mathrm{m}$, belonging to carrier $\mathrm{c}$ and flying over range $r$ during year $t$ (Ref. 1$)$

Note: The Civil Aeronautics Board tape for Schedule T-2 (Ref. 2) was not available for the last quarter of 1977. Consequently fuel use in this quarter was calculated by computing the average fuel use per departure, in each category, during the first three quarters, and multiplying the result by the number of departures in each category during the fourth quarter of 1977.

102. U.S. supplemental air carrier jet fuel use, by range, 1974-77

The amount of fuel (nearly all jet fuel) consumed by supplemental air carriers is directly available from the Civil Aeronautics Board Form 41, Schedule. P-12(A) (Ref. 6). No data prior to 1974 exist, and no breakdown by state is possible. These national totals were derived from Ref. 6 first by estimating the fuel used in domestic and international operations and then by discounting half the international fuel (since tuel purchased in forelgu cuuntries is not included in this data base). The domestic and international breakdown was got by allotting fuel use to each in the same ratio as the number of aircraft hours flown in 1976 in domestic and international supplemental air carrier service, obtained from the Transportation Systems Center (Ref. 7). 
In summary,

$$
F_{r t}= \begin{cases}\frac{H_{r}}{H} F_{t} & \text { if } r \neq \text { regional (i.e., domestic) } \\ \frac{{ }_{r}}{H}\left(\frac{1}{2} F_{t}\right) & \text { if } r=\text { international }\end{cases}
$$

where 31

$$
\begin{aligned}
& F_{\underline{r t}}=\text { jet fucl used by U.3. supptemetral afr carriere opcrating over } \\
& \begin{aligned}
& H_{r}=\text { aircraft hours flown over range } r \text { by U.S. supplemental air } \\
& \text { carriers in } 1976 \text { (Ref. 7) }
\end{aligned} \\
& H=\text { total aircraft hours flown by U.S. supplemental air carriers } \\
& \text { in } 1976 \text { (Ref. 7) } \\
& F_{t}=\underset{\text { reported jet fuel used by U.S. supplemental air carriers in }}{\text { year }} \\
& \text { Only the domestic fuel use so calculated is recorded on the data }
\end{aligned}
$$

103. Foreign flag air carrier jet fuel use, 1973-77, by state

The only available data concerning foreign-flag air carrier activity from the U.S. are the number of aircraft departures by airport, which were provided by the Transportation Systems Center (Ref. 7). The fucl used by foreign planes leaving a given airport must be estimated by supposing the average flight uses the same amount of fuel as the average international flight of a U.S. plane providing similar service. For example, to calculate the foreign-flag fuel use at Kennedy airport the average fuel used by a U.S. plane providing service to Europe would be used, This average is calculated by dividing the fuel used by U.S. carriers providing such service by the number of such flights, information available from Refs. 1 and 2 . 
In summary,

$$
F_{s t}=\sum_{p \varepsilon s} D_{p t}^{\text {for }} \cdot \frac{F_{(p) t}^{\text {u.s. }}}{D_{(p) t}^{u . s .}}
$$

where

$$
\begin{aligned}
& \begin{aligned}
\mathrm{F}_{\text {st }}= & \text { amount of jet fuel used by foreign-flag carriers leaving } \\
& \text { airports in state s during year } t \text { (recorded in File } 8 \text { ), }
\end{aligned} \\
& \text { pes indicates that airports } p \text { in state } s \text { are included in the sum } \\
& \mathrm{D}_{\mathrm{pt}}^{\mathrm{for}}=\underset{\text { number of departures of foreign-flag aịcraft from airport } \mathrm{p}}{\text { during year } t \text { (Ref. } 7 \text { ) }} \\
& D_{(p) t}^{\text {u.s. }}=\text { number of departures during year } t \text { of U.S. aircraft providing } \\
& \text { international service similar to that provided by foreign- } \\
& \text { flag aircraft leaving airport p during year } t \text { (Ref. 1) } \\
& F_{(p) t}^{\text {u.S. }}=\text { jet fuel used during year } t \text { by U.S. aircraft providing } \\
& \text { international service similar to that provided by foreign- } \\
& \text { flag aircraft leaving airport } p \text { during year } t \text { (Ref. 2) }
\end{aligned}
$$

104. General aviation use of aviation gasoline, 1974-77, by fuel by state

Because few reliable data are available concerning general aviation fuel use, these values must be calculated as a residual. The aviation gasoline uscd in each state by certificated, supplemental and foreign-flag carriers is subtracted from the total aviation gasoline sold in that state (Ref. 4). Since the supplemental fuel (Method 102) is not broken down by state, it is allotted to the states in the same proportion as certificated air carrier fuel, for the purposes of this calculation. The formula is,

$$
F_{s t}=T_{s t}-C_{s t}-I_{s t}-\frac{C_{s t}}{C_{t}} s_{t}
$$


where

$$
\begin{aligned}
& F_{\text {st }}=\begin{array}{l}
\text { aviation gasoline used by general aviation in state } s \text { during } \\
\text { year } t
\end{array}
\end{aligned}
$$

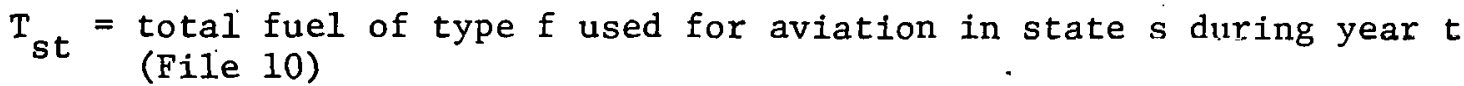

$$
\begin{aligned}
& \begin{array}{l}
\mathrm{C}_{\text {st }}=\text { fuel of type } \mathrm{f} \text { used by certificated air carriers in state } \mathrm{s} . \\
\text { during year } t \text { (from Method } 107 \text { ) }
\end{array} \\
& 1_{\mathrm{H}}=\text { fuel of type } f \text { liser hy foreign-flag oarricro ocrving state } s \\
& \text { during ycar } t \text { (from Method 103) } \\
& c_{t} \text {. fuel' of lype } I \text { used by cercificated air carriers nationwide } \\
& \text { during year } t \text { (from Method 101) } \\
& S_{t}=\text { fuel of type } f \text { used nationwide by supplemental air carriers } \\
& \text { during year } t \text { (from Method 102) }
\end{aligned}
$$

Unfortunately, no breakdown by aircraft type is possible.

The state-by-state estimation of jet fuel use by general aviation is impossible due to a basic incommensurability of data sources. Air carriers use the bulk of jet fuel sold in the U.S., and Method 101 divides this use among the states in a way based on the fuel consumed in flight legs originating in each state. The fuel burned in a leg starting in Kentucky, however, may have been sold in New York. Consequently the jot fuel uoed by certificated carriers in some states exceeds the total jet fuel sales in those states. This is particularly true of those states that do not contain major air terminals, terminals where refueling is more often done. If general aviation jet fuel use is estimated as a residual in these states, a negative number results (as can be seen in File 10). This problem does not arise in the estimation of aviation gasoline use by general aviation because air carriers consume relatively little aviation gasoline and because the distances between refuelings of aviation gasoline are shorter. Also, general aviation jet fuel use is yet estimable on a national level:

$$
F_{t}=T_{t}-C_{t}-I_{t}-S_{t}
$$

where

$$
\begin{aligned}
& F_{t}=\text { general aviation jet fuel use nationwide in year } t \\
& T_{t}=\text { total jet fuel use nationwide in year } t
\end{aligned}
$$

For comparison, total sales of aviation gasoline and jet fuels, by state, are recorded in the data base; these are also recorded in File 10. 


\section{5.' Aggregations}

Most of the energy use categories not already explicitly provided estimates in Methods 101-104 can be computed simply by summing these estimates over appropriate breakdown(s). For instance, the jet fuel used by common carriers providing domestic passenger service in 1977 is the sum of that used in all states by certificated carriers in this category (Method 1.01) and in all states by supplemental carriers in' this category (Method 102). Certain estimates involving foreign service, however, cannot be computed by suming over breakdowns. These are the estimates of jet fuel used by noncertificated air carrlers providing service to other countries. The difficulty is that part of this jet fuel is counted among the estimates of U.S. supplemental carrier fuel use (Method 102), and the rest among the estimates of foreign-flag carrier fuel use (Method 103). Consequently estimates in this category are documented here, Method 105, and they are derived from estimates described in Methods 102 and 103 in the following way:

$$
F_{t}=F_{t}^{\text {supp } 1}+\sum_{s} F_{s t}^{\text {for }}
$$

where

$$
\begin{aligned}
& F_{t}=\text { jet fuel used by noncertificated common carriers providing } \\
& F_{t}^{\text {suppl. }}=\text { jet fuel used by supplemental common carriers of type a } \\
& F_{\text {ft }}^{\text {for. }}=\text { jet fuel used by foreign-flag common carriers providing }
\end{aligned}
$$

Note that only within the foreign-flag carrier class is the fuel use of noncertificated common carriers providing service to other countries broken down by state. Consequently estimates of jet fuel use by common. carriers providing service to other countries (except for certificated carriers), when broken down by state, omit all fuel used by supplemental carriers. 


\section{Input Data Files}

File 1. U.S. certificated air carrier fuel use, by fuel by range by use by aircraft type by state, 1972. File name = AIR72.100

Format: $\operatorname{col}$.

2-6 carrier code (interpretation of the codes not available at the time of writing)

7-8 year

11-13 state or nation code (only the state codes are relevant here; they are the same as the census codes used in the End Use Data Base, as described in Sec. 8.2, except that the last 5 codes are different*), right-justified integer

16-17 aircraft type code** (right-justified integer)

18-32 fuel used for scheduled flights, in gallons (decimal point in col. 30 )

33-47 fuel used for nonscheduled flights (decimal point in col. 45)

48-62 scheduled + nonscheduled fuel use (decimal point in col. 60)

63-77 lubricating ofl used for scheduled flights (decimal point in col. 75)

78-92 lubricating oil used for nonschedule flights (decimal point in col. 90)

93-107 scheduled + nonscheduled lubricating oil (decimal point in col. .105)

*state codes that differ are:

$\begin{array}{ll}\text { California } & 91 \\ \text { Oregon } & 92 \\ \text { Washington } & 93 \\ \text { Alaska } & 01 \\ \text { Hawai1 } & 02\end{array}$

**the alrcraft type codes are:

1 - propeller (excluding turbo-prop)

2 - mlscellaneous curbinè

3 - 2-engine narrow body

4 - 3-engine narrow body

5 - 3-engine wide-body

6 - 4-engine narrow body

7 - 4-engtne wide body

Source: Method 101

Files 2-6. Same content as File 1, except for years 1973-77 respectively. File names $=$ AIR73.100, AIR74.100, .., AIR77.100

Format: Same as File 1.

Source: Same as File 1. 
File 7. U.S. supplemental air carrier jet fuel use, by range, 1974-78. File name $=$ SUPPLE .100

Format: $\operatorname{col}$.

1-2 year

3-12 supplemental air carrier fuel use for domestic service (right-justified integer), gallons

13-22 supplemental air carrier fuel use for international

Source: Method 102

File 8. Foreign-flag air carrier jet fuel use, by state, 1973-7.7. File name $=$ FORGN .100

Format: $\operatorname{col}$.

1-2 year

4-5 state FIPS code (see Sec. 8.2)

6-20 jet fuel use in gallons (decimal point in col. 20)

\section{$\therefore$ Source: Method 103}

File 9. General aviation fuel use, by fuel by state, 1974-77. File name $=$ GENRL. $: 100$

Format: col.

$1-2$

$4 \div 5$

state FIPS code (see Sec. 8.2):

$11-20$

year

$21-30$

aviation gasoline use in thousands of gallons (rightjustified integer)

21-30 jet fuel use in thousands of gallons, calculated as a residual (right-justified integer)

Source: Method 104

File 10. Total sales of jet fuel and aviation gasoline, by fuel by state, 1974-77. File name = FUEL. 100 .

Format: $\operatorname{col}$.

1-2 state FIPS code (see Sec. 8.2)

4-5 year

11-20 sales of aviation gasoline, in thousands of gallons (right-justified integer)

21-30 sales of jet fuel, in thousands of gallons (rightjustified integer)

Source: Ref. 4 
Data Quality Numbers

Method 101. All fuel and energy estimates for certificated carriers, however broken down

Method 102. total fuel and energy use estimates for supplemental. air carriers providing

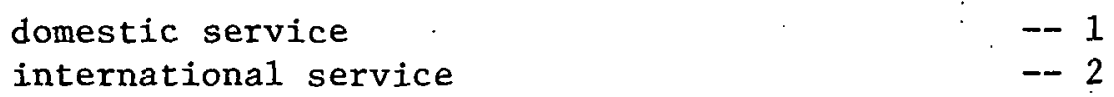

Method 103. All fuel and energy estimates for foreign-flag air carriers providing service to other rnuntries from the U.S., broken down by year by state --2

Method 104. All estimates of the use of aviation gasoline and of energy in that form by aircraft other than common carriers, however broken down

Method 105. All fuel and energy estimates for noncertificated common carriers providing service to other countries, broken down by year only

The data quality numbers for all aggregations of these estimates are computed as described in Method 900. 


\section{$\underline{\text { References }}$}

1. National Archieves and Records Service, Machine-Readable Archives Division, CAB Form 41, Schedule T-3, Washington, D.C., 1970-77.

2. National Archives and Records Service, Machine-Readable Archives Division, CAB Form 41, Schedule T-2, Washington, D.C., 1970-77.

3. A. B. Rose, The Energy Intensity and Related Parometers of Selected Transportation Modes: Freight Movements, ORNL-5554, Oak Ridge, TN, 1979.

4. Unpublished data obtained from the Federal Aviation Administration.

5. Civil Aeronautics Board, Handbook of Airline Statistics: Supp.lement.

6. Civil Aeronautics Board Form 41 Schedule P-12(A), Washington, D.C., 1974-77.

7. Personal communfcations from D. Schieder, Transportation System Center, U.S. Dept. of Transportation, Cambridge, MA. 
Method 200

RAIL

Categories used:

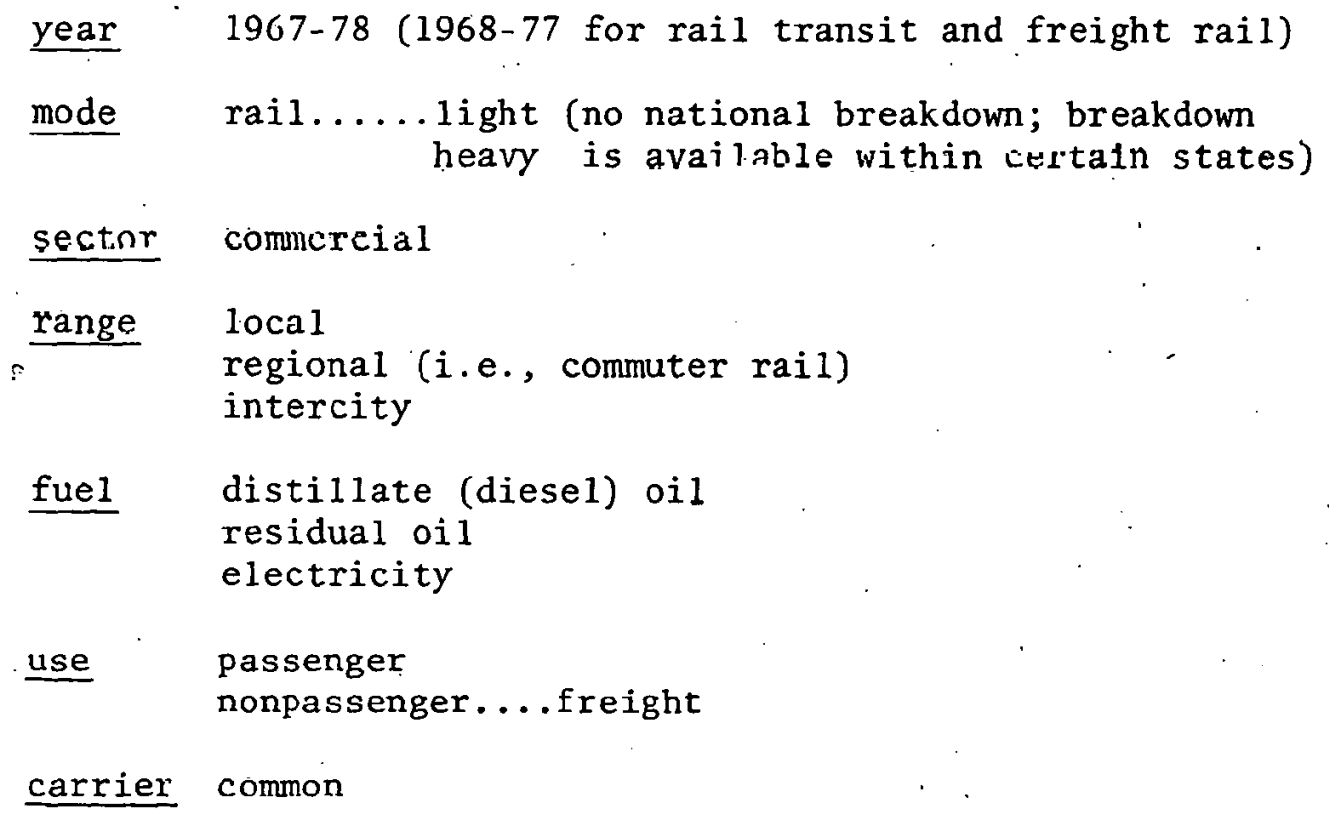

region and state

Tho cnergy isinsumption of a rallroad is the energy content of the oil it burns plus the Btu equivalent of the electricity it takes from the catenary or third rail. An exception is local rail transit (e.g., subways), whose energy consumption is taken to be the energy consumed both for traction and for operating the facilities generally. No account is taken of the energy wasted in the generation and transmiooinn $i f$ electricity (see Sec. 1..?). D1c3el-tlectric locomotives are viewed as consuming the energy content of the fuel they burn, cves. Lhough their trastion engines die actually powered by electricity generated by diesel engines on board the locomotive.

"Heavy rail" refers to crailis pulled by a locomotive, such as intercity freight and passenger trains and subway trains. "Light rail" refers to rail cars individually equipped with engines, such as rail trolley cars. All light rail systems are transit systems.

Rail energy use is best estimated by determining passenger rail energy use first, and then treating the far larger freight rail energy use as a residual. Local, commuter and intercity passenger rail are. treated separately. The local rail operations are the transit systems, usually subterranean or elevated. Commuter rall service, here classified under the "regional" category of the range breakdown, is service between 
major cities and outlying towns and suburbs. Intercity rail service includes only the rail lines that connect major cities with each other or with smaller cities beyond ordinary commuting distance.

201. Rail transit electricity use, by weight (light/heavy) by state, 1968-77

Rail transit operations are classified in the End Use Data Base as local common-carriers in the commercial sector, even if most are supported in part by public funds. Energy use figures are obtained from the individual systems in the following way:

1. The systems operating in a given year are obtained from The American Public Transit Association's Transit Fact Book (Ref. 1).

2. The energy use of those reporting to the American Public Transit Association is obtained from Ref. 2.

3. The energy use of the remaining systems is gotten by contacting the operators directly.

Al1 rail transit systems run their trains with electricity.

Although, in general, this procedure yields excellent results, the user should be aware of several caveats. Principally, the data problems center around the fact that several transit systems do not maintain fully accurate records of their energy use while others report only traction energy use. (Refer to the above discussion of the definition of rail energy use.) These data problems have necessitated the following approximations:

1. New York City Transit Authority (i.e., the New Yuik subway syotem). The system reported only traction energy use for all years except 1975. In order to yield estimates to total energy use the nontraction energy use of 369.5 million kilowatt-hours for 1975 (Ref. 3) was assumed to remain constant over time and was added to the traction energy use for the other years to yield estimates of total energy use.

2. Southeastern Pennsylvania Transportation Authority (SEPTA), Philadelphia, Pennsylvania. Actual energy use values for 1970 and 1971 were not available. Included in the totals are SEPTA estimates for those years.

3. Greater Cleveland Regional Transit Authority (RTA), cieveland, Ohio. Actual values for 1967-69 were not available. Included in the totals are RTA estimates for those years. 
4. Municipality of Metropolitan Seattle (i.e., the Seattle monorail), Seattle, Washington. Only traction energy use values were available and were permitted to serve as estimates of total energy use.

5. Dillard's Department Store Tandy Line, Forth Worth, Texas. No exact time-series data are available. Since operations remained relatively constant, and the entire system consists of about one mile of line, the monthly energy use of roughly 55,000 kilowatt-hours was assumed to remain constant over time.

6. Port Authority Trans-Hudson Corporation (PATH), New York, NY. The total energy use values are known, but since the system operates in both New York and New Jersey the energy use by stace had to be estimated by allocating equal amounts to each state.

7. Wash1ngton Metropolitan Area Transit Authority (Metro), Washington, D.C. No values were available for 1976 and 1977 , so that the national totals consistently omit the energy used by this system.

In spite of these approximations, the state-level reported data should deviate less than $10 \%$ (except in. Washington state) from the true value, for the years for which data are provided.

Breakdown into light and heavy rail is difficult, since several systems operate both types of rail and often cannot rellably separate the two with respect to energy use. The inability of the large Boston system alone (i.e., Massachusetts Bay Transportation Authority) to make the separation makes a national breakdown by light and heavy impossible. State level breakdowns by light/heavy, however, are provlded for chose states containing systems which operate only one type of rail. The light vs. heavy rall estimates that were available from some of the dual systems were judged not to be reliable enough to report. The situation is summed up below:

\section{State Light/heavy breakdown? State Light/heavy breakdown?}

$\begin{array}{llll}\text { California } & \text { yes } & \text { New Joroey } & \text { yes } \\ \text { Illinois } & \text { yes } & \text { New York } & \text { yes } \\ \text { Louisiana } & \text { yes } & \text { Nhio } & \text { no } \\ \text { Michigan } & \text { yes } & \text { Texas } & \text { yoa } \\ \text { Maseachusetts } & \text { no } & \text { Washington } & \text { no }\end{array}$

The states not listed are those that contain no rail transit lines.

If one wishes a formulaic rendering of the above method, he might use the one below:

$$
F_{s t}=\sum_{r \dot{\varepsilon} s} F_{r s t}
$$


where

$$
\begin{aligned}
& \mathrm{F}_{\text {st }}=\text { electricity used by rail transit in state } s \text { during year } t \\
& \mathrm{~F}_{\text {rst }}=\text { electricity used by system } r \text { in state } s \text { during year } t \text { (File } 1 \text { ) } \\
& \text { res indicates that rail system } r \text { is in state } s .
\end{aligned}
$$

$$
F_{w s t}=\sum_{\substack{r \varepsilon s \\ w(r)=w}} F_{r s t}
$$

where

$$
\begin{aligned}
F_{w s t}= & \text { electricity used by rail transit classified as weight } w \\
& \text { (light or heavy) in state } s \text { during year } t \text {, where state } s \\
& \text { contains systems each of which operates one weight class } \\
& \text { only }
\end{aligned}
$$

202. Commuter rail fuel use, by fuel by state, 1967-78

Commuter rail traffic is distinguished both from local rail transit and from regular intercity service by placing it in the "regional" category of the range breakdown. The railroads providing commuter service are heavy rail operations in the commercial sector. Their energy use is not classified as commuting energy use because it is unknown how many of their passengers make short business trips or go into the city for shopping or entertainment. Rather, there is no use breakdown at all, except to classify all the energy as used for passenger transport. It should also be noted that although the eastern seaboard's passenger lines (Washington, D.C., to Boston) are heavily patronized by commuters, these trains have been classified as providing intercity transport and are accounted for in Method 203.

During the years $1972-78$ commuter service was provided by lines devoted exclusively to commuter service, with the exception of a small Amtrak commuter line in Detroit. This is because Amtrak had assumed responsibility for all intercity passenger service. (The Southern Railroad's passenger lines are here considered part of the Amtrak system.) The commuting fuel use in these years, then, is simply the total fuel use for passenger service of rallroads other than Amtrak, plus the fuel consumption of Amtrak's line (obtained directly from the company). These 
fuel use figures appear sometimes in the ICC annual reports (Ref. 5), and otherwise were obtained directly from the railroads.

Breakdown by state was obtained by attributing a commuter railroad's fuel use to the state in which it is located. Commuter railroads serving two or more metropolitan areas in different states were contacted to learn how much fuel is used in each.metropolitan area. If a metropolitan served by a commuter railroad lies in more than one state, the fuel use was. allocated to the states in proportion to the fraction of route-miles in each state.

Prior to 1972 the fuel consumption of these railroads for passenger service, except for such purely commuter lines as the Long Ioland Railroad, included fuel used for both commuter and regular intercity service. In most cases the railroads kept no distinguishing records, so that for each year 1967-71 their commuter fuel was crudely estimated to be the average annual fuel consumption after 1971. (Although Amtrak was operating in 1971, the year was one of transition and the data are of ten incomplete.)

In some cases a railroad's commuter fuel use in a given state even in years after 1971 could not be learned, often because the railroad serves several states and could not provide a breakdown. For these years, the railroad's fuel use was estimated to be the average annual consumption during years for which data are available. In other cases a commuterintercity breakdown was available from a railroad for years earlier than 1972. The data quality numbers reflect these complexities as follows. Whenever a state's fuel use in year $t$ is different than its fuel use in year $t-1$ ( $t>1967)$, the recorded data quality is 1 ; ntherwise it is 2 . 'lhis ensures that estimates that are mere averages are given the lower quality number. When all the years 1967-78 show the same fuel consumption, however, each is given a data quality of 1 , since these are cases in which the railroads concerned have assurances that their fuel consumption changes little from one year to the next.

In summary, the calculation of commuter rail fuel consumption is:

$$
F_{f s t}=\left\{\begin{array}{ll}
\sum_{c \in s} \sum_{r \in c} s^{-} \sum_{r c} \frac{R_{1 \omega s^{-}}}{R_{r c}} F_{\text {frct }} & \text { when } t>t_{I} \\
\sum_{r \varepsilon s} F_{f r s t} & \text { when } t \leq t_{r}
\end{array} .\right.
$$

where

$$
\begin{aligned}
F_{f s t}= & \text { fuel of type } f \text { used by commuter railroad service in state } s \\
& \text { in year } t \text { (recorded in File } 2 \text { ) } \\
t_{r}= & \begin{aligned}
\text { usually } 1971 ; \\
\text { it depends on the data available from railroad }
\end{aligned}
\end{aligned}
$$




\begin{abstract}
ces indicates that metropolitan areas $c$ that lie mainly in state $s$ are included in the sum.

rEc . indicates that rail systems $r$ serving metropolitan area $c$ are included in the sum

$s^{\prime}$ Erc indicates that state $s^{\prime \prime}$ reached by the lines serving metropolitan area $c$ and operated by system $r$ are included in the sum

$R_{\text {rcs }}=$ number of route-miles in state $s$ serving metropolitan area $c$ and belonging to system $r$ (Ref. 4)

$R_{r c}=$ total number of route-miles serving metropolitan area $c$ and belonging to system $r$ (Ref.4)

$F_{\text {frc }}=$ fuel of type $f$ used by commuter rail system $r$ for passenger service in metropolitan area c. (Ref. 5, or learned by direct contact with railroad)
\end{abstract}

$$
F_{\text {frst }}=\sum_{t^{\prime}=t_{r}+1}^{1978} F_{r s t^{-1}} /\left(1978-t_{r}\right)
$$

203. Intercity passenger rail fuel use, by fuel by state, 1967-78

The basic sources for estimating energy use in intercity passenger service are again the Official. Guide of the Railways (Ref. 4), which lists the railroads providing passenger service before the advent of Amtrak, their route structure and their frequency of service by route, and the ICC annual report (Ref. 5), which provides, total train-miles, fuel use by railroad, gross ton-miles and other operating data for passenger service for each railroad. Since some of the railroads provide commuter service as well, the fuel used for commuter service by each railroad (as determined in Method 202) must be subtracted from each railroad's total passenger fuel use.

Energy use by state, before Amtrak, is estimated differently than more recent fuel use. For the years 1967-71 each railroad's energy use for passenger service must be allocated to the states in which that railroad operates in proportion to the number of train-miles traveled in each state. A railroad's train-miles in a given state was calculated by hand after, consulting Ref. 4 for the frequency of each run in that state and the number of miles covered in that state by each run. The breakdown by fuel was obtained by assuming that all trains using tracks with a catenary (electric wires) overhead run on electricity and that all other trains burn diesel fuel. 
State-by-state fuel use by Amtrak (1972-78) can be estimated with somewhat greater accuracy by allocating Amtrak's fuel use to the states in proportion to the number of ton-miles (rather than train-miles) of movement in each state. Ton-miles were calculated by hand, based on the frequency and length of each run in each state and on the weight of each train. The Amtrak Annual (Ref. 8) provides not only the Amtrak schedules but the type of engine and types of cars in the consist of each scheduled train, so that the train's weight could be readily calculated.

In formulas, the calculations are:

$$
F_{f s t}= \begin{cases}\sum_{r \varepsilon s} \sum_{u \in f r s} \frac{L_{u s}{ }^{N} u}{V^{N T}}\left(F_{f r t}-C_{f r t}\right) & \text { for } t \leq 1971 \\ \sum_{u \in f s} \frac{W_{u} L_{u s} N_{u}}{T M_{f}}\left(F_{f t}-C_{f t}\right) & \text { for } t>1971\end{cases}
$$

where

$$
\begin{aligned}
& \mathrm{F}_{\mathrm{fst}}=\text { consumption of fuel } \mathrm{f} \text { by intercity rail passenger service in } \\
& \text { state } s \text { during year } t \text { (recorded in File } 3 \text { ) } \\
& \mathrm{r} \varepsilon \mathrm{s} \text { indicates that all railroads } \mathrm{r} \text { providing intercity passenger } \\
& \text { service in state } s \text { are included in the sum } \\
& \text { uefrs indicates that all trains } u \text { run by railroad } r \text { on tracks } \\
& \text { designed for trains using fuel } f \text { in state } s \text { are included in } \\
& \text { the sum } \\
& \mathrm{L}_{\mathrm{us}}=\text { length of the route covered by train } \mathrm{u} \text { in state } s \text { (Ref. 4) } \\
& \mathrm{N}_{\mathrm{u}} \text { = number of runs of train } \mathrm{u} \text { annually (Ref. 4) } \\
& \begin{aligned}
F_{\text {frt }}= & \text { fuel of type } f \text { consumed by railroad } r \text { for passenger service } \\
& \text { ln year } t \text { (Ref. 5) }
\end{aligned} \\
& \dot{C}_{\text {frt }}=\text { fuel of type } f \text { consumed by railroad } r \text { for commuter services } \\
& \text { in year } t \text { (Method 202) } \\
& \mathrm{VMT}_{\mathrm{fr}}=\sum_{\mathrm{r}} \sum_{\mathrm{u} \dot{f} \mathrm{fr}} \mathrm{L}_{\mathrm{u}} \mathrm{N}_{\mathrm{u}}=\begin{array}{l}
\text { total train-miles traveled by rallroad } \mathrm{r} \text { over } \\
\text { tracks designed for locomotives using fuel } \mathrm{f}
\end{array} \\
& \mathrm{L}_{\mathrm{u}}=\text { total length of the route covered by train u (Ref. 4) } \\
& \text { uEfr indicates that all trains } u \text { run by railroad } r \text { over tracks } \\
& \text { designed for locomotives } \\
& \text { uEfs indicates that all Amtrak trains u running over tracks } \\
& \text { designed for locomotives using fuel } f \text { in state } s \text { are included } \\
& \text { in the sum }
\end{aligned}
$$




$$
\begin{aligned}
& W_{u}=\text { weight of train } u \text { (calculated from Ref. 8) } \\
& \mathrm{TM}_{\mathrm{f}}=\sum_{\mathrm{u} \varepsilon f} \mathrm{~L}_{\mathrm{u}} \mathrm{W}_{\mathrm{u}} \mathrm{N}_{\mathrm{u}}=\begin{array}{l}
\text { total ton-miles of Amtrak passenger train } \\
\text { movements over tracks designed for locomotives }
\end{array} \\
& \text { using fuel } \mathrm{f} \\
& \text { uef indicates that all trains running on track designed for } \\
& \text { locomotives using fuel } f \text { are included in the sum } \\
& F_{f t}=\text { fuel of type } f \text { consumed by Amtrak in year } t \\
& C_{f t}=\text { fuel of type } f \text { consumed by Amtrak for commuter service in }
\end{aligned}
$$

204. Freight rail fuel use, by fuel by state, 1968-77

.. The energy used in freight operations accounts for the vast majority of all rail energy use. Consequently it is possible to calculate freight energy use as a residual, since even large errors in the estimation of the rest of rail energy use would have a very small relative effect on the freight consumption. Energy Data Reports (Ref. 6) provides the total railroad distillate (diesel) and residual oil use by state for the years 1967-78, and The Edison Electric Institute (Ref, 7) provides the railroad electricity use by state. Fuel use by transit, commuter and intercity passenger rail is subtracted from these values:

$$
F_{f s t}=R_{f s t}-T_{f s t}-C_{f s t}-I_{f s t}
$$

where

$$
\begin{aligned}
& \mathrm{F}_{\text {fst }}=\text { freight rail consumption of fuel } \mathrm{f} \text { in state } \mathrm{s} \text { during year } t \\
& \text { (recorded in Files 5, 6) } \\
& R_{\text {fst }}=\text { total rail consumption of fuel } f \text { in state } s \text { during year } t \\
& \text { (Ref. 6, 7) } \\
& \mathrm{T}_{\text {fst }}=\underset{\text { rail transit consumption of fuel } \mathrm{f} \text { in state } \mathrm{s} \text { during year } t}{ } \\
& \begin{aligned}
C_{\text {fst }}= & \text { commuter rail consumption of fuel } f \text { in state } s \text { during year } t \\
& \text { (from Method 202) }
\end{aligned} \\
& \begin{aligned}
I_{f s t}= & \text { intercity passenger rail consumption of fuel } f \text { in state } s \\
& \text { during year } t \text { (from Method 203) }
\end{aligned}
\end{aligned}
$$


Input Data Files

File 1. Rail transit energy use, by system, 1967-78. File

name $=$ TRNSIT. 200

Format: $\operatorname{col}$.

Card 1: 1-5 system abbreviation

7-8 state abbreviation

10-11 state FIPS code, (see Sec. 8.2), right-justified integer..

13 the letter A

14 H for heavy rail system, L. for light rail, blank for dual syslem

15-74 6 flelds of 10 columns earh, rontaining kilowatt-hours of electricity used, in thousands (decimal point in col. 9 of field). A birank field indicates data were not available; 0.0 indicates zero consumption. The fields correspond respectively to 1967-72.

Card 2: 1-14 same as Card 1, except that the letter B appears in co1. 13

15-74 same 6 fields as in Card 1, corresponding respectively to $1973-78$

Source: Ref. 2 and direct contacts with rail transit systems.

File 2. Commuter rail fuel use, by fuel by state, 1967-78, File

name $=$ COMMUT. 200

Format: $\operatorname{col}$.

1-2 Etate abbrcviation

3-4 state FIPS code (see Sec. 8.2)

6 the number 3

$7 \quad 1$ for diesel fuel, 2 for electricity

9-80 12 fields of 6 columns each, corresponding to the years 1967-78, showing fuel use in thousands of bbl or m1llions of kwh (right-jubtified integers)

Source: Method 202

Flle 3. Incercitỹ p̈assenger rail diesel fuel use, by state, 1967-78.

File name $=$ PASSD. 200

Format: $\operatorname{col}$.

4-5 state FIPS code (see Sec. 8.2), right-justified

7-126 12 fields of 10 columns each, corresponding respectively to 1967-78, showing diesel fuel use in thousands of bbl (right-justified integer)

Source: Method 203 
File 4. Intercity passenger rail electricity use, by state, 1967-78. File name $=$ PASSE. 200

Format: Same as File 3; electricity use expressed in millions of kwh. Source: Method 203

File 5. Freight rail diesel fuel use, by state, 1967-78.

Format: col.

1-2 state FIPS code (see Sec. 8.2), right-justified

3-122 $12 \mathrm{fields}$ of $10 \mathrm{cols}$. each, corresponding to diesel fuel use in thousands of barrels (right-justified integer) respectively in $1967, \ldots, 1978$.

Source: Ref. 6 .

Note: When punched on cards, the last 42 cols. of each record are punched in cols. 1-42 of a continuation card immediately following the initial card.

F1le 6. Freight rail residual oil use, by state, 1967-78.

Format: col.

1-2 state FIPS code (see Sec. 8.2), right-justified

6 the number 2

7-80 12 fields of 6 . cols. each, corresponding to residual ofl use in thousands of barrels (right-justified integer) respectively in $1967, \ldots, 78$

Source: Ref. 6

Data Quality Numbers

All estimates except those for commuter rail and local transit -- 2

Estimates for commuter rail (see Method 202) -- 1 or 2

Estimates for local transit 


\section{References}

1. American Public Transit Association, Transit Fact Book, 1967-79 editions, Washington, D.C.

2. American Public Transit Association, Transit Operating Report, 1967-77 editions, Washington, D.C.

3. Stanford Research Institute, Energy Study of Rai $i$ Passenger Transportation, Vol. 2, Men1o Park, Cal., 1977.

4. National Railway Publication Company, The Official Guide of the Raitways, New York, July editions 1967-78.

5. National Railway Publication Company, Annual Report to the Interstate Commerce Conmission for the Year Ended December 31, 19--, 1967-78 editions, Washington, D.C.

6. Energy Information Administration, Table 10 in "Fuel 0il Sales Annual," Energy Data Reports, Washington, D.C., 1967-78.

7. Edison Electric Institute, Statistical Yearbook of the Electric Utility Industry, 1967-78 editions, Washington, D.C.

8. National Railroad Passenger Corporation (Amtrak), 1978-79 Annual, Rail Transportation Archives, San Francisco. 
Method 310

AUTO

Categories used:

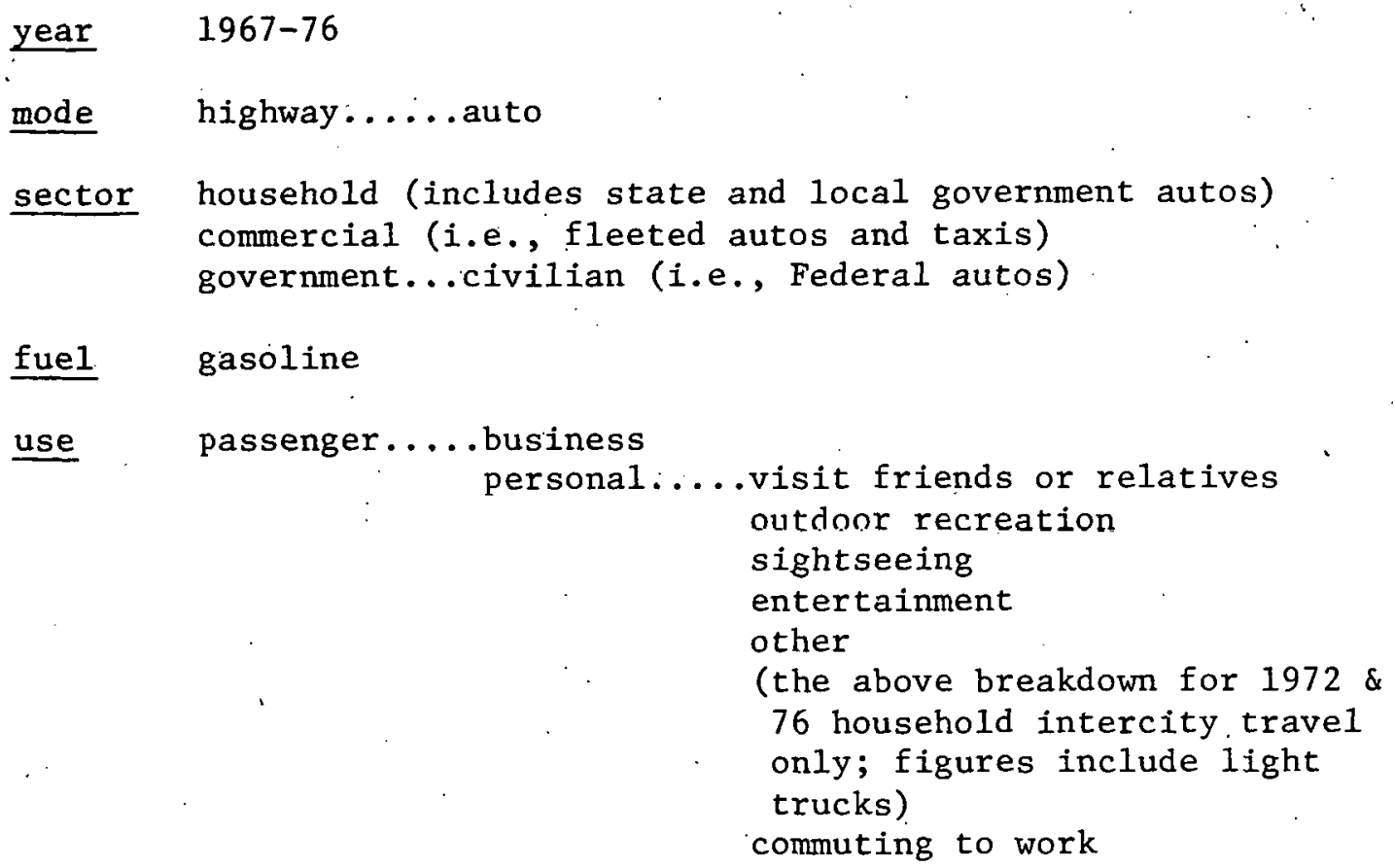

fuel gasoline

use passenger..... business personal....visit friends or relatives outdoor recreation

income see Method 315 (breakdown for intercity travel only and for years 1972 and 1976 only; figures include travel in light trucks)

carrier common (i.e., taxis) private (everything but taxis)

range intercity (i.e., trips over 100 miles)

local

(breakdown for household autos only)

region (no breakdown for estimates broken down by use by income)

state (no breakdown for estimates broken down by income class)

N.B.: When auto fuel use is broken down. by trip purpose it includes the fuel used by both autos and light trucks, since the available survey data do not distinguish the two. The recorded total over all purposes for intercity travel likewise includes trucks. All other auto figures recorded encompass autos only. 
It should also be noted that auto fuel use in the household sector includes that used by state and local government vehicles, since it was impossible to separate the two.

The energy consumption of an auto is taken to be the energy content of the fuel it burns.

In view of the predominance of the automobile among highway vehicles, surprisingly little is known about its fuel use. The reason for this is simply that primary data on fuel sales to automobiles are not collected.

closest one can come is the household expenditure data available in the 1973-74 Consumer Expenditures Survey (Ref. 12), and even this includes purchases for household trucks and off-highway lises and excludes much gasoline use in automobiles outside the household sector. Because of this, fuel use by the most prevalent vehicle type must be determined largely as a residual from other uses.

311. Commercial sector gasoline use (excluding taxicabs) 1967-76, by state

While the household sector is certainly the largest owner and user of automobiles, commercial use is undoubtedly a large component of total use. Although not all commercial automobiles are in fleets, it is probable that the vast majority of them are. Automobiles operated in fleets of four or more comprise about $10 \%$ of cars on the road. Perhaps two-thirds of a 1 tleet vehicles (in fleets of 10 or more) are used by businesses, with the remainder divided between governments, utilities, police and taxis, in order of importance (Ref. 1, pp. 15-16). Fleet vehicle use by households is apparently confined to small shares of the daily rental and leasing fleets or unofficial use of business fleet vehicles. (The National Association of Fleet Administrators guesses that this is about $15 \%$ of fleet vehicle use.) Thus it would appear to be reasonable to approximate commercial gasoline use by automobiles as that used by fleeted automobiles. Unfortunately it is not that straightforward. There is no universally accepted definition of what constitutes a fleet. Statistics are reported for fleets of 10 or more or 4 or more cars operated jointly. The distinction is important for two reasons: (1) almost as many cars are operated in fleets of 4-9 in size as in fleets of 10 or more, and (2) it would seem reasonable to expect cars in large fleets to be operated differently and have different usage rates than cars in smaller fleets. Unfortunately, the data necessary to make these distinctions are not avallable. As a result, estimates of tleet and, therefore, commercial auto gasoline use must be crude and very uncertain.

All automobile fuel use is assumed to be gasoline. A sector breakdown of this use will be made using cars in fleets of 4 or more minus state and local government and police cars to represent commercial 
gasoline use and treating household use as what is left after truck, truck, motorcycle and commercial and government auto gasoline use have been subtracted from total highway gasoline use.

The procedure for computing estimates of fleet auto use (excluding taxis) is uncomplicated. Taxicab energy use will be estimated separately in the next section. Shonka (Ref. 1) surveyed all existing sources of data on fleet operations in the U.S., and most of the data required for this estimation can be found in her study. The number of vehicles in fleets of 10 or more by state in which the fleet operator is located can be obtained from a 1975 survey performed by Commercial Car Journal (Ref. 19). This distribution is used to share the estimated auto fleet pópulation nationwide in fleets of 4 or more for each year. These national data are available from Automotive Fleet magazine (Ref. 2). They are first adjusted to remove government vehicles and taxis from the national total, again using data from Ref. 1 (p. 16). Fuel use by state is then obtained by multiplying the number of fleet vehicles by a constant 20,000 miles per year and dividing the total miles by an estimated 13.5 miles per gallon. The former number is a conservative estimate of average annual vehicle-miles for fleet autos in the U.S., as the figures below indicate.

$$
\text { Estimates of fleet automobile use }
$$

Annual VMT Year

22,244

24,322

21,563

24,000
1972

1972

1976

1978

Source

A series of annual data from a single source, such as the American Automotive Leasing Association, is not used because one source will show average miles per car rising while another shows it falling in the same period of time (Ref. 1, p. 24). The miles per gallon figure (13.5) is almost exactly the national average for automobiles estimated by the Federal Highway Administration for the period 1967-76 (Ref. 10). It compares with a National Association of Fleet Administrators estimate of 13.4 for 1976 (Ref. 9). It seems more than likely that these efficiencies have varied across states and over time. Therefore, the accuracy of the resulting estimates is unknown.

The estimation of commercial fleet gasoline use can be formulated as shown below.

$$
F_{s t}=\frac{V m t}{M P G}\left(1-\frac{M 10_{t}}{N 10}\right) \frac{N^{4} s, 1975}{N 41975} N 4_{t}
$$


where

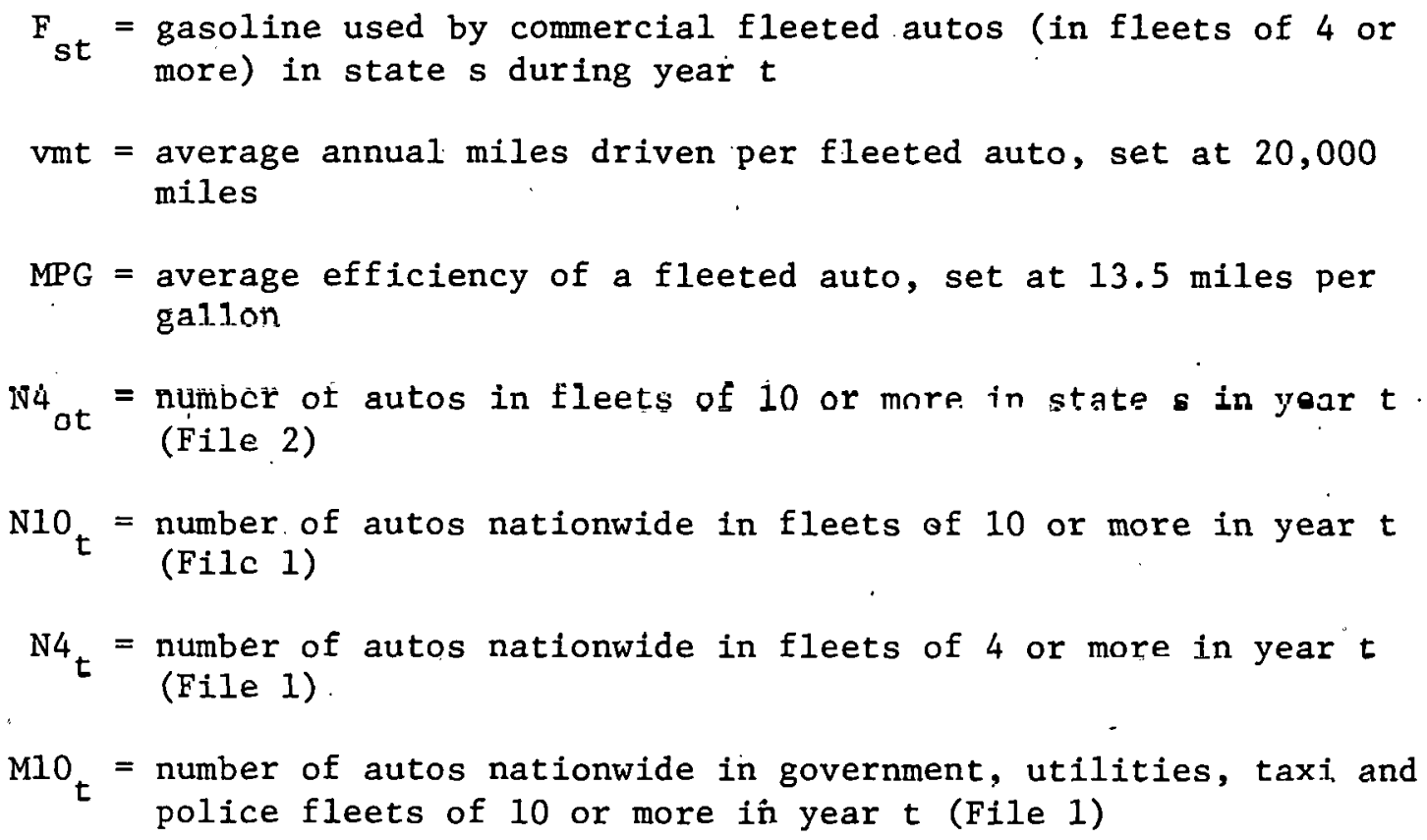

312. Taxicab gasoline use, 1967-76, by state

Taxicabs are treated separatel.y. They represent the commercial sector vehicles that can be classified as common carriers. National estimates of numbers of taxis in use and annual vehicle-miles are available for 1970, 1973 and 1975 in Taxicab Operating Characteristics (Ref. 4). Estimates are made for the intervening years using the relative magnitudes of the taxi fleet estimates reported by Automotive Fleet magazine for 1966-76 (Ref. 2). Specifically, both the number of taxis operating and the average vehicle-miles per taxi (in an intervening year) are estimated by taking a weighted average of these quantities in 1970 and 1973 (or 1973 and 1975), where the weights are based on the Automotive Fleet figures for the intervening year in question. This allows trends in the vehicle-miles per taxi, as well as the number of taxis, to be taken into account. Details of the calculation are made clear in the formula below. Applying a national average miles-per-gallon figure of 11.45 results in a nation estimate of taxi gasoline use. The national total is shared to states based on the number of persons reporting taxi as their means of journeying to work in the 1970 Census of Population (Ref. 11). These data were judged to be most indicative of taxicab use. However, the accuracy of the approach is unknown. The formula is: 


$$
F_{s t}=\left\{\begin{array}{rr}
\frac{V M T}{t} \frac{P_{s}}{P} & \text { when } t=\begin{array}{l}
1970, \\
73,75
\end{array} \\
\frac{1}{\operatorname{mpg}}\left(N_{73} w_{1}+N_{75} w_{2}\right)\left(\frac{V M T_{73}}{N_{73}} w_{1}+\frac{V M T_{75}}{N_{75}} w_{2}\right) \frac{P_{s}}{P} & \text { when } t=1974,76 \\
\frac{1}{m p g}\left(N_{70 w_{3}}+N_{73} w_{4}\right)\left(\frac{V M T_{70}}{N_{70}} w_{3}+\frac{V M T_{73}}{N_{73}} w_{4}\right) \frac{P}{P} & \text { when } t=\begin{array}{l}
1967,68, \\
69,71,72
\end{array}
\end{array}\right.
$$

where

$$
\begin{aligned}
& \mathrm{F}_{\text {st }}=\text { gasoline consumption by taxicabs in state } s \text { during year } t \\
& \text { VMT }_{t}=\text { vehicle-miles traveled by taxis nationwide in year } t \text {, } \\
& t=1970,73,75 \text { (File 3) } \\
& \mathrm{mpg}=\text { national average taxi efficiency, set at } 11.45 \text { miles per } \\
& \text { gallon }
\end{aligned}
$$

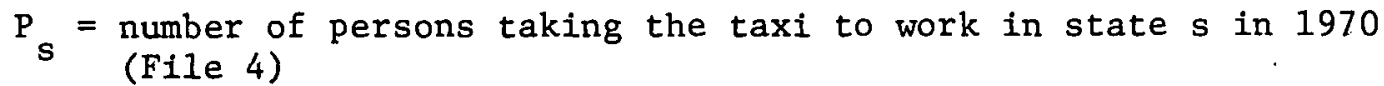

$$
\begin{aligned}
& P=\text { total number of persons taking taxi to work in } 1970 \text { (File 4) } \\
& \mathrm{N}_{t}=\underset{\text { (File } 3)}{\text { number }} \text { of taxis in operation in year } t, t=1970,73,75 . \\
& w_{1}=\frac{M_{75}-M_{t}}{M_{75}-M_{73}} \quad w_{2}=\frac{M_{t}-M_{73}}{M_{75}-M_{73}} \\
& w_{3}=\frac{M_{73}-M_{t}}{M_{73}-M_{70}} \quad w_{4}=\frac{M_{t}-M_{70}}{M_{73}-M_{70}} \\
& M_{t}=\text { number of taxis in fleets of } 10 \text { or more in year } t \text { (File } 1 \text { ) }
\end{aligned}
$$

313. Federal government civitian gasoline use, by state, 1967-76

Data on Ferera1 gnvernment/civilian gasoline use is readily available in the "Federal Motor Vehicle Fleet Reports" of the General Services Administration for 1967-76 (Ref. 6). The reports contain the number, vehicle-miles traveled, and fuel consumed by government-owned sedans, station wagons and ambulances. Total Federal civilian auto gasoline use is shared to the states based on their percentage share of Federal automobiles. The latter data are reported annually by the Federal Highway Administration (Ref. 10, Table MV-7). In short, 


$$
F_{s t}=F_{t} \frac{N_{s t}}{N_{t}}
$$

where

$$
\begin{aligned}
& F_{s t}= \text { gasoline used by Federal civilian autos in state } s \text { during. } \\
& \text { year } t
\end{aligned}
$$

Very little is known about state and local government fuel use, as pointed out elsewhere in the discussion of truck. fuel use estimation methods. Here, again, this fuel use is included with the household sector due to a general lack of data. Another reason for not attempting to estimate these data is the fact that fragmentary data provided to ORNL by several states indicates widely varying annual consumption rates.

314. Household and state and local government gasnline 1se, 1967-76, by state

After all the above estimates plus estimated gasoline use by other vehicles have been subtracted from the highway gasoline use control total, the remainder constitutes an estimate of household and state and local government gasoline use by state. That is,

$$
F_{s t}=H_{s t}-C_{s t}-G_{s t}-T X_{s t}-B_{s t}-T_{s t}-M_{s t}
$$

where

$$
\begin{aligned}
& \begin{aligned}
F_{s t}= & \text { total household and state and local government auto gasoline } \\
& \text { use in state } s \text { during year } t
\end{aligned} \\
& \begin{aligned}
\mathrm{H}_{\text {st }}= & \text { total gasoline sold for highway use in state } \mathrm{s} \text { during year } \mathrm{t} \\
& (\text { File } 7)
\end{aligned} \\
& \begin{aligned}
\mathrm{C}_{\text {st }} & =\text { total commercial gasoline use, except taxis, in state s during } \\
\text { year } \mathrm{t} \text { (Method } 311 \text { ) } &
\end{aligned} \\
& \begin{aligned}
& G_{\text {st }}= \text { total Federal government auto gasoline use in state } s \text { during } \\
& \text { year } t \text { (Method 313) }
\end{aligned}
\end{aligned}
$$




$$
\begin{aligned}
\mathrm{TX}_{\text {st }}= & \text { total taxicab gasoline use in state } \mathrm{s} \text { during year } \mathrm{t} \text { (Method } \\
& 312) \\
\mathrm{B}_{\mathrm{st}}= & \text { total bus gasoline use in state } \mathrm{s} \text { during year } \mathrm{t} \text { (see below) } \\
& \text { File } 22 \\
\mathrm{~T}_{\mathrm{st}}= & \text { total truck gasoline use in state } \mathrm{s} \text { during year } \mathrm{t} \text { (Method } \\
& 330 \text { ) File } 23 \\
\mathrm{M}_{\mathrm{st}}= & \text { total motorcycle gasoline use in state } \mathrm{s} \text { during year } \mathrm{t} \\
& \text { (Method } 340 \text { ) File } 24
\end{aligned}
$$

Since transit bus gasoline use, as estimated by Method 323, is not broken down by state, it must be approximated by allotting to each state a fraction of the national consumption based on its share of the transit bus gasoline use reported to the American Public Transit Association. That is,

$$
B_{s t}=B_{s t}+B_{s t}+B_{t} \frac{\mathrm{APTA}_{s t}}{\mathrm{APTA}_{t}}
$$

where

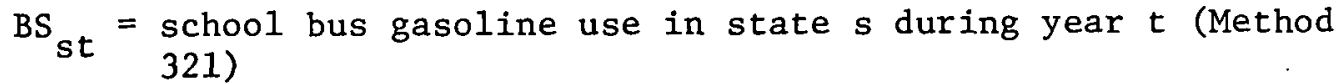

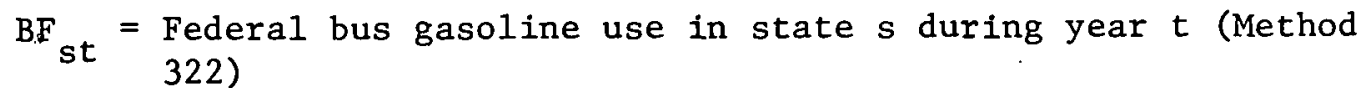

$$
\begin{aligned}
& \mathrm{BT}_{t}=\text { national transit bus gasoline use during year } \mathrm{t} \text { (Method 323) } \\
& \begin{aligned}
\text { APTA }_{\text {st }}= & \text { transit bus gasoline use reported to the American Public } \\
& \text { Transit Association (APTA) by state } s \text { in year } t \text {. (File 5, }
\end{aligned} \\
& \text { Method 320) } \\
& \begin{aligned}
\text { APTA }_{t}= & \text { total transit bus gasoline use reported to APTA in year } t \\
& (\text { File 5, Method 320) }
\end{aligned}
\end{aligned}
$$

The estimate of intercity household gasoline use to be provided by Method 315 allows a breakdown by range of travel. As Method 315 explains, intercity travel must here be defined as trips of at least 100 miles. So, we have

$$
F_{\text {rst }}= \begin{cases}I_{s t} & \text { when } r=\text { intercity } \\ F_{s t}-I_{s t} & \text { when } r=\text { local }\end{cases}
$$


where

$$
\begin{aligned}
I_{s t}= & \text { auto and light truck household gasoline use for intercity } \\
& \text { travel in state } s \text { during year } t \text { (from Method } 315) \\
F_{s t}= & \text { total household and state and local government auto gasoline } \\
& \text { usc in state } s \text { during year } t \text {, from formula (1) above }
\end{aligned}
$$

An obvious difficulty here is that $F_{\text {st }}$ includes state and local government auto gasoline use as well as household use, and $\mathrm{I}_{\text {st }}$ includes intercity light truck gasoline use as well as auto use. In the computation of local auto gasoline use these two distortions will to some extent cancel each other, but how much they will do so is impossible to know.

... Another difficulty is that $F_{S t}$ includes the fuel used by state and local government trucks (see Method 336) and that used by buses that are not common carriers, other than school and Federal buses (see Method 325). The resulting overage is likely to be insignificant, however, in relation to the voracious consumption of gasoline by household autos.

Finally, although household autos are in any state the vehicle-sector combination burning more gasoline than any other, they still consume only about half of all highway gasoline. Thus errors in the estimation of other fuel uses can compound to cause considerable errors in these household and local government estimates. The uncertainty of these convoluted estimation methods serves to point up the desperate need for basic reliable data on the uses of highway gasoline.

315. Intercity household gasoline use, by use by income (1972 \& 76), by income by region $(1972 \& 76)$, and by use by state (1972-76).

There are relatively few data available on household automobile gasoline use by purpose and income. The primary data sources used to obtain this information are the National Travel Surveys for 1972 and 1977 (Ref. 5) and the Journey to Work Survey for 1975 (Ref. 1). In each of these sources, the data are given by mode of travel with automobiles and light trucks combined as one category.

In the estimation to follow intercity auto travel has been broken down into that for business purposes and that for personal use. Personal travel has been further divided into that for visiting friends and relatives, recreation, sightseeing, entertainment, and other purposes. In addition Method 316 estimates the gasoline use for commuting to work, which is classified as local travel. These estimates are made by computing the vehicle-miles traveled in each category and dividing by an appropriate fuel efficiency number (miles per gallon). 
An intercity trip is defined by the National Travel Survey as one in which the traveler goes to a place at least 100 miles from home and returns. Intercity trips exclude (a) travel as a part of an operating crew on a train, plane, bus, truck or ship, and (b) commuting to a place of work, as well as (c) students' trips to school or trips of those taking students to school.

The breakdown of in'tercity auto and light truck travel by income class is limited to two years, 1972 and 1976. Because of the sample size of the National Travel Survey and the large number of income categories used for each year, there are no estimates by income class by state. Rather, there are estimates (for 1972 and 1976 only) by income class by region and by income class by use. There is also a third set of estimates broken down by use by state. (The estimates of gasoline use by commuters is broken down by state and is provided for 1975 only.)

The distribution of VMT (vehicle-miles traveled) for household intercity travel is available only from the 1963, 67, 72 and 77 National Travel Surveys. Furthermore, the definition of a trip was changed from "travel to a place at least 100 miles away from home in one day or travel out of town one or more nights" for the 1963 and 1967 surveys to a definition of "travel to a place at least 100 miles away from home and return" for the 1972 and 1977 surveys. Therefore the 1963 and 67 survey results are not comparable with the results of the 1972 and 77 surveys. For this reason only the data from the 1972 and 77 surveys are used to estimate vehicle-miles traveled for intercity travel.

The trip purpose categories for both 1972 and 1977 are the same. Therefore if one assumes a constant rate of change in VMT by purpose and state between 1972 and 1977 he can estimate the intervening years. However, the income data available from the two surveys are given in the following categories:

\begin{tabular}{clc} 
Income class & \multicolumn{1}{c}{1972 NTS } & $\underline{1977 \text { NTS }}$ \\
\hline 1 & under $\$ 1000$ & under $\$ 2000$ \\
2 & $1000-1999$ & $2000-2999$ \\
3 & $2000-2999$ & $3000-3999$ \\
4 & $3000-3999$ & $5000-5999$ \\
5 & $4000-4999$ & $6000-7499$ \\
6 & $5000-5999$ & $7500-9999$ \\
7 & $6000-7499$ & $10,000-11,999$ \\
8 & $7500-9999$ & $12,000-14,999$ \\
9 & $10,000-14,999$ & $15,000-19,999$ \\
10 & $15,000-24,999$ & $20,000-24,999$ \\
11 & over 25,000 & $25,000-34,999$ \\
12 & unclassified & $35,000-49,999$ \\
13 & & over 50,000
\end{tabular}


Because the income data for each year are given in current dollars, rather than constant dollars, the data are not readily comparable. For this reason and because there is no justification for assuming a linear relationship between household income and year, it is not possible to use these data to estimate VMT by income class for intervening years. Therefore the income breakdown is provided for two years only: 1972 (from 1972 NTS income and VMT data), and 1976 (from 1977 NTS income and VMT data).

'l'he match between the End Use Data Base use categories and those of the NTS are as follows:

End Use Category (USE1...USE2)

busliess

personal...outdoor recreation

...visit friends or relatives

...vacation \& sightseeing

...entertainment

...other
1972 NTS Category

buslness \& cunventions

outdoor recreation

visit friends or relatives

sightseeing

entertainment

personal \& family affairs
1977 NTS Category

business

conventions

recreation

visit friends

or relatives

sightseeing

entertainment

other

other

Formulas for estimating household intercity gasoline use are as follows :

$$
F_{\text {nst }}=\mathrm{VMT}_{\text {us }, 1972, \mathrm{r}^{\mathrm{t}-19 \mathrm{~s}}}
$$

where

$$
\begin{aligned}
& \mathrm{r}_{\mathrm{uS}}=\left(\mathrm{VMT}_{\mathrm{us}, 1977^{/ \mathrm{VMT}}} \mathrm{us}, 1972^{\frac{1}{4}}\right. \\
& \mathrm{F}_{\text {ust }}=\begin{array}{l}
\text { household intercity gasoline use for use } u \text { in state } s \\
\text { during year } t
\end{array} \\
& \begin{aligned}
\mathrm{VMT}_{\text {ust }}= & \text { household intercity vehicle-miles traveled for use } u^{\prime} \text { in } \\
& \text { state } \mathrm{s} \text { during year } t, t=1972 \text { or } 1977 \text { (Files } 12,13 \text { ) }
\end{aligned}
\end{aligned}
$$

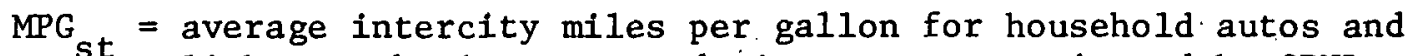


For the years 1972 and 1976,

$$
\begin{aligned}
& F_{\text {irt }}= \begin{cases}V_{\text {ir }, 1972} / M P T_{r, 1972} & \text { for } t=1972 \\
V_{\text {MT }}, 1977^{/ M P G} & \text { for } t=1977\end{cases} \\
& F_{\text {uit }}= \begin{cases}\mathrm{VMT}_{\mathrm{ui}, 1972^{/ M P G_{1972}}} & \text { for } t=1972 \\
\mathrm{VMT}_{\mathrm{ui}, 1977^{/ M P G}} & \text { for } t=1977\end{cases}
\end{aligned}
$$

where

$$
\begin{aligned}
& \mathrm{F}_{\text {irt }}=\text { household intercity gasoline use by families in income } \\
& \text { class } i \text { in region } r \text { during year } t \\
& F_{\text {uit }}=\text { household intercity gasoline use for use u by families in } \\
& \text { income class } i \text { during year } t \\
& \begin{aligned}
\mathrm{VMT}_{\text {irt }}= & \text { household intercity vehicle-miles traveled by families in } \\
& \text { income class } i \text { in region } r \text { during year } t, t=1972,1977
\end{aligned} \\
& \text { (Files 8, 9; but see note below) } \\
& \mathrm{VMT}_{\text {uit }}=\text { household intercity vehicle-miles traveled for use } u \text { by } \\
& \text { families in income class } i \text { during year } t, t=1972,1977 \\
& \text { (Files 10, 11) } \\
& M P G_{r t}=\text { estimated miles per gallon for intercity household auto and } \\
& \text { light truck travel, based on EPA estimates and fleet mix. } \\
& \text { in region } r \text { in year } t \text { (File } 18 \text { ) } \\
& \text { MPG } \mathrm{t}_{\mathrm{t}}=\text { estimated miles per gallon for intercity household auto and } \\
& \text { light truck travel, based on EPA and national fleet mix in } \\
& \text { year } t \text { (File 18) }
\end{aligned}
$$

Note that the foregoing method is based on two assumptions:

(a) The annual rate of change in VMT for intercity trips is constant between 1972 and 1977 for each state s and each use u.

(b) VMT for intercity trips by income class in 1976 is the same as that for 1977.

Note: The 1977 National l'ravel Survey occasionally combines states in order to protect the anonymity of respondents. New Hampshire and Vermont are combined, as are Montana, North Dakota, South Dakota and Wyoming, as are Alaska, Idaho and Washington. In order to secure a complete breakdown by state, the car-miles reported for these combinations has been attributed to the individual states in the same proportions they exhibited in 1972. That is, 


$$
\mathrm{VMT}_{\mathrm{us}, 1976}=\frac{\mathrm{VMT}_{\mathrm{us}, 1972}}{\mathrm{VMT}_{\mathrm{uc}, 1972}} \mathrm{VMT}_{\mathrm{uc}, 1976}
$$

where

$$
\begin{aligned}
& \begin{aligned}
\mathrm{VMT}_{\text {ust }}= & \text { car-miles traveled for use } \mathrm{u} \text { in state } \mathrm{s} \text { during year } t \text {, as } \\
& \text { used in formula (1) above }
\end{aligned} \\
& \begin{aligned}
\mathrm{VMT}_{\text {uct }}= & \text { car-miles traveled for use } u \text { in combination of states } \mathrm{c} \\
& \text { during year } t
\end{aligned}
\end{aligned}
$$

This same merger of state dảa causes difflcullles luı Llie 1970 lreakdown by region by income and for that by region by use, since the last two combinations mentioned above lie astride regional boundaries. The second combination was placed wholly in region 8 , the third wholly in regtun 9 , and corrections were made as follows:

$$
\mathrm{VMT}_{\text {ir }, 76}=\frac{\mathrm{VMT}_{\text {ir }, 76}^{-}}{\mathrm{VMT}_{\mathrm{r}, 76}^{-}} \sum_{\mathrm{s} \varepsilon \mathrm{r}} \mathrm{VMT}_{\mathrm{s}, 76}
$$

where

$$
\begin{aligned}
& \mathrm{VMT}_{\text {irt }}=\text { car-miles traveled by persons in income class } i \text { in region } r \\
& \text { during year } t \text {, as used in formula (2) above } \\
& \text { VM'L }{ }_{\text {ir }}=\text { car-miles traveled by persuls in income class i in region } r \text {, } \\
& \text { during year } \tau \text {, as taken frum File } 9 \text {, which uses the grouping } \\
& \text { mentioned above } \\
& \mathrm{VMT}_{\mathrm{rt}}^{\prime}=\mathrm{VMT}_{\text {irt }}^{\prime} \text { summed over all income classes } i \\
& \mathrm{VMT}_{\text {et }}=\mathrm{VMT}_{\text {ust }} \text { summed over all uses } u \\
& s \varepsilon r \text { indicates that state } s \text { is in region } r
\end{aligned}
$$

316. Gasoline used for commuting to work, 1975, by state

For each SMSA (standard metropolitan statistical area), the 1975 Journey to Work Survey provides estimates of the number of trips of persons living in the central city within that SMSA, of persons living in the SMSA but outside the central city, and of persons living outside the SMSA (Table 1, Ref. 1). The vehicle-miles traveled nationwide by persons living in each of these three types of areas is computed from the person-miles traveled in one-way trips to work of those traveling 
alone and of those traveling in a carpool. The latter figure is divided by the average number of travelers per carpool in each individual state, an average that varies from state to state. Consequently the resulting VMT estimate is indexed by state. This computation is carried out for 1975 only.

$$
\mathrm{VMT}_{\mathrm{a}(\mathrm{s})}=2\left(\mathrm{PMT}_{\mathrm{a}}^{\text {alone }}+\frac{\mathrm{PMT}_{\mathrm{a}}^{\mathrm{poo}}}{\mathrm{L}_{\mathrm{as}}}\right)(250 \mathrm{days} / \mathrm{yr})
$$

where

$$
\begin{aligned}
& \mathrm{VMT}_{\mathrm{a}(\mathrm{s})}=\text { vehicle-miles traveled nationwide by commuters driving } \\
& \text { to work from type of area a (see above for explanation), } \\
& \begin{aligned}
\mathrm{PMT}_{\mathrm{a}}^{\text {alone }}= & \text { person-miles traveled nationwide by commuters driving to } \\
& \text { work alone from type of area a (File 16) }
\end{aligned} \\
& \mathrm{PMT}_{\mathrm{a}}^{\text {pool }}=\text { person-miles traveled nationwide by commuters driving to } \\
& \text { work in carpools or vanpools from type of area a (File 16) } \\
& \mathrm{L}_{\text {as }}=\text { average number of persons per carpool driving to work } \\
& \text { from type of area } a \text { in state } s \text { (File 19) }
\end{aligned}
$$

The vehicle-miles traveled by commuters in a particular state can now be estimated by taking a weighted average of the vehicle-miles traveled by residents of the three types of areas, and apportioning the result among the states according to the number of nonfarm employees in each state. The weights used are the estimated percentages of the population surrounding a given central city that occupy the three types of areas. It is aseumed that these percentages are the same for the population surrounding a given city as they are for the state as a whole. For instance, it is assumed that the percentage of population commuting to Philadelphia that lives, say, in Philadelphia proper is the same as the percentage of Pennsylvania's commuting population that lives in central cities. Once the commuting VMT is computed for each state, it can be divided by an estimated miles per gallon to determine the gasoline use in that state. In order to reflect the fact that longer-distance driving gets better gas mileage, the miles per gallon figure used is made to depend on the type of area from which the commuter is traveling. The mileage figure used for commuters who live within the SMSA in which they work is an adjusted EPA city mpg estimate for autos or trucks, and the figure used for commuters living outside the SMSA is an adjusted EPA highway mpg estimate. The adjustments are based on a regression of actual on EPA fuel economies developed by McNutt et al. (Ref. 20). The mpg figures used in each state ref.lect the fleet mix of autos and light trucks in that state. The formulas are, 


$$
F_{s}=\frac{E_{s}}{E} \sum\left(\operatorname{VMT}_{a}(s) \frac{P_{a s}}{P_{a}} / M_{a s}\right)
$$

where

$$
\begin{aligned}
& \mathbf{F}_{\mathbf{S}}=\text { gasoline used in state } s \text { in } 1975 \text { by commuters to work; } \\
& \text { includes both autos and light trucks } \\
& \therefore=\text { number of employees in nonagricultural establishments in } \\
& \text { state s in 1975, from Table 675, Ref. } 2 \text { (File 14) } \\
& \text { E - total humber of employees in nonagicicultural establishments } \\
& \text { in the U.S. in 1975, from Table 675, Ref. } 2 \text { (File 14) } \\
& \mathrm{VMT}_{\mathrm{a}}(\mathrm{s}) \text { is given by formula (1) above } \\
& P_{\text {as }}=\text { percentage of the population of state } \varepsilon \text { that lives in type } \\
& \text { of area a in } 1975 \text { (i.e., in a central city, in an SMSA but } \\
& \text { outside the contained central city, or in no SMSA), given } \\
& \text { by formula (3) below } \\
& \begin{aligned}
\mathrm{MPG}_{\text {as }}= & \text { estimated miles per gallon for type of area a and state } s \\
& \text { in } 1.975 \text { (File 18) }
\end{aligned} \\
& \mathrm{P}_{\mathrm{as}}=\left\{\begin{array}{l}
\mathrm{C}_{\mathrm{s}}\left(\mathrm{POP}_{\mathrm{s}}-\mathrm{POP}_{\mathrm{s}}^{\mathrm{Out}}\right) / \mathrm{POP}_{\mathrm{s}} \mathrm{a}=\text { Inside central city } \\
\left(1-\mathrm{C}_{\mathrm{s}}\right)\left(\mathrm{POP}_{\mathrm{s}}-\mathrm{POP}_{\mathrm{s}}^{\mathrm{Out}}\right) / \mathrm{POP}_{\mathrm{s}} \mathrm{a}=\begin{array}{l}
\text { Ins1de SMSA } \\
\text { but outside } \\
\text { central city }
\end{array} \\
\mathrm{POP}_{\mathrm{s}}^{\mathrm{Out} / \mathrm{POP}} \mathrm{a}=\text { outside central city }
\end{array}\right.
\end{aligned}
$$

where

$$
\begin{aligned}
& \mathrm{C}_{\mathbf{g}}=\text { percent of } 1970 \text { population residing in an SMSA in state } s \\
& \text { that live in a central city, from Table 41, Ref. } 3 \text { (File 15) } \\
& \text { POP }=1975 \text { population of state } \mathrm{s} \text {, from Table 19, Ref. 2 (File 17) } \\
& \begin{aligned}
\mathrm{POP}_{\mathrm{S}}^{\text {out }}= & 1975 \text { population of state } \mathrm{s} \text { living outside any SMSA, from } \\
& \text { Table 19, Ref. } 2 \text { (File 17) }
\end{aligned}
\end{aligned}
$$




\section{Input Data Files}

File 1. U.S. cars in fleets of 10 or more, by type of fleet, 1967-76. File name $=$ FLEE 10.310

Format: col.

$1-2$

4-6 company-owned cars in business fleets of 25 or more

8-11 leased cars in busines's fleets of 25 or more

13-15 company-owned cars in business fleets of 10-24

17-19 leased cars in business fleets of 10-24

21-23 cars in government fleets of 10 or more

25-27 cars in utilities fleets of 10 or more

29-31 cars in police fleets of 10 or.more

33-35 cars in taxi fleets of 10 or more

37-39 cars in daily rental fleets of 10 or more

41-42 cars in driver school fleets of 10 or more

44-48 cars in all fleets of 4 or more

all numbers are in thousands and are right-justifled integers

Source: Ref. 2, p. 22; Ref. 1, p. 16

File 2. U.S. cars in fleets of 4 or more, by state, 1975. File

name $=$ FLEET4.310

Format: $\operatorname{col}$.

1-2 FIPS state code (see Sec. 8.2), right-justifled integer

4-9 number of cars in fleets of 4 or more (right-justified integer)

Source: Ref. 3, p. 43

File 3. Taxicabs in use and taxi-miles, taxicab industry estimates,. 1970, 73, 75. File name $=$ TAXI. 310

Format: $\operatorname{col}$.

1-2 year

10-15 number of taxicabs in use (right-justified integer)

21-27 annual vehicle-miles in thousands (right-justified integer)

Source: Ref. 4. 
File 4. Percent taking taxi to work, number of workers, by state, 1970 . File name $=$ WORCAB. 310

Format: $\operatorname{col}$.

1-2 FIPS state code (see Sec. 8.2), right-justified integer

5-7 percent of state's workers who take the taxi to work (decimal point in col. 6)

10-16 number of workers in state (right-justified integer)

Source: Ref. 5, Table 152

File 5. Fuel consumed by Federal government autos, 1967-76. File name $=$ FEDGAS .310

Format: col.

1-2 year

- 4-11 fuel consumed by sedans, gallons (right-justified

13-20 fuel consumed by station wagons, gallons (rightjustified)

22-28 fuel consumed by ambulances, gallons (right-justified)

Source: Ref. 6

File 6. Number of Federal civilian vehicles, by type, 1967-76. File name $=$ FEDCAR. 310

Format: col.

1-2 year

4-5 FIPS state code (see Sec. 8.2), right-justified

7-10 number ot automobileo (right-justified integer)

12-14 number of buses (right-justified)

16-20 number of trucks and tractor-trucks (right-justified)

22-24 number of motorcycles (right-justified)

Source: Ref. 7, Table MV-7

File 7. Gasoline sold for highway use, by state, 1967-76. File name = ت̈As. 310

Furmat: $\operatorname{col}$.

Card 1.: 1-2 state TIF3 gole (tut Se: 8.2), righe justified

4-5 year

6-13 gallons (in thousands) of highway gasoline

15-16 year

18-24 gallons

26-27, yeur

29-35 gallons

37-38 year

40-46 gallons

48-49 year

50-57'gallons 


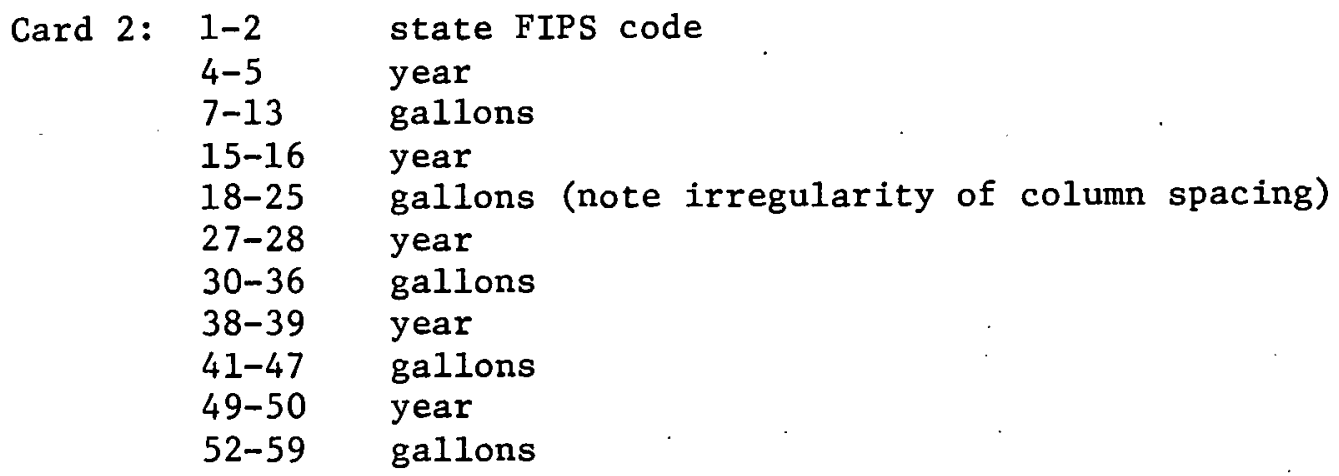

Source: Ref. 7, Tables $M F-23$ and MF-25

File 8. Car-miles by income by region, 1972, from National Travel Survey. File name $=$ INRG72.310

Format: col.

1-15 car-miles (left-justified integer), followed by a blank, followed by income class code*, followed by a blank, followed by region codet*

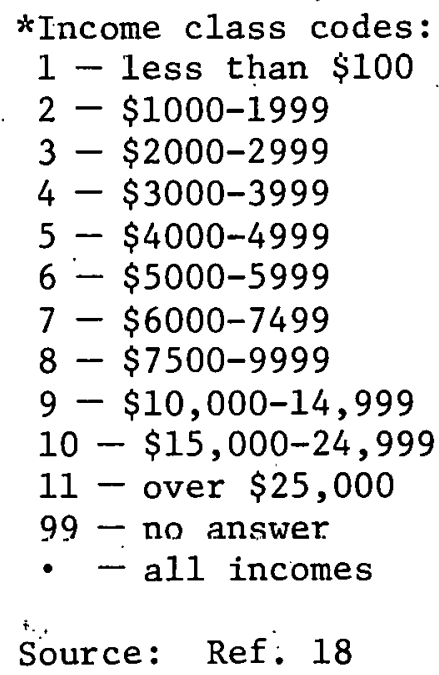

File 9. Car-miles by income by region, 1977, from National Travel Survey. File name $=$ INRG77.310

Format: $\operatorname{col}$.

1-26 region code* ( 1 or 2 digits, left-justified), followed by a blank, followed by income class code**, followed by a blank, followed by number of cars (integer), followed by a blank, followed by number of car-miles (integer) **The income class codes are: * Region codes

$$
\begin{array}{ll}
1-\text { less than } \$ 2000 & 1-\text { New England } \\
2-\$ 2000-2999 & 2-\text { Mid-Atlantic }
\end{array}
$$




$$
\begin{aligned}
& 3-\$ 3000-3999 \\
& 4-\$ 4000-4999 \\
& 5-\$ 5000-5999 \\
& 6-\$ 6000-7999 \\
& 7-\$ 8000-9999 \\
& 8-\$ 10,000-11,999 \\
& 9-\$ 12,000-14,999 \\
& 10-\$ 15,000-19,999 \\
& 11-\$ 20,000-24,999 \\
& 12-\$ 25,000-34,999 \\
& 13-\$ 35,000-49,999 \\
& 14-\$ 50,000 \text { or over } \\
& . . \text { al1 licultes }
\end{aligned}
$$

3 - South Atlantic

4 - East North Central

5 - East South Central

6 - West North Central, minus ND \& SD

7 - West South Central

8 - Mountain, plus ND \& SD, minus ID

9 - Pacific, plus ID

- - all regions

Source: Ref. 18

File 10. Car-miles by income by purpose, 1972, from NTS. File name $=$ INPR7 2.310

Format: col.

1-15 car-miles (1eft-justifled integer), followed by a blank, followed by purpose code*, followed by a blank, followed by income class code

*The purpose codes are:

1 - visit friends or relatives

2 - business and conventions

3 - outdoor recreation

4 - entertainment

5 - sightseeing

6 - personal \& family affairs, other

Income class codes are those for File 8.

Source: Ref. 18

File 11. Car-miles by income by purpose, 1977, from NTS, File name $=$ INPR77.310

Format: $\operatorname{col}$.

1-26 purpnse rnie*, fn11nised hy a h1 ank, followed by income class code, followed by a blank, followed hy numher of. cars, followed by a blank, followed by number of car-miles (all integers)

*The purpose codes are:

11 - visit friends or relatives.

12 - business

13 - conventions

14 - recreation

15 - entertainment

16 - sightseeing

20 - other 
The income class codes are those for File 9.

Source: Ref. 18

File 12. Car-miles by state by purpose, 1972, from NTS. File name $=$ STPR72.310

Format: $\operatorname{col}$.

1-16 number of car-miles, followed by a blank, followed by purpose code, followed by a blank, followed by FIPS state code (all integers)

The purpose codes are those for File 10 .

Source: Ref. 18

File 13. Car-miles by state by purpose, 1977, from NTS. File, name $=$ STPR77.310

Format: col.

1-26 special state code*, followed by a blank, followed by purpose code, followed by a blank, followed by number of cars, followed by a blank, followed by number of car miles (all integers)

The purpose codes are those for File 11.

*The state codes are:

$$
\begin{array}{ll}
01-\mathrm{AL} & 28-\mathrm{MS} \\
04-\mathrm{AZ} & 29-\mathrm{MO} \\
05-\mathrm{AR} & 31-\mathrm{NE} \\
06-\mathrm{CA} & 32-\mathrm{NV} \\
08-\mathrm{CO} & 34-\mathrm{NJ} \\
09-\mathrm{CT} & 35-\mathrm{NM} \\
10-\mathrm{DE} & 36-\mathrm{NY} \\
11-\mathrm{DC} & 37-\mathrm{NC} \\
12-\mathrm{FL} & 39-\mathrm{OH} \\
13-\mathrm{GA} & 40-\mathrm{OK} \\
15-\mathrm{HA} & 41-\mathrm{OR} \\
17-\mathrm{IL} & 42-\mathrm{PA} \\
18-\mathrm{IN} & 44-\mathrm{RI} \\
19-\mathrm{IO} & 45-\mathrm{SC} \\
20-\mathrm{KS} & 47-\mathrm{TN} \\
21-\mathrm{KY} & 48-\mathrm{TX} \\
22-\mathrm{LA} & 49-\mathrm{UT} \\
23-\mathrm{ME} & 50-\mathrm{NH} \& \mathrm{UT} \\
24-\mathrm{MD} & 51-\mathrm{VA} \\
25-\mathrm{MA} & 53-\mathrm{AK}, \mathrm{ID} \& \mathrm{WA} \\
26-\mathrm{MI} & 54-\mathrm{WV} \\
27-\mathrm{MN} & 55-\mathrm{WI} \\
& 56-\mathrm{MT}, \mathrm{ND}, \mathrm{SD} \& \mathrm{WY}
\end{array}
$$

Source: Ref. 18 
File 14. Nonagricultural employees by state, 1975. File name = EMP75.310

Format: col.

1-2 state FIPS code, right-justified

4-8 number of employees, thousands (right-justified integer)

Source: Ref. 15

File 15. Population in SMSA's, in central cities, and outside SMSA's, by state, 1970 Census. File name $=$ POP70.310

Format: $\operatorname{col}$.

1-2 state FIPS code (right-justified)

4-11 population inside SMSA's (right-justified integer)

13-19 population ineide central citics (right-justified integer)

21-27 population outside SMSA's (right-justified integer)

Source: Ref. 16

File 16. Commuter person-miles by area of residence, 1975. File name $=$ TOWORK. 310

Format: $\operatorname{col}$.

$1 \quad 1$ = driving alone, 2 = carpooling

3-6 miles driven twice a day to or from work in 1975; represents the median value of a range (decimal point in (ol. . 5)

7-16 number of persons driving this distance twice a day who live in the central city (thousands, decimal. point in col. 14)

17-26 number of persons driving this distance twice a day who live in an SMSA but not in the central city (thousands, decimal point in col. 24)

27-36 number of persons driving this distance twice a day who live outside any SMSA (thousands, decimal point in

co]. 34)

Snurce: Ref. 14

File 17. Population inside and outside metropolitan areas, by state, 1975. File name $=$ POP 75.310

Format: $\operatorname{col}$.

1-2 state FIPS code (see Sec. 8.2), right-justified

4-9 population of metropolitan areas (SMSA's), rightjustified integcr

11-15 population living outside metropolitan areas, rightjustified integer

all population figures in thousands

Source: Ref. 15 
File 18. Estimated average miles per gallon for autos, by state, 1967-77. File name $=$ MPG. 310

Format: col. .

1-2 state alphabetic code (see Sec. 8.2), right-justified integer

4-69 11 fields of 6 columns each, corresponding respectively to average MPG in $1967, \ldots, 1977$. A decimal point occupies the fourth position in each field.

Source: Axe1 Rose, ORNL

File 19. Commuter auto load factors, by region by type of area of residence, 1975. File name $=$ LOAD. 310

Format: col.

1 region code (see Sec. 8.2)

3-7 average number of persons per car in carpools whose participants live within central cities

9-13 persons per car, for persons who live in SMSA's but outside central cities

15-19 persons per car, for persons who live outside any SMSA (Standard Metropolitan Statistical Area)

A decimal point occurs in the second position of each of the last three fields.

Source: Ref. 14

File 21. Estimated average urban and rural miles per gallon for autos, by state, 1975. File name $=$ MPG2.310 (File 20 is an output file)

Format: $\operatorname{col}$.

1-2 state alphabetic code (see Sec. 8.2), right-justified

5-9 urban MPG (decimal point in col. 7)

11-15 rural MPG (decimal point in.col. 13)

Source: Axel Rose, ORNL

Data Quality Numbers

Method 311. Commercial autos

a11 estimates 
Method 312. Taxicabs

$$
\begin{array}{ll}
\text { national estimates } & --2 \\
\text { state estimates } & --3
\end{array}
$$

Method 313. Federal autos

$$
\begin{array}{ll}
\text { national estimates } & --1 \\
\text { state estimates } & --
\end{array}
$$

Method 314. Household autos

$$
\begin{array}{ll}
\text { ndaliumal estimales } & --2 \\
\text { state estimates } & --3
\end{array}
$$

s

trave1

a11 estimates

Method 316. Commuting

$$
\text { all estimates }
$$




\section{References}

1. D. B. Shonka, Characteristics of Automotive Fleets in the U.S., 1966-77, ORNL/TM-6449, Sept. 1978.

2. Bobit Publications, Automotive Fleet, Redondo Beach, Cal. Several monthly issues in the 1967-76 period.

3. Motor Vehicle Manufacturer's Association, Motor Vehicle Facts and Figures, Detroit, 1977.

4. Contro1 Data Corporation, Wells Research'Company, Taxicab Operating Characteristics.

5. Bureau of the Census, U.S. Dept. of Commerce, General Social and Economic Characteristics, Census of Population, 1970.

6. General Services Administration, Federal Motor Vehicle Fleet Report, 1976, U.S. Gov. Printing Office, June 1977.

7. Federal Highway Administration, U.S. Dept. of Transportation, Highway Statistics, Section 1: Vehicles, Drivers and Fuels, U.S. Government Printing office, Washington, D.C., annually 1967-76.

8. Bobit Publications, Automotive Fleet, Redondo Beach, Cal. Automotive Fleet Fact Book.

9. National Association of Fleet Administrators, personal communication, April 1977.

10. Federal Highways Administration, U.S. Dept. 'of Transportation, National Personal Transportation Survey, U.S. Govt. Printing office, 1972.

11. Bureau of the Census, U.S. Dept. of Commerce, 1967 Census of Transportation: National Transportation Study, TC67-N1, U.S. Govt. Printing office, 1969.

12. Bureau of Labor Statistics, U.S. Dept. of Labor, Consumer Expenditure Sumey, 1973-7.4, U.S. Govt. Printing Office.

13. Wagner, Naughton, Brooks, Light-Duty Highway Fleets, draft briefing prepared by Brookhaven National Laboratory for the Dept. of Energy, April 18, 1978.

14. Bureau of the Census, U.S. Dept. of Commerce, The Journey to Work in the U.S.: 1975, July 1.979.

15. Bureau of the Census, U.S. Dept. of Commerce, Statistical Abstract of the United States, 1978. 
16. Bureau of the Census, U.S. Dept. of Commerce, 1970 Census of Population: Number of Inhabitants, U.S. Sumary, December 1971.

17. Federal Highway Administration, U.S. Dept. of. Transportation, Nationwide Personal Transportation Study, computer tape.

18. Bureau of the Census, U.S. Dept. of Commerce, National Travel Survey, computer țapes, 1972 and 1977.

19. Dorothy Denunsus (staff member of Commercial Car Joumal), Census of the motor fleet market, a statistical analysis in 1975, Radnor, Pa. (see Ref. 1, p. 6).

20. B. D. MeNutt, D. Plrkey, R. Dulla, C. Miller, A Comparison of Fuel Economy Results from EPA Tests and Actual In-Use Experience, 1974-77 Model Year Cars, U.S. 
Method 320

BUS

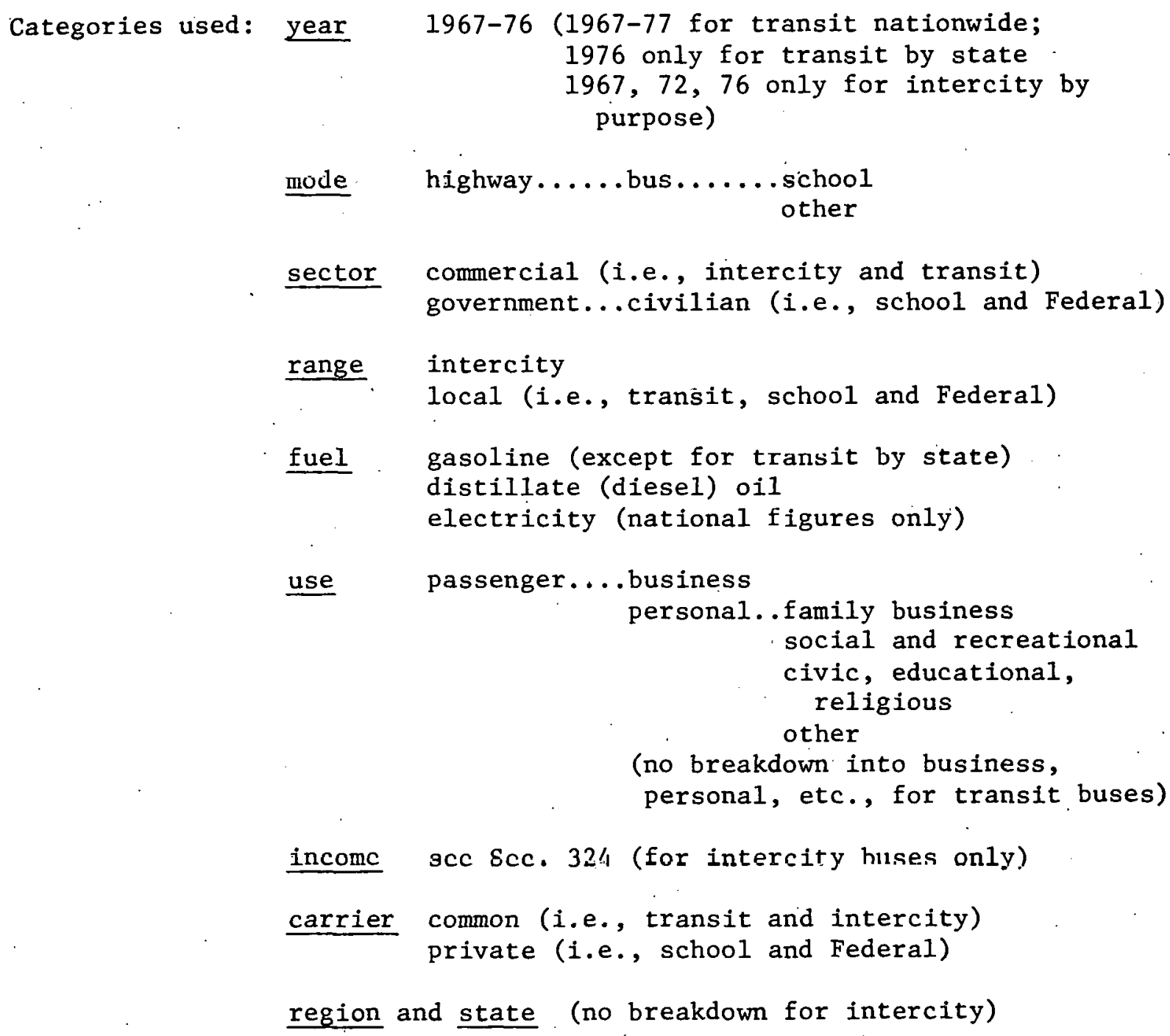

The energy consumption of a bus is the energy content of the fuel the bus burns. Bus energy use is broken down into four modal subcategories, each of which uses one fuel type for the overwhelming majority of its operations and is either exclusively local or exclusively intercity in its range of operation. These are: (1) intercity common carriers, (2) local transit buses, (3) school buses, and (4) government buses (Federal civilian only). Data are available from the American Public Transit Association (APTA, Ref. 1) for both gasoline and diesel fuel use for many transit systems. The General. Services Administration (GSA) reports that all Federally-owned buses use gasoline (Ref. 2), and it is assumed for these estimates that all school buses use gasoline. while all 
intercity buses use diesel oil. Breakdowns by bus size and weight are generally unavailable. Transit buses are presumed to be local in their range of operation as are Federal and school buses, while intercity buses are clearly just that.

The reader is warned that division of energy use by purpose or income group is problematic. Buses are multipassenger vehicles by definition and there is no obviously correct way to attribute responsibility for the fuel use to different passengers. What has been done here is to attribute fuel use according to passenger-miles of travel. (These passenger-mile data are available for intercity bus travel only.) It is particularly important to understand that if a certain group of people. are attributed $x \%$ of the fuel use in this way, one cannot infer that total bus fuel use would be reduced by $x \%$ if these people were to quit riding the bus. The obvious reason is that all or most of the same buses might yet run with reduced.loads and so consume nearly as much fuel as before.

321. School bus gasoline use, by state, 1967-76

All school buses are regarded as private (i.e., not common) carriers providing local transportation. The available data (Files 1,2 and 3 ) cover school buses operated at public expense and consequently are likely to reflect a very few buses carrying private school children. Noncthcless all these buses are classified as part of the government sector, since government pays for them. There is nn reasnnoble way to octimatc the fuel use of buses funded privately, except to say it is a very small portion of school bus fuel use. The government sector estimate of school bus fuel use in fact serves, in the data base, as an estimate of fuel use in both the private and government sectors. Schnnl hus rnnsumption in tho commercial sector is taken, by definitional fiat, to he zero.

Total annual school bus miles traveled is avallable for almost all states for the years 1967-76 from the National Safety Council (Ref. 3, File 1) which also reports the number of school buses by state (Ref. 3, File 1). To obtain an estimate of school bus gasoline consumption this annual mileage is divided by an estimate. of national average school bus miles per gallon obtained from Table VM-1 published by the Federal Highway Administration (Ref. 5, File 2):

$$
F_{s t}=\frac{V M T}{s t}
$$


where'

$$
\begin{aligned}
\mathrm{F}_{\text {st }} & =\text { gallons of fuel consumed in state } \mathrm{s} \text { during year } t \\
\mathrm{VMT}_{\mathrm{st}} & =\text { school bus miles traveled in state } \mathrm{s} \text { during year } t \text { (File } 1) \\
\mathrm{MPG}_{t} & =\text { average national school bus miles per gallon in year } t \\
& \text { (File } 2)
\end{aligned}
$$

For states where total school bus miles are missing for certain years, gasoline use is estimated based on the number of school buses registered (NSC statistics, File 1, where available, otherwise FHWA, Ref. 5, File 3) and on the state average miles per school bus for other years where data are available for that state. More precisely,

$$
\mathrm{F}_{s t}=\mathrm{N}_{s t} \mathrm{vmt}_{\mathrm{s}} / \mathrm{MPG} \mathrm{G}_{\mathrm{t}}
$$

where

$$
\begin{aligned}
& \mathrm{N}_{\mathrm{st}}=\underset{\text { (File } 1 \text { or } 2)}{\text { number of }} \\
& \begin{aligned}
\mathrm{vmt}_{s}= & \text { the average of VMT } \\
\text { and } \mathrm{N}{ }^{-} / \mathrm{N}_{s t} & \text {, are known. }
\end{aligned}
\end{aligned}
$$

$\mathrm{N}_{\text {st }}$ is taken directly from File 1 if it occurs there. Otherwise, the number of registered school buses reported in File 3 is adjusted to reflect the fact that registration statistics evidently provide incomplete coverage. The adjustment factor is the average ratio of the total number of school buses (as reported to the National Safety Council, File 1) to the number of registered buses, over the years in which both figures are available. That is, when $\mathrm{N}_{\mathrm{st}}$ is not available in File 1;

$$
\mathrm{N}_{s t}-\mathrm{R}_{s t} \frac{1}{\mathrm{n}} \sum_{t^{-}}\left(\mathrm{N}_{s t^{-}} \mathrm{R}_{s t^{-}}\right)
$$

where

$$
\begin{aligned}
\mathrm{R}_{\mathrm{st}}= & \text { number of registered school buses in state } \mathrm{s} \text { in year } t \text { (File } 3) \\
\mathrm{n}= & \text { number of years, } 1967-76, \text { in which } \mathrm{N}_{s t} \text { is reported to the } \\
& \text { National Safety Council } \\
\mathrm{t}^{\prime} \quad & \text { ranges over the years in which } \mathrm{N}_{\mathrm{st}} \text { is reported to the National } \\
& \text { Safety Council }
\end{aligned}
$$

If $\mathrm{VMT}_{\varepsilon t^{\prime}}$ is not known for any year $t^{\prime}$, the national average-miles per school bus replaces the state average vmt ${ }^{\cdot}$. That is, 


$$
F_{s t}=N_{s t} v_{t} / M P G_{t}
$$

where

$$
\begin{aligned}
\text { vmt }_{t}= & \text { average miles per school bus nationwide in year } t \text { (computed } \\
& \text { from File } 1 \text { ) }
\end{aligned}
$$

For years in which neither $\mathrm{VMT}_{\text {st }}$ nor number of buses is in the NSC data, the state is given the same share of total national school buses as it had in the most recent year for which data are available. That is,

$$
F_{s t}=\frac{N_{s t^{\prime}}}{N_{t^{\prime}}} N_{t} v_{t} / M_{t}
$$

where

$$
\begin{aligned}
\mathrm{N}_{t^{\prime}}= & \text { number of } s c h o o l \text { buses registered in the U.S. in year ' } t^{\prime} \\
& \text { (File } 1 \text { or } 3 \text { ) } \\
t^{\prime}= & \text { latest year prior to year } t \text { for which } N_{s t^{\prime}} \text { is known }
\end{aligned}
$$

322. Federal civilian bus gasoline use, by state, 1967-76

Al1 Federal buses are presumed to transport passengers 1 nrally and their use is classified as use for business purposes. They are not classified as common carriers.

The General. Services Administration (Ref. 2) reports annual gallons of gasoline consumed and average miles per gallon of Federally-owned buses for each year (File 4). These data are available at only the national level. The Federal Highway Administration, however, reports the number of federally-owned buses in each state for each year (File 3 ). These data may be used to obtain order of magnitude estimates of Federal bus gasoline use by state, hy simply sharing the total national uac amnng the states according to their percentage share of Federal bus registrations. That is,

$$
F_{s t}=\frac{N_{s t}}{N_{t}} F_{t} .
$$


where

$$
\begin{aligned}
F_{s t}= & \text { fuel consumed by Federal buses in state } s \text { during year } t \\
N_{s t}= & \text { number of Federal buses registered in state } s \text { in year } t \\
N_{t}= & \text { total number of Federal buses registered nationwide (File } 3 \text { ) } \\
F_{t}= & \text { total fuel consumed nationwide by Federal buses (File 4) }
\end{aligned}
$$

These buses are all civilian buses.

323. Transit bus fuel use, nationally 1967-76, diesel fuel use by state for 1976

While many transit bus systems are publicly owned and typically subsidized by public funds, their fuel use is classified here in the commercial sector. Transit buses are also classified as common carriers. The basic source of statistics on transit bus fuel use is the Transit operating Reports published by APTA (Ref. 1, File 5). This annual document covers all but a few of the major public transit systems in the U.S. and the majority of transit bus operations. Operating statistics such as numbers of buses, bus and passenger-miles, and fuel use by type are reported for APTA member systems. There are unfortunately a few major and many minor systems which do not report. (e.g., Seattle) and several systems (e.g., Boston) which report only combined fuel use data for all transit operations, including rail. As a result, the APTA data may cover only about two-thirds of transit bus fuel use, with a bias toward omission of the smaller systems.

Fortunately, data on the number of peak period buses for all. 899 local transit operations in the U.S. are available from the U.S. Department of Transportation for 1977-78 (Ref. 6, 7, 8; File 6). The data are reported by state and urbanized area. It was decided to use these data to estimate fuel use in transit systems that do not report to APTA, simply by multiplying the number of buses in these systems by the average tuel usage per bus. The average usage per bus was estimated from the APTA data in the following way. The systems reporting to APTA were divided into five groups by population of urbanized area: (1) less than 10,000, (2) $100,000-250,000$, (3) $250,000-500,000$, (4) $500,000-1$ million, and (5) over 1 million. Systems operating more than 500 buses were excluded from this grouping because virtually all of the systems missing from the APTA reports are small ones, and because systems with more than 500 buses exhibited widely differing levels of fuel use per peak period bus. The average fuel use per bus was calculated for each group, and these averages 
were employed as estimates of fuel usage per bus in the systems not reporting to APTA.

Recall, however, that the Department of Transportation data on the number of buses operating is available only for 1977-78. The latest APTA data are for 1976. To make matters worse, the number of buses in operation varies considerably over the years. Consequently the method described above was used to estimate only 1976 transit fuel consumption. To attempt earlier years would be to risk considerable error in supposing that the number of buses operating in these years is similar to the number operating in 1977.

There appearis to be no reliable way to estimate the state-by-state fuel consumption in years preceding 1976. As mentioned earlier, the APTA data compass only a fraction of the transit systems in operation. In 1976, for instance, the total diesel fuel consumption reported to APTA was 258.6 million gallons, which is only $66 \%$ of the actual consumption of 383.3 million gallons, as estimated in the way described above., In addition, priur to 1972 or so the consumption of gasoline becomes a significant fraction ( $10 \%$ or more) of fuel consumption, whereas in 1976 it accounts for only $1.3 \%$ of fuel consumption (Ref.: 9, Table 17). In order to permit diesel consumption estimates in these earlier years, attempts were made to regress a system's diesel consumption on its number of buses, on the number of customers it serves, on both of these, and on the urbanized area population, in each case without success. Similar failure beset attempts to run regressions of a system's diesel use on its number of buses within individual regions, and a regression of a region's total diesel use on its total number of buses.

To sum up, a state's transit rnnsumption of dieool fuel is computed:

$$
F_{s t}=\sum_{b \in s} F_{b t}
$$

where

$$
\begin{aligned}
& F_{b t}=\text { diegel fucl uscd by transil buses tn stace } s \text { during year } t \\
& F_{b t}=\left\{\begin{array}{l}
\text { the fucl consumed by bus system } b, \text { if it is reported to APTA } \\
(\text { File 5) } \\
\mathrm{N}_{b t}-f_{\mathrm{P}_{b} t}, \text { if } \mathrm{F}_{\mathrm{bt}} \text { is not reported to APTA }
\end{array}\right. \\
& \mathrm{N}_{\mathrm{bt}^{-}}=\text {number of peak period buses operating in bus system } \mathrm{b} \text { in } \\
& \mathrm{f}_{\mathrm{p}_{\mathrm{b}} \mathrm{t}}=\begin{array}{l}
\text { average gallons consumed per bus during year } \mathrm{t} \text { in cities in } \\
\text { population group } \mathrm{pb} \text {, excluding cities that operate more than }
\end{array} \\
& 500 \text { buses (calculated from File 5) }
\end{aligned}
$$




$$
\begin{aligned}
p_{b} & =\begin{array}{l}
\text { the population group to which the city served by bus system } b \\
\text { belongs }
\end{array} \\
t & =1976, \quad t^{\prime}=1977
\end{aligned}
$$

In the meantime, APTA provides estimates of national transit diesel and gasoline use for all the years 1967-77 (Ref. 9, Table 17), and these figures (File 8) are included in the data base (except for the 1976 diesel figure, which is estimated as above). The APTA estimates that in 1976, 389.2 million gallons of diesel oil and 5.2 million gallons of gasoline were burned by transit buses, showing close agreement with the 383.3 million gallons of diesel oil estimated using the method described above. The APTA also provides estimates (File 8) of transit electricity consumption nationwide for 1967-77, and these appear in the data base. Estimates of 1976 total transit energy use by state is based solely on the diesel consumption by state.

324. Intercity common carriers fuel use, 1967-76, by trip purpose by income class, $1967,72,76$

For intercity commercial buses national fuel use estimates are available for 1972-77 from the American Bus Association (ABA) (Ref. 13, File 9). These estimates include Interstate Commerce Commission (ICC) regulated Class I, II, III companies and carriers in interstate service. They are based on fuel use data reported by the companies to the ICC. Total annual vehicle-miles traveled (VMT) for the same buses are also available in ABA publications covering 1967-76 (Ref. 10, File 9). ABA statistics indicate that intercity bus miles per gallon varied only from 6.06 to 6.22 over the period 1972-77. Thus fuel use for years prior to 1972 can reasonably be estimated from annual VMT and the 1972 figure of, 6.07. Regional or state breakdowns are not available, and since the nature of these bus operations is intercity it would not be appropriate to estimate fuel use on the basis of state commercial bus registration data. All intercity common carriers are presumed to burn diesel fuel.

The National Travel Surveys (Ref. 4) for 1967, 72 and 77 can be used to obtain a division of passenger-miles of travel on intercity buses (viz., those making trips longer than 200 miles) by trip purpose or by income of traveler (File 10). The percentage of passenger-miles by: purpose are used to share energy use among passengers by giving each passenger-mile an equal share of energy use. The mapping from the National Travel Survey trip purposes to the End Use data base categories is as follows. 
End Use Data Base

business

personal

$$
\text { ...visits to friends }
$$
and relatives

..outdoor recreation

...entertainment

...vacation and sightseeing

...family business

...other
1967 NTS

business and conventions

personal and

family affairs

outdoor recreation

entertainment

sightseeing

other pleasure

(none)

no answer
1972 NTS

1977 NTS

business

conventions

personal or

family affairs

family affairs

visit friends and

relatives

outdoor recreation

entertainment

entertainment

sightseeing

sightseeing

(none)

shopping

other

medical

no answer other

Income category breakdowns are similarly based on passenger-miles and utilize current dollars. The family income categories are:

\begin{tabular}{|c|c|c|c|}
\hline \multirow{2}{*}{ Income group } & \multicolumn{2}{|c|}{ Dollar range } & \multirow[b]{2}{*}{1977} \\
\hline & 1967 & 1972 & \\
\hline 1 & $0=3999$ & $0-4999$ & $0-1999$ \\
\hline 2 & $4000-5999$ & $5000-7499$ & $2000-2999$ \\
\hline 3 & $6000-7499$ & $7500-9999$ & $3000-3999$ \\
\hline 4 & $7500-9999$ & $10,000-14,999$ & $4000-4999$ \\
\hline 5 & $10,000-14,999$ & $15,000-u p$ & $5000-5999$ \\
\hline 6 & $15,000-$ up & & $6000-7499$ \\
\hline 7 & & & $7500-9999$ \\
\hline 8 & & & $10,000-11,999$ \\
\hline 9 & & & $12,000-14,999$ \\
\hline LU & & & 15, VUU-19,999 \\
\hline 11 & & & $20,000-24,999$ \\
\hline 12 & & & $25,000-34,999$ \\
\hline 13 & & & $35,000-49,999$ \\
\hline 14 & & & $50.000-u p$ \\
\hline
\end{tabular}

Due to the incommensurability of the income categories, no income breakdown is provided for years other than 1967, 72 and 76 . The 1977 NTS is used for the 1976 breakdown, without correction for inflation. Since the subcategories of the personal use category are likewise incomparable, only the business/personal USE2 breakdown is provided (and the USE3 breakdown is not provided) for years other than 1967, 72 and 76. Again, the 1977 survey is used for the 1976 estimates. The business/personal breakdown for the intervening years is estimated by interpolating linearly the breakdown in 1967, 72 and 77 . 
In fine, intercity bus fuel use is calculated according to the following formulas. When $t=1967, \ldots, 76$ and $p$ is the personal or business category,

$$
\begin{aligned}
& F_{t}= \begin{cases}F_{t} \text { (as reported) } & \text { when } t \geq 1972 \\
\operatorname{VMT}_{t}{ }^{M P G} & \text { when } t<1972\end{cases} \\
& F_{p t}= \begin{cases}\frac{1}{5} F\left[p_{p, 1972}(1977-t)+p_{p, 1977}(t-1972)\right] & \text { when } t \geq 1972 \\
\frac{1}{5} \operatorname{VMT}_{t} M_{t}\left[p m_{p, 1967}(1972-t)+p_{p, 1972}(t-1967)\right] & \text { when } t<1972\end{cases}
\end{aligned}
$$

When $t=1967,72$ or 76 and $p$ is unrestricted,

$$
\begin{aligned}
& F_{p t}= \begin{cases}F_{t}{ }^{p m_{p}}, 1977 & \text { when } t=1976 \\
F_{t}{ }_{p t} & \text { when } t=1972 \\
\mathrm{VMT}_{t} \mathrm{MPG}_{t}{ }^{\mathrm{Mm}} \mathrm{pt} & \text { when } t=1967\end{cases} \\
& F_{i t}= \begin{cases}F_{t} \mathrm{pm}_{i, 1977} & \text { when } t=1976 \\
F_{t} \mathrm{pm}_{i t} & \text { when } t=1972 \\
\mathrm{VMT}_{t} \mathrm{MPG}_{t} \mathrm{pm}_{i t} & \text { when } t=1967\end{cases}
\end{aligned}
$$

where

$$
\begin{aligned}
F_{t}= & \text { intercity common carrier fuel use during year } t \text { (File } 9 \text { for } \\
& t \geq 72) \\
F_{p t}= & \text { intercity common carrier fuel use for purpose } p \text { during year } t \\
F_{i t}= & \begin{array}{l}
\text { intercity common carrier fuel use by persons in income class } i \\
\text { during year } t
\end{array} \\
\mathrm{VMT}_{\mathrm{t}}= & \text { total intercity bus-miles traveled nationwide in year } t \\
& \text { (File } 9 \text { ) } \\
\mathrm{MPG}_{\mathrm{t}}= & \text { estimated miles per gallon for intercity buses during the } \\
& \begin{array}{l}
\text { years prior to } 1972, \text { set at } 6.07 \text { miles per gallon, the } \\
\text { observed efficiency for } 1972
\end{array} \\
\mathrm{pm}_{\mathrm{pt}}= & \text { fraction of passenger-miles traveled for purpose } \mathrm{p} \text { in year } t \\
& \text { (from File } 10 \text { ) } \\
\mathrm{pm}_{\mathrm{it}}= & \text { fraction of passenger-miles traveled by persons in income } \\
& \text { class } i \text { during year } t \text { (from File 11) }
\end{aligned}
$$




\section{Private carrier fuel use}

It is not known how much fuel is consumed by buses not operated as common carriers, with the exception of the school buses and Federal buses already canvassed. This gap in the data deprives us of consumption estimates for church buses and buses operated by institutions other than schools and the civilian branches of the Federal government.

\section{Input Data Files}

File 1. Number of buses and total bus mileage, hy state 1967-76 (National Safety Counoil Survcy), File nane = 3CHOOT. 320

Format: cols.

\section{1-2 year}

4-5 state FIPS code (see Sec. 8..2), right-justified integer

7-15 number of school buses registered (right-justified integer); a period in col. 15 indicates missing data

17-25 school bus-miles traveled (right-justified integer); a period in col. 25 indicates missing data

Source: Ref. 3

File 2. Average miles per gallon for school buses, 1967-76. File name $=$ SCLIMPG. 320

Format: cols.

1-70 Ju fiplds of $\overline{7}$ columns each, oach corrcsponding to a year in the period 1967-76, in chronological order. Each number contains a decimal point in the second column of the field. The file contains only one card.

Source: Ref. 5, Table VM-1

File 3. Number of buses by state in five classification, 1967-76. File name $=$ BUSES 320

Format: cols. 1-2 $10-11$ state FIPS code (see Sec, 8.2), left-justified integer

20-29 number of commercial gasoline buses (left-justified integer)

30-39 number of commercial diese1 buses (left-justified integer)

40-49 number of school buses (left-justified integer)

50-59 number of Federal buses (left-justified integer)

60-69 number of public school buses (left-justified integer)

Source: Ref. 5, Table 
File 4. Federal bus fuel consumed and miles per gallon, 1967-76. File name $=$ FED. 320

Format: cols.

$1-2$ year

3-11 gallons of fuel consumed (right-justified integer)

12-15 miles per gallon (decimal point in col. 14)

Source: Ref. 2

File 5. American Public Transit Association data for transit buses, 1967, $71,74,75,76$. File name $=\mathrm{APTA} .320$

Format: cols. Card 1: 1-2

3-10

$12-15$

state FIPS code (see Sec. 8.2), right-justified integer

$17-19$

abbreviated name of transit system (characters)

month and year. (month right-justified in 12-13)

$21-30$

system code number (right-justified integer), which has

diesel fuel consumed by revenue equipment, line $15 \mathrm{~A}^{*}$

(dollars)

31-40 gasoline consumed by revenue equipment, line 16A* (dollars)

41-50 lubricating oil consumed by. revenue equipment, line 17A* (do1lars)

51-60 line service bus hours, line $7 \mathrm{~B} *$

61-70 special (charter) bus hours, line $8 \mathrm{~B} *$

71-80 nonrevenue bus-hours, line 9B*

Card 2: $\quad 1-10$

$11-20$

line service bus-miles, line $3 B *$

$21-30$

charter bus-miles, line 4B*

$31-40$

41-50

$51-60$

$61-70$

$76-77$

$78-80$

nonrevenue bus-miles, line 5B*

gallons of diesel fuel consumed, line 12B*

diesel bus-miles, line 13B*

diesel bus-hours, line 14B*

gallons of gasoline consumed, line 15B*

year

system code number

Card 3: $1-10$

$11-20$

21-30

gasoline bus-miles, line 16B*

$31-40$

41-50

$51-60$

$61-65$

gasoline bus-hours, line 17B*

gallons lube-oil, line 18B*

$66-70$

total revenue passengers, line $27 \mathrm{~B}$ *

special (charter) passengers, line 28B*

total passengers carried, line $35 \mathrm{~B}$ *

$71-75$

transit buses owned and leased, line 40B*

intercity buses owned and leased, line 42B*

*denotes line numbers in Ref. 1, 1975. A indicates financlal

data, $B$ indicates operating data. Numbers are sometimes

left-justified, followed by a decimal point if there is room, 
and other times right-justified without decimal point. A period somewhere in the field indicates a missing datum.

Source: Ref. 1

File 6. Number of buses in operation at peak hours (UMTA data), 1967, $71,74,75,76$. File name $=$ UMTA. 320

Format: cols.

1-2 FIPS state code (see Sec. 8.2)', right-justified integer

3-10 abbreviated transit system name (characters)

11-35 five fields of 5 columns each, containing peak buses in operalium respectively in $1967,71,74,75$ and 76 (right-justified integers); a period in the fifth column of a field indicates that the missing number is available in File 7

42-49 urban area population (right-justified integer)

Source: Ref. $6,7,8$

File 7. Number of buses in operation at peak hours (APTA data), 1967, $71,74,75,76$. File name $=\operatorname{APTA} 2.320$

Format: cols.

1-2 state FIPS code (see Sec. 8.2), right-justified

3-10 abbreviated transit system name (characters)*

20-23 number of peak buses (right-justified integer); period in col. 23 indicates a missing datum

$30-31$ year

42-49 population of urban area (right-juslified inleger)

* the system abbreviations are standard codes that can be matched with the abbreviations in File 6 .

Source: Ref. 1

File 8. Transit bus fuel consumption (APTA estimates), 1945-77. File name $=$ APTA3.320

Format: cul.

1-2 ycar

3-10 electric power consumed, millions of kwh (right-justified integer)

11-20 gasoline consumed, thousands of gallons (right-justified integer)

21-30 diese1 Iuel consumed, thousands of gallons (rightjustified integer)

31-40 propane consumed, thousands of gallons (right-justified integer)

Source: Ref., 9, Table 17 
File 9. Intercity bus passenger-miles, bus-miles and fuel use, 1967-76. File name $=$ NTRCTY $: 320$

Format: col.

Card 1: $1-60$

10 fields of 6 columns each, containing revenue passenger-miles in regular intercity service, respectively in 1967-76, Class I only (left-justified integers); figures in millions

Card 2: $1-60$ 10 fields of 6 columns each, containing vehicle-miles for 1967-76 respectively, Class I only (decimal point in fourth column of field); in millions

Card 3: 1-70 10 fields of 7 columns each, containing fuel consumption for 1967-76 respectively, class I only (decimal point in fifth column of field); figures in millions of gallons

Card 4: 1-70 10 fields of 7 columns each, containing fuel consumption for 1967-76 respectively, Classes I, II and III (decimal point in fifth column of field); figures in millions of gallons (original data for 1972-76 only)

Card 5: 1-60 10 fields of 6 columns each, containing bus-miles in millions for 1967-76 respectively, Classes I, II and III (decimal point in sixth column of field)

The file contains only five cards.

Source: Ref. 10 (Cards 1-3), Ref. 14 (Cards 4-5)

File 10. Passenger-miles by trip purpose (National Travel Survey), 1967, 72, 77. File name $=$ PURPOS .320

Format: $\operatorname{col}$.

1-2. purpose code*, right-justified

4-5 year

7-18 passenger-miles (round-trip passenger-miles for 1977), right-justified integer

* the codes are as follows:

1977 codes: 1 - business.

2 - convention 7 - personal or family affairs

3 - entertainment 8 - shopping

4 - medical $y$ - sightseeing

5 - other 10 - visit relatives or friends

1972 codes: 1 - visit friends or relatives

2 - business and conventions

3 - outdoor recreation

4 - sightseeing and entertainment

5 - other

1967 codes: 1 - business and convention

2 - visits to friends and relatives

3 - outdoor recreation

4 - entertainment and sightseeing

5 - other pleasure 


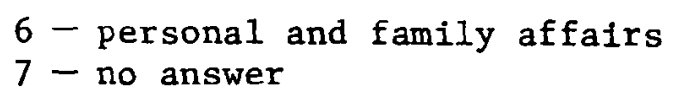

File 11. Passenger-miles by income class. (National Travel Survey), 1967, 72, 77. File name $=$ INCOME. 320

Format: $\operatorname{col}$.

1-19 income class code ( 1 or 2 digits)*, followed by a blank, followed iumedlately by an integer showing the number of passenger-miles traveled on interrity buocs by

*the income class codes are indicated in Sec. 324.

Source: Ref. 11 (1967 and 72) and 12 (1977)

Data Quality Numbers

Method 321. School buses $\quad \therefore 2$

Method 322. Eederal buses -- 1

Method 323. Transit buses $\quad-=3$

Melkod 324. Intercity buses $\rightarrow 1$ 


\section{References}

1. American Public Transit Association, Transit Operating Report, annua1ly.

2. General Services Administration, Federal Motor Vehicle Fleet Report, annua11y.

3. National Safety Council, Accident Facts, 1973, p. 93.

4. National Travel Survey.

5. Federal Highways Administration, Highway Statistics, U.S. Department of Transportation, annually.

6. U.S. Department of Transportation, Directory of Regularly Scheduled, Fixed-Route, Local Public Transportation Service in U.S. Urbanized Areas over 200,000 Population, December 1978.

7. Urban Mass Transit Administration, "Transit Data for 173 Urbanized Areas between 50,000 and 200,000 Population," Technical Notice 非-77, released August 11, 1977.

8. UMTA, "Non-Urbanized Areas of Less than 50,000 Population with Fixed-Route, Local Bus Service Scheduled Every Weekday, Available to the General Public," Technical Notice \#9-78, released May 3, 1978.

9. American Public Transit Association, Transit Fact Book, 1977-78 edition.

10. American Bus Association, America's No.. 1 Passenger Transportation Service, 1976, Tabie 1, p. 26.

11. Bureau of the Census, 1.972 Census of Transportation, Vol. 1: National Travel Survey, 1967 (Table 12) and 1972 (Table 4).

12. Bureau of the Census, National Travel Survey 1977 data tape, available from Customer Services Branch, Data User Services Division, Bureau of the Census, Washington, D.C. 20233.

13. American Bus Association, letter of Frederick H. Mueller to Axel Rose, Aug. 14, 1978. 
Categories used (see next page for breakdowns available): year $\quad 1967-76$

(weight class) (body type)

mode highway...truck....1ight (under 10,000 1b........pickup, panel, gross vehicle weight) multi-stop, medium $(10,000-20,000 \mathrm{lb})$ platform liglil-heavy ( $20,000-$ $26,0001 \mathrm{~b})$ heavy-heavy (over 26,000 1b)

insulated, nonrefrigerated van

(for Federal trucks only:) light (under 12,500 1b) medium $(12,500-17,0001 \mathrm{~b})$ light-heavy (over $17,000 \mathrm{lb}$ )

insulated, refrigerated van

furniture van, open top van other enclosed. van beverage truck utility truck garbage truck winch or cralue wrecker pole or logging truck auto transport truck dump truck tauk truck (1iquids) tank truck (dry bulk) concrete mixer uther

sector commercial

government (Federal government civilian only)

range intercity local

fuel gasoline

diesel oil

other (i.e., LPG) 
use passenger

nonpassenger...freight......agriculture

construction

manufacturing

wholesale and retail trade

utilities

for hire

forestry and lumber

mining

other

services

$\underline{\text { region } \text { and state }}$

Breakdowns available, 1967-76:

Household and commercial fuel use,

by sector by fuel by range by weight class by body type (Method 331)

by sector by fuel by range by state (Methods $-332,333,334$ )

Household and commercial intercity fuel use, by sector by fuel by weight class by use (Method 335)

Household and commercial intercity gasoline use,

by sector by weight class by state (Method 334)

Federal government civilian fuel use,

by weight class by state (Method 336)

A11 commercial fuel use is classified under the nonpassenger use category.

N.B. Beware. All household and commercial truck fuel use estimates are based. on comprehensive surveys for the years $196 \%$ and 1972 only. Estimates for the intervening years 1968-71 are derived by allotting to each category of fuel consumption an interpolated fraction of reported highway fuel used in those years. Estimates for 1973-76 are similarly based on extrapolation of these fractions. Consequently the 1967 and 1972 estimates alone represent genuine data, and the rest should be interpreted with extreme caution. They are provided for the convenience of those who may find such interpolations useful. (Extrapolation to 1976 was necessary because the 1977 Truck Inventory and Use Survey tape had not been received by the completion of thie project. The incorporation of the 1977 data would improve the 1973-76 estimates considerably.)

N.B. The fuel use reported for each USE and RANGE category is the total fuel use of trucks whose operation falls primarily into that category. Local fuel use, for instance, represents the total fuel used by trucks that usually operate locally. 
N.B. Household truck fuel use is defined here as the total fuel consumption of trucks described in the Truck Inventory and Use Survey as used primarily for personal transportation - i.e., of trucks "used in place of an automobile to go from home to work; for outdoor recreation; camping; fishing; etc." The dramatic rise in intercity truck fuel use in the household sector between 1967 and 1972 should be interpreted with this in mind.

More complete information is available for trucks and truck use than for any other highway vehicle type. The 1967 and 1972 Truck Inventory and Use Surveys (TIUS, Ref. 1), conducted by the Rurpau of the Census as part of the Census of Transportation, contains infurmation on annual miles traveled and number of trucks by state, range of operation, major use category, size, fuel type and other characteristic.s. The sample contains over 100,000 trucks, enabling fairly detailed breakdowns even at the state level. Government trucks, however, are not included in the survey. The TIUS, together with Federal government fleet statistics (Ref. 2) and Federal Highway Administration statistics on numbers of publicly owned vehicles (Ref. 3) comprise the basic data sources for estimating truck fuel use.

1. Household and commercial sectors, Methods 331-35

From the TIUS, numbers of trucks and annual vehicle-miles of travel are obtained for 11 use categnrips, 3 fuel typoo, 4 wcight caltyus las, and $J$ lduges of operation (see above). These data are currently available Iur 1967 and 197\%. (At the time this study was completed, the 1977 survey tape had still not been received.) Intervening years are estimated by linear interpolation of shares of highway fuel use by fuel type between survey years. The years 1973-76 are similarly estimated by extrapolation. That is,

$$
F_{f c t}=\frac{1}{5}\left[(1972-t) \frac{F_{f c, 19 b /}}{F_{f, 1967}}+(t-1967) \frac{F_{\tilde{f}_{c, 1972}}}{F_{f, 1972}}\right] \cdot F_{f t}
$$

where

$$
\begin{aligned}
\mathrm{F}_{\mathrm{fct}}= & \text { consumption of fucl } \mathrm{f} \text { in category } \mathrm{c} \text { during year } t ; c \text { can be } \\
& \text { any category or Intersection of categories for which fuel } \\
& \text { use might be estimated (except state and year categorics), } \\
& \text { such as light trucks or intercity diesel-burning heavy-heavy } \\
& \text { trucks } \\
\mathrm{F}_{\mathrm{ft}}= & \text { total consumption of fuel } \mathrm{f} \text { in year } t \text { (Files } 8,11 \text { ) }
\end{aligned}
$$


For data broken down by state, a more accurate interpolation can be had by using the total fuel consumption figures in each state:

$$
F_{f c s t}=\frac{1}{5} \cdot\left[(1972-t) \frac{F_{f c s, 1967}}{F_{f s, 1967}}+(t-1967) \frac{F_{f c s, 1972}}{F_{f s, 1972}}\right] \cdot F_{f s t}
$$

where

$$
\begin{aligned}
\mathrm{F}_{\mathrm{fcst}} & =\text { consumption of fuel } \mathrm{f} \text { in category } \mathrm{c} \text { in state } \mathrm{s} \text { during year } \mathrm{t} \\
\mathrm{F}_{\mathrm{fst}} & =\text { consumption of fuel } \mathrm{f} \text { in year } \mathrm{t}
\end{aligned}
$$

However, if this is done the total fuel use, summed over a breakdown by state, would not equal other summations that ought to yield the same total. That is, we would have

$$
\sum_{c} \sum_{\mathrm{s}} \mathrm{F}_{\mathrm{fcst}} \neq \sum_{\mathrm{c}} \mathrm{F}_{\mathrm{fct}}
$$

For. this reason formula (2) is not used, and formula (1) serves as the interpolation formula for all categories.

The use of formula ( 1 ) to extrapolate beyond 1972 yields negative estimates in certain categories of fuel use, namely those in which the consumption level dropped drastically between 1967 and 1972. Most of the negative numbers occur in rather disaggregate categories of LPG use. The tables and data tapes record a zero in place of every negative number, since it may be assumed that a quantity that had been shrinking so rapidly prior to 1972 would remain close to zero after 1972. Aggregate data, however, are computed by summing the original negative numbers rather than zeros. This means, for instance, that the recorded LPG use for individual truck body types in 1976 may sum to a figure larger than that recorded for all body types, since some of the extrapolated estimates for individual body types may have been negative. This method of summation is followed so that formula (1) will remain valid for all categories $c$, aggregate or disaggregate. In the meantime, it is to be admitted that extrapolation is not a happy way to estimate fuel use, even if it is only extrapolation of relative rather than absolute amounts. The incorporation of 1977 data into the computations would enormously upgrade the estimates for $1.973-76$.

The TIUS includes both commercial and household truck use. It is assumed that the use of trucks in the household sector is equivalent to the TIUS major use category "personal transportation." It is not clear from the TIUS" survey instrument whether this question may have been interpreted by some firms to mean, the transportation of persons rather than transportation in personal trucks. It 1s likely, however, that any such definitional problem is of minor consequence. The remainder of the 
TIUS major use categories are considered to represent use of trucks in the commercial sector.

\section{General Method}

Since the TIUS data provide vehicle-miles of travel by state, use, fuel, weight and range of operation, fuel consumption in these categories can (generally speaking) be estimated by dividing the vehicle-miles of travel in a certain category by the fuel efficiency of trucks in that category. That is,

$$
F_{\text {SCE }}=\frac{V_{\text {SCt }}}{M P G_{i}}
$$

where

$$
\begin{aligned}
F_{\text {sct }}= & \text { fuel consumption in state } s \text { in category (or intersection } \\
& \text { of categories) c during year } t \\
\mathrm{VMT}_{S C t}= & \text { truck-miles of travel in state } s \text { in category c during year } t \\
\mathrm{MPG}_{\mathrm{C}}= & \text { miles per gallon in category } \mathrm{c}
\end{aligned}
$$

Estimates of miles per gallon for each weight class for gasoline and diesel powered trucks by range of operation were obtained (Ref. 4). LPG-powered truck miles per gallon estimates were calculated by assuming that diesel and LPG vehicles achieved the same milee por Btu. Thus diesel miles per gallon were multiplied hy the ratio of LPG to diesel Btu content per gallon. That is,

$$
M P G_{r W, L P G}=\frac{H_{L P G}}{H_{\text {diese } \perp}} M P G_{r W, \text { diesel }}
$$

where

$$
\begin{aligned}
M \mathrm{PG}_{\mathrm{rwf}}= & \text { average miles per gallon achieved by trucks in weight } \\
& \text { Glass } \mathrm{w} \text { oporating over range } \mathrm{r} \text { and burning tue } \perp \text { (File } 7) \\
& \cdot \\
\mathrm{H}_{\mathrm{f}}= & \text { heat content of fuel } \mathrm{f} \text {, in Btu/gal (see Sec. 2.1) }
\end{aligned}
$$

331. Household and commercial truck fuel use nationwide, by sector by fuel by weight by body type by range of operation, 1967-76

It is possible at the national level to estimate energy use for 21 body type categories by fuel type, weight and range of operation. 


$$
F_{\text {fwbrht }}=\frac{\operatorname{VMT}_{\text {fwbrht }}}{M P G_{f w r}}, t=1967,72
$$

where

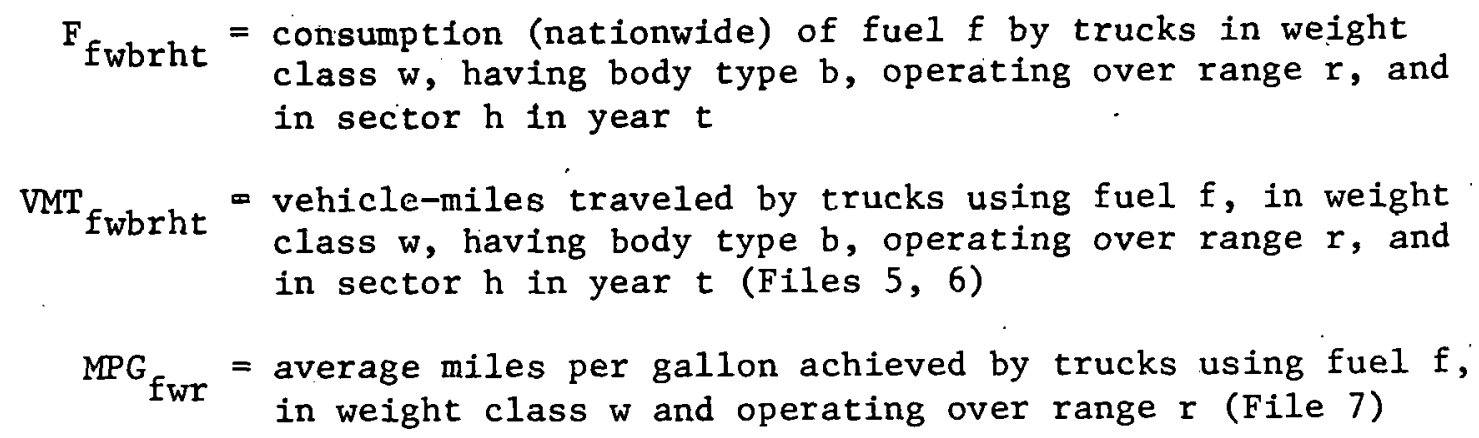

Truck diesel and LPG fuel use together with bus diesel fuel use must add up to total highway diesel fuel and special fuel (LPG) use at the national level. To provide for this, intercity truck diesel fuel use is normalized by multiplying it by the ratio of (a) actual highway diesel and special fuel use minus local truck diesel and LPG use minus bus diesel use to (b) the estimated total intercity truck diesel fuel use. The formula (5), then, must be amended for the calculation of intercity diesel fuel use:

$$
\mathrm{F}_{\text {wbht }}^{\prime}=\mathrm{F}_{\text {diesel,wb, intercity, ht }} \frac{\mathrm{H}_{t}-\mathrm{L}_{t}-\mathrm{B}_{t}-\mathrm{IL}_{t}}{\mathrm{D}_{t}}, t=1967-76
$$

where

$$
\begin{aligned}
& \begin{aligned}
\mathrm{F}_{\text {whht }}^{\prime}= & \text { adjusted national consumption of diesel fuel by intercity } \\
& \text { trucke in weight class } w \text {, having body type } \mathrm{b} \text { and in }
\end{aligned} \\
& \text { sector } h \text { during year } t \\
& \mathrm{VMT}_{\text {wbht }}=\text { truck-miles of travel by intercity trucks using diesel } \\
& \text { fuel and in weight class } w \text {, having body type } b \text { and in } \\
& \text { sector } h \text { during year } t \\
& \begin{aligned}
M P G_{w}= & \text { average miles per gallon of intercity diesel trucks in } \\
& \text { weight class } \mathrm{w}
\end{aligned} \\
& H_{t}=\begin{array}{l}
\text { total sales of diesel and special fuel for highway use } \\
\text { during year } t \text { (File } 8 \text { ) }
\end{array} \\
& \begin{aligned}
& \mathrm{L}_{t}= \text { total local truck consumption of diesel fuel and LPG during } \\
& \text { year } t \text { [from formula. (5) above] }
\end{aligned} \\
& B_{t}=\text { total bus consumption of diesel fuel in year } t
\end{aligned}
$$




$$
\begin{aligned}
D_{t}= & \text { total diesel fuel used by intercity trucks in year } t \text {, as } \\
& \text { calculated by formula (5) above } \\
t= & \begin{array}{l}
\text { total LPG used by intercity trucks in year } t \text {, as calculated } \\
\text { by (5) }
\end{array}
\end{aligned}
$$

Note that this adjustment is made in the interpolated and extrapolated estimates as well as in the 1967 and 72 estimates.

It is interesting to compare the intercity diesel truck fuel use before and after adjustment. I'he results are as follows.

Thousands of harrels of dieocl fucl.

$1967 \quad 1972$

Total reported highway diesel

fuel use (FHWA)

$120,232 \quad 202,843$

Less estimated bus diesel fuel

and LPG use (Method 320)

$12,436 \quad 11,244$

Less estimated total local

truck diesel fuel and LPG use.,

using formula (5) above

\begin{tabular}{lr}
16,779 & 34,412 \\
905 & 1,070 \\
90,112 & 156,117 \\
97,003 & 142,665 \\
\hline$-6,891$, & $+13,452$ \\
$-5.7 \%$ & $+6.6 \%$ \\
$-7.1 \%$ & $+19.4 \%$
\end{tabular}

Less estimated intercisty truck

LPG use, from formula (5)

\begin{tabular}{rr}
16,779 & 34,412 \\
905 & 1,070 \\
90,112 & 156,117 \\
97,003 & 142,665 \\
\hline$-6,891$, & $+13,452$ \\
$-5.7 \%$ & $+6.6 \%$ \\
$-7.1 \%$ & $+19.4 \%$
\end{tabular}

Yields approximate intercity

truck diesel fuel use

$-7.1 \% \quad-19.4 \%$

Less intercity truck diesel fue1

use estimated by formula (5)

Yields adjustment necessary

...as \% of highway diesel use

...as \% of estimated intercity

truck diespl fuel use

The adjusted intercity truck diesel fuel use, then, is got by decreasing the formula (5) estimate by $7.1 \%$ for 1967 and increasing it by $9.4 \%$ for 1972. These results suggest that, even before the adjustment in formula (6) is made; the ORNL estimates both of total highway diesel use and of intercity truck diesel use are accurate to within $\pm 10 \%$. One can be fairly confident, then, that the adjusted figures are similarly accurate, at least for the survey years 1967 and 1972. The highly disaggregated estimates, however, are another matter entirely, and the data quality numbers reflect this. 
332. Local household and commercial truck fuel use, by sector by fuel by state, 1967-72

Energy use estimates at the state level for local trucks can be made and broken down by sector (household or commercial) by fuel type. First, miles per gallon estimates by sector by fuel type at the national level $\cdots$ were developed by taking the weighted harmonic mean fuel efficiency across weight classes for each sector. For each sector the fractions of truck-miles by weight class were used as weighting factors. Given these miles per gallon estimates by sector, fuel consumption was simply derived by dividing sectior truck-miles by miles per gallon for each fuel type. In notation,

$$
F_{\text {sfht }}=\frac{V M T_{\text {sfht }}}{M P G_{\text {fht }}}
$$

where

$$
\begin{aligned}
& \begin{aligned}
F_{\text {sfht }}= & \text { consumption of fuel } f \text { by local trucks in state } s \text { and } \\
& \text { sector } h \text { during year } t
\end{aligned} \\
& \begin{aligned}
\mathrm{VMT}_{\text {sfht }}= & \text { vehicle-miles traveled by trucks burning fuel } f \text { in state } s \\
& \text { and sector } h \text { during year } t \text { (Files } 3,4)
\end{aligned}
\end{aligned}
$$

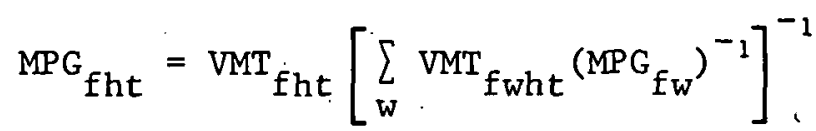

$$
\begin{aligned}
& \begin{aligned}
& \mathrm{VMT}_{\mathrm{fwht}}= \text { total vehicle-miles traveled by trucks in weight class } \mathrm{w} \\
& \text { burning fuel } \mathrm{f} \text { in sector } \mathrm{h} \text { during year } t \text { (Files } 5,6 \text { ) }
\end{aligned} \\
& \mathrm{VMT}_{\mathrm{fht}}=\text { total vehicle-miles traveled by trucks burning fuel } \mathrm{f} \text { in } \\
& \text { sector } h \text { during year } t \text { (Files } 5,6 \text { ) } \\
& \begin{aligned}
M P G_{f_{W}}= & \text { average miles per gallon of trucks burning fuel } f \text { and in } \\
& \text { weight class } w(\text { File } 7)
\end{aligned}
\end{aligned}
$$

333. Intercity household and commercial truck diesel fuel-use, by state, 1967-76

The TIUS data are reported by state of registration. While it is certainly reasonable to attribute fuel use by local trucks and perhaps even short haul trucks to their state of registration, this method is clearly inappropriate for trucks in long-haul operations. Such trucks traverse state boundaries as a rule, so that the location of their fuel purchases is unknown. (Experimentation with attributing long-haul fuel use to state of registration confirmed this judgment. Trucks registered 
in Delaware in 1975, for example, were estimated to have consumed approximately four times as much diesel fuel as was actually sold in the state.) For this reason, the TIUS data are not directly used to determine state fuel sales for intercity trucking. Instead local truck diesel use; and bus diesel fuel and LPG use are subtracted from total state diesel and LPG fuel sales for highway use. The remainder represents sales of diesel fuel and LPG to intercity (i.e., short- and long-haul) trucking in the state. Sales of diesel fuel alone is got by adjusting this remainder to account for the national proportion of intercity truck diesel and LPG use represented by consumption of diesel fuel alone. More succinctly,

$$
F_{s t}=\left(H_{s t}-L_{s t}-B_{s t}\right) \frac{I_{t}-I L_{t}}{I_{t}}, t=1967-76
$$

where

$$
\begin{aligned}
& \begin{aligned}
& \mathrm{F}_{\text {st }}= \text { consumption of diesel fuel by intercity trucks in state } \mathrm{s} \\
& \text { during year } t
\end{aligned} \\
& \begin{aligned}
\mathrm{H}_{\mathrm{st}}= & \text { sales of diesel and special fuel for highway use in state } \mathrm{s} \\
& \text { during year } t \text { (File } 8)
\end{aligned} \\
& B_{s t}=\text { consumption of diesel fuel and LPG by buses in state } s \text { during } \\
& \text { year } t \text { [see formula (9) below] } \\
& L_{\text {st }}=\text { consumption of diesel fuel and LPG by local trucks in state } s \\
& \text { during year } t \text { (as estimated in Method } 332 \text { above) } \\
& I_{t}=\text { estimated national consumption of diesel fuel and LPG by } \\
& \text { intercity trucks in year } t \text { (Method 331) } \\
& \mathrm{IL}_{\mathrm{t}}=\text { estimated national consumption of LPG by intercity trucks in }
\end{aligned}
$$

Since Method 320 estimates bus diesel fuel and LPG use on a national level only, it is necessary somehow to obtain a state-by-state breakdown. For present purposes it suffices simply to allot bus diesel fuel and LPG. use to the states in proportion to the number of commercial diesel fuel buses registered in each state:

$$
B_{s t}=\left(T_{t}+I_{t}\right)\left(N_{s t} / N_{t}\right)
$$

where

$$
\mathrm{T}_{\mathrm{t}}=\underset{\text { national transit bus diesel fuel and LPG use in year } t}{\text { (Method 323) }}
$$




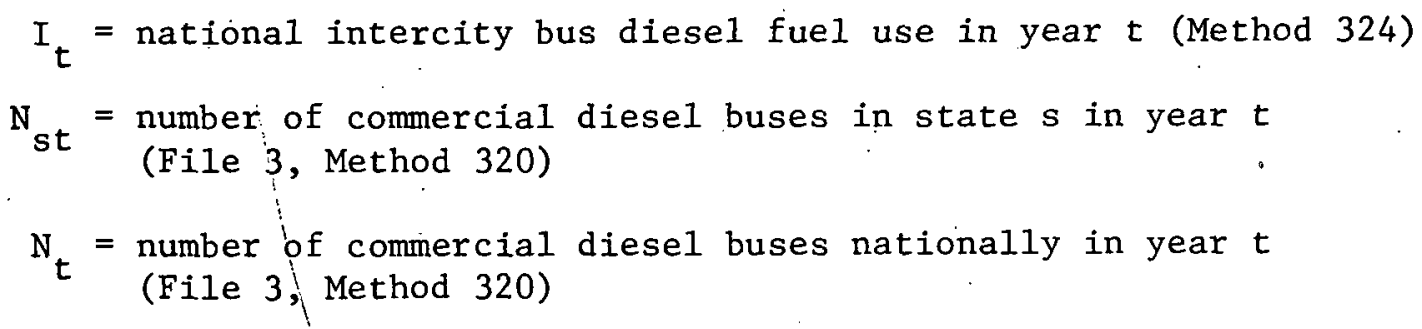

The resulting numbers are obviously too crude to serve as state estimates of bus diesel fuel use. But since buses consume less than a fifth as much diesel fuel as intercity trucks, these estimates are accurate enough to calculate the residual that is taken here to be intercity truck diesel fuel consumption.

334. Intercity household and commercial truck gasoline use, by state by sector by weight class, 1967-76

Diesel fuel is by far the predominant fuel used in long-haul trucking. According to the 1972 TIUS, diesel trucks account for over $80 \%$ of 1 ong-haul truck-miles although they comprise only about half of all trucks reporting that range of operation. Their share of long-range fuel use will be even greater, though, since $95 \%$ of the heaviest weight class trucks in long-range use are diesels. Gasoline powered trucks in long-haul use tend to be less than $20,000 \mathrm{lb}$ gross vehicle weight, the majority being light trucks and thus using less fuel per vehicle-mile. There is no obvious way to allocate their fuel use to states. It is assumed here that their fuel purchase patterns will follow those of diesel long-haul trucks. The total national fuel use by these vehicles is first computed by dividing total vehicle-miles by estimated miles per gallon for each weight class, and these totals are then allotted to each state in proportion to long-haul diesel fnel use. Or,

$$
F_{\text {swht }}=\frac{D_{\text {st }}}{D_{t}} \cdot \frac{V M T T_{\text {wht }}}{M P G_{w}}, t=1967,72
$$

where

$$
\begin{aligned}
& \begin{aligned}
\mathrm{F}_{\text {swht }}= & \text { consumption of gasoline by intercity trucks of weight } \\
& \text { class } \mathrm{w} \text { in eector } \mathrm{h} \text { in state. s during year } \mathrm{t}
\end{aligned}
\end{aligned}
$$

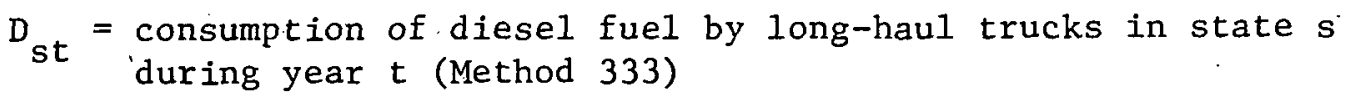

$$
\begin{aligned}
& D_{t}=\text { national consumption of diesel fuel by long-haul trucks } \\
& \text { during year } t \text { (Method 333) }
\end{aligned}
$$




$$
\begin{aligned}
\mathrm{VMT}_{\mathrm{wht}}= & \text { vehicle-miles traveled nationwide by gasoline-burning } \\
& \text { intercity trucks of weight class w in sector } \mathrm{h} \text { during } \\
& \text { year } \mathrm{t} \text { (Files 5, 6) } \\
\mathrm{MPG}_{\mathrm{w}}= & \text { average miles per gallon of gasoline-burning intercity } \\
& \text { trucks of weight class } \mathrm{w} \text { (File } 7)
\end{aligned}
$$

There is no way to assess the accuracy of this allocation of fuel use, due to 1 ack of data.

335. Intercity household and commercial truck fuel use nationwide, by sector by use by fuel by weight class, 1967-76

At the national level the TIUS data can be used straightforwardly to estimate intercity truck fuel consumption by sector, use, fuel type and wcight class:

$$
f_{\text {hfwut }}=\frac{\mathrm{VMT}_{\text {hfwut }_{\text {wut }}}}{\mathrm{MPG}_{\mathrm{fw}_{\mathrm{w}}}}, \mathrm{t}=1967,72
$$

where

$$
\begin{aligned}
& \mathrm{F}_{\text {hfwut }}=\text { consumption of fuel } \mathrm{f} \text { by intercity trucks of weight } \\
& \text { class } w \text { for use } u \text { in sector } h \text { during year } t \\
& \begin{aligned}
\mathrm{VMT}_{\text {hfwut }}= & \text { vehicle-miles traveled for use } u \text { by intercity trucks of } \\
& \text { welght class w burning fuel } \mathrm{f} \text { in sector h during year } t
\end{aligned} \\
& \text { (Files 1, 2) } \\
& M P G_{f_{\mathrm{w}}}=\text { average miles per gallon of intercity trucks of weight } \\
& \text { class } w \text { burning tuel } f \text { (File 7) }
\end{aligned}
$$

Again, trucks designated as short-haul or long-haul in TIUS are considered to be intercity trucks. As in Method 331, intercity diesel fue1. use is adjusted.so as to sum to the difference between highway diesel and special. fuel use and the comblned diesel tuel and LPG use of local trucks and of buses. That is,

$$
F_{\text {hwut }}^{\dot{ }}=F_{\text {h, diesel, wut }} \cdot \frac{H_{t}-\dot{L}_{t}-B_{t}-I L_{t}}{D_{t}}
$$

where

$$
\begin{aligned}
\mathrm{H}_{\mathrm{t}}= & \text { total sales of diesel and special fuel for highway use in } \\
& \text { year } \mathrm{t} \text { (File } 8 \text { ) }
\end{aligned}
$$




$$
\begin{aligned}
L_{t}= & \text { total local truck consumption of diesel fuel and } L P G \text { during } \\
& \text { year } t \text { (Method 332) } \\
B_{t}= & \text { bus diesel fuel consumption in year } t \text { (Method } 320 \text {, File 12) } \\
I L_{t}= & \text { estimated intercity truck LPG use in year } t \text { [from formula (11)] }
\end{aligned}
$$

\section{Federal government civilian truck fuel use, by state, 1967-76}

Data on truck use in the government sector are sparse. For the Federal government, national total fuel consumption and average miles per gallon by truck weight classes (less than 12,500 1bs, 12,500-17,000 1b, more than 17,000 1b) are available (Ref. 2), but only total numbers of Federal trucks are available by state. Thus it is possible to report this fuel use by weight class at the national level, but only use by all trucks can be estimated at the state level. State level estimates are generated by assuming that VMT and miles per gallon do not vary across states, so that fuel use is proportional. to the number of trucks. An estimate of only order of magnitude accuracy results.

$$
F_{s w t}=\frac{N_{s t}}{N_{t}} F_{w t}
$$

where

$$
\begin{aligned}
& \begin{aligned}
\mathrm{F}_{\text {swt }}= & \text { consumption by Federal government trucks of weight class } \mathrm{w} \\
& \text { in state } \mathrm{s} \text { during year } t
\end{aligned} \\
& \mathrm{~N}_{\mathrm{st}}=\underset{\text { (File } 9)}{\text { number of Federal government trucks in state } s \text { during year } t} \\
& N_{t}=\text { number of Federal government trucks nationwide in year } t \\
& \text { (File 9) } \\
& \mathrm{F}_{\mathrm{wt}}=\mathrm{VMT}_{\mathrm{wt}} / \mathrm{MPG}_{\mathrm{w}} \\
& \mathrm{VMT}_{\text {wt }}=\text { vehicle-miles traveled by Federal government trucks of weight } \\
& \text { class w during year } t \text { (File 10) } \\
& \begin{aligned}
& \mathrm{MPG}_{\mathrm{w}}= \text { miles per gallon of Federal government trucks of weight } \\
& \text { class } \mathrm{w}(\text { File 10) }
\end{aligned}
\end{aligned}
$$

For purposes of converting fuel consumption to energy consumption, it is assumed that all trucks less than 12,500 burn gasoline, half between 12,500 and $17,0001 \mathrm{~b}$ burn gasoline and half diesel fuel, and all trucks over $17,0001 \mathrm{~b}$ burn diesel fuel. The resulting errors are smaller than the errors in the estimation of fuel use. 
At the state government and local government level the situation is even worse. Data on VMT and fuel use by vehicle type are generally unavailable and, of course, there are no average national figures. Only numbers of trucks and tractor-trucks registered to state, county and municipal governments combined are available. In an effort to obtain some usable data, letters were sent to all state energy offices requesting any information available on fuel use by government vehicles in the state. of the 51 letters mailed, 19 responses were received, the majority indicating that they hadn't the vaguest notion of what state, let alone local, government vehicle fuel usage was. Those which were able to supply statistics varied widely both in the level of detail of the data und the quantity of fuel use per vehicle which they implied. The North Carolina Department of Commerce, for example, estimated gasoline and diesel fuel use by state government vehicles at 40 millinn gallons for 1978. Ohin, a larger state, is believed by its energy office to use 17 million gallons. New York reported 160 million gallons for gasoline use by state and municipal vehicles, comprising $2.1 \%$ of total gasoline sales in the state. It appears that state and local government use is substantially greater than Federal government use. Unfortunately, the inconsistent figures for fuel use by vehicle of a given type makes it impossible to estimate state level breakdowns of state and local government energy use by trucks.

\section{Input Data Files}

File 1. Truck-miles traveled, by weight class by range by fuel. hy nse, 1967. File name $=$ USE67.330

Format: 4 groups of 9 records, corresponding respectively to light, medium, 1ight-heavy and heavy-heavy trucks (see categories at beginning of Method 330 for definition of weight classes), each group containing 3 groups of 3 records, corresponding respëctively to gasoline, diesel fuel and $L P G$, each group containing 3 reçords, corresponding to local, short-haul and long-haul travel, each record having the format:

col.

1-132 12 fields of 11 columns each, showing thousands of truck-miles, corresponding respectively to the following uses: personal, agriculture, forestry, mining, construction, manufacturing, wholesale/retail, utilities, servires, for-hire, other, short term lease (right-justified, decimal point in last column of field)

Source: Ref. 1 
File 2. Truck-miles traveled, by weight class by range by fuel by use, 1972. File name $=$ USE72.330

Format: same arrangement as File 1, except that each record has the format:

col.

1-132 11 fields of 12 columns each, showing tens of truckmiles, corresponding respectively to the following uses: agriculture, forestry, mining, construction, manufacturing, wholesale and retail trade, for-hire, personal, utilities, services, other

Source: Ref. 1

File 3. Truck-miles traveled locally, by state by fuel by sector by body type, 1967. File name $=$ STAT67.330

Format: 5 groups of 6 record pairs, corresponding respectively to the 5 each group containing 3 groups of 2 record pairs, corresponding respectively to gasoline, diesel fuel and LPG, each group containing 2 record pairs, corresponding respectively

to household and commercial; each record pair having the format: col.

Record 1 1-121 11 fields of 11 columns each, showing thousands of truck-miles, corresponding respectively to the following 11 body types: multistop, platform, cattle rack, insulated nonrefrigerated, insulated refrigerated, furniture, open top, all other vans, beverage, garbage, winch (right-justified, decimal point in last column of field)

Record 2 1-109 one field of 10 columns followed by 9 fields of 11 columns each, showing truck-miles, corresponding respectively to the following 10 body types: wrecker, pole, auto, utility, pickup/panel, dump, tank (liq), tank (dry), concrete, other (right-justified, decimal point in last column of field)

Each of the 5 groups of 6 record pairs is preceded by an additional record showing the FIPS state code, right-justified, in $\operatorname{col}$. 1-2.

Source: Kef. 1

File 4. Truck-miles traveled locally, by state by fuel by sector by body type, 1972. File name $=$ STAT72.330

Format: same as File 3, except that the figures represent tens of truck-iniles and the body types are: 
Record 1 pickup or multistop or panel, platform with added device, other platform, cattle rack, insulated nonrefrigerated, insulated refrigerated, furniture, open top, other vans, beverage, utility

Record 2 garbage or refuse, winch, wrecker, pole, auto, dump, tank (1iq), tank (dry), concrete, other

Source: Ref. 1

File 5. Truck-miles traveled, by weight class by range by fuel hy sector by body type. File name $=$ BODY 67.330

Format: 4 groups of 18 record pairs, rorresponding reepectivcly to light, medium, 1ight-heavy and heavy-heavy,

each group containing 3 groups of 6 record pairs, corresponding respectively to gasoline, diesel fuel, LPG,

each group containing 3 groups of 2 record pairs, corresponding respectively to local, short-haul, long-haul,

each group containing 2 record pairs, corresponding to the household and commercial sectors,

each pair of records having the same format as pairs in File 3

Source: Ref. 1

File 6. Truck-miles traveled, by weight class by range by fuel by sector by bodỹ type. File name $=$ BODY 72.330

Format: 4 groups of 18 record pairs, corresponding respectively to light, IItedl Im!, 11gkt-heavy and heavy heavy,

earh group containing 3 groups of 6 recurd palrs, corresponding respectively to local, short-haul, lóng-haul,

each group containing 3 groups of 2 record.pairs; corresponding respectively to gasoline, diesel fuel, LPG,

each group containing 2 record pairs, corresponding to the household and commercial sectors, each pair of records having the same format as pairs in File 4

Source: Ref. 1

File 7. Truck-miles per gallon estimates, by weight class by range by fuel. File name $=$ MPG.330

Format: $\operatorname{col}$.

Card 1 1-23 MPG estimates for local gasoline-burning trucks, respectively for light, medium, light-heavy and

Card 2 1-24 MPG estimates for intercity gas-burning trucks, one

Card 3 1-23 MPG estimates for local diesel-burning trucks, one estimate for each weight class 
Card 4 1-23 MPG estimates for intercity diesel-burning trucks, each Card 5 1-23 MPG estimates for local LPG-burning trucks, each weight

class

Card 6 1-23 MPG estimates for intercity LPG-burning trucks, each weight class

All figures are separated by at least one blank and have a decimal point followed by two digits.

Source: Ref. 4

File 8. Diesel and special fuel consumption for highway use, by state, 1967-76. File name $=$ DIESEL 330

Format: $\operatorname{col}$.

$1-2$

3-72 10 fields of 7 columns each, corresponding respectively to $1967,68, \ldots, 76$ (right-justified integers); fuel use in thousands of gallons

Source: 1967-74: Ref. 3, Table MF-225; 1975: Ref. 5, Table MF-25; 1976: Ref. 5, Table MF-1

File 9. Number of Federal government vehicles, by vehicle type by state, 1967-76. File name = FED. 330

Format: $\operatorname{col}$.

1-2 year

4-5 state FIPS code, right-justified (see Sec. 8:2)

7-10 number of autos (right-justified integer)

12-14 number of buses (right-justified integer)

16-20 number of trucks (right-justified integer)

22-24 number of motorcycles (right-justified integer)

Source: Ref. 2

File 10. Average miles per gallon and gallons of fuel consumed by Federal trucks nationwide, by weight class, 1967-76. File name $=$ FEDGAL. 330

Format: $\operatorname{col}$.

1-2 year

4-44 Eix numbers; parh twn separated by one blank, corresponding to:

MPG for trucks under $12,5001 \mathrm{~b}$ (one digit after decimal point)

MPG for trucks between 12,500 and 17,000 1b (ditto)

MPG for trucks over $17,0001 \mathrm{~b}$ (ditto)

gallons used by trucks under 12,500 lb (integer) 
gallons used by trucks between 12,500 and $17,0001 \mathrm{~b}$ (integer)

gallons used by trucks over 17,000 1b (integer)

Source: Ref. 2

File 11. Total highway consumption of gasoline, by state, 1967-76. File name $=$ GAS .330

Format: see File, Method 310.

File 12. Bus diesel fuel and LPG consumptinn, 1967-76. Filo name $=$ RUS. 330

Format: $\operatorname{col}$.

1-4 intercity bus diesel fuel consumption, in thousands of bbl.

6-9 transit bus diesel. fuel consumption, in thousands of bbl

11-13 transit bus LPG consumption, in thousands of bbl (all numbers are left-justified integers)

There are 10 cards, corresponding respectively to the years 1967-76.

Source: Method 320

Data Quality Numbers

Household and commercial trucks:

Disaggregate data:

1967, 1972 esLImates -- 2

other years (interpolated \&

extrapolated estimates) -- 3

extrapolated estimates

raised trom negative

to zero

$=4$

Aggregate data:

computed as described in Method 900

Federal trucks:

National level

State level

$--1$

$--3$ 


\section{$\underline{\text { References }}$}

1. Bureau of the Census, Census of Transportation, Truck Inventory and Use Survey, 1967 and 1972 data tapes, Washington, D.C.

2. General Services Administration, Federal Motor Vehicle Fleet Report, annual, U.S. Government Printing Office, 1967-76.

3. Federal Highway Administration, U.S. Dept. of Transportation, Highway Statistics; Summary to 1975, U.S. Government Printing office, Washington, D.C., 1977.

4. Jack Faucett Associates, Trucking Activity and Fuel Consumption, 1973, 1980, 1985, and 1990, Washington, D.C., 1976.

5. Federal Highway Administration, U.S. Dept. of Transportation, Highway Statistics, Section 1: Vehicles, Drivers and Fuels, U.S. Government Printing office, Washington, D.C., 1975, 76. 
Method 340

MOTORCYCLE

Categories used:

year 1967-76 (1974-76 includes off-road and breakdown by state and by use;

1967-73 includes on-road only and nn hreakdown by state or by use)

mode highway......motorcycle

sector household

fuel gasoline

$\underline{\text { use }}$

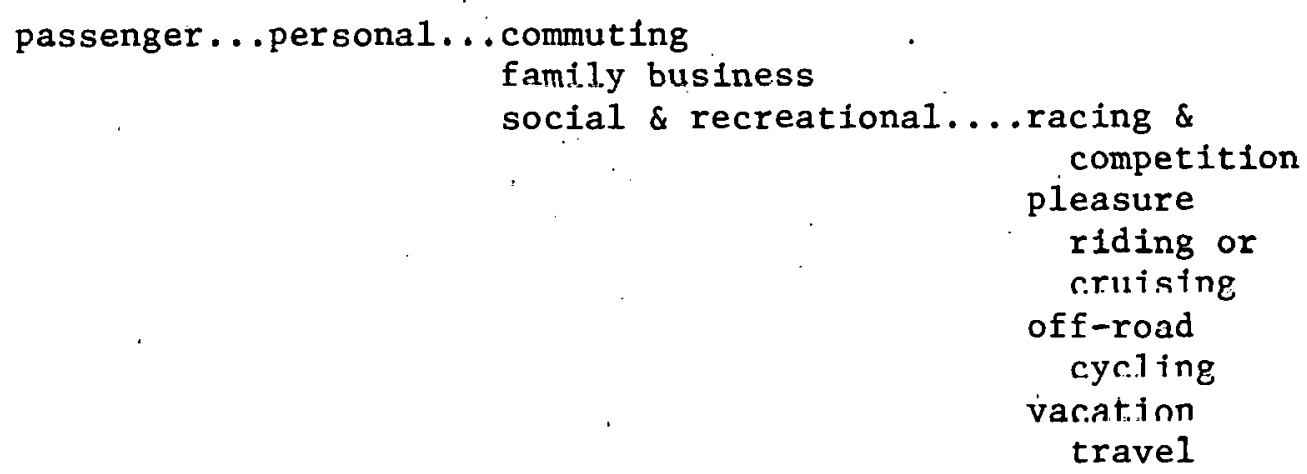

other

carrier private

state and region (for $1974-76$ only)

N.B.: Energy and fuel use estimates for years prior to 1974 exclude unregistered motorcycles and are therefore incomparable with 1974-76 figures, which do not exclude them. See below.

Motorcycle energy use is the energy content of the fuel the motorcycle burns. The energy supplied by the rider of a moped is not counted.

While there are relatively few data on motorcycle usage and fuel consumption, it is clear that motorcycle energy use is insignificant in. comparison to that of automobiles and trucks: The Motorcycle Industry Council estimated that there were 8.4 million motorcycles in use in the U.S. in 1976 (including mopeds, which have been variously estimated to number between 400,000 and 700,000 ). If one assumes that each one used the somewhat high figure of 100 gallons of gasoline per year, total annual 
fuel use would amount to less than one percent of highway gasoline use. Motorcycle fuel use is minor, and even substantial errors in its estimation will have little effect on the gross pattern of highway energy use.

341. Household motorcycle fuel use, 1967-76, by state, and by use, 1974-76

There are two major sources of statistics on the motorcycle population, vehicle-miles traveled and fuel use in the household sector:. the Federal Highway Administration (FHWA) and the Motorcycle Industry Council (MIC). FHWA reports annual motorcycle registrations by state (Ref. 6, Table MV-1). However, a substantial number of motorcycles are apparently off-road, unregistered vehicles. The MIC estimates that off-read cycles are more than a third of the total cycle population ( 3.0 out of 7.9 million in 1977). They have produced estimates, based on sales and scrappage, of the number of off-road, on-road and dual-purpose vehicles by state for 1976 (Ref. 3, p. 6). These state estimates are used in conjunction with FHWA registrations data for 1974 and 1975 to estimate total motorcycle populations by state for these two years. It is assumed that the ratio of vehicles in each of the three categories to FHWA registrations remains constant for 1974-76. That is,

$$
N_{c s t}=\frac{M_{c s, 76}}{M_{s, 76}} N_{s t}
$$

where

$$
\begin{aligned}
& \begin{aligned}
& \mathrm{N}_{\mathrm{cst}}= \text { number of motorcycles in category } c \text { (on-road, off-road or } \\
& \text { dual-purpose) in state } s \text { in year } t, t=1974-76
\end{aligned}
\end{aligned}
$$

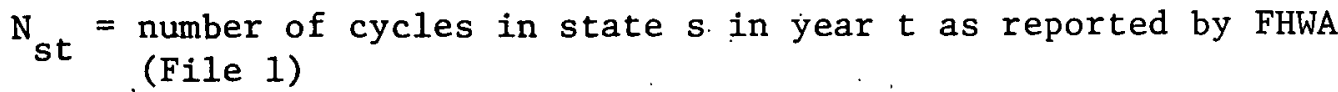

$$
\begin{aligned}
& \begin{aligned}
M_{c s t}= & \text { number of cycles in category } c \text { in state } s \text { in year } t \text {, as } \\
& \text { reported by MIC (File 2) }
\end{aligned} \\
& M_{s t}=\text { total number of cycles in state } s \text { in year } t \text {, as reported by }
\end{aligned}
$$

For years prior to 1974 off-road vehicles are neglected, and FHWA data alone are used for state. Thus, estimates for 1967-73 are not consistent with those for subsequent years.

Data on bike-miles traveled are difficult to come by. At the national level FHWA and the MIC have estimated 4500 and 3176 miles per 
cycle, respectively, for 1977. During the spring and summer of 1977, National Family Opinion, Inc., conducted a survey of motorcycle involvement in the U.S. (Ref. 5). The 3163 household survey recorded an estimate of approximate annual mileage and vehicle engine size for each household by state of residence. Additional-information included in what months the vehicle was regularly ridden and the average monthly mileage for various purposes during this riding season as well as whether the vehicle was predominately on- or off-road. From this survey tape were extracted (with considerable labor) the average miles per bike, for on-road, off-road and dual-purpose bike, in each state in 1977 (Ref. 5).. These figures were taken to be tolerably accurate for estimating fuel use in the years 1974-76. For prior years a weighted average of the 1977 miles per bike, over the three categories was used as a crude estimate of the average miles per bike nationwide. The weighting factors are the number of bikes in each category; formula (2) below makes the calculation explicit. No breakdown by state was attempted for years prior to 1974 .

The remaining information necessary for computing motorcycle gasoline consumption is miles per gallon by engine si.ze. Unfortunately such information is scarce. Cycle, a monthly motorcycle enthusiast magazine has published 65 road test fuel economies for street bikes from 1975 through 1979 (Ref. 1). These data were statistically analyzed in order to determine a relation between engine size and fuel economy: Only one bike in the sample was below $300 \mathrm{cc}$ in size, the largest being over $1200 \mathrm{cc}$. Regression analysis revealed that a statistically significant but trivially small relationship between displacement and fuel economy was present in the data. Systematic variation about the mean of $42 \mathrm{mpg}$ was slight. The results were unsatisfactory. While it is obvious that some relationship between engine size and fuel consumption exists (mnpeds, for example, are clalmed to achieve between 125 and $150 \mathrm{mpg}$ ), in attempting to quantify this relationship one is on very shaky ground. In the belief that some correction for engine size is better than none the following approach is used: The MIC estimates of fuel consumption and bike-miles traveled in 1977 lead to an overall mpg estimate of 48 . If $42 \mathrm{mpg}$ is assumed for bikes over $350 \mathrm{cc}$ (of which there were approximately 3.3 million in 1977) then under the assumption of equal miles traveled for all engine sizes and solving the formula for the harmonic mean gives an estimate of approximately. $53 \mathrm{mpg}$ for bikes under $350 \mathrm{cc}$. That is, if we set

$$
\mathrm{mpg}=\mathrm{N}\left(\frac{\mathrm{N}_{1}}{\mathrm{mpg}_{1}}+\frac{\mathrm{N}_{2}}{\mathrm{mpg}_{2}}\right)^{-1}
$$

where

$$
\begin{aligned}
\mathrm{mpg} & =\text { gas mileage for all motorcycles, set at } 48 \mathrm{mpg} \\
\mathrm{mpg}_{1} & =\text { gas mileage for cycles under } 350 \mathrm{cc} \text {, unknown } \\
\mathrm{mpg}_{2} & =\text { gas mileage for cycles at least } 350 \mathrm{cc} \text {, set at } 42 \mathrm{mpg}
\end{aligned}
$$




$$
\begin{aligned}
& N=\text { number of motorcycles in } 1977 \text {, set at } 7.9 \text { million } \\
& N_{1}= \text { number of cycles under } 350 \mathrm{cc} \text { in } 1977 \text {, set at } 4.6 \text { million } \\
& N_{2}=\begin{array}{l}
\text { number of cycles of at least } 350 \mathrm{cc} \text { in } 1977 \text {, set at } 3.3 \\
\text { million }
\end{array}
\end{aligned}
$$

then solution for $\mathrm{mpg}_{1}$ yields $\mathrm{mpg}_{1}=$ about 53 . Rounding to the nearest $5 \mathrm{mpg}$ to eliminate pretense of accuracy gives $40 \mathrm{mpg}$ and $55 \mathrm{mpg}$ for the two size classes.

Now the gas mileage by state can be computed as follows. For the years 1974-76, a weighted harmonic mean $\mathrm{mpg}$ is calculated for each bike category (on-road, off-road and dual-purpose) and for each state, based on the 1977 distribution of engine sizes above and below $350 \mathrm{cc}$ in each state. Since it is unreasonable to extend the 1977 survey results to earlier years, prior to 1974 cycles are presumed to average $48 \mathrm{mpg}$ in all. states. Consequently the 1974-7.6 figures are considerably better than the others, not only because of inaccuracy in the earlier. mileage figures but because, as mentioned earlier, the earlier bike population figures do not include unregistered bikes.

Breakdown by trip purpose for $1974-76$ is reasonably based on the 1977 survey results. The survey categories are matched with the End Use Data Base categories as follows:

End Use categories

Motorcycle survey categories

under passenger....personal:

commuting

family business

outdoor recreation....pleasure riding or cruising racing \& competition off-road riding

$$
\begin{aligned}
& \text { transportation to and from } \\
& \text { work/school } \\
& \text { other business purposes } \\
& \text { recreation/fun riding } \\
& \text { organized competition \& } \\
& \text { practice } \\
& \text { trail/off-road riding } \\
& \text { touring/vacation travel } \\
& \text { general transportation } \\
& \text { other types of riding }
\end{aligned}
$$

vacation \& sightseeing

other personal

The calculations are more precisely summed up in the following formulas. For the years 1967-73, 


$$
F_{t}=N_{t} \frac{v m t}{m p g}
$$

where

$$
\begin{aligned}
F_{t} & =\text { total motorcycle gasoline used nationwide in year } t \\
N_{t} & =\text { number of registered cycles nationwide in year } t \text { (File 1) } \\
m p g & =\text { national average miles per gallon for cycles, set at } 48 \\
v m t & =\frac{1}{M} \sum_{c=1} M_{c}{ }^{v m t} c \\
M_{c} & =\text { number of cycles in category c in } 1976 \text { (File 2) } \\
M & =\text { tota1 number of cycles in the U.S. in } 1976 \text { (File 2) } \\
v_{1} t_{c} & =\text { average miles per bike in category c in } 1977 \text { (File 3) }
\end{aligned}
$$

For the years 1974-76,

$$
F_{s t}=\sum_{c=1}^{3} N_{c s t} \frac{v m t_{c c}}{m p g_{c s}}
$$

where

$$
\begin{aligned}
& F_{s t}=\text { motorcycle gasoline used in state } s \text { in year } t
\end{aligned}
$$

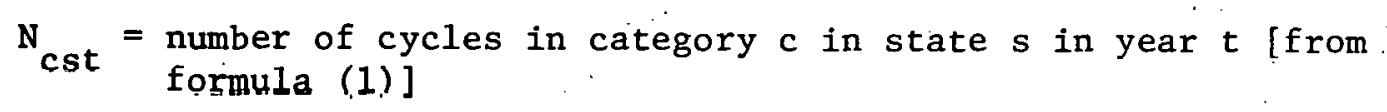

$$
\begin{aligned}
& \mathrm{vmt}_{\mathrm{cs}}=\text { average miles per bike in category } \mathrm{c} \text { in state } \mathrm{s} \text { (File 4) } \\
& \mathrm{mpg}_{\mathrm{cs}}=\left(\mathrm{n}_{1 \mathrm{cs}} / \mathrm{mpg}_{1}+\mathrm{n}_{2 \mathrm{cs}} / \mathrm{mpg}_{2}\right)^{-1} \\
& \begin{aligned}
n_{1 c s}= & \text { fraction of rycles in } 1 \text { dass c and stace s that have engine } \\
& \text { displacements under } 350 \mathrm{cc} \text { (File 4) }
\end{aligned} \\
& \begin{array}{r}
n_{2 c s}=\text { fraction of cycles in class } c \text { and state s that have engine } \\
\text { displacement of. at least } 350 \mathrm{cc} \text { (File } 4)
\end{array} \\
& \mathrm{mpg}_{1}=\text { gas mileage of cycles of less than } 350 \mathrm{cc} \text {, set at } 55 \mathrm{mpg} \\
& \mathrm{mpg}_{2}=\text { gas mileage of cycles of at least } 350 \mathrm{cc} \text {, set at } 40 \mathrm{mpg}
\end{aligned}
$$

The breakdown by use for the years $1974-76$ is given by 


$$
F_{u t}=\sum_{c=1}^{3} N_{c t} \frac{{ }^{v m t} u c}{m_{p g}}
$$

where

$$
\begin{aligned}
& F_{u t}=\text { gasoline burned by cycles in year } t \text { for use } u \text { nationwide } \\
& \mathrm{N}_{\mathrm{ct}}=\text { number of cycles in category } \mathrm{c} \text { in year } t \text { [from formula (1)] } \\
& \begin{aligned}
\text { vmt }_{\text {uc }}= & \text { average miles per bike nationwide in category c traveled for } \\
& \text { use } u \text { in } 1977 \text { (File 3) }
\end{aligned} \\
& \mathrm{mpg}_{\mathrm{c}}=\left(\mathrm{n}_{1 \mathrm{c}} / \mathrm{mpg}_{1}+\mathrm{n}_{2 \mathrm{c}} / \mathrm{mpg}_{2}\right)^{-1} \\
& \mathrm{n}_{1 c}=\text { fraction of cycles nationwide in class } c \text { that have engine } \\
& \text { displacement under } 350 \mathrm{cc} \text { (File 4) } \\
& \begin{aligned}
\mathrm{n}_{2 c}= & \text { fraction of cycles nationwide in class } c \text { that have engine } \\
& \text { displacement of at least } 350 \mathrm{cc} \text { (File 4) }
\end{aligned}
\end{aligned}
$$

342. Government motorcycle fuel use (no data)

Although the number of Federal, state and local government motorcycles is reported by the Federal Highways Administration, no data are available on government bike-miles traveled or fuel used. Consequently there is no basis on which to make estimates.

\section{Input Data Files}

File 1. U.S. motorcycle registration by state, 1967-76. File.

$$
\text { name }=\text { CYCLES } .340
$$

Format: $\operatorname{col}$.

$$
\begin{aligned}
& \text { 1-2 FIPS state code (see Sec. ), right-justifled integer } \\
& \text { 4-9 } 1967 \text { motorcycle registration, including private, } \\
& \text { commercial and publicly-owned cycles (right-justified } \\
& \text { integer) } \\
& \text { 11-16 } 1968 \text { registration } \\
& \text { 18-23 } 1969 \\
& \text { 25-30 } 1970 \\
& \text { 32-37 } 1971 \\
& \text { " (all numbers are } \\
& \text { " right-justified integers) }
\end{aligned}
$$




$\begin{array}{llc}39-44 & 1972 & \text { registration } \\ 46-51 & 1973 & " 1 \\ 53-58 & 1974 & " \\ 60-65 & 1975 & " \\ 67-72 & 1976 & \text { " }\end{array}$

Source: Ref. 6, Table MV-I

File 2. 1976 and 1977 motorcycle population by model type, Motorcycle Industry Council figures. File name $=$ MIC. 340

Format: $\operatorname{col}$.

1-2 FIPS state code (see șec, ). left-just.ffied 'integer

$10-11$ year

20-29 number of on-road motorcycles (1eft-justified integer)

30-39 number of off-road motorcycles (left-justified integer)

40-49 number of dual-purpose motorcycles (left-justified ( integer)

Source: Ref, 3, p. 6 .

File 3. Average miles per motorcycle, by model type and use, 1977.

File name $=$ BYUSE. 340

Format: col.

1 9-19 average miles ridden by street bikes (decimal point in

20-29 average miles, dual-purpose bikes (decimal point in col. 23)

30-39. average miles, dirt blkes (decimal point in col. 33)

(a decimal polnt alone indicates missing data or zero)

* the use codes are:

1 - general

2 - trail/off road (miles per month)

3 - recreation/fun riding (miles per month)

4 - transportation to and from work/school (miles per month)

3 - other business purposes (miles per month)

6 - all purposes (miles per month)

7 - touring/vacation travel (miles per year)

8 - other types of riding (miles per month)

9 - organized competition and practice (miles per month)

Note: Dual-purpose and off-road bikes were combined in this data set. Consequently the same figures appear for each.

F1le 4. Relative numbers of cycles by category in 1977: by model type by engine size by state by mileage class. File name $=$ CELLS .340

Format: $\operatorname{col}$.

1 engine size*

$3 \cdot \operatorname{model}$ type** 


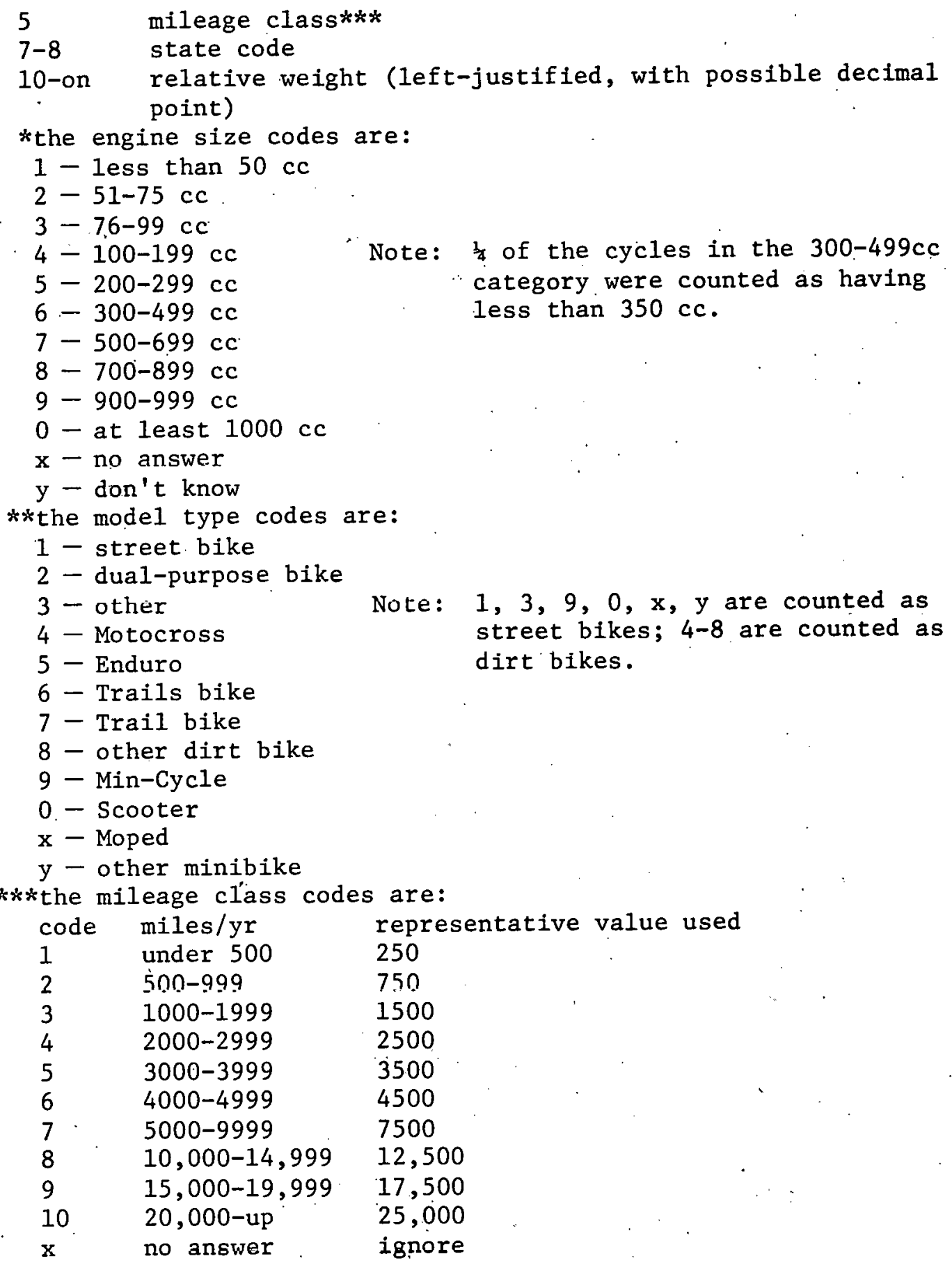

Source: Ref. 5 
Data Quality Numbers

National and regional estimates -- 2

State estimates

$-3$ 


\section{References}

1. "Cycle Road Tests," Cycle, Ziff Publishing Company, New York. Several issues in the 1975-79 period.

2. J. D. Power and Associates, 1977 Motorcycle Market Survey, Los Angeles, pp. 50-58 in Volumes 2,3 and 4 .

3. "U.S. Motorcycle Population and Penetration by Region and State," Motorcycle Statistical Annual, Motorcycle Industry Council, Newport Beach, California, 1978, 79.

4. "Average Miles Per Year," Survey of Motorcycle Ownership, Usage and Maintenance, Motorcycle Industry Council, Newport Beach, California, 1975.

5. Motorcycle Marketing Survey tape, prepared by J. D. Power and Associates in conjunction with National Family Opinion, Inc., 1977.

6. U.S. Department of Transportation, Federal Highway Administration, Highway Statistics, U.S. Government Printing Office, Washington, D.C., annually. 
Method 400

MARINE

Categories used:

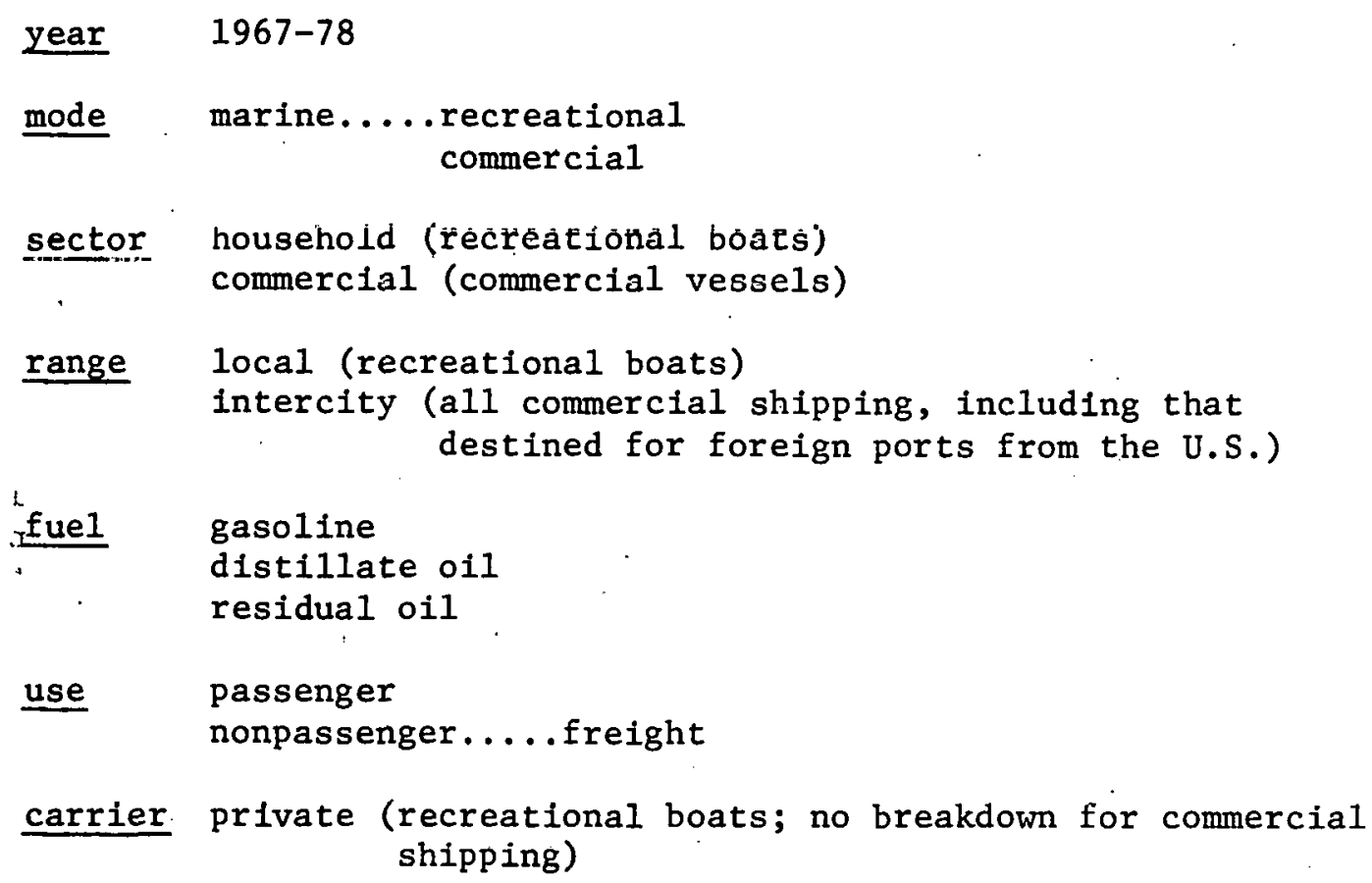

\section{region and state}

N.B. All commercial sh1pping fuel use figures indicate sales of fuel in the U.S. for both foreign and domestic trade. The fuel use attributed to a particular state is the fuel sold in that state. The recreational boat fuel use attributed to a state is that used by boats registered in that state or (if not registered) owned by residents of that ctate.

No data were available for military shipping. This matter is discussed as part of Method 600 .

401. Recreation boat fuel use, by fuel by state, 1967-78

Estimates of the number of boats in operation in 1973 and 1976 by size and type of boat (inboard/outboard) can be obtained from the Natlonwide Boating Survey tape (Ref. 1). The four size classes are: less than $16 \mathrm{ft}, 16-25 \mathrm{ft}, 25-40 \mathrm{ft}$, and over $40 \mathrm{ft}$. The tape also 
supplies reported estimates of the average annual fuel use of each type and size of boat, by fuel. These estimates are not based on actual sales records but are merely estimates provided by respondents to the survey. These data can form the basis of estimates of recreational boat energy use in the entire period 1967-78 broken down by state, with the help of. two other sources of information. They are the boat registration statistics by state published by the Coast Guard (Ref. 2) and the registration requirements of each state, as reported by International Marine Expositions, Inc. (Ref. 3).

The first task is to estimate the number of boats of each type and in each size class, by state. Later, these estimates can be multiplied by the average fuel use of boats in each class to obtain the total fuel use. (The breakdown by type of fuel will be provided for shortly.) There are two obstacles to estimating the number of boats: not all states, especially in past years, have required registration of the smallest motorboats, and not all boats whose registration is required are in fact registered. The first difficulty is overcome by supposing that the size of the horsepower class of boats whose registration is not required in a given state bears the same ratio to the number of registered boats in that state as the size of that same horsepower class nationwide bears to the number of other boats nationwide. The national figures are obtained from the Boating Survey figures for the year closest to the year in question. That is,

$$
R_{i j s t}=\left\{\begin{array}{l}
R_{i j s t}^{r(s t)}, \text { as reported } \\
R_{i j s t}^{r(s t)}
\end{array}\left[1+\frac{N_{i j y(t)}^{n r(s t)}}{N_{i j y(t)}-N_{i j y(t)}^{n r(s t)}}\right]\right.
$$

if registration of all motorboats required by state $s$ in year $t$

where

$$
\begin{aligned}
i= & \text { outboard } \\
j= & \text { less than } 16 \mathrm{ft} \\
\mathrm{R}_{i j s t}= & \text { adjusted number of registered recreational boats of type } i \\
& \text { and size } j \text { in state } s \text { in year } t \text {, increased to account for } \\
& \text { boats whose registration was not required } \\
\mathrm{R}(\mathrm{st})= & \text { actual number of registered recreational boats of type } i \\
\mathrm{ijst} & \text { and size } i, \text { all in the horsepower class } \mathrm{r}(\mathrm{st}) \text {, in state } \mathrm{s} \\
& \text { in year } t \text { (Ref. } 2) \\
\mathrm{r}(\mathrm{st})= & \text { horsepower class of boats whose registration was required } \\
& \text { by state } \mathrm{s} \text { in year } t \text { (e.g., all boats of } 10 \text { hp or more) }
\end{aligned}
$$




$$
\begin{aligned}
& \begin{aligned}
N_{i j y}(t)= & \text { number of recreational boats in operation, of type } i \text { and } \\
& \text { size } j \text {, nationwide in year } y(t) \text { (Ref. } 1 \text { ) }
\end{aligned} \\
& y(t)=\left\{\begin{array}{l}
1973 \text { if } 1967 \leq t \leq 1974 \\
1976 \text { if } 1975 \leq t \leq 1978
\end{array}\right. \\
& \mathrm{N}_{i j y(t)}^{\mathrm{nr}(s t)}=\text { number of recreational boats in operation, of type } i \text { and } \\
& \text { size } j \text {, in year } y(t) \text { and in horsepower class nr(st) (Ref. 1) } \\
& n r(s t)=\text { horsepower class of all boats not in } r(s t) \text {; i.en, } \\
& \text { horsepower class of boats whose registration is not } \\
& \text { required by state } s \text { in year } t
\end{aligned}
$$

Note that it assumed that all boats whose registration is not required, since they are always the smallest boats, are outboard-motorboats less than $16 \mathrm{ft}$ long.

The difficulty that not all boats whose registration is required are in fact registered is overcome simply by adjusting the state-by-state registrations. to reflect the shortfall of the registration figures nationwide when compared with the Boating Survey estimates. That is,

$$
N_{i j s t}=\frac{N_{i j y(t)}}{R_{i j y(t)}} R_{i j s t}
$$

where

$$
\begin{aligned}
& R_{1 f y(t)}=\text { total adjusled rey1strations nationwide in year } y(t) \text {, } \\
& \mathrm{N}_{i j s t}=\begin{array}{l}
\text { number of recreational boats of type } i \text { and size } j \text { in } \\
\text { state } s \text { in year } t
\end{array}
\end{aligned}
$$

Now the fuel use in each state is computed by multiplying the number of boats by the reported average fuel use per boat per year:

$$
F_{\varepsilon t}=\sum_{i} \sum_{j} f_{i j y(t)} N_{i j o t}
$$

where

$$
\begin{aligned}
& F_{\text {st }}=\text { fuel used by recreational boats in state } s \text { during year } t \\
& f_{i j y(t)} \begin{array}{l}
\text { average annual fuel use of a boat of type } i \text { and size } j \\
\text { in year } y(t)
\end{array}
\end{aligned}
$$

Note that if a resident of Indiana operates his motorboat solely on Tennessee lakes, his energy use is nonetheless charged against Indiana. Note also it is assumed that the average annual fuel use of a boat does 
not vary significantly from state to state. Since this assumption is significantly false, the state-by-state figures are necessarily subject to considerable error. The national figures should be markedly better.

A breakdown by fuel is based on the fact that $98.3 \%$ of the fuel use reported in the Nationwide Boating Survey was gasoline. A state-by-state accounting of gasoline use is provided simply by taking $98.3 \%$ of the total fuel use in each.state.

$$
F_{\text {st }}^{\text {gas }}=F_{\text {st }} \cdot(98.3 \%)
$$

where

$$
\begin{aligned}
& F_{\text {st }}^{\text {gas }}=\text { gasoline used by recreational boats in state } s \text { during year } t \\
& F_{\text {st }} \text { is given by formula (3) and is recorded in File } 1
\end{aligned}
$$

No attempt is made to allocate diesel fuel consumption to the states, since the errors would likely be enormous. Instead, we have

$$
\mathrm{F}_{\mathrm{t}}^{\mathrm{diesel}}=\mathrm{F}_{\mathrm{t}} \cdot(1.7 \%)
$$

where

$$
\begin{aligned}
F_{t}^{\text {diesel }}= & \text { total diesel fuel used by recreational boats in year } t \\
F_{t}= & \text { total fuel used by recreational boats in year } t \text { [File } 2, \\
& \text { also given by formula (3)] }
\end{aligned}
$$

402. Commercial ship fuel use, by fuel by state, 1967-78

The Department of Energy accounts for U.S. bunker fuel sales by state In its Energy Data Report series (Ref. 4). Figures for distillate and residual oil sales are reported separately.

The portion of bunker fuel sold in the U.S. for foreign trade is reported in the Census Bureau's U.S. Foreign Trade Bunker Fuels Annual (Ref. 5) but it was found that in some states the foreign trade sales exceeded the total sales as reported by the Department of Energy. For this reason no attempt was made to obtain a breakdown by domestic and foreign trade. Various schemes were attempted for distinguishing coastal from inland shipping and for obtaining a breakdown by the size of ship, but without success. Cunseyueitly the data reported are oimply 


$$
\begin{array}{r}
F_{\text {fst }}, \text { as reported in Ref. } 4 \text { (and recorded in } \\
\text { Files } 3 \text { and 4). }
\end{array}
$$

where

$$
F_{f s t}=\text { sales of fuel } f \text { (distillate or residual) in state } s \text { for }
$$

Inpue Data Filés

File 1. Recreational boat fuel use (gasoline and diesel fuel), by state, 1967=78. File name - BOAT.400

Format: col.

$$
\begin{aligned}
& \text { 2-3 state abbreviation } \\
& \text { 4-5 } \\
& \text { state FIPS code (see Sec. 8.2), right-justified } \\
& \text { 12 fields of } 15 \text { col. each, showing gallons of fuel } \\
& \text { used by recreational boats in 1967-78 respectively } \\
& \text { (right-justified, decimal point in last col. of field) }
\end{aligned}
$$

File 2: Recreational boat fuel use, national totals, 1967-78. File name $=$ TBOAT. 400

Format: eoi.

8-187 12 fields of 15 col. each showing gallons of fuel used by recreational boats in 1967-78 respectivel.y (right-justified, decimal point in last col. of field)

Source: Ref. 1

File 3. Commercial ship distillate oil use, by state, 1967-78. File name $=\vec{B} O \dot{A} T D .400$

Format: col.

1-2 state l'll's cúde (sée Sec. 82.), right-justified

6 the number 4

9-80 $\quad 12$ fields of $6 \mathrm{col}$. each, showing diesel fuel used by commercial vessels in thousands of barrels (rightjustified integers)

Source: Ref. 4 
File 4. Commercial ship residual oil use, by state, 1967-78. File name $=$ BOATR. 400

Format: col.

1-2 $\quad$ state FIPS code (see Sec:8.2), right-justified

9-80 12 fields of $6 \mathrm{col}$. each, showing residual oil used by commercial vessels in thousands of barrels (rightjustified integers)

Source: Ref, 4

Data Quality Numbers

All estimates -- 2 
References

1. U.S. Coast Guard, The National Boating Survey, 1973 and 1976 surveys, Washington, D.C.

2. U.S. Coast Guard, Boating Statistics; 1967-78 editions, Washington, D.C.

3. International Marine Expositions, Inc., State Boat Registration, 1968-78, Chicago, Ill., 1979.

4. U.S. Dept. nf Energy, Energy Data Rapurls, "Sales of fuel 011 and Kerosine," 1967-78 editions, liable 11.

5. U.S. Dept. of Commerce, Bureau of the Census, U.S. Foreign Trade Bunker Fuels Annual, Washington, D.C., 1967-78.

- 5-106 
Method 510

NATURAL GAS PIPELINE

Categories used:

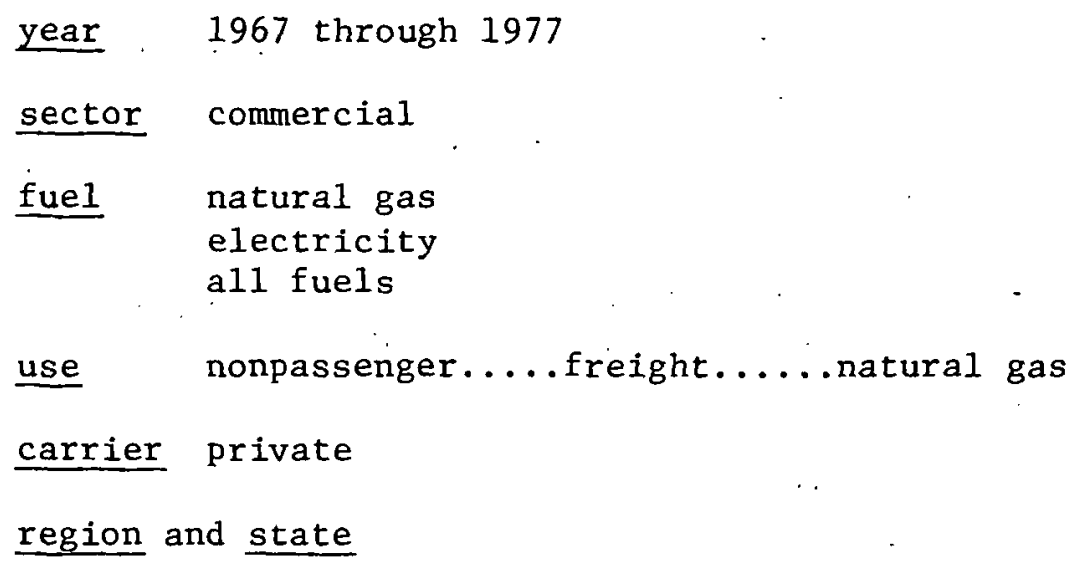

The energy consumption of a natural gas pipeline is, taken to be the energy content of the fuel used to drive the pumps. Included are pumps attached to transmission, distribution and field gathering lines as well as to storage facilities.

The energy content of natural gas, which is extracted from the pipelines to power a majority of the pumps, is taken to be the higher heating value of the gas burned.

The consumption reported for Maine includes that for Vermont and New Hampshire, while the Vermont and New Hampshire consumption is reported as zero. Consumption reported for Maryland includes that for the District of Columbia. (These practices are imposed by Ref.1.)

\section{Consumption of natural gas, by year by state}

The amount of natural gas consumed as pipeline fuel in a given year and state is reported in Ref. 1 (File 1 ). The figures are provided the Energy Information Administration in the Energy Department on Form 6-1341, submitted by all interstate and most intrastate pipeline companies. (The gas volumes are based on a pressure of 14.73 . psia at $60^{\circ} \mathrm{F}$, the Bureau of Mines standard.)

The energy content of this natural gas is found by multiplying the amount of gas consumed as pipeline fuel in a given state and year (in 
cubic feet) by the average higher heating value of natural gas sold by utilities in the state and year in question. The heating values used are those reported annually to the American Gas Association by its membership and reported in Ref. 2 (File 2). It is assumed that the average heating value of the gas taken from the pipelines to drive the pumps in a given state is the same as that of the gas sold in that state, since the gas sold is taken, from the same pipelines at roughly the same places. (The AGA misplaced the 1970 and 1971 data during its relecation in those years. Consequently the heating values for 1970 and 1971, nationwide and in each state and region, were calculated from a straight-line interpolation of the heating values for 1969 and 1972. Also the 1977 values were not yet available and were taken to be the average of the 1975 and 1976 values. These estlmates are permissible because, over the years, the average heating value nationwide or in a given state fluctuates only a few Btu per cubic foot about a value in the vicinity of 1000 Btu per cubic foot.)

\section{Consumption of all fuels, by year by state}

The total energy consumed by natural gas pipelines (all fuels) was estimated by taking the amount of energy $\mathrm{U}_{\mathrm{G}}$ consumed in the form of natural gas and increasing it slightly to reflect the fact that some $94 \%$ of the installed pumping horsepower nationwide is supplied by natural gas (Ref. 3, pp. 2-5). This sort of estimate is necessary because the consumption of other fuels is otherwise unknown. It does not suffice simply to divide $U_{G}$ by $94 \%$, however, since the remaining $6 \%$ of the horsepower is generated more efficiently (mostly by electric motors) than the $94 \%$. The following calculations take into account the different efficiencies with which horsepower is provided by fuels other than natural gas.

First, it is convenient to define some symbols as shown below.

Type of engine

Gas turbine
Reciprocating (piston)
gas engine.
Steam turbine
Electric motor

Efficiency of eng Ine

$\begin{aligned} E_{t}= & 18 \% \text { (Ref. } 4, \\ & p \cdot 12 / 359) \\ E_{p}= & 31 \% \text { (ibid.) } \\ E_{S}= & 36 \% \text { (ibid.) } \\ E_{c}= & 93 \% \text { (Ref. } 5, \\ & p \cdot 15-46)\end{aligned}$

Fraction of installed horsepower, nationwide

$$
\begin{aligned}
& \mathrm{H}_{\mathrm{t}}= 22 \% \text { (Ref. } 3, \\
& \mathrm{p} .2-5 \text { ) } \\
& \mathrm{H}_{\mathrm{p}}=72 \% \text { (ibid.) } \\
& \mathrm{H}_{\mathrm{S}}=1 \% \text { (ibid.) } \\
& \mathrm{H}_{\mathrm{e}}=5 \% \text { (ibid.) }
\end{aligned}
$$

The gas is pumped by two types of compressors: 
Type of compressor

Centrifugal

Reciprocating
Efficlency

$$
E_{C}=82 \%(\operatorname{Ref} \cdot 4, \mathrm{p} \cdot 8 / 51)
$$$$
E_{r}^{C}=84 \% \text { (ibid.) }
$$

Typically driven by

Gas turbines

Reciprocating gas engines

Steam turbines

Electric motors

For purposes of comparison, the overall engine-pump efficiency of natural-gas-driven pumps was calculated to be

$$
E_{G}=\frac{E_{t} E_{c} H_{t}+E_{p} E_{r} H_{p}}{H_{t}+H_{p}}=23 \%
$$

The engine-pump efficiencies of steam-powered and electrically powered pumps, respectively, are approximately

$$
\begin{aligned}
& E_{S}=E_{s} E_{r}=30 \% \\
& E_{E}=E_{e} E_{r}=78 \%
\end{aligned}
$$

The total energy consumed by steam-powered and electrically powered pumps was then estimated by taking a fraction of the gas-powered consumption based on the percentage of horsepower supplied by steam or electricity, and adjusting for the differing efficiencies:

$$
\begin{aligned}
& \mathrm{U}_{\mathrm{S}}=\frac{\mathrm{E}_{\mathrm{G}}}{\mathrm{E}_{\mathrm{S}}} \mathrm{H}_{\mathrm{S}} \cdot \mathrm{U}_{\mathrm{G}}=.008 \mathrm{U}_{\mathrm{G}} \quad \text { (steam) } \\
& \mathrm{U}_{\mathrm{E}}=\frac{\mathrm{E}_{\mathrm{C}}}{\mathrm{E}_{\mathrm{E}}} \mathrm{H}_{\mathrm{e}} \cdot \mathrm{U}_{\mathrm{G}}=.015 \mathrm{U}_{\mathrm{G}} \text { (electricity) }
\end{aligned}
$$

On the assumption that no significant amount of steam powering steam-driven pumps is generated by burning natural gas, the total pipeline energy consumption was estimated simply by adding the amounts consumed in the form of gas, steam and electricity:

$$
\mathrm{U}_{\mathrm{G}}+\mathrm{U}_{\mathrm{S}}+\mathrm{U}_{\mathrm{E}}=1.023 \mathrm{U}_{\mathrm{G}}
$$

In other words, the total pipeline energy was computed by multiplying the energy consumed in the form of natural gas by the factor 1.023 . 


\section{Consumption of electricity, by year by state}

The consumption in the form of electricity was estimated by multiplying that consumed in the form of natural gas $U_{G}$ by 0.015 , a factor derived above. The resulting estimate is necessarily crude, much more so than the above estimate of tutal pipeline energy consumption. The consumption of electricity (regarded as a fuel) in kilowatt-hours was got simply by multiplying the energy use in Btu, just calculated, by the conversion factor $29.307 \times 10^{-5} \mathrm{kwh} / \mathrm{Btu}$.

\section{Consumption of other fuels}

Steam for steam-driven pumps could be produced by burning diesel or residual oil or even coal. But since no information on how much of each is used was available, no estimates of fuel use in these categories was attempted. It is known only that, together they consume about 0.008 times as much energy as natural-gas-driven pumps.

\section{Input Data Files}

File 1. Higher heating values of natural gas, by state by year.

FulHAL: conts.

1-2 state alphabetic code (see Sec. 8.2). 10 indicates all of region 1 , etc.; $01=$ all of USA.

3-5 blank

6-59 11 fields of 5 columns each, containing heating values for 1967-77 in Btu/cu ft (right-justified integers): A zero indicatco that a particular value was unavallable (occurs in years 1970 and 71 except for the national If gure).

Soùrce: ReF. 1

File 2. Natural gas consumed as pipeline fuel, by year by state.

Format: cols.

1-2 state code (same convention as above)

3-79 11 7-column fields containing natural gas consumption for 1967-77 in millions of cubic feet (right-justified integers).

Source: Ref. 2 


\section{Data Quality Numbers}

Consumption of natural gas nationally and by region and state -- 1

Consumption of all pipeline energy and of energy in the form of natural gas, nationally and by region and state - 1

Consumption of electricity nationally and by region and state -- 3 


\section{References}

1. "Consumption of natural gas by use and state," in Natural Gas Production and Consumption, Mineral Industry Surveys, Bureau of Mines, 1967-75; same document as part of the Energy Information Administration's Energy Data Reports, 1976-77.

2. "Gas utility industry sales by state and class of service," in Gas Eacts, American Gas Association, 1967-76 (annually).

3. E. N. Cart et al., Exxon Research and Engineering Company, Altemate Energy Sources for Non-Highway Transportation. Dept. of Finergy contract EC-77-C-05-5438, Dec. 15, 1978.

4. American Gas Association, Gas Engineer's Handhonk, Industrial.Press, 1966.

5. Baumeister et al., Marks' Standard Handbook for Mechanical Engineers, 8th edition, McGraw-Hill, 1978. 
Method 520

LIQUIDS PIPELINE

Categories used:

year 1967-77 (same order-of-magnitude estimate provided for each year; slurry pipeline estimate for 1971-77 only)

mode pipeline........1iquids

sector commercial

range intercity (o11 \& slurry pipelines only)

fuel electricity

use nonpassenger.....freight.....crude oil pipeline oil products plpeline water pipeline

slurry pipeline

carrier common (i.e., oil pipelines)

private (other pipelines)

The energy consumption of crude oil, oil products and water pipelines is not known. On1y order-of-magnitude estimates are avallable. The best of these have been put forward by William F. Banks (Ref. 1), who also estimates the energy consumption of the one coal slurry pipeline in the united States. His estimates are as follows:
crude oil pipelines
0.07 quads (i.e., quadrillion Btu)
products pipelines
0.068 quads
water pipelines
0.050 quads
coal slurry pipeline
0.0054 quads

These estimates are recorded on the data tapes for the sake of completeness. The first three are listed under each of the ten years 1967-76, since there have been no dramatic trends over the years, so that the change is probably far less than the margin of error. The coal slurry energy estimate is for 1971-77 only.

The oil pipeline figures include all energy used at the pumping stations, including that used to pump oil in and out of storage tanks. Although some pumps are driven by gas, diesel and LPG engines and even. steam turbines, the bulk of. the energy is provided by electricity. Consequently these "ball park" estimates are classified as consumption exclusively of electricity. 
The water pipeline figure includes pumping energy only and excludes energy used in treatment. Nearly all this energy is used either to pump water into. high-level storage tanks or through aqueducts, and nearly all of it is provided by electricity.

The coal slurry figure is of somewhat greater accuracy than the others. $\mathbf{z}$ includes the energy cost of supplying water and removing the coal from the slurry as well as that of pumping the slurry through the pipe. This quantity is estimable because there is only one operational coal slurry pipeline in the United States, the Black Mesa line in Arizona. All the energy is consumed in the form of electrlcity, most of it taken from the power grid.

Banks' calculations assume an efficlency of 0.22 in the conversion of primary fuel to electricity. Since the End Use Data Base ascribes to transportation only the electrical energy delivered to the motors; Banks' flgures must be multiplied by 0.22 to yield the following estimates of electricity consumption:

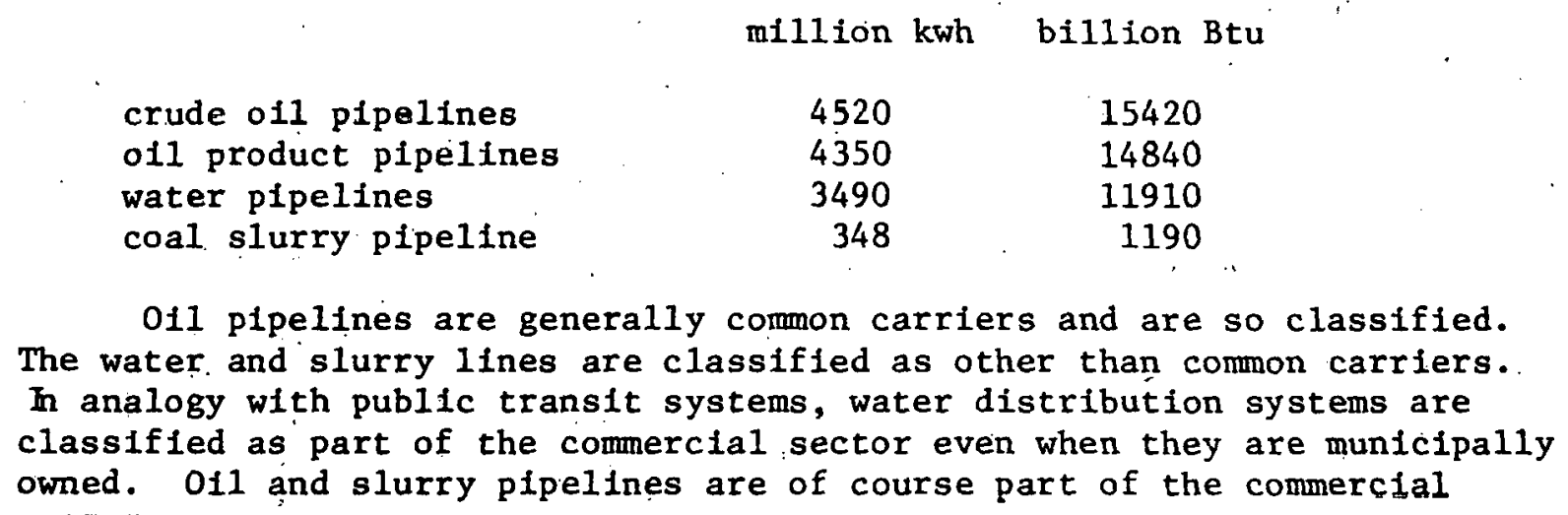

011 pipelines are generally common carriers and are so classified. The water. and slurry lines are classifled as other than common carriers. In analogy with public transit systems, water distribution systems are classified as part of the commercial sector even when they are municipally owned. 011 and slurry pipelines are of course part of the commercial sector.

An effort (by J. N. Hooker) to estimate more accurately the energy use of crude oil and oil product pipelines is underway at ORNL. The resuits should be forthcoming by April of 1980 .

\section{Data Quality Numbers}

Crude oll, oil products and water pipelines -- 4

Coal slurry pipeline

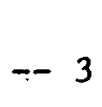




\section{Reference}

1. William F. Banks, "Energy Consumption in the Pipeline Industry,". U.S. Dept. of Energy Report SAN-1171-2, 1977, p. 2-2. 
Method 600

MILITARY FUEL

Categories used:

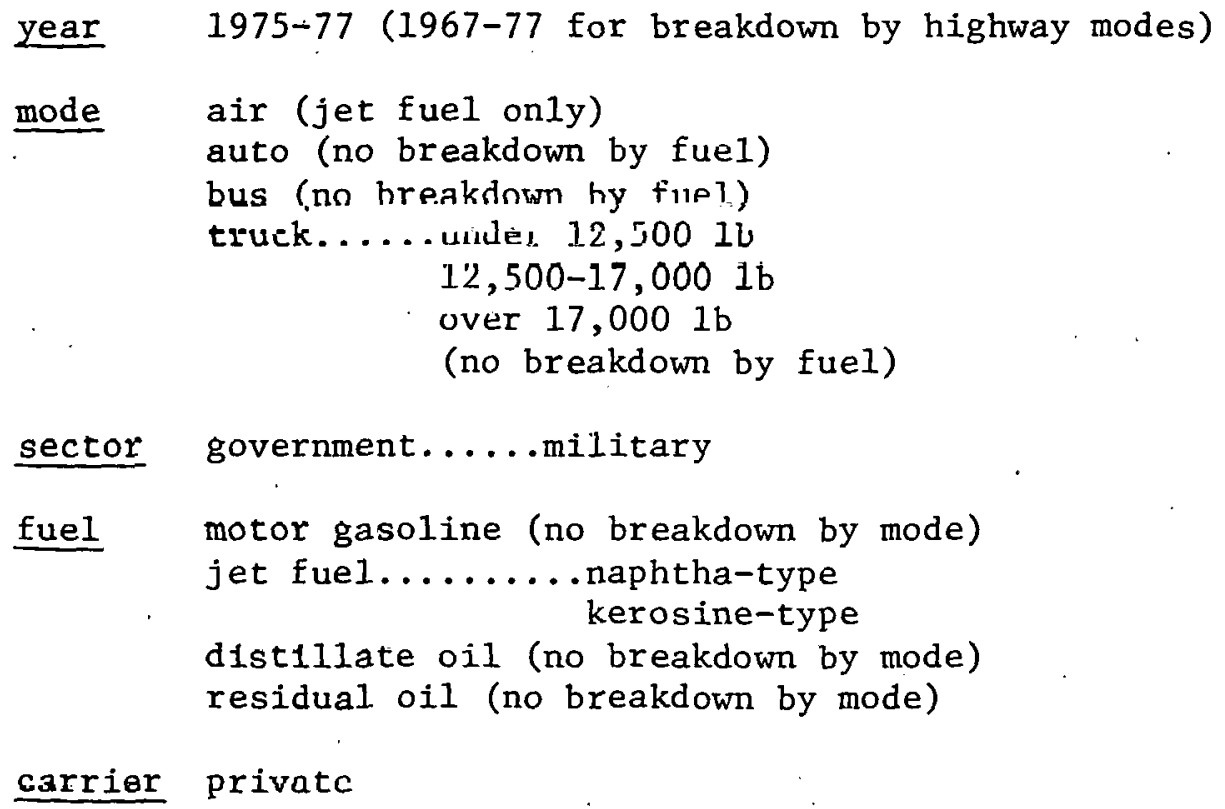

region and state (no breakdown for estimates broken down by mode. or for jct fuel estimates)

In the area of military fuel use, data are unsurprisingly scarcest of all. Three sourccs have been tapped. One is the series of tables of aviation fuel consumption by the U.S. military, published in the Energy Data Reports series (Ref. 1). There is no breakdown by state. Another is a series of tables of fuel consumed hy military highway vehicles, appearing in the Federal Motor Vehicle Fleet Report (Ref. 3). The types of fuel consumed are not indicated. The third source is a state-by-state accounting of military fuel use (excluding jet fuel) maintained by the . Defense Fuel Supply Center in the Department of Defense (Ref. 2). These figures, also available from the Defense Fnergy Information System, an agency established in December of 1973, are broken down by fuel type but not by mode. It may be presumed, however, that since states having ports show by far the largest consumption of residual oil, the bulk of the residual oil consumption is ascribable to naval operations.

As for the air mode, all jet fuel consumption has been ascribed to it. It should be realized, however, that some jet fuel may be used to fuel tanks and other vehicles (Ref. 2). Opinions differ on this matter, and no official resolution could be obtained. Unlike commercial aircraft, which use almost entirely a kerosine-type of jet fuel, military aircraft 
use prominently a naphtha-type (sometimes called a gasoline-type) fuel, usually JP-4 (jet propulsion fuel 4). JP-4 is somewhat more hazardous to handle on the ground than commercial jet fuel, but it offers a greater yield per barrel of crude. The major.kerosine type of jet fuel used by the military is JP-5. A small unitemized portion of military aircraft fuel is counted here as of the naphtha type, since it is likely to include the naphtha-based fuels ordinarily used in high-altitude aircraft. The. different heating values of naphtha-type and kerosine-type fuels are taken into account in the conversion of barrels to Btu (see Sec. 2.1).

The fuel use reported, then, is as follows:

$$
F_{f t}^{a}
$$

where

$$
\begin{aligned}
& f=\text { naphtha and kerosine and } \\
& t=1975-77
\end{aligned}
$$

and where

$$
\begin{aligned}
& F_{f t}^{a}=\text { jet fuel of type } f \text { used by the military in year } t \text { (File 2) } \\
& \qquad \mathrm{F}_{\mathrm{mt}}^{\mathrm{h}},
\end{aligned}
$$

where

$$
\begin{aligned}
\mathrm{m}= & \text { auto } \\
& \text { bus } \\
& \text { truck, } 0-12,5001 \mathrm{~b} \\
& \text { truck, 12,500-17,000 1b } \\
& \text { truck, 17,000 1b-up and } \\
\mathrm{t}= & 1967-77
\end{aligned}
$$

and where

$$
\begin{gathered}
\mathrm{F}_{\mathrm{mt}}^{\mathrm{h}}=\text { fuel used by highway mode } \mathrm{m} \text { in the military in year } t \text { (File } 3 \text { ) } \\
\mathrm{F}_{\mathrm{fst}},
\end{gathered}
$$

where

$$
\begin{aligned}
& \mathbf{f}=\text { gasoline, distillate, residual oil } \\
& \mathrm{t}=1975-76
\end{aligned}
$$


and where

$\begin{aligned} F_{\text {fst }}= & \text { total fuel of type } f \text { used by the military in state } s \text { in year } t \\ & (\text { File } 1)\end{aligned}$

\section{Input Data Files}

File 1. Military fuel consumed, by state, 1975-78. File name = FuEL.600

Format: col.

$1-2$

4-5 state FIPS code (see Sec. 8.2), right-justified integer

10-69 5 10-column fields, containing consumption respectively of auto diesel fuel, diesel fuel $\# 1$, diesel fuel $\$$ 2, distillate oil, motor gasoline, residual oil (decimal point in col. 8 of field). Duc to an error in preparation for keypunching, flgures show $1 / 42$ of consumption in bbl.

Source: Ref. 2

File 2. Jet fuel consumed by the military, nationwide, 1974-77. File name $=\mathrm{JET} .600$

Format: col.

free-form year (2 digits), followed by consumpllon of JP-4, followed by consumption of JP-5, followed by consumption of other jet fuels, in thousands of barrels (decimal points occur)

Source: Ref. 1

File 3. Military highway fuel conoumed, by mode, 1967-77. File name $=$ MODES. 600

Format: col.

frpp-form yeal ( 2 digits), followed by auto fuel conoumptiun, followed by bus fuel consumption, followed by three truck fuel consumption figures, respectively for trucks under $12,5001 \mathrm{~b}$ gross weight (i.e., 1-ton trucks), trucks from 12,500 to 17,000 lb gross weight ( $1 \frac{1}{2}$ to $2 \frac{1}{2}$ ton trucks), and trucks over $17,0001 \mathrm{~b}$ gross weight. Figures are in millions of gallons.

Source: Ref. 2 
Data Quality Numbers

Consumption of jet fuel

classified as the consumption of military aircraft -2 not so classified

Military consumption of gasoline, distillate and residual oil

$--1$

Military use of highway fuel, by mode 


\section{$\underline{\text { References }}$}

1. Crude Petroleum, Petroleum Products and Natural Gas Liquids (Annual Petroleum statement), in Energy Data Reports series, U.S. Dept. of Energy, 1975-77.

2. Data obtained direct1y from William Vance, Defense Fuel Supply Information Center, Cammeron St., Alexandria, VA, 22314.

3. Federal Motor Vehicle Fleet Report (annual), General scrvices Administration, 1967-76. 
Al1 recorded consumption data that cite Method 900 as documentation are sums of data documented elsewhere in this report. They are sums over one or more breakdowns. To take an example, Method 332 describes explicitly how to estimate the gasoline used by local commercial trucks in 1976 in each of the states, but nowhere is there provided an explicit formula for estimating this quantity nationwide. Naturally all one needs to obtain a national estimate is to add together the estimates for the individual states, and this has been done; the resulting total is tagged as computed by Method 900 . In like manner the energy use by local commercial trucks nationwide (all fuels) can be computed by adding the estimates for eachr:combination of fuel and state; this, too, has been done. In general, all totals whose computation the available data permit are provided, with two minor exceptions noted in Sec. 3.9. See the introduction to Chap. 3 for an illustration of how aggregate data are computed, Sec. 6.1 for a mathematical analysis of the notion, and Sec. 6.2 for a technical description of how the aggregate data are generated. When an aggregate datum and its method number, Method 900, are recprded, the data quality number and the units of measurement must be reroried as we11. These are determined in the way described below.

\section{Data Quality Numbers}

Recal1 that each datum is assigned one of these quality numbers:

1 - less than $10 \%$ error

2 - less than $25 \%$ error

3 - less than $50 \%$ error

4 - quality unknown.

For present purposes we will assume the final category can be fairly represented by saying there is less than $100 \%$ error. We will also suppose each of these represents a confidence interval (a matter discussed further in Sec. 2.2), where $p$ is the level of confidence ( $80 \%, 90 \%$ or whatever). That is, we will suppose that if a datum is given quality number 1 and if 
$\mathrm{P}=90 \%$, then one can be $90 \%$ sure that the reported value lies within $\pm 10 \%$ of the true value.

Now suppose that $n$ observed data $a_{1}, \ldots, a_{n}$ are to be added together to get an aggrcgate datum. The true values corresponding to these $n$ measurements are $n$ unknown numbers $b_{1}, \ldots, b_{n}$. Let us assume momentarily that if several measurements were available for a single true value $b_{i}$, the distribution of these measurements would be normal with a mean at the crue value $b_{i}$ and $\bar{a}$ variance $\sigma_{i}^{2}$. In other words, these measurements afford an unbiased estimate of the true value, and their standard deviation from the true value is $\sigma_{i}$. Let us also suppose that the percentage confidence intervals that come with the $n$ observations are $\pm r_{1}, \ldots, t_{n}$. Each $r_{i}$, then, stands for $10 \%, 25 \%, 50 \%$ or $100 \%$, which correspond to the four quality codes. This means that one can have a confidence of $p$ that the true value lies within $\pm r_{i} b_{i}$ of the true value $b_{i}$, for each $i$. These intervals can be written in terms of the standard deviations of the distributions,

$$
\mathbf{r}_{i} b_{i}=c_{p} \sigma_{i}
$$

where $c_{p}$ is the appropriate constant. If $p=90 \%$, then one can read from a table of the normal distribution that $c_{p}=1.645$. Now if the $n$ distributions of measurements are independent, the distribution of their $\operatorname{sum} \sum_{i} a_{i}$ is also normal with mean $\sum_{i} b_{i}$ and variance $\sum_{i} \sigma_{i}^{2}$. The confidence interval for this sum distribution, which we can write as $r b_{i}$, is again the constant $c_{p}$ times the standard deviation:

$$
r \sum_{i} b_{i}=c_{p} \sqrt{\sum_{i} \sigma_{i}^{2}}
$$

Substituting $\sigma_{i}=r_{i} b_{i} / c_{p}$, from (1), we have

$$
r \sum_{i} b_{i}=\sqrt{\sum_{i}\left(r_{i} b_{i}\right)^{2}}
$$

or 


$$
r=\sqrt{\sum_{i}\left(r_{i} b_{i}\right)^{2}} / \sum_{i} b_{i}
$$

This provides a calculation of the percentage confidence interval of the sum in terms of the percentage intervals $r_{i}$ for the addends and the true values $b_{i}$. Since the true values are not known, we must use a maximum Iikelihood estimate of the sum's confidence interval. Such an estimate can be had by substituting the observed data $a_{i}$ for the true values $b_{i}$ :

$$
r_{\text {est. }}=\sqrt{\sum_{i}\left(r_{i} a_{i}\right)^{2}} / \sum_{i} a_{i}
$$

Formula (2) says that the data quality interval for the aggregation is a weighted root mean square of the intervals for the addends. There is an inherent tendency, then, for the percentage error to decrease as the level: of aggregation becomes greater. In the special case in which the addends are of equal size, the addition of $n$ addends each having $a$ percentage confidence interval of $\pm r$ results in a sum having a confidence interval of $\pm r / \sqrt{n}$. . The percentage error, then, varies roughly with the inverse square root of the number of terms added.

Unfortunately formula. (2) is based on the false premise that the $n$ error distributions are independent. In reality it is likely they will all be biased in the same direction; they may all, for example, be underestimates. Consequently the error does not decrease so rapidly with the level of aggregation as (2) implies. Formula (2) is in fact unusable, because it gratuitously puts nearly all of the high-level aggregations into the $10 \%$ error bracket, regardless of the error in the disaggregate data.

One approach to this problem is to attempt to quantify, if only in the crudest of ways, the portion of error that is due to bias and the portion due to random and independent deviations. Let us suppose that the $i$-th distribution still has a variance of $\sigma_{i}^{2}$ but has a mean at $b_{i}+k \sigma_{i}$ rather than at $b_{i}$. The $i-t h$ measurement, then, is a biased estimator of the true value $b_{i}$, and the amount of the bias is expressed as a fraction $k$ of the standard deviation. Now, the distribution of the 
$\operatorname{sum} \sum_{i} a_{i}$ has a mean at $\sum_{i} b_{i}+k \sum_{i} \sigma_{i}$ and a vartance of $\sum_{i} \sigma_{i}^{2}$. The problem is to derive the sum's percentage confidence interval $\pm r$ from the confidence intervals $\pm r_{i}$ for the addends.

Let us begin by defining $\mathrm{r}_{i}$ ' to be the percentage confidence interval distribution $i$ would have if its bias were removed without changing its variance. That is, suppose that the $i$-th distribution has variance $\sigma_{i}^{2}$ and has mean $b_{i}$ rather than $b_{i}+k \sigma_{i}$. Suppose also that $A(a, b)$ is the area under a standard normal curve between the abcissas $a$ and $b$. Let $s_{i p}$ be the number that satisfies

$$
A\left(\frac{s_{i p}}{\sigma_{i}}, \frac{s_{i p}}{\sigma_{i}}\right)=p \text {, }
$$

where $p$ is again the level of confidence. Then

$$
r_{i}^{\prime}=s_{i p} / b_{i}
$$

The interval $\mathbf{r}_{i}$ can be defined in a parallel way with respect to a biased distribution. If $t_{i p}$ is the number satisfying

$$
A\left(k-\frac{t_{i p}}{\sigma_{i}}, k+\frac{t_{i p}}{\sigma_{i}}\right)=p
$$

then $r_{i}=t_{i p} / b_{i} \cdot r_{i}$ is of course larger than $r_{i}^{\prime}$, since a larger interval is required to take in a fixed area $p$ when the distribution is off center. The shrinkage from $r_{i}$ to $r_{i}^{\prime}$ is measured by the ratio

$$
r_{i} / r_{i}^{\prime}=t_{i p} / \varepsilon_{i p}
$$

and can be determined from tables of the normal curve for a given level ot contidence $p$ and a given value of $k$. Some sample ratios are shown in Table 1. Let us define $m_{k}$ to be the ratio $r_{i} / r_{i}^{\prime}$, at a stated level of confidence $p$, when the original bias is given by $k$. Since $m_{k}$ does not vary much with the confidence level, the choice of $\mathrm{p}$ will not be critical.

Once values for $m_{k}$ are available, the sum's percentage confidence interval $\pm r$ can be calculated in terms of the $r_{i}$ 's. First recall that $r_{i}{ }^{\prime}$ is defined so that 
Table 1. The ratio $\mathrm{r}_{\mathrm{i}} / \mathrm{r}_{\mathrm{i}}{ }^{\prime}$

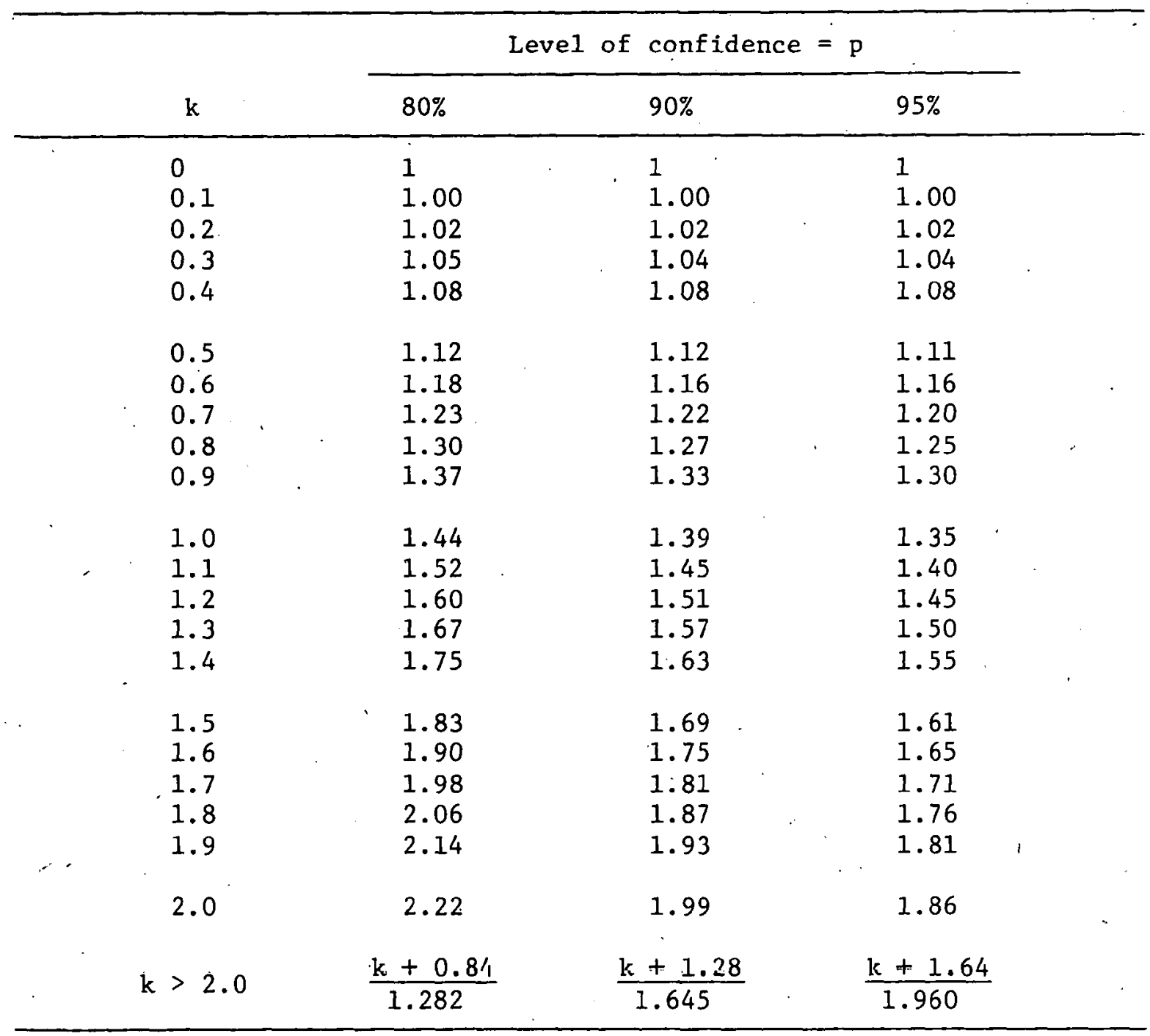

$$
r_{i}{ }^{\prime} b_{i}=c_{p} \sigma_{i}
$$

where $r_{i} b_{i}$ is the confidence interval (at level of confidence $p$ ) the $i-t h$ distribution would have if it were unbiased with variance $\sigma_{i}^{2}$. If $\pm r^{\prime}$ is the percentage confidence interval the sum's distribution would have if its bias were removed (and its variance were still. $\sum_{i} \sigma_{i}^{2}$ ), we can say in analogous fashion,

$$
x^{\prime} \sum_{i} b_{i}=c_{p} \sqrt{\sum_{i} \sigma_{i}^{2}}
$$


Substituting $r_{i} / m_{k}$ for $r_{i}^{\prime}$ and solving Eq. (3) for $\sigma_{i}$, we get

$$
\sigma_{i}=r_{i} b_{i} / m_{k} c_{p}
$$

Substituting this into Eq. (4) yields,

$$
r^{\prime} \sum_{i} b_{i}=\frac{1}{m_{k}} \sqrt{\sum_{i}\left(r_{i} b_{i}\right)^{2}}
$$

In order to find $\mathbf{r}$ in terms of $\mathbf{r}^{\prime}$, we need only recall that

$$
r / r^{\prime}=m_{k} ;
$$

where $k^{\prime}$ indicates the relative bias of the sum's distribution. But $k^{\prime}$ is the ratio of the absolute bias to the sum's standard deviation:

$$
k^{\prime}=k \sum_{i} \sigma_{i} / \sqrt{\sum_{i} \sigma_{i}^{2}}
$$

Substituting the expression for $\sigma_{i}$ in (5), $k^{\prime}$ can be written in terms of $k$ times a correction factor:

$$
k^{\prime}=k\left[\sum_{i} r_{i} b_{i} / \sqrt{\sum_{i}\left(r_{i} b_{i}\right)^{2}}\right]
$$

Unce $k^{\prime}$ is found, $m_{k}$, can be read from the above table, and we can substitute $r^{\prime}=r / m_{k}$, into $(6)$ and solve for the sum's percentage confidence interval $x$ :

$$
i=\frac{m_{k}}{m_{k}} \sqrt{\sum_{i}\left(i_{i} b_{i}\right)^{2}} / \sum_{i} b_{i}
$$

Again a maximum likelihood estimate of $k^{\prime}$ and of $r$ can be had by substituting $a_{1}$ for $b_{1}$ :

$$
\begin{aligned}
& k^{\prime}=k\left[\sum_{i} r_{i} a_{i} / \sqrt{\sum_{i}\left(r_{i} a_{i}\right)^{2}}\right] \\
& r_{\text {est }}=\frac{m_{k}}{m_{k}} \sqrt{\sum_{i}\left(r_{i} a_{i}\right)^{2}} / \sum_{i} a_{i}
\end{aligned}
$$


where

$m_{k}, m_{k}$ are given by the above table of ratios $r_{i} / r_{i}^{\prime}$

$k=$ the ratio of the bias to the standard deviation of the addend distributions, to be set at a reasonable value shortly

$k^{\prime}=$ the same ratio for the sum's distribution, given by formula (7)

$r_{i}=$ the percentage confidence interval given for the $i$-th addend $\left(r_{i}=10 \%, 25 \%, 50 \%\right.$ or $\left.100 \%\right)$

$a_{i}=$ the observed value of the $i-t h$ addend

Comparison of formulas (8) and (2) reveals that the effect of adding bias to the addend distributions is simply to enlarge the sum's percentage confidence interval by a factor of $m_{k}-/ m_{k}$.

The next task is to arrive at a reasonable value for $k$, which indicates the amount of bias in the addend distributions relative to the amount of random variation. Obviously there are no grounds for calculating or otherwise deducing a precise value for $k$, but the compilers of the End Use Data Base agree on two general observations that can suggest what a reasonable value would be. One is that random variation among the estimates for categories in a given breakdown normally makes a significant contribution to error. The other is that bias nonetheless generally dominates random variation as a source of error, and that bias among categories in a given breakdown is usually in the same direction. Let us say, then, that on the average about $2 / 3$ of an estimate's error is attributable to bias, bias that lies in the same direction as that of other estimates in the breakdowns over which a sum is to be taken.

Now we must decide what it means to say that a certain portion of error is due to bias. The following analysis, while not the only reasonable one, seems to harmonize with the intuitions that delivered the $2 / 3$ figure just mentioned. Let us say that the $i-t h$ distribution of estimates is biased downward by an amount $k \sigma_{1}$; that is, the mean of the distribution is $b_{i}-k \sigma_{i}$. If the observed value $a_{i}$ is less than $b_{i}-k \sigma_{i}$, one is inclined to say that bias contributes $k_{i}$ to the error and random 
variation contributes the rest, $b_{i}-a_{i}-k \sigma_{i}$. If $a_{i}$ is greater than $b_{i}$, it is reasonable to say that the error is due entirely to random variation, since without the bias the error would have been even worse. If $a_{i}$ is between $b_{i}-k \sigma_{i}$ and $b_{i}$, one is inclined to say that all of the error is due to bias, since the estimate would not have fallen short at all if the distribution had been unbiased. The postulate that, on the average, $2 / 3$ of the error is due to bias can be approximately fulfilled by adjusting $k$ so that halt the time, bias contributes at 1east $2 / 3$ uf the error, and the rest of the time it contributes less than $2 / 3$. So, the probability that $a_{i}$ lies between $b_{i}-1.5\left(k \sigma_{i}\right)$ and $b_{i}$ should be $50 \%$. If $k$ is set at 0.54 , this condition is met. Let us decree, then, that $\mathrm{k}=0.54$.

No further argument for this choice of $k$ can be adduced, except to say that it seems reasonable and leads to reasonable results. The results can be judged in the table below. Here the effect on the confidence interval of adding $n$ estimates of equal size is shown, first on the assumption that the distributions are independent and then that they are biased all in the same direction by an amount equal to $(0.54) \sigma_{i}$. The original percentage confidence interval of each addend is taken to be $\pm 50 \%$, a figure at the upper end of data quality rating 3 . The level of confidence is set at $p=90 \%$.

\section{Effect of aggregarion on percentage confidence interval}

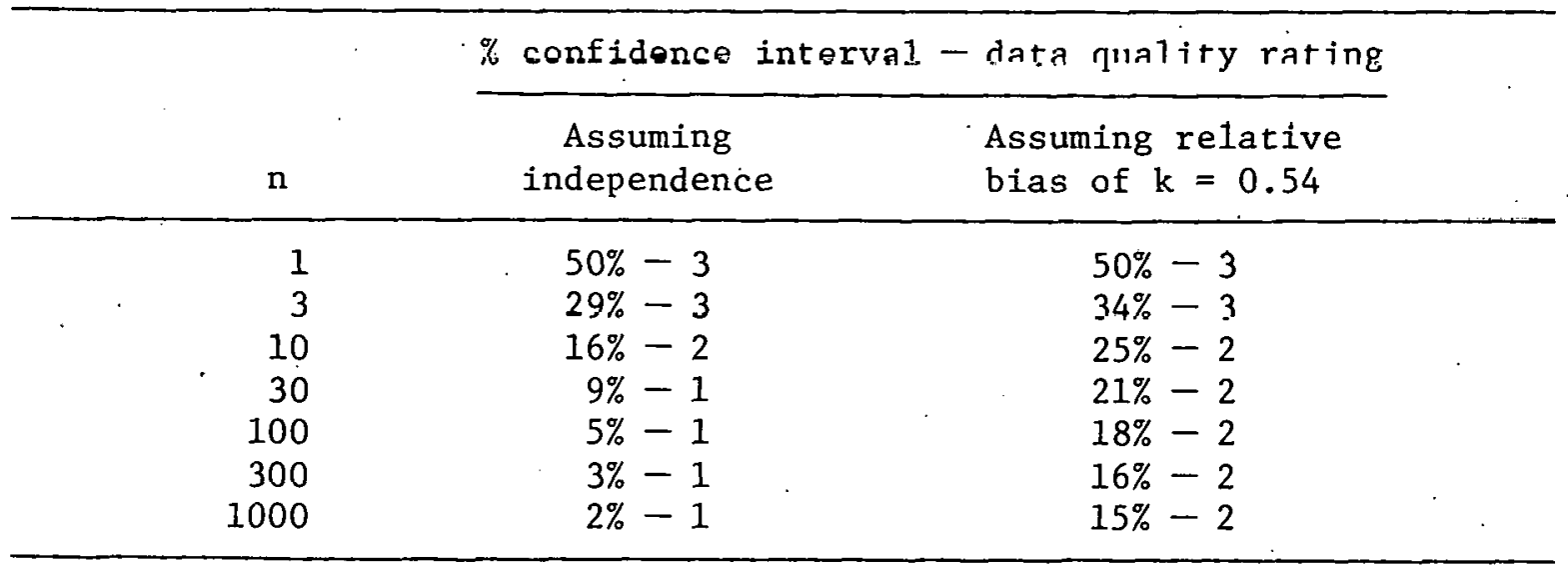


The rate at which $k=0.54$ slows the shrinkage of the confidence interval seems reasonable.

Units of Measurement

If all the data to be aggregated are expressed in the same units, their sum will of course be expressed in those same units. Otherwise, their sum is meaningless and is not taken. All energy values are expressed in the same units, Btu (on the data tape, billions of Btu), but the fuel units can vary. Fuel quantities are never added when the fuels. are different, even if the units are the same; there is no point in adding barrels of gasoline to barrels of diesel fuel. The units of measurement are discussed in detail in Sec. 


\section{CHAPTER 6. TECHNICAL ÁRTICLES}

\subsection{Estimating the Number of Aggregate Data}

The final data tapes containing the End Use Data Base must contain not only the data generated using the methods described herein, but all possible aggregations of these data as well. This section provides a feeling for the number of aggregate data likely to be generated, in order to gauge the magnitude of the task of adding them to the data base. The following section details an algorithm for adding them to the data base.

Ideally, the data base would consist of an $n$-dimensional array $A$ whose every cell contains a number $a_{i_{1}} \ldots i_{n} \cdot$ A tiny illustrative data base, for instance, might break consumption down by mode of transportation fuel and year. If it covered 5 modes, 3 fuels and 10 years, its data would ideally fill a $5 \times 3 \times 10$ array. Cell $a_{123}$ in the array would represent the consumption of fuel 1 by mode 2 in year 3 . We will refer to the data in this array as elementary data.

Once the elementary data are known, the aggregate data, or sums over breakdowns, can be computed. If one computes a sum over $k$ breakdowns, the result is a k-dimensional sum. For instance, the total consumption of fuel 1 by all modes in year 3 , or $\sum_{i=1}^{5} a_{1 i 3}$, is a 1-dimensional sum, whereas the consumption of fuel 1 by all modes in all years, or $\sum_{i=1}^{5} \sum_{j=1}^{10} a_{1 i j}$, is a 2-dimensional sum. In general, a k-dimensional sum is a sum over elementary data $a_{i_{1}} \ldots i_{n}$. where $k$ of the indices are allowed to vary and the other $n-k$ are held fixed. Such a sum can be written

$$
s\left(i_{t_{1}}, \ldots, i_{t_{n-k}}\right)=\sum_{i_{j}} \ldots \sum_{i_{k}} a_{i_{1}} \ldots i_{n}
$$

where $t_{1}, \ldots, t_{n-k}$ are all different from $i_{1}, \ldots, j_{k}$. Here, the indices $i_{t_{1}}, \ldots, i_{t_{n-k}}$ are fixed and the remaining indices $i_{j_{1}}, \ldots, i_{j_{k}}$ vary. 
A 0 -dimensional sum $s\left(i_{1}, \ldots, i_{n}\right)$ is simply the elementary datum $a_{i_{1}} \ldots i_{n}$, and the single n-dimensional sum $S()$ is the sum of all the elementary data. It should be understood that the notation $s\left(i_{t_{1}}, \ldots\right.$, $\left.i_{t_{n-k}}\right)$ is not complete until each $i$ is given a subscript. To return to the above illustration, the notation $S\left(1_{1}, 3_{3}\right)$ refers to the total consumption of fuel 1 by all modes in year 3 , but the notation $S(1,3)$ is meaningless.

The estimation of the number of aggregate data can begin by supposing, for simplicity, that the data base in fact begins as an $r_{1} \times r_{2} \times \ldots \times r_{n}$ array completely filled with elementary data. It is clear that the number of k-dimensional sums is just the number of collections of $\dot{n}-k$ indices $i_{t_{1}}, \ldots, i_{t_{n-k}}$. The choice of $t_{1}, \ldots, t_{n-k}$ can be made in $\left(\begin{array}{c}n \\ n-k\end{array}\right)=\left(\begin{array}{l}n \\ k\end{array}\right)$ ways. For each choice the indices $i_{t_{1}}, \ldots$, $i_{t_{n-k}}$ can jointly assume $r_{t_{1}} r_{t_{2}} \ldots r_{t_{n-k}}$ possible values., So, the number of $k$-dimensional sums is

$$
\sum_{c \varepsilon c^{n-k}}\left(\prod_{i \varepsilon c} r_{i}\right)
$$

where $c^{n-k}$ is the set of all $\left(\begin{array}{l}n \\ k\end{array}\right)$ combinations of $n-k$ of the first $n$ positive integers. The total number of aggregate and elementary data is the total number of $k$-dimensional sums as $k$ varies from 0 to $n$ :

$$
\sum_{k=0}^{n} \sum_{c \varepsilon c^{n-k}}\left(\begin{array}{cr}
\prod_{i \varepsilon c} & \\
i
\end{array}\right)
$$

Note that the products $\prod_{e \varepsilon c} r_{i}$ are simply the cross-products in the expansion of

$$
\prod_{i=1}^{n}\left(r_{i}+1\right)
$$

This last expression, then, provides a simpler calculation of the number of elementary and aggregate data. It also suggests that if the original 
data base is conceived as an $r_{1} \times \ldots \times r_{n}$ array, the addition of aggregate data adds a layer of cells to $n$ sides of this array, creating an $\left(r_{1}+1\right) \times \ldots \times\left(r_{n}+1\right)$ array. Indeed the added cells correspond to the $k$-dimensional sums in a systematic way. The new corner cell having coordinates $\left(r_{1}+1, \ldots, r_{n}+1\right)$ represents the $n$-dimensional sum $s()$; any k-dimensional face (or edge or vertex), one cell thick, on the. expanded cube that contains this corner cell consists of cells representing sums of dimensions $n-k$ through $n$.

In the special case in which the original array of data is a cube, so that $r_{1}=\ldots=r_{n}=r$, the number of elementary and aggregate data is given by the simpler formula,

$$
(r+1)^{n}
$$

An odd corollary of this formula is that the number of elementary and aggregate data can be computed in the same way as one computes compounded interest. If the volume $\mathrm{r}^{\mathrm{n}}$ of the original $\mathrm{n}$-dimensional cube represents the principal, then the volume $(r+1)^{\mathfrak{n}}$ of the expanded cube represents the increased principal after $n$ years at an annual interest rate of $1 / \mathrm{r}$, compounded annually. The number of data increases with dimension, then, exactly as one's bank account increases over the years. Perhaps one reason it is easy to underestimate the number of aggregate data that pertain to an array of $\mathrm{n}$ dimensions is that it is even:more difficult to visualize the effect of several dimensions than that of several years.

A concrete example of the increase in the number of data can be had in the small data base described earlier. It begins with $5 \times 4 \times 10=150$ elementary data and spawns aggregate data, that bring the total to $6 \times 5$ $\times 11$ = 330 data, more than double the original size. The expansion is even more dramatic in data bases having more than 3 dimensions.

Formula (3) implies that the addition of aggregate data to a cubic array of $n$ dimensions increases the number of data by a factor of $(1+1 / r)^{n}$. Supposing conservatively that $\mathrm{n}=10$ and $\mathrm{r}=5$, the data become 6.2 times more numerous. 


\subsection{Adding Aggregate Data to the Data Base}

The task of adding aggregate data to the End Use data base is far from trivial. In this section the nature of the task and the algorithm used to accomplish it are described.

The problem is to append to the data base all possible sums

$s\left(i_{t_{1}}, \ldots, i_{t_{n-k}}\right)$ that can be constructed from the data already there. As argued in the previous section these sums may well outnumber the original data, and consequently it is imperative that a reasonably efficient algorithm be devised. The unpredictable nature and degree of completeness of the data, however, severely iimit the speed of any algorithm.

Difficulties begin with the fact that the original data base is hardly the completely dense array of elementary data described in the previous section. On the contrary, very few if any of the data are likely even to be elementary. Rather, they are assorted $k$-dimensional sums where $k$ varies over most of the range from 1 to $n$. One consequence of this. spottiness in the data is that many of the sums one might desire cannot be computed simply because none of the original data are sufficiently disaggregate. For example, it may be impossible to compute the total fuel use by taxis in Pennsylvania in 1976 (summing over all other breakdowns) because nothing more finely categorized than fuel use by taxis nationwide is known in the first place. Put formally, a sum $s\left(i_{t_{1}}, \ldots, i_{t_{n-k}}\right)$ is unrecoverable when no sum recorded in the data base has $i_{t_{1}}, \ldots, i_{t_{n-k}}$ among its indices.

Still other sums are likely to be unrecoverable because some of the addends are missing. For example, national fuel use by motorboats is unrecoverable if the only available data are motorboat fuel use figures for every state but Florida. Again in formal terms, $s\left(i_{t_{1}}, \ldots, i_{t_{n-k}}\right)$ is unrecoverable when for every value of $j\left(j \neq t_{1}, \ldots, t_{n-k}\right)$, a nonzero sum $s\left(i_{j}, i_{t_{1}}, \ldots, i_{t_{n-k}}\right)$ is missing or unrecoverable for at least one value of $i_{j}$. 
The algorithm devised to generate aggregate data was required to circumvent these difficulties while overcoming a far greater obstacle: keeping an inordinate number of running totals in addressable storage at once. Generally speaking, the algorithm accomplishes its task by generating the sums in stages, storing the running totals on hundreds or thousands of ordered linked lists, and locating the beginning of each linked list with a hash code based on the pattern of indices of the totals in the list. (A linked list is a series of data records stored at random locations on some storage device, where each record contains a number or "pointer" that indicates the location of the next record in the list.. The list is said to be ordered when the records are arranged in order according to some datum on the records. When the location of a data item is a computable function of some characteristic of the item, the value of that function for a given item is said to be the item's hash code.)

The algorithm runs as follows. As remarked earlier it generates the sums in stages. Each stage involves one pass over the data base that results from the previous pass. The first pass is of course a pass over the original data base, and it generates 1-dimensional sums only. Many of these sums; of course, are!likely to occur in the data base already. When a certain 1-dimensional sum both occurs in the data base and can be generated by summing over elementary data, the preexistent sum is used rather than the computed sum. Since during the first pass only those data that are elementary data or 1-dimensional sums are relevant, the reot of the dald are ignored.

The second pass is a pass over the union of the original data base with the sums created during the first pass. Only 1- and 2-dimensional sums in the input data are relevant this time, and 2-dimensional sums are generated. There is no need to process elementary data, sincc any 2-dimensional sum that can be recovered from the available elementary data can be more quickly recovered from the 1-dimensional sums just generated. This procedure continues in analogous fashion through a total of $n$ passes, after which all recoverable aggregate data have been recovered. 
The details of the algorithm can be seen by examining more closely the $\mathrm{k}$-th pass, which generates $\mathrm{k}$-dimensional sums. During this pass both $(k-1)$-dimensional and $k$-dimensional input sums are processed. These two types of input sums are treated separately below.

Case 1. A (k-1)-dimensional input sum is processed. For convenience, let us speak of $k$-dimensional sums of the form $s\left(i_{t_{1}}, \ldots, i_{t_{n-k}}\right)$, where $i_{t_{1}}, \ldots, i_{t_{n-k}}$ are allowed to vary but $t_{1}, \ldots, t_{n-k}$ are not, as being of the same type. The sum $s\left(i_{u_{1}}, \ldots, i_{u_{n-k}}\right)$ will be regarded as a k-dimensional sum of a different type if the ser of illices $u_{1}, \ldots, u_{n-k}$ is not identical to the set of indiceo $t_{1}, \ldots, t_{n-k}$. Now note that the $(k-1)$-dimensional sum $s\left(i_{t_{1}}, \ldots, i_{t_{n-k+1}}\right)$ to be processed can become an addend in as many as $n-k+1$ different types of $k$-dimensional sums. These types are simply sums of the form $s\left(i_{t_{1}}, \ldots, i_{t_{n-k+1}} / i_{j}\right)$, where $j$ varies over the values $t_{1}, \ldots, t_{n-k+1}$, and where the $/ i_{j}$ notation indicates that $i_{j}$ is to be removed from among the indices $i_{t_{1}}, \ldots$, $i_{t_{n-k+1}}$. A separale linked list of running totals is maintained in a computer disk file for each such type of k-dimensional sum. A total of $n$ such lises are kept, but a given addend rnnrrghutes to a sum in only $n-k+1$ of them.

Within a given linked 1ist, space is not reserved for a particular running total until an addend that would contribute to that total is encountered. When all the Impul lata have bcon prosessed, it is assumed that all the running totals started during the process are now complete (i.e., all the required addends have been added in), unless a total has heen marked otherwise. For it has been the policy in preparing the data base that any categories of energy consumption for which consumption is nonzero and yet unknown are represented in the data base by special data records containing "missing data" flags in place of the usual data. When the aggregate algorithm attempts to add one of these missing data tlags to a running total, that total is itself marked as a total that cannot be completed because at least one of the necessary addends is missing. Since 
presumably all missing data are flagged, unmarked totals are presumed complete.

Case 2. A k-dimensional input sum $s\left(i_{t_{1}}, \ldots, i_{t_{n-k}}\right)$ is processed. When such a sum is read from the data base, it must be entered in $k$ of the linked lists described earlier. This is because running totals of this form can be generated in $k$ different ways by adding together sums of any of $k$ types. These $k$ types are represented by the sums $s\left(i_{j}, i_{t_{1}}, \ldots\right.$, $\left.i_{t_{n-k}}\right)$ as $j$ ranges over the integers from 1 to $n$ other than $t_{1}, \ldots, t_{n-k}$. If a given linked list contains a running total having the same indices as an incoming sum $s\left(i_{t_{1}}, \ldots, i_{t_{n-k}}\right)$, the running total is replaced by the inçoming sum, in accordance with the policy noted earlier. The new total is marked as one taken directly from the data base, so that no further addends will be added to it, and so that it will not be inserted into a data base that already contains it. If no running total having the same indices as the incoming sum is found, the incoming sum is simply appended to the linked list and similarly marked.

These linked lists can unfortunately grow very long. Consider, for example, the ideal data base of the last section consisting of a cubic array of $r^{n}$ elementary data. Immediately after the $k-t h$ pass the $j-t h$ linked list contains all sums of the form $s_{i}\left(i_{t_{1}}, \ldots, i_{t_{n-k+1}} / i_{j}\right)$. The secondary indices $t_{1}, \ldots, t_{n-k+1}$ (excepting $j$ ) can assume any of $r^{n-k}$ combinations of values. For each of these the primary indices $i_{t_{1}}, \ldots$, $i_{t_{n-k+1}}$ (excepting $\left.i_{j}\right)$ can assume $\left({ }_{n-k}^{n-1}\right)$ combinations of values. Each linked 1ist, then, has a length of $\left(\begin{array}{l}n-1 \\ n-k\end{array}\right) r^{n-k}$ items after the $k-t h$ pass. Supposing conservatively that $\mathrm{n}=10$ and $\mathrm{r}=5$, the linked lists reach a peak length of 3.5 million items after the second pass. The search time in such a list is grossly prohibitive.

The search time is reduced to manageability by splitting each linked list into many sublists, each located by means of an index. Each incoming datum $s\left(i_{t_{1}}, \ldots, i_{t_{n-k+1}}\right)$ is assigned a hash code based on its type; each 
of the $\left(\begin{array}{c}n \\ n-k+1\end{array}\right)$ possible types is assigned a unique code. The index just mentioned matches each code $z$ to an array of $n$ pointers. The $j-t h$ pointer is the location of the first total in a linked sublist. " Each total in this sublist is the result of adding data having code $z$, where the value of the $j$-th key varies and the rest are fixed. To speed the search further the sums in each sublist are ordered by their primary indices $i_{t_{1}}, \ldots i_{\tau_{n-k}}$

The $j$-th linked list accepts only Lluse addends of the form $s\left(i_{t_{1}}, \ldots, i_{t_{n-k+1}} / i_{j}\right)$. The number of poss1ble hash cules assigned to data of this form is $\left(\begin{array}{c}n-1 \\ n-k\end{array}\right)$. Consequently, since in the ideal case under consideration each linked list contains $\left(\begin{array}{l}n-1 \\ n-k\end{array}\right) r^{n-k}$ totals, each of its sublists will contain $\left(\begin{array}{c}n-1 \\ n-k\end{array}\right) x^{n-k} /\left(\begin{array}{c}n-1 \\ n-k\end{array}\right)=r^{n-k}$ items. One might question the utility of defining these sublists, then, since immediately after the first pass each linked list contains only one sublist, which in turn. contains $r^{n-1}$ items. In the case where $n=10$ and $r=5$, for instance, each of the first-pass sublists contains 1.95 million items. It is little comfort that the sublists after subsequent passes are smaller. As it happens, however, the number of elementary data in the actual data base is practically zero, simply because data so finely categorized are not available. The most finely categorized data are already at least 3- or 4-dimensional suths, for whlch sublists become moro numerous. And, up to a point, as $k$ increases the number of $k$-dimensional sums in the data base increases along with the number of sublists in which the running totals are stored. If the sublists are yet expected to become too long, finer hashing codes can be tailored to particular passes. Upon the generation of sums during each pass, the number of sums generated can be counted in order to guide the formulation of a hashing code for the next pass.

A factor that complicates the generation of aggregate data is that a given k-dimensional sum $s\left(i_{t_{1}}, \ldots, i_{t_{n-k}}\right)$ can, as remarked earlier, be recovered in $k$ different ways by summing over any of $k$ types of $(k-1)-$ dimensional sums. Consequently a given total may occur among the linked 
lists of totals as many as $\mathrm{k}$ times. Unfortunately it is necessary to maintain all of these duplicate totals, because it is not known until the end of a pass which totals will be discarded because of missing addends. It is easily possible that only one of the $k$ totals will in the end be completed. This unavoidable duplication, however, requires that any duplicate totals be eliminated when the totals are finally appended to the data base after a pass is completed.

The following algorithm, which was used to eliminate duplicate tota1s, helps to ininimize the time required for this considerable task. Beginning with the lowest-coded sublist of the first linked list of totals, the totals are examined one by one, in the order listed, for appendage to the data base. When a given total $s\left(i_{t_{1}}, \ldots, i_{t_{n-k}}\right)$ is examined, it is deleted if marked as an incomplete total. If it is not so marked, a duplicate is sought in the appropriate sublist in the linked lists already examined. Since a given total occurs only once in a single linked list, there is no need to scan the sublist containing the sum now under examination. Also there is no need to scan a sublist in the $j$-th linked list, whenever $j$ is equal to one of the indices $t_{1}, \ldots, t_{n-k}$. The proper sublist of any linked list $j$ that is scanned is the one indexed by the hash code of sums of the form $s\left(i_{j}, i_{t_{1}}, \ldots, i_{t_{n-k}}\right)$. Consequently all duplicates of totals in a given linked sublist will be found, in the same order, in a single sublist. These and other factors permit duplicates to be found fairly quickly. If a duplicate total is found, it is replaced with the total having the better data quality number, and the total currently under examination is deleted. If no duplicate is found, the total under examination is simply kept. The result is that as more of the totals are examined, more totals are deleted from among those that must be scanned for duplicates each time a total is examined.

A FORTRAN implementation of the above algorithm was found to run intolerably slowly unless the input data were presorted in descending order. This presorting enabled each incoming datum to be placed at the head of the linked lists to which it is appended; thus reducing the number of disk acceseer to a minimuim. The time required for presorting is not 
significant. The time required for removing duplicate totals was found to be only a fairly small fraction of that required to generate the totals, even after presorting was instituted.

A number of other, smaller efficiency improvements were also made. The resulting program is usable but slow. The difficulty lies partly in the inefficiency of the FORTRAN implementation. It is likely that a good assembly language coding, or even a carefully optimized FORTRAN coding, would speed the computation considerably. The main difficulty, however, stems from the inherent complexity of the problem. Recall that in the ideal case in which the input data fill an n-dimensiund ariay containing

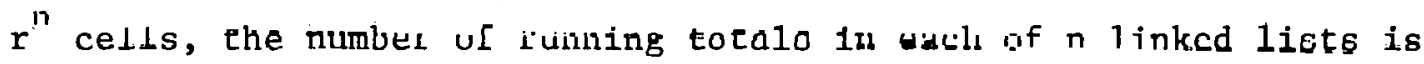

$$
\left(\begin{array}{c}
n-1 \\
n-k
\end{array}\right) r^{n-k}
$$

after the $k$-th pass. Consequently the number of totals computed through the $\mathrm{n}$ passes comes to

$$
\sum_{k=1}^{n} n\left(\begin{array}{c}
n-1 \\
n-k
\end{array}\right) r^{n-k}=n(r+1)^{n-1} / r
$$

Since each total. undergoes $r$ additions, the complexity of any summation algorithm must be at least propurtional to

$$
n(r+I)^{n-1}
$$

The romplexity of the problem, Llew, is rathcr scverely exponential. (The problem does not lie even in the class NF of problcmo that are soluble in polynomial time by a nondeterministic algorithm.) For this reason any implementation will run prohibitively slow when the input data bet is 1argc. The cummations required for the End Use Data Base were calculable only through the painstaking use of corner-cutting techniques described at the end of Sec. 6.3 . 


\subsection{Flagging the Absence of Data}

It was mentioned in the previous section that when one of the nonzero addends of a sum is missing, the data base contains a record representing the missing addend and bearing a missing-data flag in place of a datum. It is this flag that signals the summation algorithm, described in the same section, that the total to which the missing addend would be added cannot be completed.

The difficulty with this policy of flagging absent data is that the missing-data flags are likely to be very numerous, perhaps more so than . the data that are present. Some calculations to follow substantiate this. This difficulty, as well as a simple technique that was used to circumvent it, are the subject of this section.

Before going further it is important to point out that although the technique of using missing-data flags has an alternative, the alternative is even worse. The alternative is simply to omit from the data base all records representing missing data and to include a record for each datum equal to zero. The summation routine would be informed of the possible values of every key and would reject every running total one or more of whose possible addends are not found in the data base. The number of zero-valued sums that would have to be made part of the data base, however, would exceed even the number of missing-data flags discussed above. This is because most subcategories of a given category are as necessarily empty as the passenger subcategory of pipeline transport or the coal-fueled subcategory of auto transport. Furthermore, this profusion of superfluous zeros cannot be alleviated in the way the profusion of missing-data flags was alleviated, a way to be described at the end of this section.

To get an idea of the number of missing-data flags that may be necessary, consider the typical situation in which

(a) all sums of the form $s\left(g_{1}, h_{2}, i_{3}, \ldots, i_{k}\right)$, where $g_{1}$ and $h_{2}$ are fixed but $i_{3}, \ldots, i_{k}(3 \leq k \leq d)$ vary, are known, and in which

(b) all sums of the form $s\left(g_{1}-, h_{2}, i_{3}, \ldots, i_{n}\right)$, where $i_{3}, \ldots, i_{n}$ vary, are unknown. 
This might occur if $h_{2}$ were the auto category and $g_{1}$ and $g_{1}$ ' respectively were the gasoline and diesel oil categories. That is, it might be that the consumption of gasoline in all the intersections of auto subcategories $h_{2}, i_{3}, \ldots, i_{k}(k \leq d)$ is known but the consumption of diesel oil in the intersections of auto subcategories $h_{2}, i_{3}, \ldots, i_{n}$ is unknown, simply because nothing at all is known about auto consumption of diesel oil. The known sums $S\left(g_{1}, h_{2}, i_{3}, \ldots, i_{k}\right)$. would trigger, amnng nthers, all running totals of the form $S\left(h_{2}, i_{3}, \ldots, i_{k}\right)$, each of which is incompletable. To cause each to be recognized as incompletable, each missing sum $s\left(g_{1}{ }^{\prime}, h_{2}, i_{3}, \ldots, i_{k}\right), k \leq d$, must be represented by a missing-data flag. The number of these flags is potentially

$$
\sum_{k=3}^{d}\left(\begin{array}{l}
d-2 \\
k-2
\end{array}\right) r^{k-2}
$$

which is exactly the number of known sums $s\left(g_{1}, h_{2}, i_{3}, \ldots, i_{k}\right)$.

This is perhaps tolerable, but the situation is even worse than this. It is easily possible that sums of the form $s\left(g_{1}, i_{t_{1}}, \ldots, i_{t_{j}}\right)$ exist, where at least one of the indices $t_{j}, \ldots, t_{j}$ is greater than $d$ and all are greater than 2. Each of these would trigger an incompletable miecing sum of the form $s\left(1_{t_{1}}, \ldots, i_{t_{j}}\right)$, among others. Consequently all missing. sums of the form $s\left(g_{1}{ }^{-}, i_{t_{1}}, \ldots, i_{t_{j}}\right)$ would have to be flagged to ensure that any of these incompletable sums are so recognized. These additional flags, combined with the flags already enumerated above, number

$$
\sum_{j=1}^{n-2}\left(\begin{array}{c}
n-2 \\
j
\end{array}\right) r^{j}-(r+1)^{n-2}-1
$$

Consider the case in which $n=10$ and $r=5$. If we reasonably suppose that $d=6$, then the number of known sums $s\left(g_{1}, h_{2}, i_{3}, \ldots, i_{k}\right)$, $3 \leq k \leq d$, comes to 1275 . The number of missing-dala flags would be $1,679,615$.

The absurdity of recording 1300 times as many missing-data flags as. data was avoided in the following way. The convention was adopted that 
sums over certain breakdowns are always considered to have missing nonzero addends except possibly when the addends all represent subcategories of a single mode. That is, certain distinguished breakdowns $j$ are such that any total $s\left(i_{j}, 1_{t_{1}}, \ldots, 1_{t_{k}}\right)$ is considered a priori to be incompletable unless one of the indices $t_{1}, \ldots, t_{k}$ represents a breakdown by mode. If one of the indices does represent a breakdown by mode, the sum is not presumed incompletable; it is treated as such only if a missing-data flag is discovered in place of one of its addends. Naturally, the distinguished breakdowns $f$ are chösen so that sums over them are in fact incompletable in the instances described. It was decided that sums within a mode, rather than sums within some other type of category, would not be presumed incompletable because (a) the data are generated a portion at a time, each portion corresponding to a mode, and (b) sums are very often incompletable across modes when they are' completable within modes.

To illustrate the utility of this simple convention, return to the above example and make the reasonable assumption that breakdowns 3, 4, ..., d have been distinguished as ones over which transmodal sums are presumed incompletable. Then any sum of ${ }^{1 e}$ form $s\left(g_{1}, 1_{t_{1}}, \ldots, i_{t_{j}}\right)$, where at least one of $t_{1}, \ldots, t_{j}$ is greater than $d$ and all are greater than 2, is recognized a priori to be incompletable, so that no missingdata flag need be inserted for its sake. The result is that the missing-data flags needed are merely those for the sums $\mathrm{s}\left(\mathrm{g}_{1}{ }^{\circ}, \mathrm{h}_{2}, \mathrm{i}_{3}\right.$, $\ldots, i_{k}$ ), which are 1275 in number. 'This is not ideal, but in nearly every case the known sums recorded within a particular mode considerably outnumber the unknown nonzero sums within that mode. This is because, to use the present Instance, values of $i_{1}$ for which $s\left(i_{1}, h_{2}, i_{3}, \ldots, i_{k}\right)$ exist typically outnumber values of $i_{1}$ for which nonzero sums of this form are missing.

The technique just described is easily implemented in the summation algorithm of the previous section. Before, an addend is permitted to start a running total, it is routinely checked to see whether it contains an index" corresponding to one of the distinguished breakdowns but no index 
corresponding to the mode breakdown. If so, no running total is started. Also, if a sum over modes is about to be taken, the first addend is checked to see whether it contains an index corresponding to a distinguished breakdown. If it does, no running total is started. (An addend is considered to have an index corresponding to the mode breakdown if and only if it is classified under AIR, RAIL, AUTO, BUS, TRUCK, MOTORCYCLE, MARINE, or PIPELINE. A sum is considered to be a sum over modes when it is either a sum over MODE1 with.MODE fixed at HIGHWAY, or else a sum over MODE.)

The greatest improvement was achieved by decomposing the problem into smaller problems that were later combined. For instance, the procedure below was followed with respect to the modes:

(a) Run the summation algorithm separately on each mode, in each case summing only over those breakdowns that need summation within that particular mode.

(b) Concatenate the results of these summation runs, and run the summation program again, this time summing only over undistinguished breakdowns, and summing over modes only when data are not classified under a category within one or more distinguished breakdowns. (The input to this stage can be trimmed hy purging a11 missing data flags classified under a category in any of the distinguished breakdowns.)

This procedure has a double advantage. It reduce's the time and space required by reducing the number of keys over which sums are taken. Recall that the time and space requirements vary exponentially with the number of summing keys. A second advantage is that it reduces, also in an exponential fashion, the number of missing data flags necessary. When fewer sums are attempted, fewer flags are needed to stop them.

The summation algorithm is somewhat sluggish and sprawling because it. is completely general: it requires no prior information whatever about the combination of elementary data, aggregate data and missing data flags it will be fed. The decomposition described above permits one to appropriate his prior knowledge of what sorts of sums need be attempted 
by choosing a limited number of summation keys at each stage. This cholce in effect conveys to the summation algorithm certain Information about the structure of the incoming data, and the result is an enormous improvement in performance.

In order to expedite further the summation process - indeed, to make it affordable - the same decomposition was applied to the data corresponding to some of the individual modes. On occasion the components of a single mode were themselves further decomposed. The resulting aggregations formed part of these modes' input to stage (a) above. 
CHAPTER 7. THE RETRIEVAL PROGRAM "DBRS"

A computer program designed especially to retrieve data from the End Use Energy Consumption Data Base is now in operation at ORNL. It operates "on line," meaning that one can sit at a computer terminal, ask for data of his specification, and wait a few seconds for a response. This retrieval program, called DBRS by its developers, is currently set up to read the data provided on the ORNL data tape (see Sec. 1), but it is capable of retrieving data from any data set. One need only specify the format of the data set in a manner discussed in Sec. 7.2 below. The developers of the program are Niket K. Patwardhan and Danny G. Johnson, working under the direction of Professor Derrell V. Foster of the Computer Science Department at Vanderbilt University. It is intended for.those who wish to have on-line retrieval availability of the end use data, as well as, for ORNL's own use. It was written with the aim of making it as transportable as possible, so that it could be installed on most machines with on-line capabilities in a few days at worst.

Section 7.1 below provides simple instructions for using the program, which is designed so that one with no background in computing should be able to learn to use it rather easily. Section 7.2. discusses the installation of the program. A more complete presentation of these matters can be found in the DBRS Manual: User's Guide to DBRS Version 2.3, prepared by the authors of the program, and submitted to the Office of the Consumption Data System along with this report. The point of the instructions in Section 7.1 is to provide something less formal and addressed more to the layman than the relatively technical presentation in the manual. Section 7.2 supplements the manual's installation instructions with tips based on experience gained since the manual was written.

\subsection{How tó Use It}

Begin by typing whatever command your computer requires to begin execution of DBRS. (At ORNL, where the program is installed on a PDP -10 computer, the command is RUN DBRS.) 
The computer will respond,

ENTER NAME OF DATABASE:

whereupon you should type in the name your installation is using for the data base from which you wish to retrieve data. (At ORNL, the. End Use Energy Consumption Data Base is named ENDUSE.) When the computer then says,

ENTER NAME OF RETRIEVE OUTPUT FILE:

type in the name of a file in which you want a record of your dialogue with the computer saved. You will probably need to consult with your. local computer programmers to learn what sort of name is suitable. (At ORNL, any PDP-10 file name will do.)

\section{BEADY}

After a few seconds the computer will say,

indicating that it is ready for your first command. You should never try to give the computer a command until it has finished obeying your previous command and has indicated as much by saying READY.

The computer will obey any of eight commands. They are, RETRIEVE ... WHERE ... TYPE ... retrieves data from the data base

TYPE controls the number of data printed on your

HELP $\ldots$ terminal

EXIT

SUM ... WHERE ... sums over breakdowns

INPUT ... . switches to a new data base

OUTPUT ... switches to a new output file

KEEP saves numerical data in a special output filc

Any of these commands can be abbreviated by using the first letter only. A user of LBKS need know only the tirst tour, and they are described first below.

\subsubsection{The RETRIEVE Command}

The RETRIEVE command, the most basic one, is the command that actually fetches the data you want. It reads more or less like ordinary English. For instance, two RETRIEVE commands might be:

RETRIEVE ENERGY WHERE MODE1 EQ AUTO AND STATE EQ NY AND YEAR EQ 76 R YEAR, ENERGY, EUNIT W MODEI EQ AUTO AND STATE EQ ALL

(Note that "RETRIEVE" and "WHERE" are abbreviated in the second command.) Since EQ stands for "equals" or "is," the first command says, "retrieve all energy use figures where the mode is auto, the state New York and the year 1976." The second command retrieves all national energy use figures for autos, as well as the year to which each figure pertains and the unit in which it is expressed. The import of STATE EQ ALL is to suppress all auto senergy use figures broken down by state; national totals alone will be retrieved. When printed on your terminal, the retrieved data might look like this: 


$\begin{array}{ccc}67 & 1234 & \text { BILLION } \\ 68 & 2345 & \text { BILLION } \\ 69 & 3456 & \text { BILLION BTU } \\ 70 & 4567 & \text { BILLION BTU } \\ & & \\ & & \\ 76 & 6789 & \text { BILLION BTU }\end{array}$

You can use the TYPE command (Sec. 7.1.3) to make this output appear on your terminal.

It is important to understand that a command may retrieve more figures than you expect. Let us suppose, for example, that the data base from which the data are to be retrieved is the base of transportation energy use data documented in this reported and recorded on the ORNL data tape. Then the first command above will not retrieve just one datum, representing the total energy consumption of autos in New York in 1976, but will retrieve many others as well. The reason is that this total is broken down by SECTOR, USE1, USE2, INCOME, CARRIER and RANGE (see Method 310). All these breakdown figures will be retrieved as we11, since they fall under the heading of auto energy use in New York in 1976. For instance, a figure for commercial autos other than common carriers operating in New York in 1976 will appear, as will a figure for the intercity business use of household autos in New York in 1976 by families with incomes between $\$ 10,000$ and $\$ 12,000$, and so on. Let us suppose, then, that you want to see only the total New York figure along with its breakdown by SECTOR. In this instance the following command will suffice:

R SECTOR, ENERGY, EUNIT W MODE1 EQ AUTO AND STATE EQ NY AND YEAR EQ 76; AND RANGE EQ ALL AND CARRIER EQ ALL

(Note that a semicolon must be used to indicate a continuation of the command on the next line.) Since "ALL" is synonymous with "total," the clauses RANGE EQ ALL and CARRIER EQ ALL serve to exclude all figures broken down by RANGE or by CARRIER.' The output might be,

$\begin{array}{llll}\text { HOUSEHOLD } & 3456 & \text { BILLION } & \text { BTU } \\ \text { COMMERCIAL } & 2345 & \text { BILLION } & \text { BTU } \\ \text { GOVERNMENT } & 1234 & \text { BILLION } & \text { BTU } \\ \text { ALL } & 7035 & \text { BILLION } & \text { BTU }\end{array}$

In this case it is not necessary to add the clauses USE1 EQ ALL, USE2 EQ ALL and INCOME EQ ALL, since these breakdowns are provided for intercity travel only. In general, when more numbers than expected are returned, there are two ways to correct the situation. One is to consult documentation of the database, such as the method descriptions in this . report, to see which extra conditions must be imposed to remove unwanted breakdowns (if they are in fact unwanted). Another is to reissue the command while asking for more data items to be printed out, in order to 
see which unwanted breakdowns are being provided. For example, the above command might have been augmented with requests for SECTOR, USE1, etc., on a trial and error basis, to discover which of these attributes vary among the data retrieved.

EQ is not the only relation that can be used in a WHERE clause. There are älso

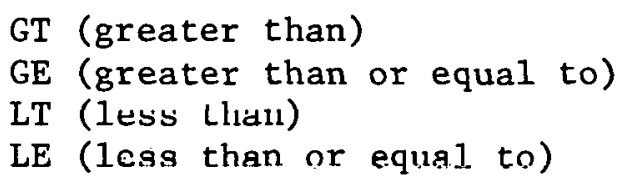

These relations can of course be used only with attributes with numeric values. For example, if you want to know which states used more than a trillion ( 1000 billion) btu's of energy to run taxis in 1976, you can say

R STATE, ENERGY, EUNIT W YEAR EQ 76 AND SECTOR EQ COMMERCIAL AND;

MODE1 EQ AUTO AND CARRIER EQ COMMON AND ENERGY GE 1000

\subsubsection{The TYPE Command}

The TYPE command specifies how many of the data retrieved are to be printed on the terminal. By itself:

TIPE

the command causes all retrieved data, no matter how many, to be printed. It is safer to specify a maximum number of lines you want to see in response to any given RETRIEVE command, such as: TYPE 35

If the number of lines is set at 25 or greater, "values missing" messages generated by the SUM command will alsso be printed on the terminal (see Sec. 7.1.5). Regardless of how many lines of data or how many "values missing" messages are printed on your terminal, all the data retrieved and all the missing value messages generated are recorded in the output file.

\subsubsection{The Help Command}

The HELP command provides you with instant information about how to use DBRS. By itself, HELP

the command causes a list of the permissible commands and their formats to be printed on your terminal. To obtain a list of the attributes recorded in the data base you are now using (MODE, YEAR, etc.), type HELP *

To obtain a list of the possible values of any given attribute, such as MODE, type the command

HELP MODE 
If the attribute specified is numeric, as is ENERGY, a message to that effect will be the response. (The numeric attributes in the transportation data base are YEAR, METHOD, QUALITY, FUELUSE and ENERGY; the rest take on predefined values.)

\subsubsection{The EXIT Command}

\section{EXIT}

When you are done; type

and the execution of the DBRS program will stop.

\subsubsection{The SUM Command}

The SUM command is a powerful instruction that computes all necessary sums over breakdowns in order to deliver a specified aggregate figure. It is not needed for the transportation data base in its delivered form, since all sums that can be derived from the available data are already recorded in the data base and can be examined with the RETRIEVE command (see Method 900). The SUM command is useful for data bases in which not all sums are recorded. Although the computer implementation of the summation algorithms appears to be working correctly, it is yet an experimental implementation and may run prohibitively slow when the data base is very large or if there are more than a dozen nonnumeric attributes.

To see how the SUM command works, suppose that total 1976 energy use figures for all states except New York are recorded for each fuel. Suppose further that the total New York energy use figures, by fuel, in the commercial and in the household sectors are recorded. The government sector totals are not recorded, by the figures for civilian and for military uses are recorded by fuel. The command SUM ENERGY WHERE YEAR EQ 1976

will compute a national energy use figure as follows: for each fuel it will add the civilian and military figures for New York to get a government sector total for that state; then for each fuel it will add up the energy used in the three sectors in New York; then for each fuel it will add up the energy consuption of the states; finally it will add up the energy consumption for each fuel, yielding a national total for 1976. The algorithm that accomplishes this is recursive in nature and is completely general, so that . it can accommodate any request and any configuration of recorded data, however complex may be the pattern of missing aggregations. It also prints a complete list of all values that would be needed to form a complete sum but that were missing in the data base; these missing value messages are triggered by missing-data flags in the data base (see Sec. 6.3).

\subsubsection{The INPUT Command}

The INPUT command switches you to another data base. To start retrieving data from the database FUEL, for instance, type INPUT FUEL 


\subsubsection{The OUTPUT Command -}

The OUTPUT command switches you to another output file. If you want to start sending the retrieved data and sums to file NEWOUT, for instance, type OUTPUT NEWOUT

\subsubsection{The KEEP Command}

The KEEP command, added to DBRS as a convenience in making tables at ORNL, saves retrieved numbers of your choice in a special output file that contains numbers only and omits all the identifying information that is recorded in the main output file. It works like this. If the last SUM or RETRIEVE command was a SUM command, the resulting sum ("grand total") is recorded in the special file. If the last SUM or RETRIEVE command was a RETRIEVE command, then the last numeric value in each 1ine of output is recorded in the special file, one number per line. For instance, if the response to a RETRIEVE command is

$\begin{array}{llrll}\text { AUTO } & \text { HOUSEHOLD } & 1234 & \text { BILLION } & \text { BTU } \\ \text { BUS } & \text { HOUSEHOLD } & 0 & \text { BILLION } & \text { BTU } \\ \text { TRUCK } & \text { HOUSEHOLD } & 123 & \text { BILLION } & \text { BTU } \\ \text { CYCLE } & \text { HOUSEHOLD } & 234 & \text { BILLION } & \text { BTU }\end{array}$

then if the KEEP command is used, the following will appear in the special output file:

\section{4 \\ 123 \\ 234}

These numbers will be right-justified in a field eleven characters wide. In the current implementation, at most 100 numbers can be saved with each KEEP command.

The name of the special output file is a matter of local implementation. At ORNL, the filename is the main output file name, minus its extension (if any), plus the extension .N. For example, if the main output file is OUT.DAT, the special output file would be OUT.N.

\subsection{How to Install It}

The following pointers on the installation of DBRS are intended only as a isupplement to Sec. III of DBRS Manual: User's Guide to DBRS Version 1.3, by Derrel1 Foster, Niket Patwardhan and Danny Johnson. 


\title{
7.2.1 Adapting the Programs to the Local Computer
}

Three FORTRAN programs are necessary for the operation of DBRS. Other than DBRS itself, they are BUILDS, which builds a schema file describing the format of the data base, and BUILDI, which builds an index. (Note that the data base must be sorted before using BUILDI.) These programs were originally developed on a DEC-1099 computer at Vanderbilt University and are currently operating on another DEC-10 machine at ORNL. Consequently the installation of the programs on some computer of another make will require several changes, especially with respect to input and output. Although DBRS was written so as to be as transportable as possible, complete compatibility with other machines is impussible, and its installation will have to be the responsibility of a computer programmer familiar both with FORTRAN and with his local system.

Practically all the necessary changes in DBRS are likely to be confined to subroutine OPENF, which opens files and constructs file names, and subroutine INIT, which reads the schema file and does similar housekeeping chores. These subroutines, written with the features of FORTRAN-10, have been especially well documented in order to ease any rewriting that may be necessary. One change that may affect users is a redefinition of the convention for naming the schema, index, data and output files.

Another necessary change, if DBRS is installed on other than a DEC-10 computer, is replacement of all INCLUDE 'COMMON.DGJ' statements with the contents of file COMMON.DGJ, which contains most of the declarations and common statements. FORTRAN-10 automatically makes this substitution, but such an inclusion feature may not be available on other machines.

The remainder of DBRS is deliberately written in universal FORTRAN and should require few alterations. The supporting programs, BUILDS and BUILDI, will require some modifications to accommodate the local input/ output and file naming conventions. Questions concerning the installation of DBRS may be directed to

\author{
John Hooker \\ phone (615) 574-5967, FTS 624-5967 \\ Transportation Energy Group \\ Oak Ridge National Laboratory, Mail Stop G-22 \\ P.O. Box X \\ Oak Ridge, Tennessee 37830
}

\subsubsection{Creating the Data Base}

The instructions on Sec. III of the DBRS manual should suffice, but for two caveats. It is that the data and schemid files are read, by DBRS, with random access read statements of the form $\operatorname{READ}(1 \mid \mathrm{k}, 1.23) \ldots$ and 
consequently may need to be written with statements of the same form. In particular, the DEC-10 system at ORNL requires that records to be randomIy accessed be recorded by writing the records with a WRITE $(1 \notin n, n n) \ldots$ statement. Failure to do so wrecks any attempt to access the file randomly, and editing of these files with TECO or sOS destroys any alignment that may have existed beforehand.

A second caveat is that retrieval may be slow if the entire database is placed on line, depending on the efficiency of the local equipment. It may prove convenient to split the data into several data sets, perhaps one for each mode, to speed retrieval.

\subsubsection{The SUM Algorithm .}

Since the implementation of the SUM command in DBRS is not as well documented in the source code as that of the other commands, the following description of its operation, written by Niket Patwardhan, is provided.

First, the retrieval routines are called with a range specification that would include all records that could be useful in generating the sum. Each attribute of any record retrieved, then, must have a value within the range specified for that attribute. If a value for an attribute is specified in the SUM command, then the allowed range for that attribute consists simply of that specified value; otherwise, any value is permitted. The record showing a zero for a given attribute, if it exists, always precedes records showing other values. When a record with a zero entry for a given attribute is retrieved, the range specification for that attribute is narrowed to include zern only be setting a sum found flag for that attribute. I'he retrieval rnitines will then not retrieve any record that is included in this sum. This takes care of multiple counting.

The sum found flag for an attribute is reset to false whenever a record is retrieved that has a different value for a higher-level attribute, so that the full range is again used for this attribute. An example would help at this stage. Consider a data base with three nonnumeric attributes, each of which can take on one of three values besides zero. The records contained in the database are shown below.

$$
\begin{array}{lll}
0 & 1 & 1 \\
0 & 1 & 2 \\
0 & 1 & 3 \\
0 & 2 & 0 \\
0 & 2 & 1 \\
0 & 3 & 1 \\
1 & 3 & 0 \\
1 & 3 & 1 \\
1 & 3 & 2 \\
2 & 3 & 0
\end{array}
$$


Let us say we want to sum over all attributes. Now when the summing routine picks up the first record, since the zero has been found for attribute 1 , it chops the search range for this attribute to zero alone. The record is then passed to the CHECK routine, which notes missing items. (It learns which values are missing by consulting the value codes in the schema file.). On this pas's these records are used in computing the sum and are also the ones retrieved:

$\begin{array}{lll}0 & 1 & 1 \\ 0 & 1 & 2 \\ 0 & 1 & 3 \\ 0 & 2 & 0 \\ 0 & 3 & 1\end{array}$

As can be seen record 0-3-1 is also retrieved. CHECK generates a request for these sums: $0-3-2$ and $0-3-3$. The process is then restarted with 0-3-2 as a search criterion. The records retrieved this time are

\section{2 \\ $\begin{array}{lll}2 & 3 & 2\end{array}$ \\ 332}

The 0-3-3 search criterion retrieves no records and so is dumped on the missing value stack, and the process ends.

The flags controlling the process are implemented in a very simple fashion. When a missing value, missing record or no sum flag is encountered in the data base, the retrieved flag is of course not added to the total, and one of three actions is taken. (1) If the flag is a no-sum flag, the record.is passed to the CHECK routine, thus inhibiting the generation of a missing value request. (2) If it is a missing value flag, the record is dumped on the missing value stack and is also passed to the check routine to prevent the calculation of the sum. (3) If it is a missing record flag, the record is ignored, and the sum-found flag is not set. 


\section{CHAPTER 8. THE TAPE FORMATS}

The transportation energy use data documented in this report are submitted on two tapes having two different formats. The two tapes contain exactly the same energy and fuel consumption data, categorized in essentially the same way. One, however, uses a format and coding scheme that has been convenient for use at ORNL, and the other is recorded with a format and coding scheme more convenient for the Energy Information Administration (EIA).

One principal difference is that the EIA tape breaks down an energy consumption estimate by year within a single record, whereas the ORNL devotes a separate record to each year. That is; the EIA tape provides space for several years' data on a single record, whereas the ORNL tape provides space for only one year on a single record.

Another difference is more subtle but more important. The ORNL tape is coded in such a way that all the categories in one breakdown that are subsumed by the categories in another breakdown are given distinct codes. For instance, the MODEl categories are all subcategorles of particular MODE categories, and all the MODE1 categories are given distinct codes. The EIA tape, however, provides subcategory codes that are distinct only among the subcategories of one particular subsuming category. For instance, the EIA tape assigns both the light rail subcategory of the RAIL category and the TRUCK subcategory of the HIGHWAY category the code 1 , while the ORNL assigns these categories the distinct codes 3 and 5, respectively. Consequently one cannot retrieve energy use figures for a subcategory from the EIA tape by specifying the subcategory code alone; he must specify the codes of the subsuming category (or categories, if there are more than one level of subsumption) as well. To emphasize this, all four levels of the MODE category codes, for instance, are concatenated and denoted with a single name, MODE, in the EIA tape, rather than given the separate names MODE, MODE1, MODE2 and MODE3. One can retrieve energy use estimates for trucks from the ORNL tape by specifying MODEl $=5$, but to retrieve such estimates from the EIA tape he must specify MODE $=3100$ (where the 3 = highway, the 1 = truck under highway, and the zeros indicate that no further breakdown by mode is destred). The same principle holds for the SECTOR/CIVMIL, FUEL/FUEL1 and USE/USE1/USE2/USE3 families of breakdowns.

As a result of these differences the EIA tape is somewhat more compact, while the ORNL tape is better suited to certain types of retrieval. The user need only choose the tape best suited to his purposes. The format and coding scheme for each tape are laid out in the followlng sectiuns. 
Both tapes are 9-track, 1600 bpi tapes with the IBM standard label. The EIA tape has the volume serial number JNHOOl, and the ORNL tape the serial number JNH002. The dataset on the former is given the dataset name ENDUSE.TRNSPORT.EIA.FEB80 and on the latter the name ENDUSE.TRNSPORT . ORNL.: FEB80.

\subsection{The EIA Tape}

'The tormat and cuding scheme of the Fit tape are as follows.

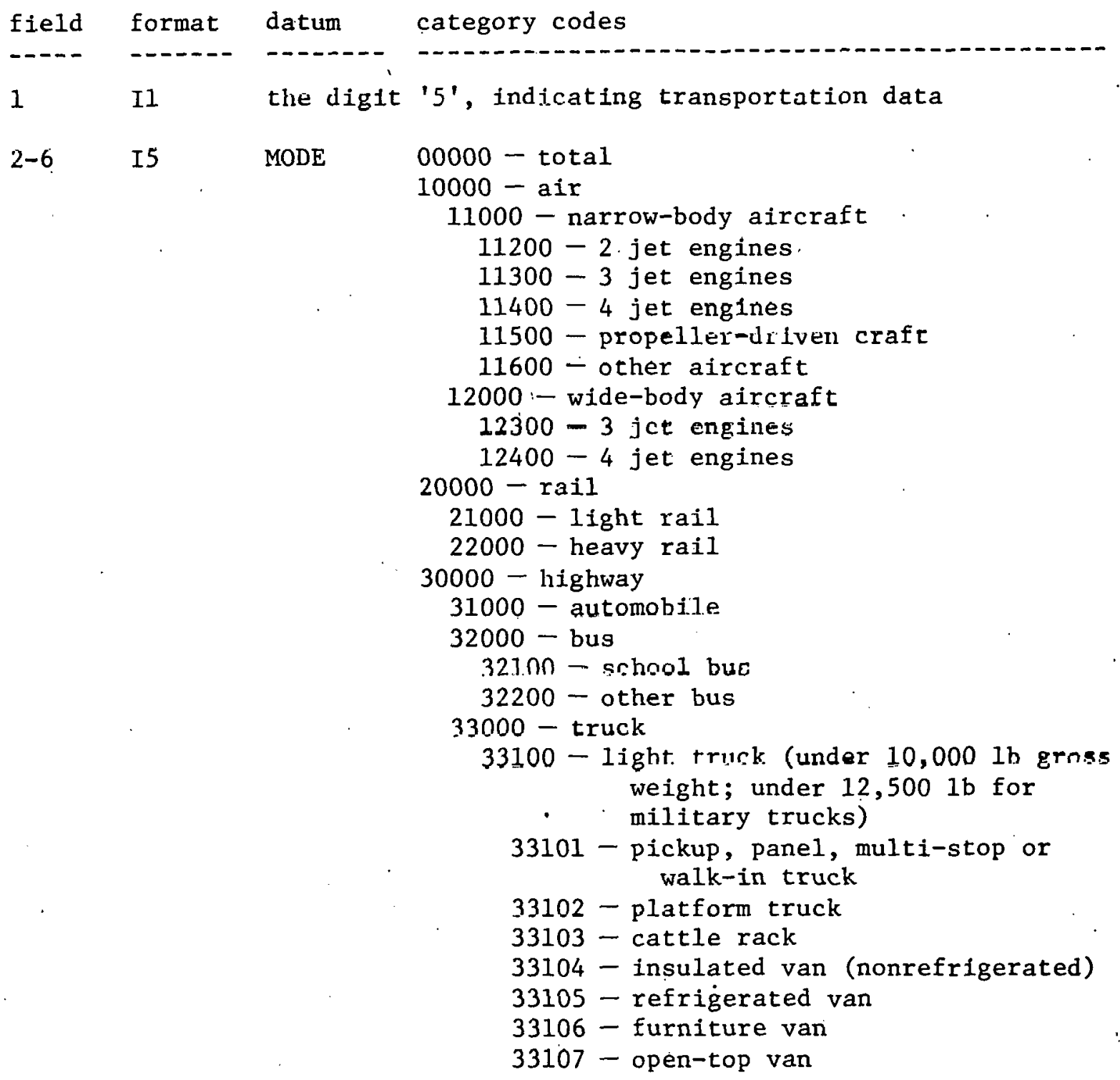




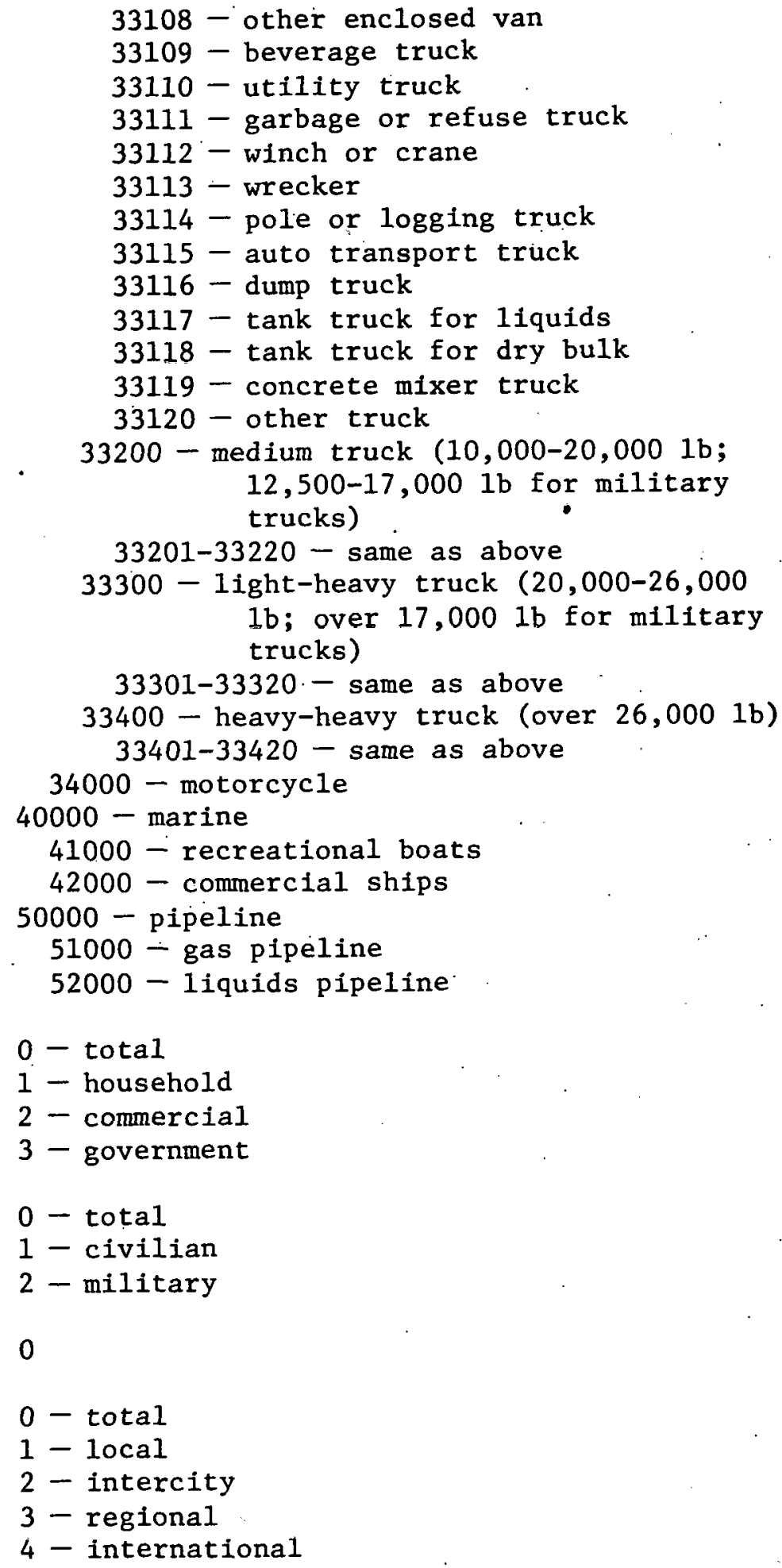


10

II

CARRIER

$0-$ total

1 - common carrier

2 - other than a common carrier

$11-15$

I5

- USE

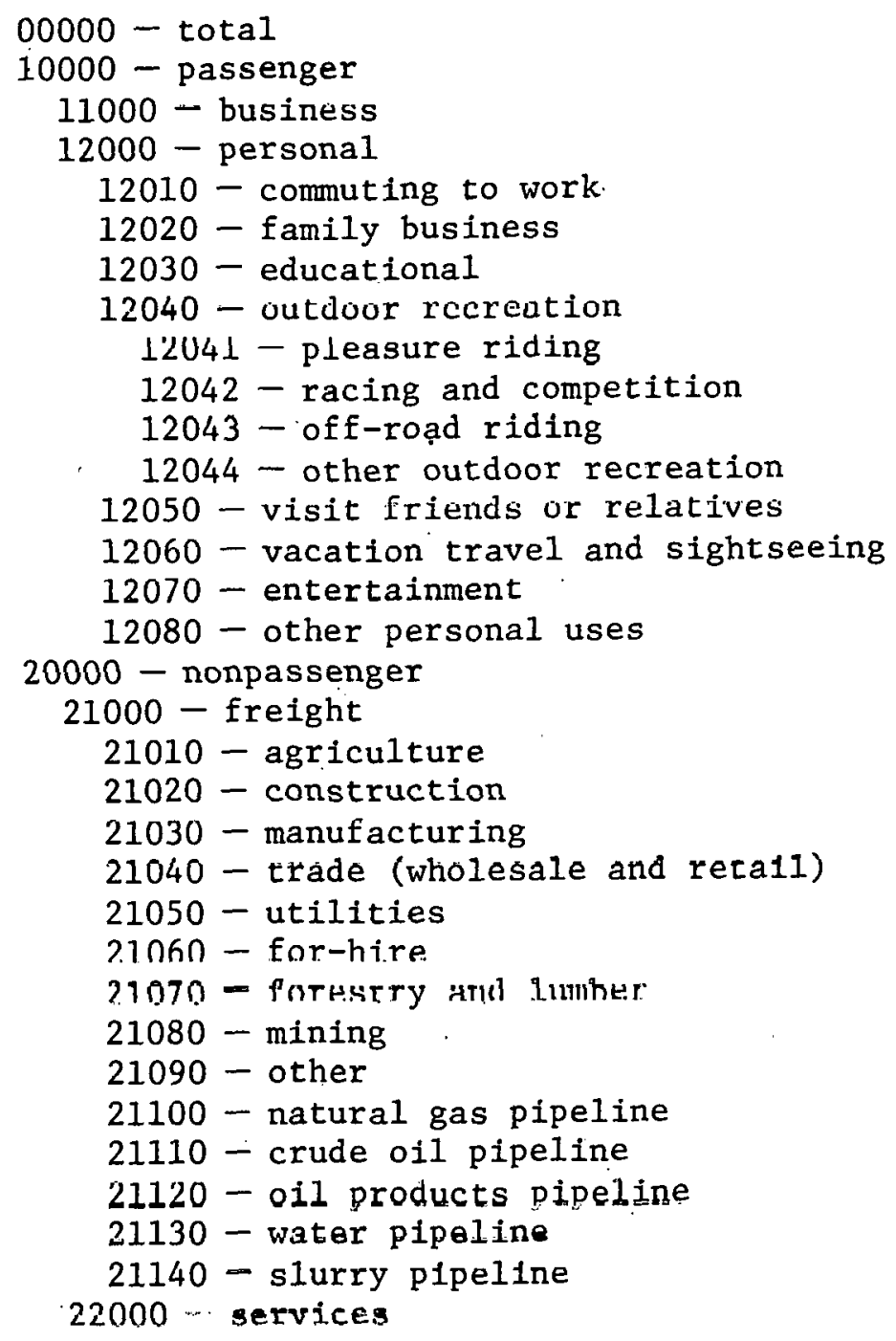

16-17 I2 FUEL $00-$ total

10 - coal (not used)

20 - motor gasoline

30 - aviation gasoline

40 - jet fuel

41 - naphtha-type jet fuel

42 - kerosine-type jet fuel

50 - distillate (diesel) oil

60 - residual oil

70 - natural gas

80 - electricity 


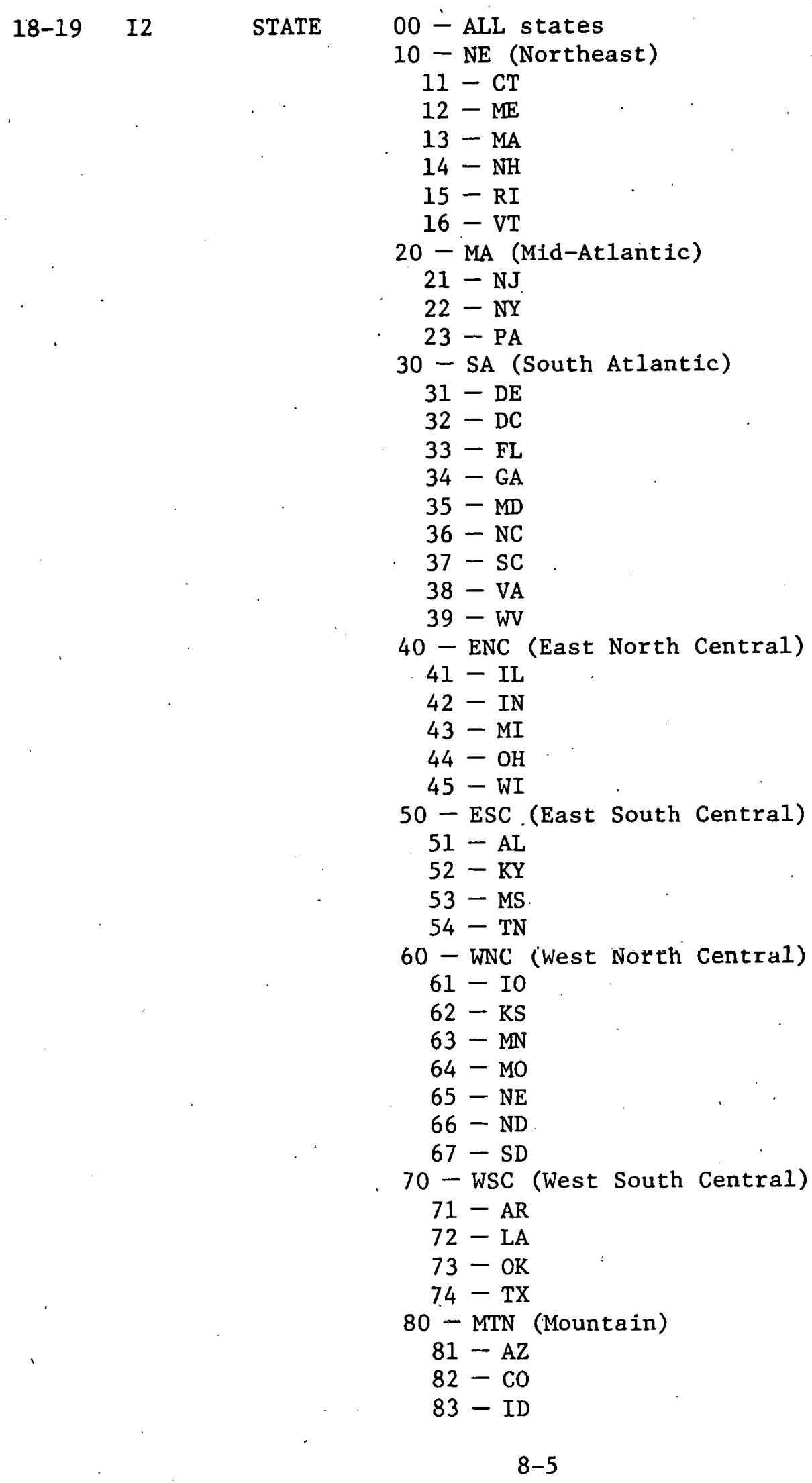




$$
\begin{aligned}
& 84-\mathrm{MT} \\
& 85-\mathrm{NV} \\
& 86-\mathrm{NM} \\
& 87-\mathrm{UT} \\
& 88-\mathrm{WY} \\
& 90-\mathrm{PAC} \text { (Pacific) } \\
& 91-\mathrm{AK} \\
& 92-\mathrm{CA} \\
& 93-\mathrm{HA} \\
& 94-\mathrm{OR} \\
& 95-\mathrm{WA}
\end{aligned}
$$

20 I1 CERIIFICATE 0 - total

1 - certificated air carrier

2 - other air carrier

24-131 12 I9 ENERGY energy use in 1967, 68, ...78 respectively, in billions of Btu; a blank fleld indicates missing data

132-239 1219 FUELUSE fuel use in $1967,68, \ldots, 78$ respectively, in the appropriate units (see Sec. 2.1); a zero indicates either that the datum is missing or that the corresponding energy figure covers more than one fuel

$240-251 \quad 12 \mathrm{II}$

QUALITY

data quality numbers for $1967, \ldots, 78$ respectively; a zero indicates that the cursespunding energy datum io not supplied

\subsection{The ORNL Tape}

The format and coding of the ORNL tape are as follows.

$\begin{array}{llll}\text { fleld } & \text { format } & \text { datum } & \text { catcgory codes } \\ 1-2 & \text { I2 } & \text { YEAR } & 67 \text { for } 1967,68 \text { for } 1968 \text {; etc. } \\ 3 & \text { I1 } & \text { MODE }, \begin{array}{l}0 \\ \end{array} & \\ & & - \text { total all } \\ & 2-\text { rail } \\ & 3-\text { highway }\end{array}$

*All numbers are right-justified in their respective fields, with no leading zeros. 


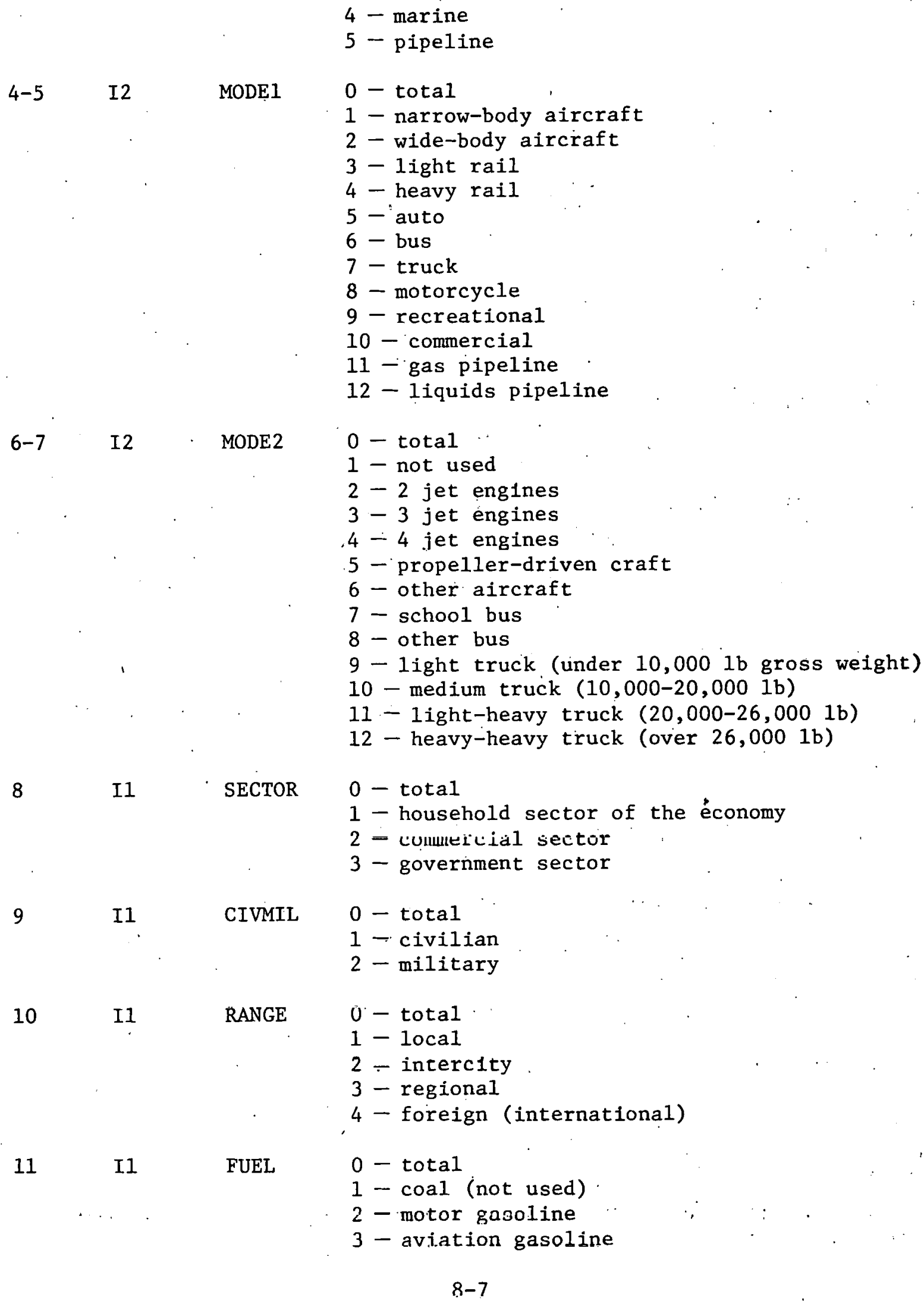

RANGE 0 - total

1 - local

2 - incerc1ty

3 - regional

4 - foreign (international)

11 II

FUEL

$$
\begin{aligned}
& 0 \text { - total } \\
& 1 \text { - coal (not used) } \\
& 2 \text { - motor gasoline } \\
& 3 \text { - aviation gasoline }
\end{aligned}
$$




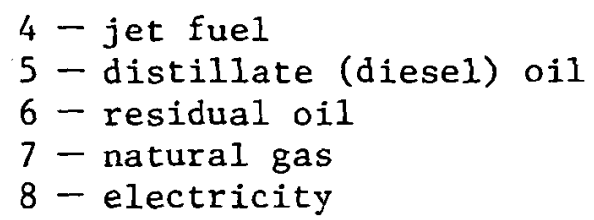

12

II

FUEL1 $\quad 0$ - total

1 - naphtha-type jet fuel

2 - kerosine-type jet fuel

13

II

USE

0 - total

1 - passenger

2 - nonpaoocnger

14

I1

USE1

0 - total

1 - business

2 - personal

3 - freight

4 - services

15-16 I2

USE2

$0-\operatorname{total}$

1 - commuting to work

2. - family business

3 - educational

4 - outdoor recreation

5 - visit friends or relatives

6 - vacation travel and sightseeing

7 enlerta1nment

8 - ullier personal

$y$ - not lised

10 - agriculture

11 - construction

12 - manufacturing

13 - tradc (wlulesale and recail)

14 - utilities

15 - for-hire

16 - forestry and lumber

17 - mining

18 - other

19 - Halural gas pipeline

20 - crude oil pipeline

21 - oil products pipeline

22 - water pipeline

23 - slurry pipeline

17

II

USE 3

0 - total

1 - pleasure riding

2 - racing and competition

3 - off-road riding

4 - other outdoor recreation 
CARRIER $0-$ total

1 - common carrier

2 - not a common carrier

19

I1

REGION

$$
\begin{aligned}
& 0 \text { - total } \\
& 1 \text { - Northeast } \\
& 2 \text { - Mid-Atlantic } \\
& 3 \text { - South Atlantic } \\
& 4 \text { - East North Central } \\
& 5 \text { - East South Central } \\
& 6 \text { - West North Central } \\
& 7 \text { - West South Central } \\
& 8 \text { - Mountain } \\
& 9 \text { - Pacific }
\end{aligned}
$$

$20-21 \quad$ I2

STATE

0 - total over region

FIPS alphabetic

11 - Connecticut

12 - Maine

code* code*

13 - Massachusetts

$09 \quad 07$

$23 \quad 20$

14 - New Hampshire

$25 \quad 22$

15 - Rhode Island

$33 \quad 30$

16 - Vermont

$44 \quad 40$

21 - New Jersey

$50 \quad 46$

22 - New York

$34 \quad 31$

23 - Pennsylvania

$36 \quad 33$

31 - Delaware

$42 \quad 39$

32 - District of Columbia $11 \quad 09$

33 - Florida $12 \quad 10$

34 - Georgia $\quad 13 \quad 11$

35 - Maryland $\quad 24 \quad 21$

36 - North Carolina $\quad 37 \quad 34$

37 - South Carollida $\quad 45 \quad 11$

38 - Virginia $\quad 51 \quad 47$

39 - West Virginia. $\quad 54 \quad 49$

41 - Illinois $\quad 17 \quad 14$

42 - Indiana $18 \quad 15$

43- Michigan $26 \quad 23$

44 - Ohio $39 \quad 36$

45 - Wisconsin $55 \quad 50$

51 - Alabama $\quad 0101$

*These state codes are often used in the input data sets and are reproduced here for the reader's convenience. The FIPS codes number 56 U.S. states, territories and possessivis alphabctically, while the "alphabet1c" codes number the 51 U.S. states a.lphabetically. 


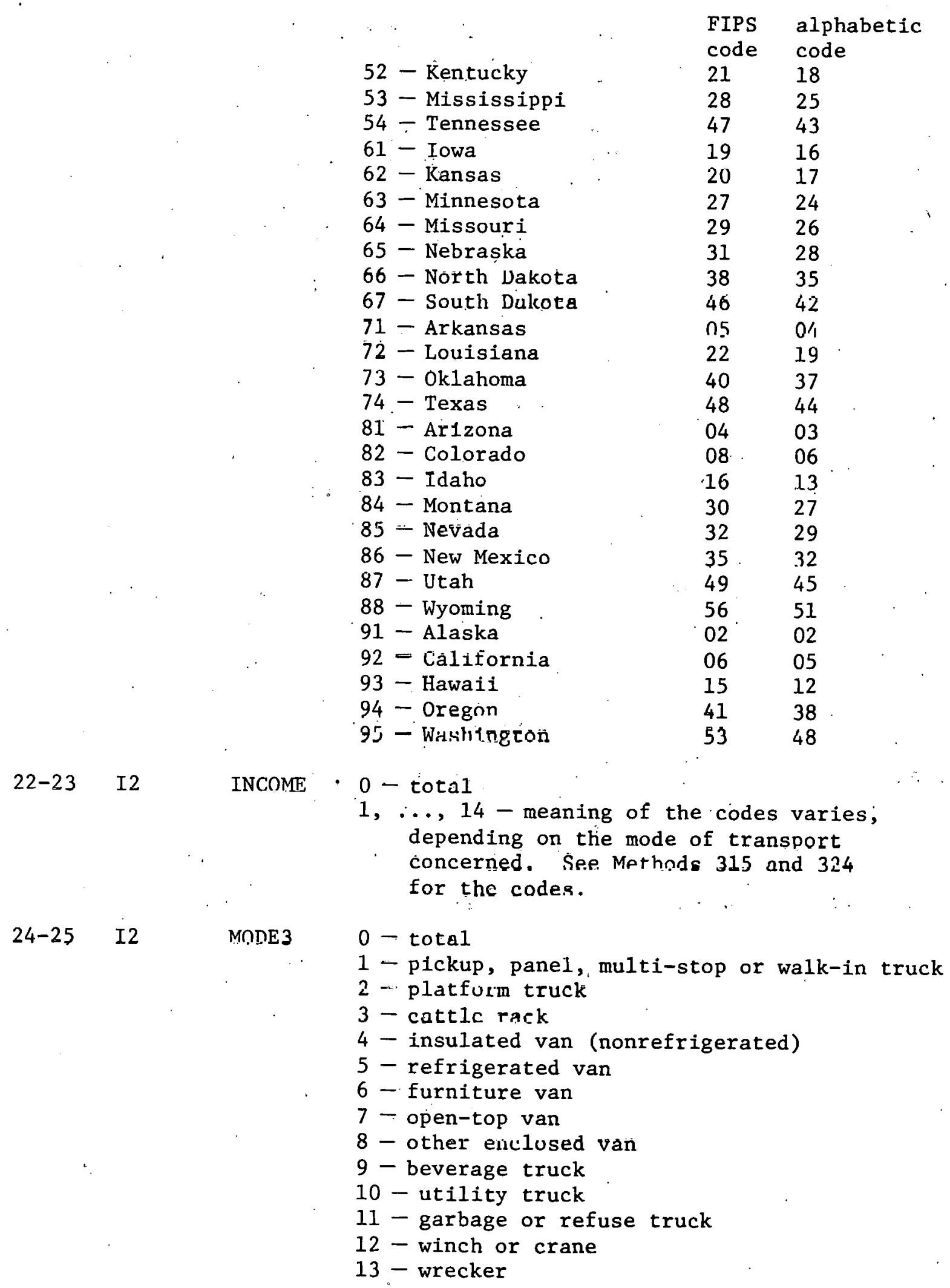




$$
\begin{aligned}
& 14 \text { - pole or logging truck } \\
& 15 \text { - auto transport truck. } \\
& 16 \text { - dump truck } \\
& 17 \text { - tank truck for liquids } \\
& 18 \text { - tank truck for dry bulk } \\
& 19 \text { - concrete mixer truck } \\
& 20 \text { - other truck }
\end{aligned}
$$

\begin{tabular}{|c|c|c|c|}
\hline $26-27$ & I2 & FUNIT & $\begin{array}{l}0 \text { - no fuel data provided (appears on records } \\
\quad \text { that represents sums over several fuels) } \\
10 \text { - thousands of barrels } \\
20 \text { - tons (not used) } \\
30 \text { - millions of cubic feet } \\
40 \text { - millions of kilowatt-hours }\end{array}$ \\
\hline 28 & I1 & EUNIT & 9 - billions of Btu \\
\hline 29 & I1 & QUALITY & $\begin{array}{l}1 \text { - less than } \pm 10 \% \text { error } \\
2 \text { - less than } \pm 25 \% \text { error } \\
3 \text { - less than } \pm 50 \% \text { error } \\
4 \text { - error unknown (see Sec. 2.2) }\end{array}$ \\
\hline $30-32$ & I3 & METHOD & $\begin{array}{l}\text { 3-digit number indicating the method used to } \\
\text { derive the data; see Chap. } 5\end{array}$ \\
\hline $33-35$ & I3 & CERT IFICATE & $\begin{array}{l}0 \text { - totai } \\
1 \text { - certificated air carrier } \\
2 \text { - other air carrier }\end{array}$ \\
\hline $36-45$ & I10 & FUELUSE & $\begin{array}{l}\text { fuel consumption } \\
\text { (a } 999999997 \text { indicates that the record } \\
\text { represents a sum over several fuels, so that } \\
\text { only an energy figure is provided) }\end{array}$ \\
\hline ;- & I10 & ENERGỴ & energy consumption, in billions of Btu \\
\hline
\end{tabular}


TABLE 1. 1A -- SIJMARY OF TBARSPORT ENEBGT USE,

BY IODE AND TYPE OP TRANSPORT, 1967-76

(PIRST OP TRO PAGES)

BNERGI OSE IN TRILLIONS OP ETV

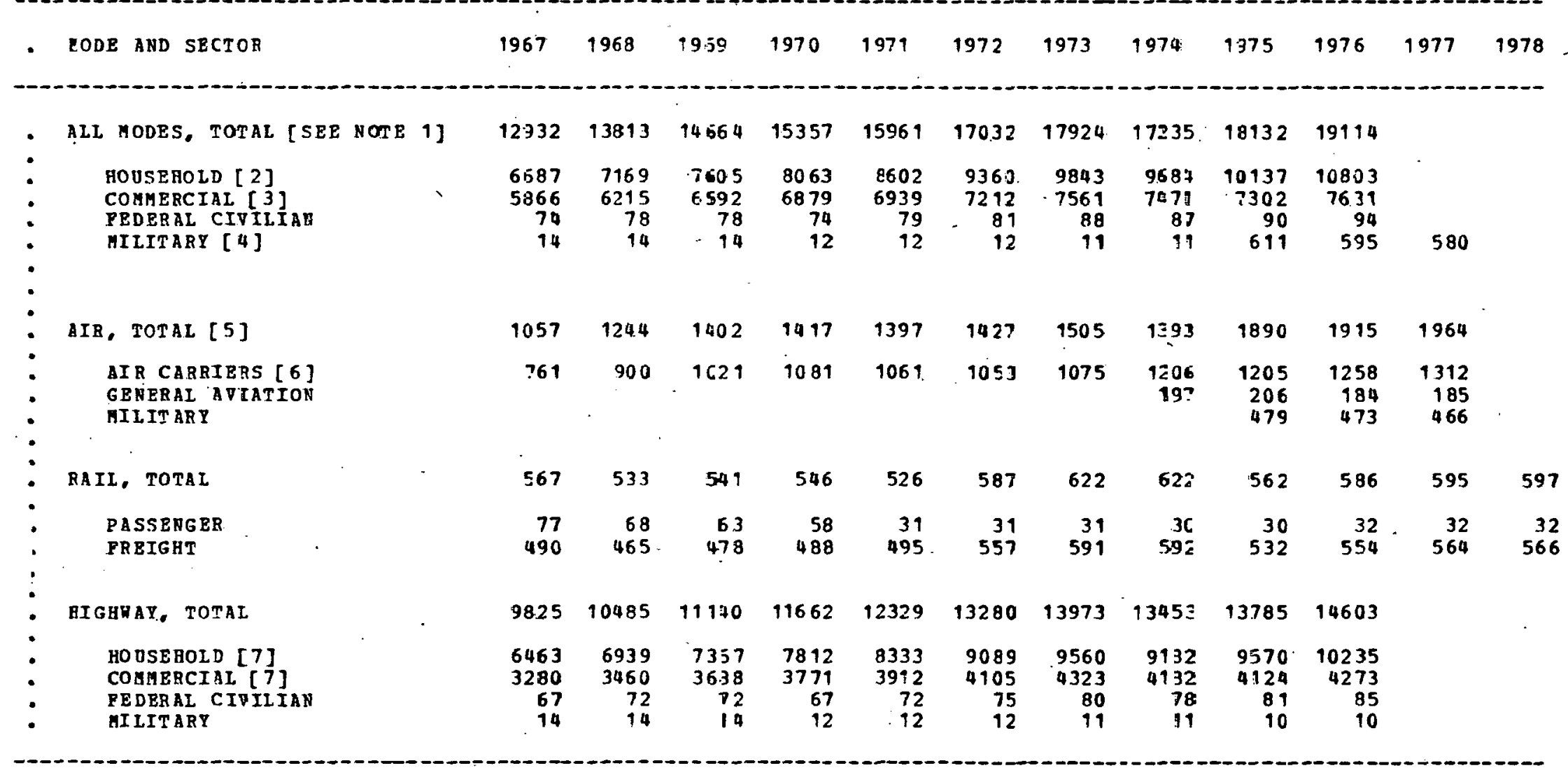

SCUFCES: SEE TABLES PERTAIHING TO $0^{\circ}$ NDITIDOAL MODES

ROT FS:

[1] 1967-74 FIGURES EXCIUDE ALI MIIITART CONSUMPTION EXCEPT AIGHRAT FUEIS.

[2] 1974-77 ESTIMATES INCLDDE RLI G3NERAI EOIAT TON BET 1967-73 ESTIAATES CMIT AIR TRAVEL. ALL ESTINATES IHCLODE HOOSEHOLD ADTOS AND TRTCKS, MOTORCYCLES. ARD RECREATIOBAI BOATS.

[3] I NCLODES AIR EARAIBRS, AIL RAIE, COAGEBCIAL ADTOS ARD TROCRS, COABEACIAL QUSES (INTERCITY AND TRANSTT), COMHEBCIAL SAIPPING AND PIPELINES.

[4] SHOHS HIGHAY ENERGY DSE ORL I IO 1967-74; SHOTS AL I BNERGY OSE. I NCL UDI NG THAT OP SHIPS. I 1975-77.

[5] 1967-74 FIGUR3S EXCLUDE GIIITARY FUEL OSE.

[6] 1967-73 ESTIHAT BS REPRESENT DOHESTIC OPERATIOQS OF 0.S. CERTIPICATED CARRIERS ONI $\mathrm{I}$.

[7] BERE, COHMERCTAL AUTOS IMCIODE TAXIS AND AOTOS IB PLEETS OP PCOR OR

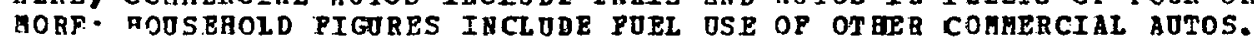

\section{SPE $=I$ AL RDTE:}

HERZ AND IT ALL SOBSEQTENT TABEES, IJSSES IN THE GENERATION ABD [ISTBIBDTIOV OF PLETT RICITY AEE NOT ACCOUNTED ROR RICI CISTER NOT ACCOUNT BD POR. DEL- VERED EC ECTRICITY IS REGISTERID. GENE RATION LOSSES. ABE RECORDBE IN THE END OSE ENERGY CONSD APTIOH DATA EASE AS PART OP THE :ONSUAPTION OF UTILITIES. 
TABL B 1. 1B -- SO MHARY OP TRABSPORT EREBGY OSE,

BY BODB AND TYPE OF TRABSPOBT, 1967-76

(LAST OF TRO PAGES)

BNERGY OSE IN TRILLIONS OP BTO

\begin{tabular}{|c|c|c|c|c|c|c|c|c|c|c|c|c|}
\hline ZODE AND SECTOR & 1967 & 1968 & 1969 & 1970 & 1971 & 1972 & 1973 & 1974 & 1975 & 1976 & 1977 & 1978 \\
\hline ROTO, TOTAL & 7048 & 7527 & 8010 & 8421 & 8891 & 9586 & 10035 & 9650 & 9980 & 10594 & & \\
\hline $\begin{array}{l}\text { HOOSEHOLD [ }[]] \\
\text { COUHERCIAL }[7]\end{array}$ & $\begin{array}{l}5980 \\
1060\end{array}$ & $\begin{array}{l}6401 \\
1117\end{array}$ & $\begin{array}{l}6772 \\
1229\end{array}$ & $\begin{array}{l}7162 \\
1249\end{array}$ & $\begin{array}{l}7699 \\
1263\end{array}$ & $\begin{array}{l}8292 \\
1285\end{array}$ & $\begin{array}{l}8696 \\
1330\end{array}$ & $\begin{array}{l}8305 \\
1334\end{array}$ & $\begin{array}{l}8639 \\
1330\end{array}$ & $\begin{array}{l}9221 \\
1362\end{array}$ & & 8 \\
\hline FEDERAL CIVILIAN & 6 & 7 & 7 & 7 & 7 & 7 & 8 & 8 & 9 & 9 & & \\
\hline UILITARY & 2 & 3 & 3 & 2 & 2 & 2 & 2 & 2 & 2 & 2 & 2 & \\
\hline $\begin{array}{l}\text { BUS, TOTAL } \\
\text { COHMERCIAL }\end{array}$ & 125 & 127 & 123 & 122 & 120 & 119 & 124 & 126 & 134 & 141 & & \\
\hline $\begin{array}{l}\text { (INTERCITY AND TRANSIT) } \\
\text { PEDERAL AQD SCHOOL }\end{array}$ & $\begin{array}{l}86 \\
37\end{array}$ & $\begin{array}{l}85 \\
41\end{array}$ & $\begin{array}{l}81 \\
40\end{array}$ & $\begin{array}{l}80 \\
40\end{array}$ & $\begin{array}{l}76 \\
43\end{array}$ & $\begin{array}{l}75 \\
43\end{array}$ & $\begin{array}{l}77 \\
46\end{array}$ & $\begin{array}{l}81 \\
45\end{array}$ & $\begin{array}{l}86 \\
47\end{array}$ & $\begin{array}{l}89 \\
59\end{array}$ & & \\
\hline UIITTARY & 2 & 1 & 1 & 1 & 1 & 1 & 1 & 1 & 1 & 1 & 1 & \\
\hline TROCK, TOTAL & 2642 & 2819 & 2995 & 3906 & 3300 & 3555 & 3791 & 3637 & 3633 & 3830 & & \\
\hline $\begin{array}{l}\text { HOOSEBOLD [8] } \\
\text { COMHEQCIAL [8] } \\
\text { PEDERAL CIVELIAN } \\
\text { MILITART }\end{array}$ & $\begin{array}{r}473 \\
2134 \\
25 \\
10\end{array}$ & $\begin{array}{r}527 \\
2258 \\
24 \\
10\end{array}$ & $\begin{array}{r}583 \\
2378 \\
25 \\
10\end{array}$ & $\begin{array}{r}636 \\
2441 \\
20 \\
9\end{array}$ & $\begin{array}{r}697 \\
2572 \\
22 \\
9\end{array}$ & $\begin{array}{r}777 \\
2745 \\
25 \\
8\end{array}$ & $\begin{array}{r}841 \\
2916 \\
26 \\
8\end{array}$ & $\begin{array}{r}837 \\
2767 \\
26 \\
8\end{array}$ & $\begin{array}{r}892 \\
2708 \\
25 \\
8\end{array}$ & $\begin{array}{r}975 \\
2822 \\
26 \\
8\end{array}$ & 9 & ' \\
\hline $\begin{array}{l}\text { HOTORCYCIE [9] } \\
\text { (HOUSEHOLD ONIT) }\end{array}$ & 10 & 11 & 12 & 15 & 18 & 20 & 23 & 40 & 39 & 39 & & \\
\hline EARINE, TOTAL & 833 & 886 & 873 & 929 & 885 & 890 & 1020 & 1023 & 1121 & 1287 & 1415 & \\
\hline $\begin{array}{l}\text { RECREATIONAI } \\
\text { COAMERCIAL }\end{array}$ & $\begin{array}{l}224 \\
609\end{array}$ & $\begin{array}{l}230 \\
657\end{array}$ & $\begin{array}{l}238 \\
635\end{array}$ & $\begin{array}{l}250 \\
679\end{array}$ & $\begin{array}{l}268 \\
617\end{array}$ & $\begin{array}{l}271 \\
619\end{array}$ & $\begin{array}{l}283 \\
737\end{array}$ & $\begin{array}{l}306 \\
717\end{array}$ & $\begin{array}{l}361 \\
760\end{array}$ & $\begin{array}{l}384 \\
904\end{array}$ & $\begin{array}{r}409 \\
1006\end{array}$ & \\
\hline EIPELINE, TOTAL & 650 & 665 & 708 & 803 & 824 & 848 & 804 & 744 & 652 & 615 & 599 & \\
\hline $\begin{array}{l}\text { GAS PIPELINE } \\
\text { LIQUIDS PIPELINE, TOTAL } \\
\text { CRODE OIL [10] } \\
\text { OIL PRODOCTS [10] } \\
\text { YATER[ } 10] \\
\text { COAL SIDRRY }\end{array}$ & $\begin{array}{r}608 \\
42 \\
15 \\
15 \\
12 \\
0\end{array}$ & $\begin{array}{r}623 \\
42 \\
15 \\
15 \\
12 \\
0\end{array}$ & $\begin{array}{r}666 \\
42 \\
15 \\
15 \\
12 \\
0\end{array}$ & $\begin{array}{r}761 \\
42 \\
15 \\
15 \\
12 \\
0\end{array}$ & $\begin{array}{r}781 \\
43 \\
15 \\
15 \\
12 \\
1\end{array}$ & $\begin{array}{r}805 \\
43 \\
15 \\
15 \\
12 \\
1\end{array}$ & $\begin{array}{r}761 \\
43 \\
15 \\
15 \\
12 \\
1\end{array}$ & $\begin{array}{r}701 \\
43 \\
15 \\
15 \\
12 \\
1\end{array}$ & $\begin{array}{r}609 \\
43 \\
15 \\
15 \\
12 \\
1\end{array}$ & $\begin{array}{r}572 \\
43 \\
15 \\
15 \\
12 \\
1\end{array}$ & $\begin{array}{r}556 \\
43 \\
15 \\
15 \\
12 \\
1\end{array}$ & \\
\hline
\end{tabular}

NCTES:

[7] SEE PREVIOUS PAGR.

[ 9 ] SEE TABLE 7.1 FOR A DEFINITION OF HOJSEBOLD AND COUHERCI AL TROCK ING.

967-74 PIGURES BEPRESENT REGISTERED HOTORCYCLBS ONLY. 
TABLE 1. $2 A--$ SU MEARY OZ TRANSPORT ENEBGY OSE, ।

BY $O O D E$ BT POBL TYPE

(PIR ST OP TAREE PAGES)

PJEL USE IN UILLIONS OP BBL, OR BILLICNS OP RAB OR CUBIF FEZT

POLLORBD $B T$ RB BRGY OSZ IN TRILLIOXS OF BTO

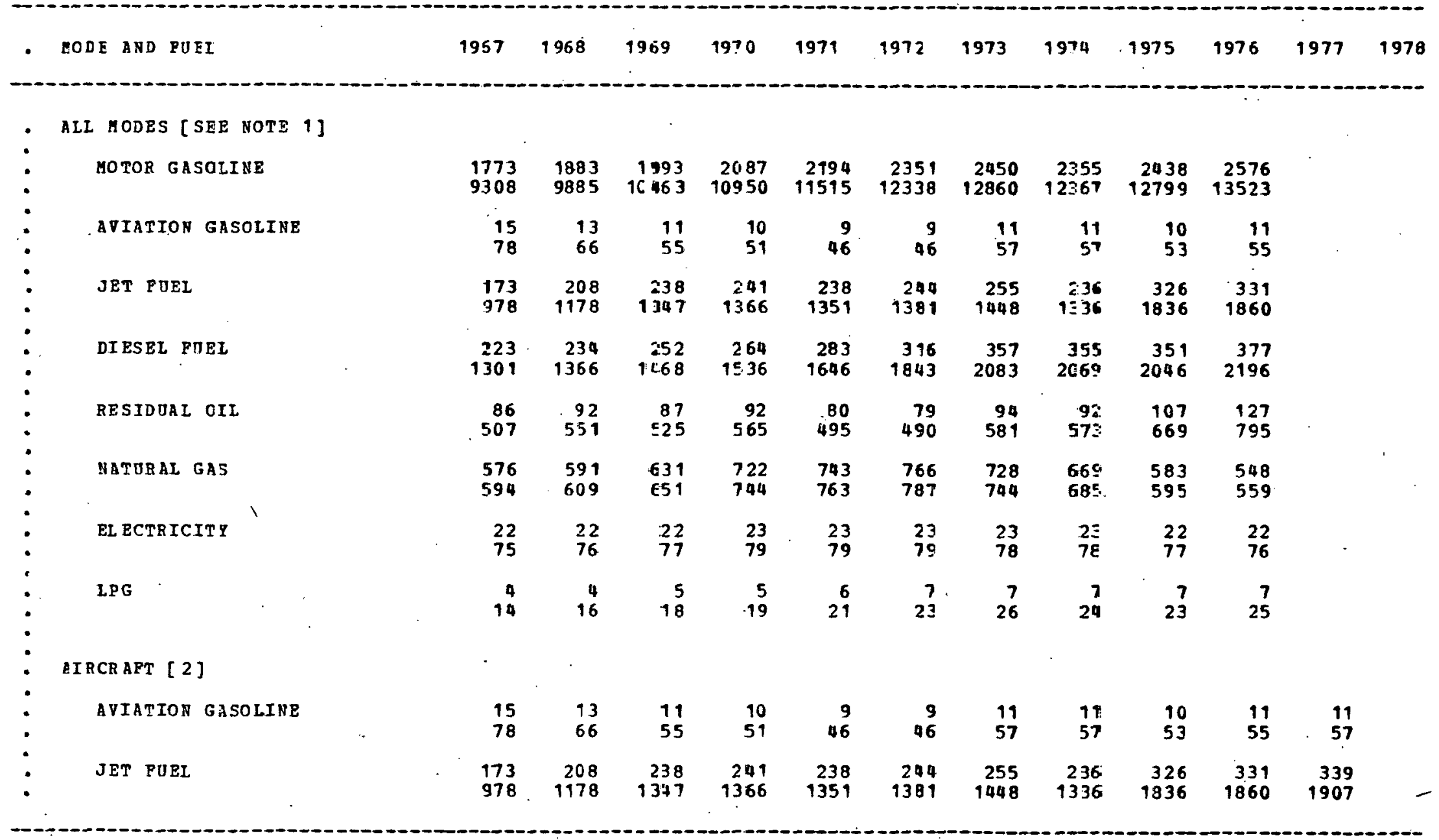

SOOECES: SEE TABLES PERTAIEING TO IRDIVIDOAL MODES.

[1] 1967-74 FIGOEES EXCLODE MIIITARY POEL OSE EXCEPT ?OB MILITABY AUTOS AND BUSES. ALI PIGURES OHIT FUEL CONSUMPTION BY EFDERAL CIVILIEA TROCRS.

[2] 1967-74 FIGOFES EXCLUDE IILITAE PUEL DSE. 
TABL B 1.2B -- SOUAART OF TRANSPORT EREBGY OSE.

BY

(SECOND OP THBEE PAGES)

FUEI OSE IN ELLIONS OP BBI, OR BILIIOHS OF RVB OR COBIC FEET

POLLORED BY ER BRGI DSE IN TRIILIONS OF BTU

- EODE AND POEL

1969197

EAIL

DIESEL POEL

RESIDUAL OII

RLECTRICITY

AOTC

MOTOR GASOIIRE

EOS

EOTOR GASOLIRE

BIESEL POBL

RL ECT RICITY

LPG

TROCK [3]

MOTOB GASOLINE

JIESEL FDEI

LPG

$\begin{array}{rrrrrrrrrrrr}89 & 84 & 86 & 88 & 86 & 97 & 103 & 103 & 93 & 98 & 99 . & 100 \\ 517 & 490 & 504 & 515 & 503 & 565 & 599 & 600 & 543 & 568 & 579 & 582 \\ 6 & 4 & 3 & 2 & 1 & 1 & 1 & 1 & 1 & 0 & 0 & 0 \\ 35 & 27 & 21 & 14 & 8 & 7 & 8 & 7 & 4 & 3 & 2 & 1 \\ 5 & 5 & 5 & 5 & 5 & 4 & 5 & 4 & 5 & 4 & 4 & 4 \\ 16 & 16 & 16 & 17 & 15 & 15 & 16 & 15 & 15 & 15 & 15 & 14 \\ & & & & & & & & & & & \\ 1343 & 1434 & 1526 & 1604 & 1694 & 1826 & 1912 & 1838 & 1901 & 2018 & & \\ 7048 & 7527 & 8010 & 8421 & 8891 & 9586 & 10035 & 9650 & 9980 & 10594 & 0 & 0\end{array}$

$\begin{array}{rrrrrrrrrr}9 & 9 & 9 & 9 & 9 & 9 & 9 & 9 & 9 & 10 \\ 45 & 48 & 47 & 46 & 48 & 47 & 49 & 46 & 49 & 52 \\ 12 & 12 & 11 & 11 & 11 & 11 & 11 & 12 & 13 & 14 \\ 68 & 68 & 64 & 64 & 62 & 62 & 66 & 79 & 76 & 79 \\ 3 & 3 & 3 & 3 & 3 & 2 & 2 & 3 & 3 & 3 \\ 9 & 9 & 9 & 9 & 9 & 8 & 8 & 9 & 9 & 9 \\ 1 & 1 & 9 & 1 & -1 & 1 & 0 & 0 & 0 & 0 \\ 5 & 3 & 3 & 3 & 2 & 2 & 1 & 0 & 0 & 0\end{array}$

$\begin{array}{rrrrrrrrrr}378 & 395 & 412 & 423 & 437 & 461 & 472 & 444 & 448 & 465 \\ 1986 & 2076 & 2161 & 2222 & 2296 & 2419 & 2476 & 2331 & 2355 & 2440 \\ 105 & 119 & 135 & 144 & 164 & 186 & 216 & 214 & 210 & 229 \\ 619 & 696 & 785 & 838 & 955 & 1082 & 1256 & 1249 & 1222 & 1332 \\ 3 & 4 & 4 & 5 & 5 & 6 & 7 & 7 & 7 & 7 \\ 11 & 13 & 15 & 16 & 19 & 21 & 25 & 24 & 23 & 24\end{array}$

SCUECES: SEE TABLES PERTAINING TO INDIVEDUAL MODES,

NCT E:

[3] EXCI DDES GOVERMMENT CONSOMPTION, CIVILIAN AND DIITTARY. 
TABLE 1.2C - SE GHARY OF TRANSPORT RNERGY DSE,

BY CODE BY PURL TYPE

(LASE OP THEEE PAGES)

POEL USE IH UILLIONS OP BBL, OR BILIICNS OP KBH OR CUBIC FEET

YOLLORED BY ENERGY OSE IN TRILIIONS OF BTO

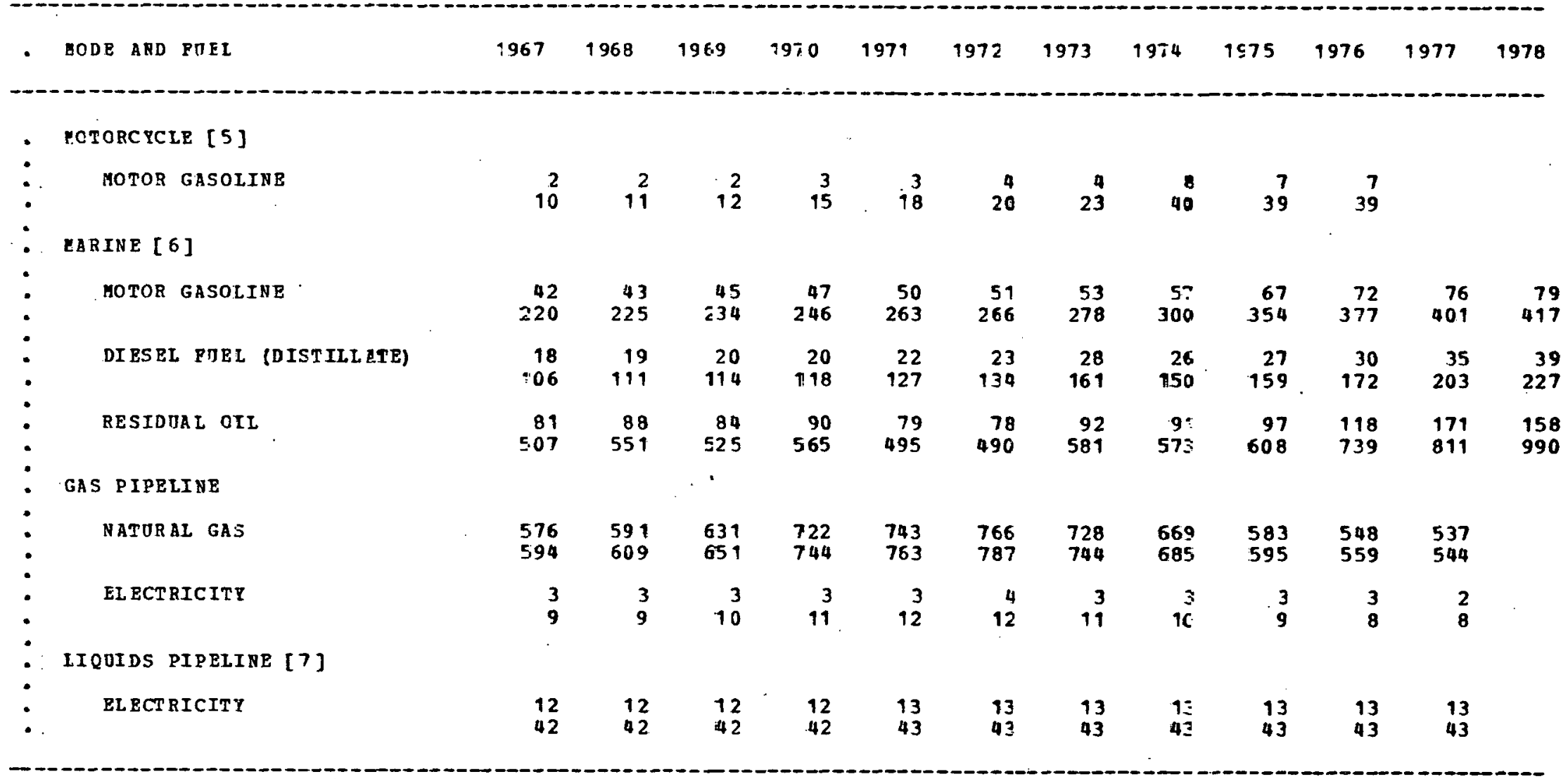

SOOECES: SEE TABLES PERTAIBING TC INDIVIDOAL RODES.

[4] EXCL DDES PEDERAL GOVERMHENT AND GIIITARY CONSUHPTION.

[5] INCL UDES HOUS BHOLD GOT CRCYCLES ONLI. 1967-73 PIGU RES COVE REGISTERED EIRES ONLY,

[6] EXCLODES HILITARY CONSUIETIOE.

[7] OTBER FMELS ACCOUNT POR ABCUT 15 OP PIPELIBE EREBST OSE. 
A GOIDE TO READING THIS TABLE CAN BE FOOND ON THE FOLIORING PAGE

METHOD

DESCRIPT $=O N$

YEA B

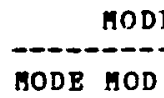

HOD 1

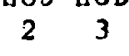

SECTOR BANGE

TOR aI

$\times \quad \times$

0. S. CERTIPICATED CARRIERS 74-77* AIR

ROACERT. DONESTEC PLIGHTS 74-77 AIR

IUTEEHATIONAL FEIGATS 74-77 AIR

104 D. S. GENERAL AVEATIOH

74-77 AIR

AL I A I ATION

67-77 $\mathrm{IIR}$

RAII TRANSIT

CONH OTBR RAIL

IXIEECITY PASSEDGER FAIL

PRETGRT RAIL

67-78 RAIL BEAVY

67-77 RAII. HEAVY

COMHERCIAL AOTO, EXC.TARI TAXICABS

FE-EEEAL DTOS

HOOSEHOLD AOTOS

67-76 RIRAY AOTO

67-76 HIM AY AOTO

67-76 BIDAY AOTO

67-76 HIPAY AOTO

72-76 HIVAY AOTO

72-76 BITAT AUTO

72.76 HIVAY AOTO

72,76 BIRAY AOTO

75 HIRAY AOTO

HOOSEHOZD AOTOS

SCBOOL BUSES

PEOEEAT BDSES

TRARST BOSES

324. IXTERCITY BUSBS

67-76 BINAY BUS SCB

67-76 BIRAY BOS OTR

67-76 HIVAY BOS OTR

67-77 HIRAY BOS OTR

76 RIRAY BUS OTR

$67-76$ HIRAY BOS OTR
67.76 HIQAY BOS OTR

$67.72,76$ HIDAY BUS OTR

331

332
333
334

334

335
336

341

GOOSERLD $E$ COURCL TROCRS

IOCAI HE C TRUCRS

INTERCITY H E C TROCRS

INTERCITY H \& C TRUCKS

INIERCITY H $\&$ C TRUCKS

PEDEEAL TRUCRS

HOTORCYCLES

$40 ?$

RECREATIONAL BOATS

402

COAMERCIAL SHIPS

510 HATORAL GAS PIPELINES

520

IIQOIDS PIDEL INES

600

\begin{tabular}{|c|c|c|c|}
\hline $\begin{array}{l}67-76 \\
67-76 \\
67-76 \\
67-76 \\
67-76 \\
67-76\end{array}$ & $\begin{array}{l}\text { HIRAY } \\
\text { RIRAY } \\
\text { HIRAY } \\
\text { BIRAY } \\
\text { BIRAY } \\
\text { HIRAY }\end{array}$ & $\begin{array}{l}\text { TRK } \\
\text { TRK } \\
\text { TRR } \\
\text { TRK } \\
\text { TRK } \\
\text { TRK }\end{array}$ & $\begin{array}{l}\mathrm{x} \\
\mathrm{X} \\
\mathrm{x}\end{array}$ \\
\hline $\begin{array}{l}67-73 * \\
74-76 \\
74-7.6\end{array}$ & $\begin{array}{l}\text { BIRAY } \\
\text { RIRAY } \\
\text { BIRAY }\end{array}$ & $\begin{array}{l}\text { CYC } \\
\text { CYC } \\
\text { CYC }\end{array}$ & \\
\hline $\begin{array}{l}67-77 \\
67-77 \\
67-77\end{array}$ & $\begin{array}{l}\text { GARI } \\
\text { GARI } \\
\text { MARI }\end{array}$ & $\begin{array}{l}\text { RECR } \\
\text { RECR } \\
\text { COMM }\end{array}$ & \\
\hline $\begin{array}{l}67-77 \\
67-77\end{array}$ & $\begin{array}{l}\text { PIP E } \\
\text { PIPE }\end{array}$ & $\begin{array}{l}\text { GAS } \\
\text { LIQ }\end{array}$ & \\
\hline $\begin{array}{l}75-77 \\
75-77 \\
67-77\end{array}$ & $\begin{array}{l}\text { * } \\
\text { HIR* } \\
\text { HIAY }\end{array}$ & 18 & \\
\hline
\end{tabular}

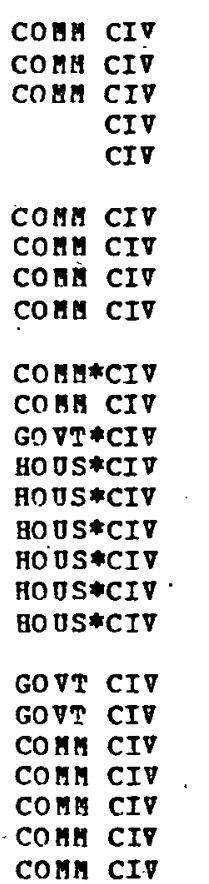

\begin{tabular}{lc}
\multicolumn{1}{c}{$\mathbb{X}$} & $X$ \\
RBG & JET \\
FOR & JET \\
REG* & $X$ \\
& $X$ \\
& \\
LOC & ELEC \\
BEG & $X$ \\
ICTY & $X$ \\
ICTY & $X$
\end{tabular}

GaS

LOC GAS

GAS

GAS
$\times$ GAS

ICTY GAS

ICTY GAS

ICIY GAS

IOC GAS

IOC GAS

LOC GAS

LOC DIES

LOC DIES

ICTY DIES

ICTY DIES

$x$
$x$

$x * \operatorname{CIV}$

Cos CIV

$x *$ CIV

$x *$ CIT
GOVT*CIV

IOC $x$

ICFY DIES
ICTY GAS

ICTY $\mathrm{X}$

HOUS CIV

HOUS CIV

HOUS CIV

म०OS CIV

BOUS CIV

COUA CIV

COHA CIT

COM CIV

GOVT IIL

GOVT IIL

GOVT MIL

GAS

GAS
PUEI

$\begin{array}{ll}\mathrm{PD}-\mathrm{FO}- \\ \mathrm{BI} & \mathrm{BI} 1\end{array}$

DSE

CARRIEE STATE INCOME CERTIF REG- STATE ION

$\begin{array}{lll}1 & 2 & \text { USE } \\ & 2 & \end{array}$

COABOX $x \quad X$ YES

COAMON

PRI V*

PASS

COA

COaEC

COMEON

Comeon

NPAS FRT

PRIV

COFHON

PRIV

PRIV

PRIV

PRIV

PRI

PRIV

PRIV

PASS $X \quad x$

PASS PER CADT

PRIV

PASS PER ED

PASS BOS.

PASS

COHEO

pass $x+$ COHBO

PASS $x \mathrm{x}$ COMAC

COBAOR

$x *$

NPAS

X* $x * x$

NPAS

$x$

PR I V

PAS

PASS PER $X X$

PASS

GAS. PASS

$\begin{array}{ll}\mathrm{GAS} & \text { PASS } \\ \mathrm{X} & \text { NPAS }\end{array}$

PRIV

PRIV

$\begin{array}{cllr}\text { ICTI } & X * & \text { IIPAS PRT GAS } & \text { PRI } \\ X & X * & \text { NPAS PRT } X & X *\end{array}$

$\underset{\text { JET }}{\mathrm{X}}$

PRI V

ERIV

PRIV
$X *$

$\mathrm{X}$ 
TABIE 2. 1 ATPEHPTS TO DRPICT ON ORE PAGB THE CATBgORIBS OF TRASPORT BQBRGY DSE POB WATCB ESTIMATES ARB PBOVIOED. A COHPLETE ACCOUBT OF TBE CATEGORIES PROVIDED IS GIVER AT THE BEGIMHIBg OP BACH HETHOD DESCRIPTION, AND ASTERISRS I\& TABLE 2-1 SIGKAL THAT THESE DESCRIPTIOHS SHOOLD BE CONSULTED POR QOALIPICATIOHS. A GLOSSABT OP ABBREIATIOYS USBD IA TABLE 2.1 APPEARS BELOR.

EACB LIAE OF THE TABLE REPBESEHTS A COLLECTIOA OF FOEL AND BAEBG OSB ESTIHATES THAT LIE IN THE CATEGORIES GERTIONBD. THB PIRST LIHB. POB IHSTANCE, REPRBSBRTS A COLLRCTIOH OP ESTIHATBS POR O-S. CBRTIPICATBD

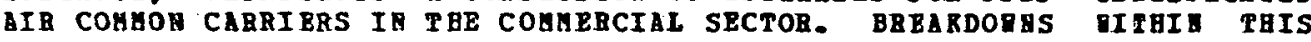
COLLECTIOE ARE SIGNALLED BY X'S. AB I APPEARIAG OBDBR A CERTAIB BREARDORE HEABS THAT ESTIMATES ABE PROVIDED POR EACB RELBVATT CATBGORY

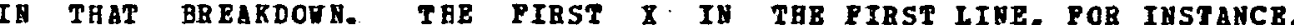

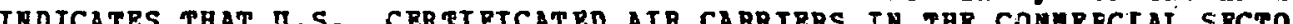

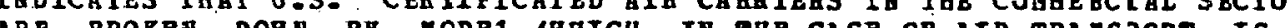
(MBICH. IN TaB CASB OP AIR TRABS?OBT. IS

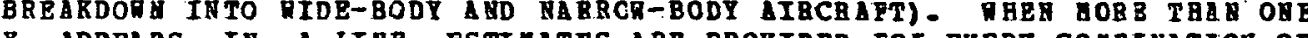
8 APPBARS IY A LIRE. BSTI $\triangle A T E S$ ARE PROVIDED POE EVBRT COABTHATION OF CATEGORIBS IN THE BBEBRDORNS MABRBD BY THE X'S. THE X'S IH THE PIBST LINE IHPLY THAT AN ESTILATE IS PROVIDED POR BVBBY COBBIAATION OF BODY TYPE (MODE1), BNGINE COHFIGURATIOH (MODE2), RABGE, PUBI, US3, FEGIOH AND STATE POR RHICH ENBRGI IS CONSUABD. ALSO EVEBT POSSIBLE AGGREGATION OP THESE ESTIMATES IS PBOVIDED.

IT IS LEPT TO THE BBADER TO DEDUCE THOSE BREARDOMES THAT ABB PRCVIDED POB AN EUTIBE MODE OP TRANSPORT, OR POR TRABSPOATAIOY AS A DMOLE. IT CAN BE IHPERBED, POR INSTANCE, THAT THEBE IS HO BREAKDOAH EY STATE POE AIB TRAVBL AS A HOLE, SIHCE PABT OP THB POEL CONSOHED (VIZ., THAT CONSULED BY D.S. SOPELEUENTAL AIB CARRIERS) IS HOT BROKBH DOUH BY STATE. SIMILARLY, THERE IS NO BRBARDODY OP TOTAL TRANSPORT BABRGY CONSTYPTIOY BY BAYGE, YOR BY HODE,

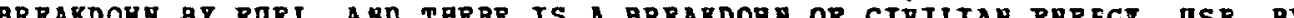
CREAKDOUK BY POELO A D TABRE IS A CAB TOO NOMEROOS TO CATALOG HERE.

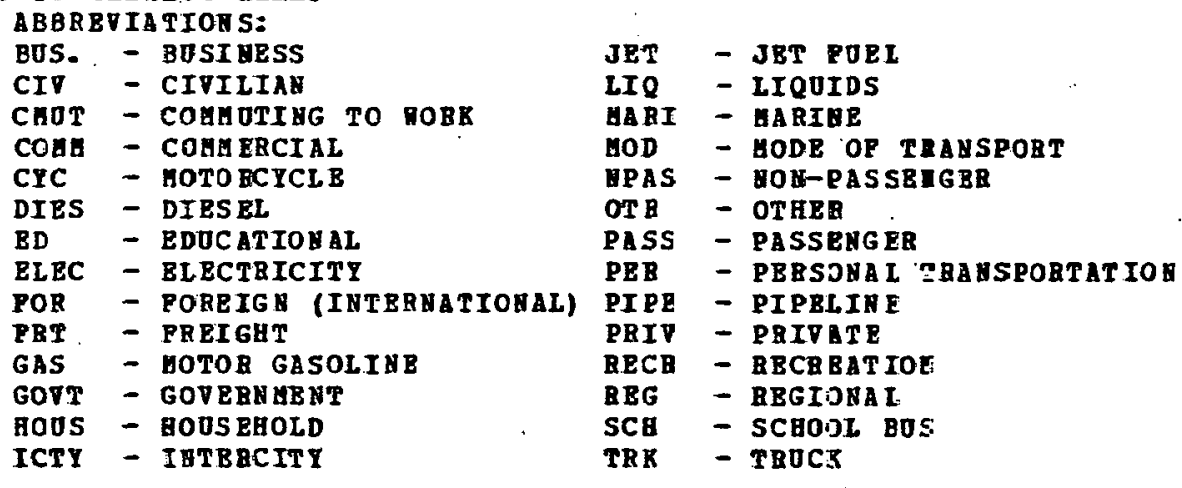


TABLE 3.1 - TOTAL CIVILIAN COASUAPTION OP ATIATION PUEt

BY POEL BI TIPB OP ACTIVITY, 1967-77

PUEL OSE IN THOOSA BDS OF BABELLS

BNEBGI DSE IV BIILIORS OP BTO

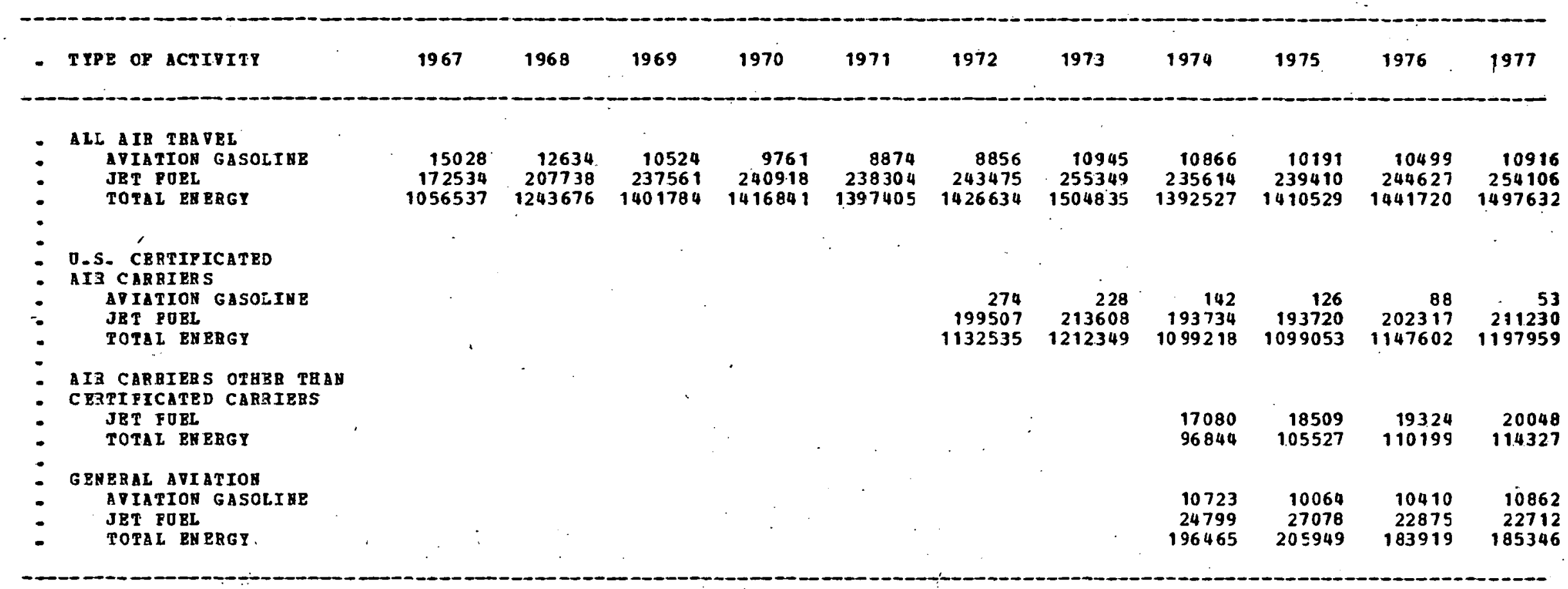

SOURCE: AETHOD 100

DATA QUAIITY: 1 (TOTALS AND CERTIFICATED), 2 (OTHER) 
TAEEE 3.2A - U.S. CERTIPICATED AIBCRAFT POEL AND ENER3Y DSE,

BY FOEL BY AIRCBAPT TYPE, 1967-77

(FIFET IN A SERIES OP THREE TABLES)

AVIATION GASOLIHE USE IN THOOSAHDS OP BARRELS

FOLLORED BY JET FUEL DSE IN THOOSANDS OP BAERELJ

ZOLLONED BY LEERICATIYG OIL USE IN THOOSANDS OP BABZELS

POLLORED EY TOTAL ENERGY OSE IN BIILIONS OP BIO

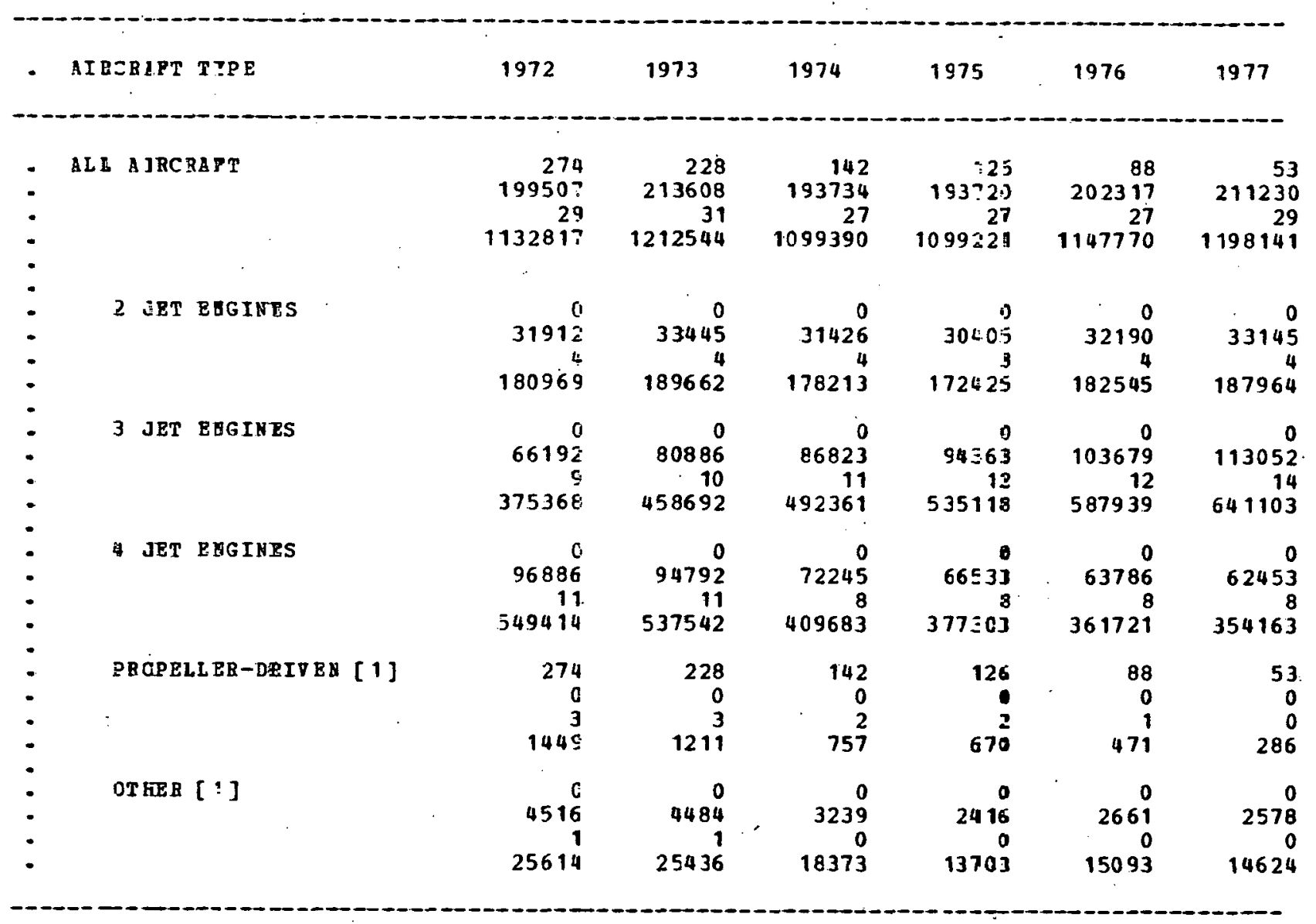

SOURCE: ERTHOE 10 !

DATA QOALITY: 1

[1] TURBC-PROFS AFE IHCLUDED ORDEB "OTHBR" 

TABLE 3.2B - O.S. CERTIPICATED ATRCRAPT PUEL AND ENEBGY OSE.
BY POELBY AIRCBATT TYPE, 1967-77

(SECOND IN A.SERIES OF TRRE TABLES)

AVIATION GASOLINE OSE IA THOUSARDS OP BARRELS

FOLLORBD BY JET FUEL USE IY THOOSANDS OP BAERELS

PCILONED BY LOBRICATING OIL OSE IN TBOOSANDS OP BARBELS

FOLLONED BY TOTAL ENERGY USE IN BILLIONS OF BTO

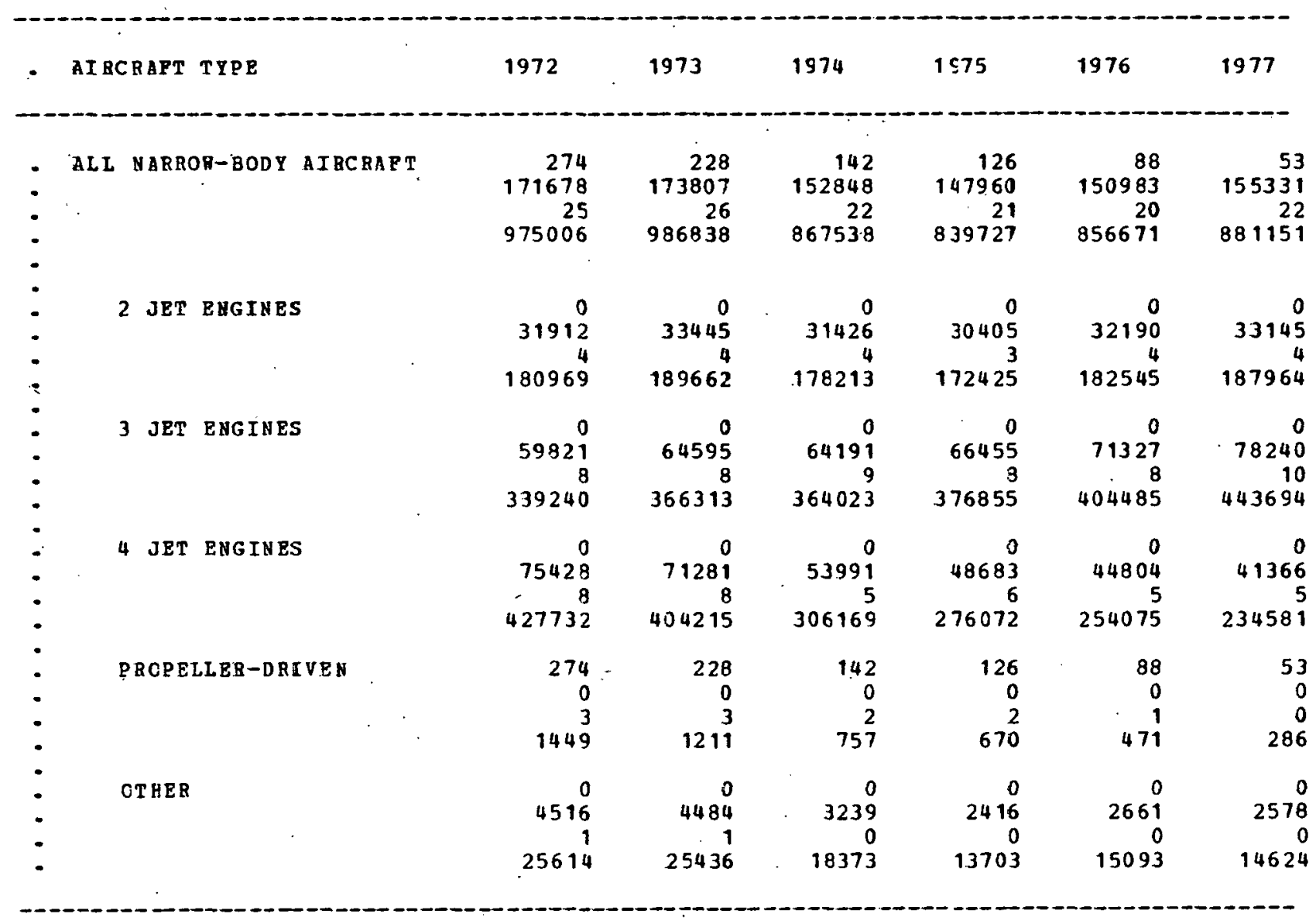

SOJRCE: NETHOD 101 DATA QUALITY: 1 
TABLE 3.2C - U.5. CBRTIPICATED AIRCBAPT PUBL AND ENBEGR U.5B, BY PUEL BY AIRCBART TYPB, 1967-77

(LAST IN A SERIES OP THBBE TABLES)

AVIATIO\& SESOLIHE OSE IY THOUSABDS OP BARRELS

FOLLORED BR JET PUBL OSB IV THOOSANDS OP BA ERBLS

FOLLORED BY LDBE ICATIHG OIL OSB IM THOUSA EDS OP BAERTLS

POLLONED BE TOTAL EURBGY OSE IN BILLIOYS OP BTT

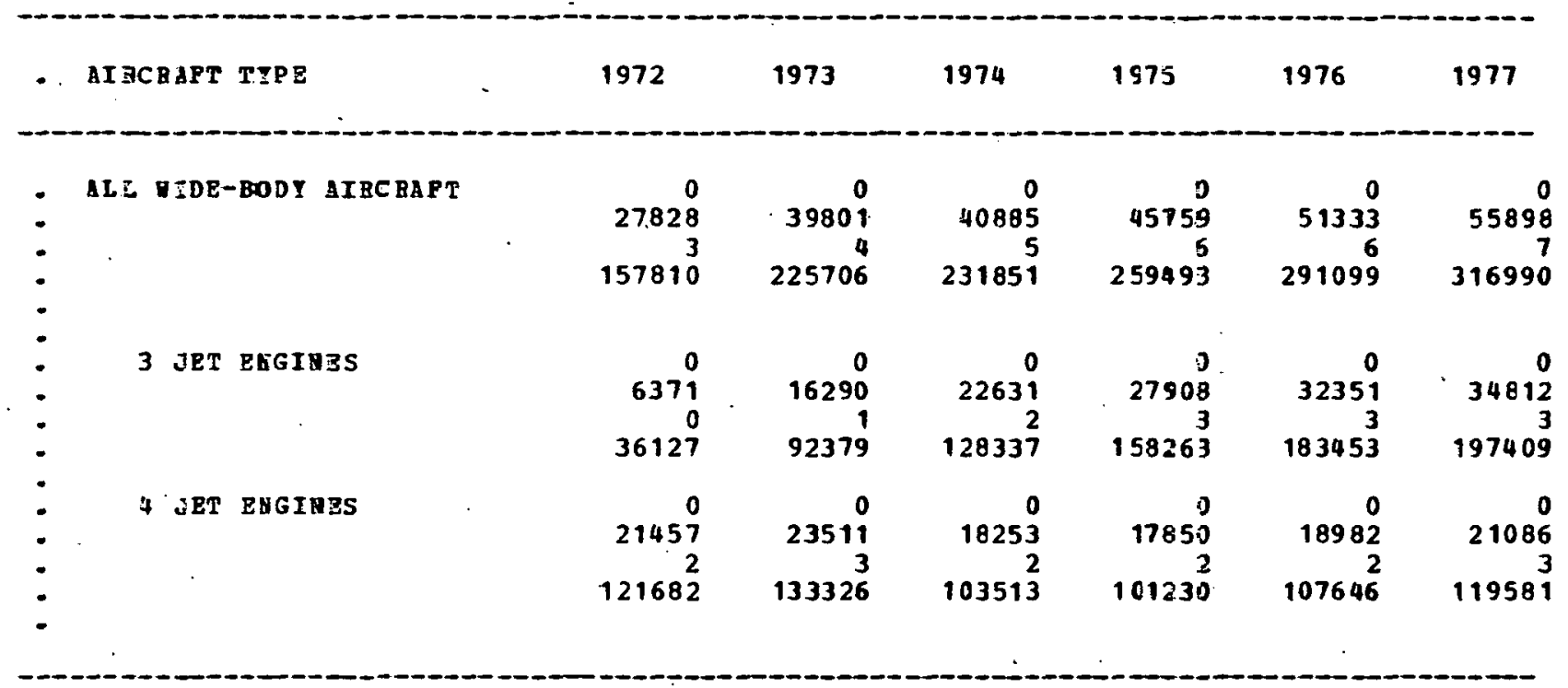

SOURCE: EBTHOB 10.1 DATA QOATITY: 1 
TABLE 3.3A -- U.S. CERTIPICATED PASSBNGER AIRCBAPT PUEL AND ENERGY USE.

BY POEI BY AIBCRAPT TYPB, 1967-77

(PIBST IN A SEBIES OF THBBE TABLES)

AVIATION GASOLIAE OSE IN THOOSABDS OP BARRELS

FOLLOHED BY JET PUEL OSE IR THOOSAUDS OP BARRELS

FOLLORED BP LUBR ICATING OIL OSE IN THOUSANDS OP BARRELS

POLLOHED BP TOTAL EAREY USE IN BILLIOHS OP BTO

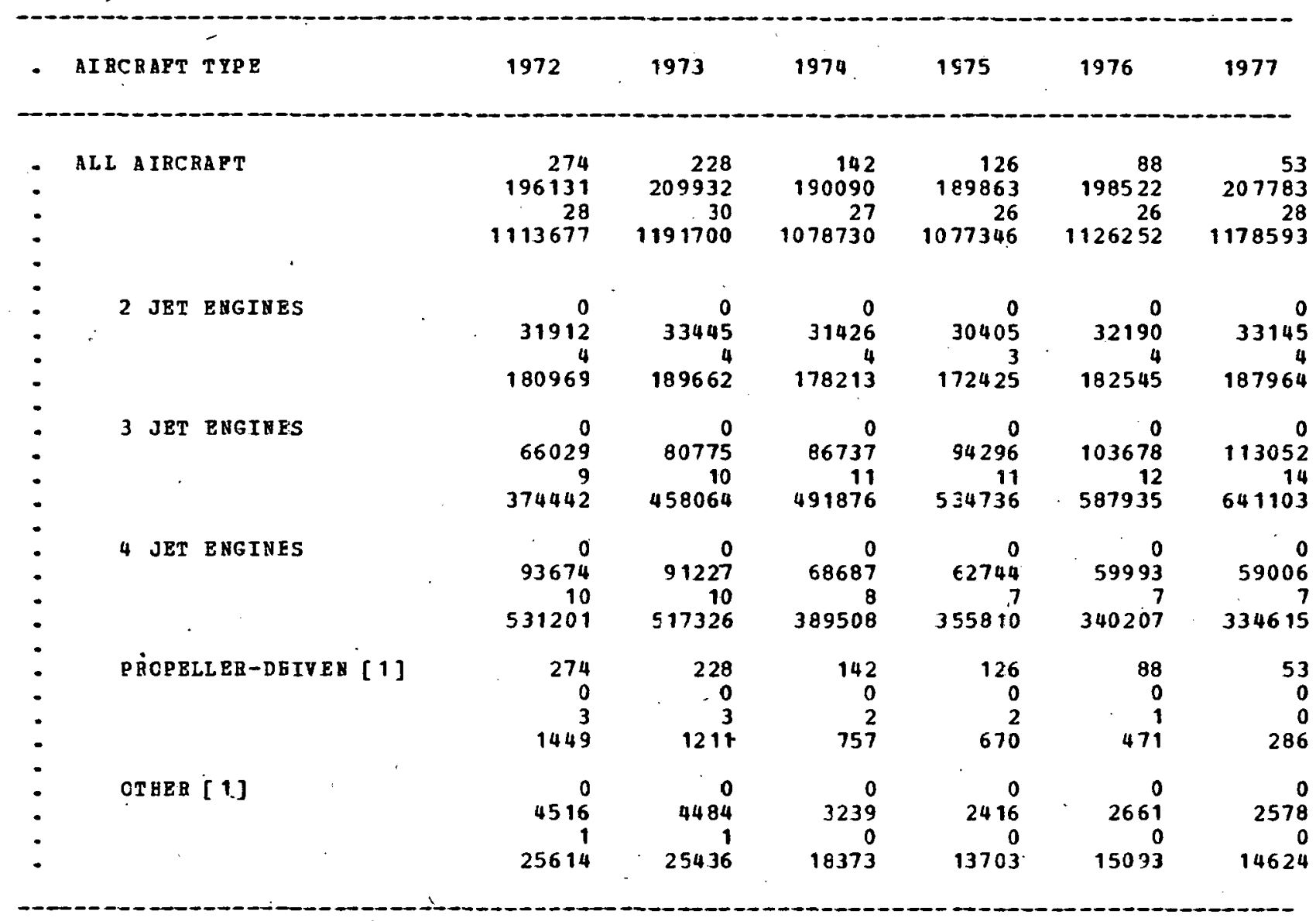

SOORCE: EETHOD 101

DATA QUALITY: 1

[1] TURBC-PROPS ARE IHCLUDED ONDER "OTHER" 
-TAELE 3. 3B -- U.S. CBRTIPICATED PASSEHGER AIRCFART PUEL AHD BHERT USE, E : POEL BY AIRCBAPT TYPE, 1967-77.

(SECOND IH A SERIES OP THREE TABLES)

AVIATIOI GASOLI OSE IN THOUSARDS OP BABB

POLLORET. BY JET POEL OSE IN THOUSANDS OF BABRELS

POLLORBD BY LUBRICATING OIL OSE IN THOOSANDS OP BABRELS

POLLONEL BT TOTAL ENEBGT USE IN BILLIONS OP BTO

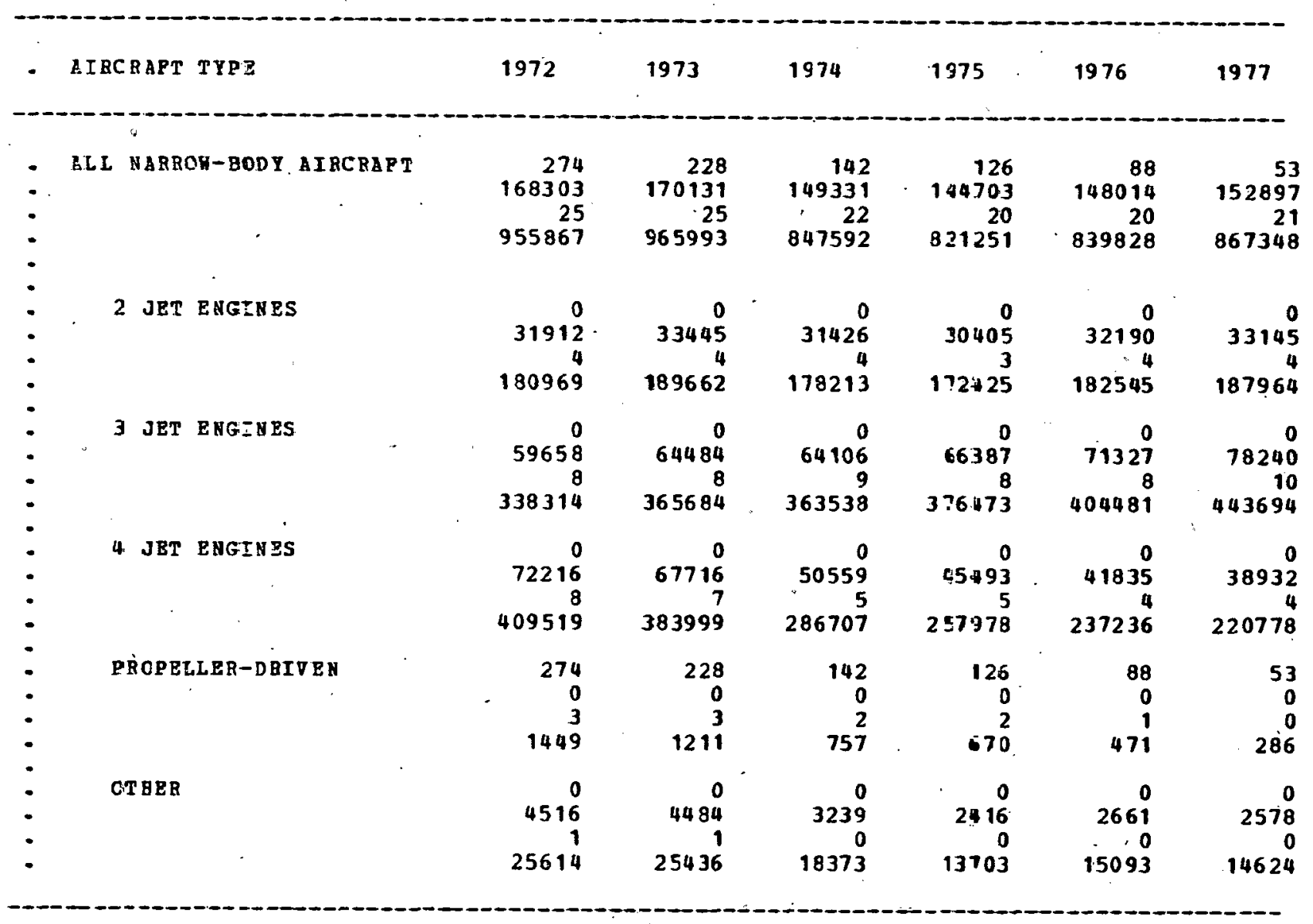


TABLE 3. 3C -- O.S. CERTIFICATED PASSEEGBR AIBCBAFT PUEL AHD BHERG USE.

BI FUEL BY AIRCEAFT TYPE, 1967-77

(LAST IN A SERIBS OP TEBEB TABLES)

AVIATIO GASOLINE OSE IH THOUSARES OP BARRES

POLLOQED BY JET POBL OSB IN THOUSANDS OF BAERELS

FOLLOGBD BY LUBRICATIRG OIL OSE IH THOUSABDS OP BABRBLS

FOLLONED BY TOTAL ENERG OSE IA BILLIONS OF BTO

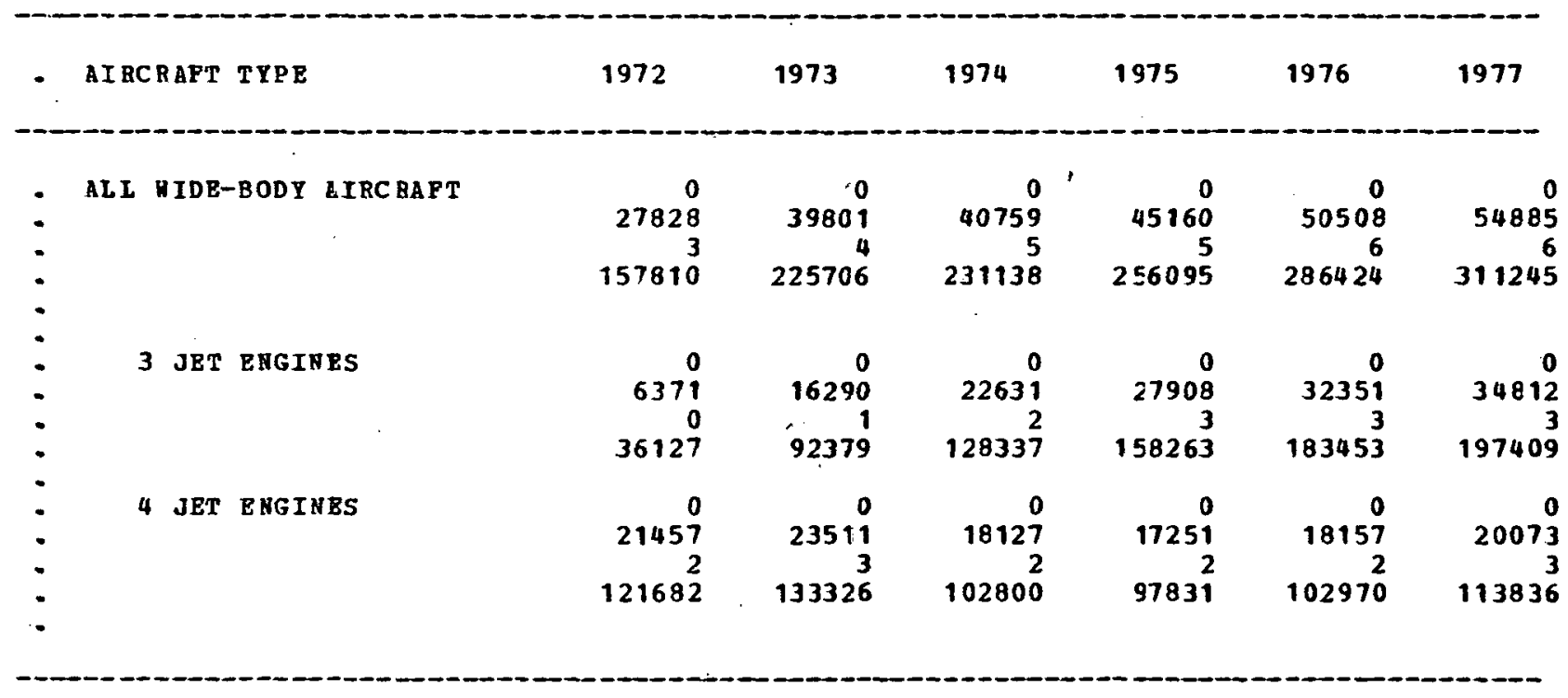

SOURCE: EETHOD 101 DATA QUALITY: 1 
TA3LE 3.4A - O.S. CERTIFICATED PREIGHT AIBCRAPT FOEL AND EHEBGY USE, 3: PUEL BI ATBCRAPT TYPE, 1967-77

(PIBST IR A SERIES OF THREE TABLES)

AVIATIOA GASOLIHB USB IN THOOSANDS OF BARgFLS

FOLLORB) BY J ET FUEL USE IB THOUSARDS OP BA GRBIS

POLLOUED BI LUBRICATIYG OIL OSE IA THOOSANDS OP BABRBLS

POLLON 3 S BY TOTAL ENBRG OSE IN BILLIOBS OP BTD

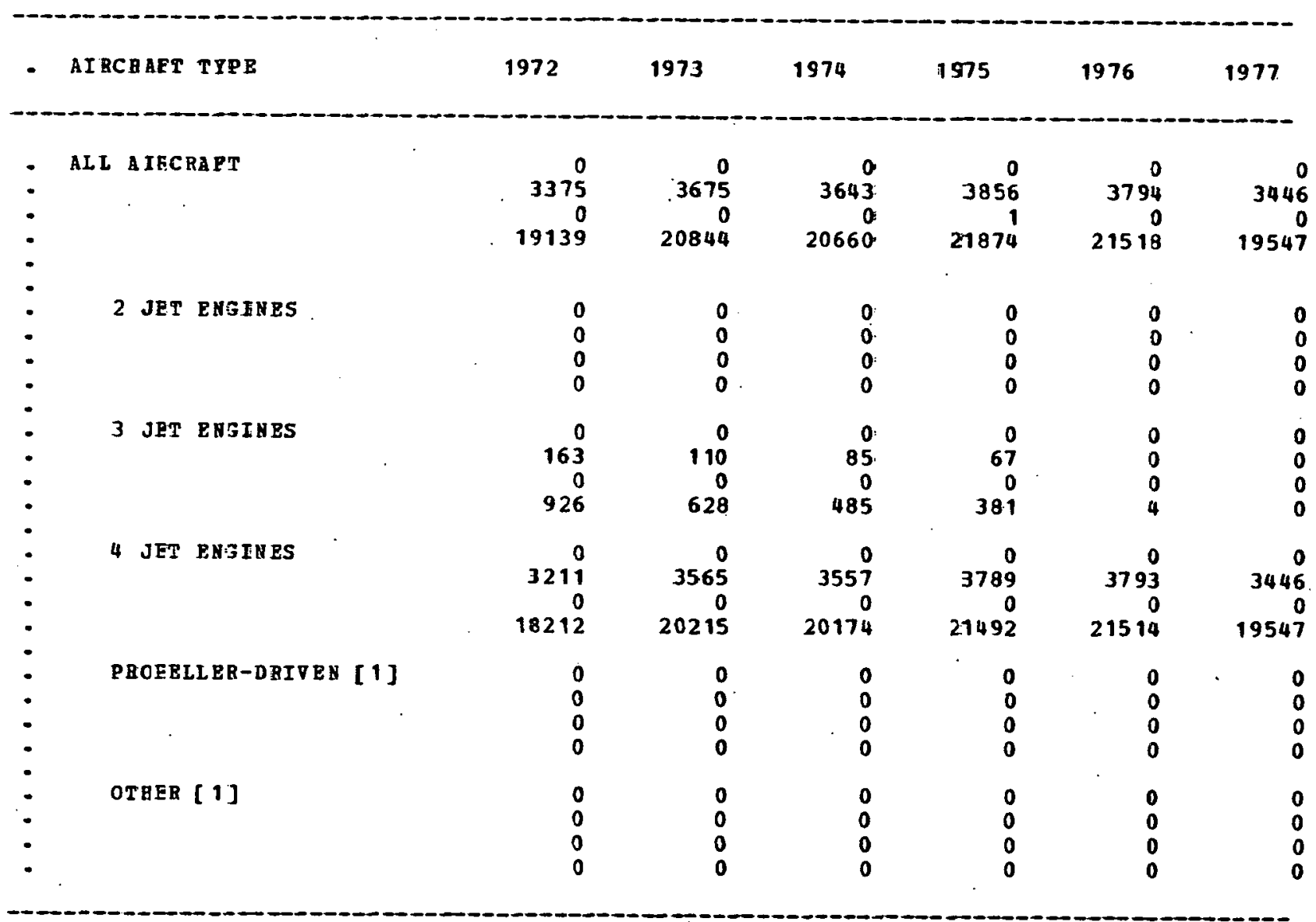

SOURC 3: AETHOD TO I DATA QDALITY: 1

[1] TURBO-PROPS INCLODED ORBEE NOTHERA 
TABLE 3.4B - 0.S. CERTIPICATED PBEIGGT AIBCBAPT FUEL AAD BHERG USB, BI POEL BY AIBCBAPT TIPBO 1967-77

(SECOND IA A SERIES OF THREB TABLBS)

AvTatiog Gasoling uSE İ THOOSARDS OP BARRELS

FOLLOHED BY JET PUBL OSE IB THOOSANDS OP BARELS

FOLLORED BI LUBRICATING OIL OSE IN THODSAUDS OP BARRLS

POLLORED BI TOTAL EYBBGY OSB IB BILLIONS OP BTU

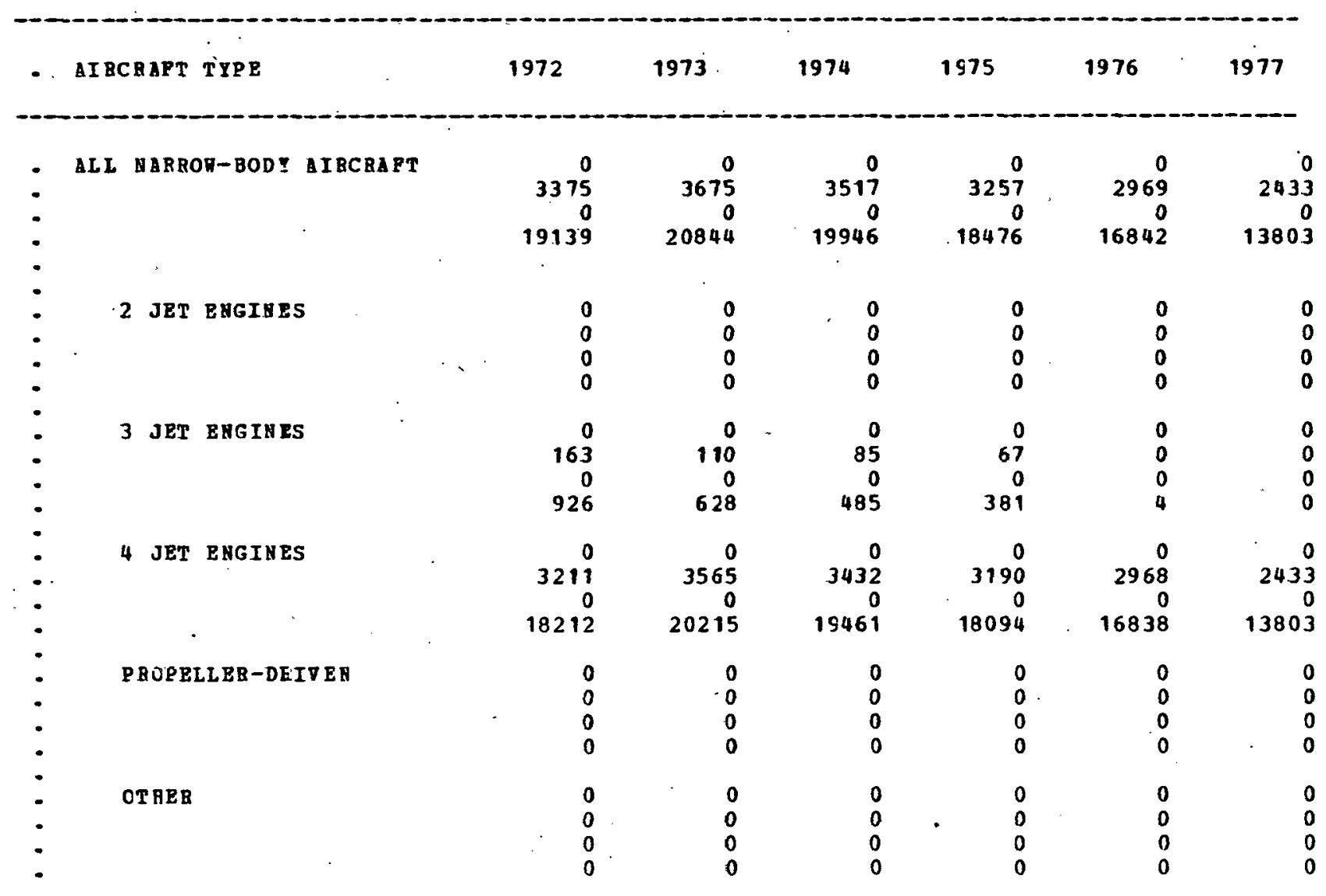

SOURCB: METHOD 101 DATA QOALITY: 1 


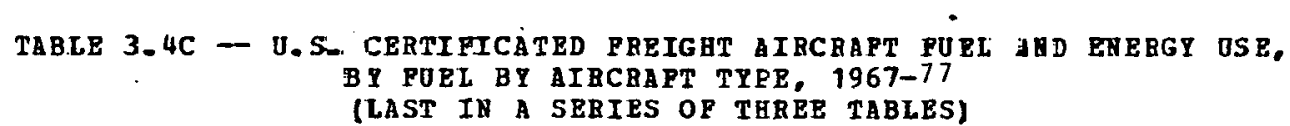

ATIATION GASCLINE USE IN THOUSARDS OP BaEETLS

FOLLORED BT JET FUEL USB IV TEOUSANDS OP EE BHELS

FOLLOHED EP LUBRICATIMG OIL OSE IN TBOUSANDS CP BABBELS

POLLORED BI TCTAL BNERG OSE IN BILLIONS GE BTO

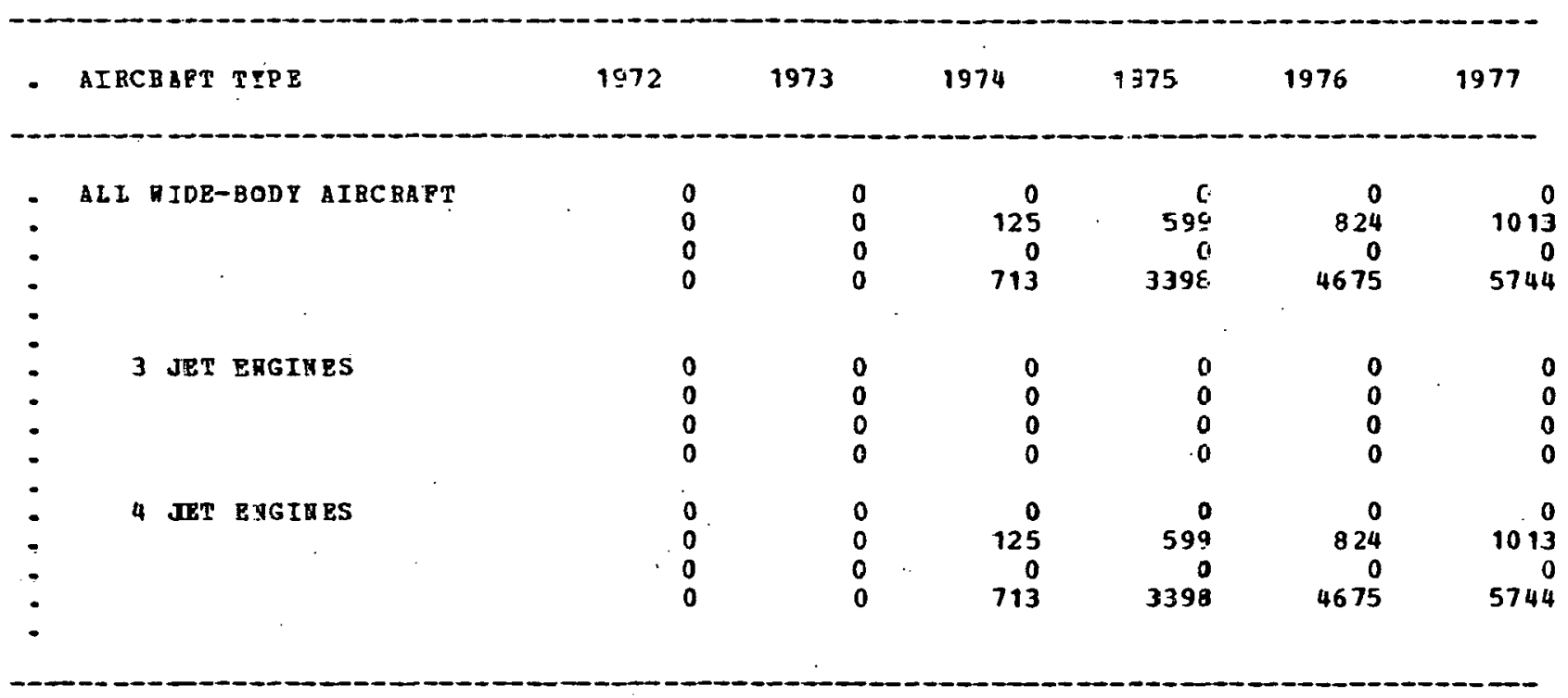

SOORCE: EETHOD 101 DATA GOALTT: 1 
TABLE 3.5A -- 0.S. CBRTIPICATBD AIRCQAFT PUEL AED ERBBG OSB, BI POEL BI STATB, 1972-77

(PIBST IN A SEAIBS OP IIMB TABLBS)

AVIATION GaSOLINE OSE IN THOUSABDS OP BARBELS

FOLLORED BY JBT FUEL OSE IN THOOSAHDS OP BA GRELS

FOLLORED BY TOTAL BABEGY OSB IA BILLIONS OP BTO

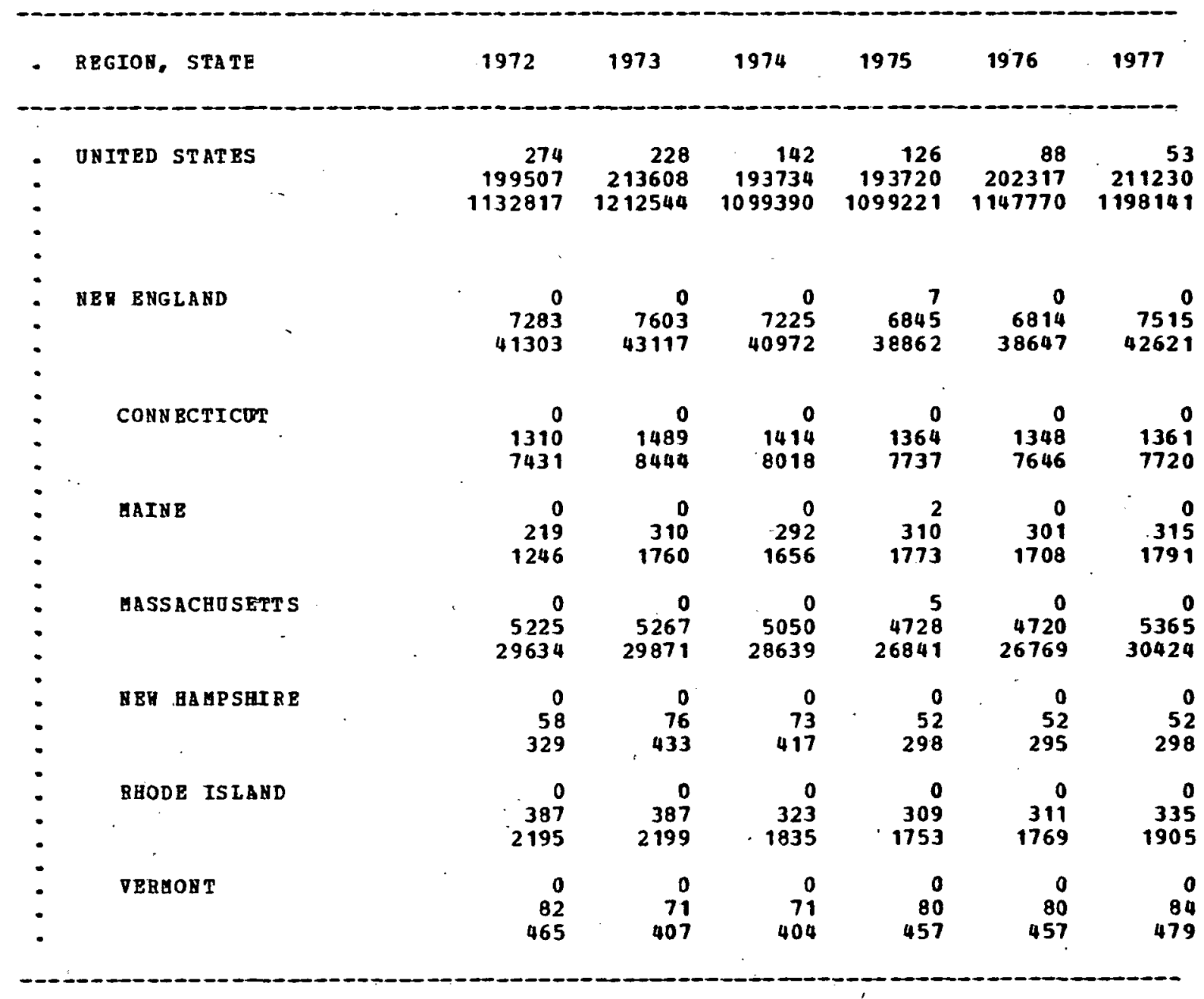

SOORCE: HBTHOD

DATA QOALITY: 1

NOTE: TOTAL ENERG PIGURE INCLODBS THE RRERG CONTEAT OP LOBAICATIYG OIL OSBD. 
TABLB 3.5B - 0.5. CERTIPICATED AIBCAAPT PUEL ABD BEgBGY OSB. BY POEL BI STATE, 1972-77

(S BCOND IH A SBIBS. OP NIAE TABLBS)

AVIATIOE GASOLIBE OSB IM THOUSABDS OP BABEELS

POLLORED BY JBT POBL USB IE THOUSARDS OR BABZBLS

FOLLORED ET. TOTAL ENERGT OSB IN BILIIOHS OP BTD

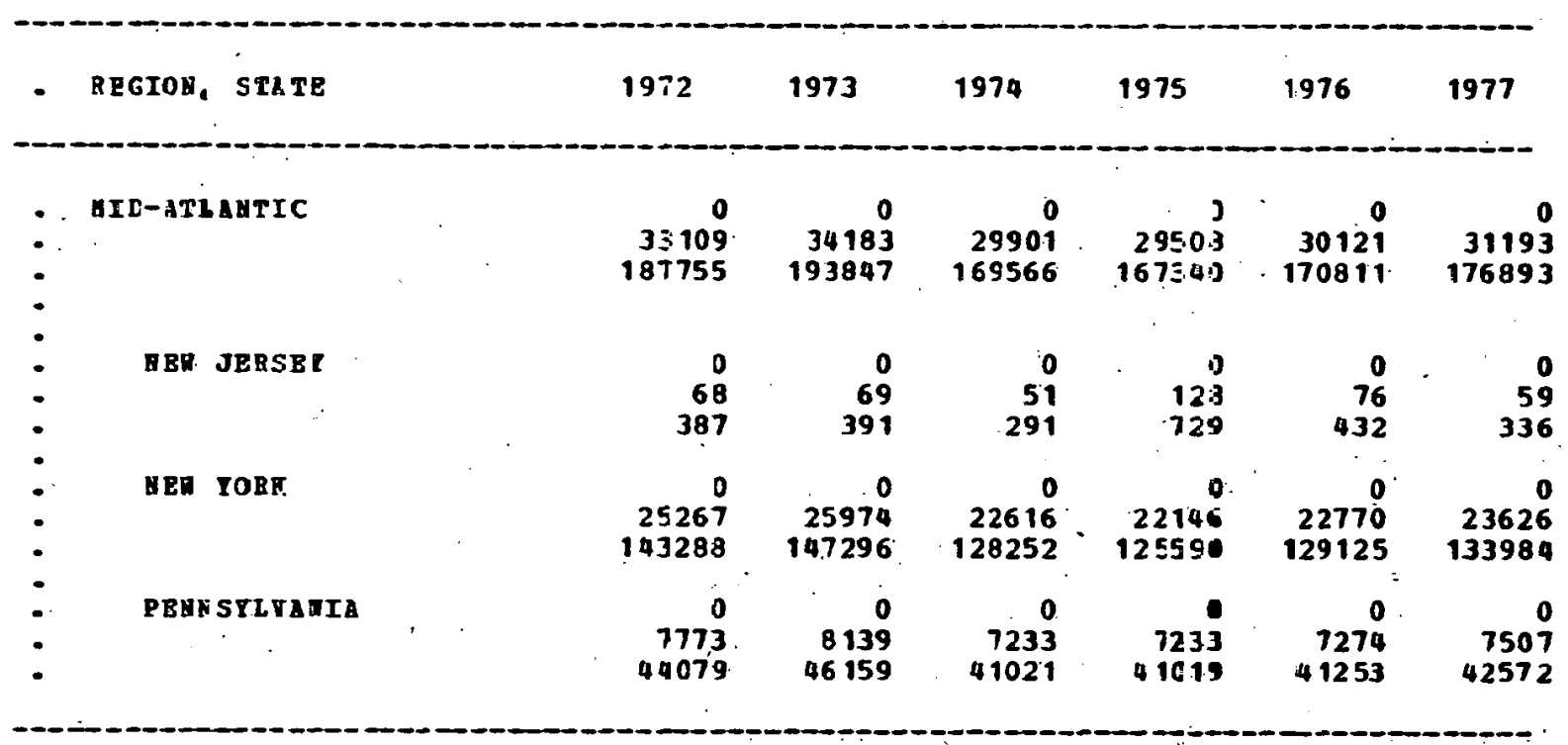

SOORCF: UETHOE 101

DATA QUALITT: 1

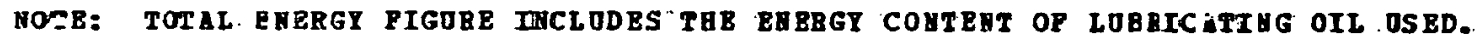


TABLB 3.5C -- 0.S. CRETIPICATED AIRCRAPT FOEL AND BEBRG OSE, BY PUEL BY STATE, 1972-77

(THIRD IN A SERIES OF HINE TABLES)

AVIATION GA SOLIHE OSE IA THOOSAMDS OP BARRELS

POLLORED BY JET FOEL OSE IE THOOSARDS OP BABRELS

FOLLOHED BY TOTAL ENBBGT OSE IY BILLIOYS OP BTO

\begin{tabular}{|c|c|c|c|c|c|c|c|c|}
\hline & REGION, STATE & & 1972 & 1973 & 1974 & 1975 & 1976 & 1977 \\
\hline . & SOOTH ATLANTIC & & $\begin{array}{r}83 \\
33486 \\
190338\end{array}$ & $\begin{array}{r}69 \\
37376 \\
212323\end{array}$ & $\begin{array}{r}49 \\
32825 \\
186415\end{array}$ & $\begin{array}{r}41 \\
33410 \\
189687\end{array}$ & $\begin{array}{r}24 \\
35714 \\
202658\end{array}$ & $\begin{array}{r}13 \\
37669 \\
213693\end{array}$ \\
\hline & & & $\cdot$ & . & . & . & $;$ & $:$ \\
\hline & DBLADABE & & $\begin{array}{r}0 \\
40 \\
227\end{array}$ & $\begin{array}{r}0 \\
25 \\
144\end{array}$ & $\begin{array}{r}\because 0 \\
20 \\
117\end{array}$ & $\begin{array}{r}0 \\
18 \\
104\end{array}$ & $\begin{array}{r}0 \\
75 \\
425\end{array}$ & $\begin{array}{r}0 \\
20 \\
114\end{array}$ \\
\hline & D.C. & & $\begin{array}{r}0 \\
5360 \\
30396\end{array}$ & $\begin{array}{r}0 \\
5769 \\
32719\end{array}$ & $\begin{array}{r}5206 \\
29524\end{array}$ & $\begin{array}{r}0 \\
5240 \\
29715\end{array}$ & $\begin{array}{r}0 \\
5601 \\
31763\end{array}$ & $\begin{array}{r}0 \\
5827 \\
33044\end{array}$ \\
\hline & $\begin{array}{l}\text { PLOBIDA } \\
\end{array}$ & & $\begin{array}{r}5 \\
13727 \\
77873\end{array}$ & $\begin{array}{r}2 \\
15538 \\
88125\end{array}$ & $\begin{array}{r}0 \\
12984 \\
73639\end{array}$ & $\begin{array}{r}0 \\
13158 \\
74621\end{array}$ & $\begin{array}{r}0 \\
14339 \\
81317\end{array}$ & $\begin{array}{r}0 \\
15182 \\
86.09 .9\end{array}$ \\
\hline & $\begin{array}{c}\text { GROBGIA } \\
\text {. }\end{array}$ & & $\begin{array}{r}61 \\
7879 \\
4.5010\end{array}$ & $\begin{array}{r}53 \\
9330 \\
53193\end{array}$ & $\begin{array}{r}38 \\
8799 \\
50102\end{array}$ & $\begin{array}{r}35 \\
9123 \\
51926\end{array}$ & $\begin{array}{r}22 \\
9583 \\
54469\end{array}$ & $\begin{array}{r}13 \\
10170 \\
57747\end{array}$ \\
\hline & GARY்LAND & “ & $\begin{array}{r}0 \\
2026 \\
11489\end{array}$ & $\begin{array}{r}0 \\
1916 \\
-10867\end{array}$ & $\begin{array}{r}0 \\
1485 \\
8424\end{array}$ & $\begin{array}{r}0 \\
1443 \\
2186\end{array}$ & $\begin{array}{r}0 \\
1416 \\
8030\end{array}$ & $\begin{array}{r}0 \\
1522 \\
8632\end{array}$ \\
\hline & MORTH CARDLINA & $\Rightarrow$ & $\begin{array}{r}1 \\
2241 \\
12719\end{array}$ & $\begin{array}{r}1 \\
2374 \\
13473\end{array}$ & $\begin{array}{r}1 \\
2126 \\
12066\end{array}$ & $\begin{array}{r}0 \\
2251 \\
12768\end{array}$ & $\begin{array}{r}0 \\
2325 \\
13187\end{array}$ & $\begin{array}{r}0 \\
2383 \\
13515\end{array}$ \\
\hline & SOUTE CARJIIAA & 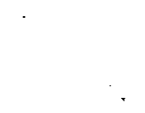 & $\begin{array}{r}15 \\
695 \\
4025\end{array}$ & $\begin{array}{r}12 \\
808 \\
4650\end{array}$ & $\begin{array}{r}9 \\
770 \\
4417\end{array}$ & $\begin{array}{r}.5 \\
830 \\
47.39\end{array}$ & $\begin{array}{r}1 \\
938 \\
5331\end{array}$ & $\begin{array}{r}0 \\
984 \\
5582\end{array}$ \\
\hline & VIRGINIA & . & $\begin{array}{r}0 \\
1247 \\
7073\end{array}$ & $\begin{array}{r}0 \\
1334 \\
7566\end{array}$ & $\begin{array}{r}0 \\
1157 \\
6561\end{array}$ & $\begin{array}{r}0 \\
1078 \\
6118\end{array}$ & $\begin{array}{r}0 \\
1162 \\
6595\end{array}$ & $\begin{array}{r}0 \\
1285 \\
7289\end{array}$ \\
\hline & REST VIRGTNIA & & $\begin{array}{r}0 \\
268 \\
1523\end{array}$ & $\begin{array}{r}0 \\
278 \\
1580\end{array}$ & $\begin{array}{r}0 \\
275 \\
1560\end{array}$ & $\begin{array}{r}0 \\
265 \\
1507\end{array}$ & $\begin{array}{r}0 \\
271 \\
1538\end{array}$ & $\begin{array}{r}0 \\
294 \\
1668\end{array}$ \\
\hline
\end{tabular}


TABLE 3.5 -- J.S. CERTIPICATED A IBCRAPT POEL AUD ERERG OSE. BI POEL BI STATB, 1972-77

(POURTH IN A SERIBS OP WIBE TABLES)

AVIATION GASOLIME USE IA THOUSANDS OP BARRELS

FOLIORED BY JET FOEL USE IY THODSANDS OP BAIRELS

FOLLOHED BY TOTAI BNERGY OSE IN BILLIONS OP BIO

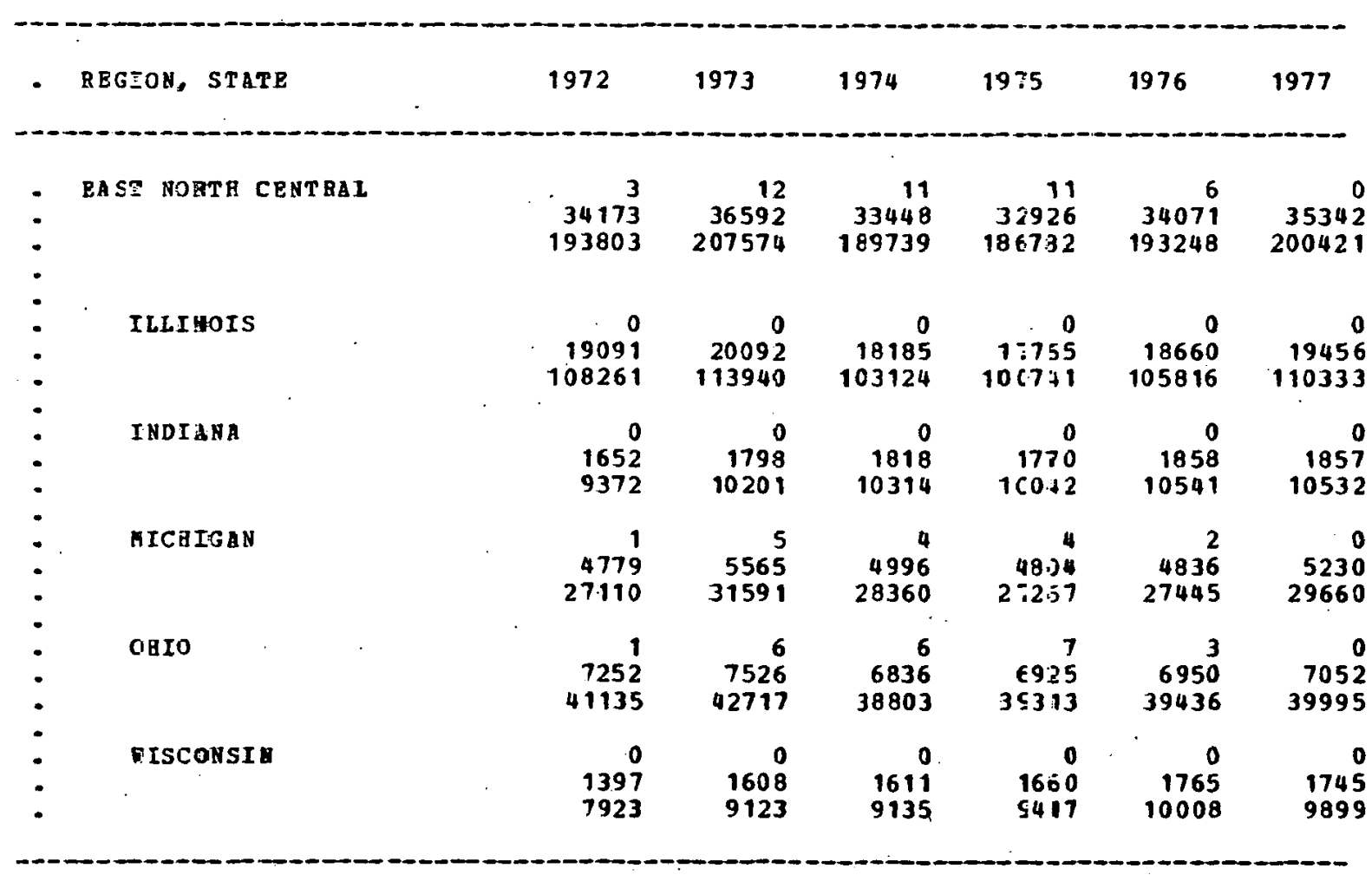

SOURCE = METHOD 101

DATA OJALTY:

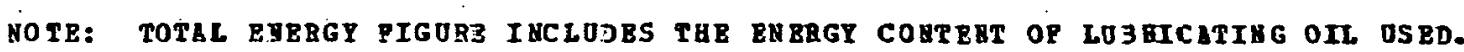



TABLE 3.5E - D.S. CERTIPICATED AIBCBAPT POBL AND FNEBGT USB,
BY PUEL BY STATE, 1972-77

(PIPTH IN A SERIES OP N.INB TABLES)

ATIATION GASOLIHE OSE IU THQUSARDS OP BABRELS

POLLORED BI JET POBL OSE IZ THOUSAHDS OP BAERELS

POLLONRD BY TOTAL BNERGY USE IY BILLIOXS OF BTO

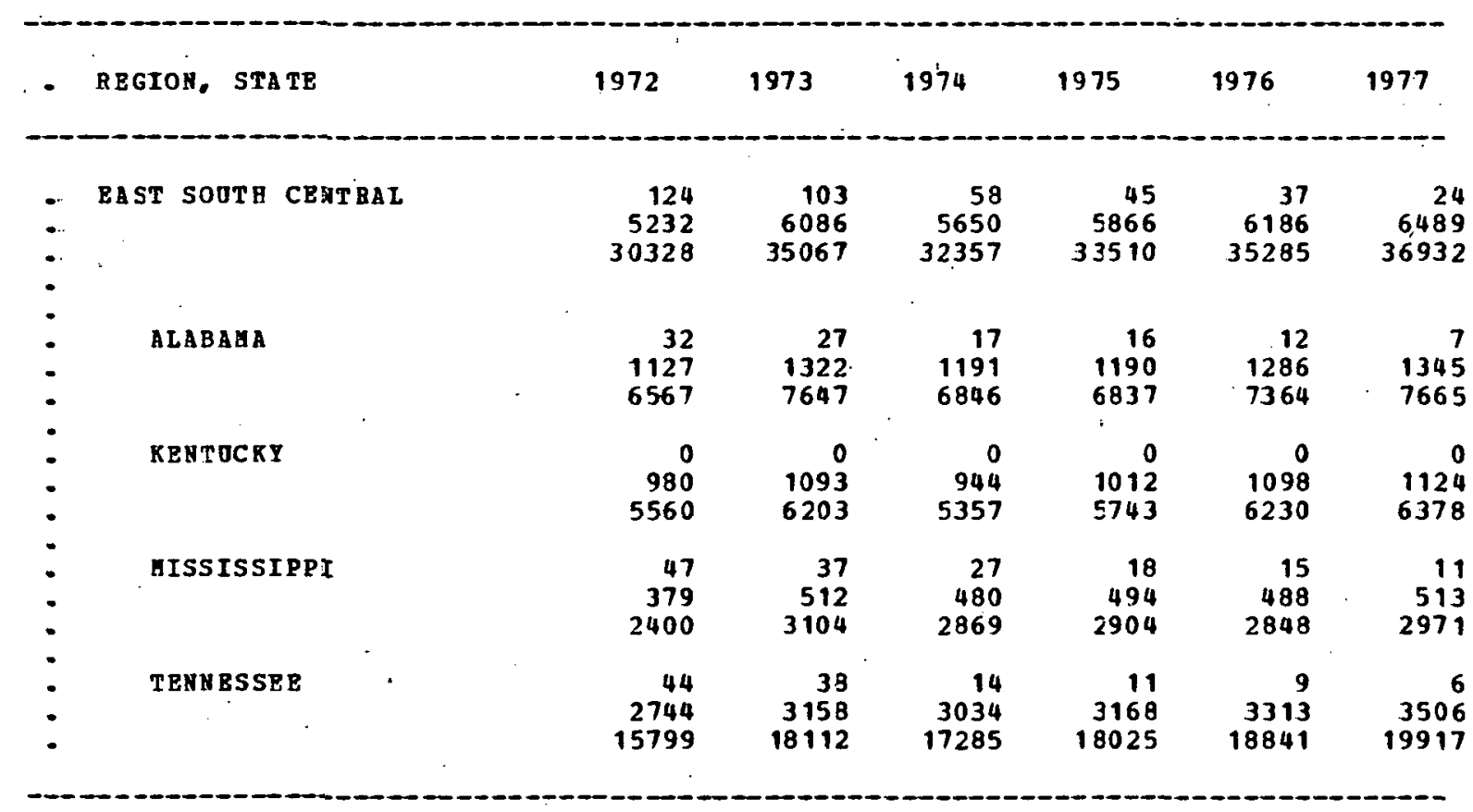

SOORCE: AETHOD 101

DATA QOALITY: 1

NOTE: TOTAL EMEBG PIGOBE INCLUDBS THB ERBRG CONTENT OF LOBBICATING OIL OSED. 
TABLE 3.5P - U.S. CERTIPICATED AIRCRAFT POEL A HD BUERG USE, BY FOBL BY STATE, 1972-77

(SIXTA IN A SBRTBS OP WIHE TABLES)

AVIATIOA GASOLIBE OSB IB THOOSAHDS OP BARREL;

POLLOYEE BY JET FOEL OSE IB TEOUSANDS OP BAFBBLS

POLLOFBD BY TOTAL ENERGY OSB IN BILLIONS OF BTO

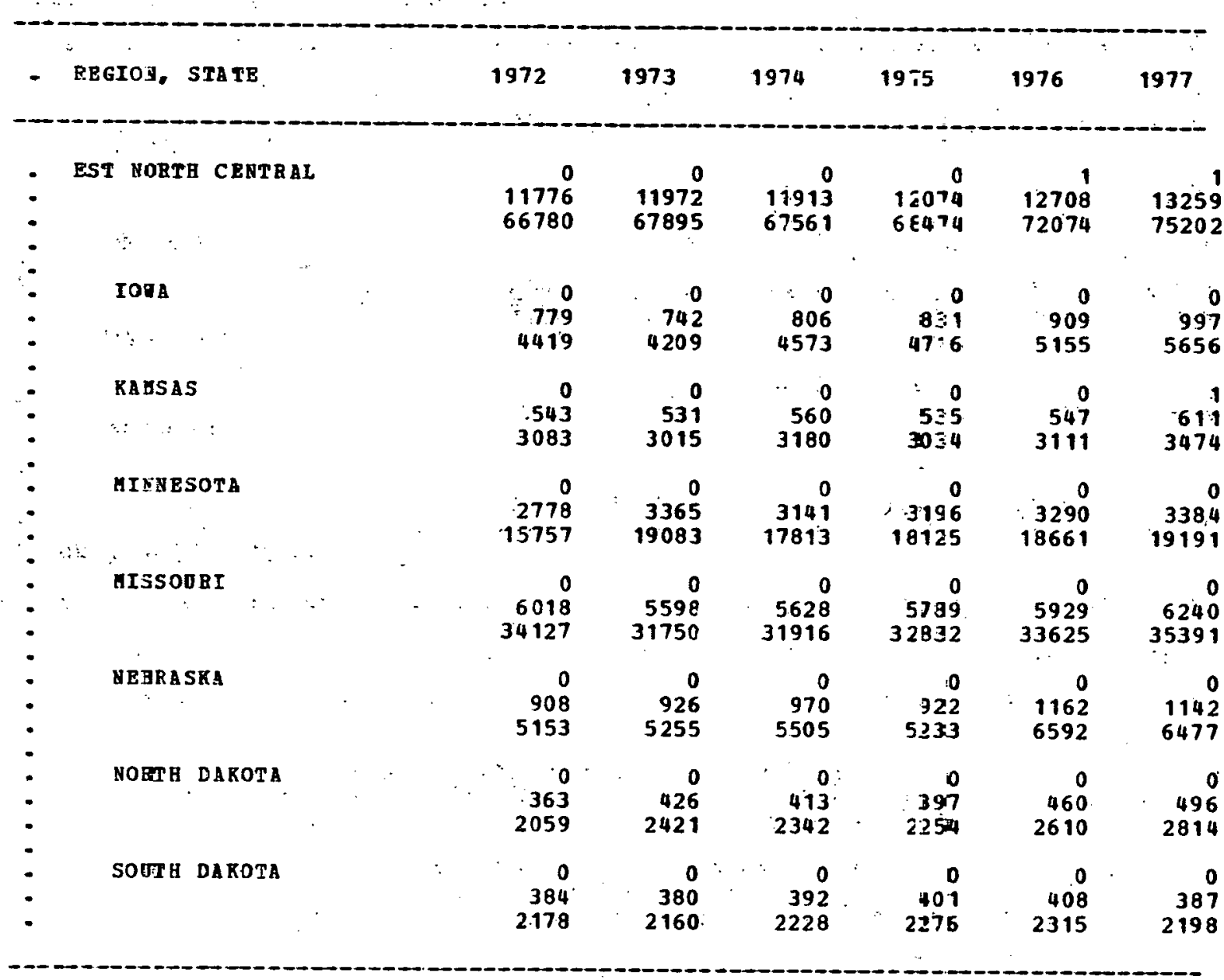

SOORCF: GETHOD 101

DETA QUALITY: 1

NOTB: TOTAL ENEBGY PIGURE INCLODES TBE EHER CONTEHT OP LUBBICATING OIL OSED. 
TABLE 3.5G - O.S. CERTIPICATED AIRCRAPT FOEL ARD EHBBG OSE, BI PUBL BI STATE, 1972-77 (SEVBNTE IA A SBRIES OP MIMB TABLES)

A PIATIOA GaSOLIGB DSE IB THOUSAMDS OP BARBELS POLLOQED BY J FT FOBL USE IB THOUSABDS OF BABRLS FOLLORED BY TOTAL ERBBGY OSE IB BILLIONS OF BTO

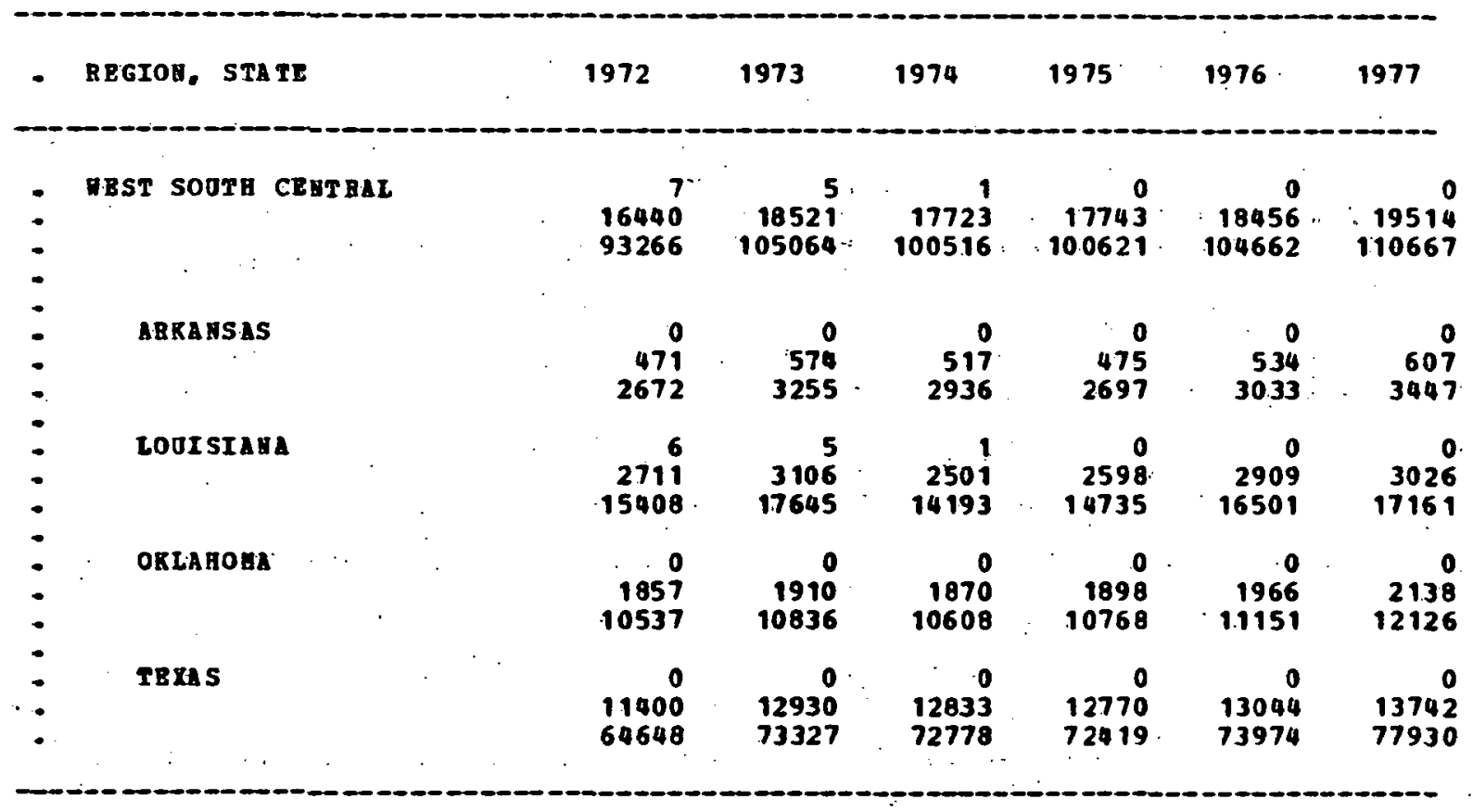

SOORCF: HETHOD:101

DATA QUALTT: 1

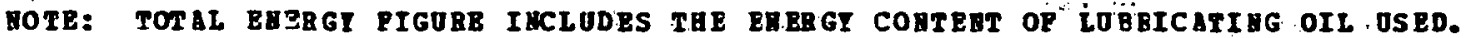


TABLE 3.5B - O.S. CERTIPICATED AIRCBAPT FUBE AUD BEEGY OSB BY POEL BI STATB, 1972-77 EIGATH IN A SBAIBS OP HIYE TABIBS)

AVIATIOY GASOLIKE OSB. IB TROUSAMDS OR BAERELS

POLLOEED BY JET POEL OSE IB THOUSAADS OF BA BBBLS

FOLLOHED BY TOTAL BHERGI DSE IN BIILIOHS GP BTO

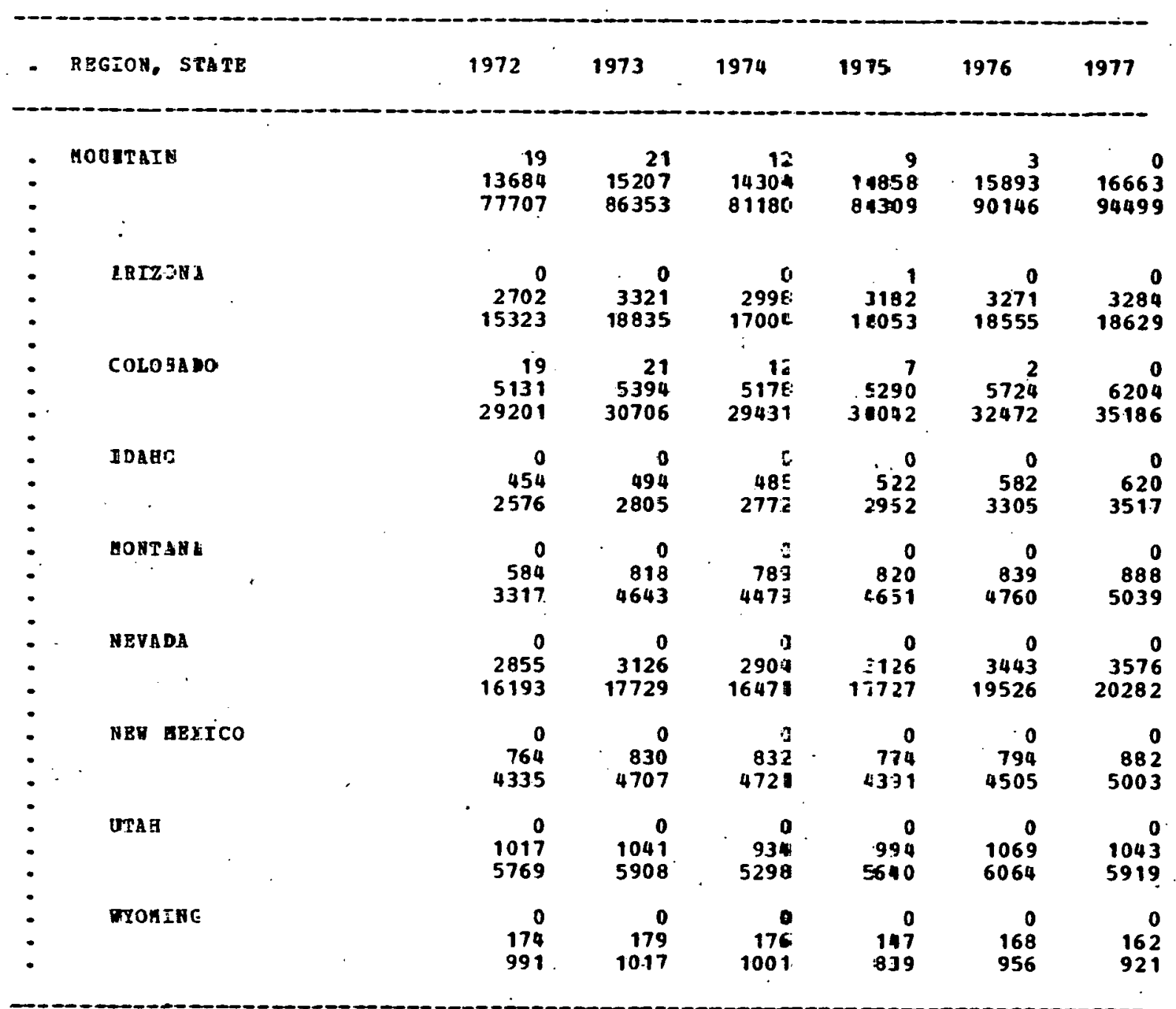

SO DRCE: URTECD 101

DATA QDALITY: 1

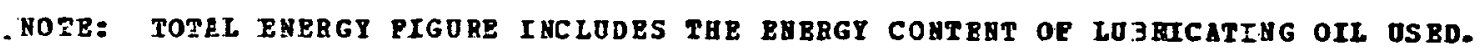


TAELE 3.5I -- 0.S. CERTIPICATED AIBCRAPT FOEL AND EAERG OSE. BY FOEL BY STATE, 1972-77

(LAST IN A SERIES OP NINE TABLES)

ATITION GASOLINE USE IN THOUSANDS OP BARRELS

FOLLORED BY JET POEL OSE IN THODSABDS OP BABQELS

POLLOHED BY TOTAL EBERG OSE IB BILLIONS OF BTU

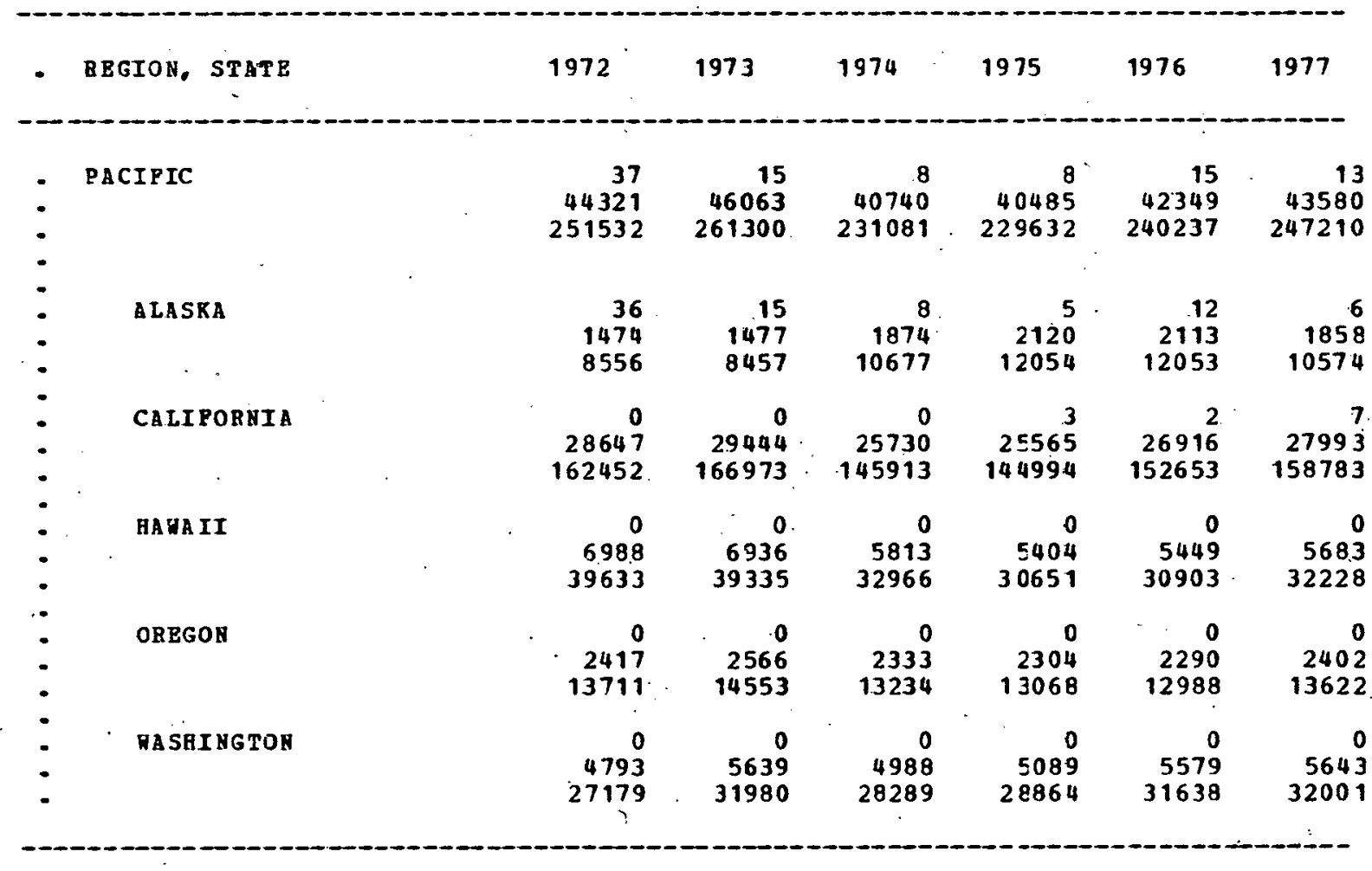

SOORCE: HETHOD 101

DATA QUALITY: 1

NOTB: TOTAL ENERGY PIGURE INCLUDES THB ENRBGY CONTERT OF LUBEICATIYG OIL OSED. 


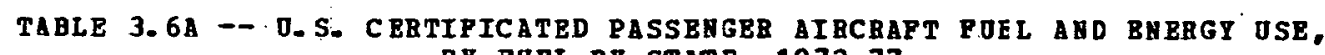
BY POEL BI STATB, 1972-77

(PIRST IA A SERIBS OP HIBE TABLES)

AVIATTON GASOLIRB USB IR THOUSANDS OP BAERELS

POLLOTED BY JBT POEL DSE IN THOUSAHDS OF BA SRBLS

FOLLONED BY TOTAL EHBBGY OSB IB BILLIONS OP BTO

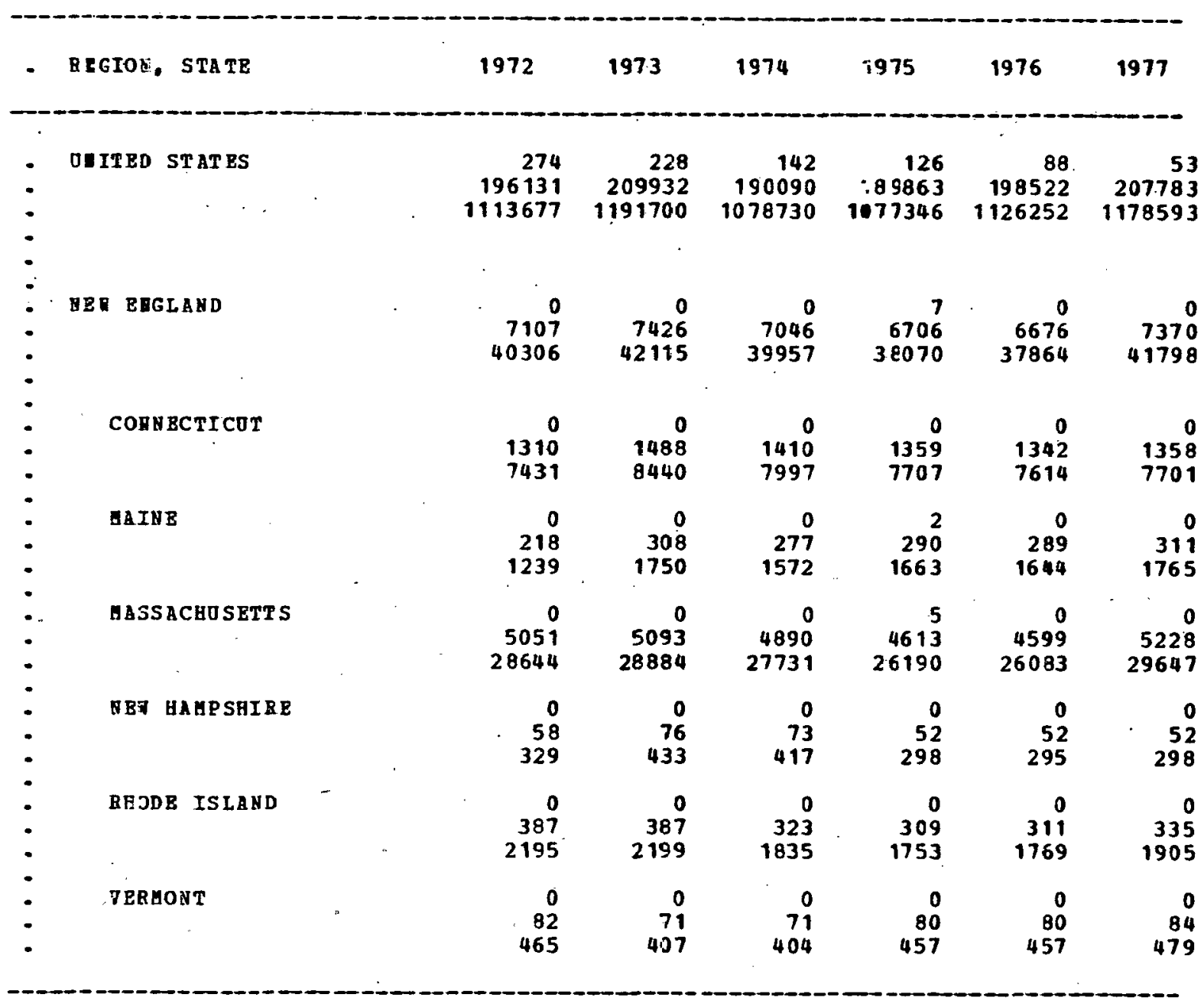

SOUBCE: $\triangle E T H O D 101$

DATA QOALITI: 1

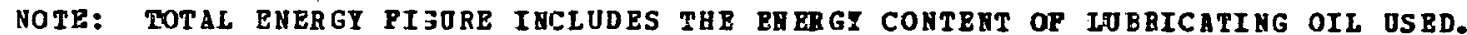


TABLE 3.6B -- D.S. CERTIPICATED PASSEHGER AIBCBATT FUEL AAD BHERG OSE, BY PUEL BY STATE. 19.72-77

(SECOND IN A SERIBS OP NINB TABLES)

AVIATIOA GASOLINE USB IA THOUSANDS OP BARBELS

POLLORED BI JET POEL USE IN THOUSANDS OP BAERELS

FOLLORBD BY TOTAL ENERGI USE IU BILIIONS OF BTO

\begin{tabular}{|c|c|c|c|c|c|c|}
\hline - REGION, STETE & 1972 & 1973 & 1974 & 1975 & 1976 & 1977 \\
\hline $\begin{array}{l}-\quad \text { UID-ATLANTIC } \\
-\quad\end{array}$ & $\begin{array}{r}0 \\
32184 \\
182513\end{array}$ & $\begin{array}{r}0 \\
33100 \\
187705\end{array}$ & $\begin{array}{r}0 \\
28774 \\
163172\end{array}$ & $\begin{array}{r}0 \\
28404 \\
161078\end{array}$ & $\begin{array}{r}0 \\
29172 \\
165433\end{array}$ & $\begin{array}{r}0 \\
30331 \\
172006\end{array}$ \\
\hline $\begin{array}{l}- \\
:\end{array}$ & $\begin{array}{r}0 \\
65 \\
373\end{array}$ & $\begin{array}{r}0 \\
66 \\
374\end{array}$ & $\begin{array}{r}0 \\
51 \\
291\end{array}$ & $\begin{array}{r}0 \\
57 \\
323\end{array}$ & $\begin{array}{r}0 \\
24 \\
136\end{array}$ & $\begin{array}{r}0 \\
38 \\
218\end{array}$ \\
\hline$\therefore$ NER TORE & $\begin{array}{r}0 \\
24349 \\
138081\end{array}$ & $\begin{array}{r}0 \\
24905 \\
141235\end{array}$ & $\begin{array}{r}0 \\
21507 \\
121966\end{array}$ & $\begin{array}{r}0 \\
21191 \\
120173\end{array}$ & $\begin{array}{r}0 \\
21928 \\
124350\end{array}$ & $\begin{array}{r}0 \\
22834 \\
129492\end{array}$ \\
\hline $\begin{array}{l}: \quad \text { PERGSTLTanta } \\
\vdots\end{array}$ & $\begin{array}{r}0 \\
7769 \\
44058\end{array}$ & $\begin{array}{r}0 \\
8128 \\
46095\end{array}$ & $\begin{array}{r}0 \\
7214 \\
40914\end{array}$ & $\begin{array}{r}0 \\
7156 \\
40580\end{array}$ & $\begin{array}{r}0 \\
7220 \\
40945\end{array}$ & $\begin{array}{r}0 \\
7458 \\
42295\end{array}$ \\
\hline
\end{tabular}

SOURCE: $\triangle E T H O D 101$

DATA QOALITY: 1

NOTE: TOTAL BNERGY PIGURE INCLODES TAE ENERGY CONTENT OF LOBRICATING OIL OSBD. 
TABL3 3.6C - O.S. CERTIFICATED PASSEHGER ALRCRAPT FOEL AND BHBRG OSE, BI POEL BI STATE, 1972-77

(CEIRD IN A SBRIBS OP HIBE TABLES)

A TIATIOA GaSOLIHB USE IA THOUSAMDS OP BARRELS

POLLOHED BY $J$ ET POEL OSE IB THOJSABDS OP BA ERELS

FOLIORED EY TOTAL BBEBGI DSE I BILLIOBS OP BTU

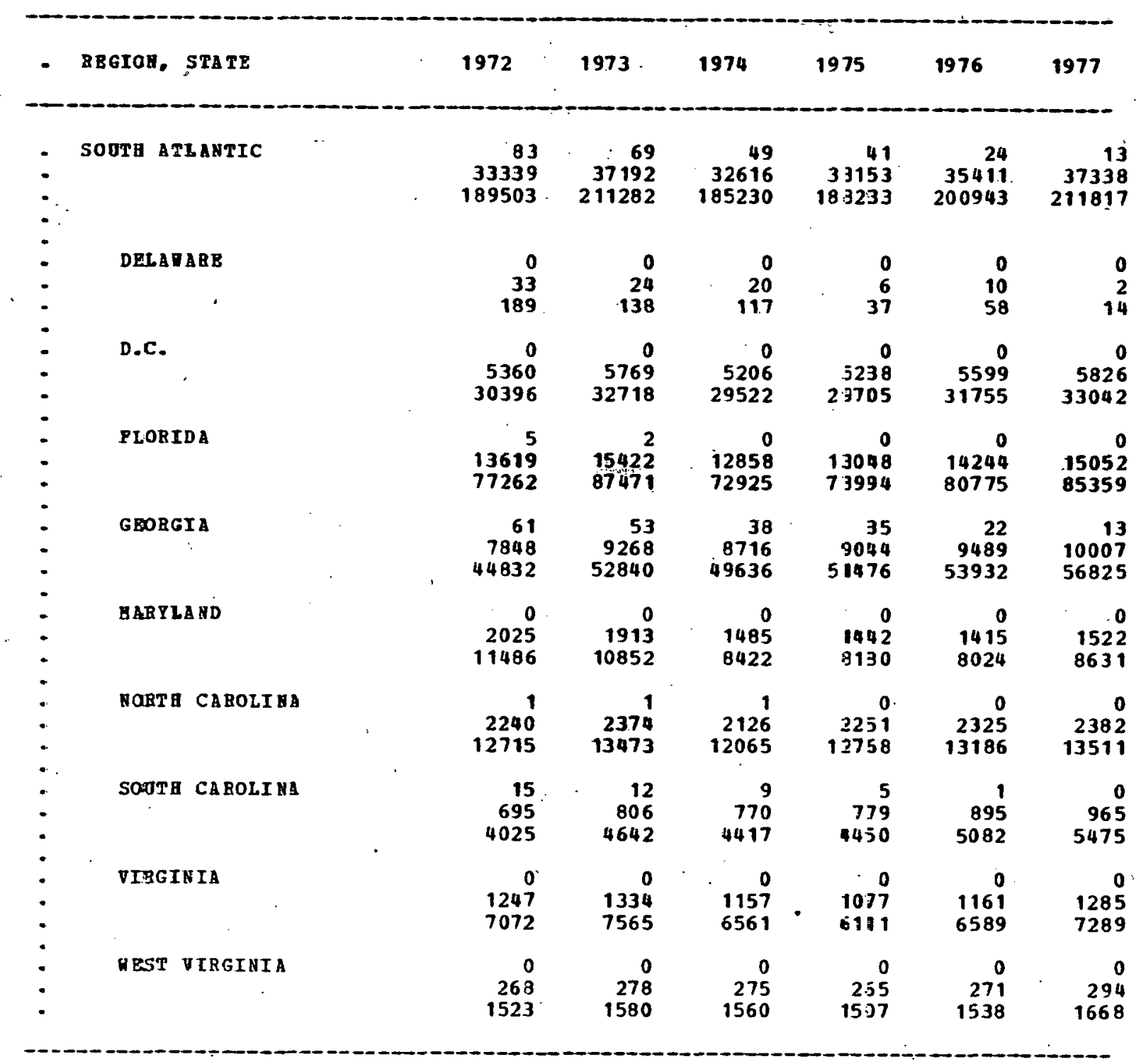


TABLE 3.6D -- D. S. CERTIPICATBD PASSBHGER AIBCBAFT POBL AMD BHERgY OSE BY $P O B I$ BY STATE $1972-77$

(FOORTH IN A SBRIBS OR. NIYE TABLES)

ATIATION GASOLIAB OSE IN THOOSANDS OP BARRELS

POLLORED BY JET POBL OSB IN THODSANDS OP BABRELS

POLLORED BY TOTAL EREBGT OSE IM BILLIOHS OP BTU

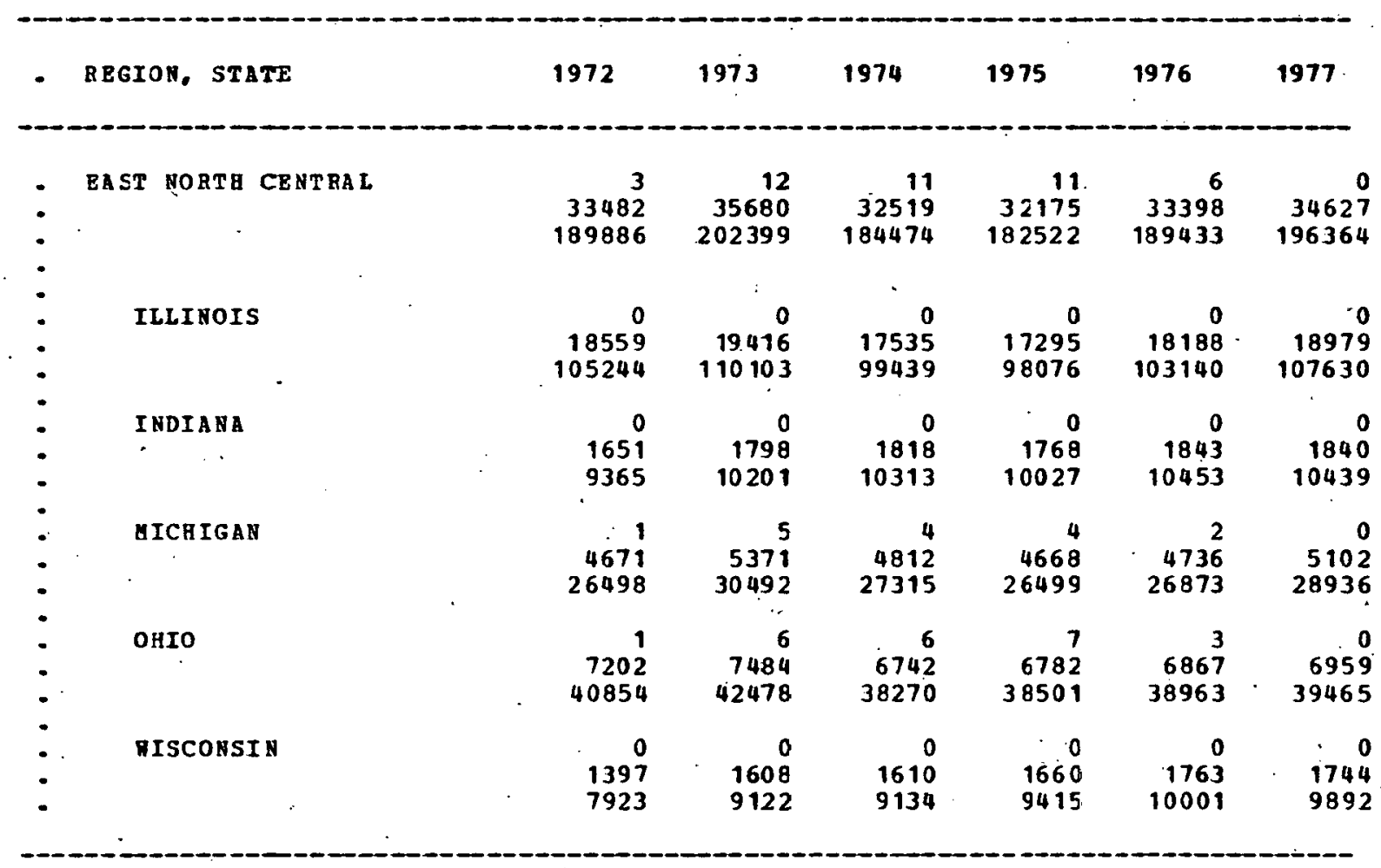

SOORCE: METHOD 101

DATA QOALITI: 1

NOTE: TOTAL EARRGY PIGURE IMCLODES THE ENBRGY CONTEHT OP LUBEICATIG OIL USED. 


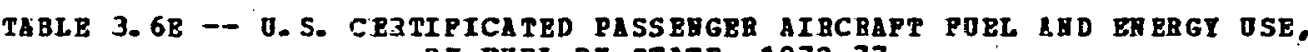
BI PUEL BI STATE, 1972-77

(PIFTH IB A SBRIBS OF HIBB TABLES)

ATIATION GASOUTBE OSB IY THOUSARDS OP BARREIS

FOLLOREO 31 J BT PUBL USE IN THOOSAIDS OP BAEERLS

POLLONED BY TOTAL ENERGY OSE IB BILLIOYS OF ETO

\begin{tabular}{|c|c|c|c|c|c|c|}
\hline - REGIGH, STATE & .1972 & 1973 & 1974 & 1975 & 1976 & 1977 \\
\hline $\begin{array}{l}-\quad \text { BAST SOJTH CBNTRAL } \\
- \\
=\end{array}$ & $\begin{array}{r}124 \\
.5232 \\
30327\end{array}$ & $\begin{array}{r}103 \\
6086 \\
35067\end{array}$ & $\begin{array}{r}58 \\
5650 \\
32355\end{array}$ & $\begin{array}{r}45 \\
5 E 65 \\
3.3503\end{array}$ & $\begin{array}{r}37 \\
6185 \\
35279\end{array}$ & $\begin{array}{r}24 \\
6488 \\
36926\end{array}$ \\
\hline$\because \quad \cdot$ & & & & & & \\
\hline ALABAGA & $\begin{array}{r}32 \\
1127 \\
6567\end{array}$ & $\begin{array}{r}27 \\
1322 \\
7647\end{array}$ & $\begin{array}{r}17 \\
1191 \\
6845\end{array}$ & $\begin{array}{r}15 \\
1190 \\
6835\end{array}$ & $\begin{array}{r}12 \\
1286 \\
7361\end{array}$ & $\begin{array}{r}7 \\
1344 \\
7663\end{array}$ \\
\hline KENTUCKY & $\begin{array}{r}0 \\
980 \\
5560\end{array}$ & $\begin{array}{r}0 \\
1093 \\
6203\end{array}$ & $\begin{array}{r}0 \\
944 \\
5357\end{array}$ & $\begin{array}{r}0 \\
1012 \\
5743\end{array}$ & $\begin{array}{r}0 \\
1098 \\
6230\end{array}$ & $\begin{array}{r}0 \\
1124 \\
6378\end{array}$ \\
\hline MISSISSIPPI & $\begin{array}{r}47 \\
379 \\
2400\end{array}$ & $\begin{array}{r}37 \\
512 \\
3104\end{array}$ & $\begin{array}{r}27 \\
480 \\
2867\end{array}$ & $\begin{array}{r}18 \\
493 \\
2897\end{array}$ & $\begin{array}{r}15 \\
488 \\
2848\end{array}$ & $\begin{array}{r}11 \\
513 \\
2971\end{array}$ \\
\hline $\begin{array}{l}- \\
-\end{array}$ & $\begin{array}{r}44 \\
2744 \\
15799\end{array}$ & $\begin{array}{r}38 \\
3158 \\
18112\end{array}$ & $\begin{array}{r}14 \\
3034 \\
17285\end{array}$ & $\begin{array}{r}11 \\
3168 \\
13025\end{array}$ & $\begin{array}{r}9 \\
3313 \\
18838\end{array}$ & $\begin{array}{r}6 \\
3505 \\
19914\end{array}$ \\
\hline
\end{tabular}

SOOBCE: SETEOD 101

BATA OOALITY: 1

DOTE: TOT AL EHERGY PIGURE INCLUDSS THB BNBRGY CONTERT OF LUB3IEATIBg OIL USED. 

TABLB 3.6P -- 0.5. CERTIPICATBD PASSEHGER AIRCBAFT FOBL ABD BNBRG OSE,
BY POBL BI STATE, 1972-77

(SI XTH IB A SERIES OF NIBB TABLES)

AVIATION GA SOLIHE OSE IM THOUSAMDS OP BAREELS

FOLLONED BY JET POEL USE II THOUSANDS OF BABRELS

FOLLORED BY TOTAL EUERGT OSE IQ BILLIONS OP BTU

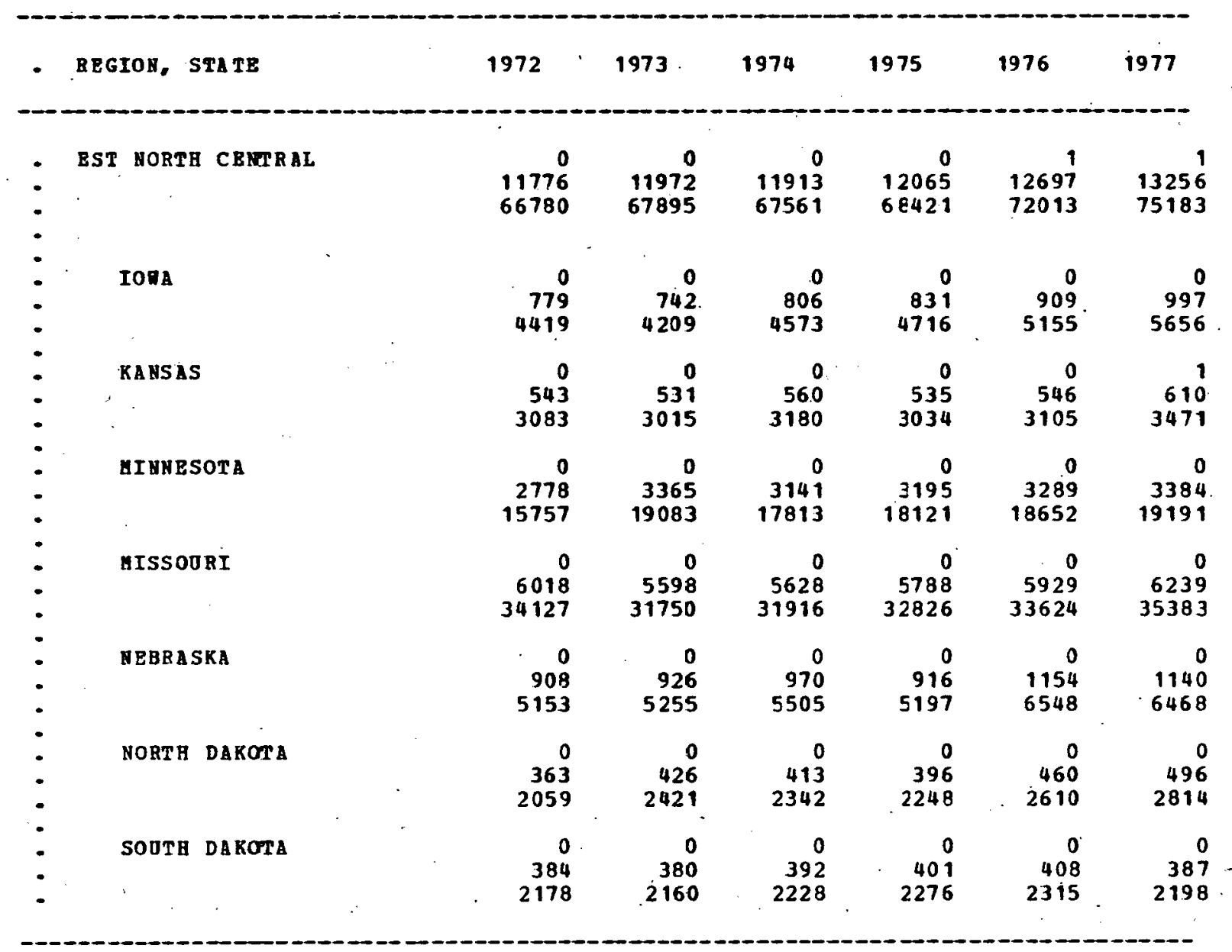

SODRCE: HETHOD TO1

DATA QUALITY: 1

NOTE: TOTAL EHERGY FIGURE INCLODES THE ENBRG CONTEAT OP LUBAICATING OIL OSBD. 
TABLE 3.6G -- 0.S. C.BRTIPICATBD PASSBNGER AIBCFAPT POEL AND EHERGT OSE, (SBVENTE TE A SBRIES OP MIBE TABLBS)

AVIATIOS GASOLTHE USB I THOOSAHOS OP BARRELS

POLIORED BI JET POEL USE IB THOUSANDS OP BABRBLS

POLLOWE BY TOTAL ERERG OSE IN BILLIONS OP BTD

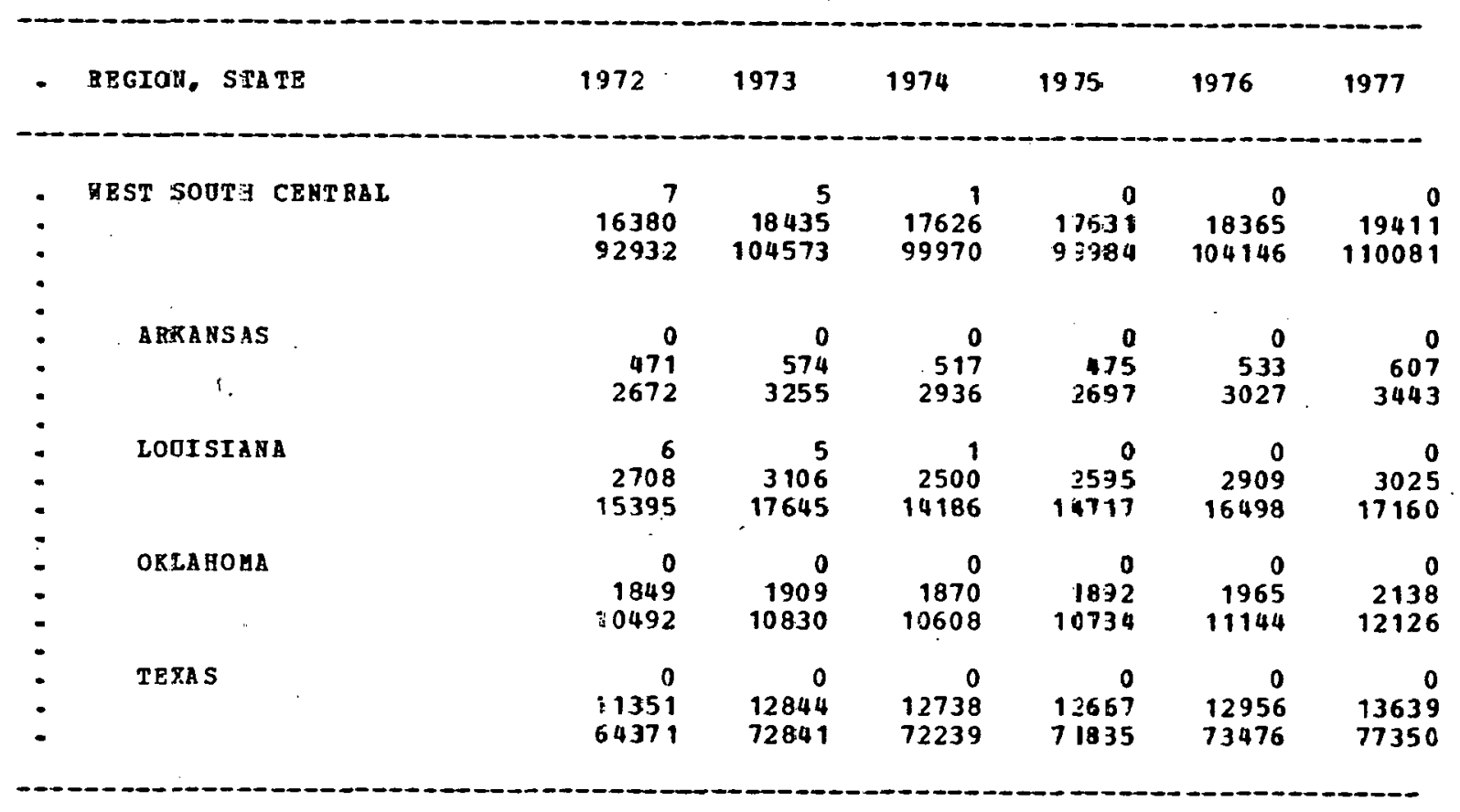

SJOECE: METHOD 101

MATA QULLITY: 1

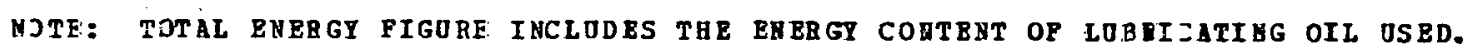



TABLE 3.6B -- O.S. CERTIFICATED PASSERGER AIRCRAPT POEL AND ENERGY USE,

(EIGHTH IN A SERIES OP NINB TABLES)

AVIATION GASOLINE USE IA THOOSANDS OP BABRELS

POLLOYED BI JET POBL OSB IN THOUSAHDS OP BABRBL

FOLLONED BI TOTAL ENERGY OSE IN BILLIONS OF BTO

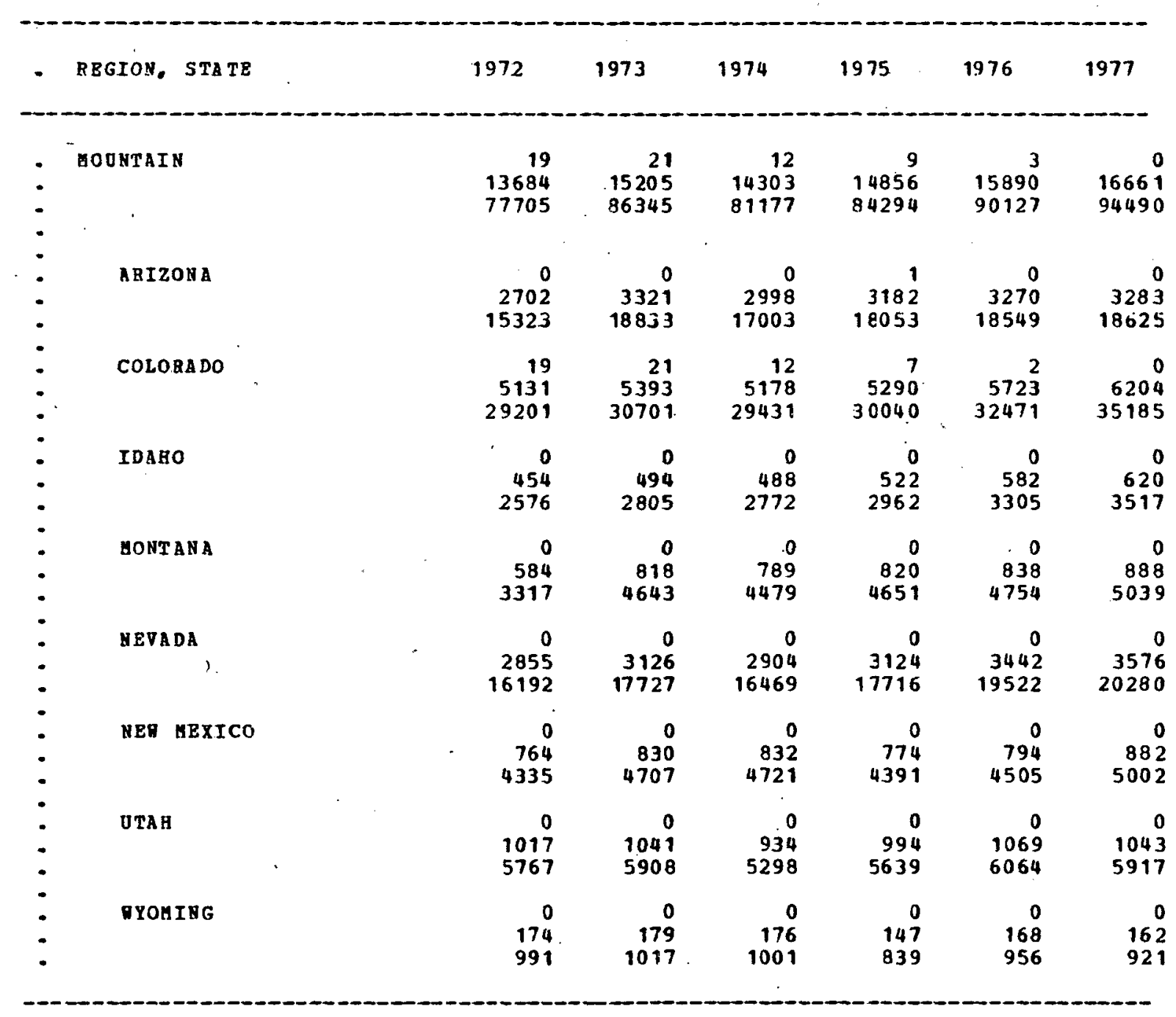

SO UACE: METHOD 101

DATA QUALITY: 1

NOTE: TOTAL BAERGY PIGORE INCLUDES THE BREBGY COHTENT OF LUBAICATING OIL USED. 
TABLE 3.ET -- O. S. CERTIEICATRD PASSELGER AIRCBAPT POEL AND ERBRY USE,

B7 POBD BY STATB 1972-77

(NIMTG IN A SBRIBS OP NIRE TABLES)

ATIATION GASOLIRE OSE IB THOUSA NDS OP BARRBLS

POLLORBD BI JET PDEL USB IY THOOSA

POLLORED BT TOTAL EREBGY OSE IV BILLIONS OP BTO

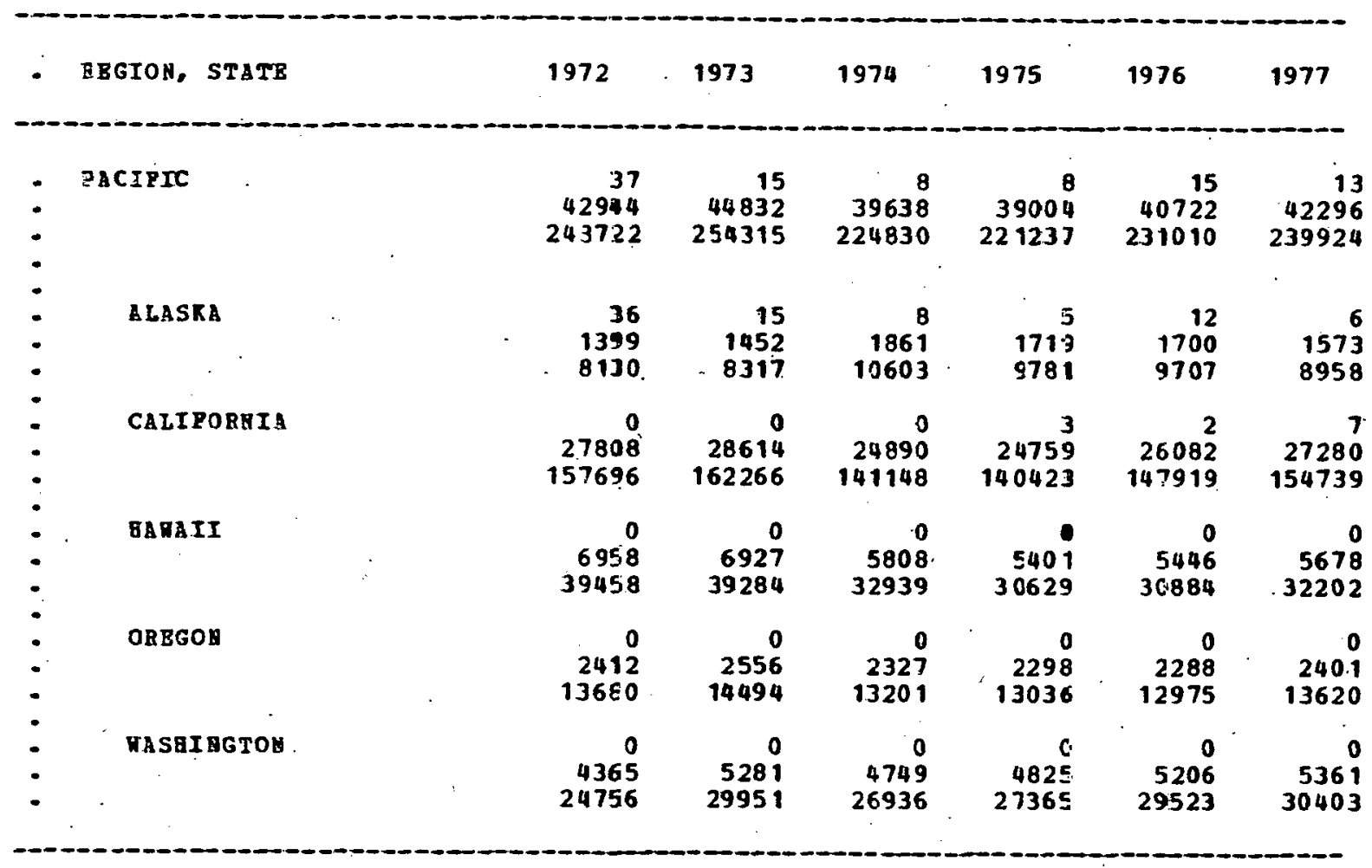

SOURCF: AETHOD 101

DATE QOALITI: 1

NOTE: TOTAL ERERG FIGURE IHCLUDES THB ENERGI CONTBHT OF LUBAICATING OIL OSED. 

TABLE 3.7A - O.S. CERTIFICATED FERTGHT ATBCBAFT FUBL AND ENEBGY USB,
BY FOEL BP STATB, 1972-77

(PIBST IN A SERIES OP NIHE TABLES)

AVIATION GASOLIHE USB IN THOUSABDS OP BABREL

FOLLORED BY JET FOEL USE IN TEOOSANDS OP BARRELS

FOLLORED BY TOTAL. ENBRGT OSE IN' BILIIONS OF'BTO

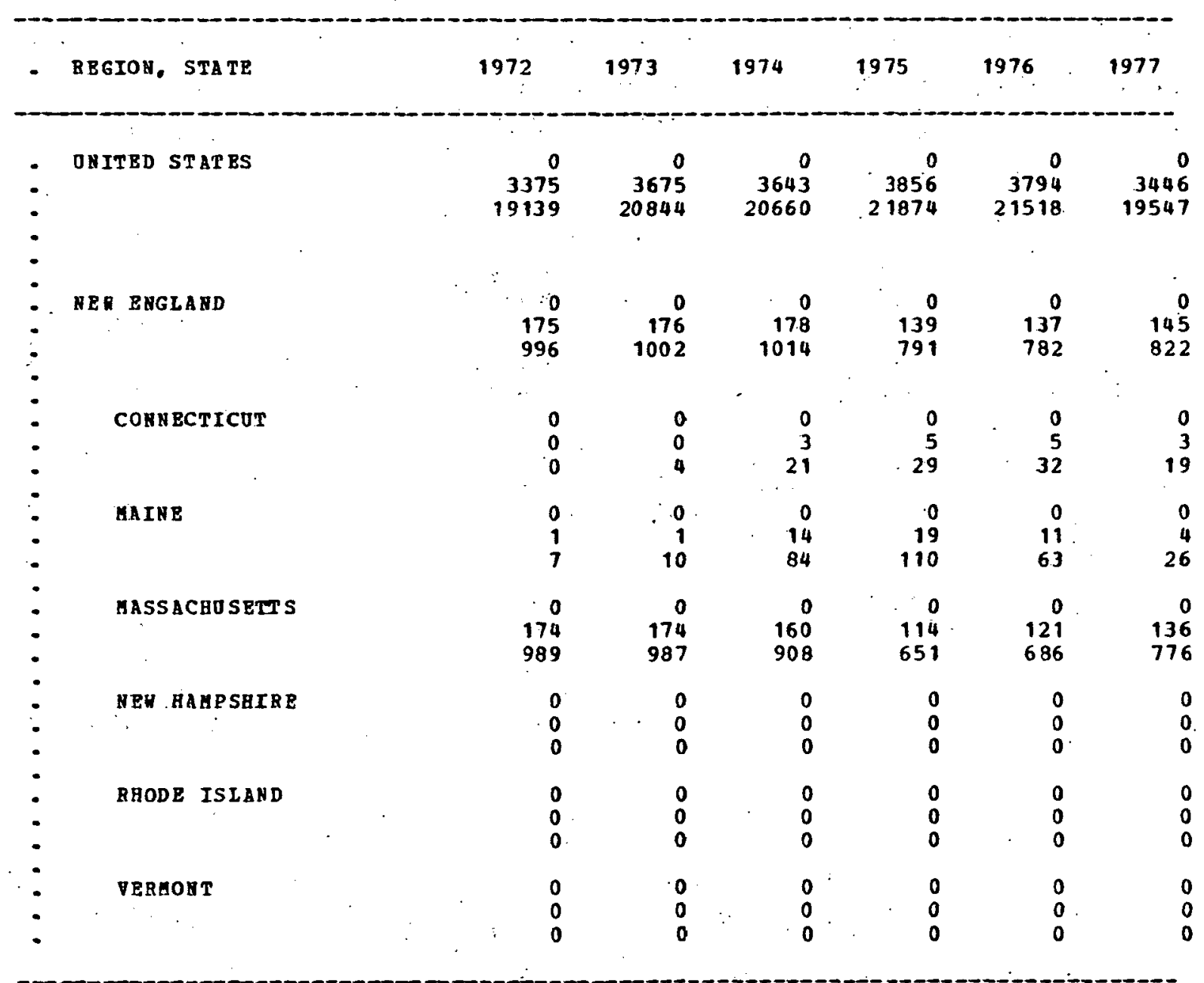

SOORCE: УETHOD 101

DATA QUALITY: 1

HOTE: TOTAL EHERGY PIGUBE INCLODES THE ERERY CONTENT OP LOBAICATING OIL USED. 


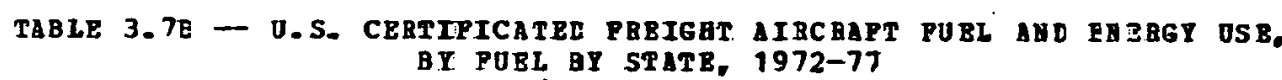

(SBCOND IN Á SBBIBS OF VIYB TABLES)

AVIATIOA GASOLIHB USB IN THOUSAHDS OP BABBRLS

ZOLLONBD BY JET FOEL OSB IB THOOSAMDS OP BABRBLS

FOLLONED BY TOTAL EYBBGI OSE IA BILLIONS OF BTO

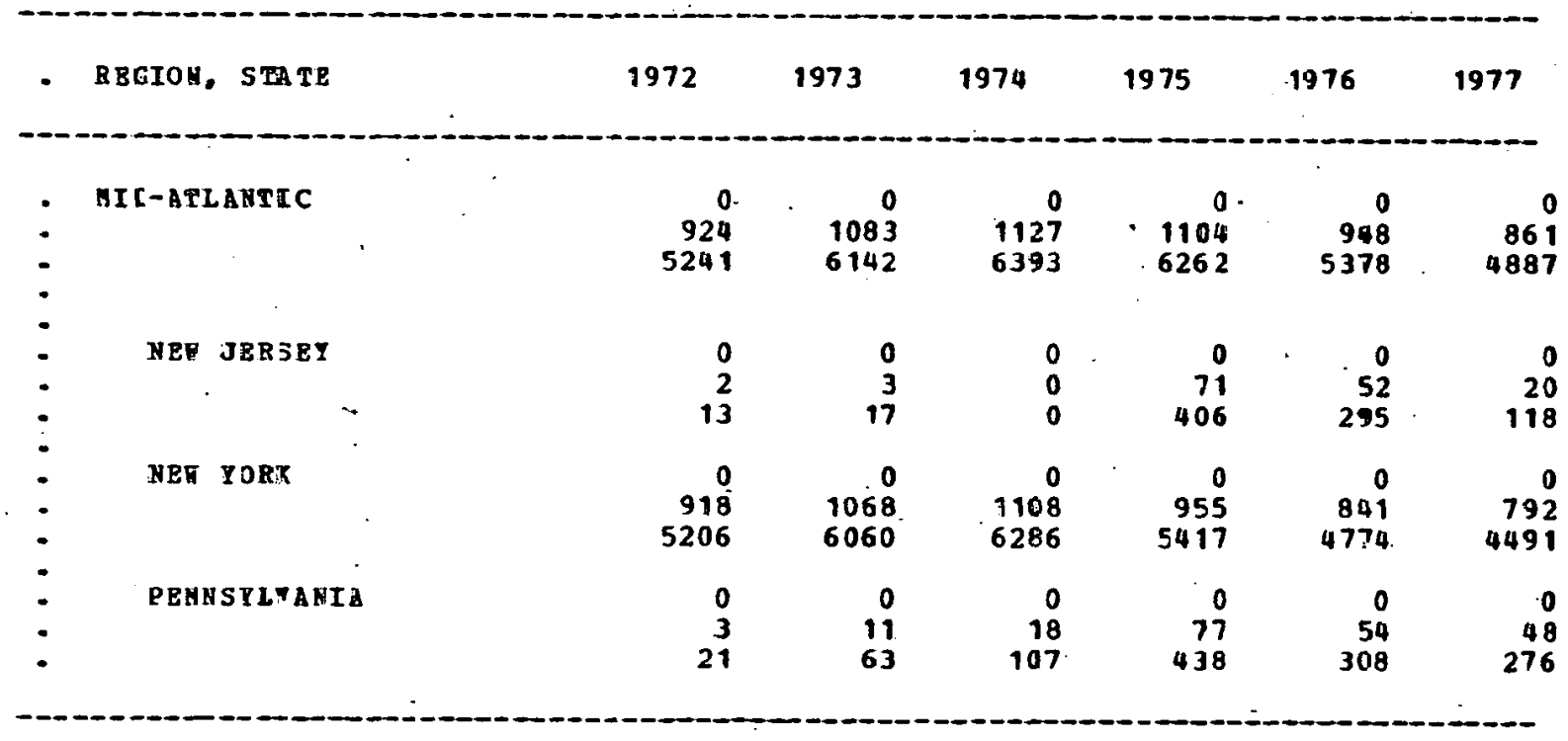

SOORCE: UETEOB 10:1

DATA GUALITY: 1

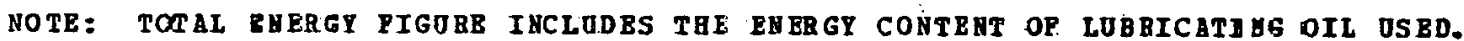




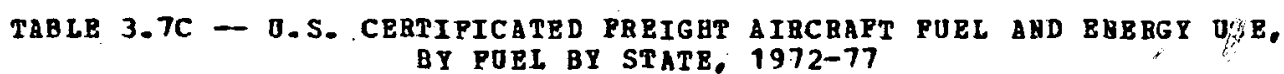

(THIRD IN A SBRIBS OP. NINE TABLES)

ATIATIOA GASOLINE OSE IN THOUSANDS OP BARRELS

FOLLOYED BY J BT POEL OSE IY THOOSABDS OF BAGRBLS

POLLOUBD BY TOTAL BHBBG OSE IN BILLIONS OP BTD

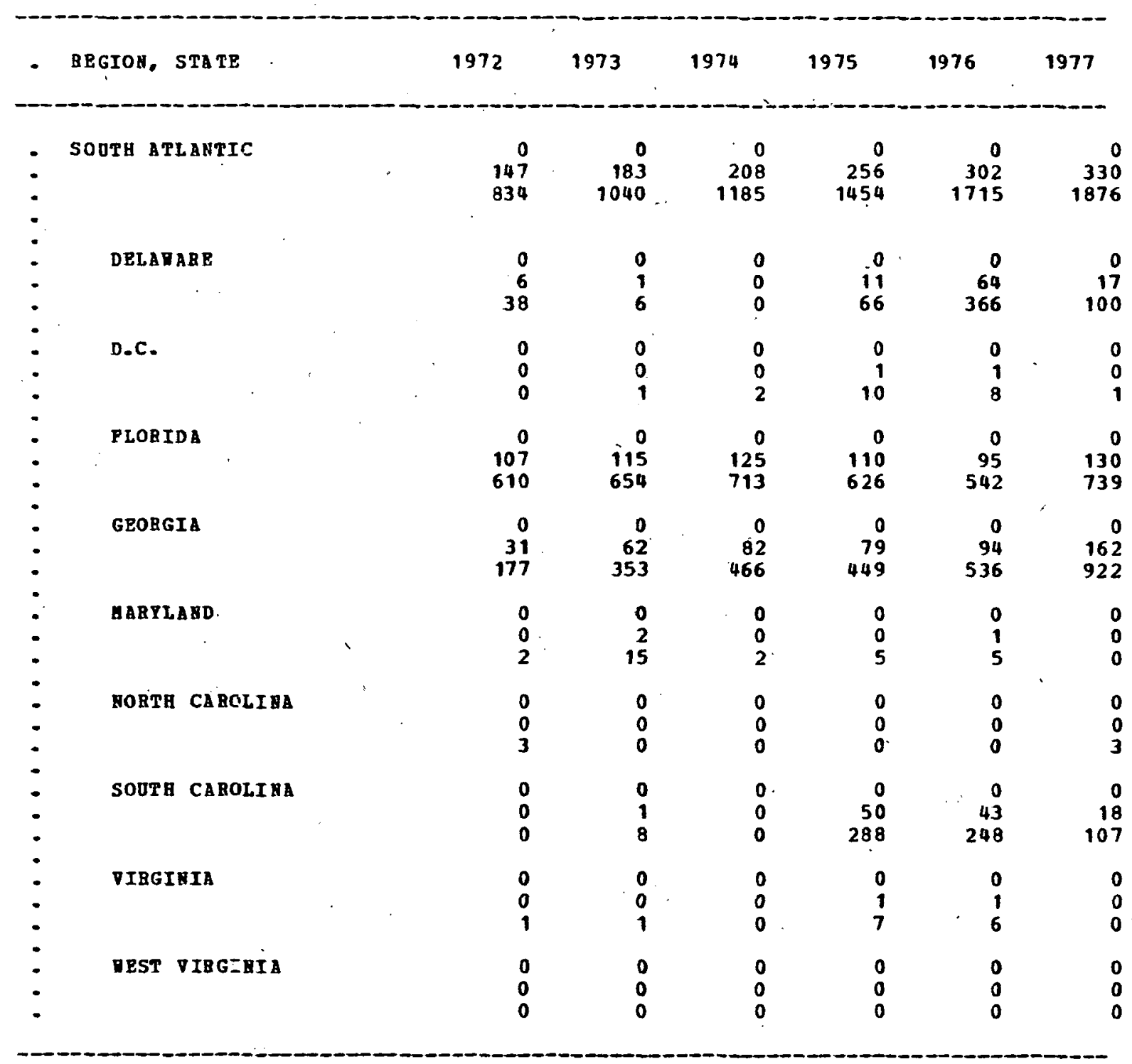

SO ORCE: AETHOD 101

DATA QUALITY: 1

NOTB: TOTAL EH3RGY PIGURE IRCLUDES THE EBEBGY CONTERT OP LOBAICATING OIL OSBD. 


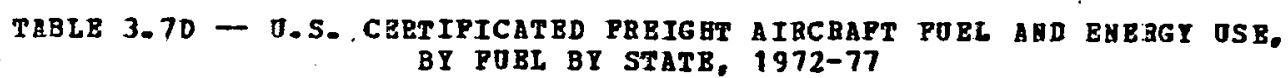

(FOJETH IM A SBRIBS OP NIMB TABLES)

APIATIOR GASOLIRE USE IE THOUSANDS OP BABRELS

FOLLOYED 35 JET POBL OSB IE THOOSABDS OP BAEAELS

FOLLORED 3Y TOTAL BRERG OSB IA BILLIOBS OP $\exists T$

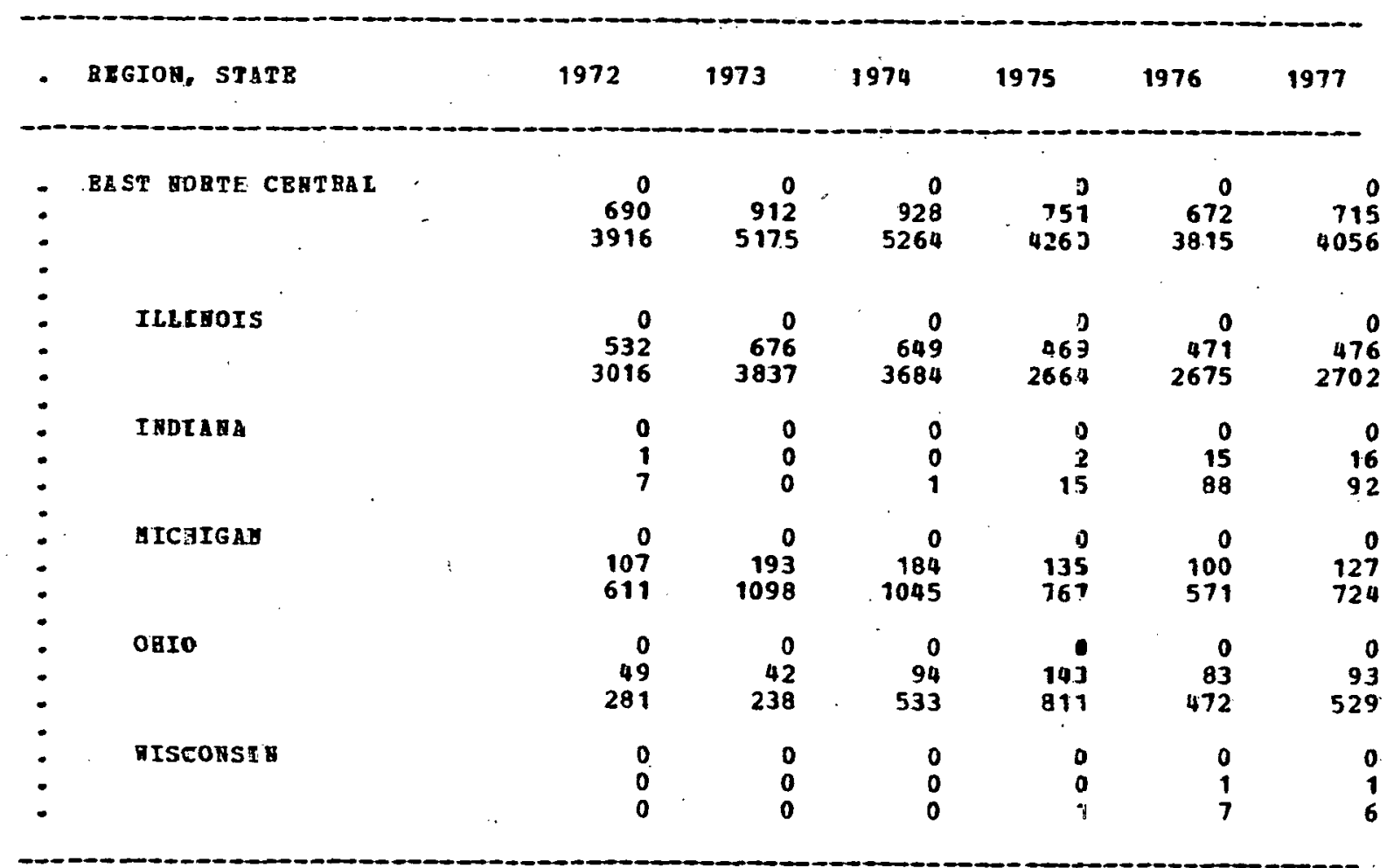

SOURCE: RETHOT 101 DSTh QOAIITY 1

NOTB: TOTAL IMERGY PIGORE INCLODES THB ERERGT COBTEAT OP LOBAICATIYG OIL OSRD. 
TABLE 3.7E - D.S. CERTIFICATBd PBEIG AT AIBCAPT FOEL ABD BNEBgY USB, BY PUEL BY STATE, 1972-77

(PIFTH IN A SERIBS OP NINB TABLES)

AVIATION GASOLIRE OSB IR THOOSABDS OP BARRELS

FOLIORBD BY JET POBL DSB IM THOOSANDS OP BABRELS

FOLLORED BY TOTAL ENBRGI OSB IN BILLIOHS OP BTO

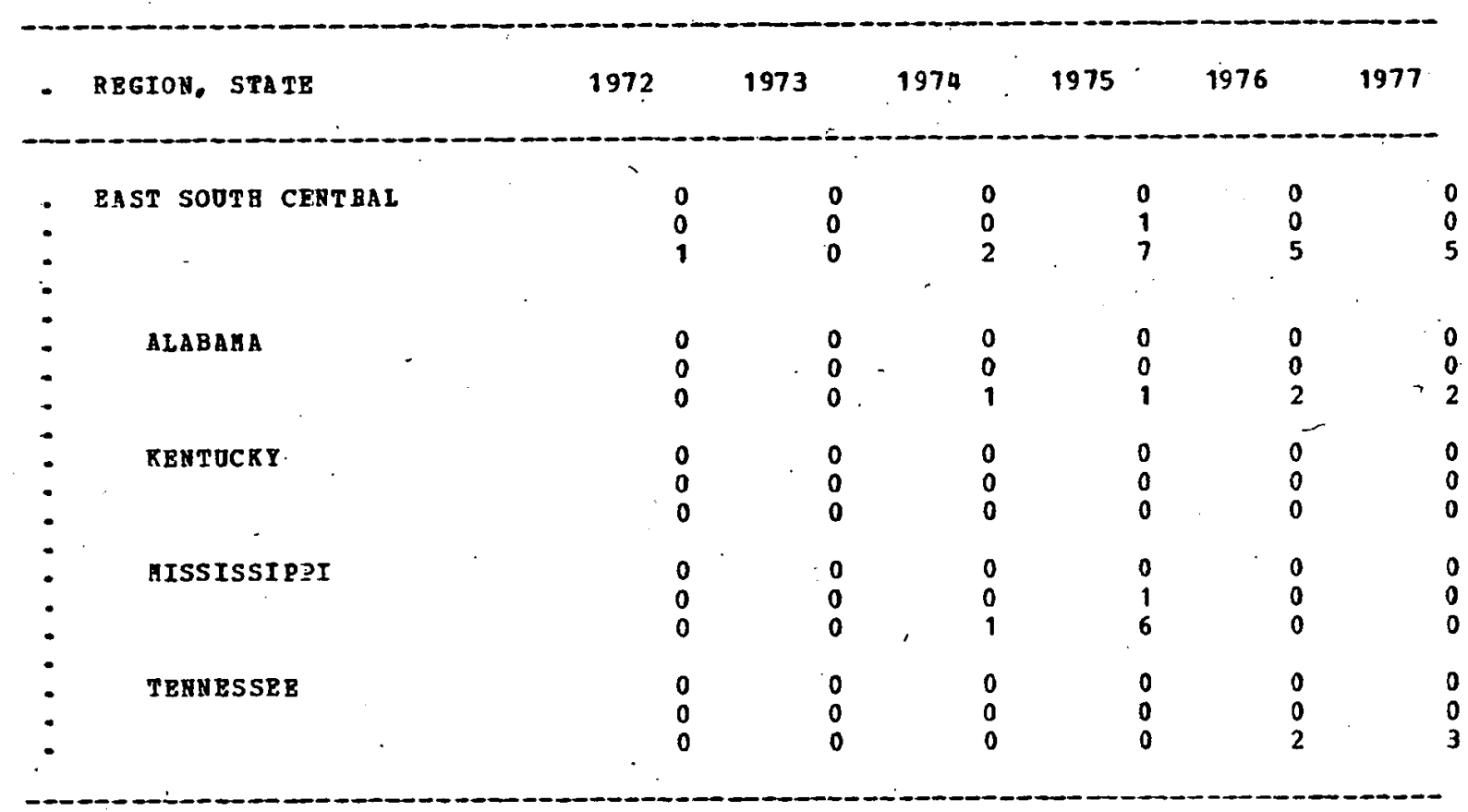

SOORCE: METHOD 101

DATA QUALITY: 1

HOTE: TOTAL EBEBGY PIGURE INCLODBS THB ENEBGY CONTENT OF LOBAICATING OIL USBD. 

TA3LE 3.7P - O.S. CEBTIPICATED FREIGHT AIBCBAPT FUBL ADD EAERGY USB,
BI POBL BY STATB, 1972-77

(SIRTH IY A SERIBS OP NIYE TABLES)

AVIATIOE: GASOLIRE OSE IR THOOSARDS OP BABRELS

POLLOR3D EY JET POBL USE IN THOUSANDS OP BA BREJS

FOLLOHBD EY TOTAL ENERGY OSE IV BILLIONS OP BTT

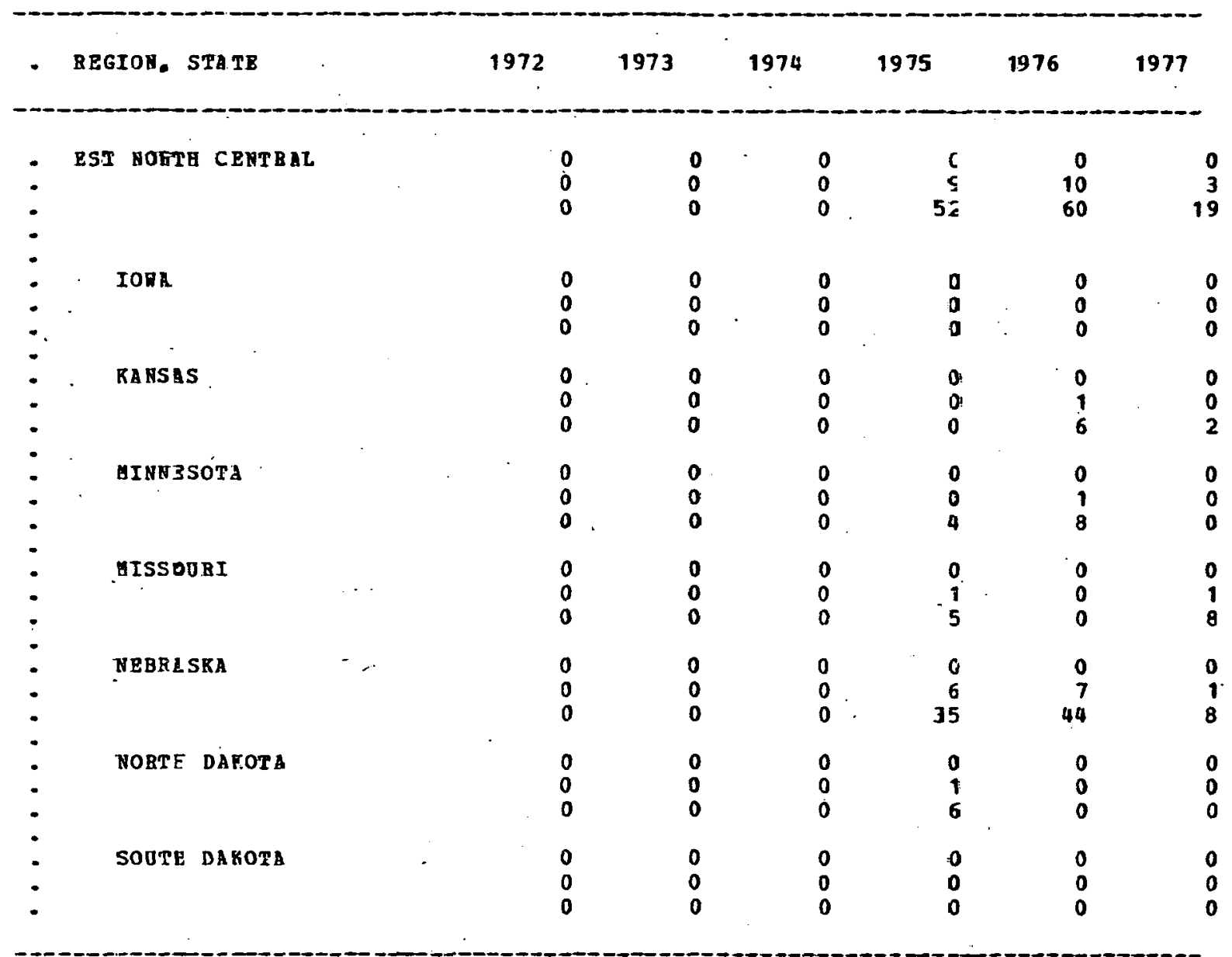

SOUECE: UETHOD 101

DATA QUALITY: 1

NOTE: TOTAL EHERGY PIGORE INCLODES THB EABRG COMTELT OF LOBAICATIMG OIL OSBD. 
TABLE 3. TG - O.S. CERTIPICATBD FBEIGHT AIBCBAPT POEL AMD EUBGT OSB, BY FUBL BI STATE, 1972-77

(SBVENTE IR A SERTBS OP NIAB TABLES)

A VIATIOA GASOLINE OSE IM THOUSALDS OP BARBES

POLLOUED BY JBT PDEL USB IA THOUSANDS OP BABRLS

POLLORED BI TOTAL BHBRG DSB I\& BILLIOSS OP BTO

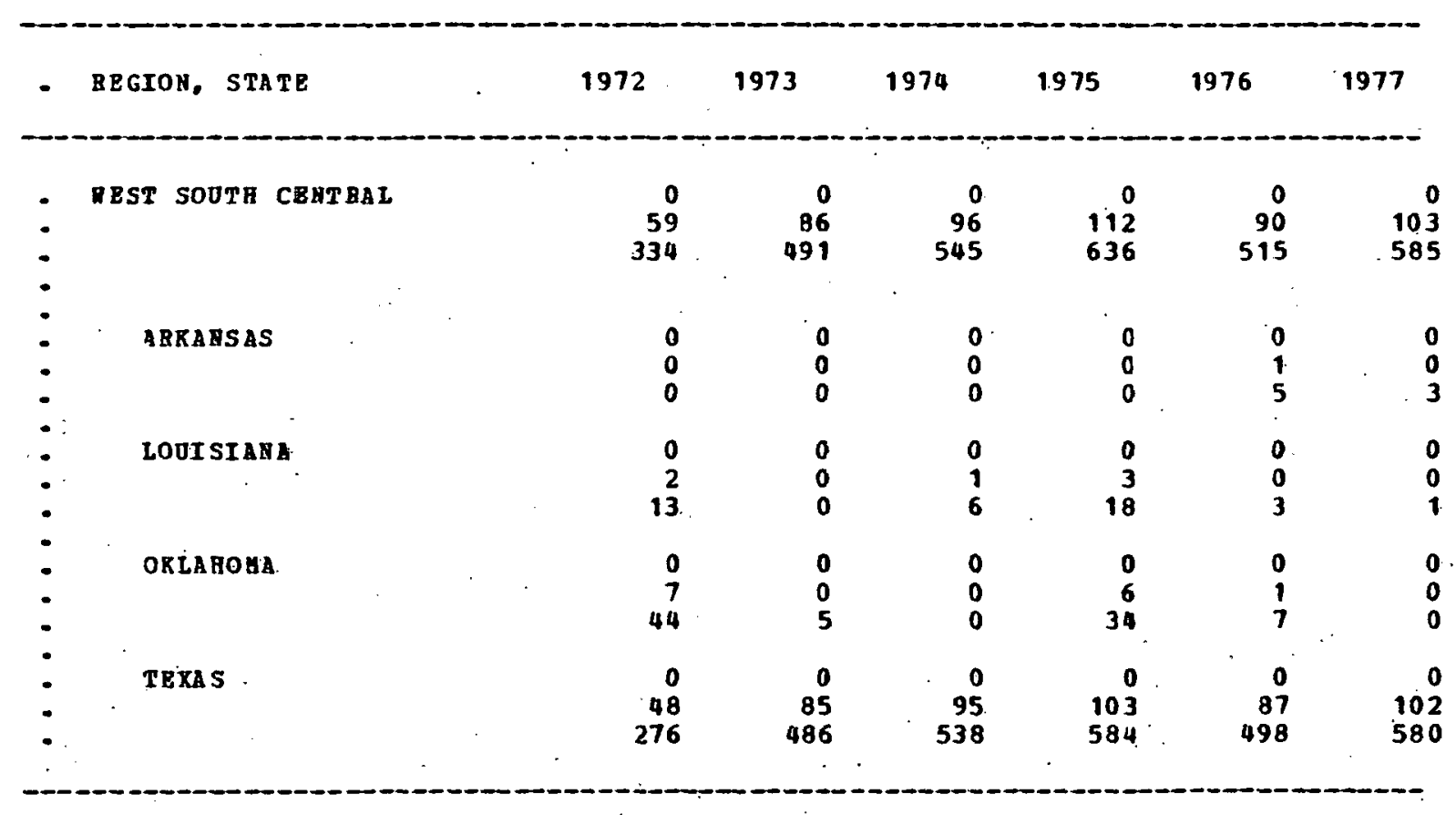

SOORCF: AETHOD 101

DATA QUALITY: 1

NOTE: TOTAI EHEBGY FIGURE INCLUDES THB EBBGI COATBHT OP LUBAICATIAG OIL USED. 


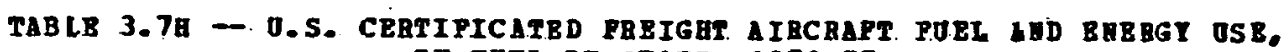
BY FUB.L BI STATB, 1972-77

(BIGHTH IN A SERIBS OP AIRB TABLBS)

AVIATIOY GASOLIUE OSB IA THOUSABDS OF BARRELS

FOLLOHES: BI JBT FOEL OSE IY THOUSARDS OF BAEBELS

POLLORSJ BI TOTAL BEERG OSE IA BILLIOHS OF BYO

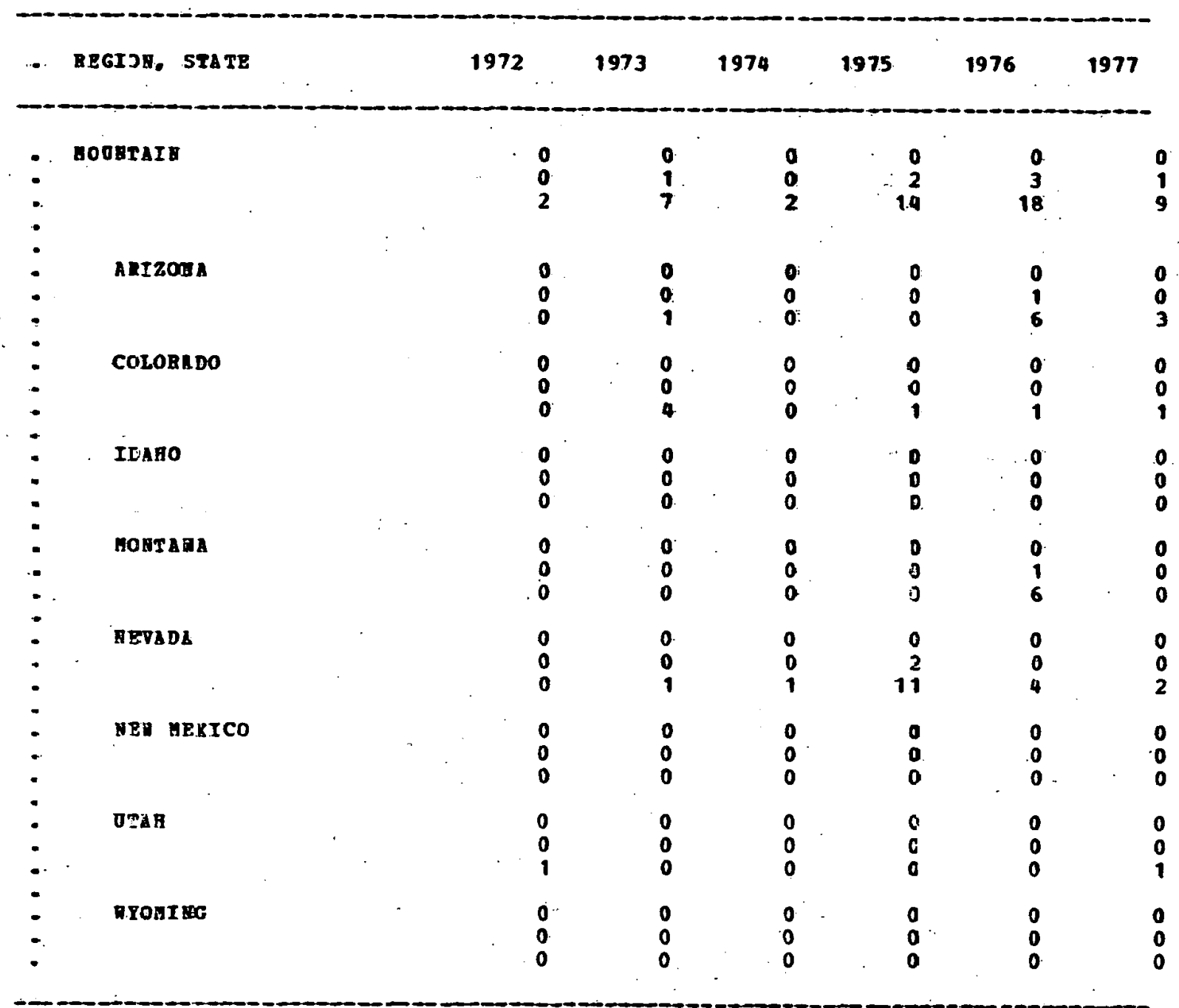

SO ORCE: GETHOD 101.

DTA QOALTT: 1

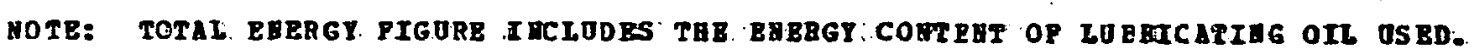


TABLE 3.7I - D.S. CERTIFICATED PREIGHT AIRCBAFT FOEL AHD ENERGY USE, BY POEL BY STATB, 1972-77

(NINTH IN A SERTES OP NINE TABLES)

AVIATION GASOLINE OSE IN THOUSAHDS OF BARRELS

FOLLORED BY JET PUEL OSB IB THOOSANDS OP BAEBELS

FOLLOAED BY TOTAL ENERGY USE IH BILLIOHS OP BTO

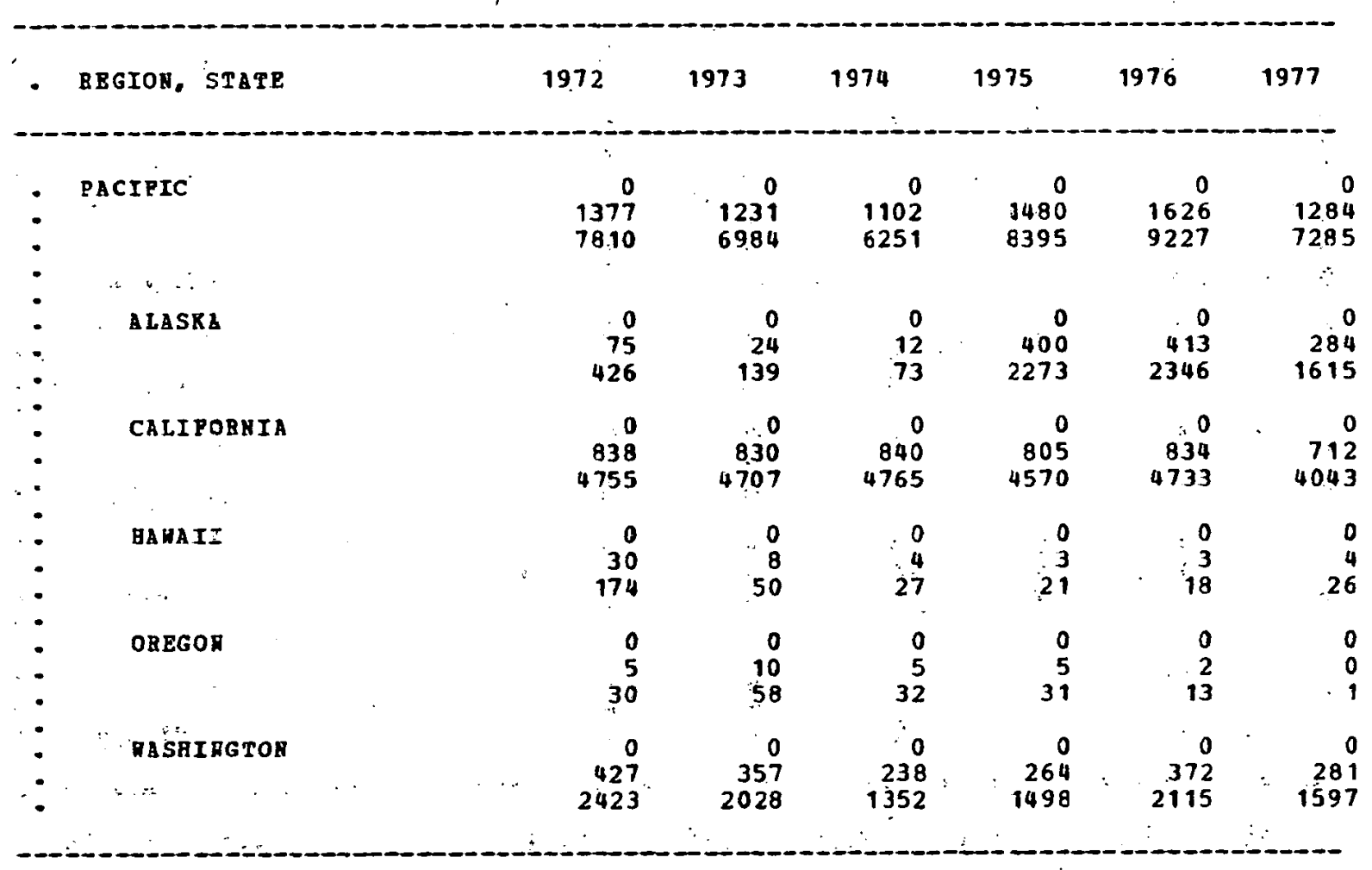

SOORCE: METIOD 101

DATA QUALITI: 1

BOTE: TOTAS EHERGY FIGURE INCIUDES TBE ERBRG CONTBNT OP LOBAICATIRG OIL. USED. 


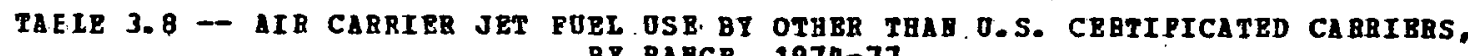
B BABG, 1974-77

JET POEI USE IA THOUSAYDS OP BARBEL.j.

FOFLOUED 3 Y EREBGI USE IN BILLIOHS OF BTO

\begin{tabular}{|c|c|c|c|c|}
\hline - BANGB & 1974 & 1975 & 1976 & 1977 \\
\hline - ALL BARGES & $\begin{array}{l}17080 \\
96844\end{array}$ & $\begin{array}{r}18611 \\
105527\end{array}$ & $\begin{array}{r}19435 \\
110199\end{array}$ & $\begin{array}{r}20162 \\
114327\end{array}$ \\
\hline DOHESTIC & $\begin{array}{r}2397 \\
13591\end{array}$ & $\begin{array}{r}2130 \\
12077\end{array}$ & $\begin{array}{r}2143 \\
12150\end{array}$ & $\begin{array}{r}2081 \\
11803\end{array}$ \\
\hline - IRTERNATIOAAL & $\begin{array}{l}14683 \\
83253\end{array}$ & $\begin{array}{l}16481 \\
93450\end{array}$ & $\begin{array}{l}17292 \\
93649\end{array}$ & $\begin{array}{r}18081 \\
102524\end{array}$ \\
\hline
\end{tabular}

SOURCE: HETHODS 102, 1 C5

DaTa QUALITI: 1 (DOHESTIC), 2 (IHTERBational) 


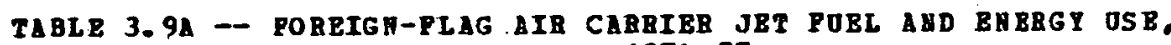
BI STATB, 1974-77

(FIRST IN 1 SBRIBS OP FIVE TABLES)

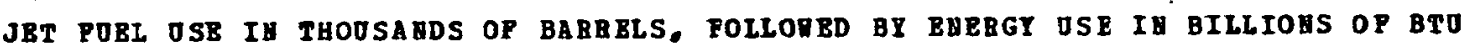

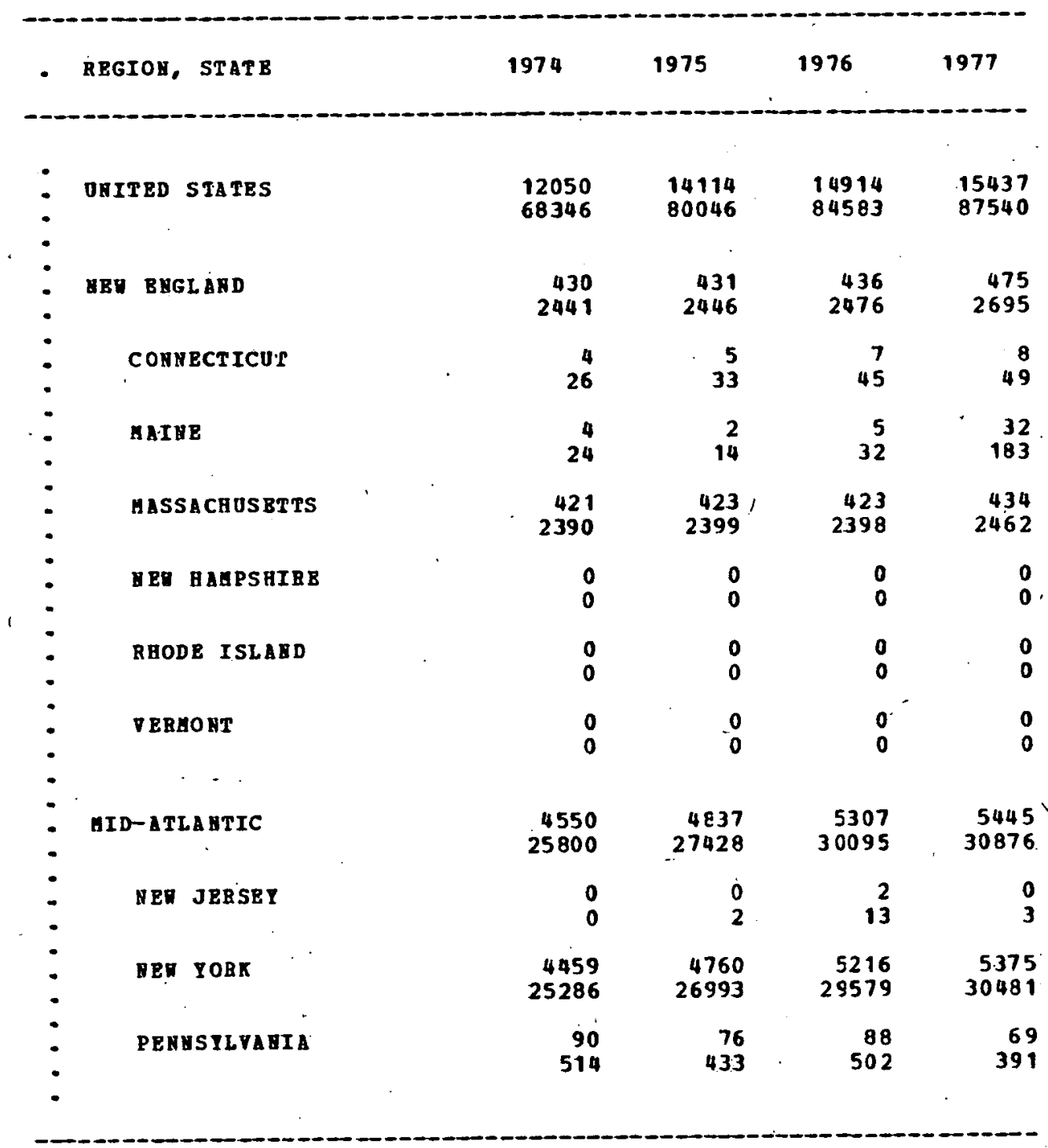


TABLE 3.9B -- POEEIGA-PLAG AIB CARRIBR JET FUBL AND EAERGS OSE, BY STATE, 1974-77 (5ECOND IN A SBRIES OP PITB TABLES)

JET PUEL USE IH THOOSAHDS OP BARBRL, FOLLORED BI BNBAGY USE IB BILLIONS OP BTO

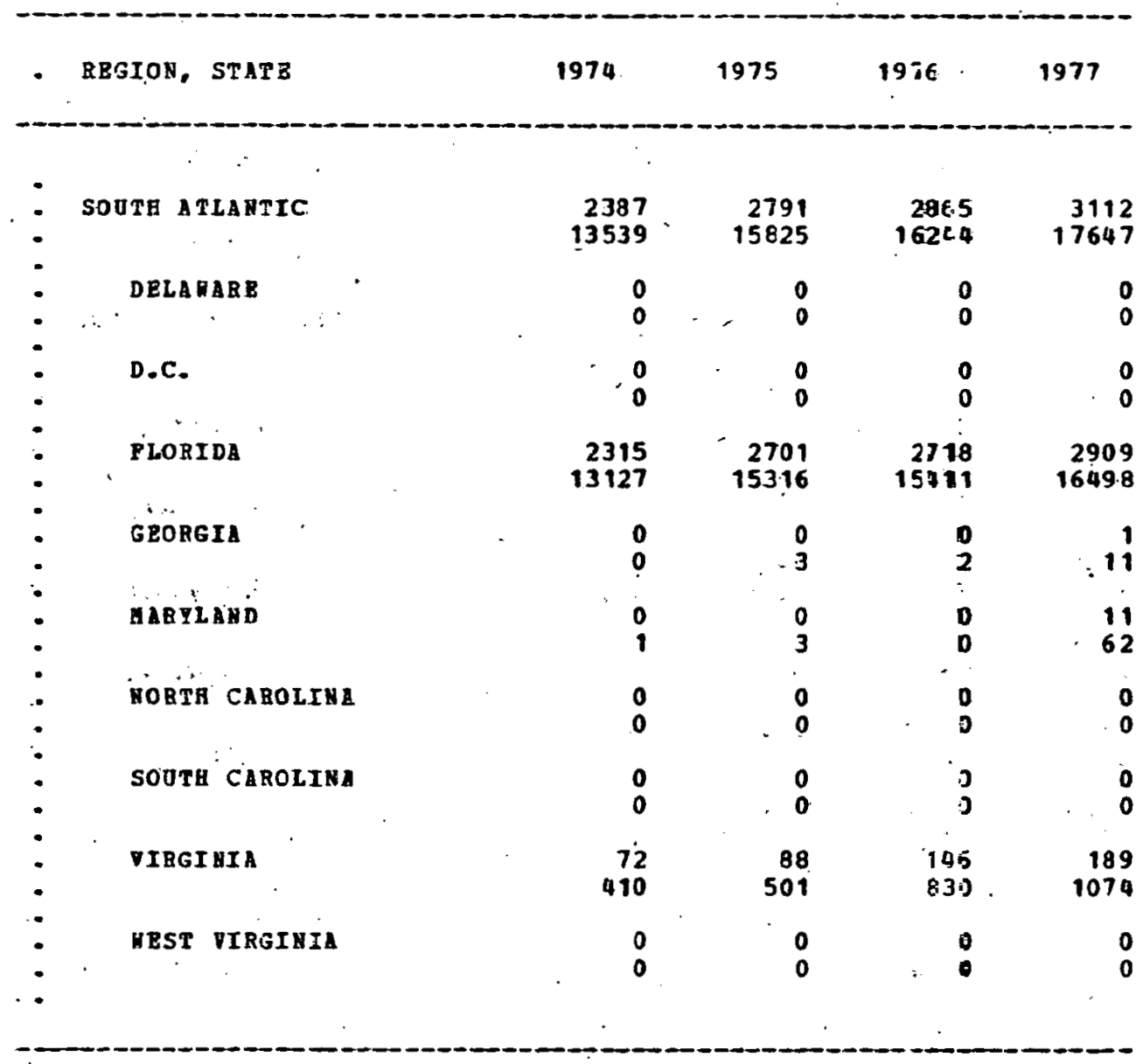

SORRE: UET HOD 10 i

QOALITY: 2 
TABLE 3. 9C - POREIG BI STATE, 1974-77 (TBIRD. IR A SBRIBS OP FITB TABLBS)

JET FOEL OSE IA THOUSANDS OP BARBBL, POLLOAED BY ENBRGY USB.IB BILLIOHS OP BTO

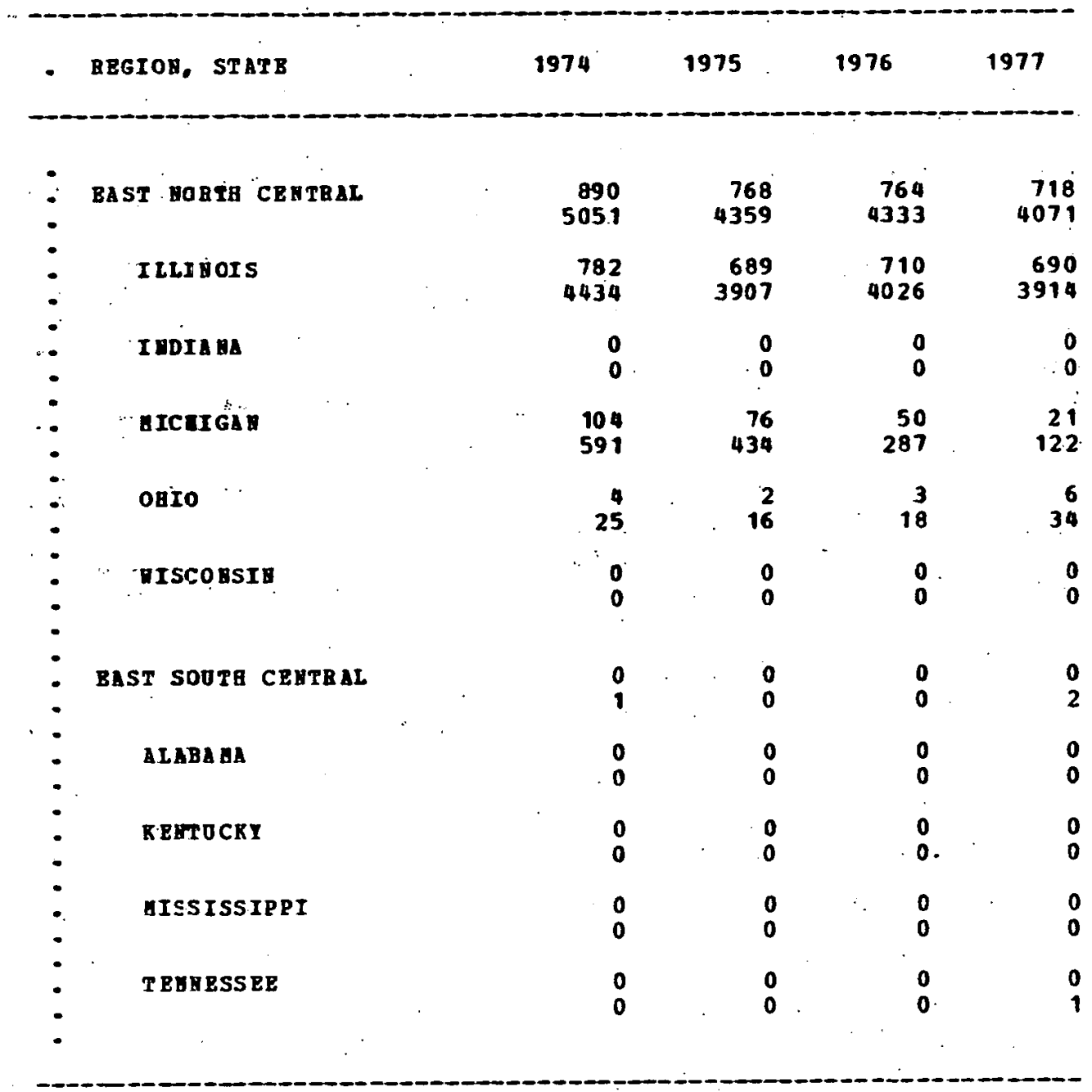




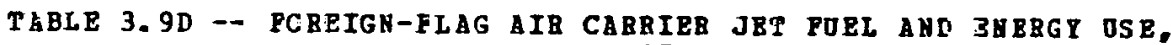
BY STATE, 1974-77 (POJRTH IN A SBRIBS OF PIVB TABLES)

JET PCEL USE IN THOUSA NDS OP BARELS, POLLONED BY ERERG OSE. IB BILLTOAS OP BTO

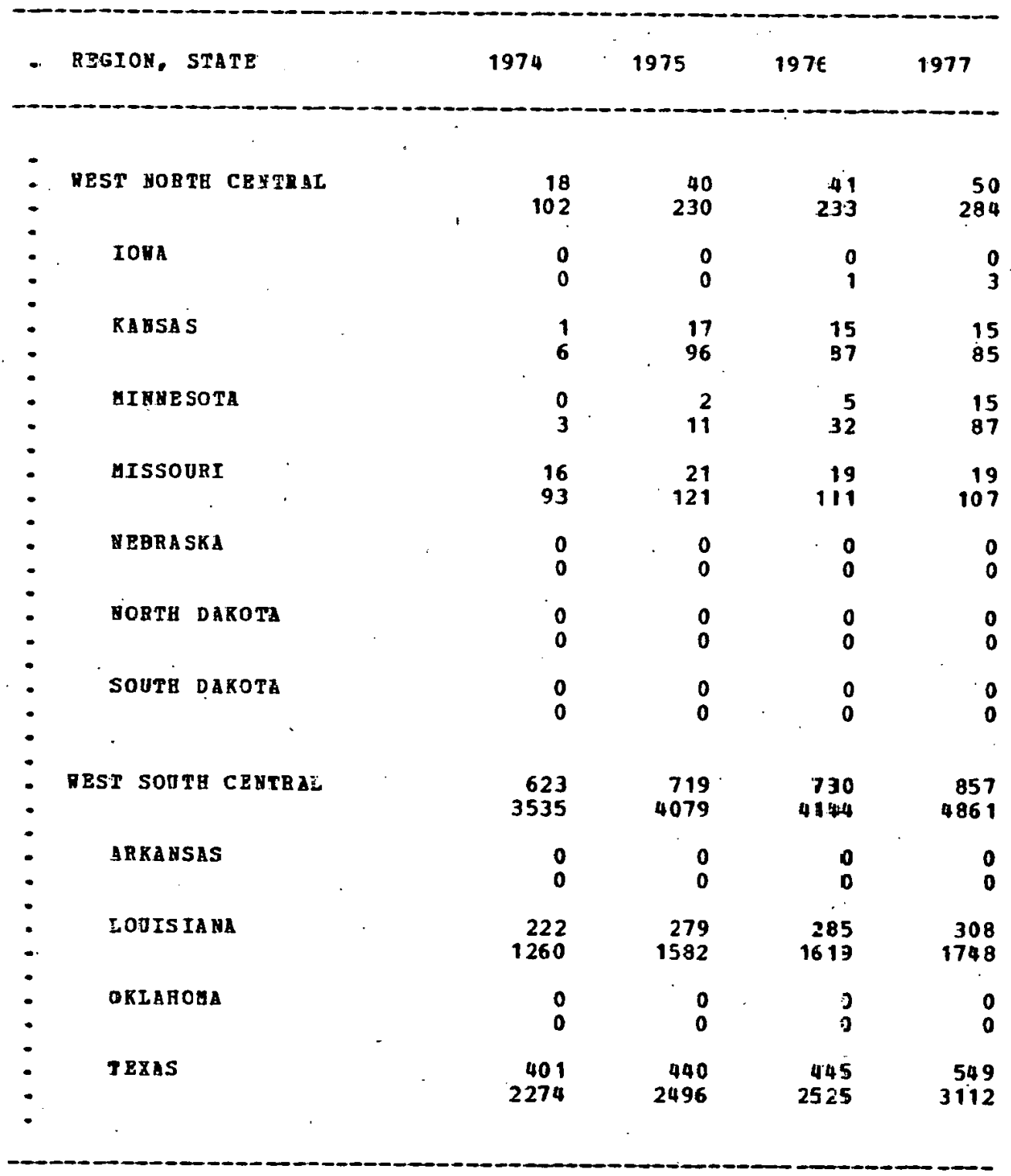



TABLE 3.9E -- POBEIGN-PLAG ATR CARBIER JET POEL AND BHEBGY OSE.

(LAST IN A SERIES OP PIVE TABLBS)

JET POEL OSE IN THOOSA MDS OF BARREL, FOLLORBD BY EHERGY OSE IN BILLIONS OP BTD

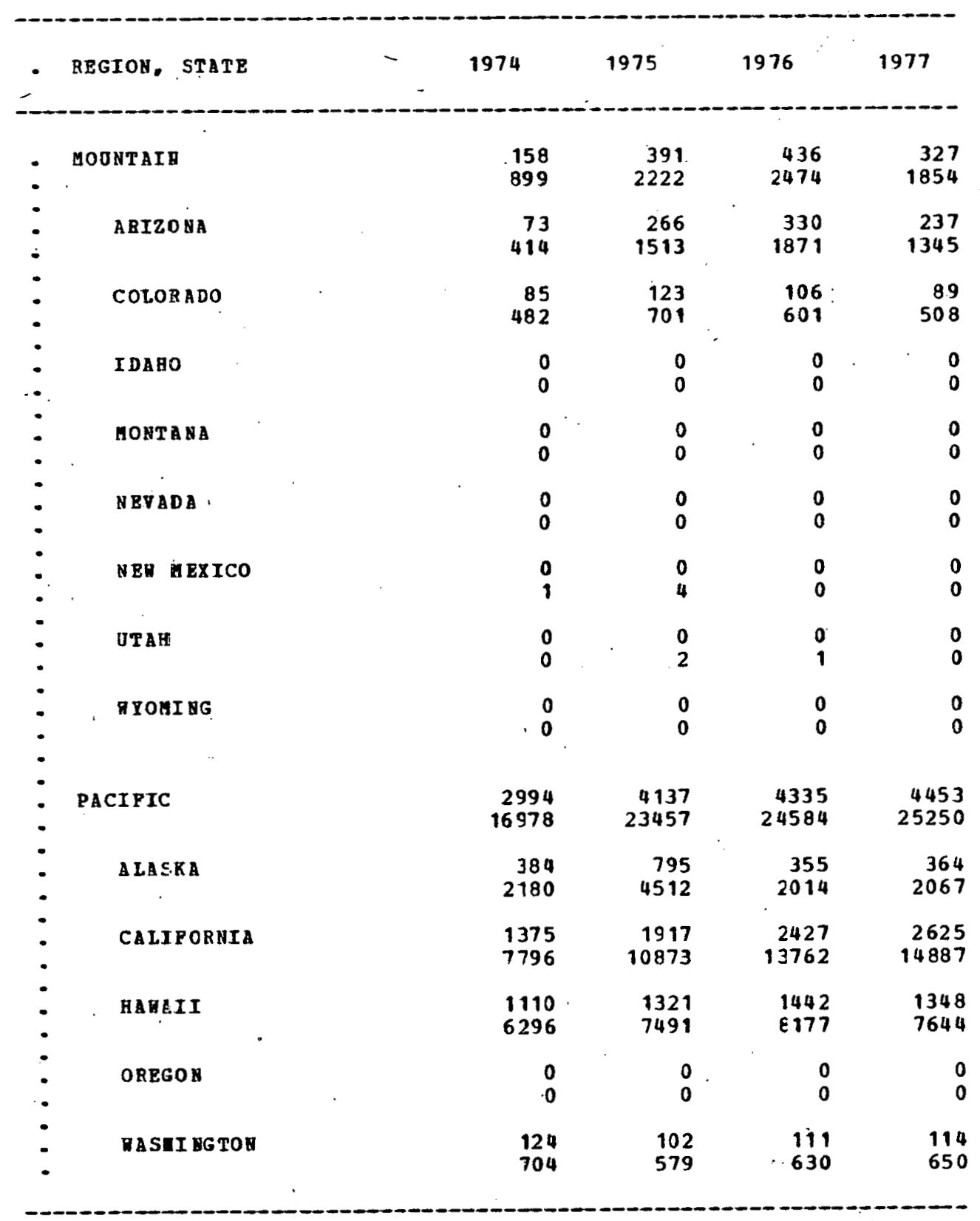


TABLE 3.10A.-- GENERAL A YJATIOY OSE OP AVIATION GASOLINE, BY STATE, 1974-77 (FIEST IN A SERIBS OF PIVE TABLES)

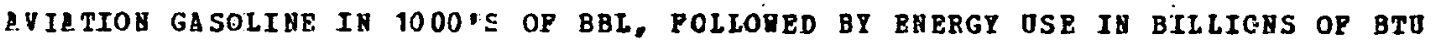

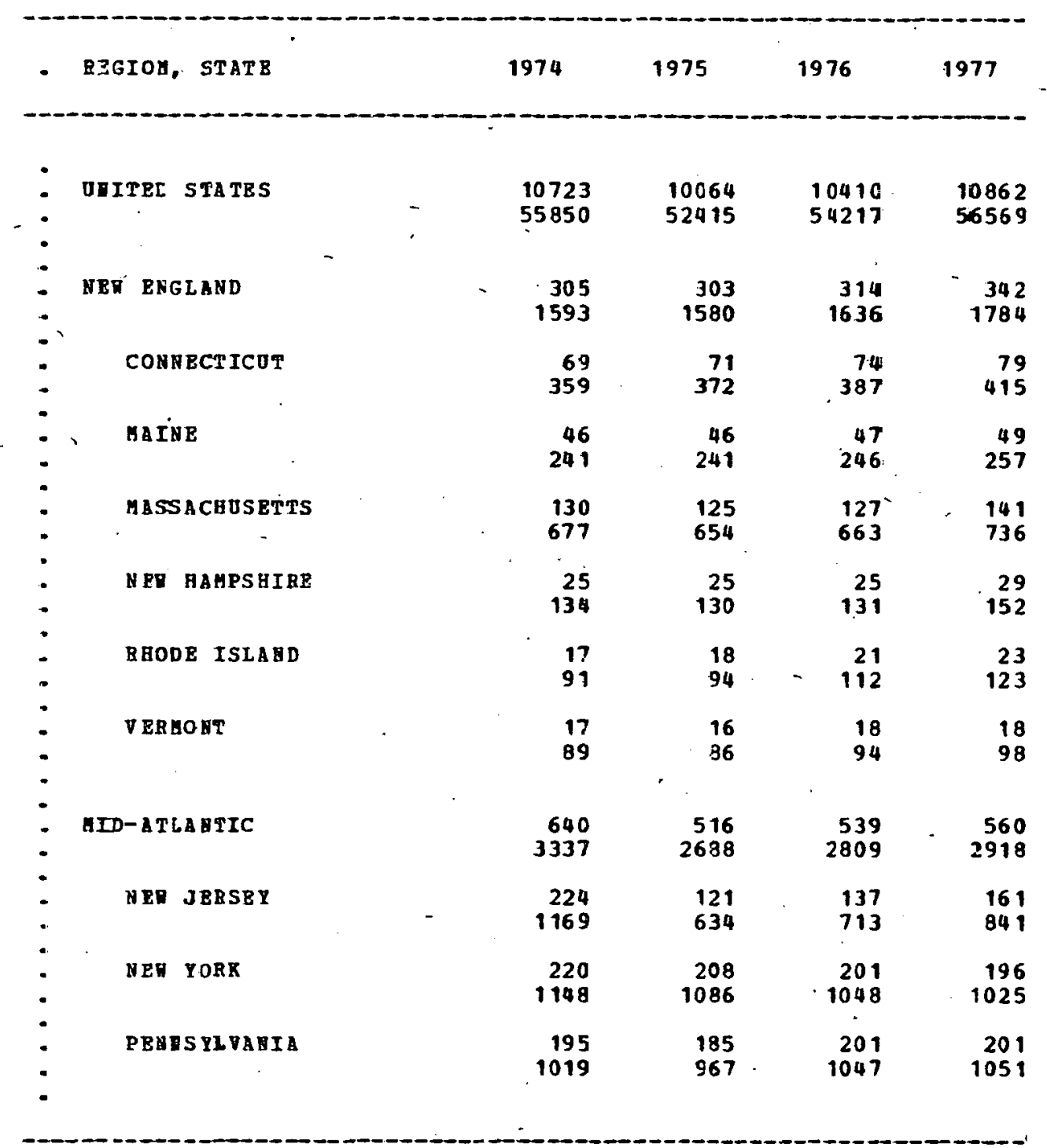

SOORCE: AETBOD 104

QEALITY: 2 
TABLE 3. 10B -- GENEBAL A TIATIOB USE OP AVIATION GASOLIAB, BY STATE, 1974-77 (SECOHD IN A SBRIES OP PIVE TABLES)

AVIATION GASOLI IN 1000 'S OF BBL, POLIORED BY RHBRGY OSE IN BILLIONS OP BTO

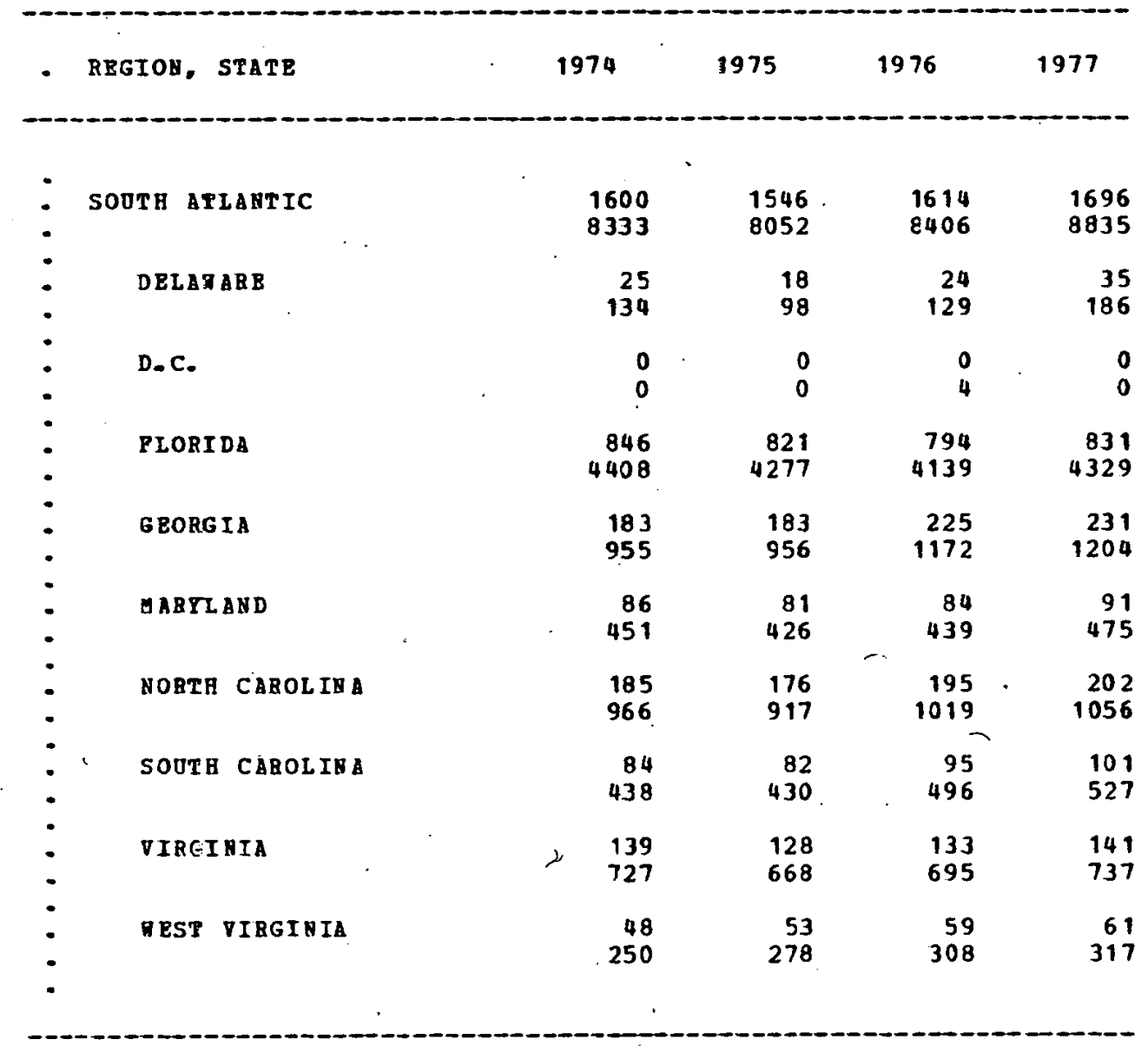

SOURCE: घETHOD 104

QOALITY: 2 
3ABLE 3. 10C -- GENERAL LVIATIOI OSE OF AVIATIOS GASOLIAE, BP STAEB, 1974-77 (TAIRD IN A SRAIES OP FIVE TABLES)

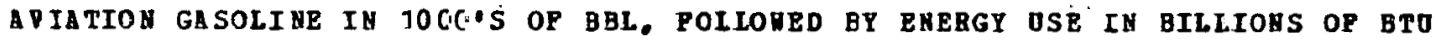

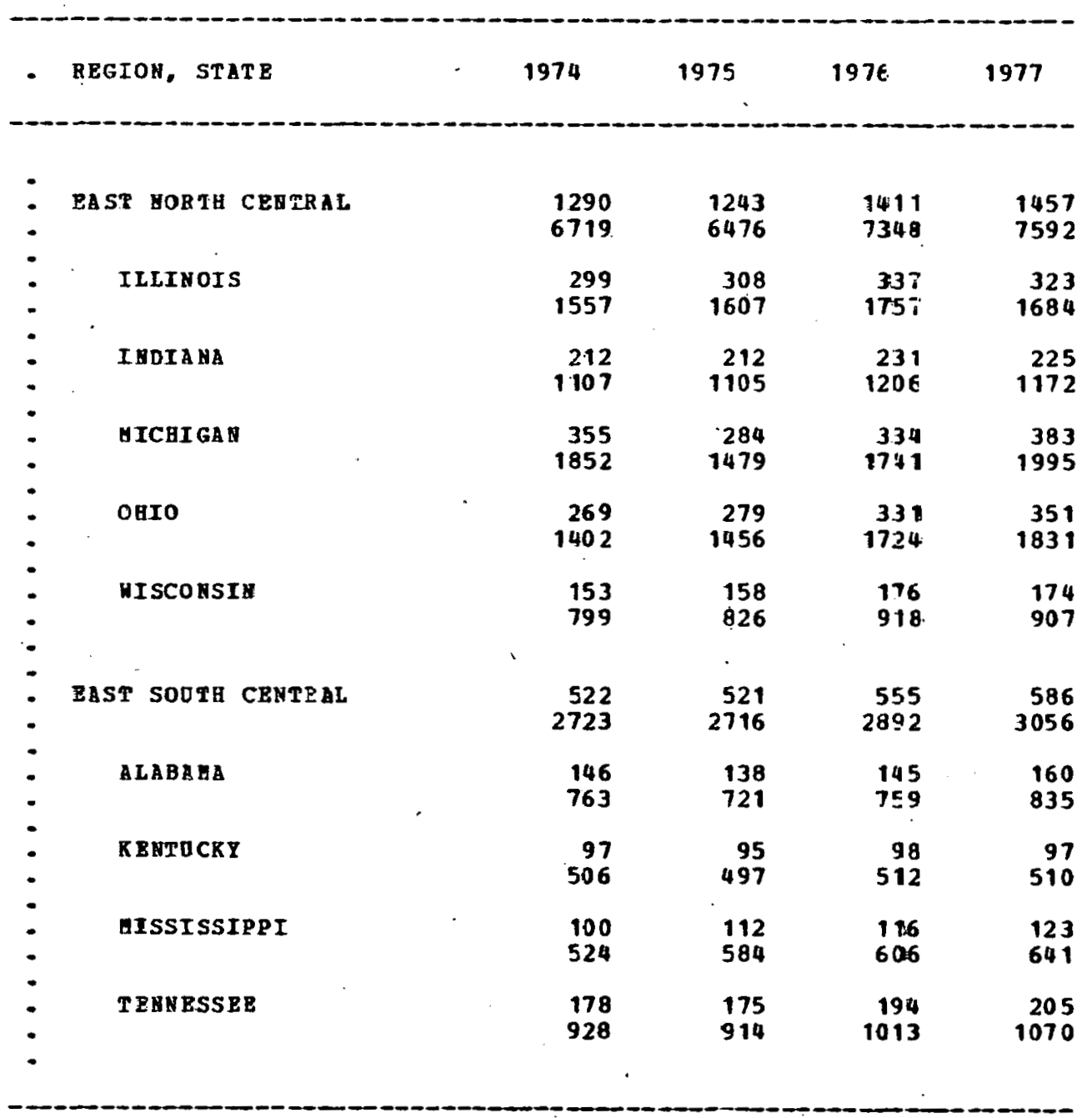

SOURCB: HETHOD 104

20BLITI: 2 
TABLE 3. 10 D - GENBRAL AVIATION OSB OP AVIATIOA GASOLIAB, BI STATE, 1974-77 (FOURTH IH A SBRIBS OP PIVE TABLES)

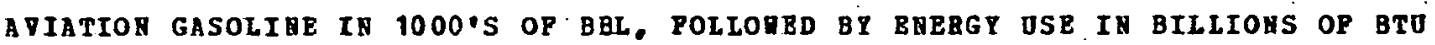

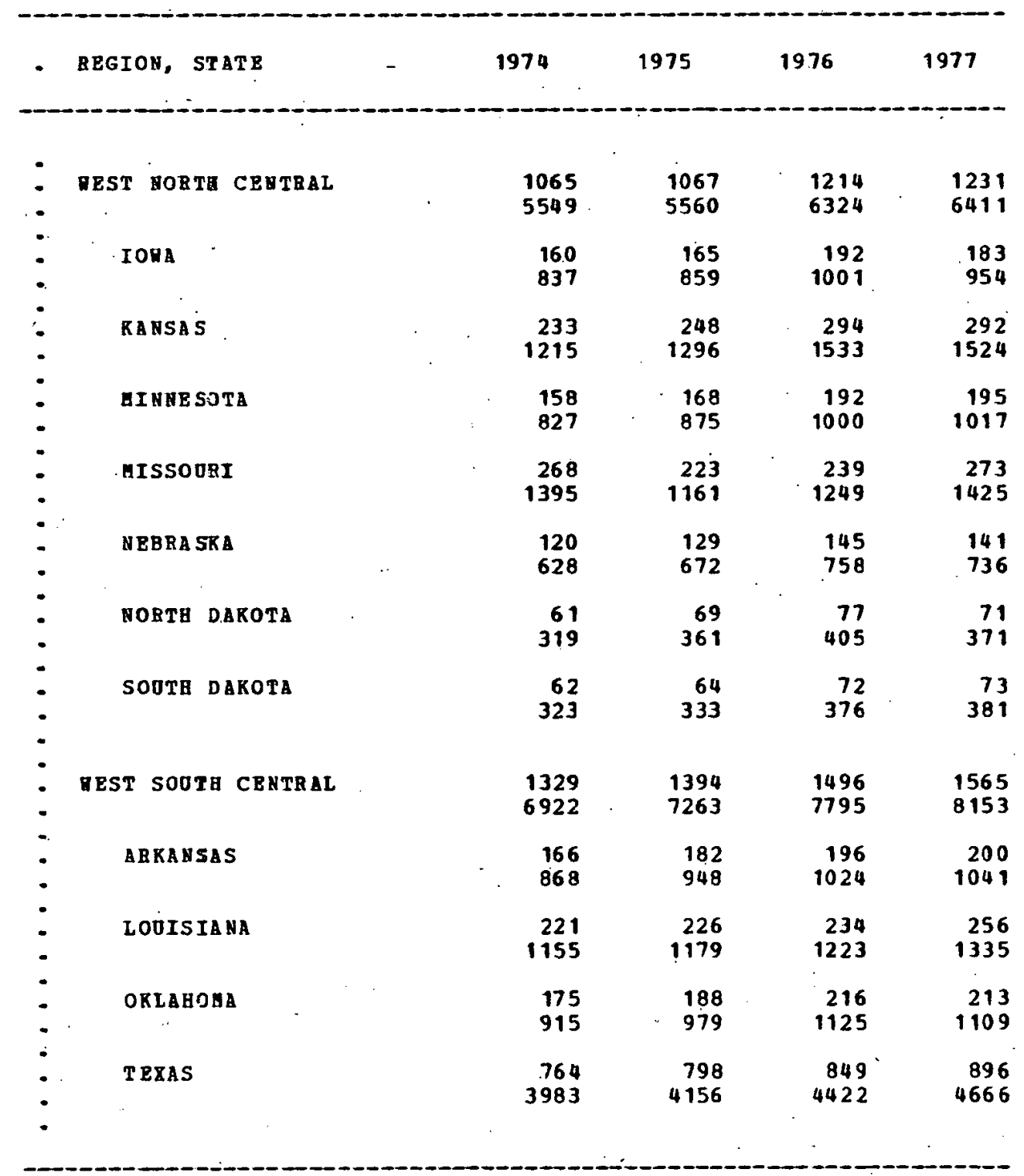


TI3LE 3.19E -- GERERAL AVIATION OSE OP AVIATIOR GASOLIHE, BY STAER, 1974-77 (LAST IH A SEBIES OF PIVB TABLES)

AVIATION GLSOLIAE IN 1000 'S OP BBL, POLLORED BY BARBGY OSE IN BILLIOYS OP BTO

\begin{tabular}{|c|c|c|c|c|c|}
\hline RBGTON, STATB & & 1974 & 1975 & 1976 & 1977 \\
\hline MOUBTAIT & & $\begin{array}{l}1000 \\
5211\end{array}$ & $\begin{array}{r}997 \\
5193\end{array}$ & $\begin{array}{l}1108 \\
5772\end{array}$ & $\begin{array}{l}1181 \\
6152\end{array}$ \\
\hline MRIZOHA & & $\begin{array}{r}243 \\
1266\end{array}$ & $\begin{array}{r}240 \\
1254\end{array}$ & $\begin{array}{r}259 \\
1348\end{array}$ & $\begin{array}{r}273 \\
1423\end{array}$ \\
\hline COLOBADO & & $\begin{array}{l}17.9 \\
933\end{array}$ & $\begin{array}{l}179 \\
935\end{array}$ & $\begin{array}{r}201 \\
.1049\end{array}$ & $\begin{array}{r}218 \\
1136\end{array}$ \\
\hline IDABO & & $\begin{array}{l}103 \\
540\end{array}$ & $\begin{array}{r}99 \\
519\end{array}$ & $\begin{array}{r}113 \\
-\quad 593\end{array}$ & $\begin{array}{l}112 \\
585\end{array}$ \\
\hline ADETA BA & & $\begin{array}{r}92 \\
481\end{array}$ & $\begin{array}{r}93 \\
487\end{array}$ & $\begin{array}{l}113 \\
592\end{array}$ & $\begin{array}{l}114 \\
596\end{array}$ \\
\hline MZSADA & & $\begin{array}{l}110 \\
574\end{array}$ & $\begin{array}{l}.104 \\
542\end{array}$ & $\begin{array}{l}104 \\
546\end{array}$ & $\begin{array}{l}122 \\
639\end{array}$ \\
\hline BEV MEXICO & & $\begin{array}{l}123 \\
641\end{array}$ & $\begin{array}{l}124 \\
650\end{array}$ & $\begin{array}{l}139 \\
725\end{array}$ & $\begin{array}{l}150 \\
782\end{array}$ \\
\hline OTAR & & $\begin{array}{r}86 \\
449\end{array}$ & $\begin{array}{r}89 \\
468\end{array}$ & $\begin{array}{l}102 \\
534\end{array}$ & $\begin{array}{l}107 \\
561\end{array}$ \\
\hline MTOUIDG & & $\begin{array}{r}62 \\
323\end{array}$ & $\begin{array}{r}64 \\
335\end{array}$ & $\begin{array}{r}73 \\
382\end{array}$ & $\begin{array}{r}81 \\
425\end{array}$ \\
\hline DACI FIC & - & $\begin{array}{r}2968 \\
15459\end{array}$ & $\begin{array}{r}2473 \\
12882\end{array}$ & $\begin{array}{r}2156 \\
11231\end{array}$ & $\begin{array}{r}2239 \\
11663\end{array}$ \\
\hline A LASK I & & $\begin{array}{r}333 \\
1737\end{array}$ & $\begin{array}{r}338 \\
1763\end{array}$ & $\begin{array}{r}343 \\
1787\end{array}$ & $\begin{array}{r}390 \\
203 !\end{array}$ \\
\hline CALIPOBNIA & & $\begin{array}{r}2197 \\
11443\end{array}$ & $\begin{array}{l}1675 \\
8726\end{array}$ & $\begin{array}{l}1298 \\
6760\end{array}$ & $\begin{array}{l}1277 \\
6635\end{array}$ \\
\hline HRDAII & & $\begin{array}{r}65 \\
.343\end{array}$ & $\begin{array}{r}77 \\
402\end{array}$ & $\begin{array}{r}9.3 \\
488\end{array}$ & $\begin{array}{l}114 \\
593\end{array}$ \\
\hline OREGOI & & $\begin{array}{l}156 \\
813\end{array}$ & $\begin{array}{l}155 \\
807\end{array}$ & $\begin{array}{l}173 \\
904\end{array}$ & $\begin{array}{r}197 \\
1031\end{array}$ \\
\hline VASHI IGTOB & & $\begin{array}{r}215 \\
1122\end{array}$ & $\begin{array}{r}227 \\
1183\end{array}$ & $\begin{array}{r}247 \\
1290\end{array}$ & $\begin{array}{r}263 \\
1371\end{array}$ \\
\hline
\end{tabular}


TABLE 3.11A - TOTAL CIVILIA COBSOAPTION OF AVIATIOB POBLS, BI POEL BI STATB, 1967-77

(FIBST IN S SEIBS OF MIBE TABLES)

AVIATIO\& GASOLIBB OSE IB THOOSABDS OP BARRELS

FOLLORED BY JET FOEL OSE IA THODSAYDS OP BARBELS

POLLORBD BY BRERGY DSE IN BILLIOHS OP BTO

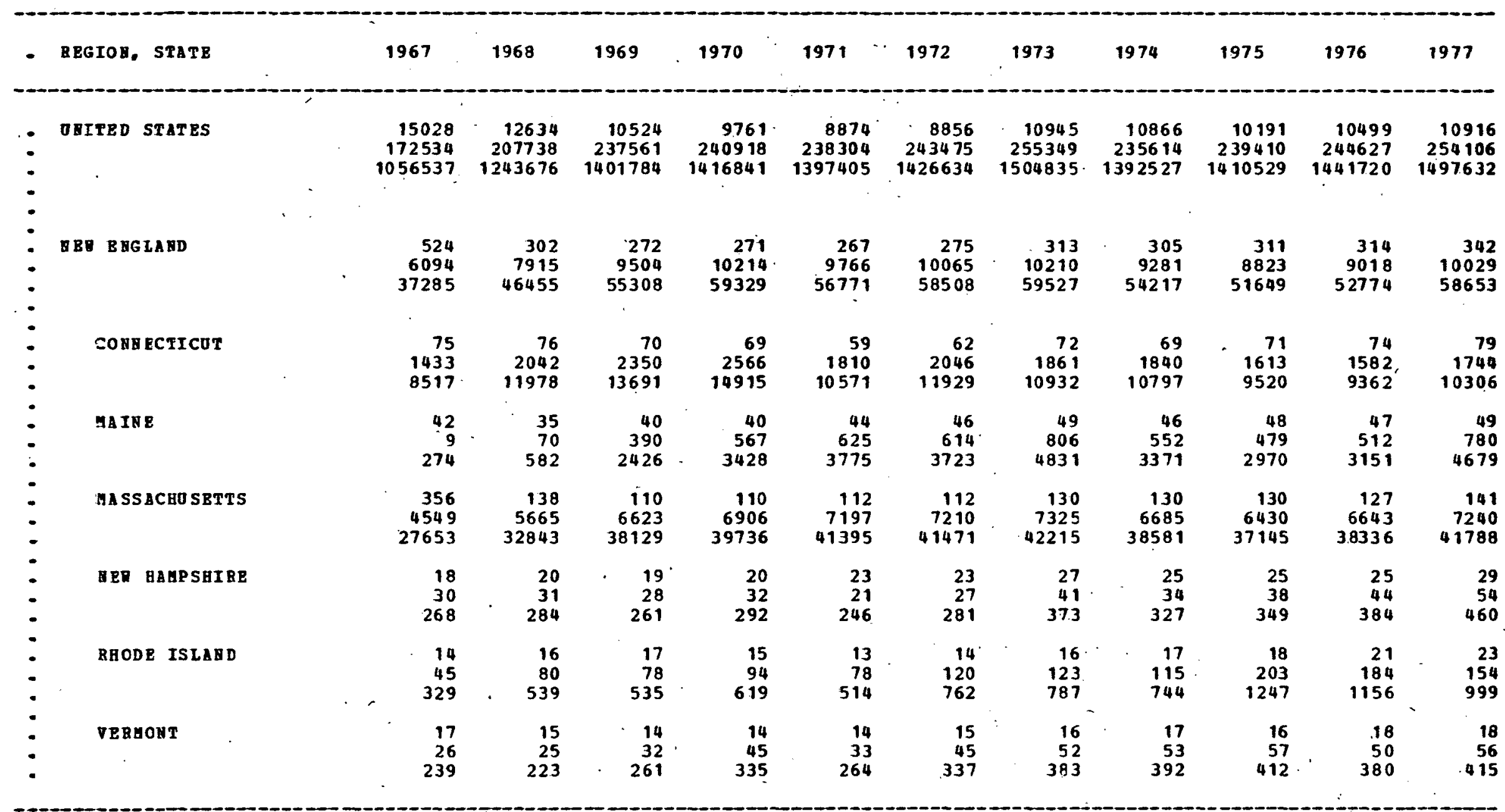



TABLE 3.11B-- TCTAL CIVILIAB COBSUAPTION OP AVIATIOB PUELS,
EY PUEL BY STATE, 1967-77

(S ZCCND IN A SBRIES OP NINE TABLES)

AVIATIOE GASOLINB OSB IR THOOSAHDS OP BARRELS

FOLLOUED BY JET PUEL DSE IR THOUSAEDS OF BABRBLS

POLLOEED BY ENERG USE IN BILLIONS OP BTO

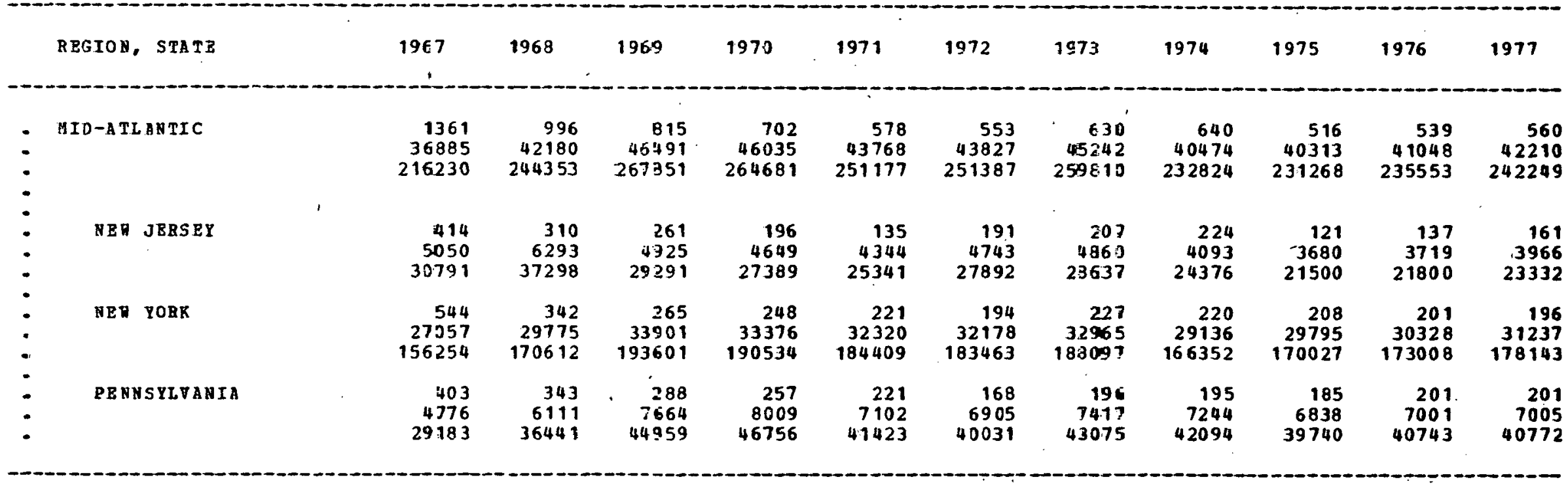



TABLE $3.11 C$ - TOTAL CIVILIA COESOAPTION OP AVIATION EOBLS,
BY PUBL BY STATE, 1967-77

(THIRD IN A SERIBS OP NINE TABLES)

AVIATIOB GASOLIBE OSE IR THOUSARDS OF BARRELS

FOLLOYED BT JET POEL DSE IN THOTSAHDS OP BABRELS

FOLLORBD BY EAERGY USE IN BILLIONS OP BTO

\begin{tabular}{|c|c|c|c|c|c|c|c|c|c|c|c|c|}
\hline - & BEGION, STATE & 1967 & 1968 & .1969 & 1970 & 1971 & 1972 & 1973 & 1974 & 1975 & 1976 & 1977 \\
\hline : & SOGTH ATLANTIC & $\begin{array}{r}2924 \\
24715 \\
155362\end{array}$ & $\begin{array}{r}2459 \\
30493 \\
185707\end{array}$ & $\begin{array}{r}2005 \\
36130 \\
215303\end{array}$ & $\begin{array}{r}1696 \\
36486 \\
215708\end{array}$ & $\begin{array}{r}1534 \\
37308 \\
219531\end{array}$ & $\begin{array}{r}1487 \\
38475 \\
225897\end{array}$ & $\begin{array}{r}1664 \\
41250 \\
242559\end{array}$ & $\begin{array}{r}1649 \\
34544 \\
204460\end{array}$ & $\begin{array}{r}1588 \\
35914 \\
211904\end{array}$ & $\begin{array}{r}1638 \\
38822 \\
228655\end{array}$ & $\begin{array}{r}1710 \\
41911 \\
246544\end{array}$ \\
\hline$\ddot{-}$ & DELAUARE & $\begin{array}{r}41 \\
67 \\
594\end{array}$ & $\begin{array}{r}36 \\
135 \\
956\end{array}$ & $\begin{array}{r}28 \\
180 \\
1168\end{array}$ & $\begin{array}{r}27 \\
154 \\
1015\end{array}$ & $\begin{array}{r}116 \\
51 \\
379\end{array}$ & $\begin{array}{r}13 \\
52 \\
365\end{array}$ & $\begin{array}{r}36 \\
67 \\
569\end{array}$ & $\begin{array}{r}25 \\
55 \\
446\end{array}$ & $\begin{array}{r}18 \\
49 \\
381\end{array}$ & $\begin{array}{r}24 \\
57 \\
456\end{array}$ & $\begin{array}{r}35 \\
73 \\
600\end{array}$ \\
\hline$\dot{-}$ & D. C. & $\begin{array}{l}0 \\
1 \\
6\end{array}$ & $\begin{array}{l}0 \\
0 \\
2\end{array}$ & $\begin{array}{r}0 \\
9 \\
52\end{array}$ & $\begin{array}{l}0 \\
0 \\
0\end{array}$ & $\begin{array}{r}1 \\
0 \\
11\end{array}$ & $\begin{array}{r}0 \\
2 \\
16\end{array}$ & $\begin{array}{l}0 \\
0 \\
4\end{array}$ & $\begin{array}{l}0 \\
0 \\
0\end{array}$ & $\begin{array}{l}0 \\
0 \\
0\end{array}$ & $\begin{array}{l}0 \\
0 \\
4\end{array}$ & $\begin{array}{l}0 \\
0 \\
0\end{array}$ \\
\hline$\ddot{-}$ & PLORIDA & $\begin{array}{r}1231 \\
12015 \\
74542\end{array}$ & $\begin{array}{r}937 \\
14354 \\
86276\end{array}$ & $\begin{array}{r}912 \\
16741 \\
99675\end{array}$ & $\begin{array}{r}768 \\
16042 \\
94959\end{array}$ & $\begin{array}{r}746 \\
17073 \\
100697\end{array}$ & $\begin{array}{r}750 \\
19124 \\
112346\end{array}$ & $\begin{array}{r}831 \\
18896 \\
111475\end{array}$ & $\begin{array}{r}847 \\
15275 \\
91025\end{array}$ & $\begin{array}{r}821 \\
15776 \\
93732\end{array}$ & $\begin{array}{r}794 \\
17194 \\
101632\end{array}$ & $\begin{array}{r}831 \\
18794 \\
110892\end{array}$ \\
\hline 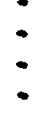 & GEOBGIA & $\begin{array}{r}399 \\
4468 \\
27421\end{array}$ & $\begin{array}{r}414 \\
5772 \\
34888\end{array}$ & $\begin{array}{r}350 \\
7222 \\
42773\end{array}$ & $\begin{array}{r}316 \\
7910 \\
46498\end{array}$ & $\begin{array}{r}263 \\
8494 \\
49534\end{array}$ & $\begin{array}{r}228 \\
8421 \\
48941\end{array}$ & $\begin{array}{r}227 \\
10615 \\
61376\end{array}$ & $\begin{array}{r}222 \\
8743 \\
50732\end{array}$ & $\begin{array}{r}219 \\
9461 \\
54788\end{array}$ & $\begin{array}{r}248 \\
10108 \\
58608\end{array}$ & $\begin{array}{r}244 \\
10752 \\
62239\end{array}$ \\
\hline$\because$ & HABYLAND & $\begin{array}{r}152 \\
2145 \\
12957\end{array}$ & $\begin{array}{r}148 \\
2713 \\
16161\end{array}$ & $\begin{array}{r}94 \\
2873 \\
16783\end{array}$ & $\begin{array}{r}88 \\
2907 \\
16944\end{array}$ & $\begin{array}{r}76 \\
2378 \\
13885\end{array}$ & $\begin{array}{r}72 \\
2010 \\
11776\end{array}$ & $\begin{array}{r}85 \\
2002 \\
11798\end{array}$ & $\begin{array}{r}86 \\
1662 \\
9878\end{array}$ & $\begin{array}{r}81 \\
1564 \\
9296\end{array}$ & $\begin{array}{r}84 \\
1719 \\
10187\end{array}$ & $\begin{array}{r}91 \\
1879 \\
11132\end{array}$ \\
\hline- & NORTA CaROLINA & $\begin{array}{r}292 \\
838 \\
6272\end{array}$ & $\begin{array}{r}288 \\
1117 \\
7842 .\end{array}$ & $\begin{array}{r}234 \\
1380 \\
9048\end{array}$ & $\begin{array}{r}172 \\
1642 \\
10208\end{array}$ & $\begin{array}{r}163 \\
1479 \\
9241\end{array}$ & $\begin{array}{r}176 \\
1114 \\
7241\end{array}$ & $\begin{array}{r}205 \\
1165 \\
7673\end{array}$ & $\begin{array}{r}186 \\
1111 \\
7273\end{array}$ & $\begin{array}{r}176 \\
1134 \\
7353\end{array}$ & $\begin{array}{r}195 \\
1189 \\
7763\end{array}$ & $\begin{array}{r}202 \\
1413 \\
9073\end{array}$ \\
\hline : & SOOTB CAROLINA & $\begin{array}{r}167 \\
112 \\
1506\end{array}$ & $\begin{array}{r}131 \\
289 \\
2327\end{array}$ & $\begin{array}{r}119 \\
378 \\
2766\end{array}$ & $\begin{array}{r}120 \\
413 \\
2974\end{array}$ & $\begin{array}{r}89 \\
368 \\
2549\end{array}$ & $\begin{array}{r}82 \\
392 \\
2653\end{array}$ & $\begin{array}{r}94 \\
359 \\
2529\end{array}$ & $\begin{array}{r}93 \\
316 \\
2283\end{array}$ & $\begin{array}{r}88 \\
337 \\
2372\end{array}$ & $\begin{array}{r}96 \\
332 \\
2387\end{array}$ & $\begin{array}{r}101 \\
394 \\
2763\end{array}$ \\
\hline$\dot{-}$ & VIRGIHIA & $\begin{array}{r}541 \\
4992 \\
31125\end{array}$ & $\begin{array}{r}411 \\
5998 \\
36156\end{array}$ & $\begin{array}{r}207 \\
7172 \\
41747\end{array}$ & $\begin{array}{r}152 \\
7237 \\
41829\end{array}$ & $\begin{array}{r}133 \\
7346 \\
42351\end{array}$ & $\begin{array}{r}122 \\
7280 \\
41915\end{array}$ & $\begin{array}{r}137 \\
8062 \\
46424\end{array}$ & $\begin{array}{r}139 \\
7285 \\
42036\end{array}$ & $\begin{array}{r}128 \\
7453 \\
42931\end{array}$ & $\begin{array}{r}133 \\
8066 \\
46432\end{array}$ & $\begin{array}{r}141 \\
8430 \\
48535\end{array}$ \\
\hline$\therefore$ & REST VIRGINIA & $\begin{array}{r}98 \\
73 \\
931\end{array}$ & $\begin{array}{r}90 \\
109 \\
1092\end{array}$ & $\begin{array}{r}58 \\
172 \\
1283\end{array}$ & $\begin{array}{r}49 \\
179 \\
1272\end{array}$ & $\begin{array}{r}43 \\
114 \\
874\end{array}$ & $\begin{array}{r}40 \\
75 \\
637\end{array}$ & $\begin{array}{r}46 \\
81 \\
70.3\end{array}$ & $\begin{array}{r}48 \\
93 \\
780\end{array}$ & $\begin{array}{r}53 \\
135 \\
1047\end{array}$ & $\begin{array}{r}59 \\
153 \\
1176\end{array}$ & $\begin{array}{r}61 \\
173 \\
1301\end{array}$ \\
\hline
\end{tabular}


TABL3 3.110 - TOThL CIYILIA COHSUAPTION OP AVIATIOA PUBL, BI POBL BY STATE, 1967-77

(FOORTE IN A SBRIBS OP BIHB TABLES)

AVIATION GESOLINB USE IR THOUSAMDS OP BARRELS

POLLONED BY 5 BT POEL OSB IR THOOSA BDS OF BABBELS

FOILORED BY ENERGY OSB II BILLIOHS OP BTO

\begin{tabular}{|c|c|c|c|c|c|c|c|c|c|c|c|}
\hline - REGION, STATE & 1967 & 1968 & 1969 & 1970 & 1971 & 1972 & 1973 & 1974 & 1975 & 1976 & 1977 \\
\hline $\begin{array}{l}\text { - EAST HORTE CENTRAL } \\
\text { - }\end{array}$ & $\begin{array}{r}2487 \\
22324 \\
139536\end{array}$ & $\begin{array}{r}1953 \\
27604 \\
166686\end{array}$ & $\begin{array}{r}1432 \\
30584 \\
183141\end{array}$ & $\begin{array}{r}13.13 \\
. \quad 31656 \\
186332\end{array}$ & $\begin{array}{r}1195 \\
31678 \\
185845\end{array}$ & $\begin{array}{r}1167 \\
33369 \\
195281\end{array}$ & $\begin{array}{r}9418 \\
35434 \\
208535\end{array}$ & $\begin{array}{r}1301 \\
30708 \\
180897\end{array}$ & $\begin{array}{r}1255 \\
30160 \\
177548\end{array}$ & $\begin{array}{r}1417 \\
31967 \\
188639\end{array}$ & $\begin{array}{r}1457 \\
33996 \\
200351\end{array}$ \\
\hline ILLINOIS & $\begin{array}{r}384 \\
6919 \\
41232\end{array}$ & $\begin{array}{r}355 \\
8938 \\
52532\end{array}$ & $\begin{array}{r}321 \\
10 C 23 \\
58501\end{array}$ & $\begin{array}{r}311 \\
10232 \\
59641\end{array}$ & $\begin{array}{r}295 \\
10613 \\
61717\end{array}$ & $\begin{array}{r}281 \\
11445 \\
66358\end{array}$ & $\begin{array}{r}312 \\
1 \equiv 597 \\
7 \varepsilon 726\end{array}$ & $\begin{array}{r}299 \\
20215 \\
11617.8\end{array}$ & $\begin{array}{r}308 \\
19823 \\
114003\end{array}$ & $\begin{array}{r}337 \\
20978 \\
120706\end{array}$ & $\begin{array}{r}323 \\
22202 \\
12757 !\end{array}$ \\
\hline I I DDIABA & $\begin{array}{r}767 \\
8723 \\
53461\end{array}$ & $\begin{array}{r}481 \\
10204 \\
60364\end{array}$ & $\begin{array}{r}249 \\
10621 \\
61523\end{array}$ & $\begin{array}{r}230 \\
11396 \\
65817\end{array}$ & $\begin{array}{r}217 \\
11122 \\
64191\end{array}$ & $\begin{array}{r}193 \\
12159 \\
69954\end{array}$ & $\begin{array}{r}233 \\
11418 \\
65960\end{array}$ & $\begin{array}{r}212 \\
1494 \\
9579\end{array}$ & $\begin{array}{r}212 \\
1537 \\
9821\end{array}$ & $\begin{array}{r}231 \\
1614 \\
10360\end{array}$ & $\begin{array}{r}225 \\
16.03 \\
10265\end{array}$ \\
\hline MICHIGAH & $\begin{array}{r}544 \\
2818 \\
: 8813\end{array}$ & $\begin{array}{r}473 \\
3628 \\
230.38\end{array}$ & $\begin{array}{r}338 \\
4477 \\
27150\end{array}$ & $\begin{array}{r}310 \\
4439 \\
26793\end{array}$ & $\begin{array}{r}265 \\
3960 \\
23836\end{array}$ & $\begin{array}{r}301 \\
3607 \\
22022\end{array}$ & $\begin{array}{r}406 \\
3900 \\
24228\end{array}$ & $\begin{array}{r}360 \\
3473 \\
21572\end{array}$ & $\begin{array}{r}288 \\
2989 \\
18454\end{array}$ & $\begin{array}{r}337 \\
3156 \\
19655\end{array}$ & $\begin{array}{r}383 \\
3555 \\
22153\end{array}$ \\
\hline$:$ & $\begin{array}{r}532 \\
3158 \\
20681\end{array}$ & $\begin{array}{r}449 \\
3752 \\
23614\end{array}$ & $\begin{array}{r}372 \\
4429 \\
270554\end{array}$ & $\begin{array}{r}320 \\
4236 \\
25690\end{array}$ & $\begin{array}{r}283 \\
4476 \\
26855\end{array}$ & $\begin{array}{r}256 \\
4637 \\
27627\end{array}$ & $\begin{array}{r}311 \\
4794 \\
28806\end{array}$ & $\begin{array}{r}276 \\
3848 \\
23261\end{array}$ & $\begin{array}{r}286 \\
4086 \\
24665\end{array}$ & $\begin{array}{r}334 \\
4445 \\
26949\end{array}$ & $\begin{array}{r}351 \\
4807 \\
29090\end{array}$ \\
\hline :- $\quad$ UISCOHST & $\begin{array}{r}258 \\
705 \\
5341\end{array}$ & $\begin{array}{r}193 \\
1081 \\
7135\end{array}$ & $\begin{array}{r}151 \\
1432 \\
89-09\end{array}$ & $\begin{array}{r}140 \\
1350 \\
8388\end{array}$ & $\begin{array}{r}134 \\
1506 \\
9241\end{array}$ & $\begin{array}{r}135 \\
1519 \\
9316\end{array}$ & $\begin{array}{r}154 \\
1773 \\
10861\end{array}$ & $\begin{array}{r}153 \\
1676 \\
10303\end{array}$ & $\begin{array}{r}158 \\
1723 \\
10600\end{array}$ & $\begin{array}{r}176 \\
1772 \\
10965\end{array}$ & $\begin{array}{r}174 \\
1827 \\
11267\end{array}$ \\
\hline
\end{tabular}


TABLE 3.11E - TOTAL CIVILIAN CONSORPTION OP AVIATIOR POELS.

BY PUBL BY STATE, 1967-77

(FIFTH IN A SERIBS OP UINB TABLES)

AviATON GASOLIAB USB I THOUSA DDS OP BARRLS

POLLORED BY JET POEL USB IA THOUSA ADS OF BAERELS

FOLLORED BY ENBRGY OSB IA BILLTOYS OP BTO

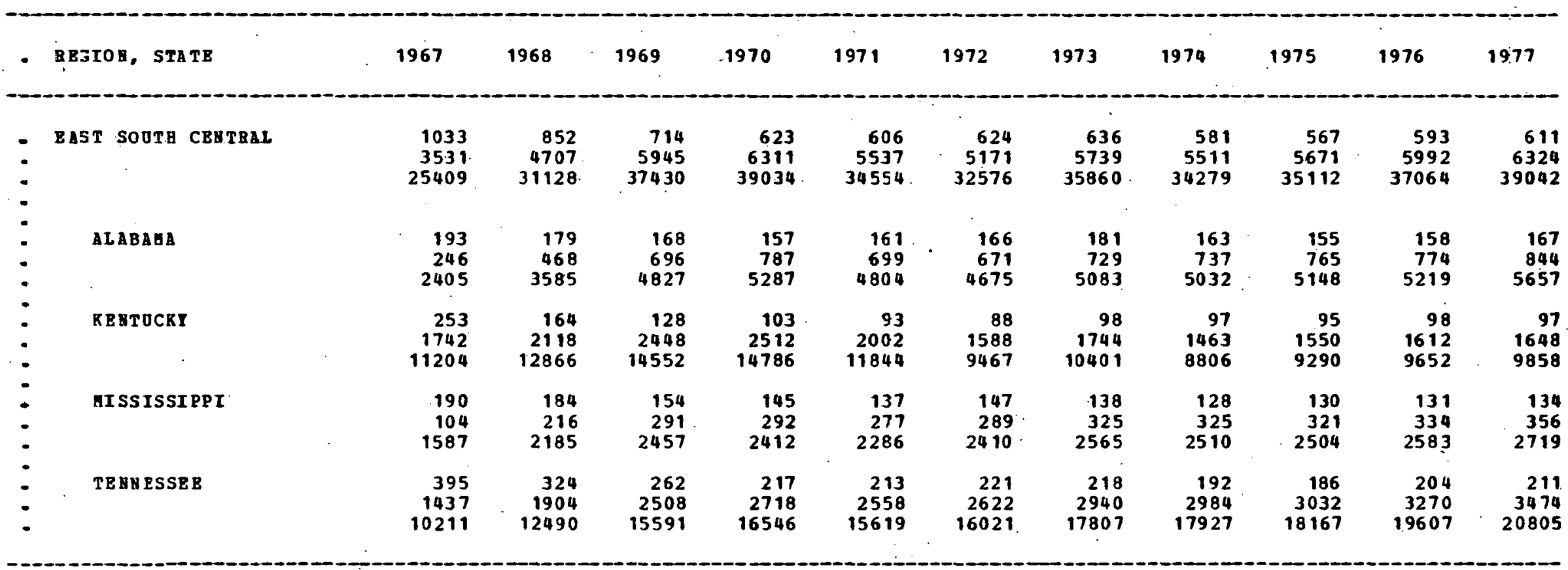

SOORCE: DBTBOD 104

QOALITY: 1 (NATIOAAL) , 2 (STATB) 
TABLE 3.11P -- TORAL CIVILIAN CO BSOGFTION OP ATIATIOA PJRLS, $3 Y$ FOBL BY STATE, 1967-77

(SIXTH IA A SERIES OP GIBB TABLES)

AVIATION GASOLINE OSE IE THOUSAHDS OP BARRELS

POLLONED BI JET POEL USE IB THOUSANDS OP BAEBRLS

POLLORED BY EYBZGY OSE IN BILLIONS OP BTO

\begin{tabular}{|c|c|c|c|c|c|c|c|c|c|c|c|c|}
\hline & REGION, STATE & 1967 & 1968 & 1969 & 1970 & 1971 & 1972 & 1973 & 1974 & 1975 & 1976 & 1977 \\
\hline - & BST NOBTA CENTRAL & $\begin{array}{r}1347 \\
9264 \\
59550\end{array}$ & $\begin{array}{l}1192 \\
11467 \\
71228\end{array}$ & 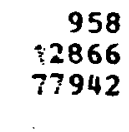 & $\begin{array}{r}919 \\
12313 \\
74606\end{array}$ & $\begin{array}{r}895 \\
11929 \\
72306\end{array}$ & $\begin{array}{r}914 \\
12498 \\
75631\end{array}$ & $\begin{array}{r}1136 \\
12328 \\
78558\end{array}$ & $\begin{array}{r}1065 \\
13033 \\
79451\end{array}$ & $\begin{array}{r}1067 \\
13459 \\
81877\end{array}$ & $\begin{array}{r}1215 \\
13333 \\
81931\end{array}$ & $\begin{array}{r}1232 \\
13554 \\
83273\end{array}$ \\
\hline . & IODA & $\begin{array}{r}174 \\
236 \\
2247\end{array}$ & $\begin{array}{r}148 \\
382 \\
2941\end{array}$ & $\begin{array}{r}141 \\
505 \\
3604\end{array}$ & $\begin{array}{r}144 \\
508 \\
3635\end{array}$ & $\begin{array}{r}146 \\
413 \\
3106\end{array}$ & $\begin{array}{r}145 \\
480 \\
3482\end{array}$ & $\begin{array}{r}167 \\
475 \\
3563\end{array}$ & $\begin{array}{r}160 \\
507 \\
3715\end{array}$ & $\begin{array}{r}165 \\
578 \\
4136\end{array}$ & $\begin{array}{r}192 \\
711 \\
5032\end{array}$ & $\begin{array}{r}183 \\
735 \\
5125\end{array}$ \\
\hline • & KA NS AS & $\begin{array}{r}266 \\
525 \\
4370\end{array}$ & $\begin{array}{r}269 \\
537 \\
4448\end{array}$ & $\begin{array}{r}230 \\
641 \\
4838\end{array}$ & $\begin{array}{r}204 \\
663 \\
4825\end{array}$ & $\begin{array}{r}182 \\
566 \\
4159\end{array}$ & $\begin{array}{r}186 \\
542 \\
4045\end{array}$ & $\begin{array}{r}239 \\
566 \\
4860\end{array}$ & $\begin{array}{r}233 \\
558 \\
4379\end{array}$ & $\begin{array}{r}248 \\
505 \\
4163\end{array}$ & $\begin{array}{r}295 \\
488 \\
4305\end{array}$ & $\begin{array}{r}294 \\
620 \\
5050\end{array}$ \\
\hline • & EI NABSOTA & $\begin{array}{r}268 \\
2313 \\
15514\end{array}$ & $\begin{array}{r}221 \\
2825 \\
17174\end{array}$ & $\begin{array}{r}162 \\
3527 \\
20847\end{array}$ & $\begin{array}{r}158 \\
3005 \\
17865\end{array}$ & $\begin{array}{r}152 \\
3265 \\
19306\end{array}$ & $\begin{array}{r}151 \\
3682 \\
21664\end{array}$ & $\begin{array}{r}159 \\
4233 \\
24837\end{array}$ & $\begin{array}{r}158 \\
4560 \\
26685\end{array}$ & $\begin{array}{r}168 \\
4562 \\
26746\end{array}$ & $\begin{array}{r}192 \\
4417 \\
26046\end{array}$ & $\begin{array}{r}195 \\
4351 \\
25689\end{array}$ \\
\hline & UISSOORI & $\begin{array}{r}337 \\
5561 \\
33289\end{array}$ & $\begin{array}{r}279 \\
6815 \\
40097\end{array}$ & $\begin{array}{r}218 \\
7023 \\
40960\end{array}$ & $\begin{array}{r}208 \\
7129 \\
41512\end{array}$ & $\begin{array}{r}195 \\
6689 \\
38945\end{array}$ & $\begin{array}{r}214 \\
6877 \\
40112\end{array}$ & $\begin{array}{r}331 \\
6565 \\
3895.2\end{array}$ & $\begin{array}{r}268 \\
6275 \\
36976\end{array}$ & $\begin{array}{r}223 \\
6742 \\
39390\end{array}$ & $\begin{array}{r}239 \\
6550 \\
38388\end{array}$ & $\begin{array}{r}273 \\
6584 \\
38761\end{array}$ \\
\hline & HE BBASKA & $\begin{array}{r}166 \\
497 \\
3690\end{array}$ & $\begin{array}{r}144 \\
601 \\
4158\end{array}$ & $\begin{array}{r}105 \\
722 \\
4648\end{array}$ & $\begin{array}{r}107 \\
662 \\
4314\end{array}$ & $\begin{array}{r}109 \\
613 \\
4048\end{array}$ & $\begin{array}{r}105 \\
587 \\
3877\end{array}$ & $\begin{array}{r}\$ 15 \\
627 \\
4 \$ 57\end{array}$ & $\begin{array}{r}120 \\
723 \\
4731\end{array}$ & $\begin{array}{r}129 \\
657 \\
4399\end{array}$ & $\begin{array}{r}145 \\
725 \\
4868\end{array}$ & $\begin{array}{r}141 \\
756 \\
5026\end{array}$ \\
\hline & NOATE DAROTA & $\begin{array}{r}57 \\
94 \\
835\end{array}$ & $\begin{array}{r}62 \\
191 \\
1410\end{array}$ & $\begin{array}{r}45 \\
275 \\
1799\end{array}$ & $\begin{array}{r}44 \\
197 \\
1349\end{array}$ & $\begin{array}{r}56 \\
250 \\
1711\end{array}$ & $\begin{array}{r}55 \\
199 \\
1417\end{array}$ & $\begin{array}{r}63 \\
200 \\
1467\end{array}$ & $\begin{array}{r}61 \\
239 \\
1679\end{array}$ & $\begin{array}{r}69 \\
242 \\
1738\end{array}$ & $\begin{array}{r}77 \\
269 \\
1931\end{array}$ & $\begin{array}{r}71 \\
302 \\
2083\end{array}$ \\
\hline & SOUTE DAKOTA & $\begin{array}{r}75 \\
36 \\
599\end{array}$ & $\begin{array}{r}67 \\
113 \\
995\end{array}$ & $\begin{array}{r}53 \\
169 \\
1240\end{array}$ & $\begin{array}{r}51 \\
146 \\
1101\end{array}$ & $\begin{array}{r}53 \\
131 \\
1026\end{array}$ & $\begin{array}{r}56 \\
129 \\
1028\end{array}$ & $\begin{array}{r}63 \\
153 \\
1217\end{array}$ & $\begin{array}{r}62 \\
168 \\
1277\end{array}$ & $\begin{array}{r}64 \\
170 \\
1298\end{array}$ & $\begin{array}{r}72 \\
172 \\
1354\end{array}$ & $\begin{array}{r}73 \\
203 \\
1534\end{array}$ \\
\hline
\end{tabular}




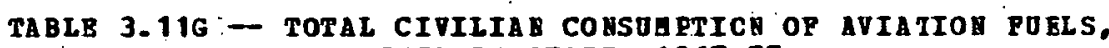
BY PUBL BY STATE, 1967-77

(SBVBETH IA A SBRIBS OP NIRE TABLBS)

AVIATION GASOLIRE OSB IB THOOSA HDS OP BARBELS

POLLODED BY JET POEL OSB IN THOOSANDS OP BARBELS

POLLOAED BY ENERGY USE IN BILLIONS OP BTO

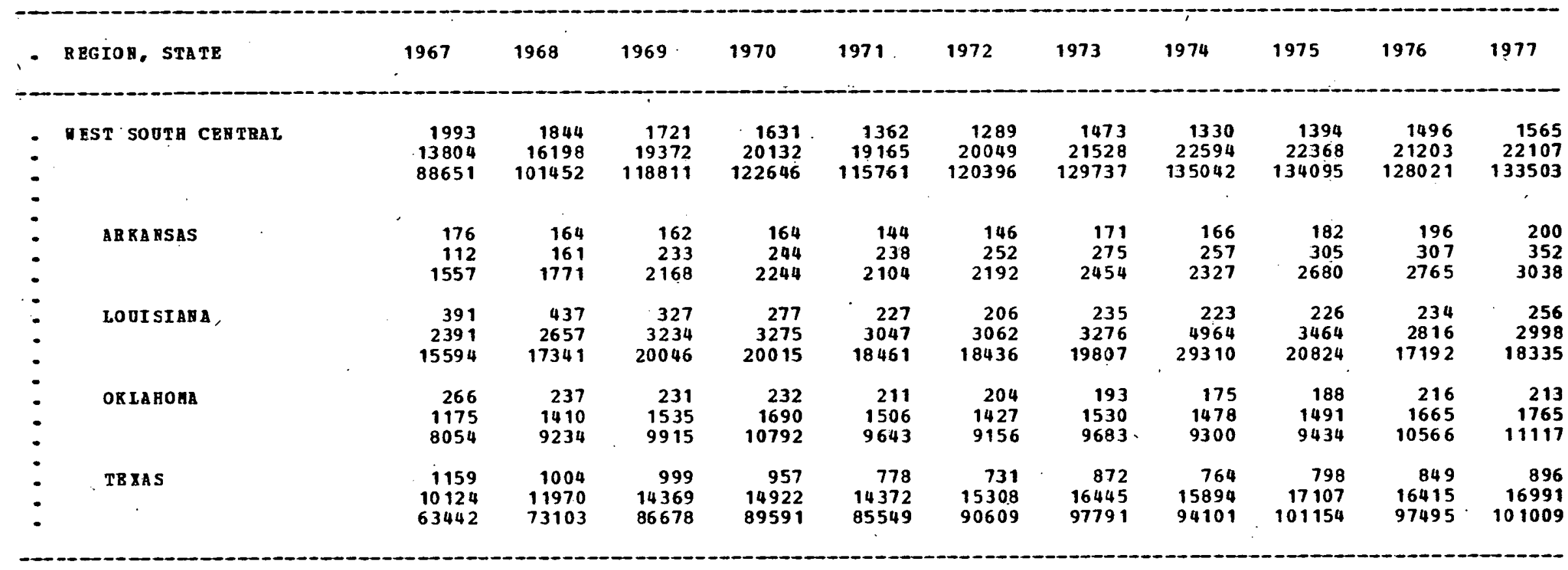


TABL3 3.11H -- TOTAL CIVILIA COYSOAPTION OP AVIATION POBLS. BP POBL BY STATB. 1967-77

(EIGHTH IN A SBRIES OF NIBE TABLBS)

AVIATION GASOLIRE OSE IA THOOSARDS OF BARBELS

POLLORED B. JET POEL OSE IM THOUSANDS OP BA EBELS

FOLIONED BY ERERGT USB IB BILLIONS OP BTO

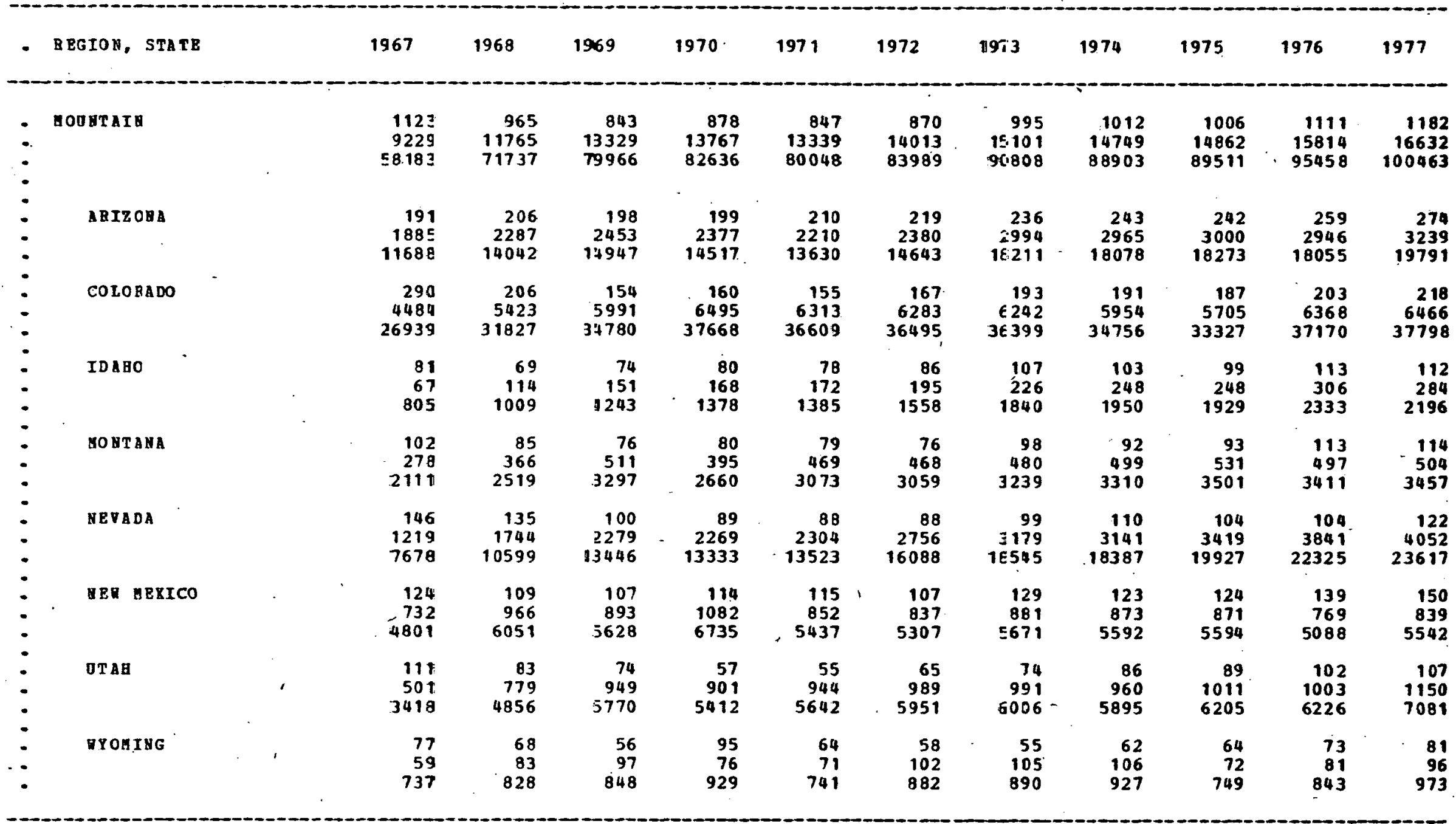


TABLE 3.11I - TOTAL CIVILIAB CONSOY PTION OP AVIATIOQ PUBLS,

BY FOBL BY STATB, 1967-77

(LAST IH A SBRIES OP BIUE TABLES)

APIATION GASOLIBB OSE. IM TROUSAUDS OP BABR RLS

POLLORED BY JET POEL DSE IB THODSA ADS OP BABRELS

POLLODED BY EABRGI OSB IA BILLIONS OP BTE

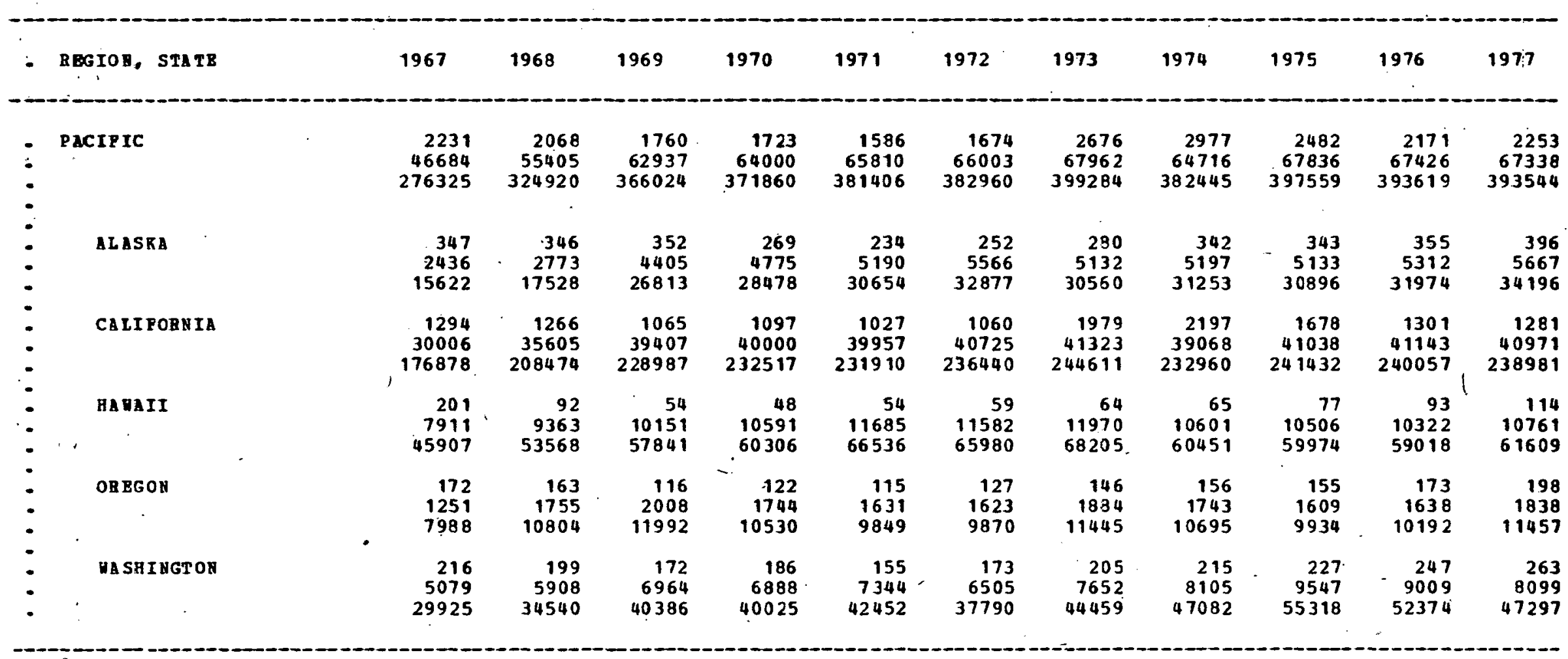

SOORCE: METHOD 104 QUALITY: 1 (NATIONAL), 2 (STATE) 
TABIE 4. 1 -- TOTAL RAIL FOEL, S ENERG USB, BY POBL BY TYPE OP CEZRATIOB, 1967-78

DIESEL FOEL USE IM THOUSAHDS OF BARRBLS

POLIONED BY RESIDOAL OIL OSB IN THOOSANDS OP EAREELS

FOLLOAED BY ELECTRICITY. DSE IB GILLIOHS OP RRE

FOLLORED BT ENERGY OSB IV BILLIONS OP BTO

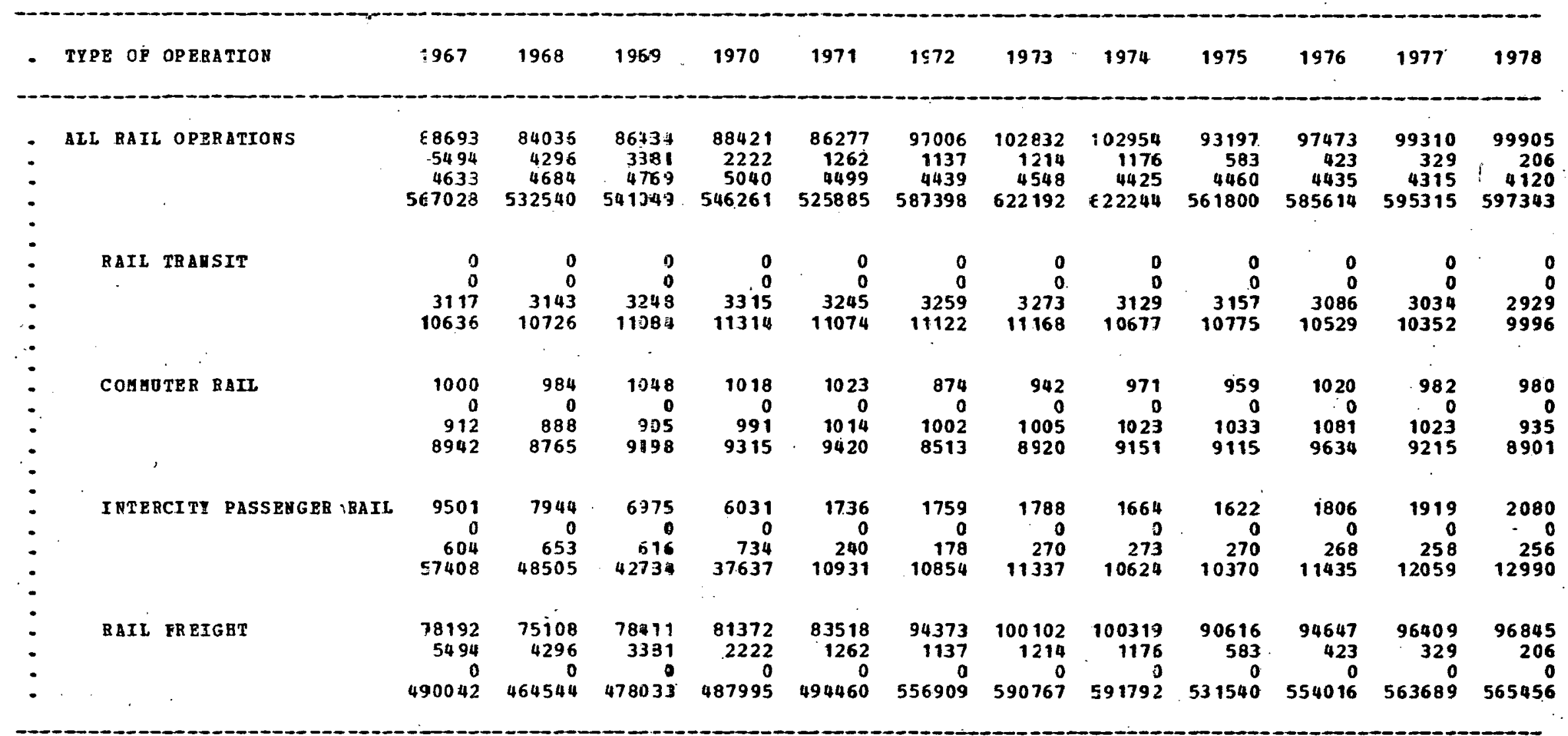


TABLB 4.2A -- RAIL TRABSIT ELECTRICITY ABD ENEBGT USB, EY STATB, 1967-78 (FIRST IH A SERIES OP PIVB TABLBS)

ELECTRICITY USE IA MILLIONS OP RHH, POLLOABD BY BHBBG OSB IN BILLIOHS OP BTU

\begin{tabular}{|c|c|c|c|c|c|c|c|c|c|c|c|c|c|c|}
\hline & REGION, STATE & . & 1967 & 1968 & 1969 & 1970 & 1971 & 1972 & 1973 & 1974 & 1975 & 1976 & 1977 & 1978 \\
\hline & UHITED STATES & & $\begin{array}{r}3117 \\
10636\end{array}$ & $\begin{array}{r}3143 \\
10726\end{array}$ & $\begin{array}{r}3248 \\
11084\end{array}$ & $\begin{array}{r}3315 \\
11314\end{array}$ & $\begin{array}{r}3245 \\
11074\end{array}$ & $\begin{array}{r}3259 \\
11122\end{array}$ & $\begin{array}{r}3273 \\
11168\end{array}$ & $\begin{array}{r}3129 \\
1067.7\end{array}$ & $\begin{array}{r}3157 \\
10775\end{array}$ & $\begin{array}{r}3086 \\
10529\end{array}$ & $\begin{array}{r}3034 \\
10352\end{array}$ & $\begin{array}{l}2929 \\
9996\end{array}$ \\
\hline - & HEM BHGLAND & & $\begin{array}{l}247 \\
843\end{array}$ & $\begin{array}{l}237 \\
810\end{array}$ & $\begin{array}{l}225 \\
768\end{array}$ & $\begin{array}{l}218 \\
747\end{array}$ & $\begin{array}{l}221 \\
756\end{array}$ & $\begin{array}{l}244 \\
833\end{array}$ & $\begin{array}{l}229 \\
781\end{array}$ & $\begin{array}{l}225 \\
768\end{array}$ & $\begin{array}{l}219 \\
747\end{array}$ & $\begin{array}{l}207 \\
708 .\end{array}$ & $\begin{array}{l}211 \\
721\end{array}$ & $\begin{array}{l}215 \\
735\end{array}$ \\
\hline - & CONHECTICOT & & $\begin{array}{l}0 \\
0\end{array}$ & $\begin{array}{l}0 \\
0\end{array}$ & $\begin{array}{l}0 \\
0\end{array}$ & $\begin{array}{l}0 \\
0\end{array}$ & $\begin{array}{l}0 \\
0\end{array}$ & $\begin{array}{l}0 \\
0\end{array}$ & $\begin{array}{l}0 \\
0\end{array}$ & $\begin{array}{l}0 \\
0\end{array}$ & $\begin{array}{l}0 \\
0\end{array}$ & $\begin{array}{l}0 \\
0\end{array}$ & $\begin{array}{l}0 \\
0\end{array}$ & $\begin{array}{l}0 \\
0\end{array}$ \\
\hline . & GAINB & & $\begin{array}{l}0 \\
0\end{array}$ & $\begin{array}{l}\mathbf{0} \\
\mathbf{0}\end{array}$ & $\begin{array}{l}0 \\
0\end{array}$ & $\begin{array}{l}0 \\
0\end{array}$ & $\begin{array}{l}0 \\
0\end{array}$ & $\begin{array}{l}0 \\
0\end{array}$ & $\begin{array}{l}0 \\
0\end{array}$ & $\begin{array}{l}0 \\
0\end{array}$ & $\begin{array}{l}0 \\
0\end{array}$ & $\begin{array}{l}0 \\
0\end{array}$ & $\begin{array}{l}0 \\
0\end{array}$ & $\begin{array}{l}\mathbf{0} \\
\mathbf{0}\end{array}$ \\
\hline 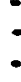 & MASSACA USETTS & & $\begin{array}{l}247 \\
843\end{array}$ & $\begin{array}{l}237 \\
810\end{array}$ & $\begin{array}{l}225 \\
768\end{array}$ & $\begin{array}{l}218 \\
747\end{array}$ & $\begin{array}{l}221 \\
756\end{array}$ & $\begin{array}{l}244 \\
833\end{array}$ & $\begin{array}{l}229 \\
781\end{array}$ & $\begin{array}{l}225 \\
768\end{array}$ & $\begin{array}{l}219 \\
747\end{array}$ & $\begin{array}{l}207 \\
708\end{array}$ & $\begin{array}{l}211 \\
721\end{array}$ & $\begin{array}{l}215 \\
735\end{array}$ \\
\hline • & NET RANPSBIBE & & $\begin{array}{l}0 \\
0\end{array}$ & $\begin{array}{l}0 \\
0\end{array}$ & $\begin{array}{l}0 \\
0\end{array}$ & $\begin{array}{l}0 \\
0\end{array}$ & $\begin{array}{l}0 \\
0\end{array}$ & $\begin{array}{l}0 \\
0\end{array}$ & $\begin{array}{l}0 \\
0\end{array}$ & $\begin{array}{l}0 \\
0\end{array}$ & $\begin{array}{l}0 \\
0\end{array}$ & $\begin{array}{l}0 \\
0\end{array}$ & $\begin{array}{l}0 \\
0\end{array}$ & $\begin{array}{l}0 \\
0\end{array}$ \\
\hline & REODB I SIAND & & $\begin{array}{l}0 \\
0\end{array}$ & $\begin{array}{l}0 \\
0\end{array}$ & $\begin{array}{l}0 \\
0\end{array}$ & $\begin{array}{l}0 \\
0\end{array}$ & $\begin{array}{l}0 \\
0\end{array}$ & $\begin{array}{l}0 \\
0\end{array}$ & $\begin{array}{l}0 \\
0\end{array}$ & $\begin{array}{l}0 \\
0\end{array}$ & $\begin{array}{l}0 \\
0\end{array}$ & $\begin{array}{l}0 \\
0\end{array}$ & $\begin{array}{l}0 \\
0\end{array}$ & $\begin{array}{l}0 \\
0\end{array}$ \\
\hline & . VRRMONT & & $\begin{array}{l}0 \\
0\end{array}$ & $\begin{array}{l}0 \\
0\end{array}$ & $\begin{array}{l}0 \\
0\end{array}$ & $\begin{array}{l}0 \\
0\end{array}$ & $\begin{array}{l}0 \\
0\end{array}$ & $\begin{array}{l}0 \\
0\end{array}$ & $\begin{array}{l}0 \\
0\end{array}$ & $\begin{array}{l}0 \\
0\end{array}$ & $\begin{array}{l}0 \\
0\end{array}$ & $\begin{array}{l}0 \\
0\end{array}$ & $\begin{array}{l}0 \\
0\end{array}$ & $\begin{array}{l}0 \\
0\end{array}$ \\
\hline & MID-ATLABTIC & & $\begin{array}{l}2438 \\
8320\end{array}$ & $\begin{array}{l}2510 \\
8566\end{array}$ & $\begin{array}{l}2631 \\
8978\end{array}$ & $\begin{array}{l}2694 \\
9193\end{array}$ & $\begin{array}{l}2634 \\
8988\end{array}$ & $\begin{array}{l}2600 \\
8871\end{array}$ & $\begin{array}{l}2533 \\
8644\end{array}$ & $\begin{array}{l}2387 \\
8146\end{array}$ & $\begin{array}{l}2361 \\
8058\end{array}$ & $\begin{array}{l}2290 \\
7815\end{array}$ & $\begin{array}{l}2223 \\
7585\end{array}$ & $\begin{array}{l}2091 \\
7138\end{array}$ \\
\hline - & NEH JERSEY & & $\begin{array}{r}33 \\
114\end{array}$ & $\begin{array}{r}35 \\
120\end{array}$ & $\begin{array}{r}70 \\
240\end{array}$ & $\begin{array}{r}72 \\
248\end{array}$ & $\begin{array}{r}74 \\
253\end{array}$ & $\begin{array}{r}77 \\
266\end{array}$ & $\begin{array}{r}74 \\
254\end{array}$ & $\begin{array}{r}75 \\
258\end{array}$ & $\begin{array}{r}75 \\
258\end{array}$ & $\begin{array}{r}74 \\
254\end{array}$ & $\begin{array}{r}70 \\
239\end{array}$ & $\begin{array}{r}70 \\
240\end{array}$ \\
\hline - & NER IORK & & $\begin{array}{l}2213 \\
7553\end{array}$ & $\begin{array}{l}2293 \\
7826\end{array}$ & $\begin{array}{l}2339 \\
7982\end{array}$ & $\begin{array}{l}2394 \\
8169\end{array}$ & $\begin{array}{l}2341 \\
7988\end{array}$ & $\begin{array}{l}2303 \\
7860\end{array}$ & $\begin{array}{l}2240 \\
7645\end{array}$ & $\begin{array}{l}2083 \\
7110\end{array}$ & $\begin{array}{l}2081 \\
710.1\end{array}$ & $\begin{array}{l}2006 \\
6846\end{array}$ & $\begin{array}{l}1967 \\
6713\end{array}$ & $\begin{array}{l}1826 \\
6230\end{array}$ \\
\hline & PENASYL VANIA & , & $\begin{array}{r}191 \\
\cdot \quad 652\end{array}$ & $\begin{array}{l}181 \\
619\end{array}$ & $\begin{array}{l}221 \\
755\end{array}$ & $\begin{array}{l}227 \\
776\end{array}$ & $\begin{array}{l}218 \\
746\end{array}$ & $\begin{array}{l}218 \\
744\end{array}$ & $\begin{array}{l}218 \\
744\end{array}$ & $\begin{array}{l}227 \\
777\end{array}$ & $\begin{array}{l}204 \\
697\end{array}$ & $\begin{array}{l}209 \\
714\end{array}$ & $\begin{array}{l}185 \\
632\end{array}$ & $\begin{array}{l}195 \\
666\end{array}$ \\
\hline
\end{tabular}

SOJBCE: METHOD 201 DATA QUALITI: 1 
TABLE 4.2B - - RAIL TRAHSIE RLECTRICITY AND BNERG USE, EY STATE, 1967-78 (SECOND IB A SBRIES OP FIVE TABLES)

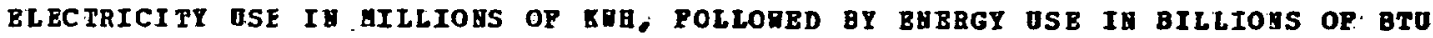

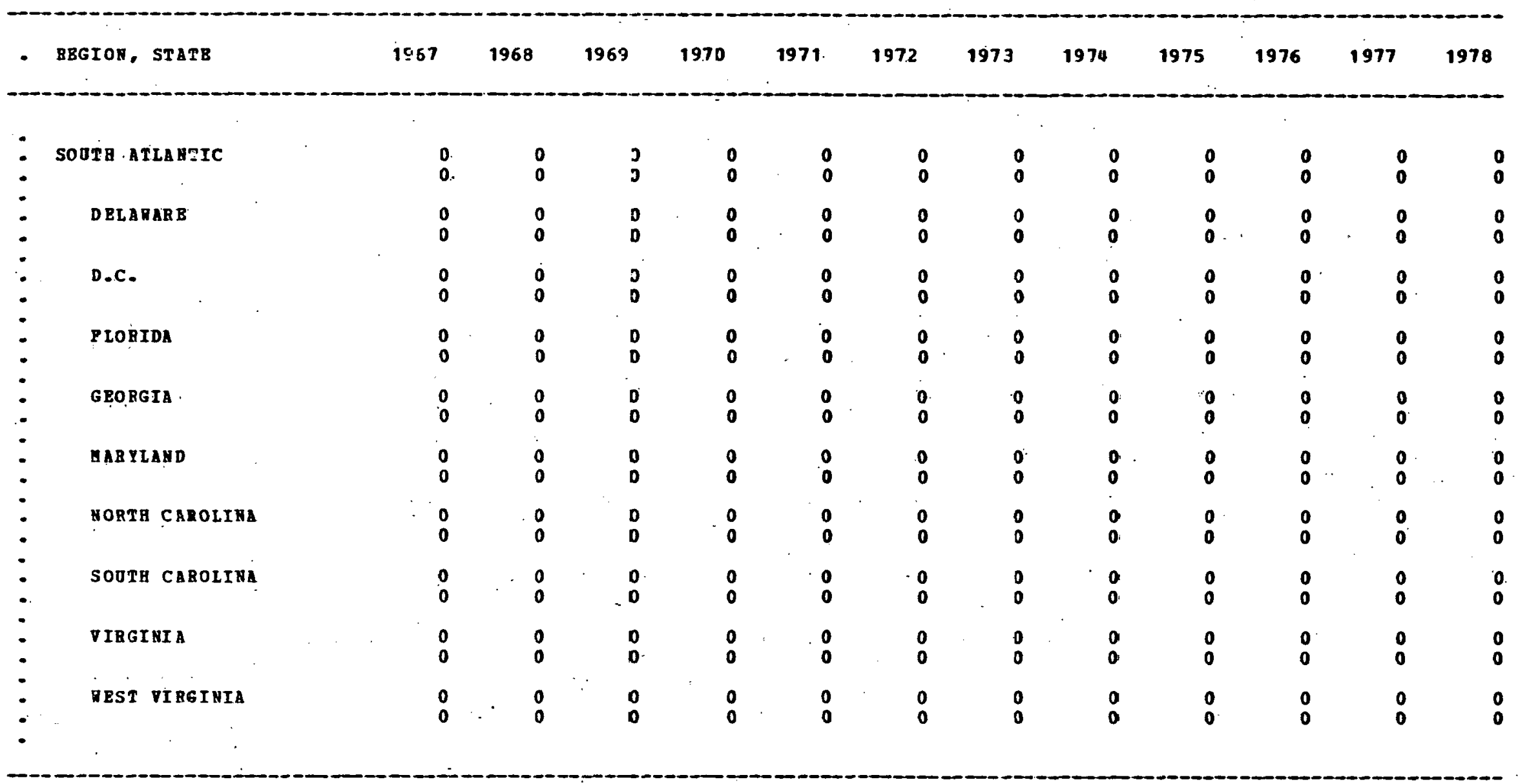

SOOBCE: HETHOS 201 DATA QOALITI: 1 
TABLE 4.2C -- RAII TRANSIT ELBCTRICITY ARD BAERG USE, EY STATE, 1967-78 (THIRD IN A SBRIBS OP PIVE TABLBS)

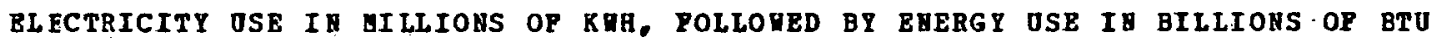

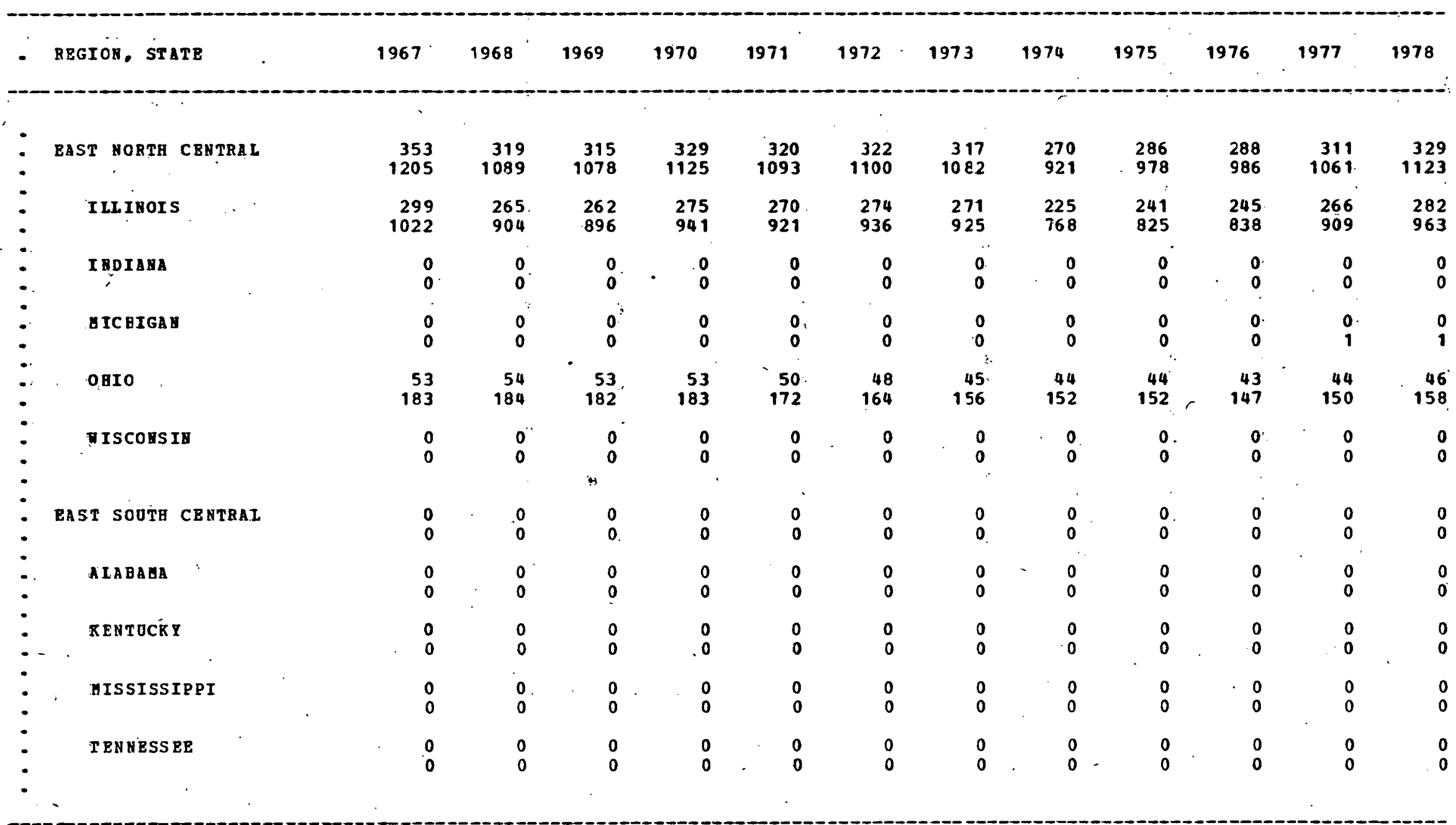


TABLB 4. 2D -- BAIL TRANSIT BLBCTRICITY A BD BBEBGY USE, EY STATE, 1967-78 (POURTH I A SERIES OF FIVE TABLBS)

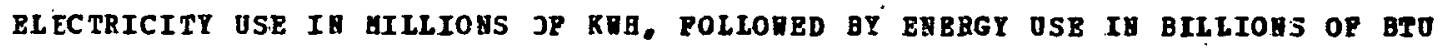

\begin{tabular}{|c|c|c|c|c|c|c|c|c|c|c|c|c|}
\hline BEGION, STATE & 1967 & 1968 & 1969 & 1970 & 1971 & 1972 & 1973 & 1974 & 1975 & 1976 & 1977 & 1978 \\
\hline DEST NOBTH CENTRAL & $\begin{array}{l}0 \\
0\end{array}$ & $\begin{array}{l}0 \\
0\end{array}$ & i & $\stackrel{0}{0}$ & $\begin{array}{l}0 \\
0\end{array}$ & : & $:$ & : & : & : & 0 & 0 \\
\hline IORA & $\begin{array}{l}0 \\
0\end{array}$ & $\begin{array}{l}0 \\
0\end{array}$ & $\begin{array}{l}0 \\
0\end{array}$ & $\stackrel{0}{0}$ & $\begin{array}{l}0 \\
0\end{array}$ & $\begin{array}{l}0 \\
0\end{array}$ & $\begin{array}{l}0 \\
0\end{array}$ & $\begin{array}{l}0 \\
0\end{array}$ & $\begin{array}{l}0 \\
0\end{array}$ & $\begin{array}{l}0 \\
0\end{array}$ & $\begin{array}{l}0 \\
0\end{array}$ & $\stackrel{0}{0}$ \\
\hline RANSAS & $\begin{array}{l}0 \\
0\end{array}$ & $\begin{array}{l}0 \\
0\end{array}$ & $\begin{array}{l}0 \\
\mathrm{y}\end{array}$ & $\begin{array}{l}0 \\
0\end{array}$ & $\begin{array}{l}0 \\
0\end{array}$ & $\stackrel{0}{0}$ & $\begin{array}{l}0 \\
0\end{array}$ & $\begin{array}{l}0 \\
0\end{array}$ & : & $\begin{array}{l}0 \\
0\end{array}$ & $\begin{array}{l}0 \\
0\end{array}$ & 0 \\
\hline AIMEBSOTA & $\begin{array}{l}0 \\
0\end{array}$ & $\begin{array}{l}0 \\
0\end{array}$ & $\vec{j}$ & $\begin{array}{l}0 \\
0\end{array}$ & $\begin{array}{l}0 \\
0\end{array}$ & $\begin{array}{l}0 \\
0\end{array}$ & $\begin{array}{l}0 \\
0\end{array}$ & $\begin{array}{l}0 \\
0\end{array}$ & $\begin{array}{l}0 \\
0\end{array}$ & $\begin{array}{l}0 \\
0\end{array}$ & $\begin{array}{l}0 \\
0\end{array}$ & o \\
\hline AISSOORI & $\begin{array}{l}0 \\
0\end{array}$ & $\begin{array}{l}0 \\
0\end{array}$ & $\begin{array}{l}J^{0} \\
\mathbf{D}\end{array}$ & $\begin{array}{l}0 \\
0\end{array}$ & $\begin{array}{l}0 \\
0\end{array}$ & $\begin{array}{l}0 \\
0\end{array}$ & $\begin{array}{l}0 \\
0\end{array}$ & $\begin{array}{l}0 \\
0\end{array}$ & $\begin{array}{l}0 \\
0\end{array}$ & $\begin{array}{l}0 \\
0\end{array}$ & $\begin{array}{l}0 \\
0\end{array}$ & : \\
\hline NRBRASKA & $\begin{array}{l}0 \\
0\end{array}$ & $\begin{array}{l}0 \\
0\end{array}$ & $\begin{array}{l}\mathbf{0} \\
\mathbf{0}\end{array}$ & $\begin{array}{l}0 \\
0\end{array}$ & $\begin{array}{l}0 \\
0\end{array}$ & $\begin{array}{l}0 \\
0\end{array}$ & o & $\begin{array}{l}0 \\
0\end{array}$ & $\begin{array}{l}0 \\
0\end{array}$ & $\begin{array}{l}0 \\
0\end{array}$ & $\begin{array}{l}0 \\
0\end{array}$ & : \\
\hline NORTE DAKOTA & $\begin{array}{l}0 \\
0\end{array}$ & $\begin{array}{l}0 \\
0\end{array}$ & $\begin{array}{l}0 \\
0\end{array}$ & $\begin{array}{l}0 \\
0\end{array}$ & $\begin{array}{l}0 \\
0\end{array}$ & $\begin{array}{l}0 \\
0\end{array}$ & $\begin{array}{l}0 \\
0\end{array}$ & $\begin{array}{l}0 \\
0\end{array}$ & $\begin{array}{l}0 \\
0\end{array}$ & $\begin{array}{l}0 \\
0\end{array}$ & $\begin{array}{l}0 \\
0\end{array}$ & $\begin{array}{l}0 \\
0\end{array}$ \\
\hline SOOTH DAKOTA & $\begin{array}{l}\mathbf{0} \\
\mathbf{0}\end{array}$ & $\begin{array}{l}0 \\
0\end{array}$ & $\begin{array}{l}\mathbf{0} \\
\mathbf{D}\end{array}$ & $\begin{array}{l}0 \\
0\end{array}$ & $\begin{array}{l}0 \\
0\end{array}$ & $\begin{array}{l}0 \\
0\end{array}$ & $\begin{array}{l}0 \\
0\end{array}$ & $\begin{array}{l}0 \\
0\end{array}$ & : & $\begin{array}{l}0 \\
0\end{array}$ & $\begin{array}{l}0 \\
0\end{array}$ & $\begin{array}{l}0 \\
0\end{array}$ \\
\hline DEST SOUTH CBHTRAL & $\begin{array}{r}5 \\
19\end{array}$ & $\begin{array}{r}4 \\
15\end{array}$ & $\begin{array}{r}4 \\
15\end{array}$ & $\mathbf{2 3}^{3}$ & $\mathbf{1 3}^{3}$ & $\begin{array}{r}4 \\
14\end{array}$ & $\begin{array}{r}4 \\
13\end{array}$ & $\mathbf{1 3}^{\mathbf{3}}$ & $\begin{array}{r}3 \\
11\end{array}$ & ${ }_{12}^{3}$ & $\begin{array}{r}\mathbf{3} \\
\end{array}$ & $1^{3}$ \\
\hline ARKANSAS & $\begin{array}{l}0 \\
0\end{array}$ & $\begin{array}{l}0 \\
0\end{array}$ & $\stackrel{a}{a}$ & $\begin{array}{l}0 \\
0\end{array}$ & $\begin{array}{l}0 \\
0\end{array}$ & $\begin{array}{l}0 \\
0\end{array}$ & $\begin{array}{l}0 \\
0\end{array}$ & $\begin{array}{l}0 \\
0\end{array}$ & $\begin{array}{l}0 \\
0\end{array}$ & $\begin{array}{l}0 \\
0\end{array}$ & $\begin{array}{l}0 \\
0\end{array}$ & : \\
\hline LOOISIAMA & $\begin{array}{r}4 \\
16\end{array}$ & $\begin{array}{r}3 \\
13\end{array}$ & 13 & $\begin{array}{r}3 \\
10\end{array}$ & ${ }_{10}^{3}$ & ${ }_{11}^{3}$ & ${ }_{11}^{3}$ & 11. & $\begin{array}{l}2 \\
9\end{array}$ & $\begin{array}{r}3 \\
10^{2}\end{array}$ & $\begin{array}{r}3 \\
10^{3}\end{array}$ & $\begin{array}{r}3 \\
10\end{array}$ \\
\hline ORLABOAA & $\begin{array}{l}0 \\
0\end{array}$ & $\begin{array}{l}0 \\
0\end{array}$ & $\begin{array}{l}\mathbf{a} \\
\mathbf{a}\end{array}$ & $\begin{array}{l}0 \\
0\end{array}$ & $\begin{array}{l}0 \\
0\end{array}$ & $\begin{array}{l}0 \\
0\end{array}$ & $\begin{array}{l}0 \\
0\end{array}$ & $\begin{array}{l}0 \\
0\end{array}$ & $\begin{array}{l}0 \\
0\end{array}$ & $\begin{array}{l}0 \\
0\end{array}$ & $\begin{array}{l}0 \\
0\end{array}$ & o \\
\hline TBDAS & $\begin{array}{l}0 \\
2\end{array}$ & $\begin{array}{l}0 \\
2\end{array}$ & $\stackrel{0}{2}$ & $\begin{array}{l}0 \\
2\end{array}$ & $\begin{array}{l}0 \\
2\end{array}$ & $\begin{array}{l}0 \\
2\end{array}$ & $\begin{array}{l}0 \\
2\end{array}$ & $\begin{array}{l}0 \\
2\end{array}$ & $\begin{array}{l}0 \\
2\end{array}$ & $\begin{array}{l}0 \\
2\end{array}$ & $\begin{array}{l}0 \\
2\end{array}$ & $\stackrel{0}{2}$ \\
\hline
\end{tabular}


TABLE 4. 2E -- BAIL TRA HSIT ELBCTRICITY ABD EABRG USB, EY STATB, 1967-78

(LAST IN A SEBIES OF PIVE TABLES)

ELECTRICITY OSE IN GILLIONS OF RRH, POLLORED BY BHERG OSE IN BILLIOHS OP BTO

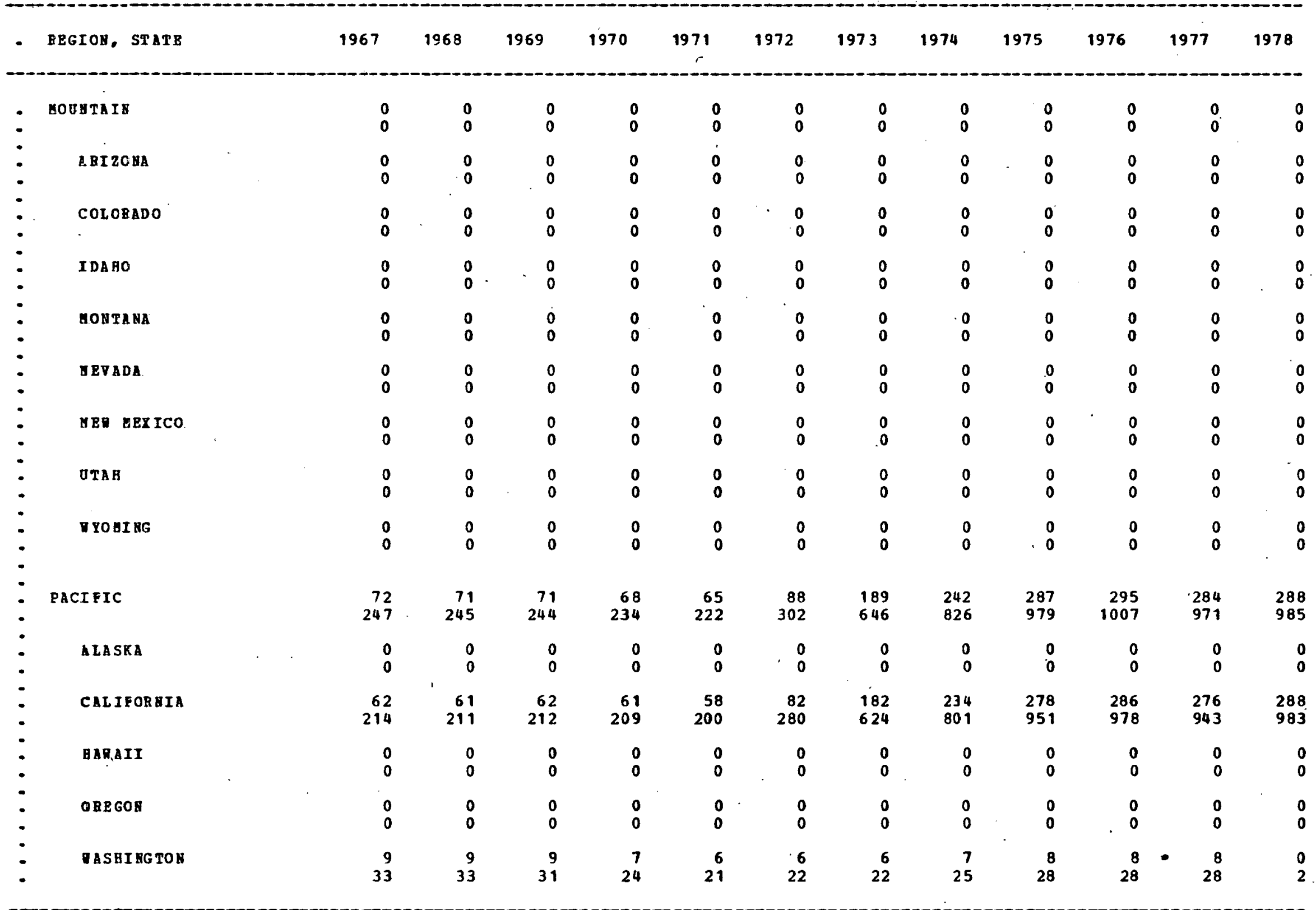


TABLE 4.3A - COAHOTEB RLIL POEL ABD BHEZGY OSE, BI POBL ET STATB, 1967-78

(PIRST EB A SBAIBS OP HIBE TABLBS)

DIESEL PUEL OSE IH THOOSARDS OP BARBBLS

POLLOTED BY RLECTBICITY OSB IV BILLTOSS OP RILORATT-BOTES

FOLLORBD BI TOLAL BABAGT. OSB IR BILLIOAS OP ETD

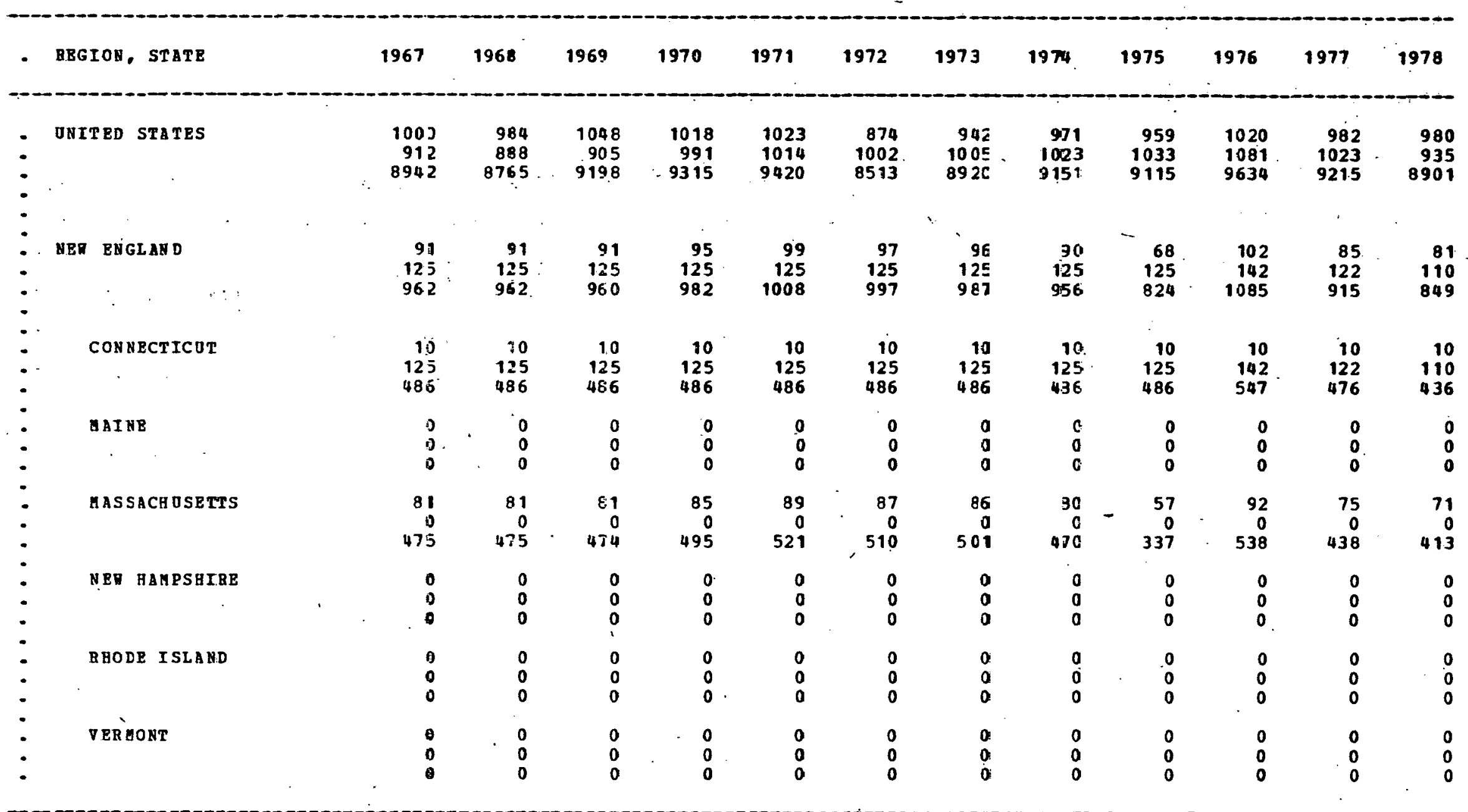


FABLE 4.3B -- COAGOTEB BAIL FUEL AND ENEBGY OSE, BY POEL BY STATE, 1967-78

(SBCOAD IA A SBBIES OF HIBE TABLES)

DIESEL POEL OSE IA THOUSABDS OP BARBBLS
FOLLODED BY BLECTRICITY OSB IB GILLIOHS OP KILOHATT-HOURS POLLORED BY TOTAL BEEBG USE IB BILLIONS OP BTO

\begin{tabular}{|c|c|c|c|c|c|c|c|c|c|c|c|c|c|}
\hline & BEGION, STATE & 1967 & 1968 & 1969 & 1970 & 1971 & 1972 & 1973 & 1974 & 1975 & 1976 & 1977 & 1978 \\
\hline . & MTD-ATLARTIC & $\begin{array}{r}439 \\
716 \\
5002\end{array}$ & $\begin{array}{r}432 \\
691 \\
4879\end{array}$ & $\begin{array}{r}472 \\
705 \\
5158\end{array}$ & $\begin{array}{r}440 \\
793 \\
5273\end{array}$ & $\begin{array}{r}453 \\
816 \\
5428\end{array}$ & $\begin{array}{r}435 \\
807 \\
5292\end{array}$ & $\begin{array}{r}419 \\
806 \\
5.195\end{array}$ & $\begin{array}{r}421 \\
827 \\
5280\end{array}$ & $\begin{array}{r}428 \\
840 \\
5360\end{array}$ & $\begin{array}{r}447 \\
873 \\
5585\end{array}$ & $\begin{array}{r}415 \\
837 \\
5275\end{array}$ & $\begin{array}{r}421 \\
761 \\
5056\end{array}$ \\
\hline 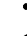 & & & & $\therefore$ & & & & & & & & & \\
\hline 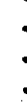 & EBU JERSEY & $\begin{array}{r}240 \\
170 \\
1979\end{array}$ & $\begin{array}{r}240 \\
170 \\
1979\end{array}$ & $\begin{array}{r}240 \\
170 \\
1979\end{array}$ & $\begin{array}{r}240 \\
170 \\
1979\end{array}$ & $\begin{array}{r}240 \\
170 \\
1979\end{array}$ & $\begin{array}{r}240 \\
170 \\
1979\end{array}$ & $\begin{array}{r}240 \\
170 \\
1979\end{array}$ & $\begin{array}{r}240 \\
170 \\
1979\end{array}$ & $\begin{array}{r}240 \\
170 \\
1979\end{array}$ & $\begin{array}{r}250 \\
168 \\
2034\end{array}$ & $\begin{array}{r}235 \\
166 \\
1935\end{array}$ & $\begin{array}{r}234 \\
177 \\
1969\end{array}$ \\
\hline & $\begin{array}{c}\text { NEW YORK } \\
\text {. }\end{array}$ & $\begin{array}{r}167 \\
378 \\
2270\end{array}$ & $\begin{array}{r}163 \\
354 \\
2162\end{array}$ & $\begin{array}{r}203 \\
367 \\
2441\end{array}$ & $\begin{array}{r}171 \\
456 \\
2556\end{array}$ & $\begin{array}{r}184 \\
478 \\
2710\end{array}$ & $\begin{array}{r}166 \\
469 \\
2572\end{array}$ & $\begin{array}{r}149 \\
469 \\
2473\end{array}$ & $\begin{array}{r}152 \\
490 \\
2561\end{array}$ & $\begin{array}{r}158 \\
502 \\
2639\end{array}$ & $\begin{array}{r}163 \\
506 \\
2681\end{array}$ & $\begin{array}{r}153 \\
472 \\
2505\end{array}$ & $\begin{array}{r}158 \\
480 \\
2562\end{array}$ \\
\hline & PERASTLVAIA & $\begin{array}{r}31 \\
167 \\
753\end{array}$ & $\begin{array}{r}28 \\
167 \\
736\end{array}$ & $\begin{array}{r}28 \\
167 \\
736\end{array}$ & $\begin{array}{r}28 \\
167 \\
737\end{array}$ & $\begin{array}{r}28 \\
167 \\
738\end{array}$ & $\begin{array}{r}29 \\
167 \\
740\end{array}$ & $\begin{array}{r}29 \\
167 \\
741\end{array}$ & $\begin{array}{r}29 \\
167 \\
739\end{array}$ & $\begin{array}{r}29 \\
167 \\
741\end{array}$ & $\begin{array}{r}32 \\
198 \\
869\end{array}$ & $\begin{array}{r}27 \\
198 \\
834\end{array}$ & $\begin{array}{r}29 \\
103 \\
524\end{array}$ \\
\hline
\end{tabular}

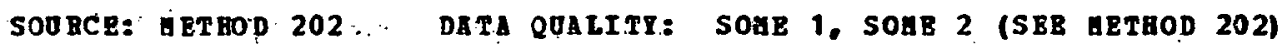




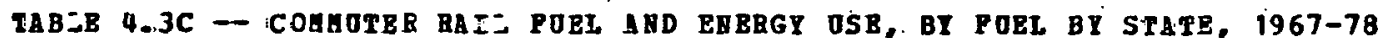

(THIRD IB A SERIES OP BIAB TABLES)

DIESEL POZL USE IA THODSAHDS OP BABREL

FOLLOLED BY ELBCTRICITY OSB IB GILLIOSS OP RILOR ATT-EOORS

FOLLONED BI FOTAL ZUBBGI OSE IY BILLIOES OF BTO

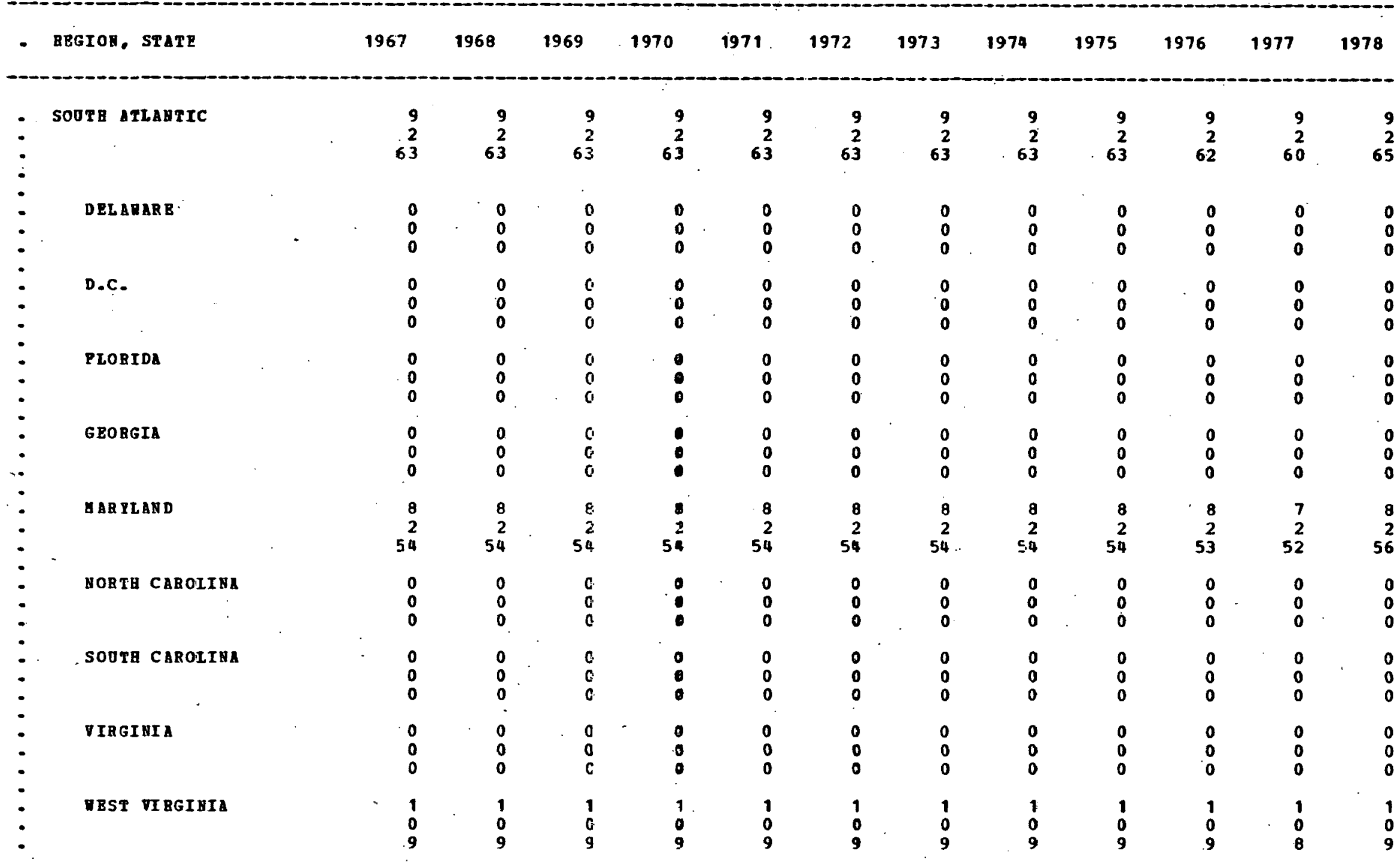


TABLE 4.3D -- COMMUTEB BAIL PUEL ARD EBBRGY OSE; BY PUBL BI STATE, 1967-78 (FOURTH IN A SBRIBS OF GIBB TABLES)

\section{DIBSEL POEL OSE ID THONSAMDS OF BABBRIS}

POLLONED BY ELECTRICITY OSB IR GILLIOUS OP RTIOR ATT-HOORS

POLLORBD BY TOTAL EBEBGY USB IH BILLIOHS OF BTO

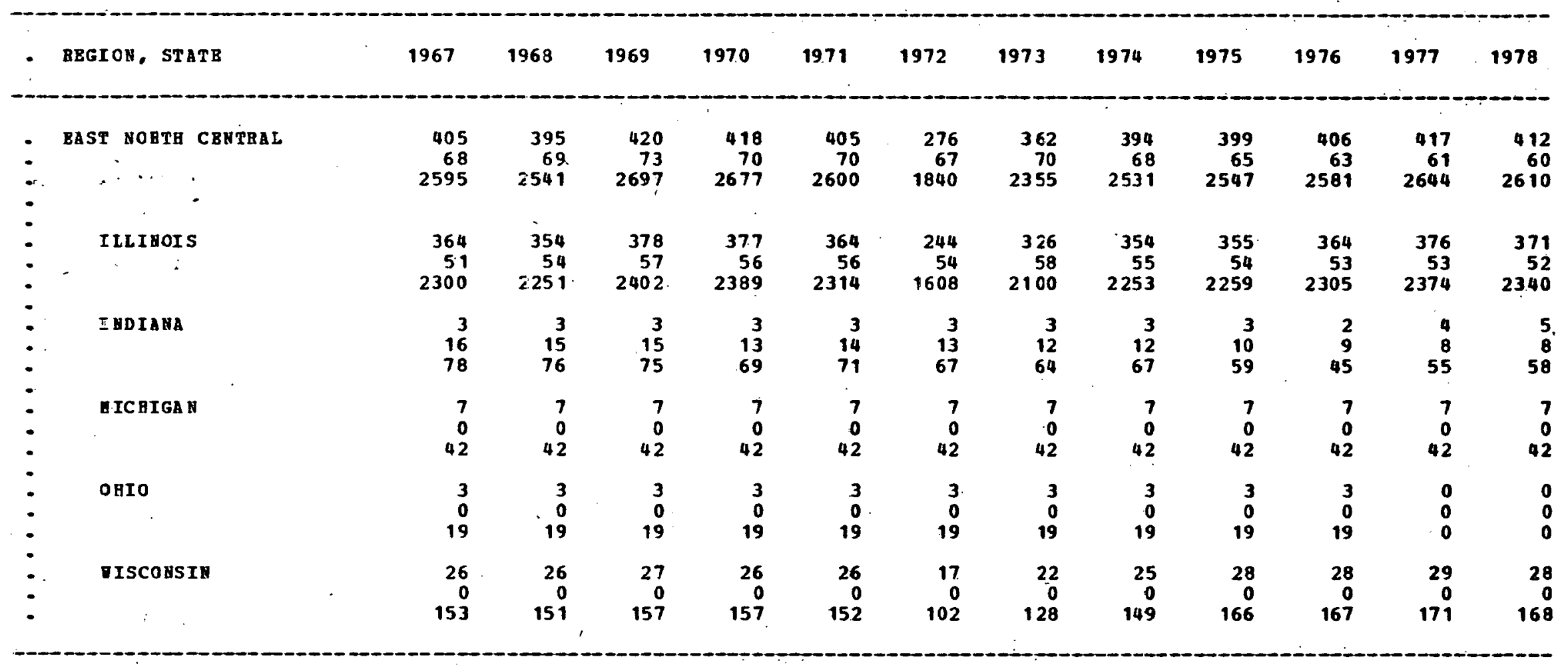

SOURCB; IETEOD 202

DAT QUALITI: SOAE 1, SOAB 2 (SBB AETHOD 202) 
TABEE 4.3B -- COBHOTEB RAIL PUBI ABD EHBRGY DSB, BY FOBL BY STATE, 1967-78

$$
\text { (EIPTA IN A SBRIBS OP HIBB TABLBS). }
$$

DIBSBL FO3L USE IR THOOSABDS OF BABRBLS

POLLJAED EY ELECTELCITY OSB IE UILLIOAS OP KILORATT-RDURS

FOLLONED BI TDTAI BNERGY OSB IU BILLIOYS OF BTD

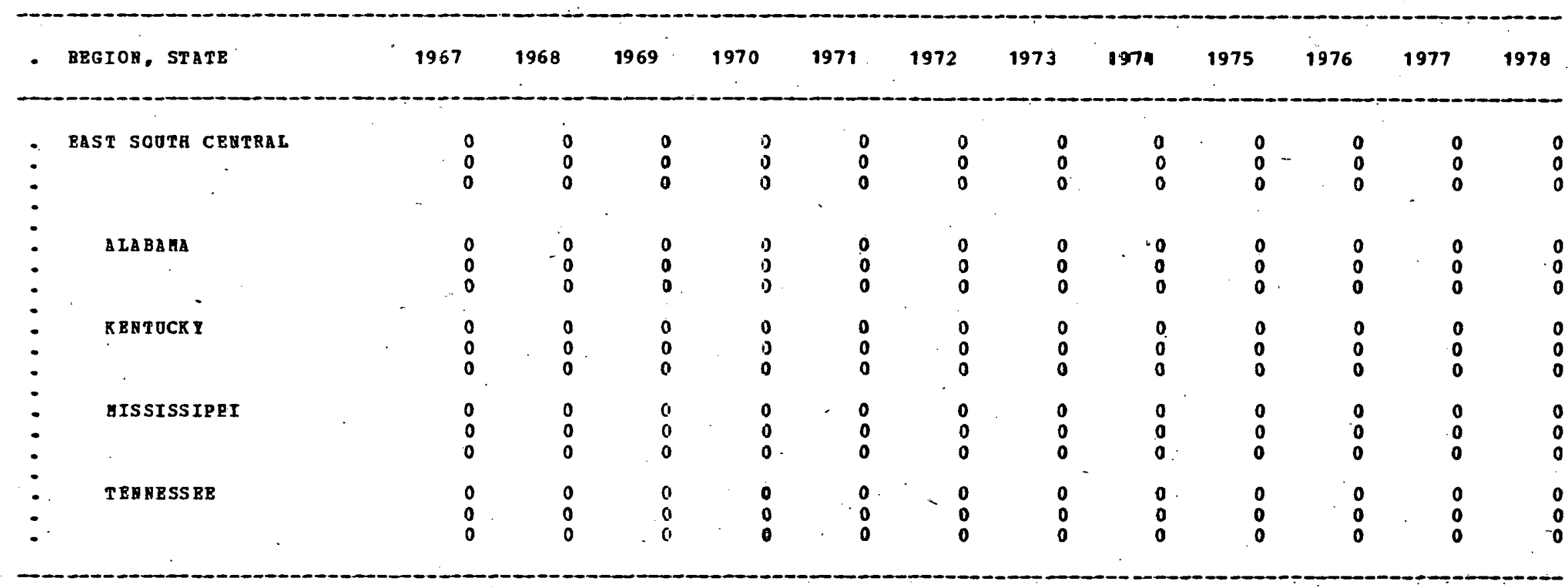


TABLE 4.3F -- COHHOTER BAIL POBL AHD BABRGI USB, BY POEL BY STATE, 1967-78

(SIXTH IH A SERTES OF HINB TABLES)

DIESEL POEL OSE IH THOOSABDS OP BARBBLS

FOLLORED BY BLECTRICITY USB IB GILLIONS OF RILORATT-BOUBS

POLLO\&ED BY TOTAL BABRGY OSE IF BILLIONS OP BTO

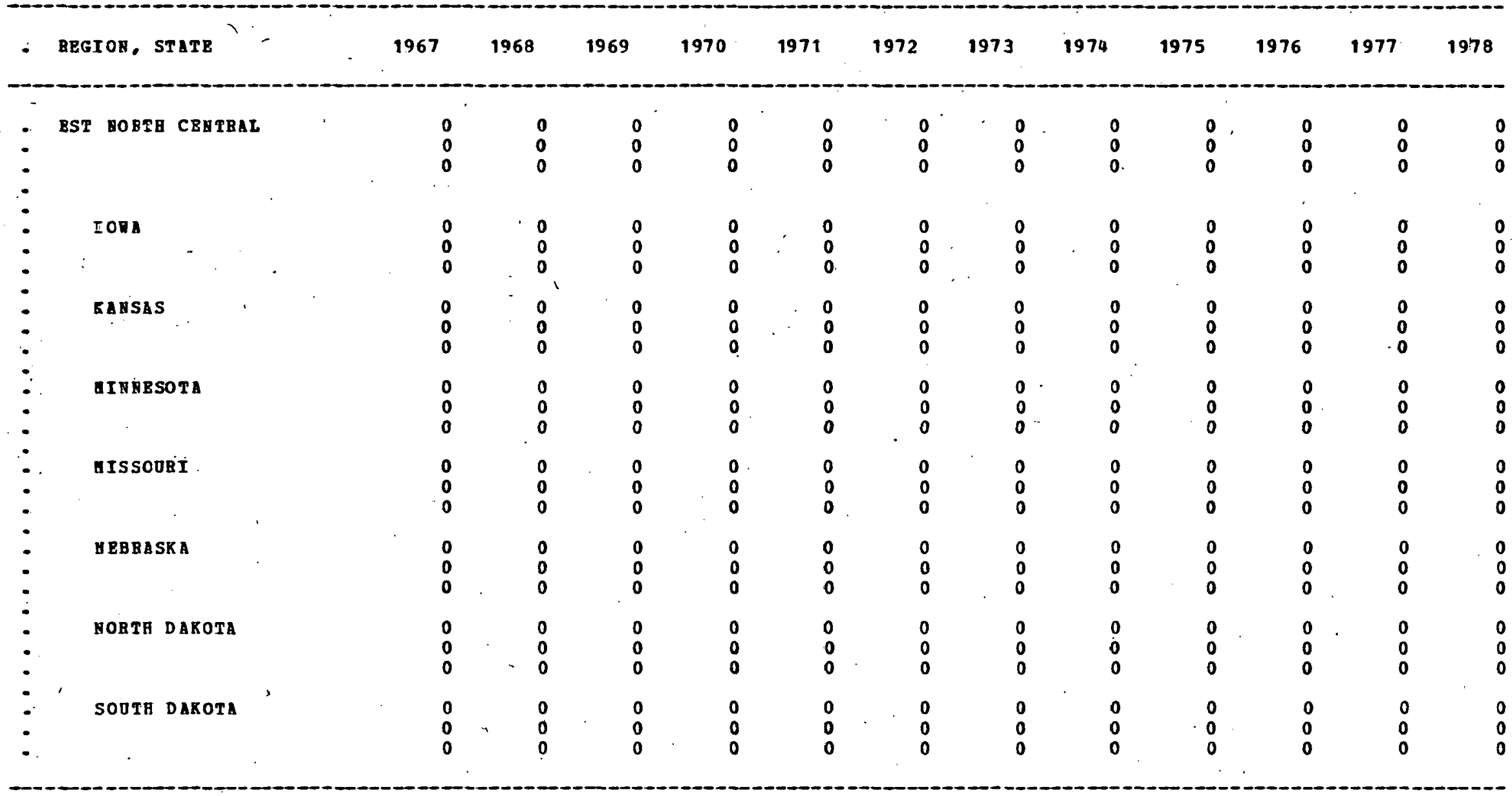

SOORCE: METHOD 202

DATA QUALITI: SONE 1, SOHB 2 (SEB GETBOD 202) 
TABIE 4.3G - EOAOTER RAII POBL ABD EABRGY OSE, BY POEL BY STAEB, 1967-78

(SBTEETB IB A SBRIBS OP GIBE TABLBS)

DIBSEL FUEL OSB IA TROOSABDS OF BABRELS

POLLONBD BY BLBCTBTCITY OSB IB UILLIOUS OF RILOR ATT-BOONS

PJLLORED BE TCTAL EHEBG DSE IB BILLIOAS OP BTU

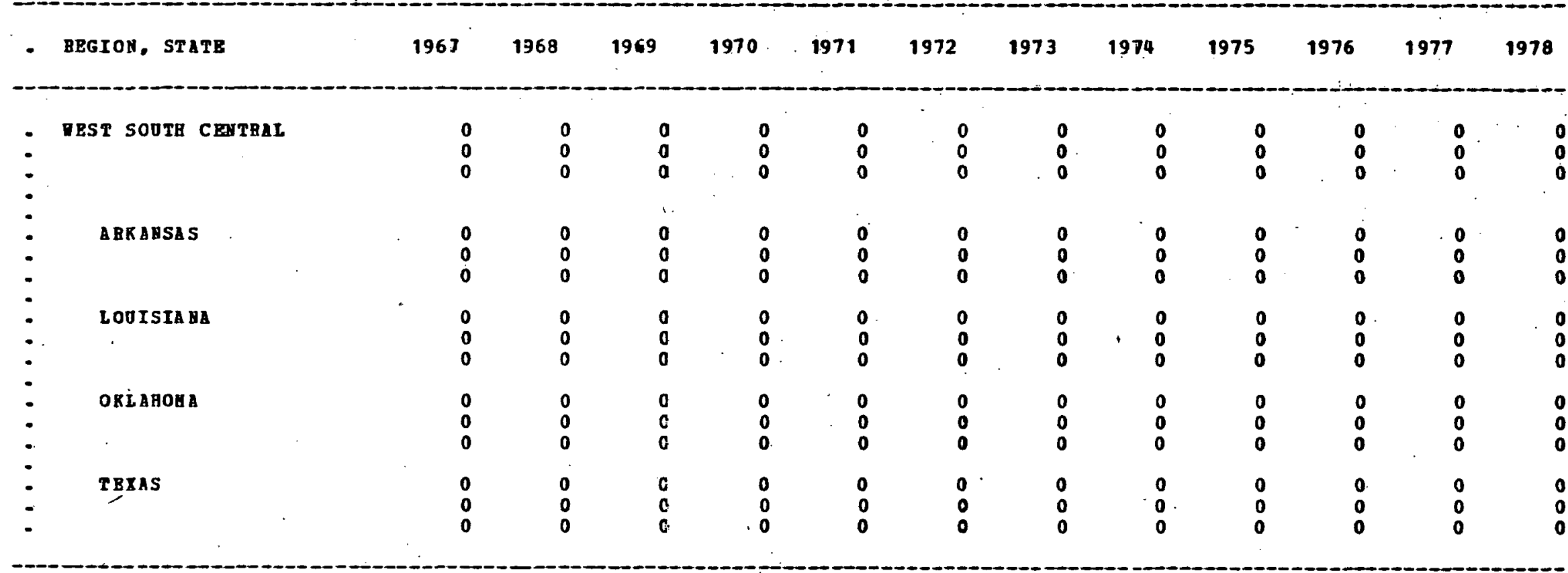

SOURCE: ВRTHOD 202

DAT QBALITY: SARB 1, SOAB 2 (SEE AETHOD 202) 
TABLB 4.38 -- COHAOTBR BAIL POBL AYD BEERGY USB, BI POEL BY STATE, 1967-78

(BIGHTB IR A SERIES OP HIHE TABLBS)

DIESEL POEL OSE IN TBOOSANDS OP BABRBLS

FOLLONBD BY BLECTRICITY USB IH IILLIONS OF KILOSATT-ROUBS

POLLONED BY TOTAL ENEBGI USE IA BILLIONS OP BTO

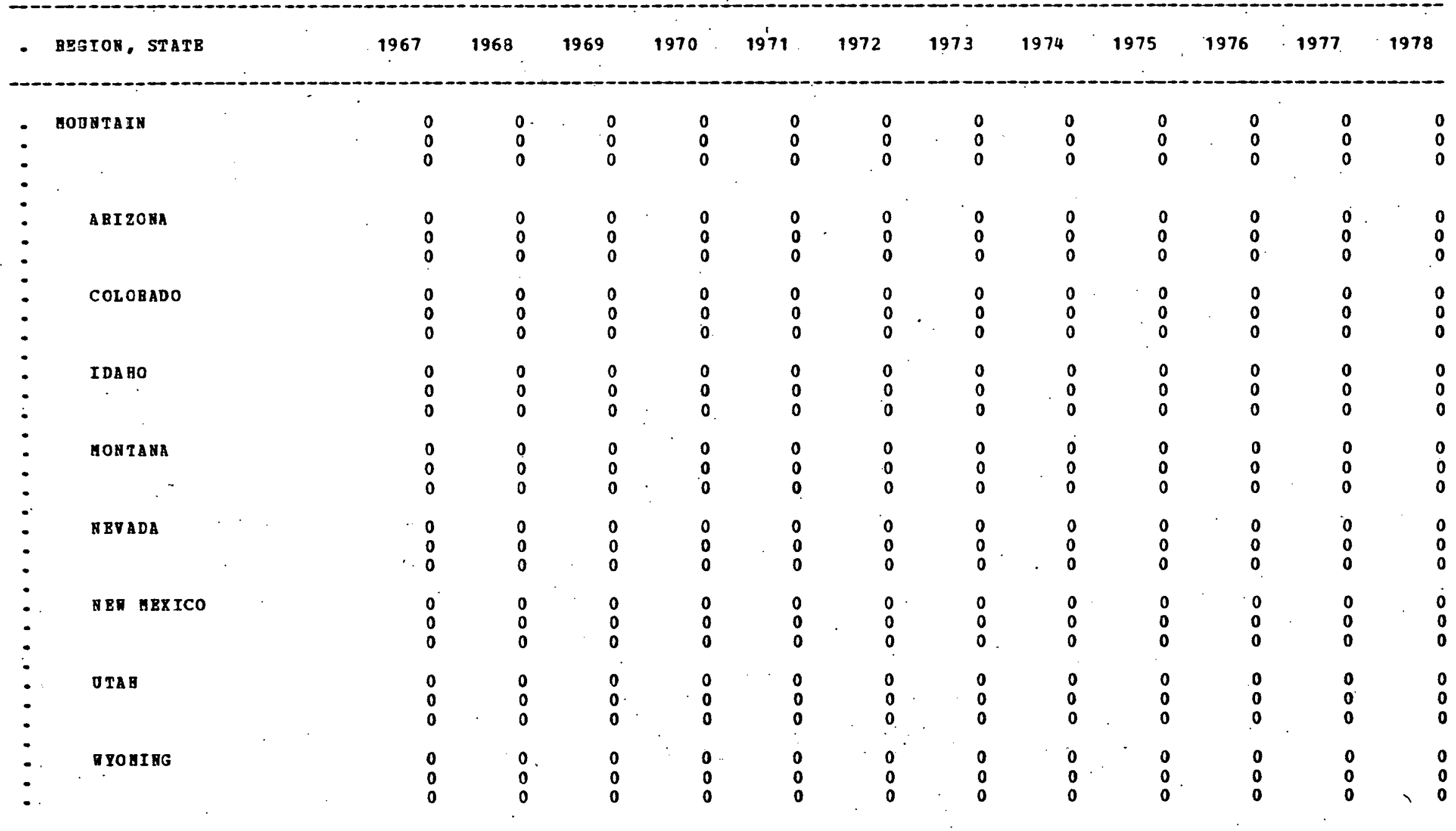


TABLE 4.3I -- COMAOTBE BAIL FOBL $\triangle$ AD BUERGY OSE, BY PUBL BY SFATE, 1967-78

(LAST IY A SBRIBS OP YI UE TABLBS)

DIBSBL POEL OSB IY THOUSAHDS OF BABRBLS

FOLLORED BY BLBCTEICITT OSB IV HILLIOHS OF KILOA ATT-HOOAS

FOLLORED BI TOTAL BBBBGI OSE IB BILLIOSS OP BTO

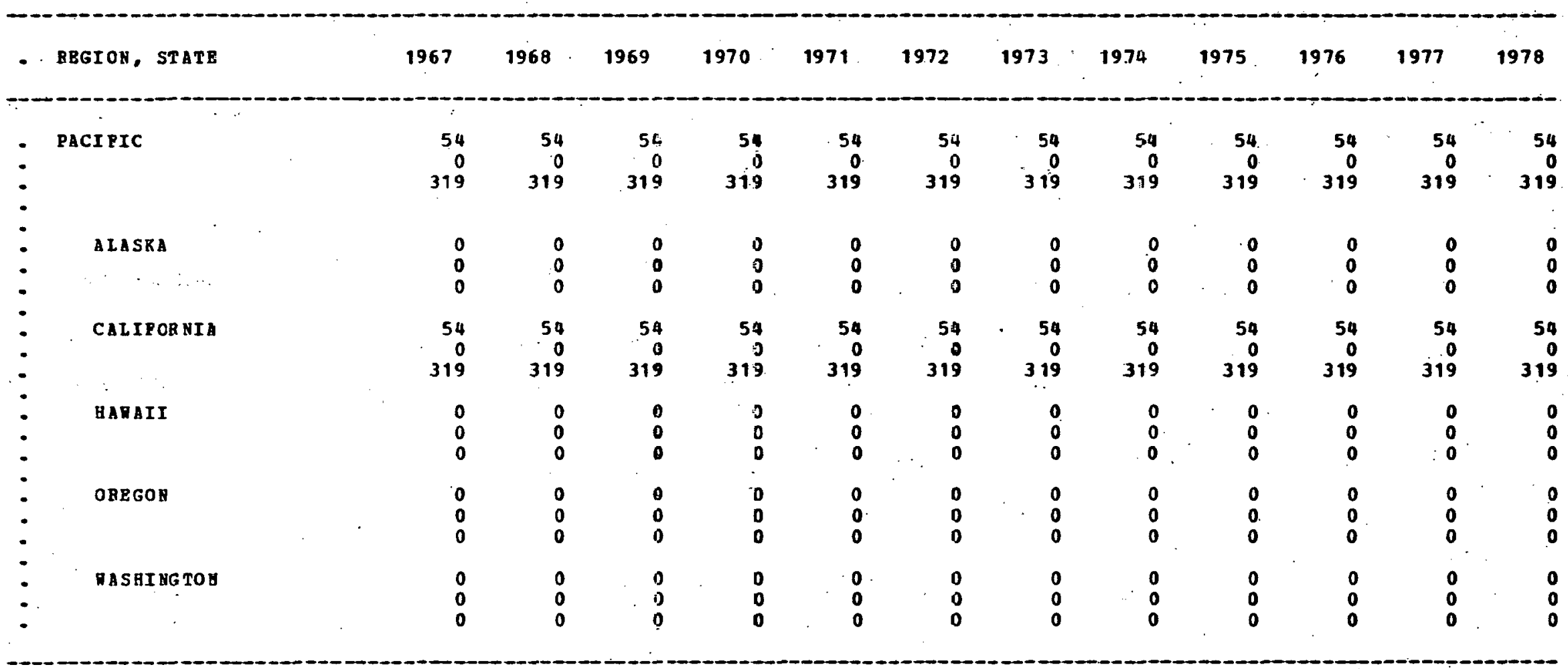

SOOBCE: ARTHOD 202

DATI QDALITI: SOHE 1; SOHE 2 [SBB UBTBOD 202) 


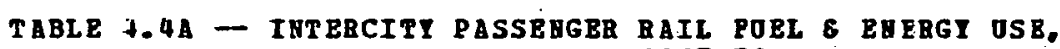
BY POBL BY STATE, 1967-78

(PIBST IA A SBRIBS OP HIBE TABLBS)

DIBSBL POEL OSB IH TBOUSABDS OP BABRELS

POLLORED BY BLBCT RICITY OSE IB GILLIOHS OF RILOHATT-HOOBS POLLOAED BI TOTAL EHERG OSE IA BILLIOAS OP BTO

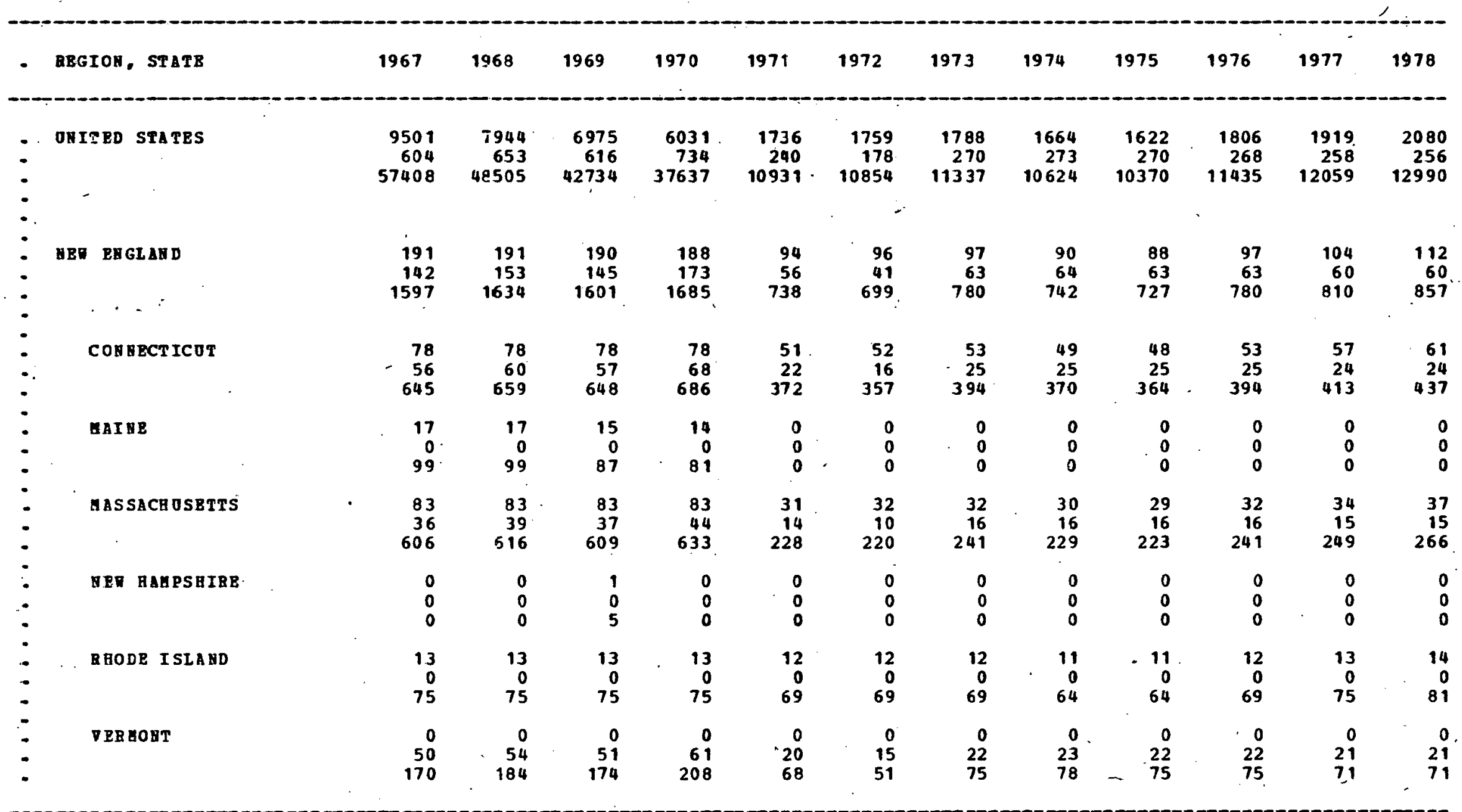


TABLE 4.4B -- INTERCITY PASSEMGER RAIL FOBL E ENER:G OSE,

B T PTEL BI STATB, 1967-78

(SECOND IN A SRRIBS OP NINB TABLES)

DIESEL FOEL USE IR THOOSANDS OP BABRBLS

FOLLORED BY BLECTRICITY USB .IN GILLIOYS OF RILORATT-HCOZS

FOLLORED BI TCTAL BNEBGY OSE IN BILLIONS OP BTU

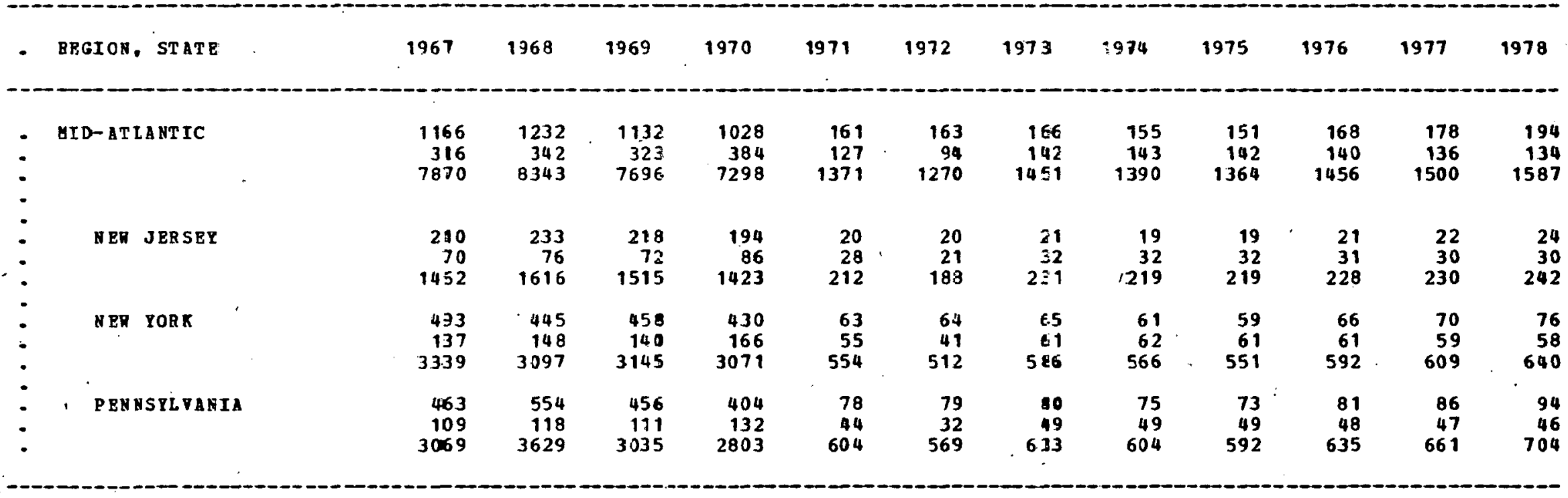

SOU BCS: HETHOD 203

DATA QUALTY: 2 
TABLE 4.4C - IHTERCITY PASSERGE RAIL FOEL E RREGY USB. BY POBL BY STATE, 1.967-78

(THIRD IN SERIBS OP RIVE TABLES)

DIESEL FORL DSE IY THOUSANDS OP BARRELS

POLLOAED. BY ELECTRICITY USE TA GILIONS OP KILOU ATT-HOORS

FOLLORED BT TOTAL EREBGY DSB IU BILLIONS OF BTU

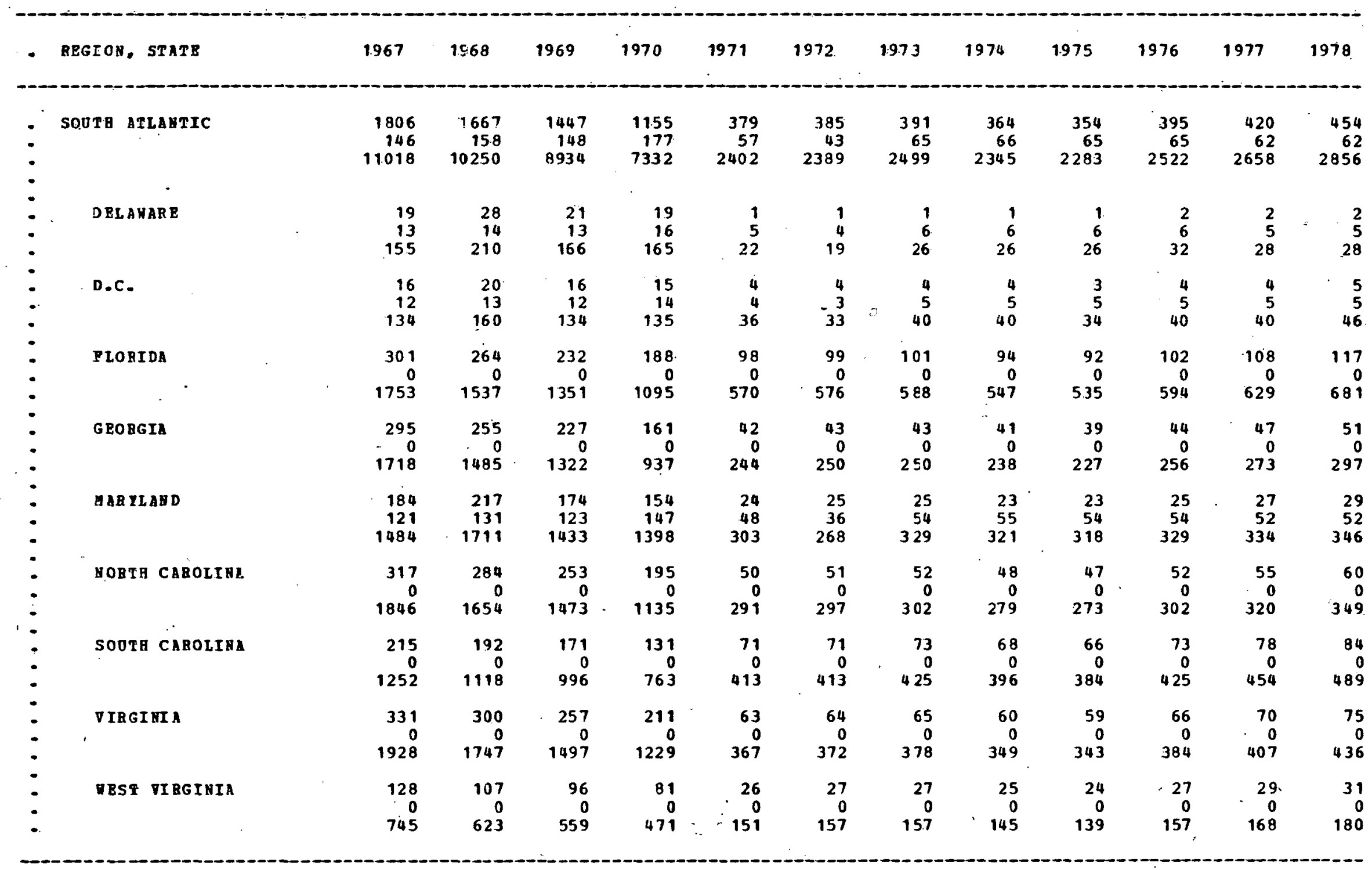


TABLE 4.40 -- INTERCITY PASSB IGER RAIL FOEL E BEEBGS USB. B.T FUEL BY STATB, 1967-78

(FOOBEA IN A SBRIBS OF NINE TABLES)

DIESEL PORL USE IN THOUSANDS OF BARRELS

POLLONED BI BLECTRICITY USE IN GILLIOBS OP KILONATT-ACOBS

POLLORED BY TOTAL ENEBGY OSE IY BILIIONS OP BTU

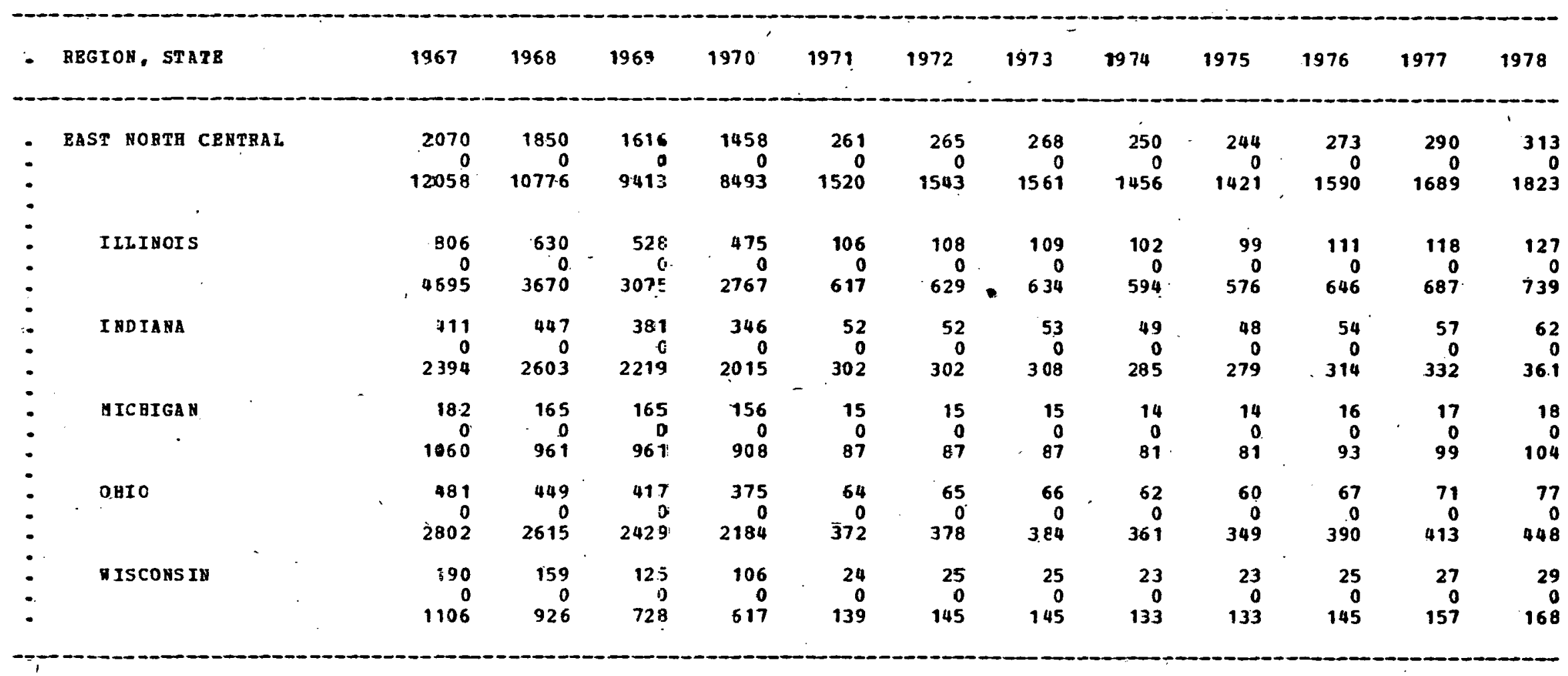


TABLE 4. 4E -- INTERCITY PASSENGER RAIL PUEL E ENERGY OSE, BY PUEL BI STATE, 1967-78

(FIPTH IN-A SERIES OP NIUE TABLES)

DIESEL FURL OSE IN THOUSANDS OP BABREL

POLLONED BY ELECTRICITY OSE IN MILLIONS OP RILOBATT-HODBS

POLLOHED BY TOTAL EAERG USE IN BILLIONS OF BTO

\begin{tabular}{|c|c|c|c|c|c|c|c|c|c|c|c|c|c|c|}
\hline & BEGION, STATB & & 1967 & 1968 & 1969 & 1970 & 1971 & 1972 & 1973 & $1974^{\circ}$ & 1975 & 1976 & $\cdot 1977$ & 1978 \\
\hline & EAST SOOTH CERTRAL & & $\begin{array}{r}801 \\
. \quad 0 \\
4666\end{array}$ & $\begin{array}{r}657 \\
0 \\
3827\end{array}$ & $\begin{array}{r}543 \\
0 \\
3163\end{array}$ & $\begin{array}{r}424 \\
0 \\
2469\end{array}$ & $\begin{array}{r}39 . \\
0 \\
227\end{array}$ & $\begin{array}{r}40 \\
0 \\
233\end{array}$ & $\begin{array}{r}42 \\
0 \\
244\end{array}$ & $\begin{array}{r}38 \\
0 \\
221\end{array}$ & $\begin{array}{r}38 \\
0 \\
221\end{array}$ & $\begin{array}{r}42 \\
0 \\
244\end{array}$ & $\begin{array}{r}44 \\
0 \\
256\end{array}$ & $\begin{array}{r}48 \\
0 \\
279\end{array}$ \\
\hline & ALABAsa & $\cdot$ & $\begin{array}{r}257 \\
0 \\
1497\end{array}$ & $\begin{array}{r}216 \\
0 \\
1258\end{array}$ & $\begin{array}{r}188 \\
0 \\
1095\end{array}$ & $\begin{array}{r}133 \\
0 \\
774\end{array}$ & $\begin{array}{r}12 \\
0 \\
69\end{array}$ & $\begin{array}{r}12 \\
0 \\
69\end{array}$ & $\begin{array}{r}12 \\
0 \\
69\end{array}$ & $\begin{array}{r}11 \\
0 . \\
64\end{array}$ & $\begin{array}{r}11 \\
0 \\
64\end{array}$ & $\begin{array}{r}12 \\
0 \\
69\end{array}$ & $\begin{array}{r}13 \\
0 \\
75\end{array}$ & $\begin{array}{r}14 \\
0 \\
81\end{array}$ \\
\hline & RENTOCKY & & $\begin{array}{r}171 \\
0 \\
996\end{array}$ & $\begin{array}{r}141 \\
0 \\
821\end{array}$ & $\begin{array}{r}108 \\
0 \\
629\end{array}$ & $\begin{array}{r}92 \\
0 \\
.535\end{array}$ & $\begin{array}{r}10 \\
0 \\
58\end{array}$ & $\begin{array}{r}11 \\
0 \\
64\end{array}$ & $\begin{array}{r}11 \\
0 \\
64\end{array}$ & $\begin{array}{r}10 \\
0 \\
58\end{array}$ & $\begin{array}{r}10 \\
0 \\
58\end{array}$ & $\begin{array}{r}11 \\
0 \\
64\end{array}$ & $\begin{array}{r}12 \\
0 \\
69\end{array}$ & $\begin{array}{r}13 \\
0 \\
75\end{array}$ \\
\hline & ISSI SS IPPI & . & $\begin{array}{r}147 \\
0 \\
856\end{array}$ & $\begin{array}{r}114 \\
0 \\
664\end{array}$ & $\begin{array}{r}99 \\
0 \\
576\end{array}$ & $\begin{array}{r}89 \\
0 \\
518\end{array}$ & $\begin{array}{r}9 \\
0 \\
52\end{array}$ & $\begin{array}{r}9 \\
0 \\
52\end{array}$ & $\begin{array}{r}10 \\
0 \\
58\end{array}$ & $\begin{array}{r}9 \\
0 \\
52\end{array}$ & $\begin{array}{r}9 \\
0 \\
52\end{array}$ & $\begin{array}{r}10 \\
0 \\
58\end{array}$ & $\begin{array}{r}10 \\
0 \\
58\end{array}$ & $\begin{array}{r}11 \\
0 \\
64\end{array}$ \\
\hline & TENBESSEB & & $\begin{array}{r}226 \\
0 \\
1316\end{array}$ & $\begin{array}{r}186 \\
0 \\
1083\end{array}$ & $\begin{array}{r}148 \\
0 \\
862\end{array}$ & $\begin{array}{r}110 \\
0 \\
640\end{array}$ & $\begin{array}{r}8 \\
0 \\
46\end{array}$ & $\begin{array}{r}8 \\
0 \\
46\end{array}$ & $\begin{array}{r}9 \\
0 \\
52\end{array}$ & $\begin{array}{r}8 \\
0 \\
46\end{array}$ & $\begin{array}{r}8 \\
0 \\
46\end{array}$ & $\begin{array}{r}9 \\
0 \\
52\end{array}$ & $\begin{array}{r}9 \\
0 \\
52\end{array}$ & $\begin{array}{r}10 \\
0 \\
58\end{array}$ \\
\hline
\end{tabular}


TABLE 4.4F -- INT

BY FUPL BI STATE, 1967-78

(SIXTE IN A SERIES OF NINB TABLES)

DIESEL FUEL USE IR THOUSANDS OP BARBRLS

POL OHED BY ELECT PICITY USE IY GILIIOBS OP KILONATT-BOJHS

POLLORED BY TOTAL EMEBGY OSE IK BILLIOIS OP BTO

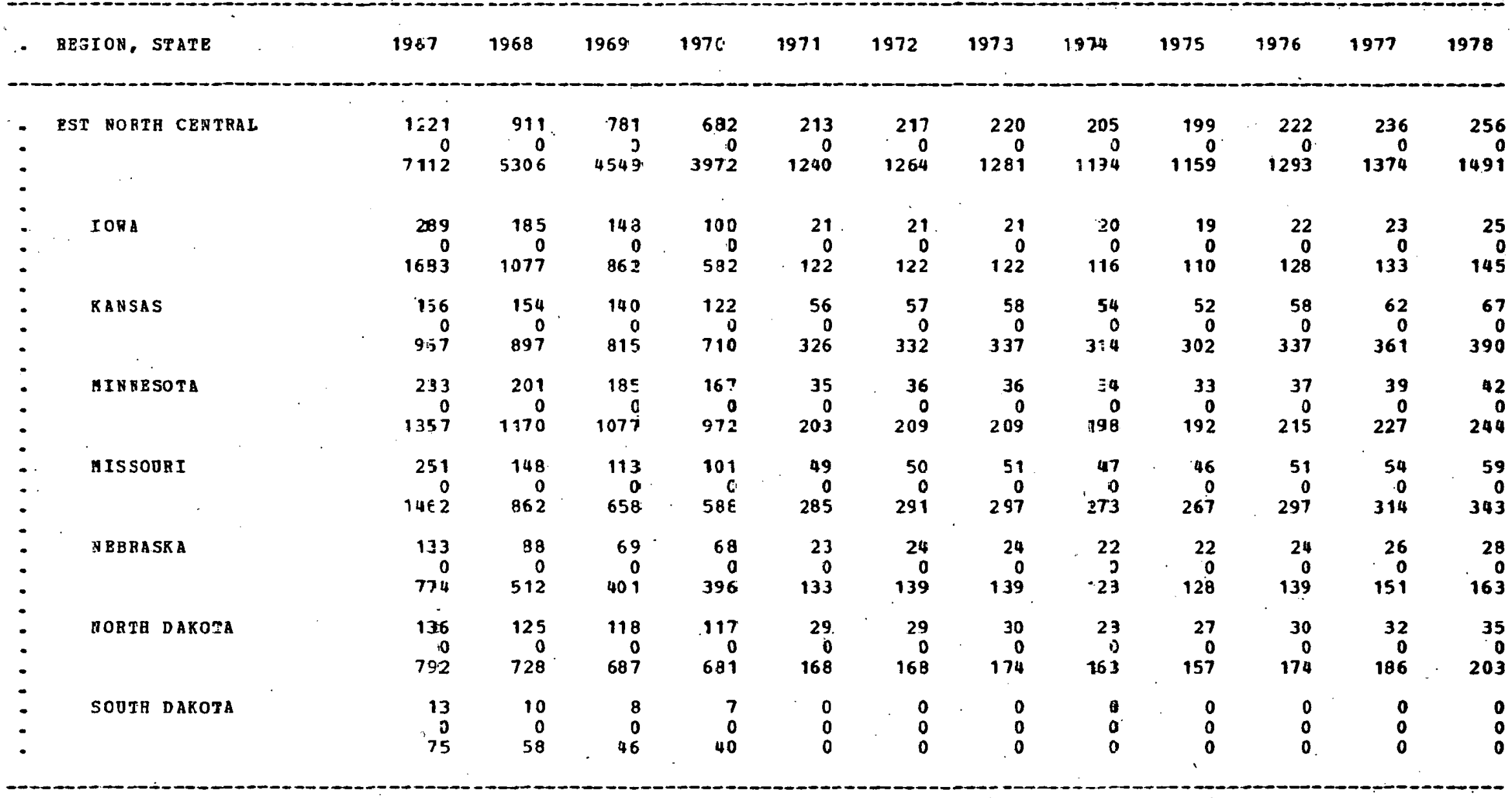


TABLE 4.4G - IATERCITY PASSENGER RATL PUEL \& ENEAgT USB,

BY POEL BY STATB, 1967-78

(SEVENTH IN A SBRIES OF NINE TABLES)

DIESEL POEL DSB IN TBOUSANDS OF BABRLLS

POLLOHED BY. ELECTRICITY DSE IN MILLIONS OP RILOHATT-HOUBS

POLLONED BY TOTAL ENEBGY OSE IN BILLIOHS OP BTO

\begin{tabular}{|c|c|c|c|c|c|c|c|c|c|c|c|c|c|}
\hline & BEGION, STATB & 1967 & 1968 & 1969 & 1970 & 1971 & 1972 & 1973 & 1974 & 1975 & 1976 & 1977 & 1978 \\
\hline & MEST SOOTH CBHTRAI & $\begin{array}{r}548 \\
0 \\
3192\end{array}$ & $\begin{array}{r}291 \\
0 \\
1695\end{array}$ & $\begin{array}{r}228 \\
0 \\
1328\end{array}$ & $\begin{array}{r}198 \\
0 \\
1153\end{array}$ & $\begin{array}{r}102 \\
0 \\
594\end{array}$ & $\begin{array}{r}102 \\
0 \\
594\end{array}$ & $\begin{array}{r}104 \\
0 \\
605\end{array}$ & $\begin{array}{r}97 \\
0 \\
565\end{array}$ & $\begin{array}{r}95 \\
0 \\
553\end{array}$ & $\begin{array}{r}105 \\
0 \\
611\end{array}$ & $\begin{array}{r}112 \\
0 \\
652\end{array}$ & $\begin{array}{r}121 \\
0 \\
704\end{array}$ \\
\hline & ARKANSA $S$ & $\begin{array}{r}33 \\
0 \\
192\end{array}$ & $\begin{array}{r}20 \\
0 \\
116\end{array}$ & $\begin{array}{r}11 \\
0 \\
64\end{array}$ & $\begin{array}{r}7 \\
0 \\
40\end{array}$ & $\begin{array}{r}4 \\
0 \\
23\end{array}$ & $\begin{array}{r}4 \\
0 \\
23\end{array}$ & $\begin{array}{r}5 \\
0 \\
29\end{array}$ & $\begin{array}{r}4 \\
0 \\
23\end{array}$ & $\begin{array}{r}4 \\
0 \\
23\end{array}$ & $\begin{array}{r}5 \\
0 \\
29\end{array}$ & $\begin{array}{r}5 \\
0 \\
29\end{array}$ & $\begin{array}{r}5 \\
0 \\
29\end{array}$ \\
\hline & toOIsIana & $\begin{array}{r}71 \\
0 \\
413\end{array}$ & $\begin{array}{r}52 \\
0 \\
302\end{array}$ & $\begin{array}{r}39 \\
0 \\
227\end{array}$ & $\begin{array}{r}35 \\
0 \\
203\end{array}$ & $\begin{array}{r}13 \\
0 \\
75\end{array}$ & $\begin{array}{r}13 \\
0 \\
75\end{array}$ & $\begin{array}{r}13 \\
0 \\
75\end{array}$ & $\begin{array}{r}12 \\
0 \\
69\end{array}$ & $\begin{array}{r}12 \\
0 \\
69\end{array}$ & $\begin{array}{r}13 \\
0 \\
75\end{array}$ & $\begin{array}{r}14 \\
0 \\
81\end{array}$ & $\begin{array}{r}15 \\
0 \\
87\end{array}$ \\
\hline & ORLAHOAA & $\begin{array}{r}79 \\
0 \\
46.0\end{array}$ & $\begin{array}{r}41 \\
0 \\
238\end{array}$ & $\begin{array}{r}35 \\
0 \\
203\end{array}$ & $\begin{array}{r}30 \\
0 \\
174\end{array}$ & $\begin{array}{r}16 \\
0 \\
93\end{array}$ & $\begin{array}{r}16 \\
0 \\
93\end{array}$ & $\begin{array}{r}16 \\
0 \\
93\end{array}$ & $\begin{array}{r}15 \\
0 \\
87\end{array}$ & $\begin{array}{r}15 \\
0 \\
87\end{array}$ & $\begin{array}{r}16 \\
0 \\
93\end{array}$ & $\begin{array}{r}17 \\
0 \\
99\end{array}$ & $\begin{array}{r}19 \\
0 \\
110\end{array}$ \\
\hline & TEXAS & $\begin{array}{r}365 \\
0 \\
2126\end{array}$ & $\begin{array}{r}178 \\
0 \\
1036\end{array}$ & $\begin{array}{r}143 \\
0 \\
833\end{array}$ & $\begin{array}{r}126 \\
0 \\
734\end{array}$ & $\begin{array}{r}69 \\
0 \\
401\end{array}$ & $\begin{array}{r}69 \\
0 \\
401\end{array}$ & $\begin{array}{r}70 \\
0 \\
407\end{array}$ & $\begin{array}{r}66 \\
0 \\
384\end{array}$ & $\begin{array}{r}64 \\
0 \\
372\end{array}$ & $\begin{array}{r}71 \\
0 \\
413\end{array}$ & $\begin{array}{r}76 \\
0 \\
442\end{array}$ & $\begin{array}{r}82 \\
0 \\
477\end{array}$ \\
\hline
\end{tabular}

SOURCE: ARTHOD 203

DATA QOALTY $=2$ 
TABLE 4.48 - IAEZRCITY PASSENGBR RAIL POEL E EHERGY OS3.

BT FUBL BY STATB, 1967-78

(EIGATE IN A SBRIBS OP HINB TABLES)

DIESEL PUEL DSE IH TBOOSAYDS OP BARRLS

POLLORED BY ELECTMICITY OSB IN MTLIOUS OP KILOHATT-HOJBS

POLLONED BY EOTAL BABRG USB IN BILLIOYS OP BTO

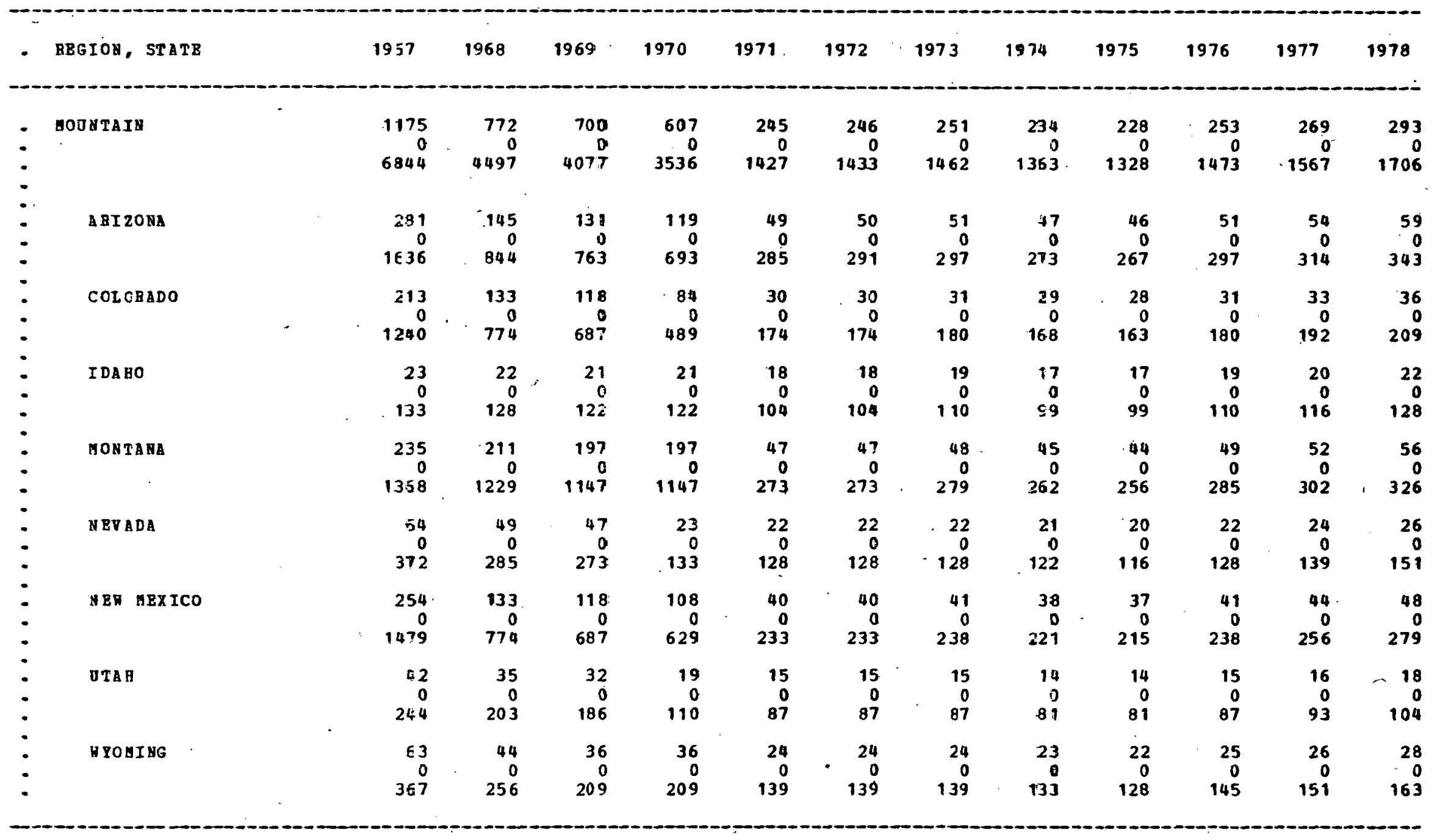


TABLE 4.4I -- IATERCITY PASSEMGBR BAIL POEL E ENBRGY USB. BY POBL BY STATE, 1967-78

(LAST IN A SERIES OP NIME TABLES)

DIESEL PUEL BSE IB THOUSANDS OP BARRELS

FOLLONED BY ELECTRTCITY DSB IV UTLLIONS OF RTLOVATT-HOOBS

FOLLOEED BY TOTAL BEEBGY OSE IA BILLIONS OP BTO

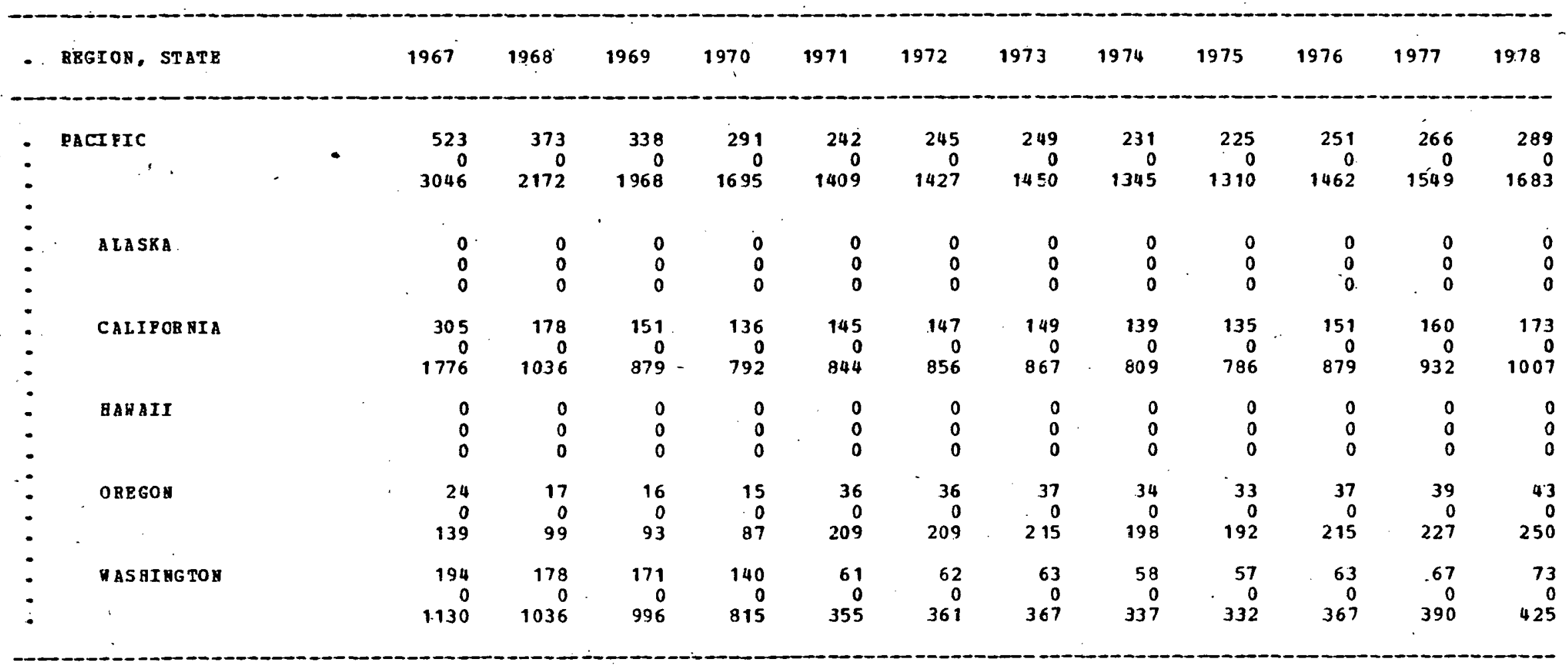


TABLE 4.5A - FREIGHT RAII PUEL ABD ENERGY USB, BY PORL EY STETE, 1967-78 (PIBST II A SERIBS OP NINE TABLES)

DIESEL ?UEL USE IN TROgSANDS OP BARRELS

POLIORED BY RESIDUAL OII USE IN THOUSANDS OP EARRELS

FOLLORED BY TOTAL BHBRG USE IN BILLIORS OF BTO

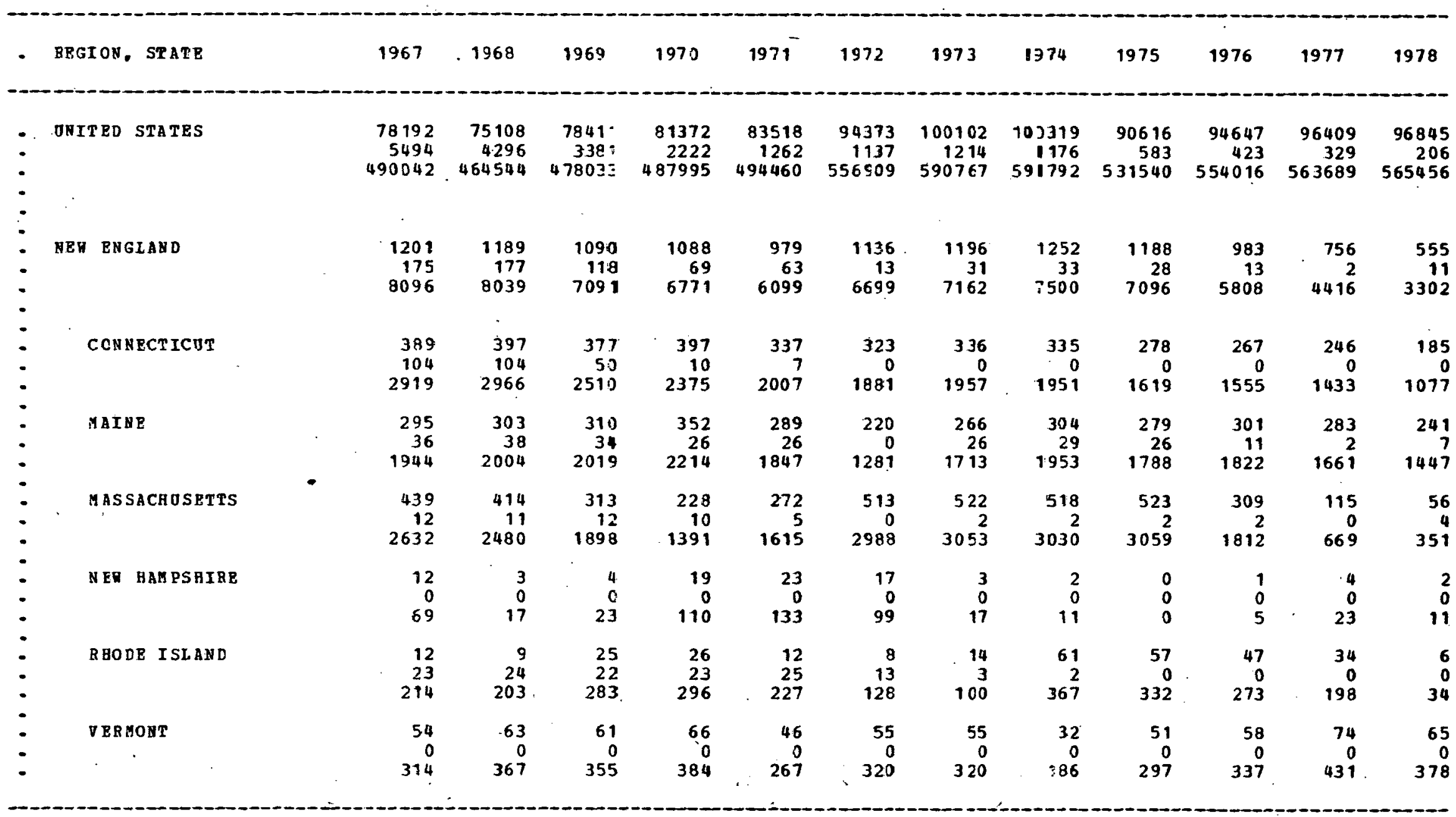

SOUBCE: BETHOD 203

DATA QDALITT: 2 
TABLE 4.5B -- PREIGHT RAIL FUEL A D ENERGT OSB, BY FOBL EY STATE, 1967-78

(SECOND IB A SERIES OF NIBB TABLES)

DIES BI. FUEL USE IH THOOSANDS OP BARRELS

POLLORED BI RESIDUAL OIL OSE IB TBOUSANDS OP EARBELS

POLLONRD BY TOTAL BNERGY USE IN BILLIONS OP BTU

\begin{tabular}{|c|c|c|c|c|c|c|c|c|c|c|c|c|c|}
\hline & BEGION, STATE & 1967 & 1968 & 1969 & 1970 & 1971 & 1972 & $1973^{\circ}$ & 1974 & 1975 & 1976 & 1977 & 1978 \\
\hline & AID-ATLABTIC & $\begin{array}{r}7664 \\
897 \\
50285\end{array}$ & $\begin{array}{r}6010 \\
906 \\
40707\end{array}$ & $\begin{array}{r}6011 \\
441 \\
37789\end{array}$ & $\begin{array}{r}6025 \\
182 \\
36242\end{array}$ & $\begin{array}{r}6025 \\
16.1 \\
36110\end{array}$ & $\begin{array}{r}6028 \\
156 \\
36096\end{array}$ & $\begin{array}{r}6065 \\
86 \\
35871\end{array}$ & $\begin{array}{r}6034 \\
59 \\
35521\end{array}$ & $\begin{array}{r}5759 \\
64 \\
33950\end{array}$ & $\begin{array}{r}7685 \\
40 \\
45019\end{array}$ & $\begin{array}{r}7194 \\
23 \\
42052\end{array}$ & $\begin{array}{r}6433 \\
0 \\
37474\end{array}$ \\
\hline & NEN JERSEY & $\begin{array}{r}1207 \\
54 \\
7370\end{array}$ & $\begin{array}{r}1150 \\
28 \\
6875\end{array}$ & $\begin{array}{r}1299 \\
8 \\
7617\end{array}$ & $\begin{array}{r}929 \\
2 \\
5424\end{array}$ & $\begin{array}{r}852 \\
3 \\
4982\end{array}$ & $\begin{array}{r}935 \\
1 \\
5453\end{array}$ & $\begin{array}{r}976 \\
1 \\
5691\end{array}$ & $\begin{array}{r}1011 \\
1 \\
5895\end{array}$ & $\begin{array}{r}851 \\
10 \\
5020\end{array}$ & $\begin{array}{r}639 \\
0 \\
3722\end{array}$ & $\begin{array}{r}907 \\
0 \\
5283\end{array}$ & $\begin{array}{r}613 \\
0 \\
3570\end{array}$ \\
\hline & NEC IORR & $\begin{array}{r}3011 \\
756 \\
2229.3\end{array}$ & $\begin{array}{r}1847 \\
733 \\
15368\end{array}$ & $\begin{array}{r}1839 \\
364 \\
13001\end{array}$ & $\begin{array}{r}1964 \\
67 \\
11862\end{array}$ & $\begin{array}{r}2036 \\
76 \\
12338\end{array}$ & $\begin{array}{r}1885 \\
98 \\
11597\end{array}$ & $\begin{array}{r}1793 \\
45 \\
10727\end{array}$ & $\begin{array}{r}1748 \\
16 \\
10283\end{array}$ & $\begin{array}{r}1684 \\
4 \\
9835\end{array}$ & $\begin{array}{r}2737 \\
0 \\
15944\end{array}$ & $\begin{array}{r}2486 \\
0 \\
14481\end{array}$ & $\begin{array}{r}1856 \\
0 \\
10811\end{array}$ \\
\hline & PENESYLVANIA & $\begin{array}{r}3446 \\
87 \\
20628\end{array}$ & $\begin{array}{r}3013 \\
145 \\
18463\end{array}$ & $\begin{array}{r}2873 \\
69 \\
17170\end{array}$ & $\begin{array}{r}3132 \\
113 \\
18955\end{array}$ & $\begin{array}{r}3137 \\
82 \\
18789\end{array}$ & $\begin{array}{r}3208 \\
57 \\
19046\end{array}$ & $\begin{array}{r}3296 \\
40 \\
19452\end{array}$ & $\begin{array}{r}3275 \\
42 \\
19342\end{array}$ & $\begin{array}{r}3224 \\
50 \\
19095\end{array}$ & $\begin{array}{r}4309 \\
40 \\
25353\end{array}$ & $\begin{array}{r}3801 \\
23 \\
22286\end{array}$ & $\begin{array}{r}3964 \\
0 \\
23091\end{array}$ \\
\hline
\end{tabular}

SOORCE: BETHOD 203

DATA QUALITY: 2 
THBLE 4.5C - PREIGHT RLIL PUEL AHD EBERGY USE, BY PJEL -EI STITB, $1967-78$

(TEIFD IN A SERIES OF NIBB TABLES)

DIES EL FUEL DSE IN THOUSARDS OP BARRBLS

POLLORED BT RESIDOAL OIL OSE IN THODSA ADS OE EAREELS

POLLORED BY TOTAL EEEBGY USE IA BILLIOES OP BTE

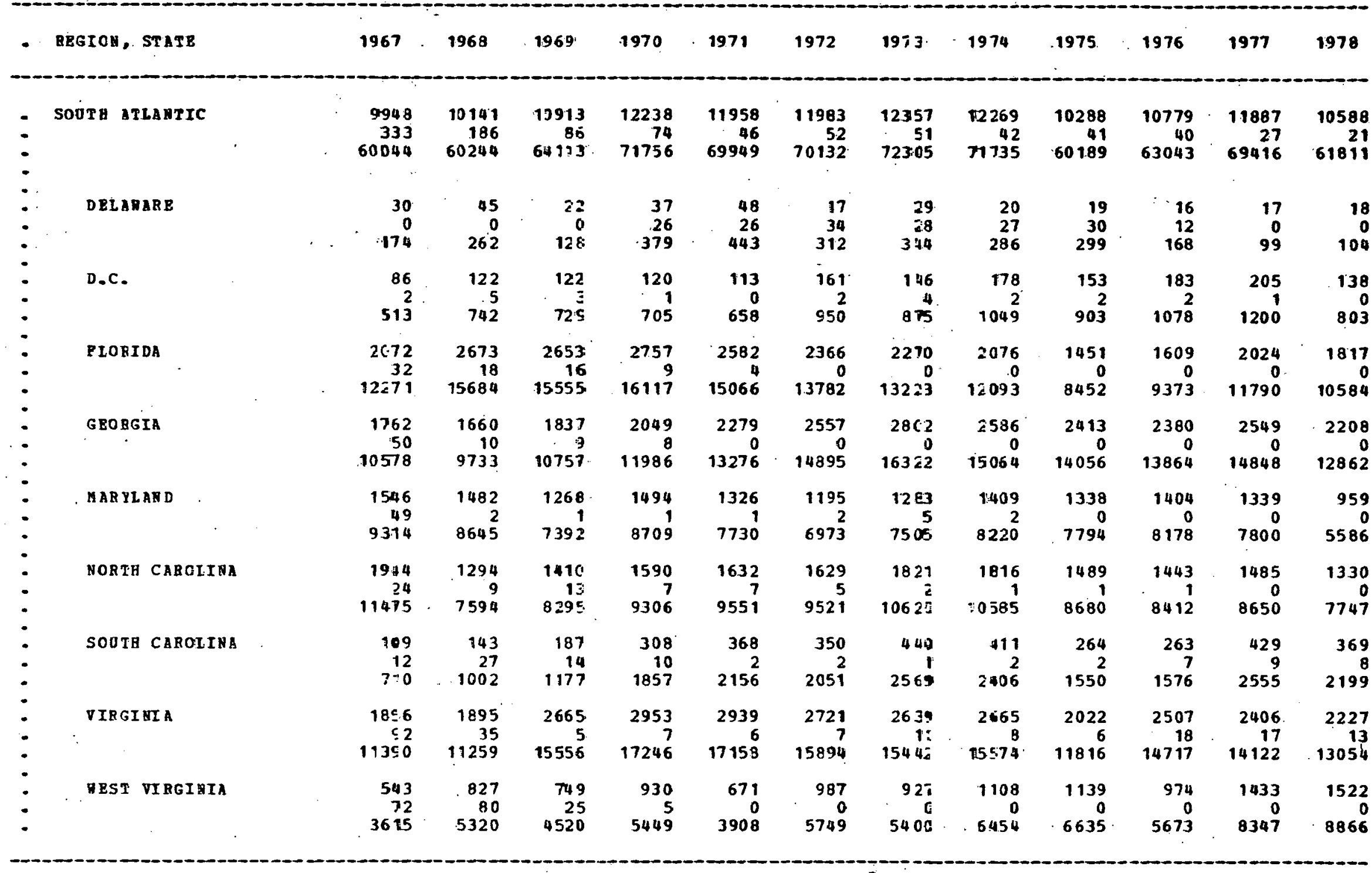


TABLE 4.5D - PREIGET RAIL FOEL AYD ENERGY USE, BY PUEL EY STATE, 1967-78

(FOURTE IN A SERIBS OP NINE TABLES)

DIESEL PUEL OSE IN THOUSANDS OF BARRELS

POLIORED BY RESIDUAL OIL USE IN THCOSANDS OP EARRELS

FOLLORED BI TOTAL ENERGY OSE IN BILLIONS OF BTU

\begin{tabular}{|c|c|c|c|c|c|c|c|c|c|c|c|c|c|c|}
\hline - & RBGION, STATE & & 1967 & $i 968$ & 1969 & 1970 & 1971 & 1972 & 1973 & 1974 & 1975 & 1976 & 1977 & 1978 \\
\hline - & BIST NOBTH CENTRAL & & $\begin{array}{r}14296 \\
863 \\
88705\end{array}$ & $\begin{array}{r}12102 \\
713 \\
74981\end{array}$ & $\begin{array}{r}12963 \\
633 \\
79494\end{array}$ & $\begin{array}{r}14114 \\
585 \\
85897\end{array}$ & $\begin{array}{r}14379 \\
265 \\
85429\end{array}$ & $\begin{array}{r}19119 \\
256 \\
112985\end{array}$ & $\begin{array}{r}19281 \\
302 \\
1142.18\end{array}$ & $\begin{array}{r}18272 \\
286 \\
108239\end{array}$ & $\begin{array}{r}16488 \\
83 \\
96571\end{array}$ & $\begin{array}{r}17813 \\
64 \\
104170\end{array}$ & $\begin{array}{r}15491 \\
50 \\
90555\end{array}$ & $\begin{array}{r}15452 \\
33 \\
90221\end{array}$ \\
\hline - & ILLINOIS & 0 & $\begin{array}{r}6123 \\
241 \\
37184\end{array}$ & $\begin{array}{r}5931 \\
198 \\
35795\end{array}$ & $\begin{array}{r}5972 \\
188 \\
35971\end{array}$ & $\begin{array}{r}6525 \\
117 \\
38746\end{array}$ & $\begin{array}{r}6526 \\
59 \\
38387\end{array}$ & $\begin{array}{r}8724 \\
117 \\
51556\end{array}$ & $\begin{array}{r}8644 \\
122 \\
51121\end{array}$ & $\begin{array}{r}8351 \\
129 \\
49458\end{array}$ & $\begin{array}{r}7268 \\
43 \\
42609\end{array}$ & $\begin{array}{r}7594 \\
33 \\
44445\end{array}$ & $\begin{array}{r}7043 \\
26 \\
41191\end{array}$ & $\begin{array}{r}5940 \\
9 \\
34659\end{array}$ \\
\hline - & I UD I AHA & . & $\begin{array}{r}1829 \\
251 \\
12232\end{array}$ & $\begin{array}{r}891 \\
192 \\
6397\end{array}$ & $\begin{array}{r}1825 \\
132 \\
11461\end{array}$ & $\begin{array}{r}2255 \\
104 \\
13790\end{array}$ & $\begin{array}{r}2237 \\
52 \\
13358\end{array}$ & $\begin{array}{r}2535 \\
0 \\
14767\end{array}$ & $\begin{array}{r}2684 \\
0 \\
15635\end{array}$ & $\begin{array}{r}2803 \\
0 \\
16328\end{array}$ & $\begin{array}{r}2476 \\
0 \\
14423\end{array}$ & $\begin{array}{r}2200 \\
-\quad 0 \\
12815\end{array}$ & $\begin{array}{r}2482 \\
0 \\
14458\end{array}$ & $\begin{array}{r}2738 \\
0 \\
15949\end{array}$ \\
\hline$\because$ & MIC BIGAN & & $\begin{array}{r}1417 \\
126 \\
9046\end{array}$ & $\begin{array}{r}944 \\
98 \\
6115\end{array}$ & $\begin{array}{r}1317 \\
99 \\
8294\end{array}$ & $\begin{array}{r}1392 \\
70 \\
8549\end{array}$ & $\begin{array}{r}1300 \\
43 \\
7843\end{array}$ & $\begin{array}{r}3004 \\
88 \\
18052\end{array}$ & $\begin{array}{r}2993 \\
130 \\
18252\end{array}$ & $\begin{array}{r}2668 \\
133 \\
16378\end{array}$ & $\begin{array}{r}2177 \\
30 \\
12870\end{array}$ & $\begin{array}{r}2219 \\
5 \\
12957\end{array}$ & $\begin{array}{r}2133 \\
0 \\
12425\end{array}$ & $\begin{array}{r}1967 \\
180 \\
11458\end{array}$ \\
\hline - & o日ro & & $\begin{array}{r}3923 \\
236 \\
24336\end{array}$ & $\begin{array}{r}3439 \\
214 \\
21379\end{array}$ & $\begin{array}{r}2981 \\
205 \\
18654\end{array}$ & $\begin{array}{r}2955 \\
292 \\
19049\end{array}$ & $\begin{array}{r}3348 \\
105 \\
20163\end{array}$ & $\begin{array}{r}3920 \\
0 \\
22935\end{array}$ & $\begin{array}{r}39 E 3 \\
0 \\
23202\end{array}$ & $\begin{array}{r}3502 \\
0 \\
20400\end{array}$ & $\begin{array}{r}3757 \\
0 \\
21886\end{array}$ & $\begin{array}{r}4969 \\
0 \\
28946\end{array}$ & $\begin{array}{r}3038 \\
0 \\
17697\end{array}$ & $\begin{array}{r}3908 \\
0 \\
22765\end{array}$ \\
\hline - & $\therefore$ ISCONSIH. & & $\begin{array}{r}1004 \\
9 \\
5905\end{array}$ & $\begin{array}{r}897 \\
11 \\
5294\end{array}$ & $\begin{array}{r}868 \\
9 \\
5113\end{array}$ & $\begin{array}{r}987 \\
2 \\
5762\end{array}$ & $\begin{array}{r}968 \\
6 \\
-\quad 5676\end{array}$ & $\begin{array}{r}936 \\
51 \\
5773\end{array}$ & $\begin{array}{r}977 \\
50 \\
6005\end{array}$ & $\begin{array}{r}948 \\
24 \\
5673\end{array}$ & $\begin{array}{r}810 \\
10 \\
4781\end{array}$ & $\begin{array}{r}831 \\
26 \\
5004\end{array}$ & $\begin{array}{r}.795 \\
24 \\
: 4782\end{array}$ & $\begin{array}{r}899 \\
24 \\
5387\end{array}$ \\
\hline
\end{tabular}


TABLE L.5E -- FREIGHT RAIL POEL A ID ERERGY OSE, BI POEL EY STATE, 1967-78

(PIFT IN A SERIBS OP WIBE TABLES)

DIESEL FOEL OSE IN THOUSANDS OF BARRRLS

POLLOUED BI RESIOUAL OIL USE IN THOUSANDS OP EAREELS

POLLORED BI TOTAL ENBRGY USE IN BILLIONS OP BT

\begin{tabular}{|c|c|c|c|c|c|c|c|c|c|c|c|c|c|c|}
\hline & REGION, STATE & & 1967 & 1968 & 1969 & 1970 & 1971 & 1972 & 1973 & 1974 & 1975 & 1976 & 1977 & 1978 \\
\hline & EAST SCOTH CEBTRAL & & $\begin{array}{r}5013 \\
148 \\
30133\end{array}$ & $\begin{array}{r}5113 \\
164 \\
30816\end{array}$ & $\begin{array}{r}514 \\
143 \\
3086\end{array}$ & $\begin{array}{r}5390 \\
147 \\
32323\end{array}$ & $\begin{array}{r}5661 \\
49 \\
33285\end{array}$ & $\begin{array}{r}6241 \\
0 \\
36356\end{array}$ & $\begin{array}{r}6584 \\
1 \\
38360\end{array}$ & $\begin{array}{r}7033 \\
3 \\
40988\end{array}$ & $\begin{array}{r}6717 \\
3 \\
39148\end{array}$ & $\begin{array}{r}7908 \\
7 \\
46111\end{array}$ & $\begin{array}{r}8035 \\
0 \\
46807\end{array}$ & $\begin{array}{r}9292 \\
0 \\
54129\end{array}$ \\
\hline & A LABAEA & & $\begin{array}{r}1043 \\
0 \\
6075\end{array}$ & $\begin{array}{r}1521 \\
\quad 0 \\
8860\end{array}$ & $\begin{array}{r}169: \\
0 \\
985 C\end{array}$ & $\begin{array}{r}1876 \\
0 \\
10928\end{array}$ & $\begin{array}{r}1796 \\
0 \\
10462\end{array}$ & $\begin{array}{r}2207 \\
0 \\
12856\end{array}$ & $\begin{array}{r}2533 \\
0 \\
14755\end{array}$ & $\begin{array}{r}2732 \\
0 \\
15914\end{array}$ & $\begin{array}{r}2712 \\
0 \\
15798\end{array}$ & $\begin{array}{r}2858 \\
5 \\
16680\end{array}$ & $\begin{array}{r}3067 \\
0 \\
17866\end{array}$ & $\begin{array}{r}2827 \\
0 \\
16468\end{array}$ \\
\hline & KंEHTOCKY & - & $\begin{array}{r}1744 \\
399 \\
11033\end{array}$ & $\begin{array}{r}1271 \\
155 \\
8378\end{array}$ & $\begin{array}{r}111 . \varepsilon \\
137 \\
: 374\end{array}$ & $\begin{array}{r}1115 \\
144 \\
7400\end{array}$ & $\begin{array}{r}1221 \\
48 \\
7414\end{array}$ & $\begin{array}{r}12.31 \\
0 \\
7171\end{array}$ & $\begin{array}{r}1341 \\
0 \\
7811\end{array}$ & $\begin{array}{r}1426 \\
0 \\
3307\end{array}$ & $\begin{array}{r}1554 \\
0 \\
9052\end{array}$ & $\begin{array}{r}2446 \\
0 \\
14248\end{array}$ & $\begin{array}{r}2247 \\
0 \\
13089\end{array}$ & $\begin{array}{r}2869 \\
0 \\
16713\end{array}$ \\
\hline & UISSISSIPPI & & $\begin{array}{r}200 \\
0 \\
1165\end{array}$ & $\begin{array}{r}300 \\
0 \\
1747\end{array}$ & $\begin{array}{r}337 \\
0 \\
1963\end{array}$ & $\begin{array}{r}362 \\
0 \\
2108\end{array}$ & $\begin{array}{r}441 \\
0 \\
2569\end{array}$ & $\begin{array}{r}435 \\
0 \\
2534\end{array}$ & $\begin{array}{r}505 \\
0 \\
2941\end{array}$ & $\begin{array}{r}615 \\
0 \\
3532\end{array}$ & $\begin{array}{r}234 \\
0 \\
1363\end{array}$ & $\begin{array}{r}320 \\
0 \\
1864\end{array}$ & $\begin{array}{r}349 \\
0 \\
2033\end{array}$ & $\begin{array}{r}365 \\
0 \\
2126\end{array}$ \\
\hline & T EN E ESS EE & & $\begin{array}{r}20.26 \\
9 \\
11858\end{array}$ & $\begin{array}{r}2021 \\
11829\end{array}$ & $\begin{array}{r}1998 \\
6 \\
11676\end{array}$ & $\begin{array}{r}2037 \\
3 \\
11885\end{array}$ & $\begin{array}{r}2203 \\
1 \\
12839\end{array}$ & $\begin{array}{r}2368 \\
0 \\
13794\end{array}$ & $\begin{array}{r}2205 \\
1 \\
12851\end{array}$ & $\begin{array}{r}2260 \\
3 \\
1 \equiv 184\end{array}$ & $\begin{array}{r}2217 \\
3 \\
12933\end{array}$ & $\begin{array}{r}2284 \\
2 \\
13317\end{array}$ & $\begin{array}{r}2372 \\
0 \\
13817\end{array}$ & $\begin{array}{r}3231 \\
0 \\
18821\end{array}$ \\
\hline
\end{tabular}


TABLE 4.5P -- PREIGRT RAIL PUEL ARD BEEBGT USE, BI POBL EI STATB, 1967-78

(SIXTE IH A SEBIBS OP HIHE TABLES)

DIESEL POEL OSE IB THOUSANDS OP BARRELS

POLLORED BY RESIDDAL OIL USE IN THOOSANDS OP EABBBLS

FOLLONED BY TOTAL BNERGY OSE IN BILLIOUS OF BTU

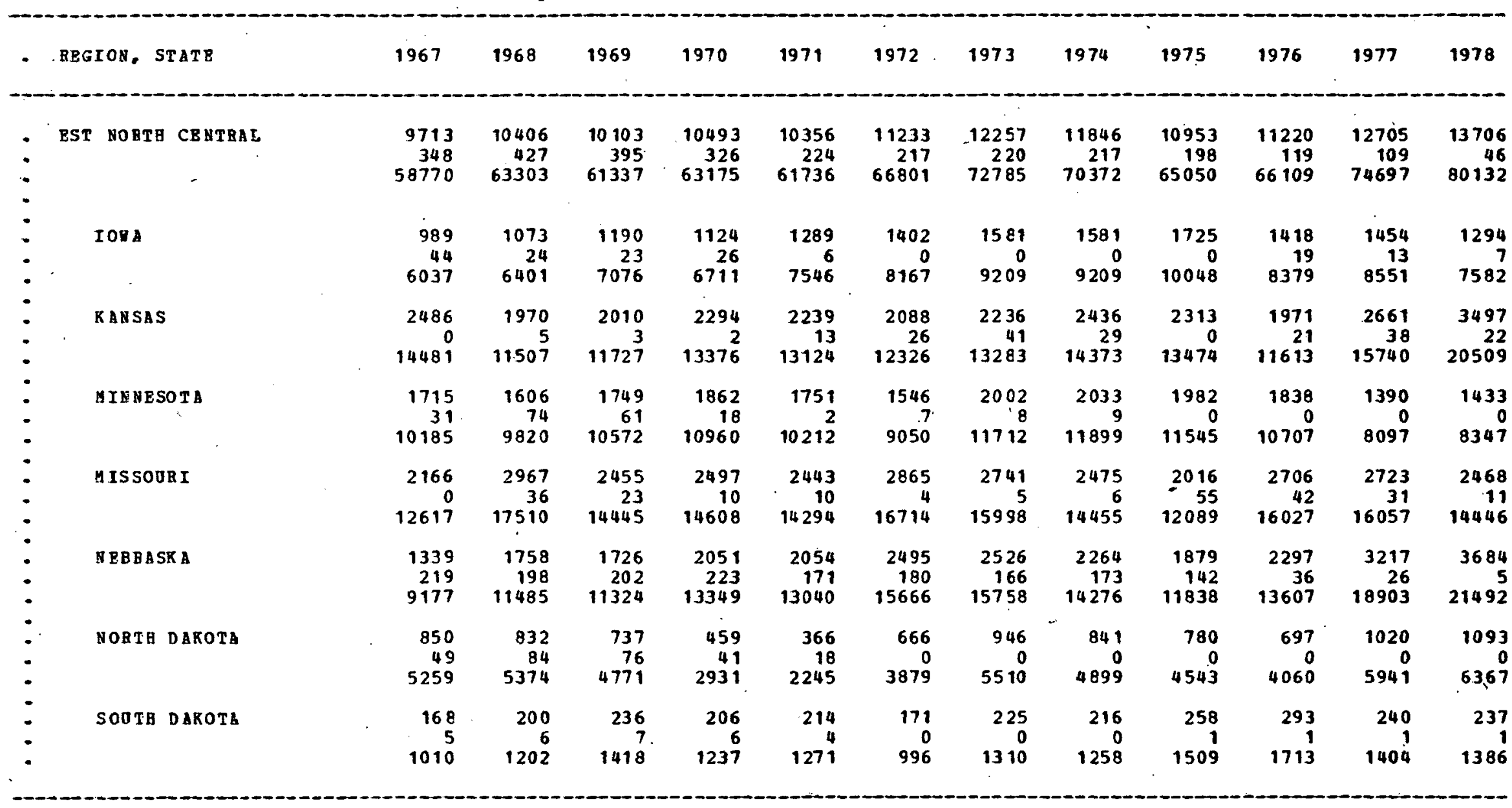


TABLE 4.5G -- PREIGHT BAIL FOEL AND BHERGY OSR, BY FOEL ET SMATE, 1967-78

(SEVENTH IN A SBRIES OF NINE TBBLES)

DIESEL POEL USE IN THOOSARDS OP BARABLS

OLLONED BY RESIDUAL OIL USE IN THOUSANDS OF EARBRLS

POLLORED BI TOTAL ENEBGT DSE IN BILLIOHS OP BTO

\begin{tabular}{|c|c|c|c|c|c|c|c|c|c|c|c|c|c|c|}
\hline - & BEGION, STAT & & 1967 & 1968 & 1969 & 1970 & 1971 & 1972 & 1973 & 1974 & 1975 & 1976 & 1977 & 1978 \\
\hline ? & BEST SOUTH C & ENTRAL & $\begin{array}{r}7611 \\
211 \\
45663\end{array}$ & $\begin{array}{r}7594 \\
149 \\
45174\end{array}$ & $\begin{array}{r}8635 \\
122 \\
51069\end{array}$ & $\begin{array}{r}10022 \\
, \quad 87 \\
58929\end{array}$ & $\begin{array}{r}10240 \\
40 \\
59903\end{array}$ & $\begin{array}{r}15658 \\
14 \\
91302\end{array}$ & $\begin{array}{r}17468 \\
1 \leq 5 \\
102732\end{array}$ & $\begin{array}{r}18862 \\
110 \\
110570\end{array}$ & $\begin{array}{r}17297 \\
83 \\
101283\end{array}$ & $\begin{array}{r}16317 \\
75 \\
95524\end{array}$ & $\begin{array}{r}16410 \\
54 \\
95934\end{array}$ & $\begin{array}{r}15553 \\
79 \\
91099\end{array}$ \\
\hline$:$ & ABKAXSAS & & $\begin{array}{r}1076 \\
0 \\
6268\end{array}$ & $\begin{array}{r}897 \\
0 \\
5225\end{array}$ & $\begin{array}{r}927 \\
2 \\
5412\end{array}$ & $\begin{array}{r}1188 \\
2 \\
6933\end{array}$ & $\begin{array}{r}993 \\
0 \\
5784\end{array}$ & $\begin{array}{r}1647 \\
0 \\
9594\end{array}$ & $\begin{array}{r}2055 \\
5 \\
12002\end{array}$ & $\begin{array}{r}2452 \\
7 \\
14327\end{array}$ & $\begin{array}{r}2387 \\
3 \\
13924\end{array}$ & $\begin{array}{r}2079 \\
0 \\
12111\end{array}$ & $\begin{array}{r}1683 \\
2 \\
9816\end{array}$ & $\begin{array}{r}1522 \\
4 \\
8891\end{array}$ \\
\hline$\because$ & LOOISTA NR & 1 & $\begin{array}{r}928 \\
20 \\
5531\end{array}$ & $\begin{array}{r}935 \\
15 \\
5541\end{array}$ & $\begin{array}{r}927 \\
3 \\
5450\end{array}$ & $\begin{array}{r}908 \\
5 \\
5320\end{array}$ & $\begin{array}{r}1015 \\
0 \\
5912\end{array}$ & $\begin{array}{r}2588 \\
0 \\
15076\end{array}$ & $\begin{array}{r}2988 \\
0 \\
17406\end{array}$ & $\begin{array}{r}2.309 \\
0 \\
16363\end{array}$ & $\begin{array}{r}2439 \\
0 \\
14208\end{array}$ & $\begin{array}{r}2175 \\
0 \\
12670\end{array}$ & $\begin{array}{r}2453 \\
14289\end{array}$ & $\begin{array}{r}2536 \\
0 \\
14773\end{array}$ \\
\hline : & ORLAHODA & & $\begin{array}{r}353 \\
96 \\
5572\end{array}$ & $\begin{array}{r}618 \\
87 \\
4147\end{array}$ & $\begin{array}{r}4=3 \\
86 \\
306\end{array}$ & $\begin{array}{r}645 \\
59 \\
4128\end{array}$ & $\begin{array}{r}376 \\
30 \\
2378\end{array}$ & $\begin{array}{r}238 \\
0 \\
1386\end{array}$ & $\begin{array}{r}289 \\
0 \\
1683\end{array}$ & $\begin{array}{r}446 \\
0 \\
2598\end{array}$ & $\begin{array}{r}580 \\
23 \\
3523\end{array}$ & $\begin{array}{r}977 \\
0 \\
5691\end{array}$ & $\begin{array}{r}854 \\
0 \\
4974\end{array}$ & $\begin{array}{r}568 \\
0 \\
3308\end{array}$ \\
\hline 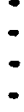 & TE.XAS & · & $\begin{array}{r}4754 \\
95 \\
28291\end{array}$ & $\begin{array}{r}5144 \\
47 \\
30261\end{array}$ & $\begin{array}{r}634 \varepsilon \\
26 \\
37143\end{array}$ & $\begin{array}{r}7281 \\
21 \\
42546\end{array}$ & $\begin{array}{r}7856 \\
10 \\
45827\end{array}$ & $\begin{array}{r}11185 \\
14 \\
65245\end{array}$ & $\begin{array}{r}12136 \\
150 \\
71640\end{array}$ & $\begin{array}{r}13155 \\
103 \\
77280\end{array}$ & $\begin{array}{r}11891 \\
57 \\
69628\end{array}$ & $\begin{array}{r}11086 \\
75 \\
65051\end{array}$ & $\begin{array}{r}18420 \\
52 \\
66853\end{array}$ & $\begin{array}{r}10927 \\
75 \\
64125\end{array}$ \\
\hline
\end{tabular}

SOUBCE: ABTBOD 203

DATA QUAITY: 2 
TABLE 4.58 - PREIGET BAIL PURL AND ENERGY USE, BY PURL PY STATB, 1967-78

(B IGHTH IN A SBBIES OP NIME TABLES)

DIESEL FUEL OSE IN TEOUSANDS OP BARBELS

POLLORED BP BESIDUAL OIL OSB IN TBOOSARDS OP EARBBLS

POLLORED BY TOTAL ENEBGY USE IN BILLIONS OP BTO

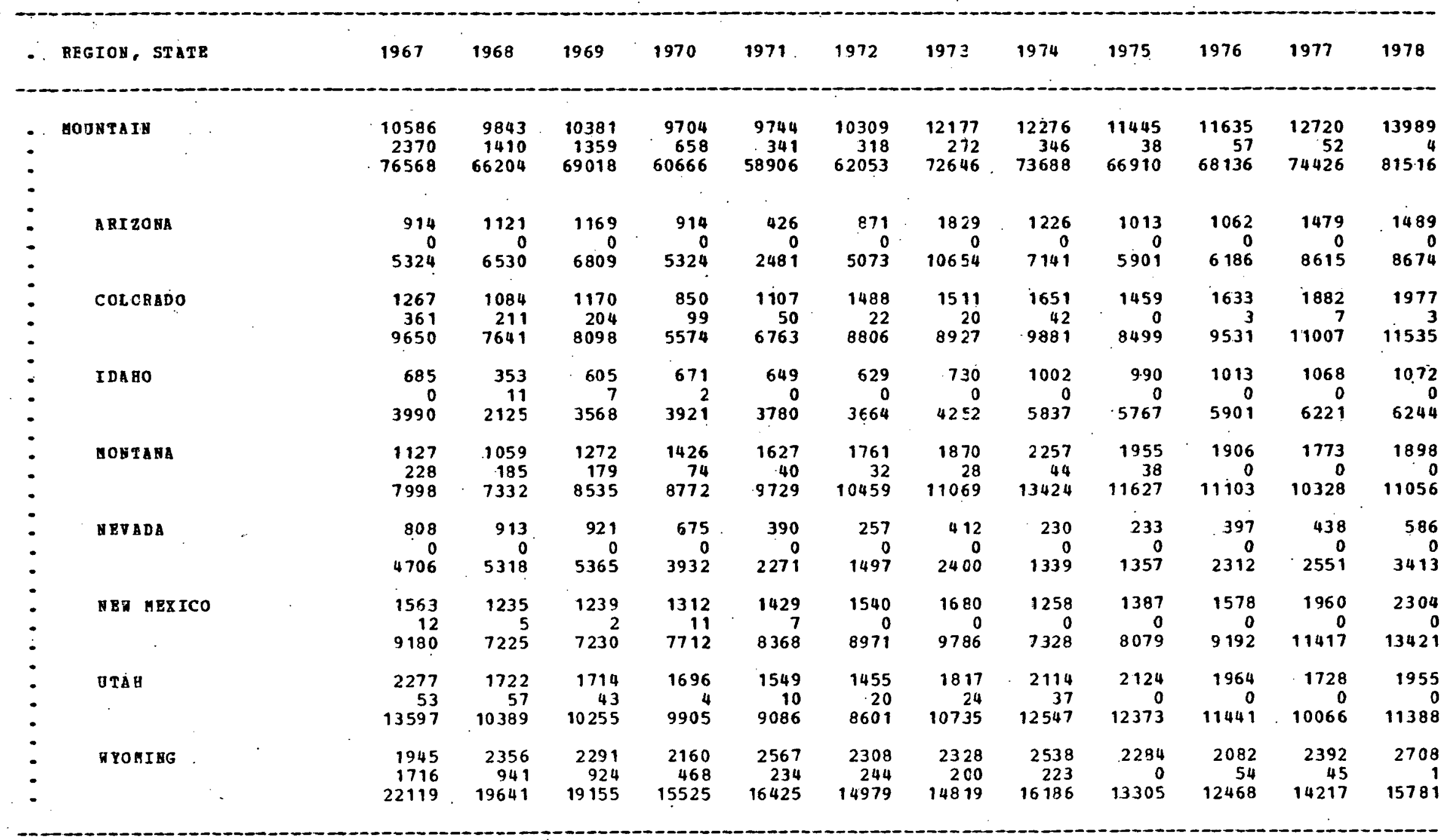

SODRCE: ШETHOD 203

DATA QUALTTY: 2 
TABLE 4.5I -- PRBIGHT RAIL FUPL AND BQEBGY OSE, BY FUEL EY STATE, 196 フ-78

(LAST IN A SERIES OP NI IE TABLES)

DIBSEL POEL USE IN THOUSARDS OF BARRLL

FOLLORED BY RESIDUAL OIL USE IN THOUSANDS OP . EAREELS

FOLLONED BY TOTAL ENBRY USE IN BILLIONS OP BTO

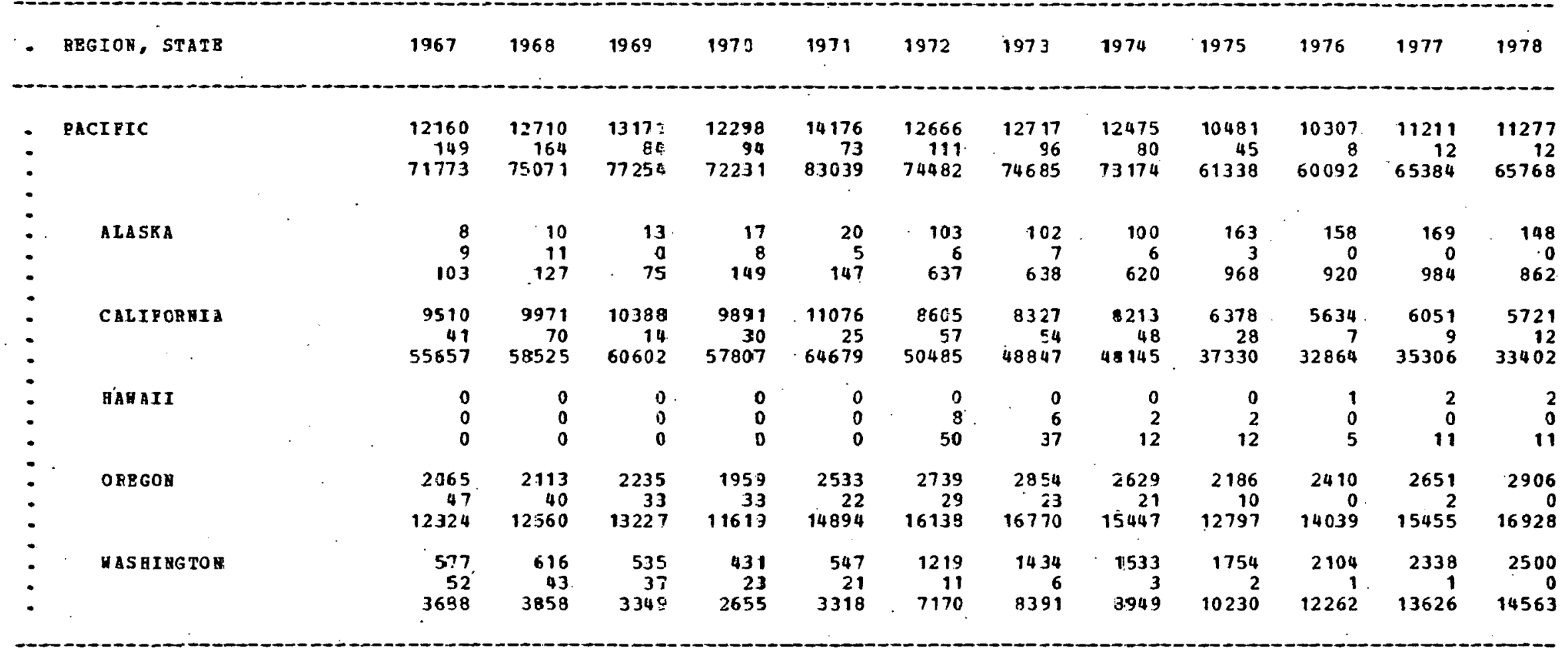


TABLE 5.1 - TOTAL CIVILIA AUTO GASOLIAE ABD ENERGi OSE, BY SBCTOB, 1967-76

GASOLINE OSE IN THOUSA BDS OP BBL, POLLONED BY EABRG OSE IN BTLLIONS OP BTO

\begin{tabular}{|c|c|c|c|c|c|c|c|c|c|c|}
\hline - SECTOR OY THE ECONOAT & 1967 & 1968 & 1969 & 1970 & 1971 & 1972 & 1973 & 1974 & $1975^{\prime}$ & 1976 \\
\hline - TOTALS & $\begin{array}{l}1342005 \\
7045732\end{array}$ & $\begin{array}{l}1433231 \\
7524669\end{array}$ & $\begin{array}{l}1525208 \\
8007560\end{array}$ & $\begin{array}{l}1603423 \\
8418199\end{array}$ & $\begin{array}{l}1693080 \\
8888872\end{array}$ & $\begin{array}{l}1825442 \\
95 \mathrm{E} 782\end{array}$ & $\begin{array}{r}1911118 \\
10033607\end{array}$ & $\begin{array}{l}1837606 \\
9647668\end{array}$ & $\begin{array}{l}1900523 \\
9977942\end{array}$ & $\begin{array}{r}2017466 \\
10591923\end{array}$ \\
\hline $\begin{array}{l}-\quad \text { HOUSBHOLD AUTOS } \\
\text { (SBE NOTE BELON) }\end{array}$ & $\begin{array}{l}1139008 \\
5979792\end{array}$ & $\begin{array}{l}1219238 \\
6400999\end{array}$ & $\begin{array}{l}1289898 \\
6771964\end{array}$ & $\begin{array}{l}1364094 \\
7161493\end{array}$ & $\begin{array}{l}1451323 \\
7639445\end{array}$ & $\begin{array}{l}1579389 \\
8291792\end{array}$ & $\begin{array}{l}1656322 \\
8695690\end{array}$ & $\begin{array}{l}1581935 \\
8305158\end{array}$ & $\begin{array}{l}1645576 \\
8639274\end{array}$ & $\begin{array}{l}1756425 \\
9221231\end{array}$ \\
\hline TAXICA BS & $\begin{array}{r}9900 \\
52088\end{array}$ & $\begin{array}{l}11046 \\
58095\end{array}$ & $\begin{array}{l}13891 \\
73032\end{array}$ & $\begin{array}{l}14267 \\
75021\end{array}$ & $\begin{array}{l}14846 \\
78043\end{array}$ & $\begin{array}{l}15435 \\
81132\end{array}$ & $\begin{array}{l}16435 \\
86403\end{array}$ & $\begin{array}{l}15757 \\
82831\end{array}$ & $\begin{array}{l}16071 \\
84460\end{array}$ & $\begin{array}{r}19417 \\
102040\end{array}$ \\
\hline $\begin{array}{l}\text { - OTHER COAABRCIAL aOTOS } \\
\text { (SEE NOTB BELOR) }\end{array}$ & $\begin{array}{r}191893 \\
1007528\end{array}$ & $\begin{array}{r}201681 \\
1058924\end{array}$ & $\begin{array}{r}220153 \\
1155917\end{array}$ & $\begin{array}{r}223683 \\
1174444\end{array}$ & $\begin{array}{r}225651 \\
1184766\end{array}$ & $\begin{array}{r}229352 \\
1204212\end{array}$ & $\begin{array}{r}236890 \\
1243788\end{array}$ & $\begin{array}{r}238332 \\
1251369\end{array}$ & $\begin{array}{r}237240 \\
1245619\end{array}$ & $\begin{array}{r}239933 \\
1259773\end{array}$ \\
\hline EEDERAL AOTOS & $\begin{array}{l}1204 \\
6324\end{array}$ & $\begin{array}{l}1266 \\
6651\end{array}$ & $\begin{array}{l}1266 \\
6647\end{array}$ & $\begin{array}{l}1379 \\
7241\end{array}$ & $\begin{array}{l}1260 \\
6618\end{array}$ & $\begin{array}{l}1266 \\
6646\end{array}$ & $\begin{array}{l}1471 \\
7726\end{array}$ & $\begin{array}{l}1582 \\
8310\end{array}$ & $\begin{array}{l}1636 \\
8589\end{array}$ & $\begin{array}{l}1691 \\
8879\end{array}$ \\
\hline
\end{tabular}

SCORCE: IETHOD 310

DATA QUALITY: 2 (HOUSEHOLD AUTOS, NATIONAL TOTALS ONLY)

3 (TAXTCABS AND OTHE COBGERCIAL A OTOS)

1 (FEDEBAL AOTOS, NATIOSAL TOTALS ONLY)

HOTE: HOOSBHOLD AUTO RIGURES INCLUDE GASOLINB OSED BI STATE AHD LOCAL GOVEANMENT

AOTOS, AS HELL AS THAT USBD BY COMMEBCIAL AOTOS NOT BELONGTHG TO PLERTS

OP. 4 OR HORE CARS. IT ALSO IRCLODES AN INS IGNIPICANT AHOUNT OP GASOLINE

USED BY STATE.ARD LOCAL GOVERNMBHT TRUCKS ARD BY BUSES OTHRB THAN COBHOH

CARRIERS (BTCEPT SCHOOL AID FEDERAL BUSES).

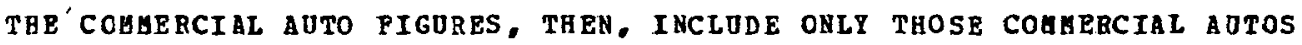

BELONGING TO PLEETS OP 4 OR MORE. 
FABLE 5.2A - COHAERCIAL QCTO GASOLI AE AND ENERGY OSE, EY STA EXCLUDZNG TAXICABS

(FIRST IN A SERIES OP 5 TABLES

GASJLINE USE IN THOOSA NDS OF BBL, POLLOAED BY ENBGE OSE IN BILLIONS CF BTU

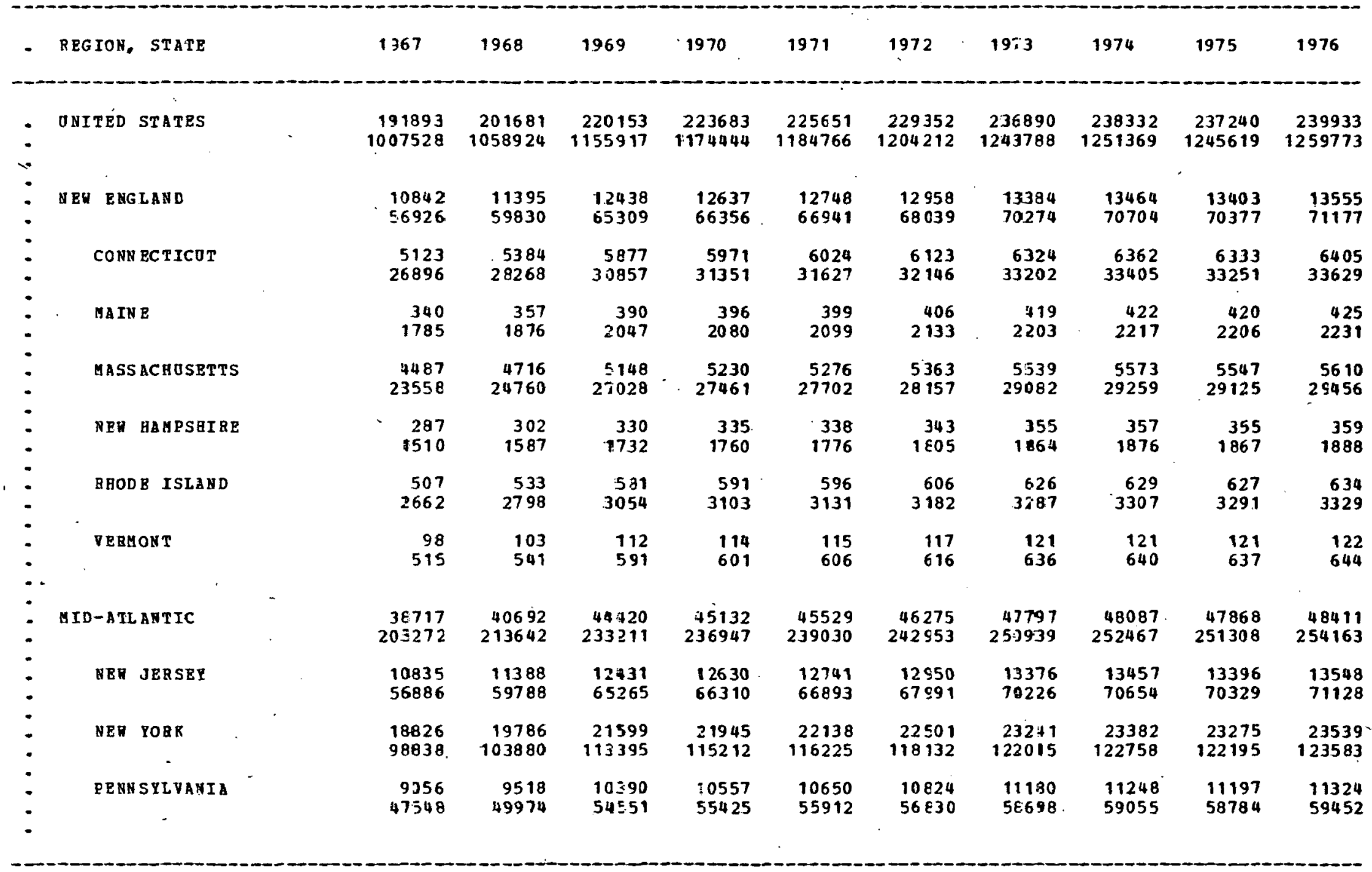

SOURCE: HETTHOD 311

DATA QUALITY: 3

ROTE: PIGORES SEONN ABE PUEI JSE ESTIMAZES FOR AUTOS IN FLEETS OP 4 OR GOBE.

POEL OSB BY OTHEB COEMEBCIAL AOTOS IS INSEPABABLE FBOA HOOSENOLD PUEL OSE

TART, E 5.5 
TABLE 5.2B -- COBHBBCIAL AUTO GASOLIBE ARD ERERG USE, EY STATE, 19.67-76 EXCL ODIHG TAXICABS

GASOLINE USB I THOOSA NDS OP BBL, POILORBD BY BNERGY USE IN BILLIONS OP BTO

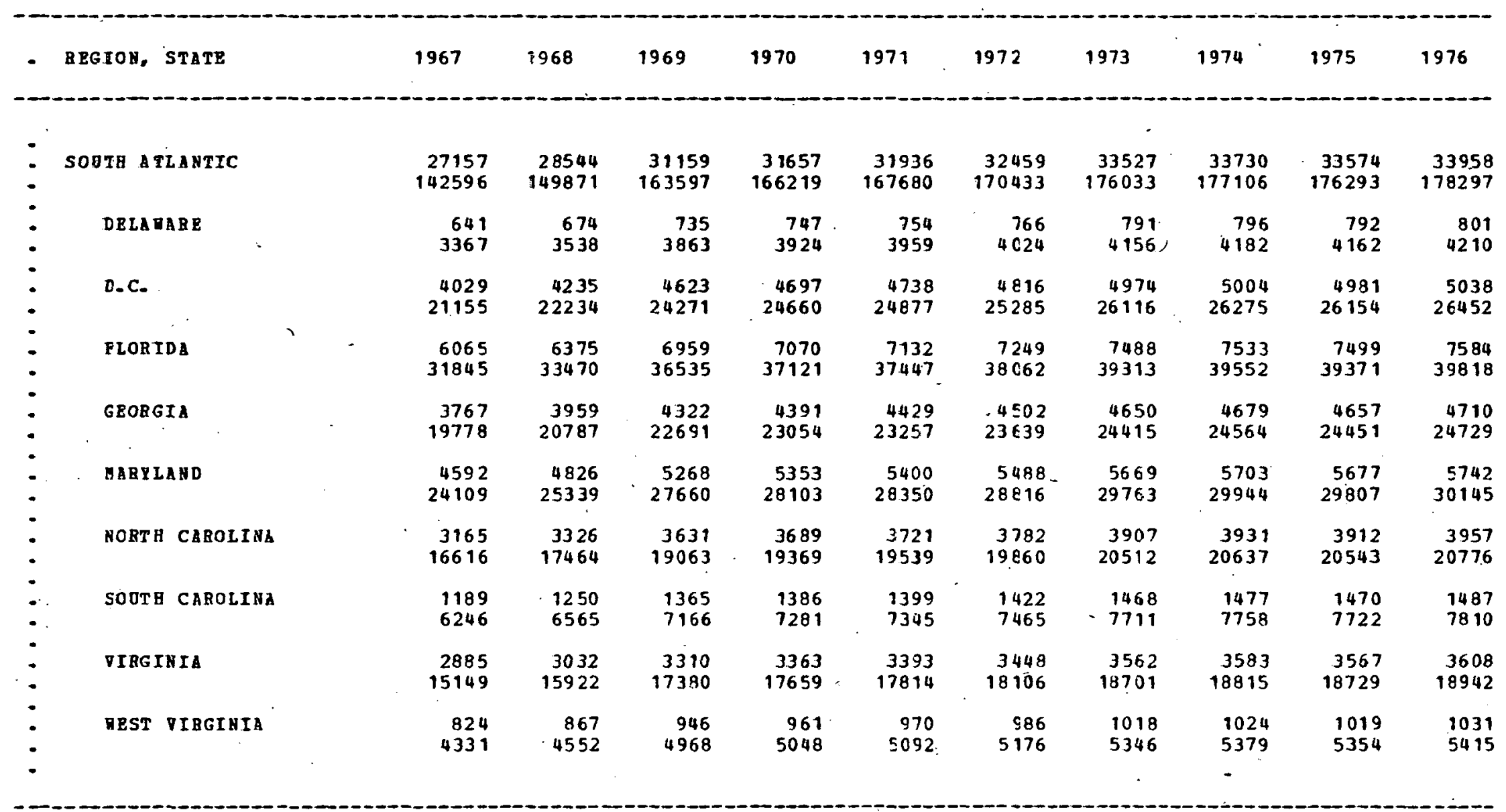


TABLE 5. 2 C - COMHERCIAL ACTO GASOLINE AND EHER̈G OSE, EY STATE, 1967-76 EXCLUDING TAXICABS

(TAIRD IN A SERIES OP 5 TABLES)

GaSOLINE USE IN THOUSA NDS OF BBL, PCLLONED BY EREBgY OSE IN BILL IONS OF BTO

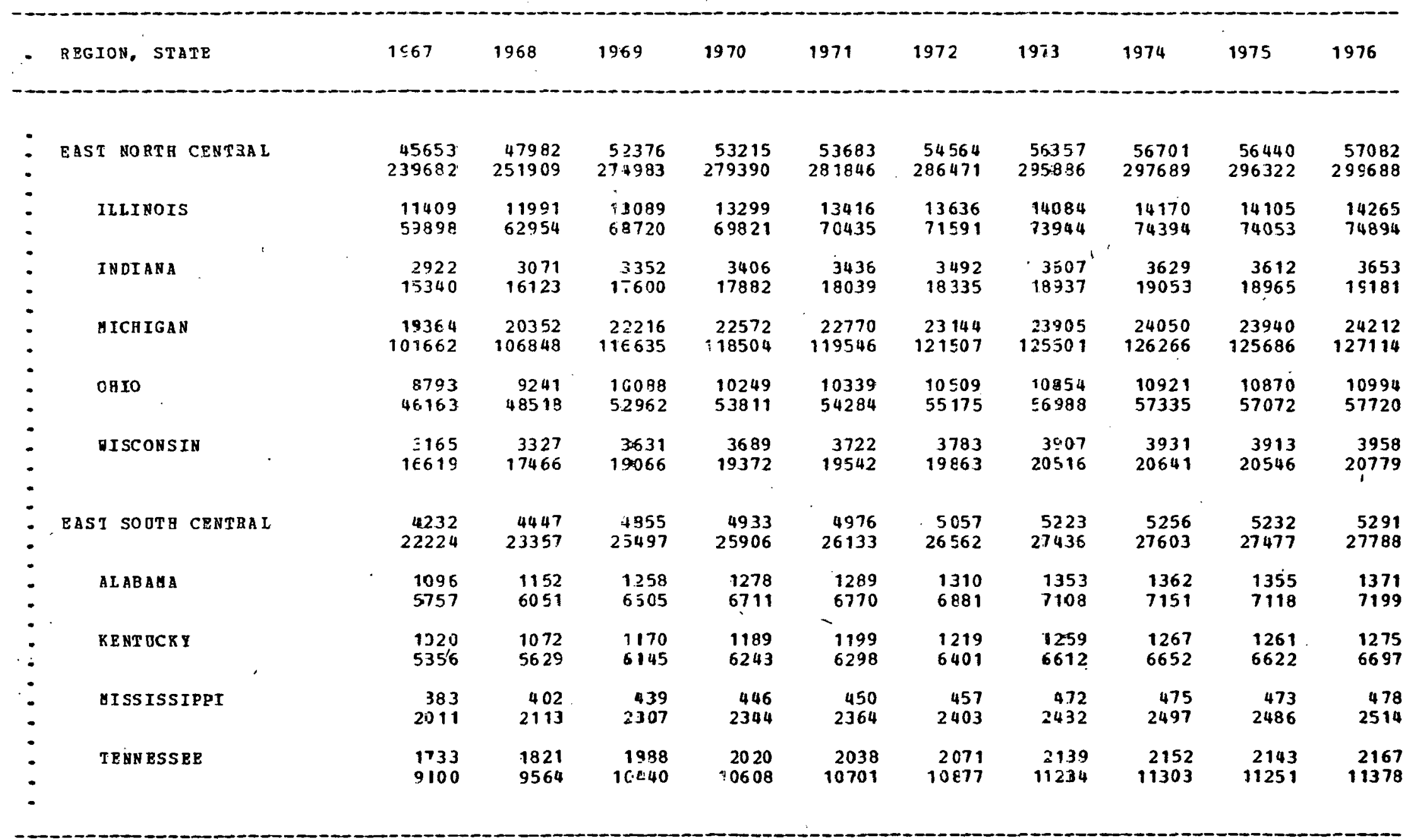




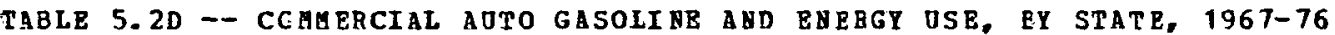
EXLUDING TAXICABS

(FOURTH IN A SERIES OP 5 TABLES)

GASOLINE USE IN TEOUSANDS OP BBI, POLLORED BY EHERGY USB IN BILLIONS OF BTO

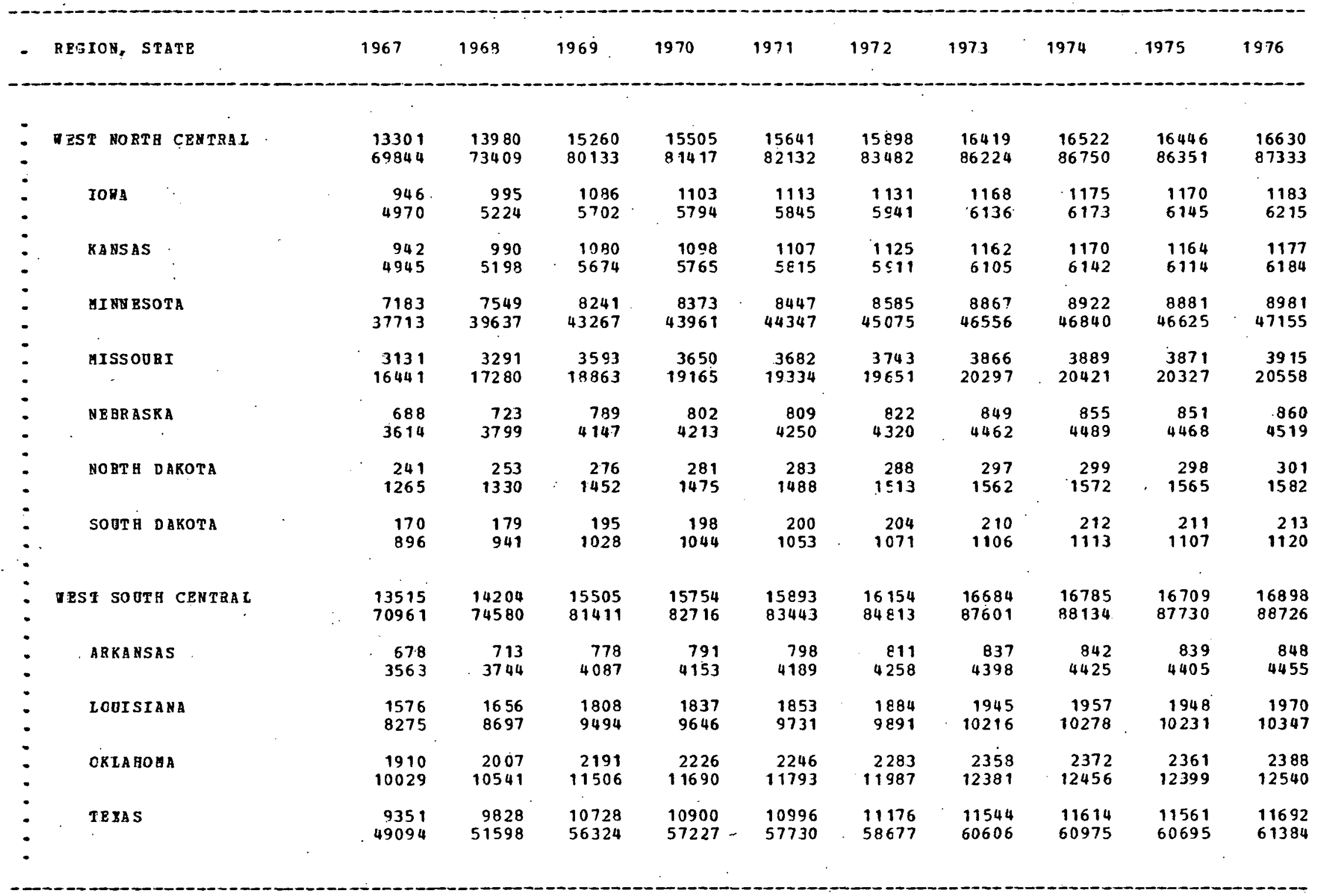


FABíE 5.2E -- COMMERCIAL AJTO GASOLINE AND ENERGY USE, BY. STATE, 1967-76 EXCLUDING TAXICABS

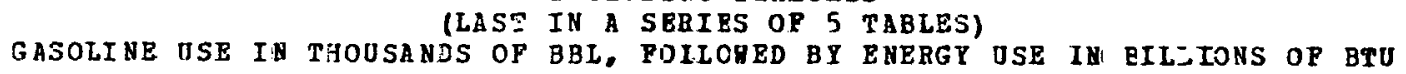

\begin{tabular}{|c|c|c|c|c|c|c|c|c|c|c|c|}
\hline & REGION， STATE & 1967 & 1968 & 1969 & 1970 & 1971 & 1972 & $: 973$ & 1974 & 1975 & 1976 \\
\hline - & MODNTAIN & $\begin{array}{r}615.3 \\
32319\end{array}$ & $\begin{array}{r}6466 \\
33965\end{array}$ & $\begin{array}{r}7058 \\
37077\end{array}$ & $\begin{array}{r}7172 \\
37673\end{array}$ & $\begin{array}{r}7236 \\
38003\end{array}$ & $\begin{array}{r}735 \% \\
3862 ?\end{array}$ & $\begin{array}{r}7596 \\
39896\end{array}$ & $\begin{array}{r}7642 \\
40140\end{array}$ & $\begin{array}{r}7607 \\
39954\end{array}$ & $\begin{array}{r}7693 \\
40410\end{array}$ \\
\hline : & ABIZ ONA & $\begin{array}{l}1876 \\
9850\end{array}$ & $\begin{array}{r}1971 \\
10352\end{array}$ & $\begin{array}{r}2152 \\
11300\end{array}$ & $\begin{array}{r}2187 \\
11481\end{array}$ & $\begin{array}{r}2206 \\
11582\end{array}$ & $\begin{array}{r}2242 \\
11772\end{array}$ & $\begin{array}{r}2316 \\
12159\end{array}$ & $\begin{array}{r}2330 \\
12233\end{array}$ & $\begin{array}{r}2319 \\
12177\end{array}$ & $\begin{array}{r}2345 \\
12316\end{array}$ \\
\hline : & COLORADO & $\begin{array}{l}168 C \\
882 C\end{array}$ & $\begin{array}{l}1765 \\
9270\end{array}$ & $\begin{array}{r}1927 \\
10120\end{array}$ & $\begin{array}{r}1958 \\
10282\end{array}$ & $\begin{array}{r}1975 \\
10372\end{array}$ & $\begin{array}{l}200 \varepsilon \\
1054 \mathrm{z}\end{array}$ & $\begin{array}{r}2074 \\
10889\end{array}$ & $\begin{array}{r}2086 \\
10955\end{array}$ & $\begin{array}{r}2077 \\
10905\end{array}$ & $\begin{array}{r}2100 \\
11029\end{array}$ \\
\hline • & IDARO & $\begin{array}{r}366 \\
1926\end{array}$ & $\begin{array}{r}385 \\
2024\end{array}$ & $\begin{array}{r}420 \\
2209\end{array}$ & $\begin{array}{r}427 \\
2245\end{array}$ & $\begin{array}{r}431 \\
2264\end{array}$ & $\begin{array}{r}43 \varepsilon \\
2302\end{array}$ & $\begin{array}{r}452 \\
2377\end{array}$ & $\begin{array}{r}455 \\
2392\end{array}$ & $\begin{array}{r}453 \\
2381\end{array}$ & $\begin{array}{r}458 \\
2408\end{array}$ \\
\hline$\bullet$ & MONTANA & $\begin{array}{r}222 \\
1166\end{array}$ & $\begin{array}{r}233 \\
1225\end{array}$ & $\begin{array}{r}254 \\
8337\end{array}$ & $\begin{array}{r}258 \\
1359\end{array}$ & $\begin{array}{r}261 \\
1371\end{array}$ & $\begin{array}{r}265 \\
1393\end{array}$ & $\begin{array}{r}274 \\
1439\end{array}$ & $\begin{array}{r}275 \\
1448\end{array}$ & $\begin{array}{r}274 \\
1441\end{array}$ & $\begin{array}{r}277 \\
1457\end{array}$ \\
\hline e & NEVADA & $\begin{array}{r}364 \\
1912\end{array}$ & $\begin{array}{r}382 \\
2010\end{array}$ & $\begin{array}{r}418 \\
2194\end{array}$ & $\begin{array}{r}424 \\
2229\end{array}$ & $\begin{array}{r}428 \\
2249\end{array}$ & $\begin{array}{r}435 \\
2286\end{array}$ & $\begin{array}{r}449 \\
2361\end{array}$ & $\begin{array}{r}452 \\
2375\end{array}$ & $\begin{array}{r}450 \\
2364\end{array}$ & $\begin{array}{r}455 \\
2391\end{array}$ \\
\hline & NEW UEXICO & $\begin{array}{r}480 \\
2525\end{array}$ & $\begin{array}{r}505 \\
2653\end{array}$ & $\begin{array}{r}551 \\
2896\end{array}$ & $\begin{array}{r}560 \\
2943\end{array}$ & $\begin{array}{r}565 \\
2969\end{array}$ & $\begin{array}{r}574 \\
3017\end{array}$ & $\begin{array}{r}593 \\
3917\end{array}$ & $\begin{array}{r}597 \\
3136\end{array}$ & $\begin{array}{r}594 \\
3121\end{array}$ & $\begin{array}{r}601 \\
3157\end{array}$ \\
\hline & OTAH & $\begin{array}{r}972 \\
5106\end{array}$ & $\begin{array}{l}1022 \\
5366\end{array}$ & $\begin{array}{l}1115 \\
5858\end{array}$ & $\begin{array}{l}11.33 \\
5952\end{array}$ & $\begin{array}{l}1143 \\
6004\end{array}$ & $\begin{array}{r}1162 \\
6103\end{array}$ & $\begin{array}{r}1200 \\
6303\end{array}$ & $\begin{array}{l}1208 \\
6342\end{array}$ & $\begin{array}{l}1202 \\
6312\end{array}$ & $\begin{array}{l}1216 \\
6384\end{array}$ \\
\hline$\theta$ & HYOMING & $\begin{array}{r}193 \\
1014\end{array}$ & $\begin{array}{r}203 \\
1065\end{array}$ & $\begin{array}{r}221 \\
1163\end{array}$ & $\begin{array}{r}225 \\
1182\end{array}$ & $\begin{array}{r}227 \\
1192\end{array}$ & $\begin{array}{r}230 \\
1212\end{array}$ & $\begin{array}{r}238 \\
1251\end{array}$ & $\begin{array}{r}239 \\
1259\end{array}$ & $\begin{array}{r}238 \\
1253\end{array}$ & $\begin{array}{r}241 \\
1268\end{array}$ \\
\hline & P AC I F IC & $\begin{array}{r}32323 \\
169704\end{array}$ & $\begin{array}{r}33971 \\
17836.1\end{array}$ & $\begin{array}{r}37082 \\
194699\end{array}$ & $\begin{array}{r}37678 \\
197820\end{array}$ & $\begin{array}{r}38009 \\
199558\end{array}$ & $\begin{array}{r}38633 \\
202832\end{array}$ & $\begin{array}{r}39 \leq 03 \\
209 \div 99\end{array}$ & $\begin{array}{r}40145 \\
210776\end{array}$ & $\begin{array}{r}39961 \\
209807\end{array}$ & $\begin{array}{r}40415 \\
212191\end{array}$ \\
\hline$\bullet$ & ALASKA & $\begin{array}{r}237 \\
1248\end{array}$ & $\begin{array}{r}249 \\
1312\end{array}$ & $\begin{array}{r}272 \\
1432\end{array}$ & $\begin{array}{r}277 \\
1455\end{array}$ & $\begin{array}{r}279 \\
1468\end{array}$ & $\begin{array}{r}284 \\
1492\end{array}$ & $\begin{array}{r}293 \\
1 \leq 41\end{array}$ & $\begin{array}{r}295 \\
1551\end{array}$ & $\begin{array}{r}294 \\
1543\end{array}$ & $\begin{array}{r}297 \\
1561\end{array}$ \\
\hline & CALI PORNIE & $\begin{array}{r}26757 \\
140474\end{array}$ & $\begin{array}{r}28121 \\
147640\end{array}$ & $\begin{array}{r}30597 \\
161363\end{array}$ & $\begin{array}{r}31189 \\
1.53746\end{array}$ & $\begin{array}{r}31463 \\
165185\end{array}$ & $\begin{array}{r}31980 \\
167895\end{array}$ & $\begin{array}{r}33031 \\
173414\end{array}$ & $\begin{array}{r}33232 \\
174470\end{array}$ & $\begin{array}{r}33079 \\
173669\end{array}$ & $\begin{array}{r}33455 \\
175642\end{array}$ \\
\hline & BADAII & $\begin{array}{r}749 \\
3933\end{array}$ & $\begin{array}{r}787 \\
4134\end{array}$ & $\begin{array}{r}359 \\
4513\end{array}$ & $\begin{array}{r}873 \\
.4585\end{array}$ & $\begin{array}{r}881 \\
4625\end{array}$ & $\begin{array}{r}895 \\
4701\end{array}$ & $\begin{array}{r}925 \\
. \quad 856\end{array}$ & $\begin{array}{r}930 \\
4885\end{array}$ & $\begin{array}{r}926 \\
4863\end{array}$ & $\begin{array}{r}936 \\
4918\end{array}$ \\
\hline & CREGON & $\begin{array}{r}2166 \\
11374\end{array}$ & $\begin{array}{r}2277 \\
11954\end{array}$ & $\begin{array}{r}2485 \\
13049\end{array}$ & $\begin{array}{r}2525 \\
13259\end{array}$ & $\begin{array}{r}2547 \\
13375\end{array}$ & $\begin{array}{r}2589 \\
13595\end{array}$ & $\begin{array}{r}2674 \\
14041\end{array}$ & $\begin{array}{r}2690 \\
14127\end{array}$ & $\begin{array}{r}2678 \\
14062\end{array}$ & $\begin{array}{r}2709 \\
14222\end{array}$ \\
\hline & HASH I HGTON & $\begin{array}{r}2414 \\
12675\end{array}$ & $\begin{array}{r}2537 \\
13321\end{array}$ & $\begin{array}{r}27.69 \\
145.42\end{array}$ & $\begin{array}{r}2814 \\
14775\end{array}$ & $\begin{array}{r}2839 \\
14905\end{array}$ & $\begin{array}{r}2885 \\
15149\end{array}$ & $\begin{array}{r}29: 30 \\
156+7\end{array}$ & $\begin{array}{r}2998 \\
15743\end{array}$ & $\begin{array}{r}2984 \\
15670\end{array}$ & $\begin{array}{r}3018 \\
15848\end{array}$ \\
\hline
\end{tabular}


TABLE 5. 3A - TAXICAB GASOLINE AND ENRQGI USE, BY STATE, 1967-76

(FIRST IN A SERIES OP 5 TABLES).

GASOLINE USE IN THOUSA NDS OP BBL, FOLLONED BY BNERG USE IN BILLIONS OP BTU

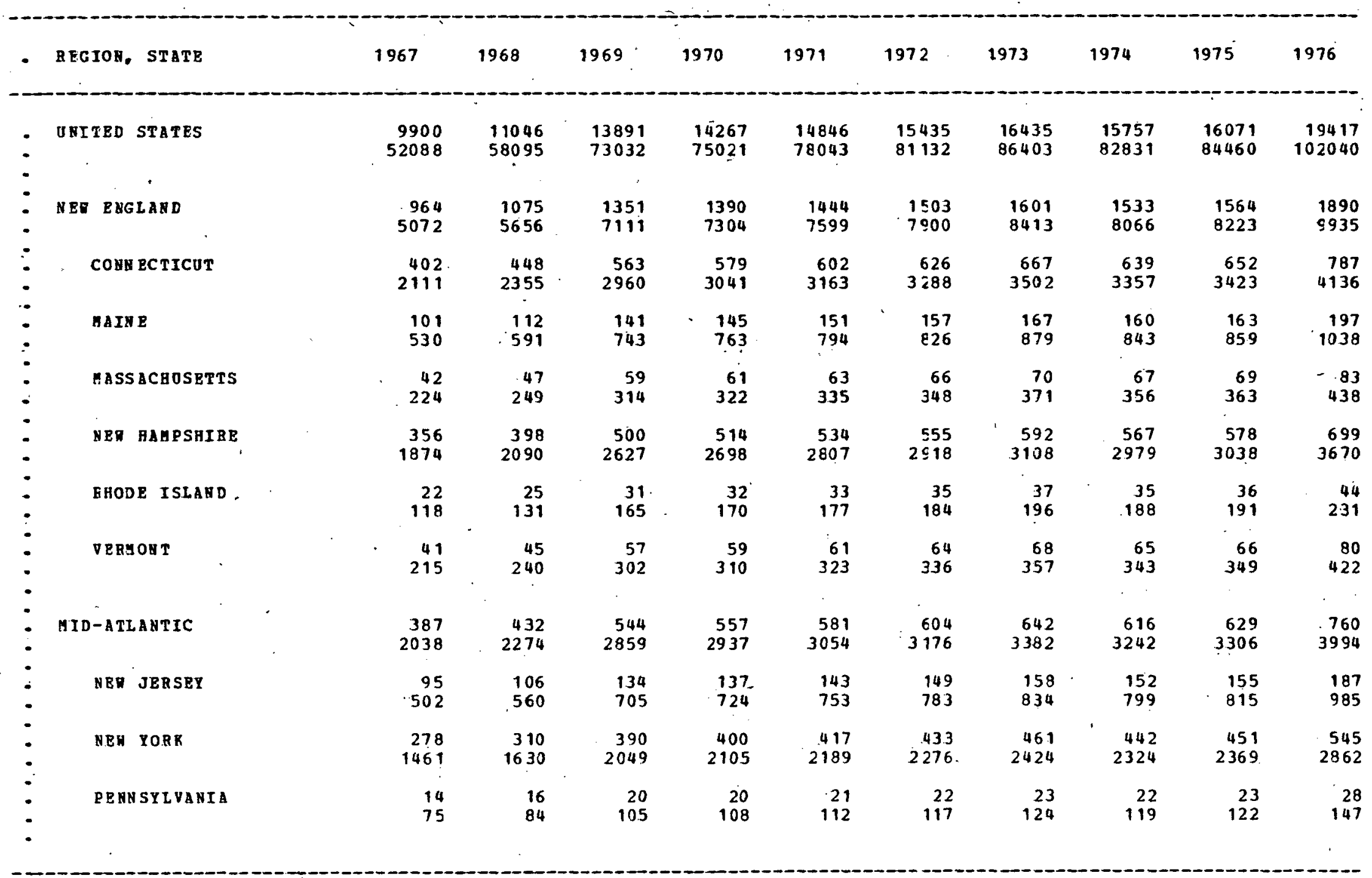


TABLE 5. JB -- TAXICAB GASOLIME AND ENERGY USE, BY STATE, 1,96.7-76 (SECOND IN A SERIES OP 5 TABLES)

GASOLYNE IEE IN THODSANDS OF BBL, FOLLOMED BY ENERGY USE IN BILLIONS OF BTO

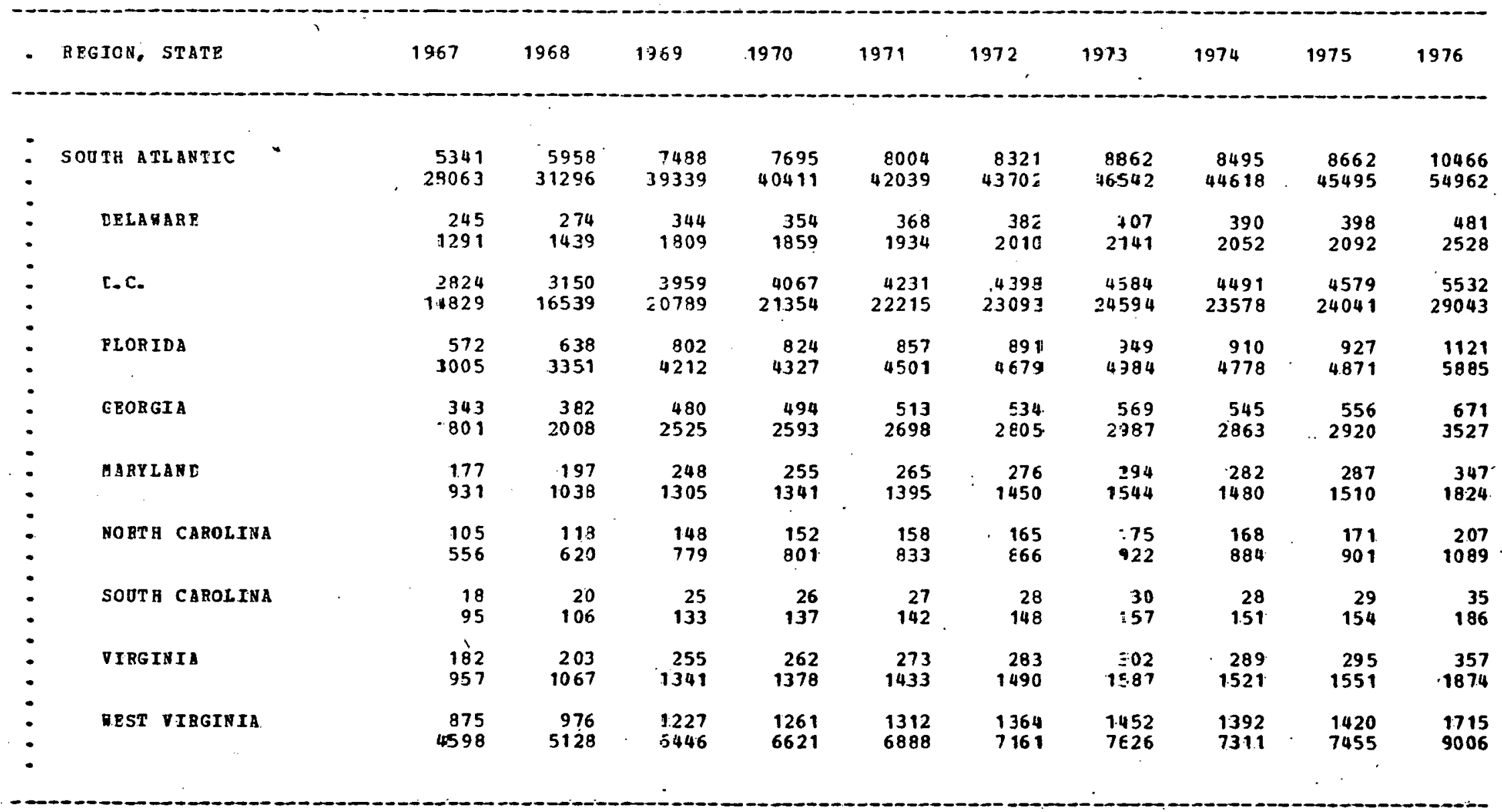


TABLE 5.3C - TAXICAB GASOLINE AND ENERGY OSE, BY STATE, 1967-76

(THIRD IN A SBRIBS OP 5 TABLES)

GASOLINE USE IN THOUSANDS OP BBL, FOLLOHBD BY ENERGY DSE IE BILLIONS OP BTO

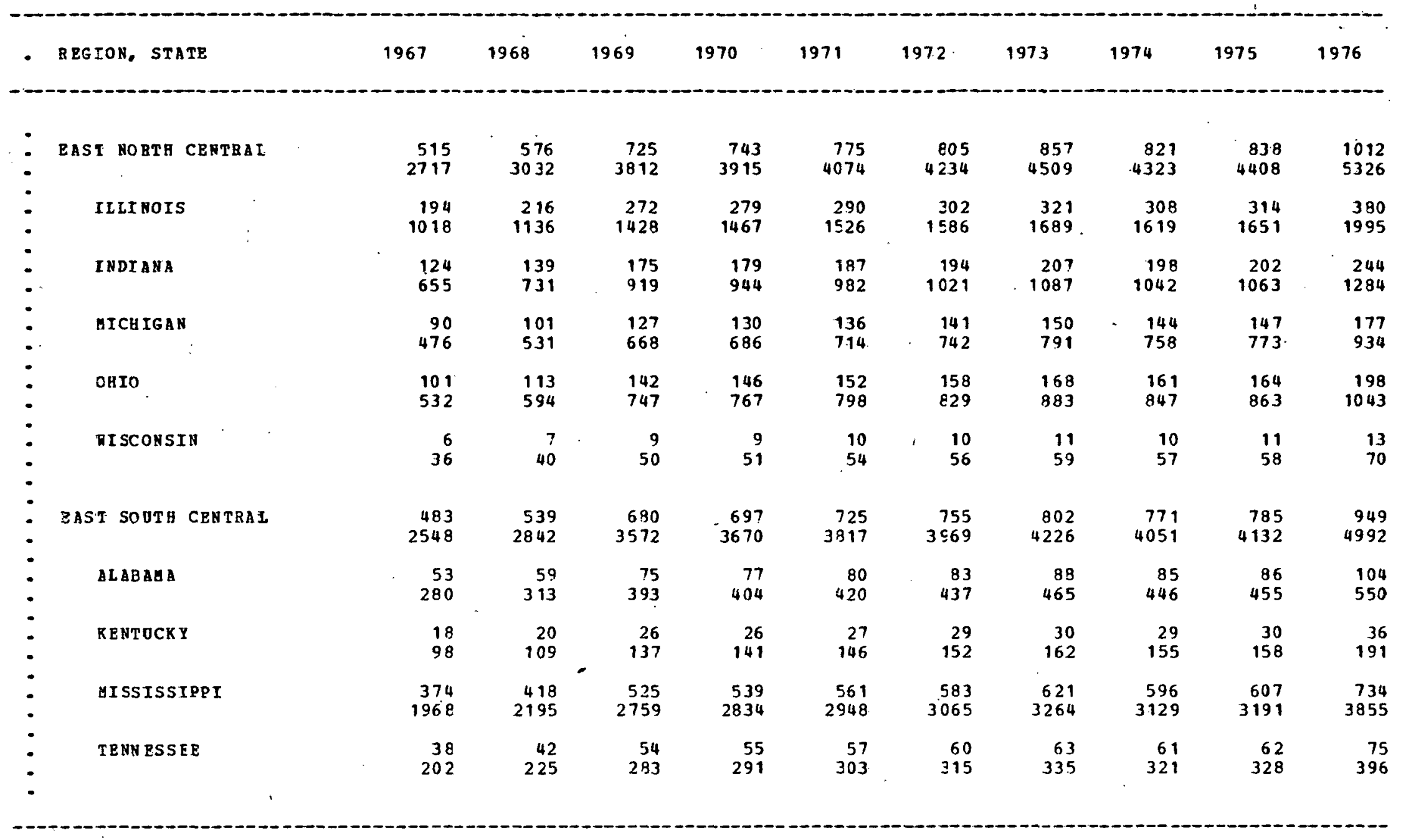

SOORCE: AETHOD 312 DATA QDALITY: 2 (NATIONAL), 3 (STATES) 
TABLE 5. 35 -- TAXICAB GASOLIAB A ED ENEBGY USE, BY STATE, 1967-76 (FOURTA IN A SERIES OP 5 TABLES)

GASOLINE USE IN THOOSANDS OP BBL, POILONED BY RNERGT OSE IB BILL TOES OP BTO

\begin{tabular}{|c|c|c|c|c|c|c|c|c|c|c|c|c|}
\hline & REGION, STATE & & 1967 & 1968 & 1957 & 1770 & 1971 & 1972 & 1973 & 1974 & 1975 & 1.976 \\
\hline & & & & & & & & & & & . & \\
\hline - & REST NORTB CENTRAL & & $\begin{array}{r}552 \\
2909\end{array}$ & $\begin{array}{r}616 \\
3247\end{array}$ & $\begin{array}{r}775 \\
4080\end{array}$ & $\begin{array}{r}796 \\
4192\end{array}$ & $\begin{array}{r}827 \\
4360\end{array}$ & $\begin{array}{r}861 \\
4533\end{array}$ & $\begin{array}{r}917 \\
4828\end{array}$ & $\begin{array}{r}878 \\
4629\end{array}$ & $\begin{array}{r}898 \\
4719\end{array}$ & $\begin{array}{l}1083 \\
5702\end{array}$ \\
\hline$\dot{-}$ & IOHA & & $\begin{array}{r}93 \\
792\end{array}$ & $\begin{array}{l}104 \\
549\end{array}$ & $\begin{array}{l}131 \\
690\end{array}$ & $\begin{array}{l}135 \\
708\end{array}$ & $\begin{array}{l}140 \\
737\end{array}$ & $\begin{array}{l}146 \\
766\end{array}$ & $\begin{array}{l}155 \\
8: 16\end{array}$ & $\begin{array}{l}149 \\
782\end{array}$ & $\begin{array}{l}152 \\
798\end{array}$ & $\begin{array}{l}183 \\
964\end{array}$ \\
\hline : & RAHSAS & & $\begin{array}{r}153 \\
304\end{array}$ & $\begin{array}{l}170 \\
897\end{array}$ & $\begin{array}{r}214 \\
1327\end{array}$ & $\begin{array}{r}220 \\
1158\end{array}$ & $\begin{array}{r}229 \\
1204\end{array}$ & $\begin{array}{r}238 \\
1252\end{array}$ & $\begin{array}{r}254 \\
1333\end{array}$ & $\begin{array}{r}243 \\
1278\end{array}$ & $\begin{array}{r}248 \\
\quad 1303\end{array}$ & $\begin{array}{r}300 \\
1575\end{array}$ \\
\hline - & MINEESOTA & & $\begin{array}{r}19 \\
101\end{array}$ & $\begin{array}{r}21 \\
113\end{array}$ & $\begin{array}{l}27 \\
42\end{array}$ & $\begin{array}{r}27 \\
146\end{array}$ & $\begin{array}{r}29 \\
152\end{array}$ & $\begin{array}{r}30 \\
158\end{array}$ & $\begin{array}{r}32 \\
158\end{array}$ & $\begin{array}{r}30 \\
161\end{array}$ & $\begin{array}{r}31 \\
164\end{array}$ & $\begin{array}{r}37 \\
199\end{array}$ \\
\hline$\bullet$ & MISSOURI & . & $\begin{array}{r}77 \\
105\end{array}$ & $\begin{array}{r}86 \\
452\end{array}$ & $\begin{array}{l}108 \\
668\end{array}$ & $\begin{array}{l}111 \\
584\end{array}$ & $\begin{array}{l}115 \\
607\end{array}$ & $\begin{array}{l}120 \\
631\end{array}$ & $\begin{array}{l}1.28 \\
672\end{array}$ & $\begin{array}{l}122 \\
645\end{array}$ & $\begin{array}{l}125 \\
657\end{array}$ & $\begin{array}{l}151 \\
794\end{array}$ \\
\hline & NEBRASKA & & $\begin{array}{r}87 \\
657\end{array}$ & $\begin{array}{r}97 \\
510\end{array}$ & $\begin{array}{l}122 \\
641\end{array}$ & $\begin{array}{l}125 \\
659\end{array}$ & $\begin{array}{l}130 \\
685\end{array}$ & $\begin{array}{l}135 \\
713\end{array}$ & $\begin{array}{l}1 \pm 4 \\
759\end{array}$ & $\begin{array}{l}138 \\
728\end{array}$ & $\begin{array}{l}141 \\
742\end{array}$ & $\begin{array}{l}170 \\
896\end{array}$ \\
\hline & NOETE DAKOTA & & $\begin{array}{r}74 \\
\equiv 97\end{array}$ & $\begin{array}{r}83 \\
437\end{array}$ & $\begin{array}{l}104 \\
549\end{array}$ & $\begin{array}{l}107 \\
564\end{array}$ & $\begin{array}{l}111 \\
587\end{array}$ & $\begin{array}{l}116 \\
610\end{array}$ & $\begin{array}{l}123 \\
650\end{array}$ & $\begin{array}{l}118 \\
623\end{array}$ & $\begin{array}{l}121 \\
635\end{array}$ & $\begin{array}{l}146 \\
767\end{array}$ \\
\hline & SOOTH DAROTA & & $\begin{array}{r}49 \\
-59\end{array}$ & $\begin{array}{r}55 \\
289\end{array}$ & $\begin{array}{r}69 \\
363\end{array}$ & $\begin{array}{r}71 \\
373\end{array}$ & $\begin{array}{r}73 \\
388\end{array}$ & $\begin{array}{r}76 \\
403\end{array}$ & $\begin{array}{r}81 \\
430\end{array}$ & $\begin{array}{r}78 \\
912\end{array}$ & $\begin{array}{r}80 \\
420\end{array}$ & $\begin{array}{r}96 \\
507\end{array}$ \\
\hline & DEST SOUTH CEATRAL & & $\begin{array}{r}564 \\
2969\end{array}$ & $\begin{array}{r}629 \\
3311\end{array}$ & $\begin{array}{r}791 \\
-\quad 4163\end{array}$ & $\begin{array}{r}813 \\
4276\end{array}$ & $\begin{array}{r}845 \\
4448\end{array}$ & $\begin{array}{r}879 \\
4624\end{array}$ & $\begin{array}{r}9 \equiv 6 \\
4926\end{array}$ & $\begin{array}{r}897 \\
4721\end{array}$ & $\begin{array}{r}916 \\
4814\end{array}$ & $\begin{array}{r}1107 \\
5816\end{array}$ \\
\hline & ABKANSAS & & $\begin{array}{r}329 \\
1729\end{array}$ & $\begin{array}{r}367 \\
1928\end{array}$ & $\begin{array}{r}751 \\
2+24\end{array}$ & $\begin{array}{r}474 \\
2490\end{array}$ & $\begin{array}{r}493 \\
2590\end{array}$ & $\begin{array}{r}512 \\
2693\end{array}$ & $\begin{array}{r}546 \\
28 \in 8\end{array}$ & $\begin{array}{r}523 \\
2749\end{array}$ & $\begin{array}{r}534 \\
2803\end{array}$ & $\begin{array}{r}645 \\
3387\end{array}$ \\
\hline & LOUI SIANA & & $\begin{array}{r}35 \\
185\end{array}$ & $\begin{array}{r}39 \\
207\end{array}$ & $\begin{array}{r}49 \\
250\end{array}$ & $\begin{array}{r}50 \\
267\end{array}$ & $\begin{array}{r}52 \\
278\end{array}$ & $\begin{array}{r}55 \\
289\end{array}$ & $\begin{array}{r}58 \\
308\end{array}$ & $\begin{array}{r}56 \\
295\end{array}$ & $\begin{array}{r}57 \\
301\end{array}$ & $\begin{array}{r}69 \\
363\end{array}$ \\
\hline & OKLA HOQA & - & $\begin{array}{l}154 \\
864\end{array}$ & $\begin{array}{l}183 \\
963\end{array}$ & $\begin{array}{r}230 \\
1211\end{array}$ & $\begin{array}{r}237 \\
1244\end{array}$ & $\begin{array}{r}246 \\
1294\end{array}$ & $\begin{array}{r}256 \\
1345\end{array}$ & $\frac{272}{1+33}$ & $\begin{array}{r}261 \\
1373\end{array}$ & $\begin{array}{r}266 \\
1400\end{array}$ & $\begin{array}{r}322 \\
1692\end{array}$ \\
\hline & TEXAS & & $\begin{array}{r}36 \\
191\end{array}$ & $\begin{array}{r}40 \\
213\end{array}$ & $\begin{array}{r}51 \\
258\end{array}$ & $\begin{array}{r}52 \\
275\end{array}$ & $\begin{array}{r}54 \\
286\end{array}$ & $\begin{array}{r}56 \\
297\end{array}$ & $\begin{array}{r}60 \\
317\end{array}$ & $\begin{array}{r}57 \\
304\end{array}$ & $\begin{array}{r}59 \\
310\end{array}$ & $\begin{array}{r}71 \\
374\end{array}$ \\
\hline & & & , & & & & & & & & & \\
\hline
\end{tabular}


TABLE 5. 3E -- TAXICAB GASOLIBB AND ENEBGY USE, BY STATE, 1967-76

(LAST IY A SERTES OP 5 TABLES)

GASOIINE USE IN THOUSANDS OF BBL, POLLOHED BY ENERG USB IN BILLIONS OP BTU

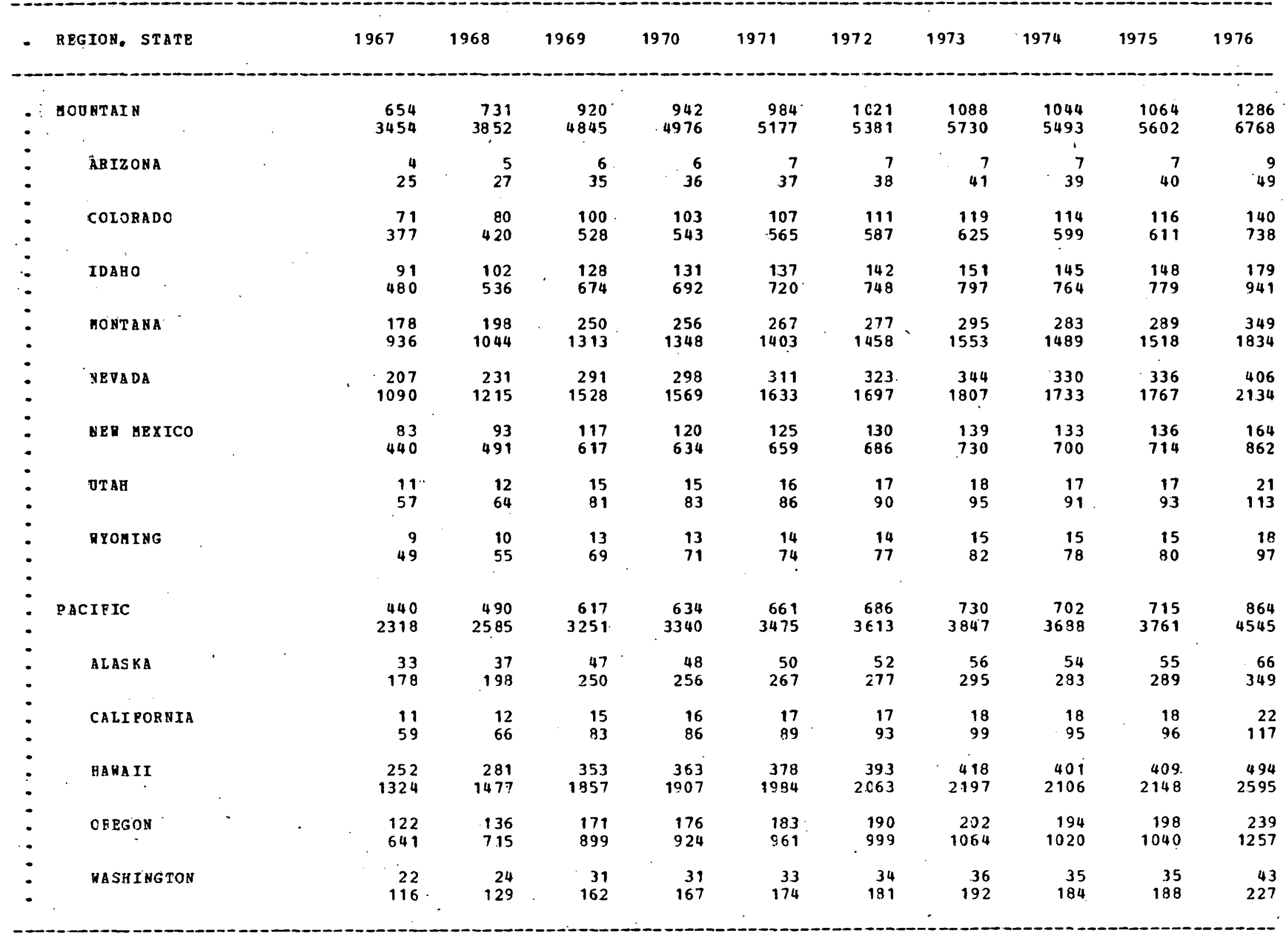


TABLE 5.4A - FEIERAL CIVILIAY AOTO GASOLINE AND BNERG USE, BY STATE, 1967-76 (FIRST IN A SBRIBS OP 5 TABLES)

GASOLINE TSE IN THOOSA NDS OP EBL, POILORED BI ERBRGT OSE IA BILE IOSS OP BTO

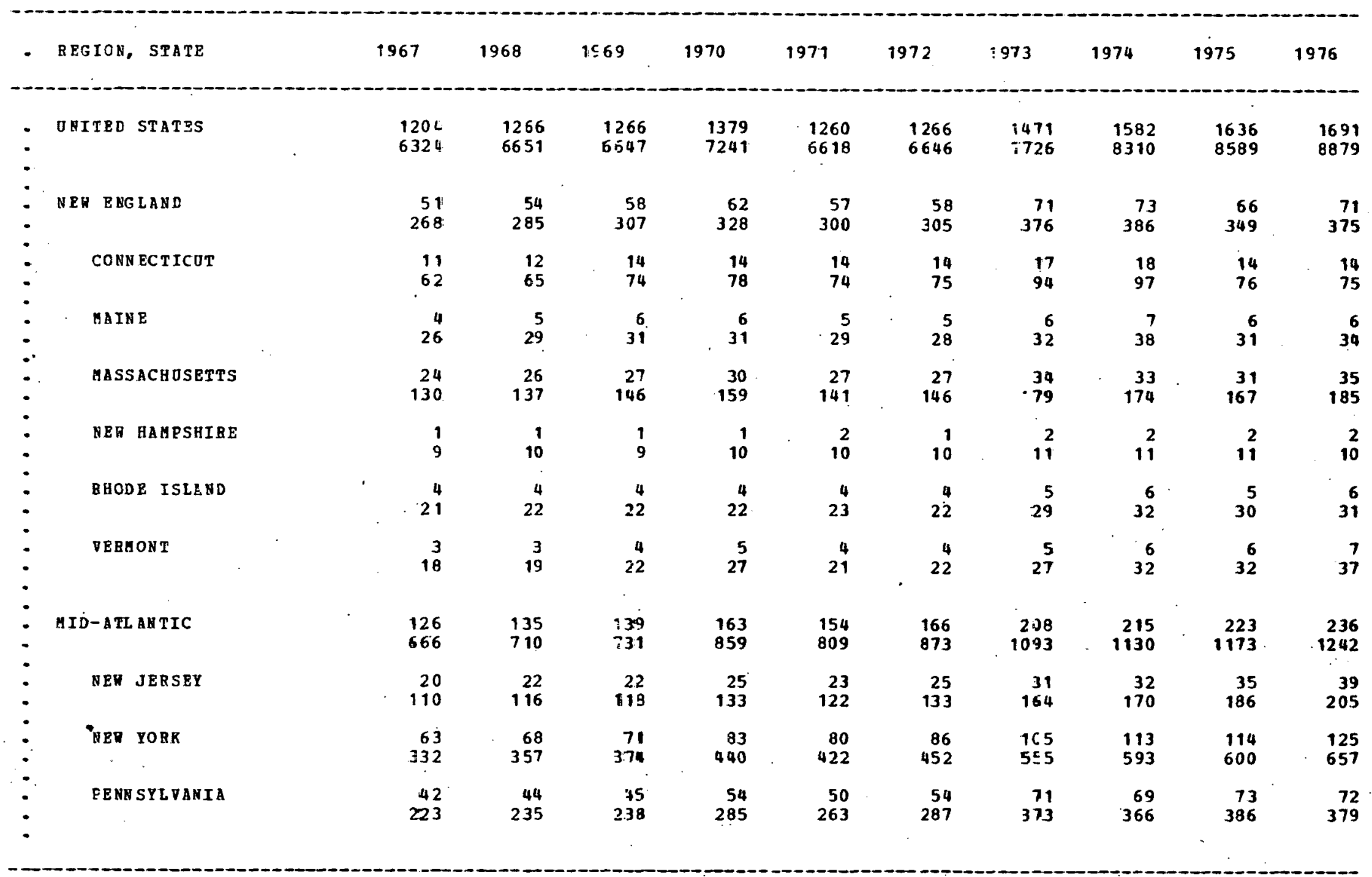


TABLz 5.4B - PEDERAL CIVILIAN GOTO GASOLIAE AND EREgGY USE, BY STATE, 1967-76 (SBCOND IN A SBRIBS OP 5 TABLES)

GASJLIEE OSE IN THOUSA HDS OF BBL, POLLORED BY ENREg USE IN BILL IOBS OP BTO

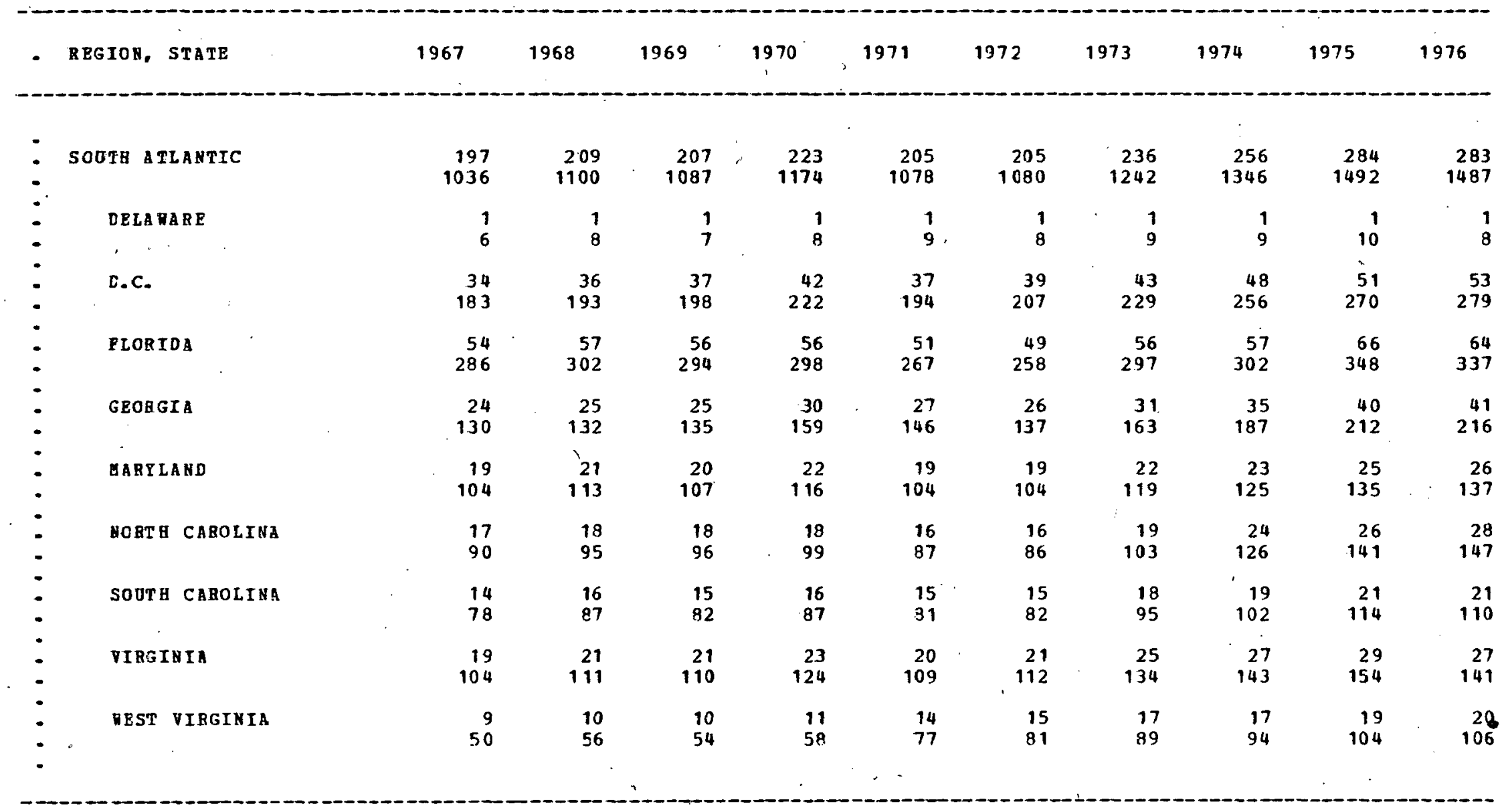

SOOBCE: METHOD 313 DATA QUALTT: 1 (NATIONAL), 2 (STATES) 
TABL 5. 4C -- PBDEEAL CIVILIAN AUTO GASOLINE AND ENERGY USE, BI STaTE, 1967-76 (THIRE IB A SERIPS OP 5 TABLES)

GASOLINE USE IS TFOOSA UDS OF BBL, FOILONED BY ENERG USE IN BILLIONS OP BTO

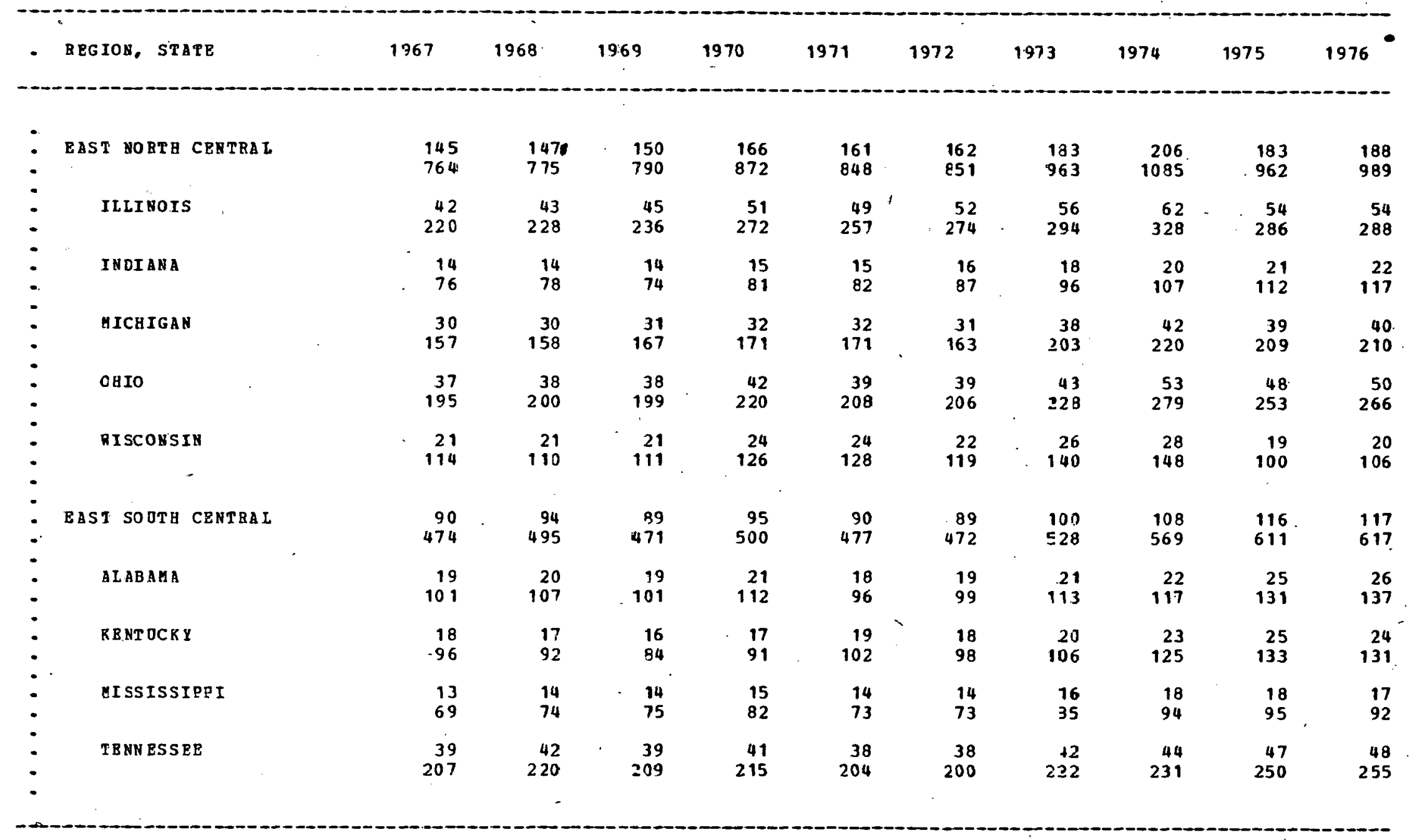


TABLB 5.4D - PEDERAL CIVILIAN AUTO GASOLI AE AND ENEBgY USE, BY STATE, 1967-76 (POURTH IN A SERIBS OP 5 TABLES)

GASOLINE OSF IN THOOSA KDS OF BBL, FOILOHED BY ENERGY USE IN BILLIOHS OP BTO

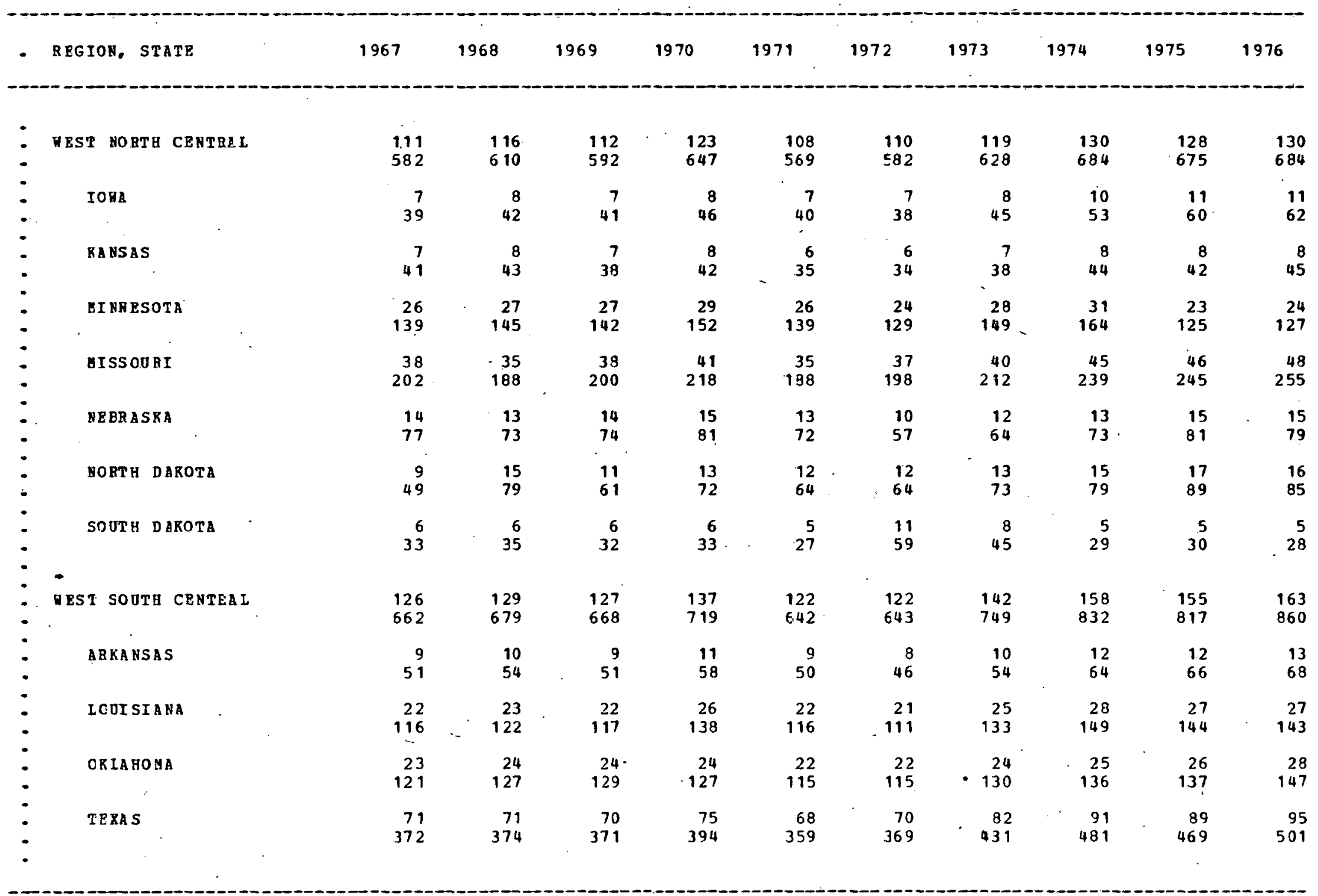




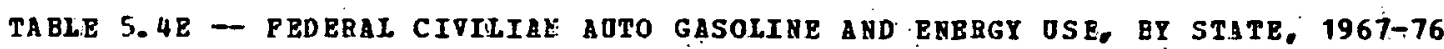
(LAST IN A SEBIES OP 5 TABLES)

GASJIINE OSE IA THOUSANDS OF BBL, POILORBD BY BUEEG USE IN BILI IONS OP BTO.

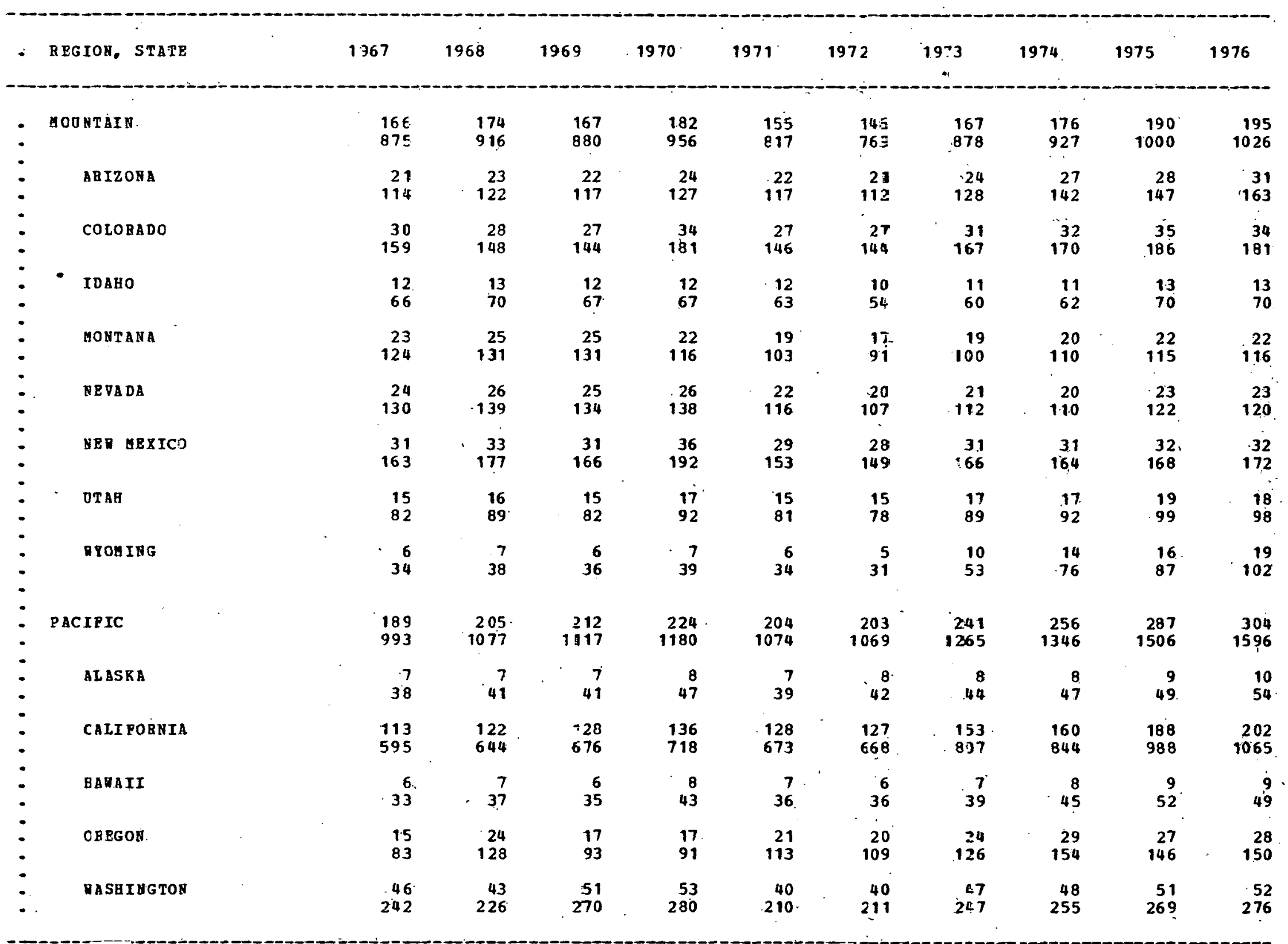


TABLE 5.5A -- HOOSEHOLD AUTO GASOLINB ABD E HEBGY OSE, BY STATE, 1967-76

(INCLODES STATE ALD LOCAL GOVERNGETT AOTO GASOLINB USE)

(PIRST IN A SERIES OP PIVE TABLES)

GASOLINE USE IN THOOSANDS OP BBL, POILOTRD BI ENERGY OSE IN BILLIONS OP BTO

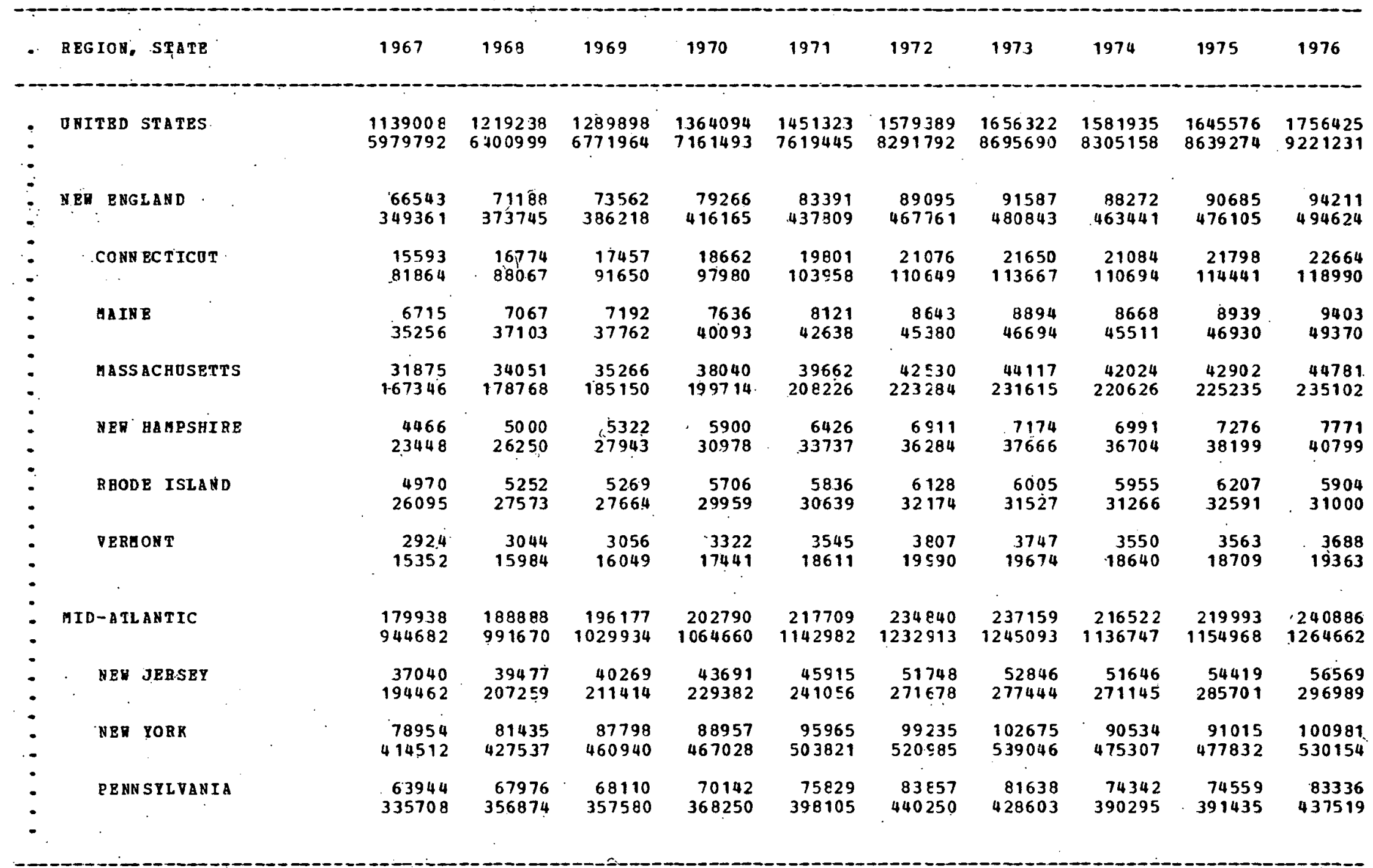

SOORCE: МЕTHOD 314

DATA QOALTTY 3

NOTE: PIGORES INCLUDE A RELATIVELY INSIGNIPICANT ALOUNT OF FOEI OSED BY. STATE

AND LOCAL GOVEBNGENT TRUCRS ARD BY BOSES THAT ARE HOT COHHON CARRIERS

(OTHER THAN SCHOOL AND PEDERAL BUSES). SER ALSO NOTE OHDER TABLE 5.2A. 
TABLE 5.58 - HOJSEHOLD AOTO GASOLIHE AHD BNEEGY OSE, BY STATE, 1967-76

(INCLJIES - ST ATE AND LOCAL GOVBRBMEHT AOTO GASOLIHE DSE'

(SECOND II A SERIES OF PIVE TABLES)

GASOLIEE OSE IH THOUSA ADS OP BEL, POILOMBD BY EREBG OSE IY BILLIONS OP BTO

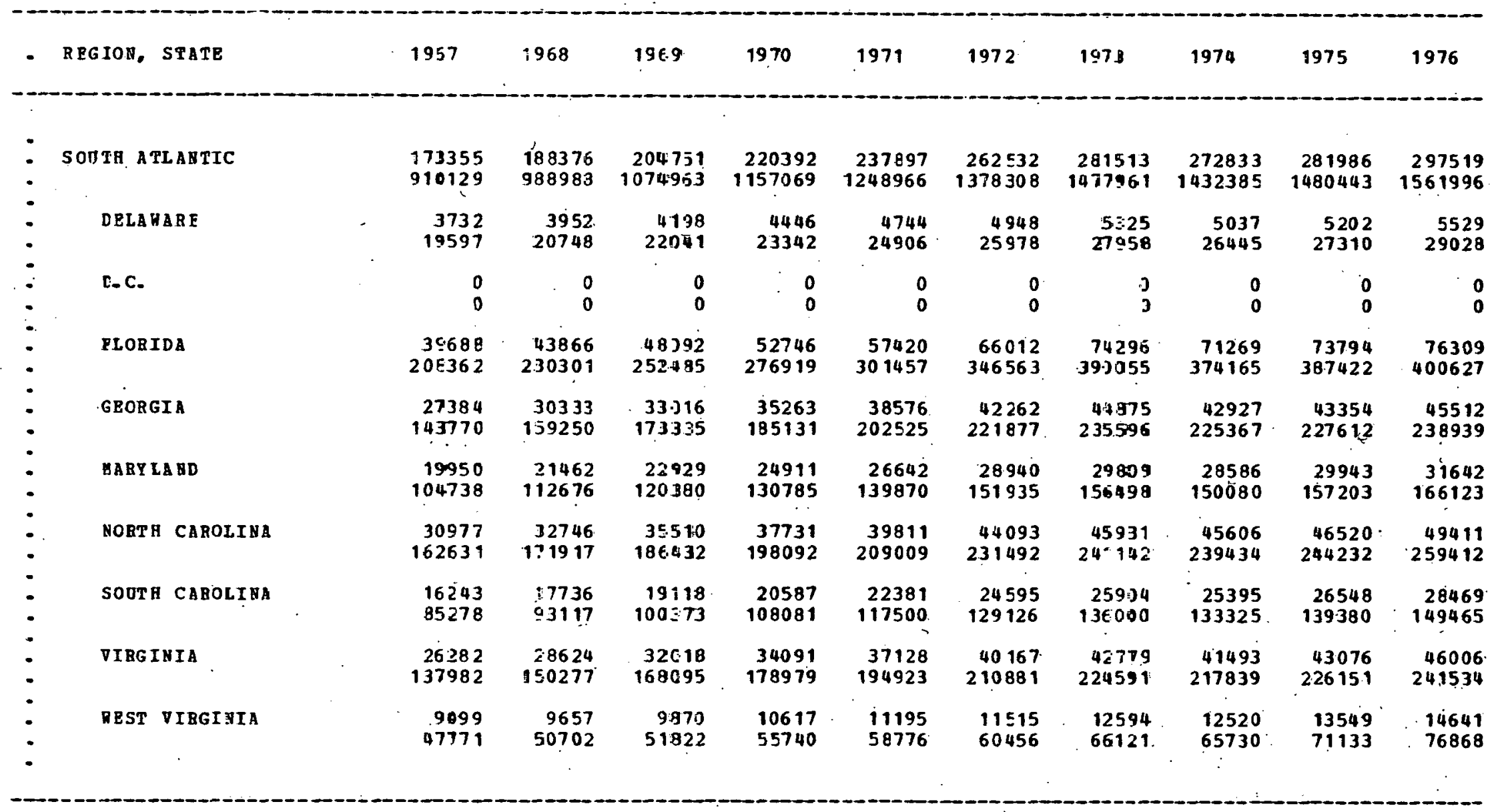

SOORCE: HRTHOD 314

DATA QOAZTTY: 3

NOTE: SEE HETHOD 314 FCR A DISCOSSION DE. SPECIAL PBOBLES BHCOONTERED

IN RSTIMATING DISTBICT DP CCIOUEIA FOEL DSE. 
- TABLE 5. 5C -- hOUSEHOLD AUTO GASOLI HE AND BNERG OSE, BY STATE, 1967-76

(INCLUDES STATE AND LOCAL GOVERNAENT AOTO GASOLINE USE)

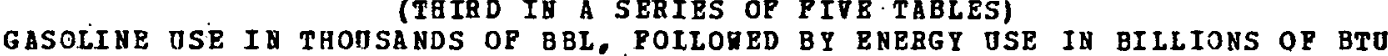

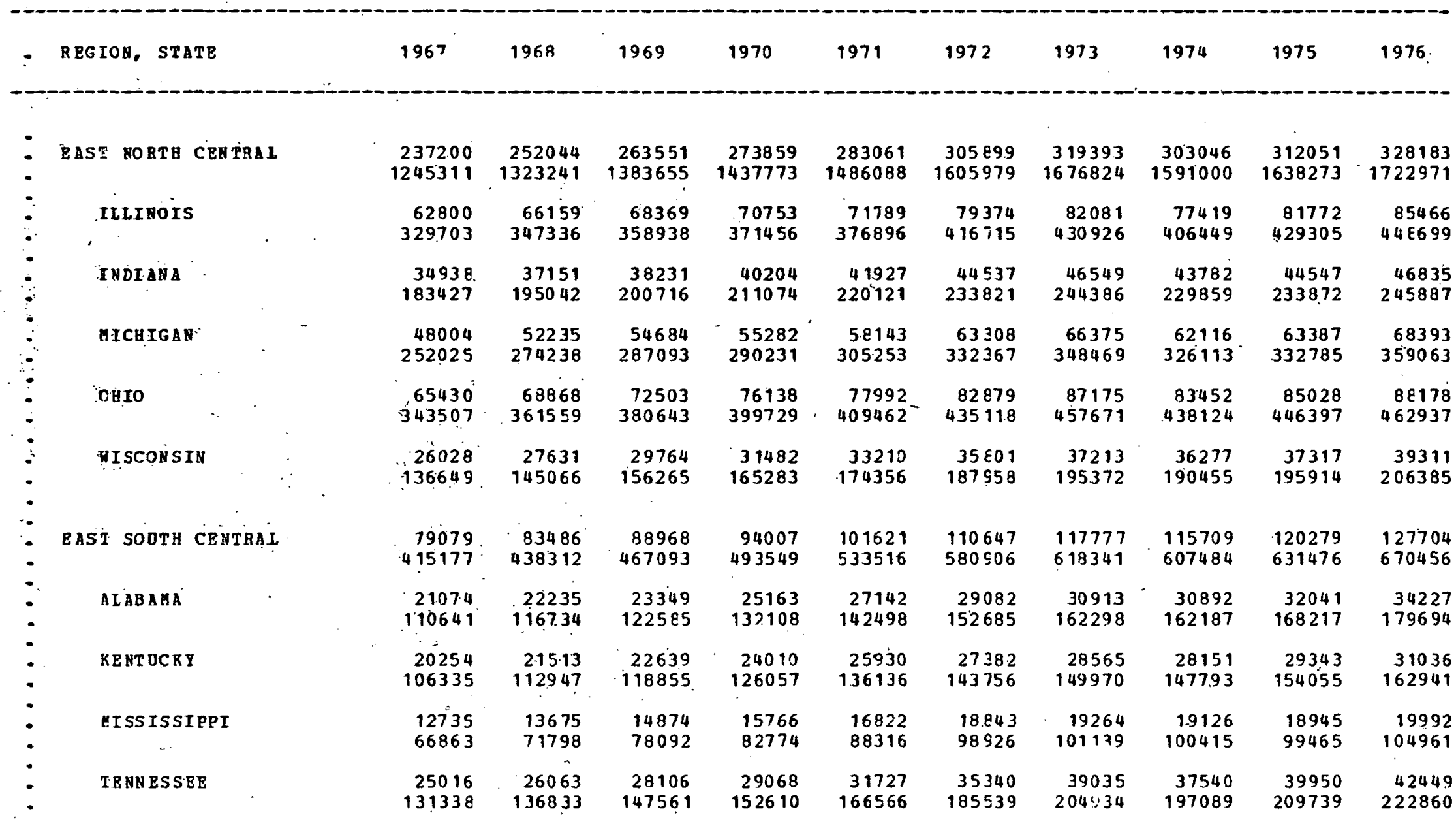


TABLF 5.5) -- HOUSEHOLD AOTO GASOLIAB AHD ENERG OSE, BY STATE, 1967-76

(IACLUDES STATE ANU LOCAL GOVERHART GOTO GASOLIHE USEI

(POURTE ID A SERIES OR PIVE TABLES)

GASOLINE USZ IN THOUSARDS OP BBL, POLLORBD BY ENBRGY USB IN BILLEONS OF BTU

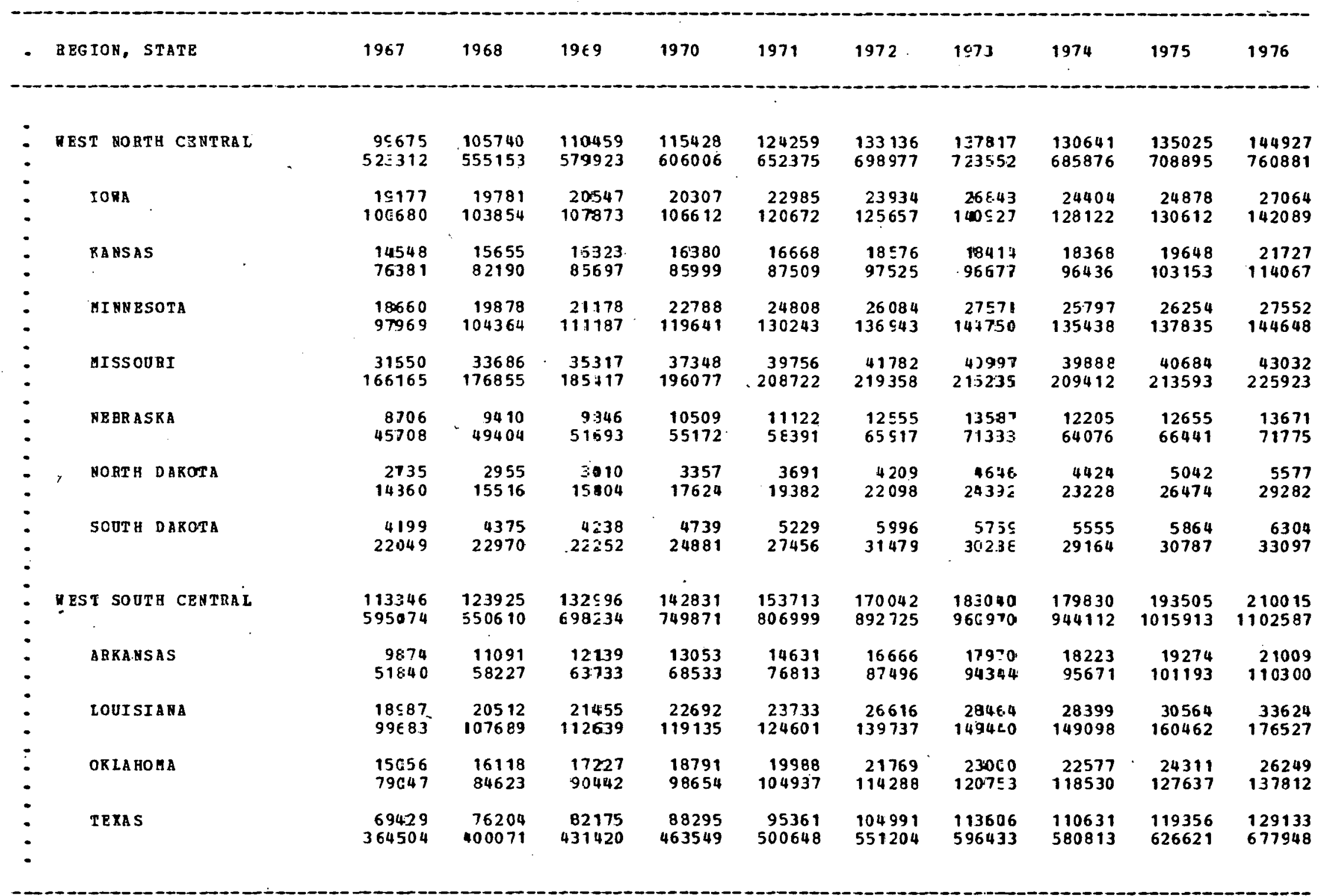


TABL 5.5E-- BOUSEgOLD AJTO GASOLINE AND ENEBGY USE, BY STATE, 1967-76

(INCLUDES STATE AND LCCAL GOVERHIENT AUTO GASOLIHE USE)

(LAST IN A SBBIES OP PIVE TABLES)

GASOLIRE DSE IN TGOUSA UDS OP BBL, POILORED BP ENERG OSE IN EILLIONS OP BTO

\begin{tabular}{|c|c|c|c|c|c|c|c|c|c|c|c|}
\hline - & REGIOH, STATE & 1967 & 1968 & 1969 & 1970 & 1971 & 1972 & 1973 & 1974 & 1975 & 1976 \\
\hline - & MOĐETAI & $\begin{array}{r}45828 \\
240611\end{array}$ & $\begin{array}{r}50361 \\
264409\end{array}$ & $\begin{array}{r}55736 \\
292626\end{array}$ & $\begin{array}{r}61446 \\
322604\end{array}$ & $\begin{array}{r}66712 \\
350253\end{array}$ & $\begin{array}{r}74977 \\
393642\end{array}$ & $\begin{array}{r}80763 \\
424015\end{array}$ & $\begin{array}{r}77024 \\
404393\end{array}$ & $\begin{array}{r}82290 \\
432042\end{array}$ & $\begin{array}{r}88248 \\
463314\end{array}$ \\
\hline - & ABIZONA & $\begin{array}{r}8160 \\
42840\end{array}$ & $\begin{array}{r}9263 \\
48631\end{array}$ & $\begin{array}{l}11124 \\
58401\end{array}$ & $\begin{array}{l}12230 \\
64208\end{array}$ & $\begin{array}{l}13443 \\
70578\end{array}$ & $\begin{array}{l}15594 \\
81869\end{array}$ & $\begin{array}{l}17379 \\
91244\end{array}$ & $\begin{array}{l}15858 \\
83256\end{array}$ & $\begin{array}{l}16830 \\
88360\end{array}$ & $\begin{array}{l}17811 \\
93508\end{array}$ \\
\hline- & COLORADO & $\begin{array}{l}11613 \\
60971\end{array}$ & $\begin{array}{l}12944 \\
67956\end{array}$ & $\begin{array}{l}13916 \\
73059\end{array}$ & $\begin{array}{l}15612 \\
81965\end{array}$ & $\begin{array}{l}16997 \\
89237\end{array}$ & $\begin{array}{l}19021 \\
99863\end{array}$ & $\begin{array}{r}19992 \\
104959\end{array}$ & $\begin{array}{r}18930 \\
99386\end{array}$ & $\begin{array}{r}20158 \\
105833\end{array}$ & $\begin{array}{r}20839 \\
109406\end{array}$ \\
\hline 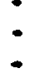 & IDAHO & $\begin{array}{r}4169 \\
21889\end{array}$ & $\begin{array}{r}4402 \\
23114\end{array}$ & $\begin{array}{r}4958 \\
26031\end{array}$ & $\begin{array}{r}5745 \\
30163\end{array}$ & $\begin{array}{r}5990 \\
31448\end{array}$ & $\begin{array}{r}6871 \\
36073\end{array}$ & $\begin{array}{r}6981 \\
36651\end{array}$ & $\begin{array}{r}6995 \\
36726\end{array}$ & $\begin{array}{r}7604 \\
39921\end{array}$ & $\begin{array}{r}8740 \\
45885\end{array}$ \\
\hline . & MOHTana- & $\begin{array}{r}386.3 \\
20283\end{array}$ & $\begin{array}{r}4241 \\
22265\end{array}$ & $\begin{array}{r}4502 \\
24163\end{array}$ & $\begin{array}{r}4778 \\
25087\end{array}$ & $\begin{array}{r}5182 \\
27207\end{array}$ & $\begin{array}{r}5581 \\
29302\end{array}$ & $\begin{array}{r}6430 \\
33758\end{array}$ & $\begin{array}{r}6198 \\
32542\end{array}$ & $\begin{array}{r}6039 \\
31709\end{array}$ & $\begin{array}{r}6985 \\
36674\end{array}$ \\
\hline & MEVADA & $\begin{array}{r}3581 \\
18801\end{array}$ & $\begin{array}{r}3987 \\
20936\end{array}$ & $\begin{array}{r}4164 \\
21862\end{array}$ & $\begin{array}{r}4832 \\
25368\end{array}$ & $\begin{array}{r}5182 \\
27208\end{array}$ & $\begin{array}{r}5 E 85 \\
30901\end{array}$ & $\begin{array}{r}6346 \\
33317\end{array}$ & $\begin{array}{r}6194 \\
32519\end{array}$ & $\begin{array}{r}6889 \\
36172\end{array}$ & $\begin{array}{r}7226 \\
37940\end{array}$ \\
\hline & NEW UEXICO & $\begin{array}{r}6361 \\
33395\end{array}$ & $\begin{array}{r}6698 \\
35164\end{array}$ & $\begin{array}{r}7312 \\
38389\end{array}$ & $\begin{array}{r}7779 \\
40840\end{array}$ & $\begin{array}{r}8797 \\
46185\end{array}$ & $\begin{array}{r}9601 \\
50405\end{array}$ & $\begin{array}{l}10488 \\
55062\end{array}$ & $\begin{array}{l}10122 \\
53145\end{array}$ & $\begin{array}{l}11010 \\
57804\end{array}$ & $\begin{array}{l}11921 \\
62585\end{array}$ \\
\hline & ОТАН & $\begin{array}{r}5481 \\
28778\end{array}$ & $\begin{array}{r}6029 \\
31656\end{array}$ & $\begin{array}{r}6616 \\
34736\end{array}$ & $\begin{array}{r}7229 \\
37956\end{array}$ & $\begin{array}{r}7783 \\
40864\end{array}$ & $\begin{array}{r}8646 \\
45393\end{array}$ & $\begin{array}{r}8955 \\
47014\end{array}$ & $\begin{array}{r}8690 \\
45623\end{array}$ & $\begin{array}{r}9106 \\
47807\end{array}$ & $\begin{array}{r}9594 \\
50369\end{array}$ \\
\hline 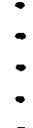 & RYOHING & $\begin{array}{r}2600 \\
13654\end{array}$ & $\begin{array}{r}2797 \\
14687\end{array}$ & $\begin{array}{r}3044 \\
15985\end{array}$ & $\begin{array}{r}3241 \\
17017\end{array}$ & $\begin{array}{r}3338 \\
17526\end{array}$ & $\begin{array}{r}3778 \\
19836\end{array}$ & $\begin{array}{r}4192 \\
22010\end{array}$ & $\begin{array}{r}4037 \\
21196\end{array}$ & $\begin{array}{r}4654 \\
24436\end{array}$ & $\begin{array}{r}5132 \\
26947\end{array}$ \\
\hline & PACIFIC & $\begin{array}{l}145531 \\
764046\end{array}$ & $\begin{array}{l}156658 \\
822461\end{array}$ & $\begin{array}{l}165499 \\
868879\end{array}$ & $\begin{array}{l}175865 \\
923299\end{array}$ & $\begin{array}{l}184606 \\
969191\end{array}$ & $\begin{array}{r}199742 \\
1048653\end{array}$ & $\begin{array}{r}208479 \\
1094530\end{array}$ & $\begin{array}{r}199454 \\
1047147\end{array}$ & $\begin{array}{r}210967 \\
1107587\end{array}$ & $\begin{array}{r}226416 \\
1188693\end{array}$ \\
\hline & ALASKA & $\begin{array}{r}852 \\
4473\end{array}$ & $\begin{array}{r}674 \\
3539\end{array}$ & $\begin{array}{r}864 \\
4538\end{array}$ & $\begin{array}{r}986 \\
5180\end{array}$ & $\begin{array}{l}.1214 \\
6375\end{array}$ & $\begin{array}{r}993 \\
5214\end{array}$ & $\begin{array}{l}1109 \\
5822\end{array}$ & $\begin{array}{l}1387 \\
7286\end{array}$ & $\begin{array}{r}1974 \\
10367\end{array}$ & $\begin{array}{r}2463 \\
12934\end{array}$ \\
\hline & CALIFORNIA & $\begin{array}{r}108019 \\
567103\end{array}$ & $\begin{array}{l}116875 \\
613595\end{array}$ & $\begin{array}{l}123398 \\
647843\end{array}$ & $\begin{array}{l}130957 \\
687526\end{array}$ & $\begin{array}{l}137189 \\
720243\end{array}$ & $\begin{array}{l}149930 \\
787135\end{array}$ & $\begin{array}{l}155845 \\
818190\end{array}$ & $\begin{array}{l}148490 \\
779574\end{array}$ & $\begin{array}{l}156863 \\
823534\end{array}$ & $\begin{array}{l}167690 \\
880372\end{array}$ \\
\hline & HARAII & $\begin{array}{r}2912 \\
15292\end{array}$ & $\begin{array}{r}3140 \\
16485\end{array}$ & $\begin{array}{r}3344 \\
17556\end{array}$ & $\begin{array}{r}3806 \\
19982\end{array}$ & $\begin{array}{r}4044 \\
21235\end{array}$ & $\begin{array}{r}4342 \\
22795\end{array}$ & $\begin{array}{r}4685 \\
24600\end{array}$ & $\begin{array}{r}4537 \\
23820\end{array}$ & $\begin{array}{r}4799 \\
25198\end{array}$ & $\begin{array}{r}5057 \\
26551\end{array}$ \\
\hline & OREGON & $\begin{array}{l}13919 \\
73074\end{array}$ & $\begin{array}{l}14546 \\
76370\end{array}$ & $\begin{array}{r}15361 \\
.80647\end{array}$ & $\begin{array}{l}16655 \\
97440\end{array}$ & $\begin{array}{l}18000 \\
94501\end{array}$ & $\begin{array}{r}19481 \\
102278\end{array}$ & $\begin{array}{r}20470 \\
107471\end{array}$ & $\begin{array}{r}19383 \\
101763\end{array}$ & $\begin{array}{r}20235 \\
106234\end{array}$ & $\begin{array}{r}22099 \\
116021\end{array}$ \\
\hline & MASEINGTON & $\begin{array}{r}19829 \\
104104\end{array}$ & $\begin{array}{r}21423 \\
112472\end{array}$ & $\begin{array}{r}22532 \\
118295\end{array}$ & $\begin{array}{r}23461 \\
123171\end{array}$ & $\begin{array}{r}24159 \\
126837\end{array}$ & $\begin{array}{r}24996 \\
131231\end{array}$ & $\begin{array}{r}26370 \\
138447\end{array}$ & $\begin{array}{r}25657 \\
134704\end{array}$ & $\begin{array}{r}27096 \\
142254\end{array}$ & $\begin{array}{r}29107 \\
152815\end{array}$ \\
\hline
\end{tabular}


TABLE 5.6A -- INTERCITY HOOSEHOLD AOTO GASOLINE \& ENERGY USE, BT STATE, 1972-76 (FERST IN A SERIES OF PIVB TABIES)

GASOLINE OSE IA THOOSA HDS OP BBL, POLLONED BY EHERGY USE IA BILLIONS OF BTO

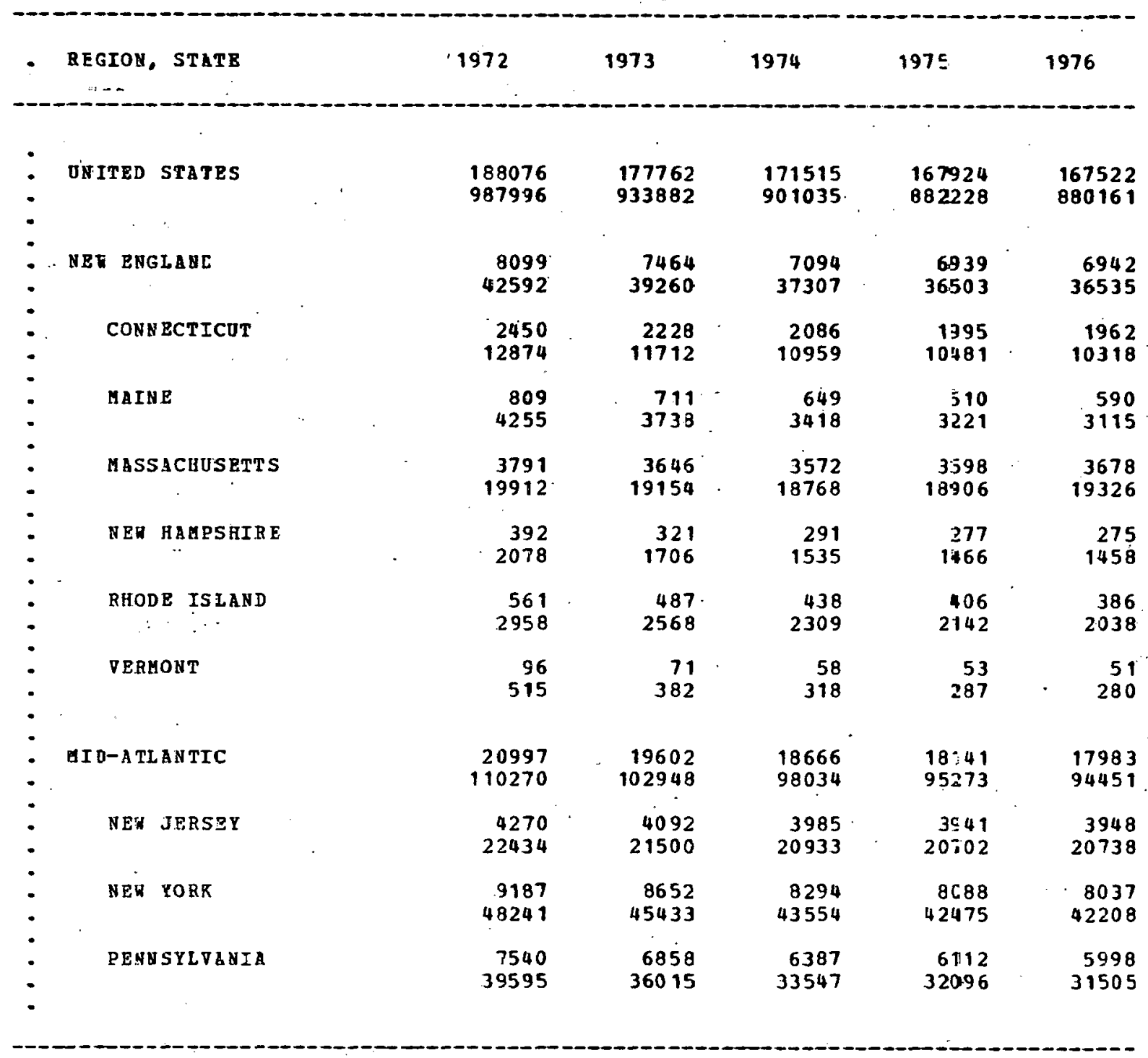

SOURCE: METHOD 394

DATA QUALITY: 2

NOTE: INTERCITI TRAYEL CONSTSTS OF TRIPS THAT REACH A POINT AT LEAST 100 MILES PROM THE ORI JTE OP THE TRIP AND THAT RETURN TO THE DRIGIN.

DATA POR YEARS BETREEN 9972 AND 1976 IS BASED ON INTERPCLATION. 
TABLE 5.6B -- INTERCITY HODSEHOLD AOTO GASOLINE \& ENERGI. OSE, BY STATE, 1972-76 (SECOND IE A SPRIES OP FIVE TABLES)

GASOLIAE JSE IN THOUSA NDS OP BBL, FOILORED BY ENERG USE IH BILLIONS OP BTO

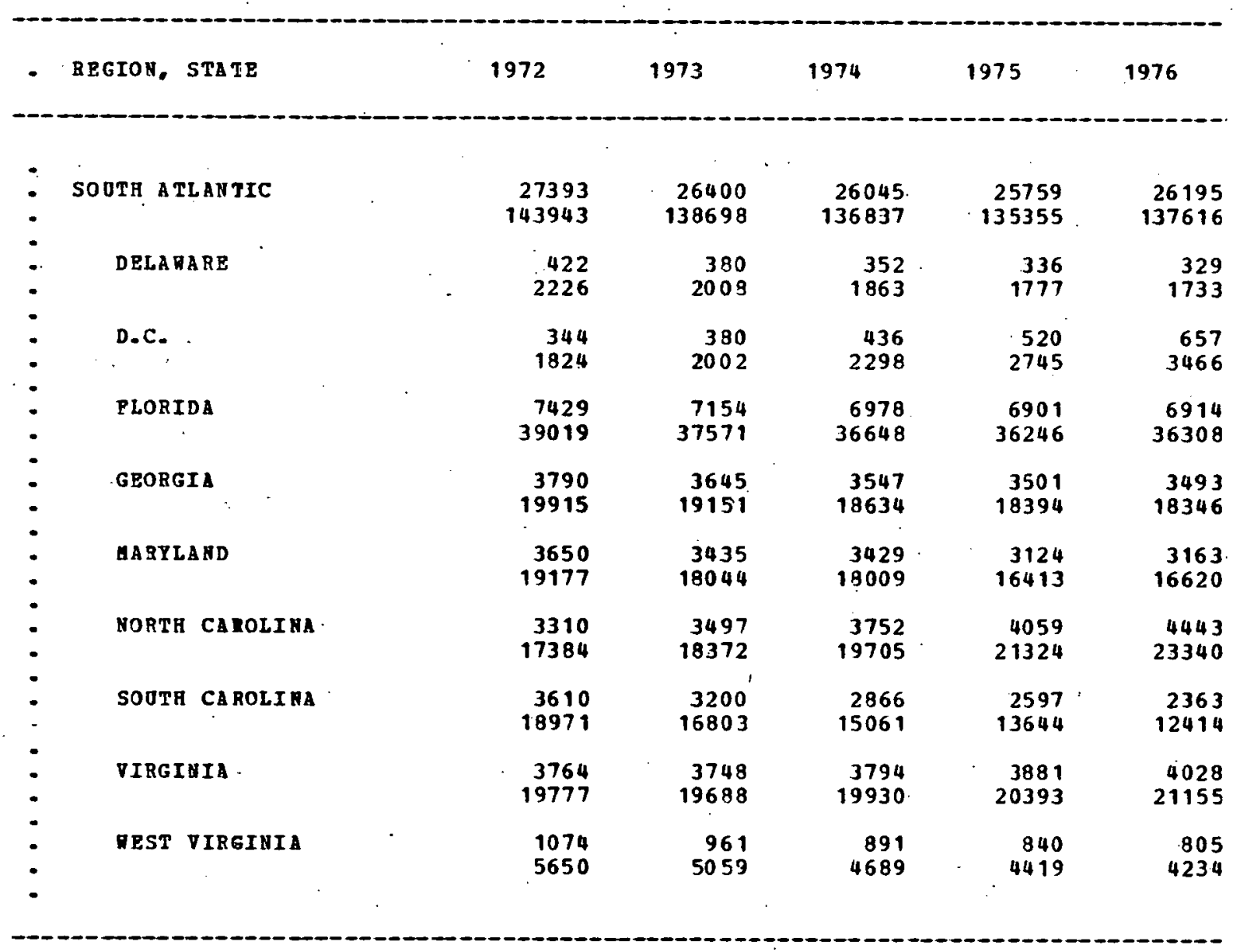

SOORCE: HETEOD 314

CATA QUALITY: 2

HOTE: INTERCITT TRAVEL CONSISTS OP TRIPS THAT BEACH A POIAT AT LEAST 100 MILES PBOK THE OBIGIN OF THE TRIP AND THAT RETURA TC THE ORIGIN.

DATA FOR YEABS BETUEEN 1972 AND 1976 IS BASED CN INTERPGLATION. 
TABLE 5.6C -- INTERCITY BOOSBHOLD AOTO GASOLIHE E BHERGY OSB, BY STATE, 1972-76 (THIRD IN A SBRIBS OF PIVE TABLES)

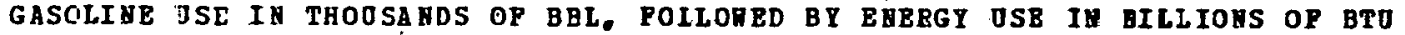

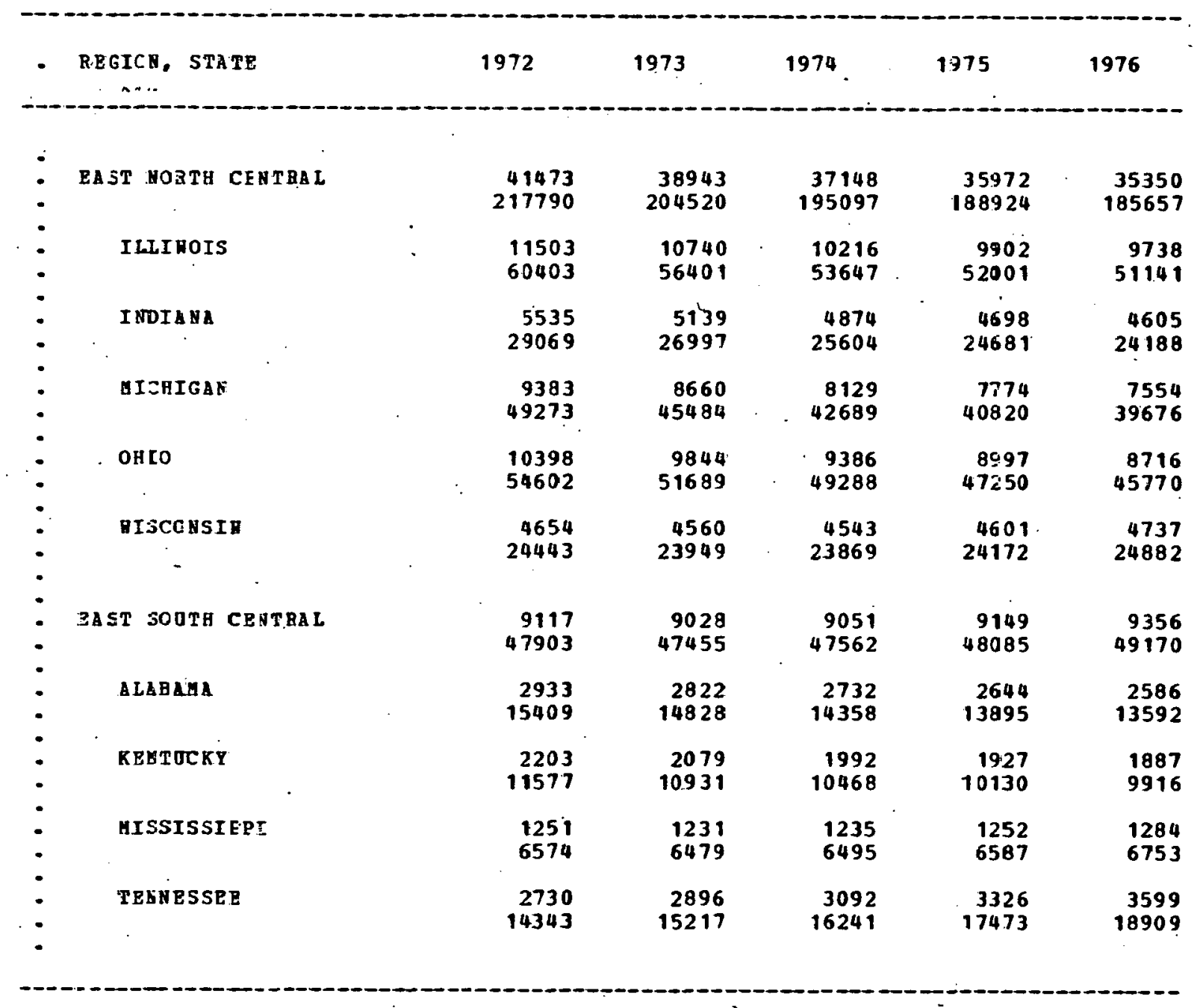

SOOECE: IETBOD 314

DATA GUALITY: 2

NOTE: INTERCITE TRAVEL CONSISTS OF TRIPS THAT REACH A POINT AT LRAST 100. HLES FROM TEE OBIGI OP THB TRIP AND TBAT BETORN TO TJE ORIGIA.

DATA POR IEARS BET勿EEN 1972 AND 1976 IS BASED OA IMTERPOLATCOA. 
TABLE 5.6D - INTERCITY BOOSBHOLD AOTO GASOLINE E ENERG USE, BY STATE, 1972-76 (FOURT IB A SBRIBS. OP FIVB TABLES)

GASOLINB OSE IR THOOSANDS OP BBL, FOILORED BY ENERG USE IN BILITONS OP BTO

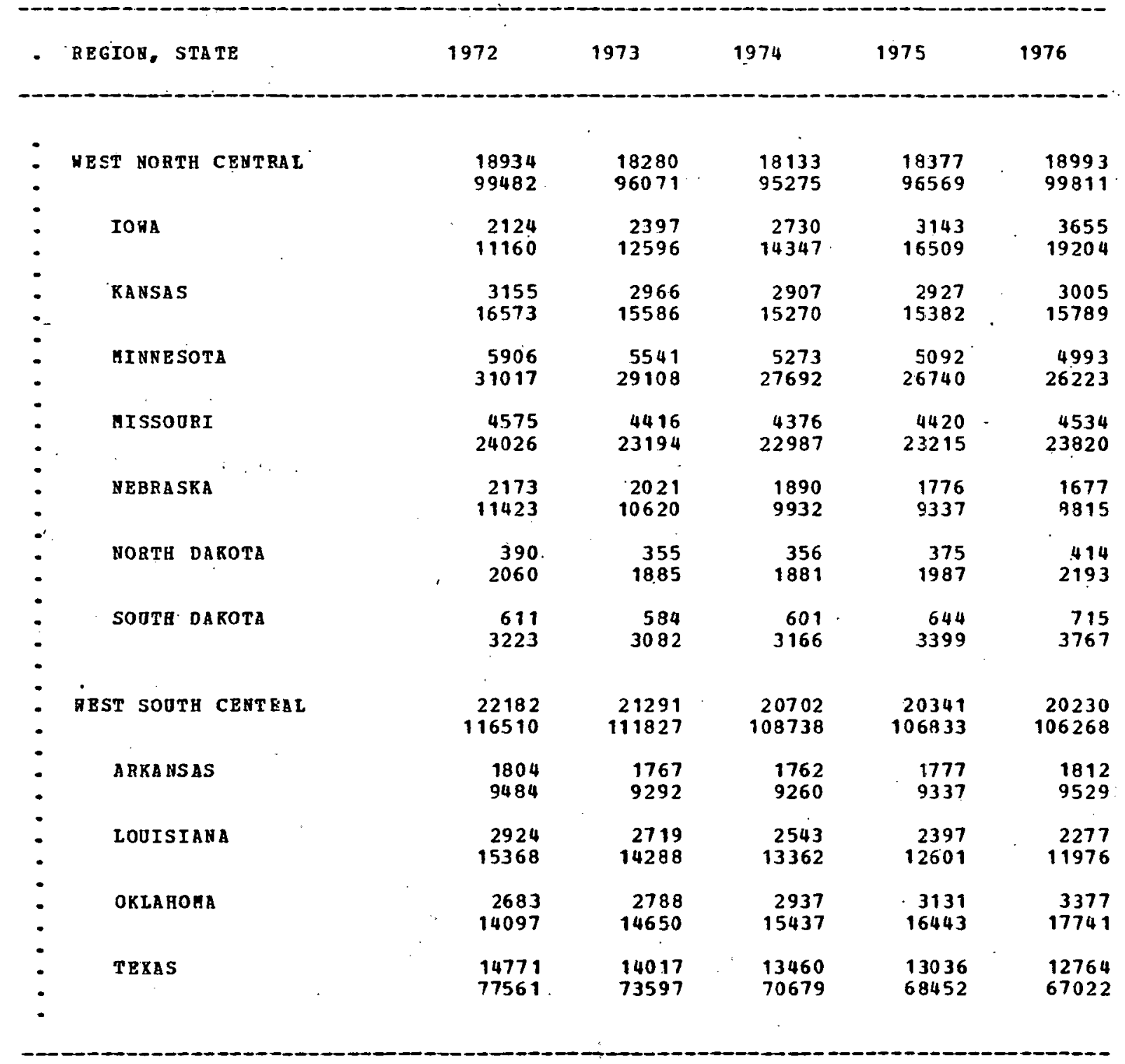

SOURCE: HETHOD 314

DATA QOALTTY: 2

NOTE: INTERCITY TBATEL CONSISTS OP TRIPS TAAT BEACH A POINT AT LEAST

100 MILES PBOA THE OBIGIN OF THE TRIP AND THAT RETORA TC THE

DATA POR YBARS BETREEN 1972 ABD 1976 IS BASBD O\& IRTERPCLATION. 
TABLE 5.6B -- INTEBCITY EOJSEHOLD AUTO GASOLINE 8 ENBBGY USF, BY STATB, 1972-76 (FIPTA IN A SRRIBS OP PIVE TABLES)

GASOEINE OSE IB THOUSANDS OP BBL, FOLLOWED BI ENBRG USE IN BILLIOHS OP BTO

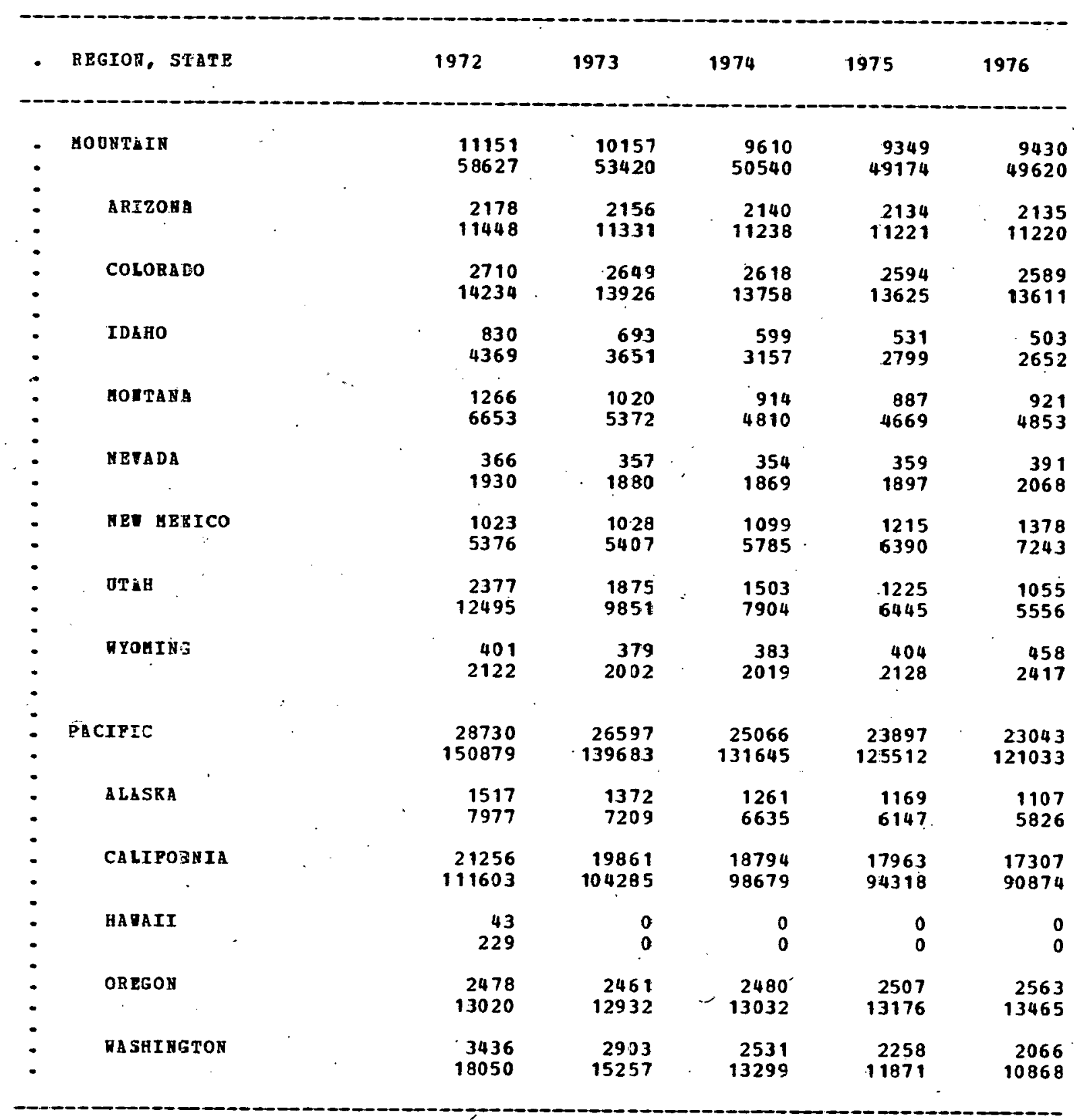


TABLE 5.7A - IRTERCITY HOOSEHOLD AOTO GASOLIHE E BNERGT OSB, BY STATE BY TRI 2 POBPOSE, 1976 (FIRST IN A SBBTES OP 5 TABLES)

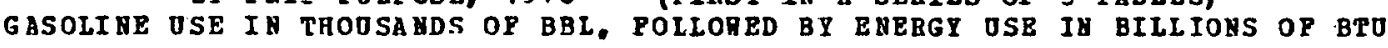

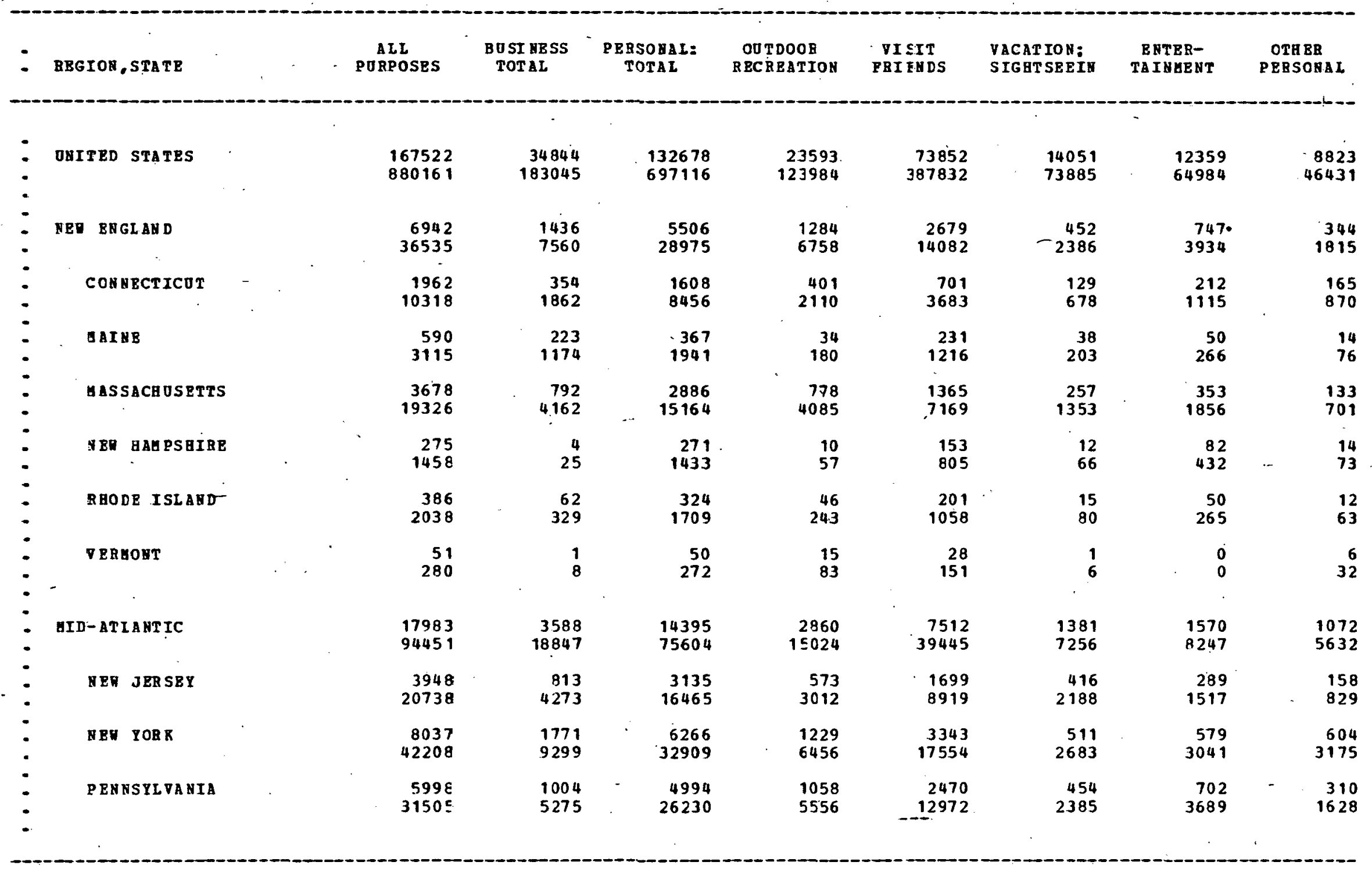

SOU RCE: METBOD 315

DATA QOALITY $=2$

SOTE: I NTERCITY TRATEL CONSISTS OP TRIPS THAT BBACH A POIRT AT IEAST 100 MILES FRON THE OBIGIN OF THE TRIP AHD THAT RETORN TO TBE OEIGIN. 
TABLE 5.7B - INTERCITY HOJSEHOLD AOTO GASOLINE E BHBR.GY USE, $3 Y$ STATE GASOLIIE USE IN THOOSA HDS OF BBL, POLLOWBD BI ENERG OSE IA BILLIONS OF BTU

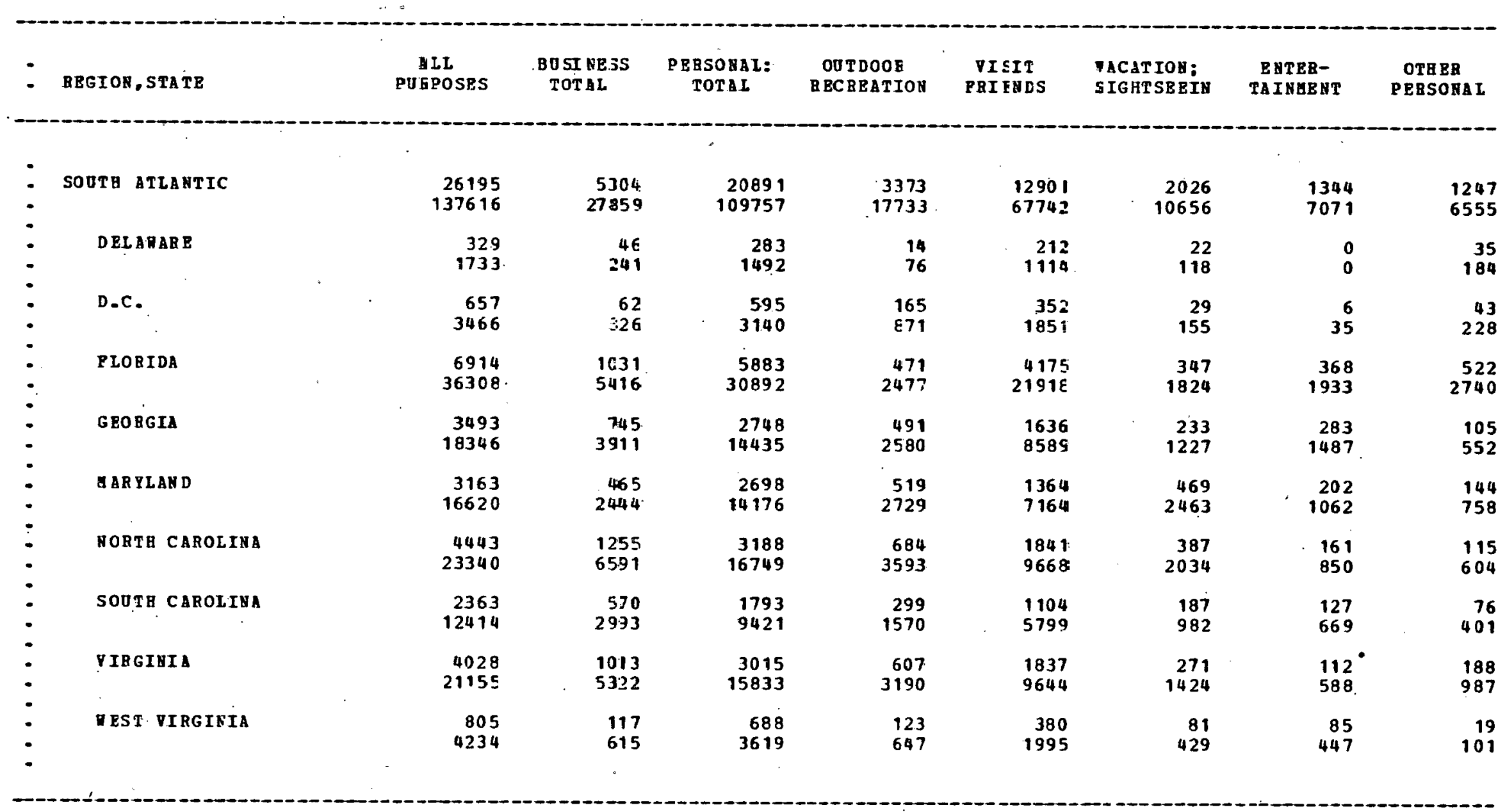

SOURCE: DETHOD 315 DATA QULLITY: 2

NOTB: I NTERCITY TRAVEL COHSESTS OE TRIPS THAT REACE A POIHT AT LEAST 100 ILES FROA THE OBIGIY OP THE TRIP AND THET EETORN TO THE OBIGIN. 
TABLE 5.7C -- INTERCITY HOUSBHOLD AOTO GASOLINE E RNERGY USE, BT STATE BY TBIP POBPOSE, 1976 (THIRD IN A SERIES OP 5 TABLES)

FASOLIAE OSE IN THOOSA NDS OP BBL, FOILORED BY RNERG USE IN BILLIOUS OP BTU

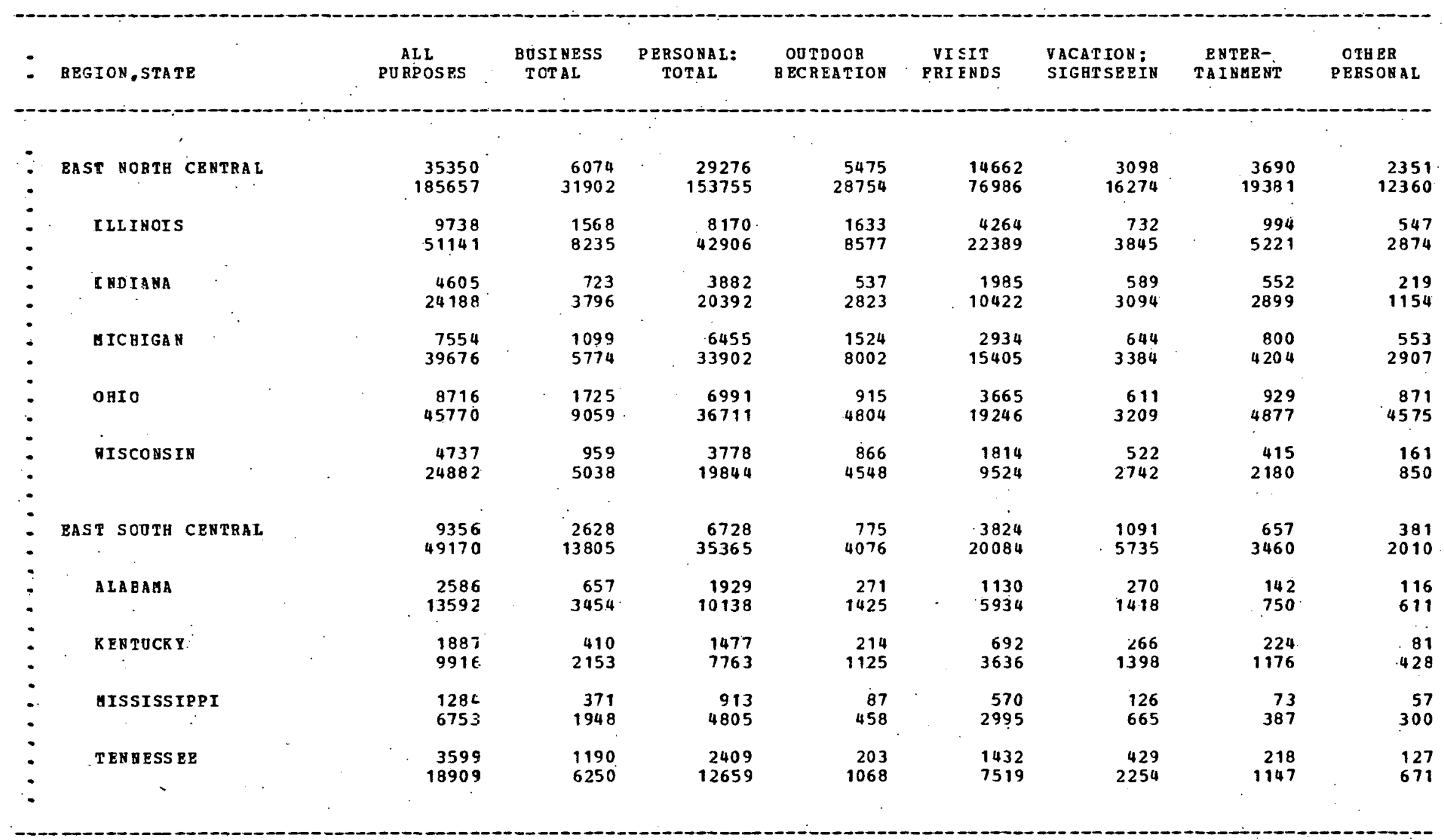

SOBRCE: AETHOD 315

DATA QUALITY: 2

NOTE: INTERCITY TRAVEL COHSISTS OP TRIPS THAT REACH A POINT AT LEAST 100 UILES FROA TEE OBIGIN OF THE TBIP AND TGAT BETURN TO THE ORIGIN. 
TABLE 5.7D - INTERCETY HOJSEHOLD AOTO GASOLIHE E BHEBGT OSE, BT STATE BI ERIP POBPOSE, 1975 (FOORTE IN A SERIES OP 5 TAELISS)

GASCLIYE USE IN THOUSANBS CP 3BL, POLLOHBD BY ENERGY OSB IH BILEIONS OP BTO

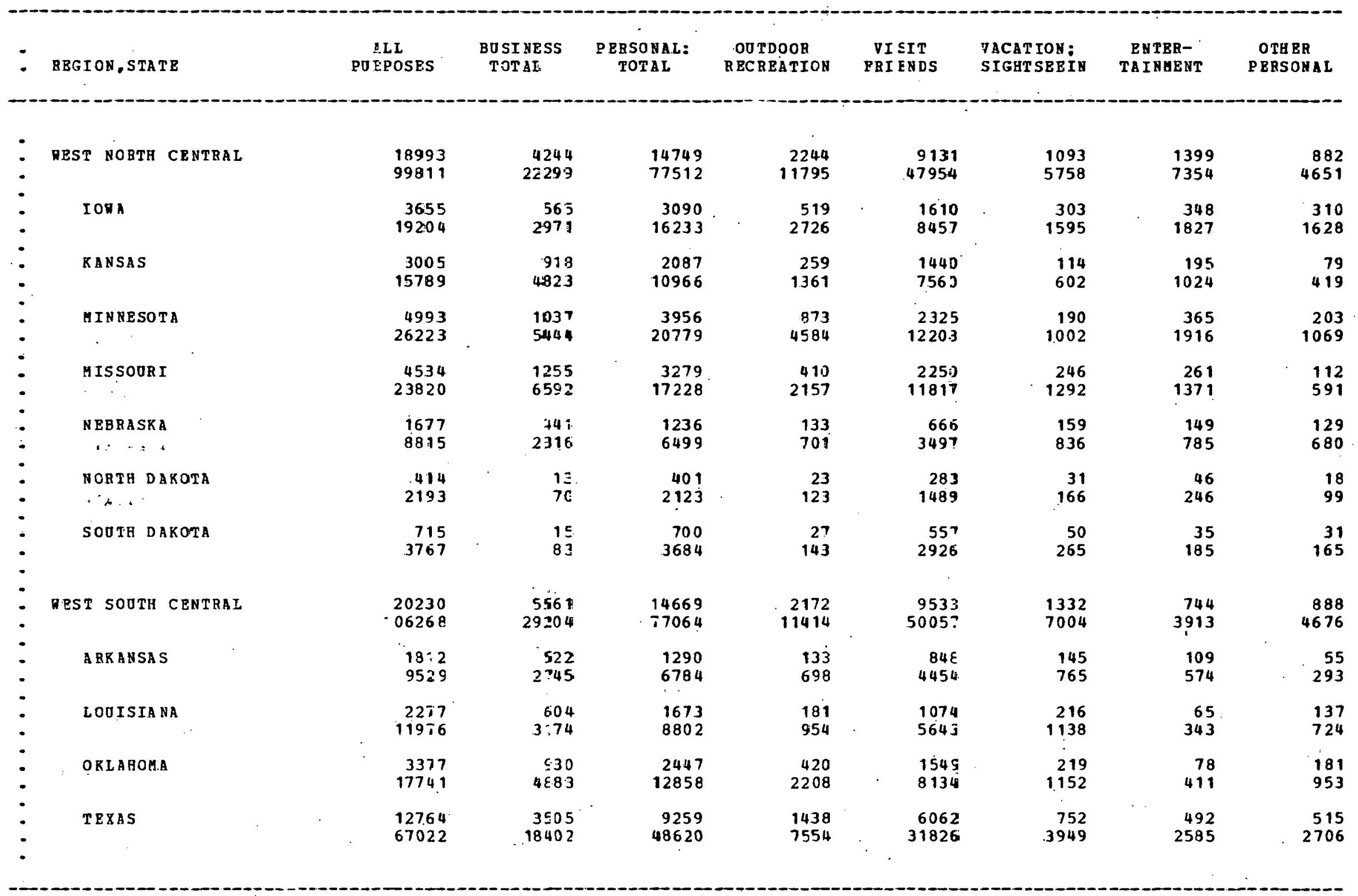

SOURCE: AETHOD 315 DATA 2UALTT: 2

NOTE: I ICITY TRAVE CONSTSTS OF TRIPS THAT BEACA A POINT AT LEAST 1 IILES FRON THR ORIGI OF THE TRIP AND THA TETORN TO THE

OEIGIN. 
TABLE 5.7E - INTERCITY HOOSBHOLD ATTO GASOLINE E ENERGI OSE, BI STATE

BY TBIP POFPOSE, 1976. (RIPTB IV SERIES OP 5 TABLES)

GASOLIYE USE IB THOUSANDS OP BBL, POILONED BY ENERGY OSE IN BILLIONS OP BTO

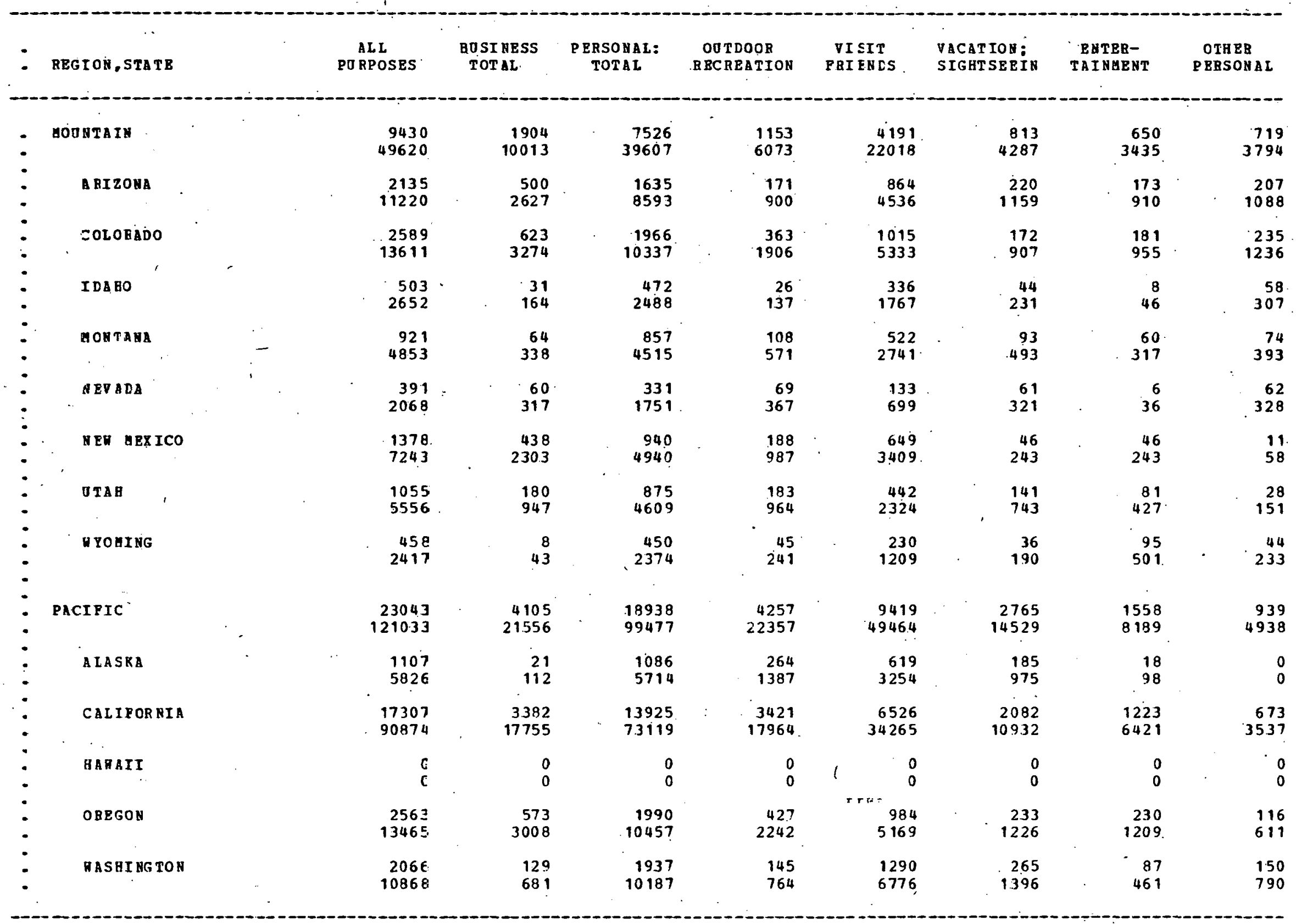


2ABLE 5. 8A -- IRTEREITY HOUSBHOLD AOTO GASOLINE AND EHERGY OSB.

BI PAIILY INCOME EY TRIP PORPOSE, 1972 AND 1976

(PIRST OP TRO TABLES)

POLLORED $3 Y$ ENBRG USE IN BILLIONS OP BTO

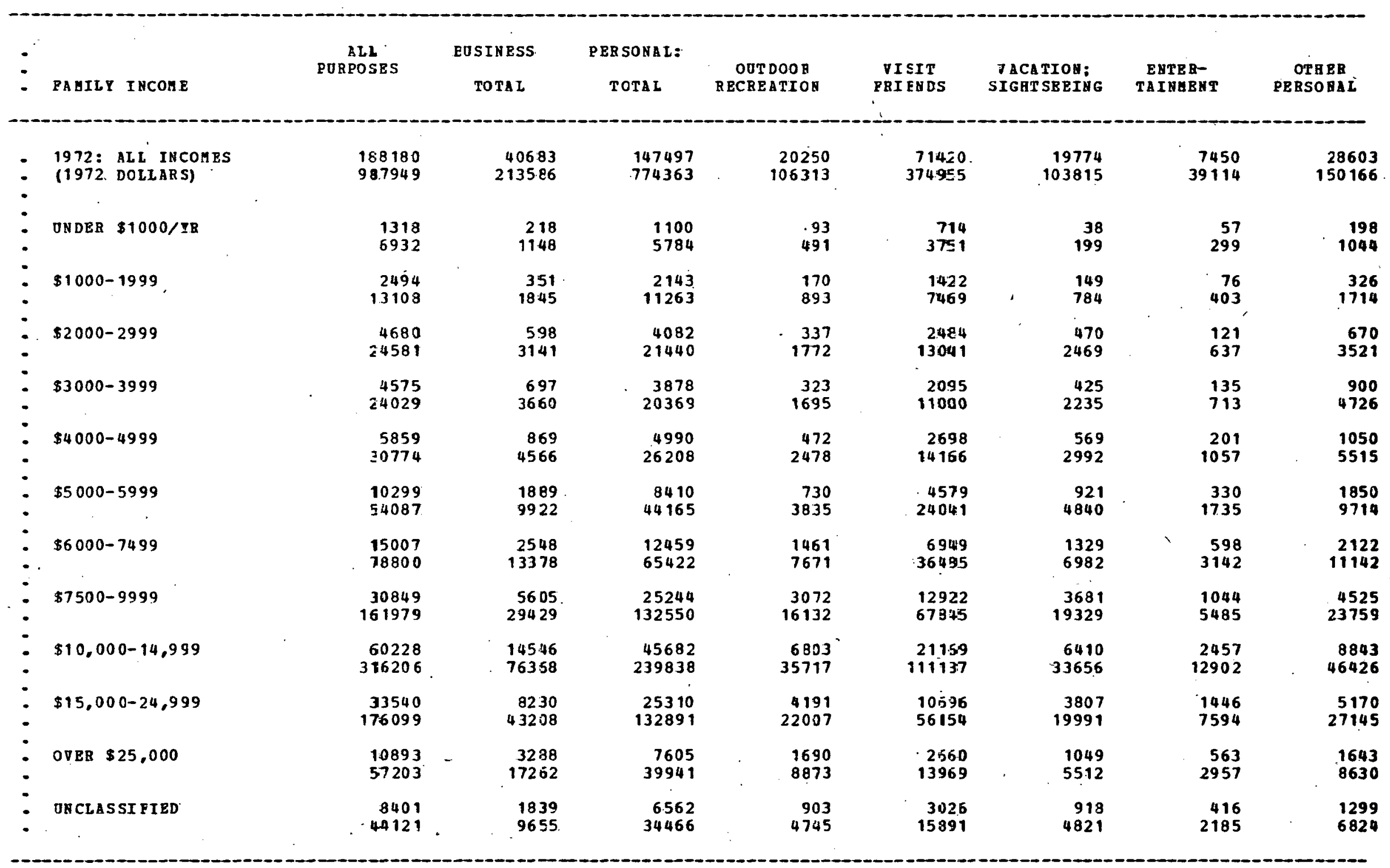

SOORCE: GETHOD 315

DATA QUALITY: 2

MOTE: I ICITY TRAVRL COUSISTS OP TRIPS FHAT REACH E POIBT AT IEAST

1 IILES PROA THE ORIGIN OP THE TREP AND THAT RETORH TO THE ORIGIN. IRCONES ARE EXPRESSED IE 1972 DOLLARS. 
TABLE 5. BB -- IHTERCITY HOOSEBOLD AOTO GASOLIUE AED ENERGY USE.

BY PAUIL IACOHE BY TRIP PURPOSE, 1972 ABD 1976

(SECOND.OP TRO TABIES)

GA SOLINE OSB IN THODSARDS OP BARRBLS

FOLLONED BY ENERGY USE IN BILLICHS. OP BTO

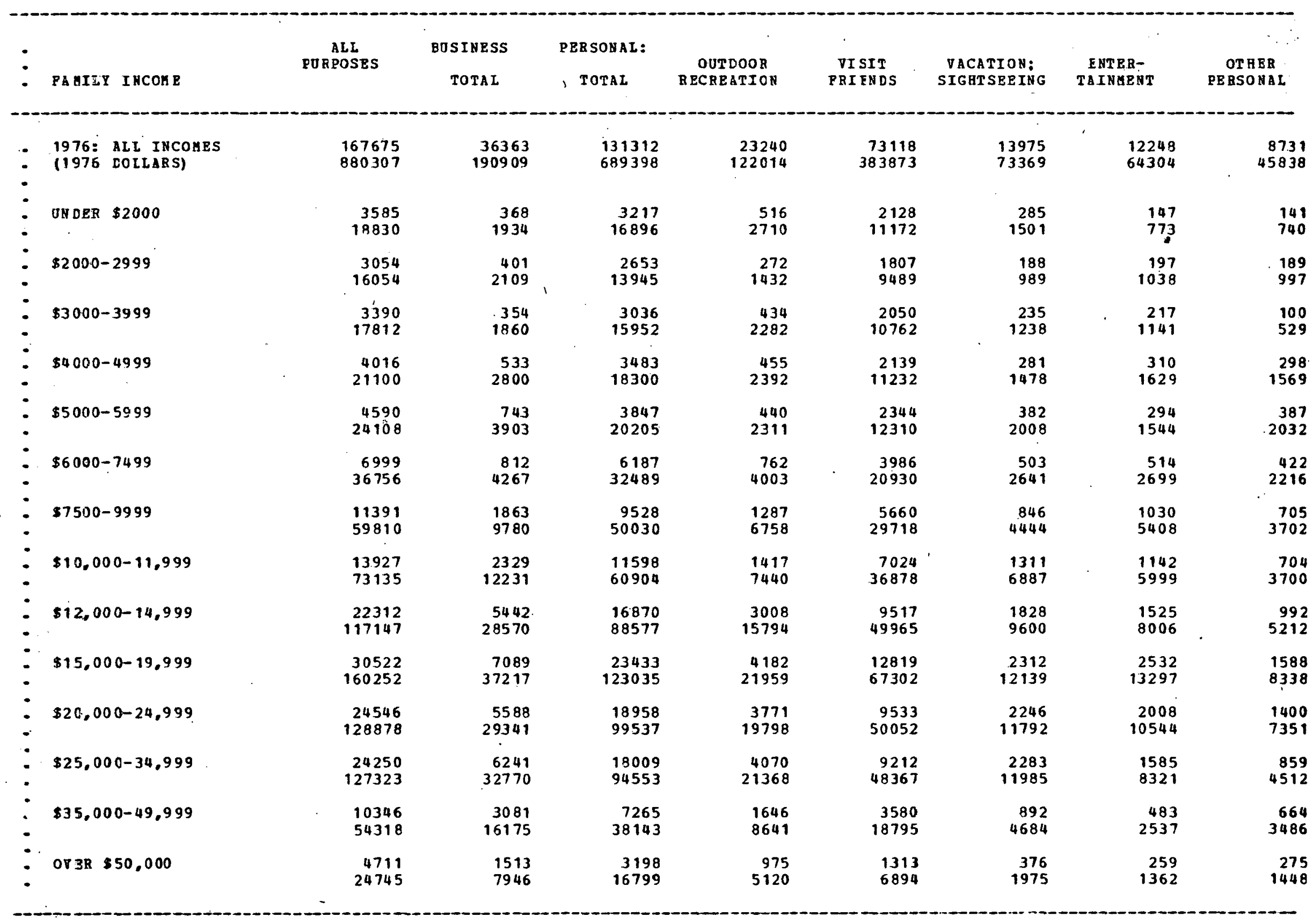


5 TABLE 5. 9A -- IMTEZCITY HDOSEgOLD AOTO GASOLINE AND BitBRG OSE。

BY FABI:I I YCOSB BY BEGIOB, 1972 A DD 1976

(PIRST OP THO TABLES)

GASQLIME USB IN THODSANDS OP BARRBLS

FOLLORED BY BHERGY OSB IN BILLIOHS OP BTO

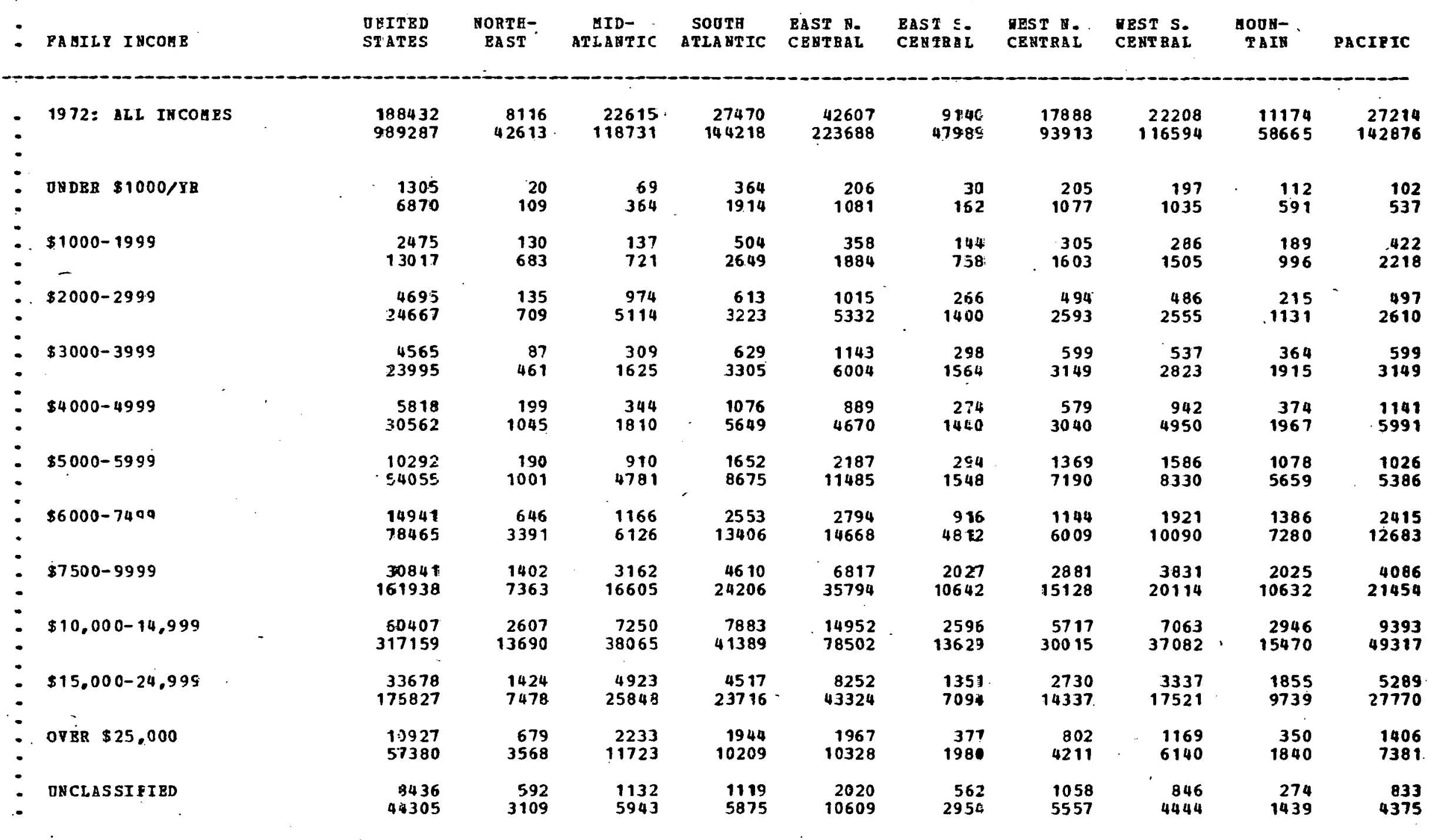

SCUBCE: HETBOD 315

DATA QOALITI: 2

NOTZ: INTERCITY TRAVEL CONSISTS OP TBIES THAT REACH A POINT AT LBAST

FILES PROA THE ORIGIN OF TRE T IIP AND THAT RETORN TO TEE OBIGIH.

INCOAB CATEGORIES ARE EXFRESSED IN 1972 DOLAARS. 
TABIE 5.9B -- INTEBCITY HOUSBHOLD AUTO GASOLINE AND ENEBGY USB,

BY PABILY INCOME BY BEGIOH, 1972 AND 1976

(SECOND OP TRO TABLES)

GASOLINE USE IN THOOSA MDS OP BARRELS

POL LORED BY. ENERGY OSE IN BILLIONS OF BTC

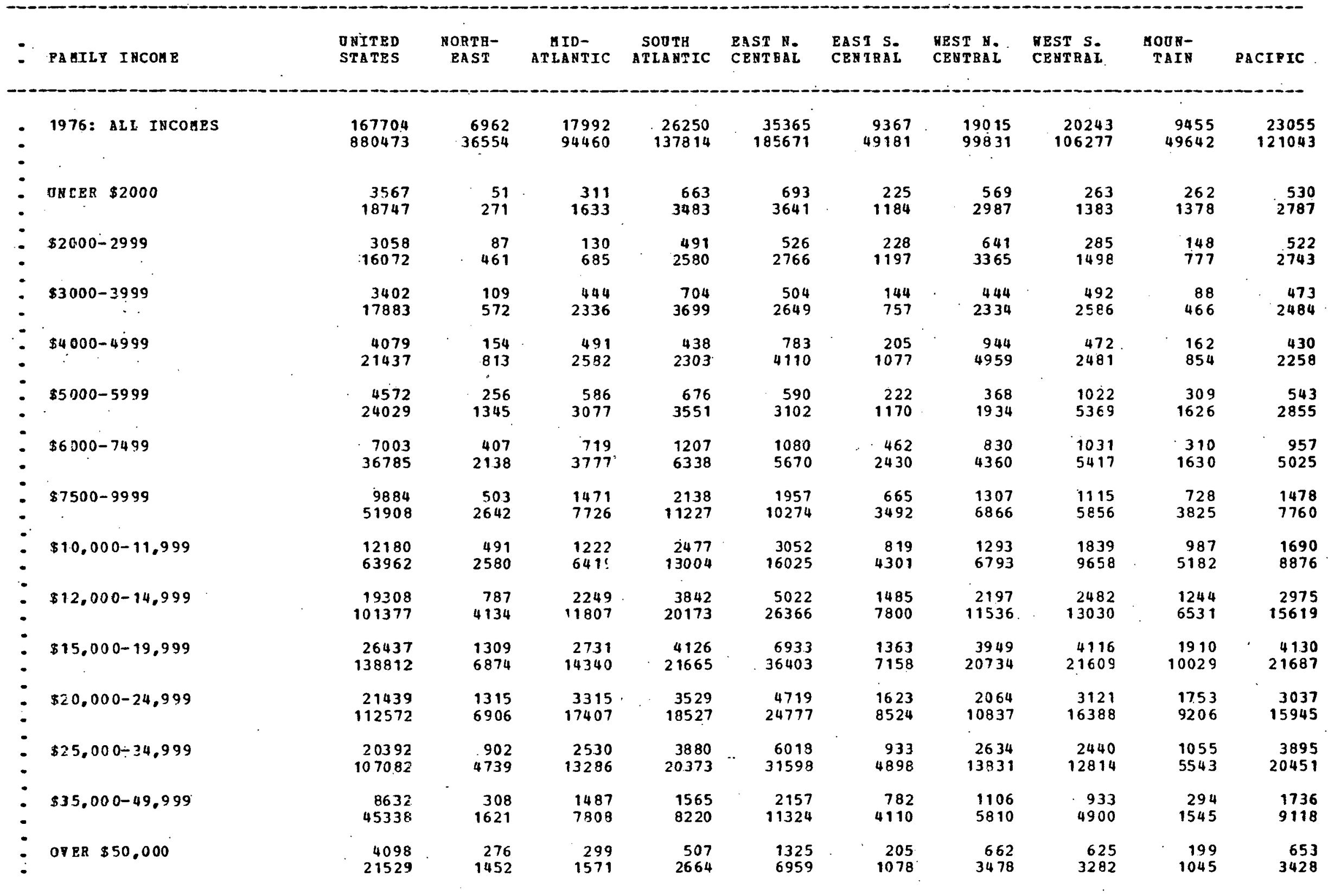


TABLE 5.10A - CORHLTER AUTO GASOLIHE AND EREBG DSB, BY STATE, 1975 (PIRST IV A SBRIES OF FIVE TABLES)

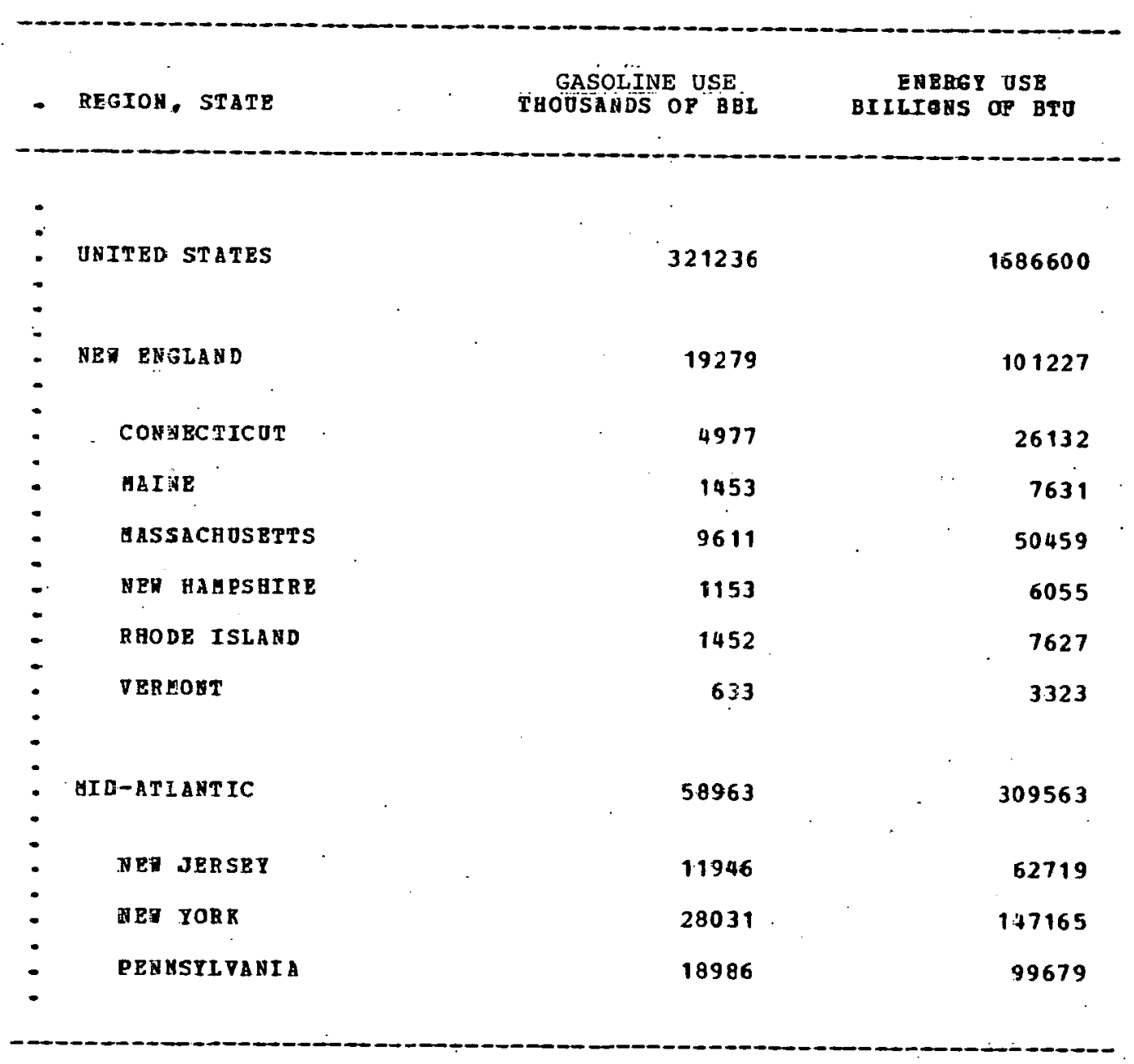


TABLE 5.10B - COAGUTER AUTO GASOLINE AND BNEGGY USE, BY STATE, 1975 (SECOND IN A SERIES OF PIVE TABLES)

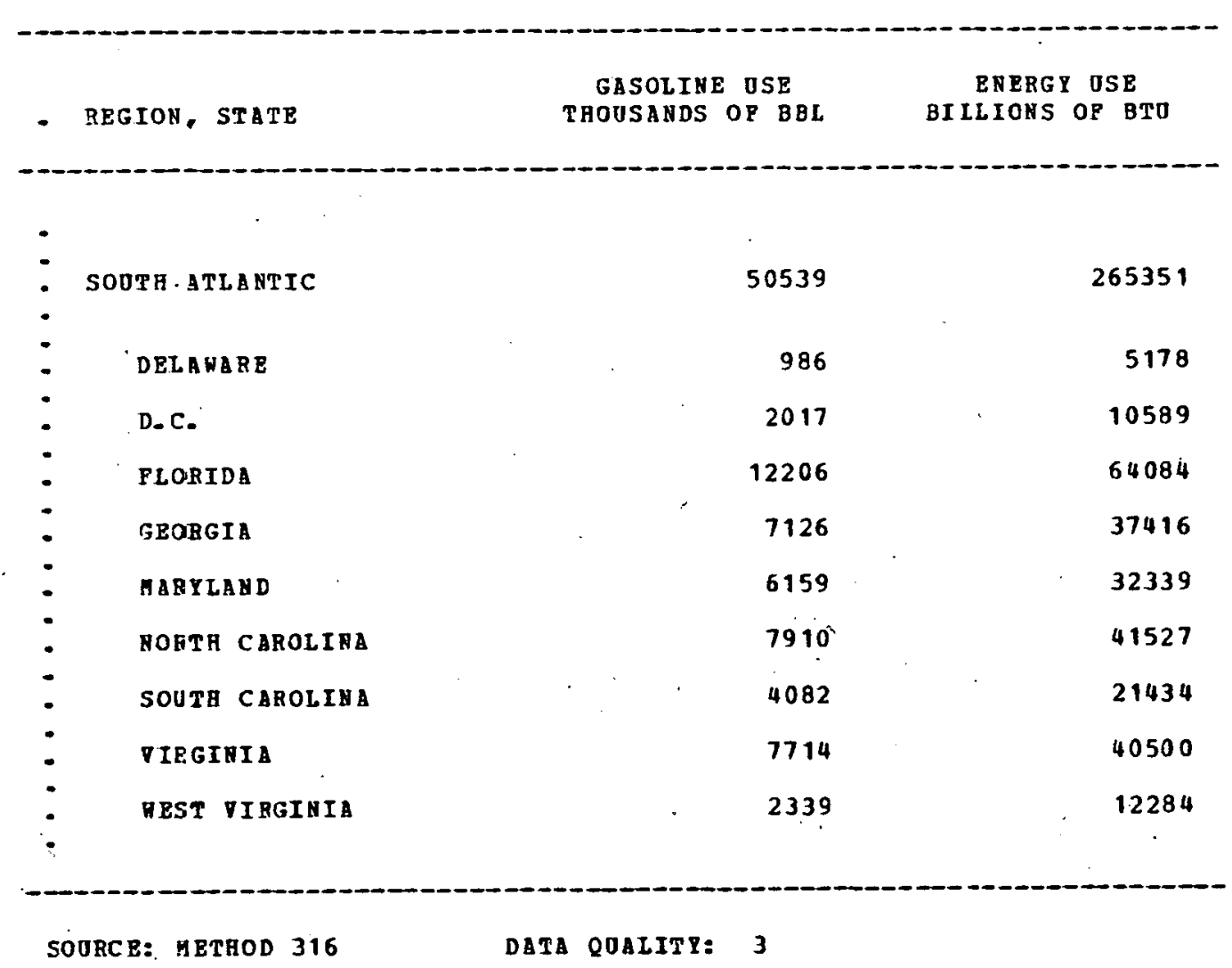


TABLB 5.10C - COAUUTER AUTO GASOLIHE AND ENERGT OSB, BI STATE, 1975 (THIRD IN A SERIBS OP PIVB TABLES)

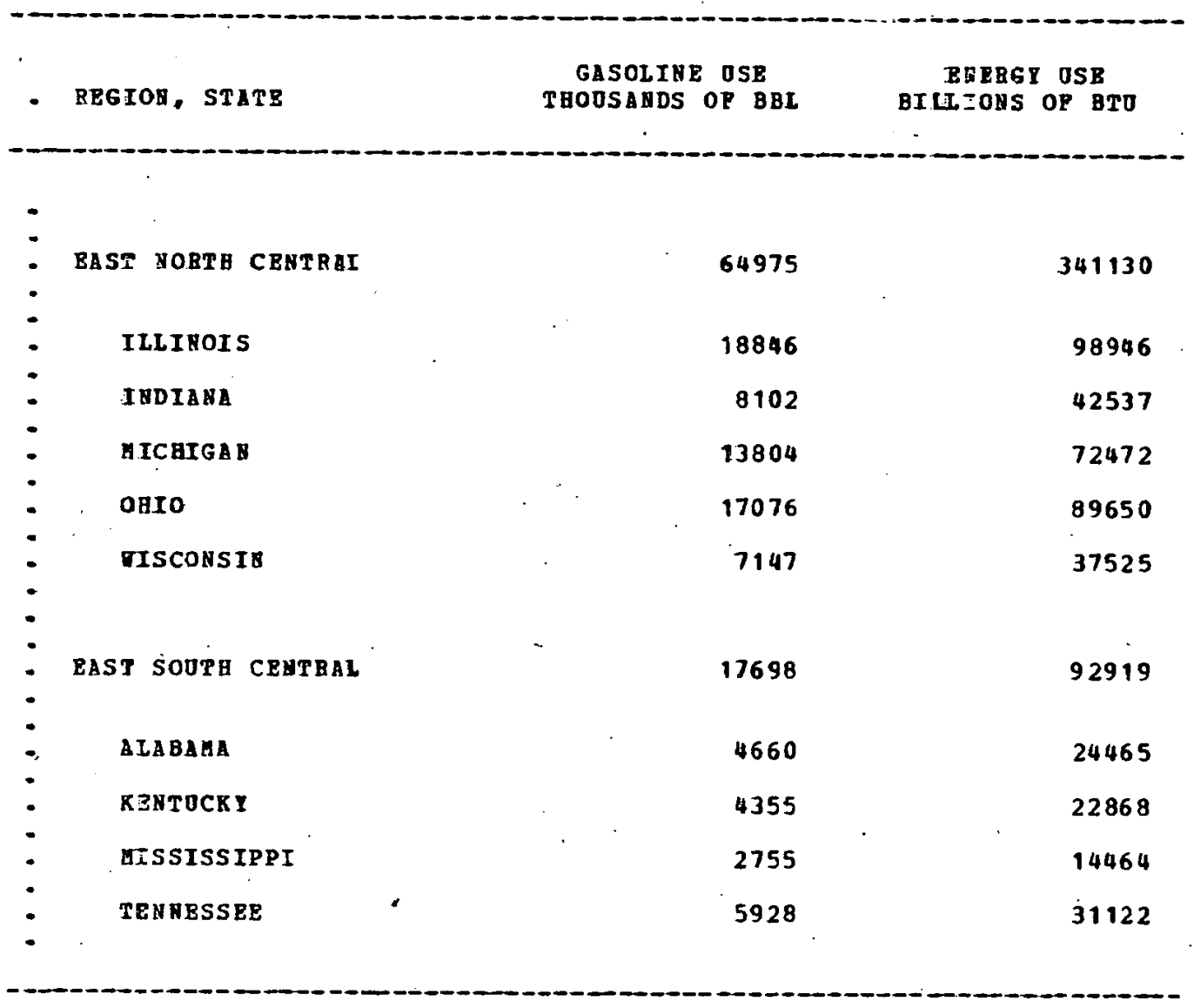


TABLE 5.10D -- COM MOTER AOTO GASOLINE AND RNERGY USE, BY STATE, 1975 (EOURTH IN SERIES OP PIVE TABLES)

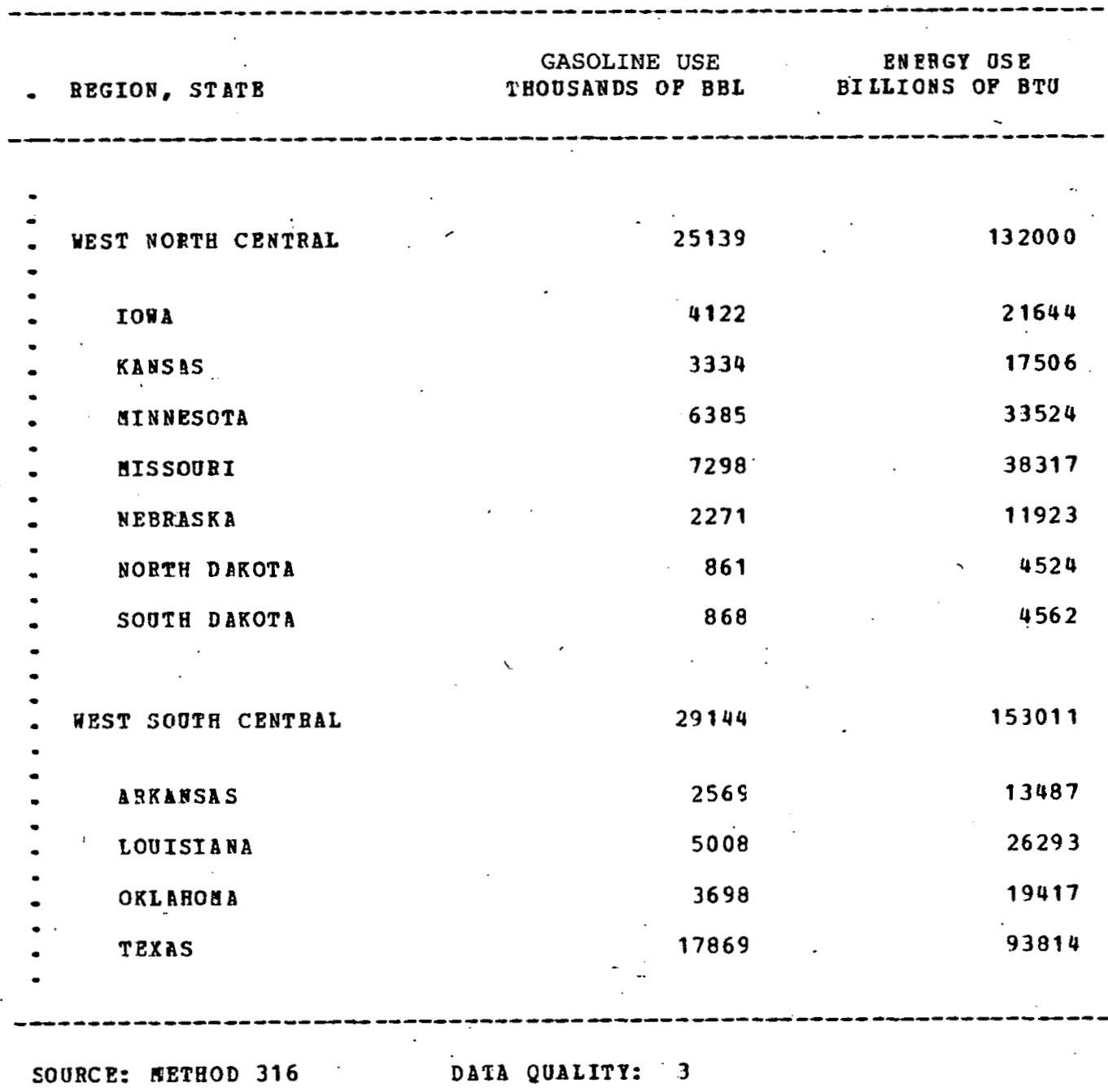


TABLE 5.10E - COBOTIER AOTJ GASOLIBE ABD EREBGY OSE, BY STATB, 1975

(IA.ST IN A SBRIES OP PIVB TABLBS)

$+\infty$

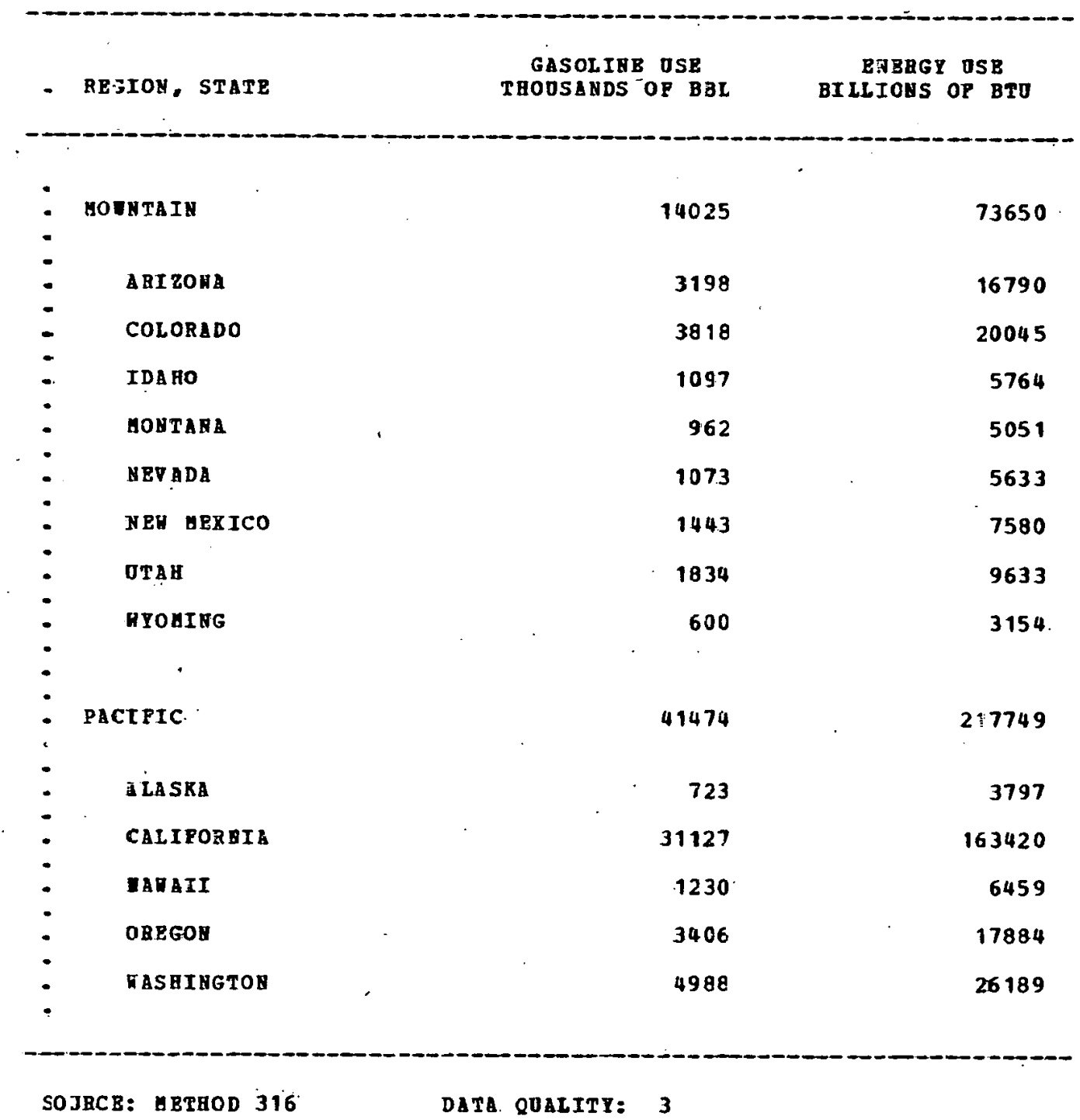




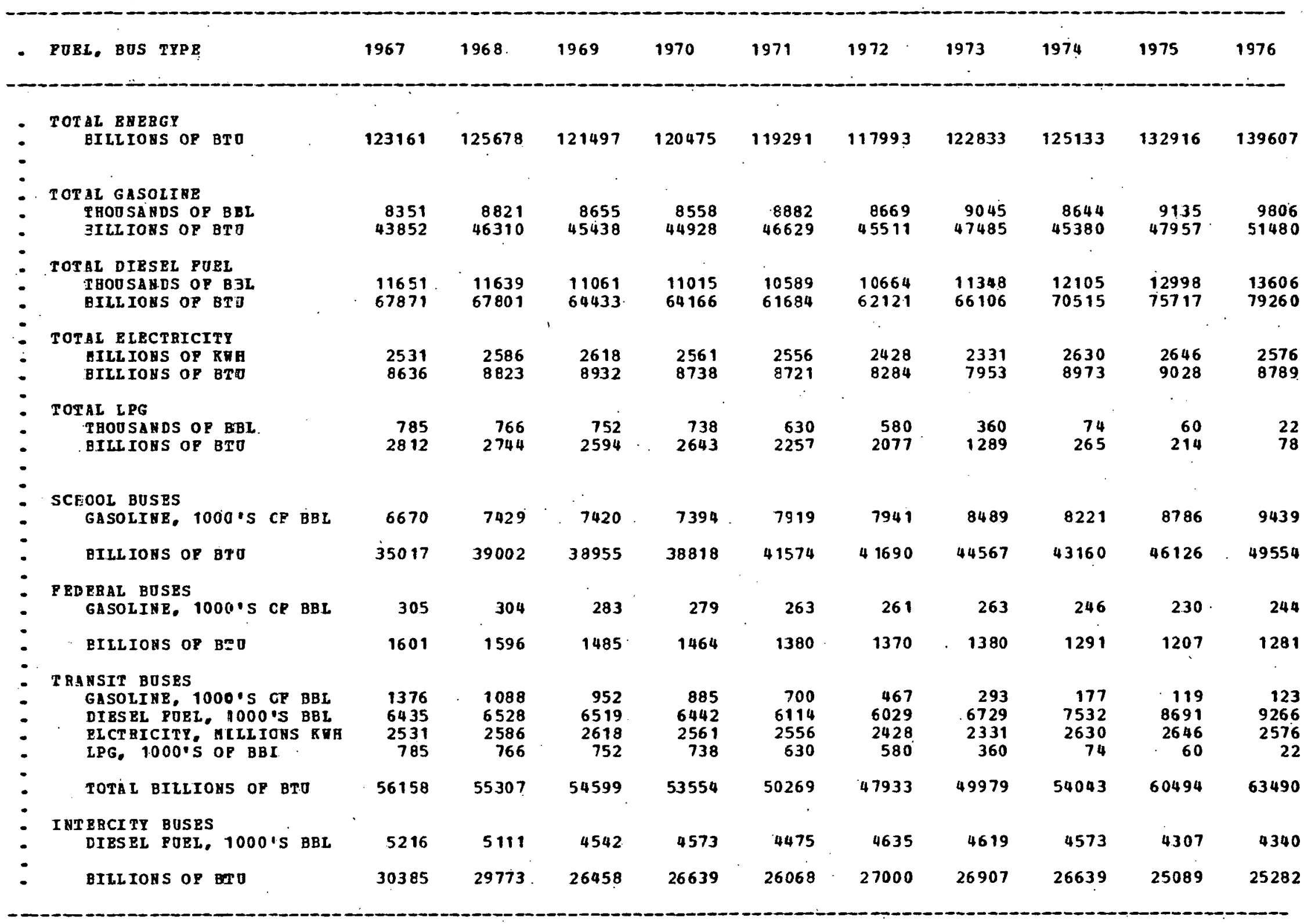


TABL3 6.2A - SCHOOL EES GASOLIBE AHD BHERGY COYSUAPTIOH, BZ STATR, 1967-76

(PIRST IN A SBIBS OP 5 TABLES)

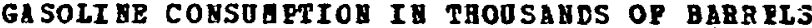

POLLONED ET ENEBGY COHSUAPTIOH IB BILLIOAS OP 330

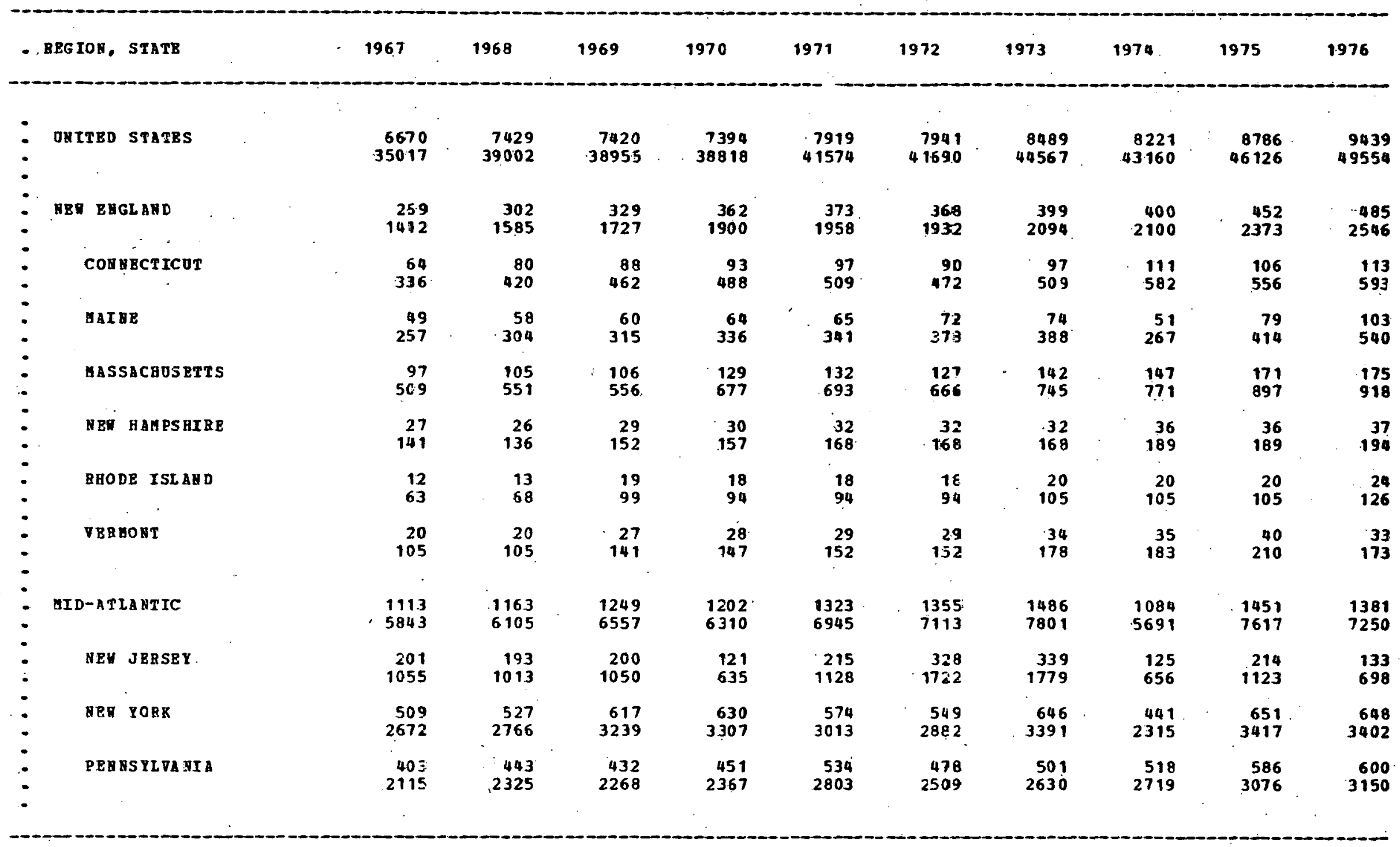


TABLE 6.2B - SCHOOL BOS GASOLIHE AND ENERGY CONSUMPTION, BY STATE, 1967-76 (SECORD IA A SERIES OP 5 TABLBS)

GA SOLI AE CONSUEPTION I THOOSANDS OP BARRELS

POLLORED EY BNERGY CORSULPTION IN BILLIONS OP BTU

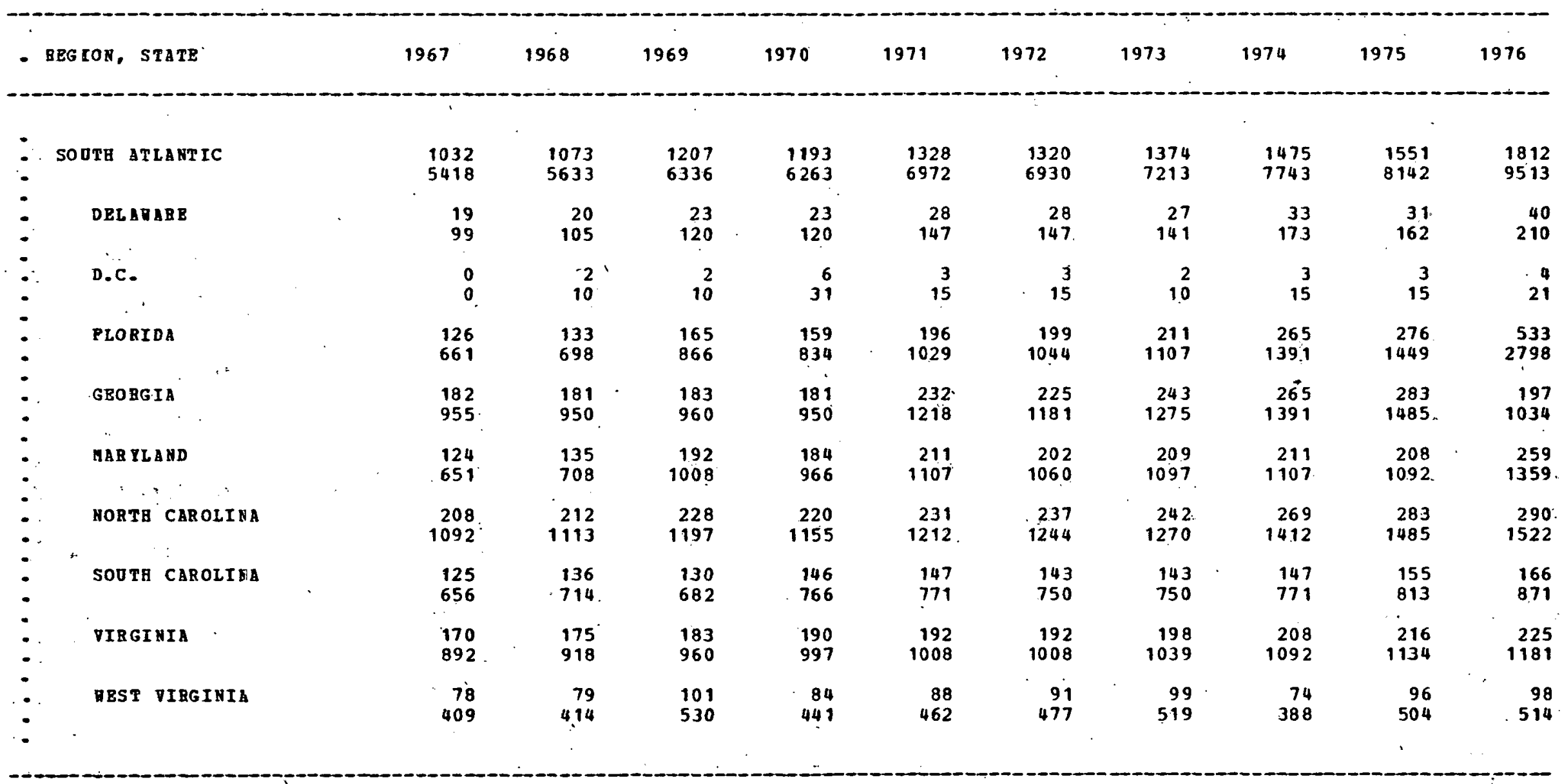

SOORCE: IFTEOD 321

LATA QOALITY: 2 
TABLE 6.2C -- SCHOOL BOS GASOLIHE AND ENBEGI CONSUAPTIOH, BY STATE, 1967-76

(TIIBD IA A SBRIES OP 5 TABLBS)

GBSOLT NE CONSOHETION IN THOUSANDS OP BARRELS

POLLORED BT ENERGY CONSUAPTION IN BILLIONS OF BTO

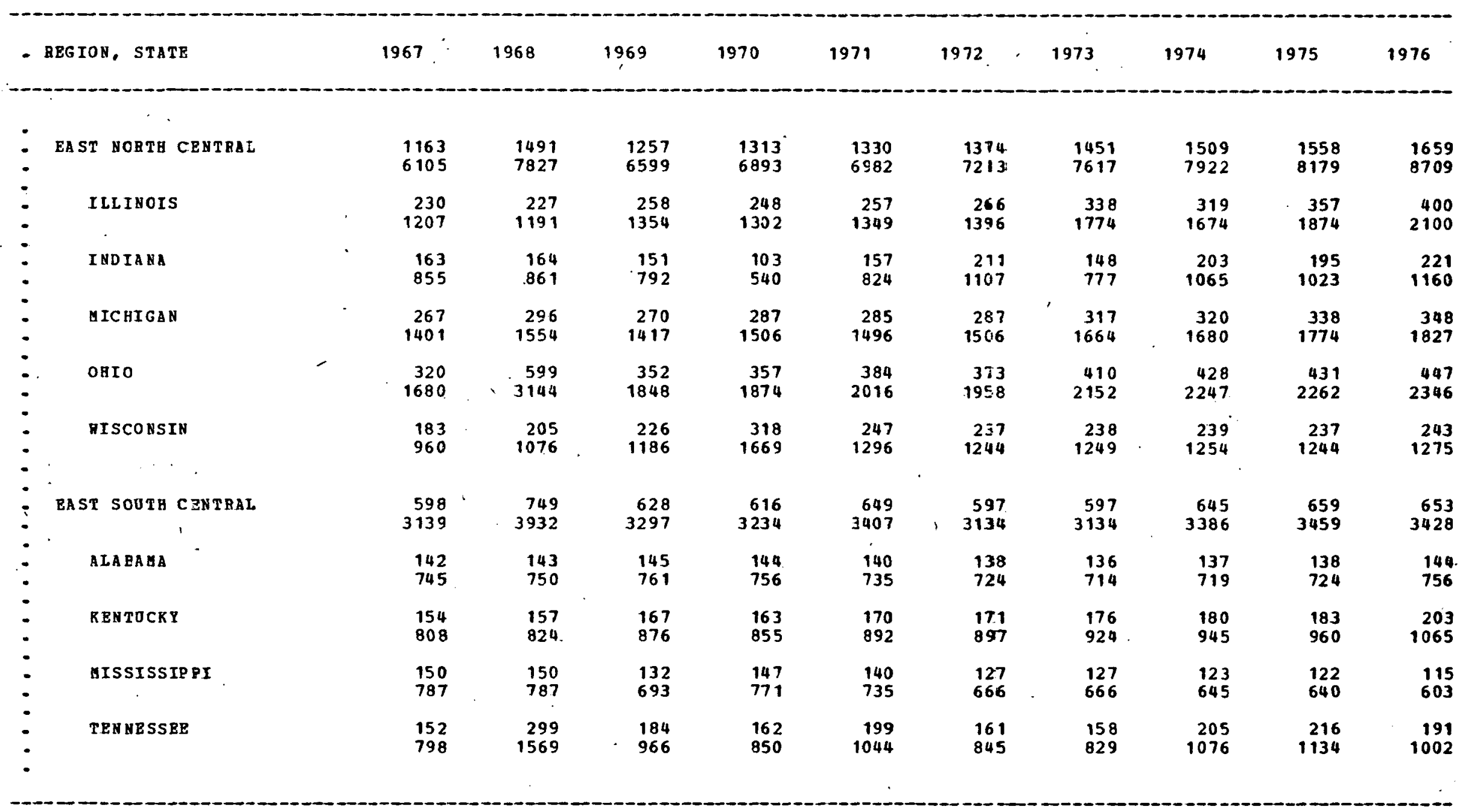


TABLE 6.2D - SCHOOL BDS GASOLINB AND ENRBGY CONSOHPTIOH, BY STATE, 1967-76 (POORTE IN A SBRIES OP 5 TABLBS)

GASOLI NE CONSUAPTION IN TEOUSA HDS OP BARBELS

FOLLONED BY EHERG Y CONSOHFTIOH IN BILLIONS OF BTU

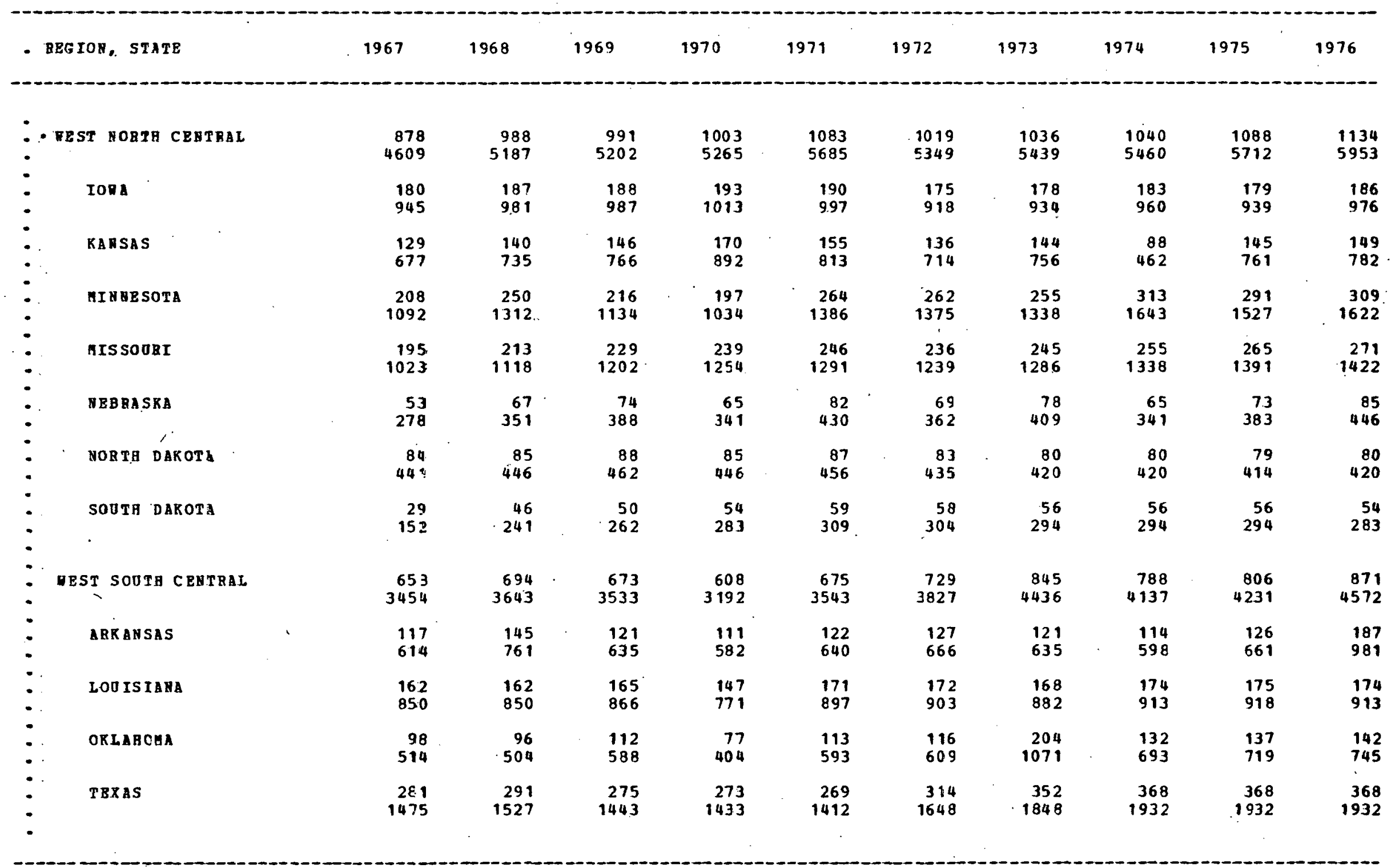


TABL 3 6. 2E - SCHOO: E.S GASOLIBE AHD ENBRGY CONSOUPTION, BY STITE, 1967-76 (LAST IN A SEEIES OP 5 TABLES)

GASOLI HE CONSUAFTION IN THOUSANDS OP BARRILS

FOLLORED EY ENERGY CONSUGETION IN BILLIOHS OI 3 TO

\begin{tabular}{|c|c|c|c|c|c|c|c|c|c|c|}
\hline - REGION, STATE & 1967 & 1968 & 1969 & 1970 & 1971 & 1972 & 1973 & 1974 & -1975 & 1976 \\
\hline - MOONTAIN & $\begin{array}{r}335 \\
1758\end{array}$ & $\begin{array}{r}318 \\
1669\end{array}$ & $\begin{array}{r}345 \\
1316\end{array}$ & $\begin{array}{r}387 \\
2031\end{array}$ & $\begin{array}{r}383 \\
2010\end{array}$ & $\begin{array}{r}396 \\
2.379\end{array}$ & $\begin{array}{r}467 \\
2451\end{array}$ & $\begin{array}{r}399 \\
2094\end{array}$ & $\begin{array}{r}455 \\
2388\end{array}$ & $\begin{array}{r}472 \\
2478\end{array}$ \\
\hline ARIZONA & $\begin{array}{r}45 \\
236\end{array}$ & $\begin{array}{r}42 \\
223\end{array}$ & $\begin{array}{r}58 \\
304\end{array}$ & $\begin{array}{r}.77 \\
404\end{array}$ & $\begin{array}{r}60 \\
315\end{array}$ & $\begin{array}{r}62 \\
325\end{array}$ & $\begin{array}{r}92 \\
483\end{array}$ & $\begin{array}{r}76 \\
399\end{array}$ & $\begin{array}{r}78 \\
409\end{array}$ & $\begin{array}{r}82 \\
430\end{array}$ \\
\hline COLORADO & $\begin{array}{r}75 \\
393\end{array}$ & $\begin{array}{r}9.5 \\
472\end{array}$ & $\begin{array}{r}92 \\
483\end{array}$ & $\begin{array}{l}104 \\
546\end{array}$ & $\begin{array}{l}107 \\
561\end{array}$ & $\begin{array}{l}103 \\
563\end{array}$ & $\begin{array}{l}140 \\
735\end{array}$ & $\begin{array}{l}133 \\
698\end{array}$ & $\begin{array}{l}130 \\
682\end{array}$ & $\begin{array}{l}124 \\
651\end{array}$ \\
\hline IDA BO & $\begin{array}{r}81 \\
425\end{array}$ & $\begin{array}{r}43 \\
225\end{array}$ & $\begin{array}{r}42 \\
220\end{array}$ & $\begin{array}{r}42 \\
220\end{array}$ & $\begin{array}{r}44 \\
231\end{array}$ & $\begin{array}{r}43 \\
-25\end{array}$ & $\begin{array}{r}44 \\
231\end{array}$ & $21^{-}$ & $\begin{array}{r}47 \\
246\end{array}$ & $\begin{array}{r}49 \\
257\end{array}$ \\
\hline MONTAKA & $\begin{array}{r}41 \\
215\end{array}$ & $\begin{array}{r}4 \Xi \\
22 E\end{array}$ & $\begin{array}{r}49 \\
257\end{array}$ & $\begin{array}{r}49 \\
257\end{array}$ & $\begin{array}{r}49 \\
257\end{array}$ & $\begin{array}{r}49 \\
257\end{array}$ & $\begin{array}{r}47 \\
246\end{array}$ & $\begin{array}{r}48 \\
252\end{array}$ & $\begin{array}{r}50 \\
262\end{array}$ & $\begin{array}{r}51 \\
267\end{array}$ \\
\hline VEVADA & $\begin{array}{l}13 \\
68\end{array}$ & $\begin{array}{l}14 \\
73\end{array}$ & $\begin{array}{l}16 \\
84\end{array}$ & $\begin{array}{l}16 \\
84\end{array}$ & $\begin{array}{l}17 \\
89\end{array}$ & $\begin{array}{l}1 \varepsilon \\
94\end{array}$ & $\begin{array}{r}21 \\
110\end{array}$ & $\begin{array}{r}24 \\
126\end{array}$ & $\begin{array}{r}25 \\
131\end{array}$ & $\begin{array}{r}28 \\
147\end{array}$ \\
\hline NER GEXICO & $\begin{array}{r}45 \\
236\end{array}$ & $\begin{array}{r}48 \\
252\end{array}$ & $\begin{array}{r}50 \\
262\end{array}$ & $\begin{array}{r}51 \\
267\end{array}$ & $\begin{array}{r}52 \\
273\end{array}$ & $\begin{array}{r}55 \\
341\end{array}$ & $\begin{array}{r}73 \\
383\end{array}$ & $\begin{array}{r}54 \\
283\end{array}$ & $\begin{array}{r}73 \\
383\end{array}$ & $\begin{array}{r}77 \\
404\end{array}$ \\
\hline DTAB & $\begin{array}{l}19 \\
99\end{array}$ & $\begin{array}{r}22 \\
115\end{array}$ & $\begin{array}{r}22 \\
115\end{array}$ & $\begin{array}{r}30 \\
157\end{array}$ & $\begin{array}{r}34 \\
178\end{array}$ & $\begin{array}{r}34 \\
178\end{array}$ & $\begin{array}{r}32 \\
168\end{array}$ & $\begin{array}{r}35 \\
183\end{array}$ & $\begin{array}{r}29 \\
152\end{array}$ & $\begin{array}{r}36 \\
189\end{array}$ \\
\hline WYOEING & $\begin{array}{r}16 \\
84\end{array}$ & $\begin{array}{l}16 \\
84\end{array}$ & $\begin{array}{l}17 \\
89\end{array}$ & $\begin{array}{r}18 \\
-94\end{array}$ & $\begin{array}{r}20 \\
105\end{array}$ & $\begin{array}{l}77 \\
89\end{array}$ & $\begin{array}{l}18 \\
94\end{array}$ & $\begin{array}{r}25 \\
131\end{array}$ & $\begin{array}{r}23 \\
120\end{array}$ & $\begin{array}{r}25 \\
131\end{array}$ \\
\hline$\because \quad$ PACIPIC & $\begin{array}{r}624 \\
3276\end{array}$ & $\begin{array}{r}651 \\
3417\end{array}$ & $\begin{array}{r}740 \\
3885\end{array}$ & $\begin{array}{r}710 \\
3727\end{array}$ & $\begin{array}{r}775 \\
4068\end{array}$ & $\begin{array}{r}J \varepsilon 3 \\
4910\end{array}$ & $\begin{array}{r}834 \\
4378\end{array}$ & $\begin{array}{r}881 \\
4625\end{array}$ & $\begin{array}{r}766 \\
4021\end{array}$ & $\begin{array}{r}972 \\
5103\end{array}$ \\
\hline ALASKA & $\begin{array}{r}9 \\
47\end{array}$ & $\begin{array}{r}9 \\
47\end{array}$ & $\begin{array}{l}10 \\
52\end{array}$ & $\begin{array}{l}12 \\
63\end{array}$ & $\begin{array}{l}13 \\
68\end{array}$ & .74 & $\begin{array}{l}17 \\
89\end{array}$ & $\begin{array}{l}18 \\
94\end{array}$ & $\begin{array}{r}20 \\
105\end{array}$ & $\begin{array}{l}19 \\
99\end{array}$ \\
\hline - CALIFOBNIS & $\begin{array}{r}421 \\
2210\end{array}$ & $\begin{array}{r}433 \\
2273\end{array}$ & $\begin{array}{r}510 \\
2677\end{array}$ & $\begin{array}{r}478 \\
2509\end{array}$ & $\begin{array}{r}513 \\
2693\end{array}$ & $\begin{array}{r}527 \\
2765\end{array}$ & $\begin{array}{r}587 \\
3081\end{array}$ & $\begin{array}{r}609 \\
3197\end{array}$ & $\begin{array}{r}488 \\
2562\end{array}$ & $\begin{array}{r}672 \\
3528\end{array}$ \\
\hline RADAII & $\begin{array}{r}5 \\
26\end{array}$ & $\begin{array}{r}5 \\
26\end{array}$ & $\begin{array}{r}9 \\
47\end{array}$ & $\begin{array}{r}8 \\
42\end{array}$ & $\begin{array}{l}11 \\
57\end{array}$ & $\begin{array}{l}11 \\
57\end{array}$ & $\begin{array}{l}13 \\
68\end{array}$ & $\begin{array}{l}13 \\
68\end{array}$ & $\begin{array}{l}13 \\
68\end{array}$ & $\begin{array}{l}14 \\
73\end{array}$ \\
\hline OREGOE & $\begin{array}{r}72 \\
378\end{array}$ & $\begin{array}{r}80 \\
420\end{array}$ & $\begin{array}{r}85 \\
446\end{array}$ & $\begin{array}{r}82 \\
430\end{array}$ & $\begin{array}{l}104 \\
546\end{array}$ & $\begin{array}{r}95 \\
498\end{array}$ & $\begin{array}{r}88 \\
462\end{array}$ & $\begin{array}{l}106 \\
556\end{array}$ & $\begin{array}{l}106 \\
556\end{array}$ & $\begin{array}{r}99 \\
519\end{array}$ \\
\hline PASHI RGTON & $\begin{array}{l}117 \\
614\end{array}$ & $\begin{array}{l}124 \\
651\end{array}$ & $\begin{array}{l}126 \\
661\end{array}$ & $\begin{array}{l}130 \\
682\end{array}$ & $\begin{array}{l}134 \\
703\end{array}$ & $\begin{array}{l}136 \\
714\end{array}$ & $\begin{array}{l}129 \\
677\end{array}$ & $\begin{array}{l}135 \\
708\end{array}$ & $\begin{array}{l}139 \\
729\end{array}$ & $\begin{array}{l}168 \\
882\end{array}$ \\
\hline
\end{tabular}


TAELE 6.3A -- FEDEBAL EUS GASOLIME ARD ENERGY CONSUMPTION, BY STATE, 1967-76 (PIRST IN A SERTES OP 5 TABLES)

GASOLI NE CONSOAPTION IN THOOSANDS OP BARRELS

FOLLORED BY ENERGY COHSUAPTION IN BILLIONS OE BTO

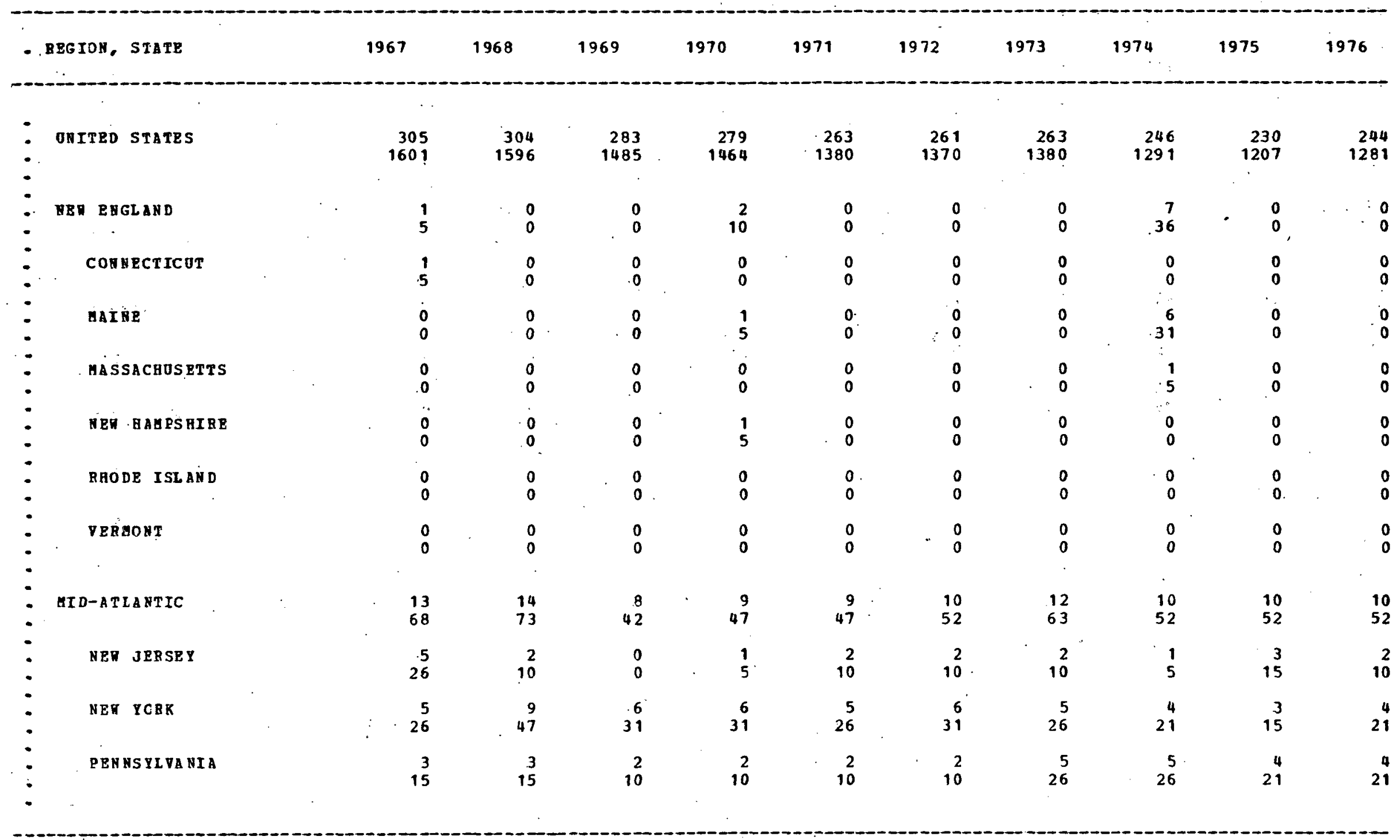


TABLE 6.3B - PBDERAL BUS GASOLINE AAD ENERGY CONSUAPTION, BP STATE, 1967-76

(SRCOND IE A SERIES OP 5 TABLES)

GASOLI B CONSOAETIOR IR THOUSANDS OP BARBELS

POLLORED BY ENBRGY CORSUAPTION IN BILLIONS OF BTU

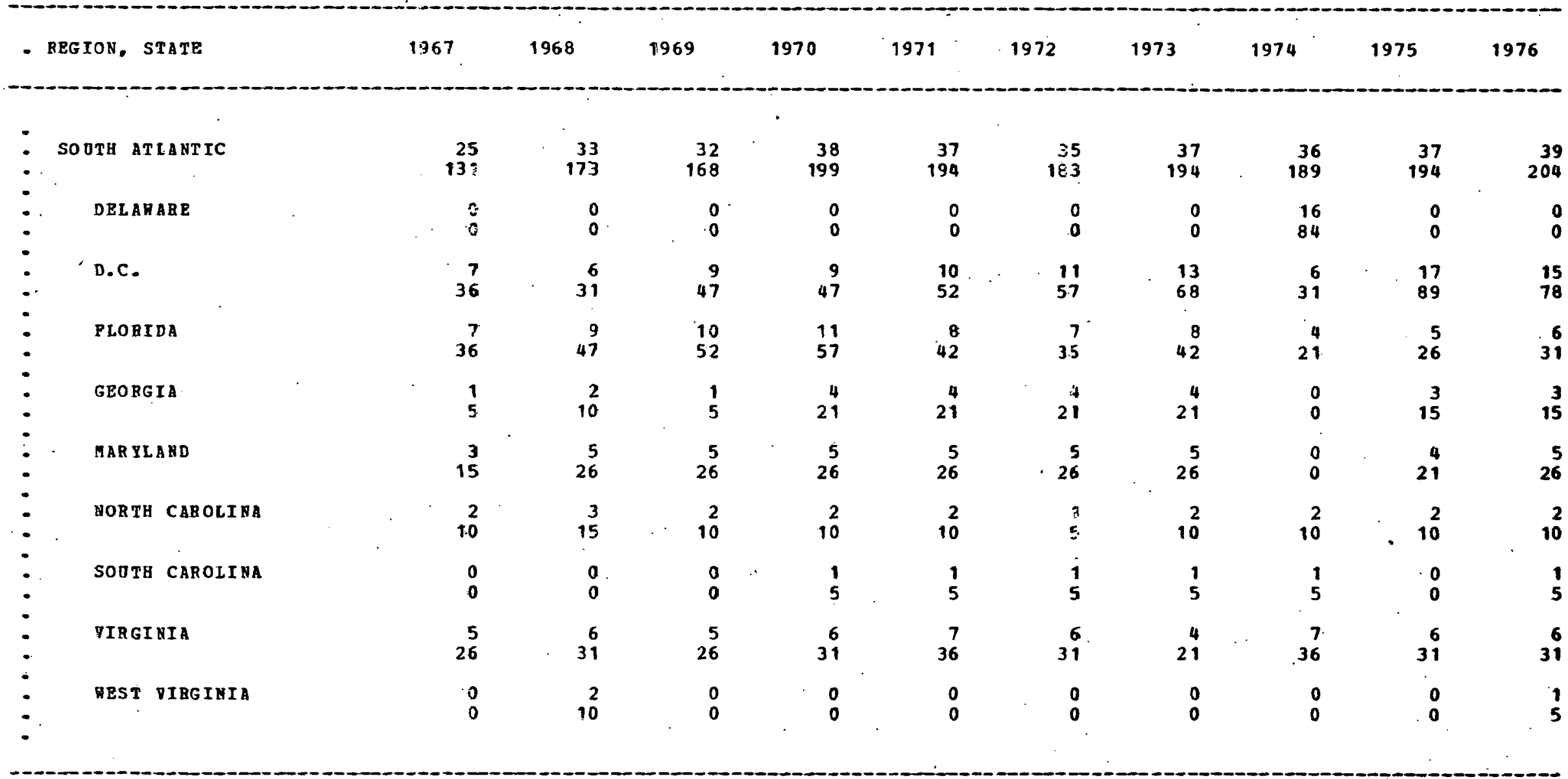


TABLE 6.3C - FEDERAL BUS GaSOLINE AND ENERGI CONSUGPTION, BY STATE, 1967-76 (THIRD IN A SERIES OF 5 TABLES)

GASOLI AE CONSOMETION IN THOUSANDS OF BARELLS

POLLOHED BY ENERGY CONSUMFTION IN EILLIONS OF BTU

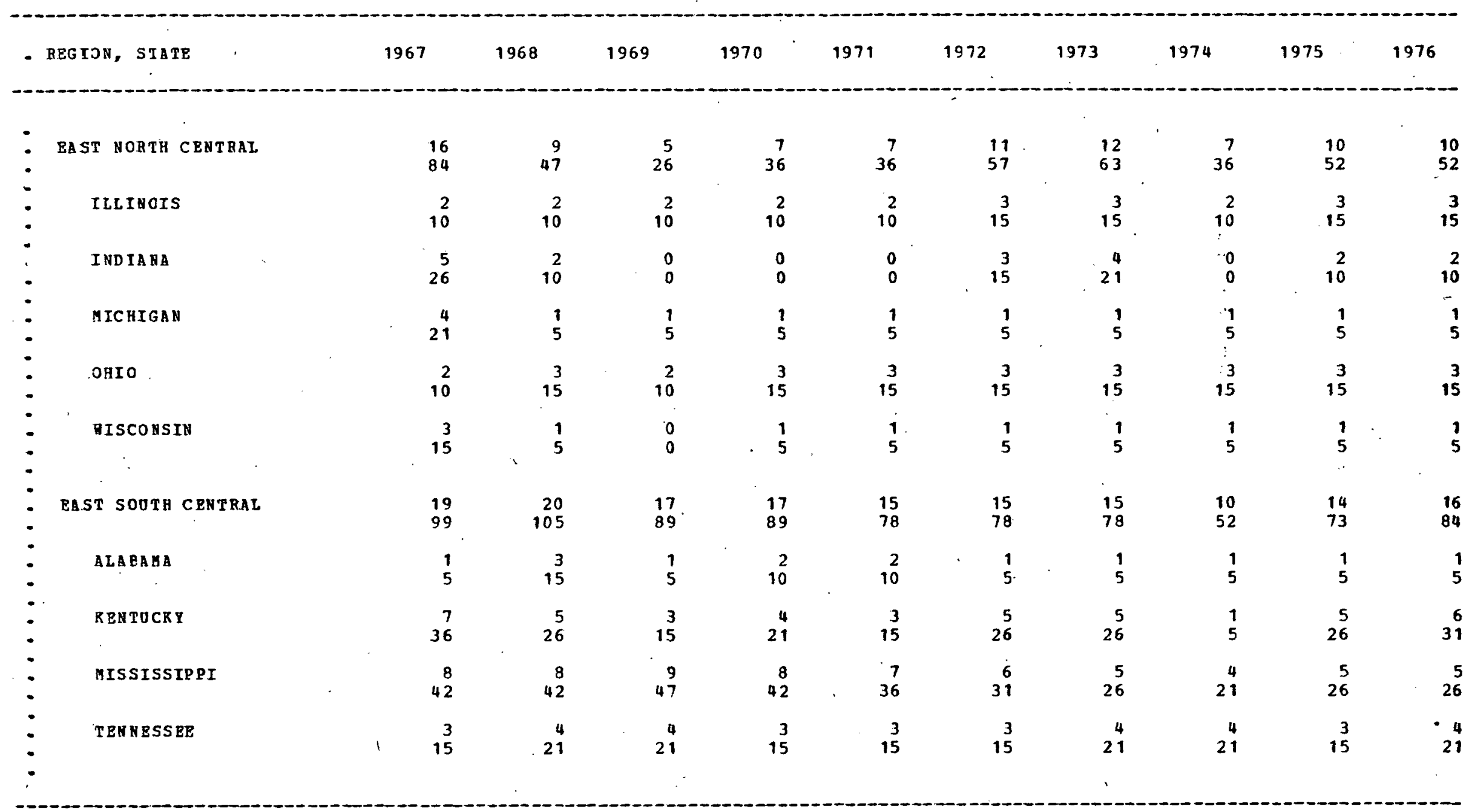


TABLE 6.3j - PEEERAL BOS GASOIINE AND ENERG CONSUMPTION, BI STATE, 1967-76

(FOORTH ZN A SERIES OP 5 TABLES)

GASOLIEP CONSUHETION IN THOUSARDS OP BARRELS

POLLORED EF ENERGT CORSOHPTION IN BILLIONS OF BTO

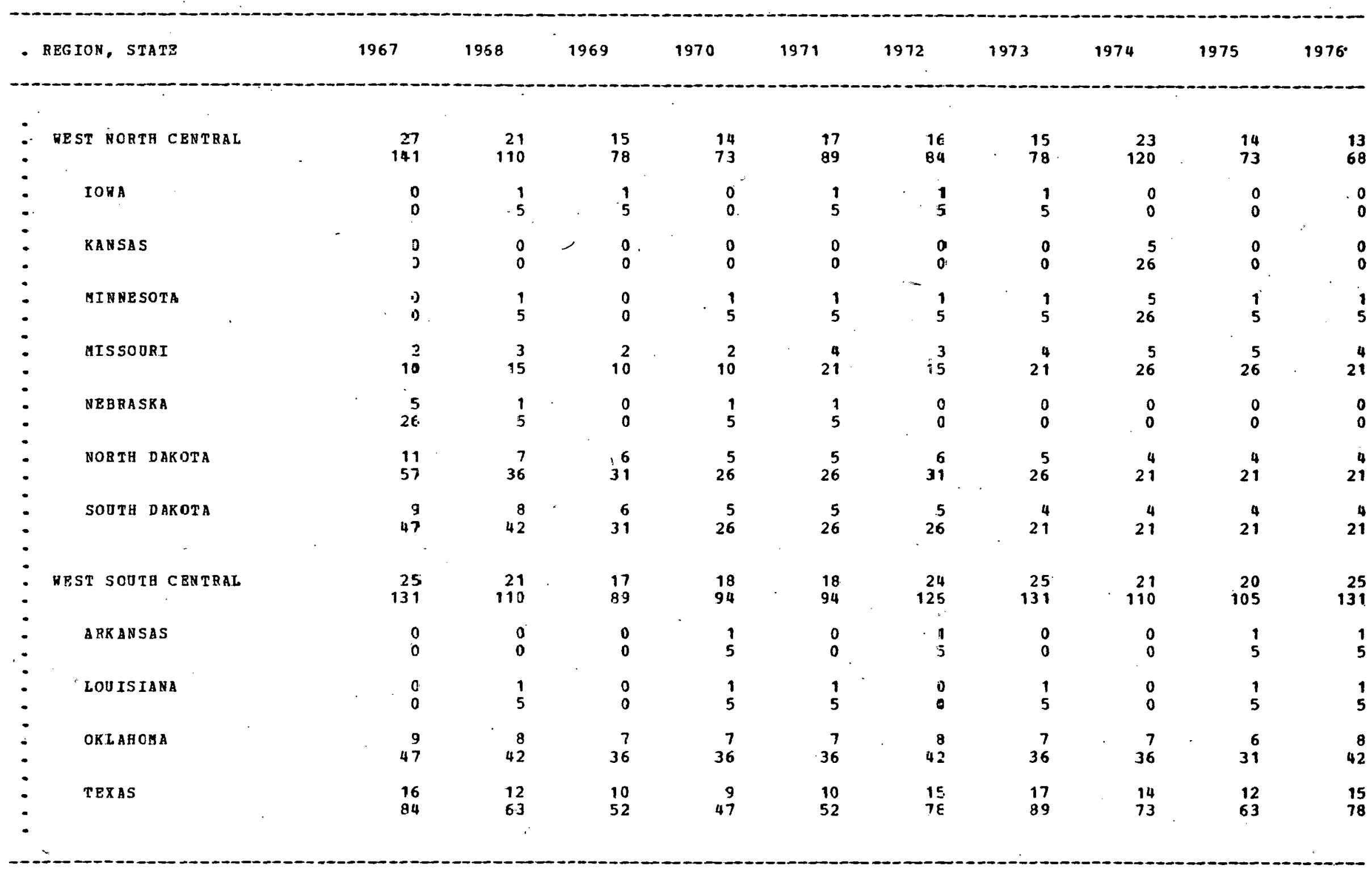


TABLB 6. 3E -- PEDERAL EOS GASOLINE A AD ENERG CONSUMPTIOA, B STATE, 1967-76

(LAST IN A SBBIES OP 5 TABLES)

GASOLI YE COHSUHPTION IH THOUSANDS OP BARRPLS

POLLOUED BY ENERG $P$ CONSOM FTION IA BILLIONS OF BTO

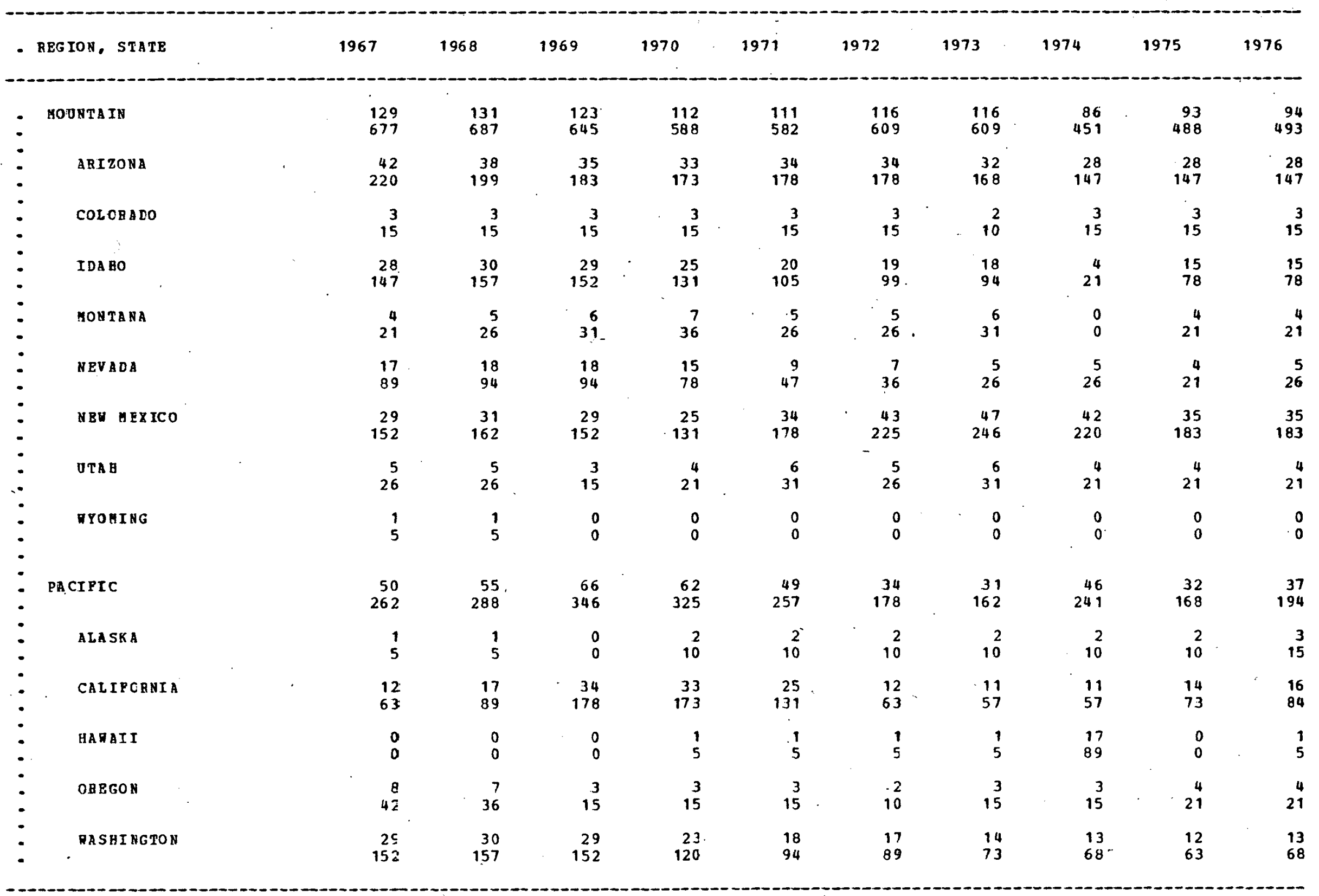


TABLE 6.4 - INTERCITY BOS DIESEL POEL AND ENEEGY DSE,
BY INCOAB OP. TRAVELERS PAHIY, 19E7,72,76

PERCEHTAGE EJEL CONSOMPTION IN EACH INCONE CLASS IS GIVEN.

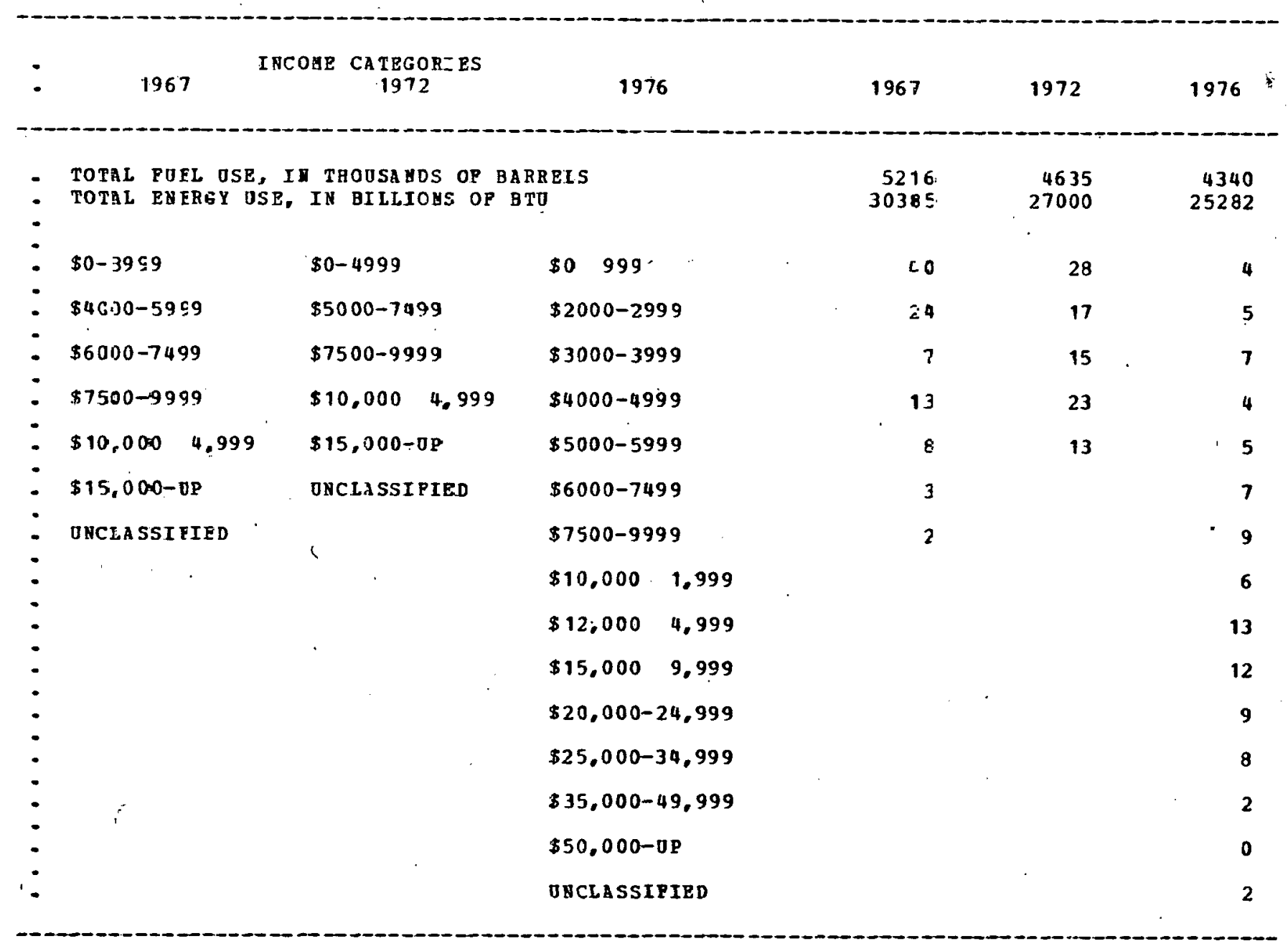


TABLE 6.5 -- TRANSIT BUS PUEL AND ENERGY USE, BY POBI, 1967-77

(APTA ESTIHATES)

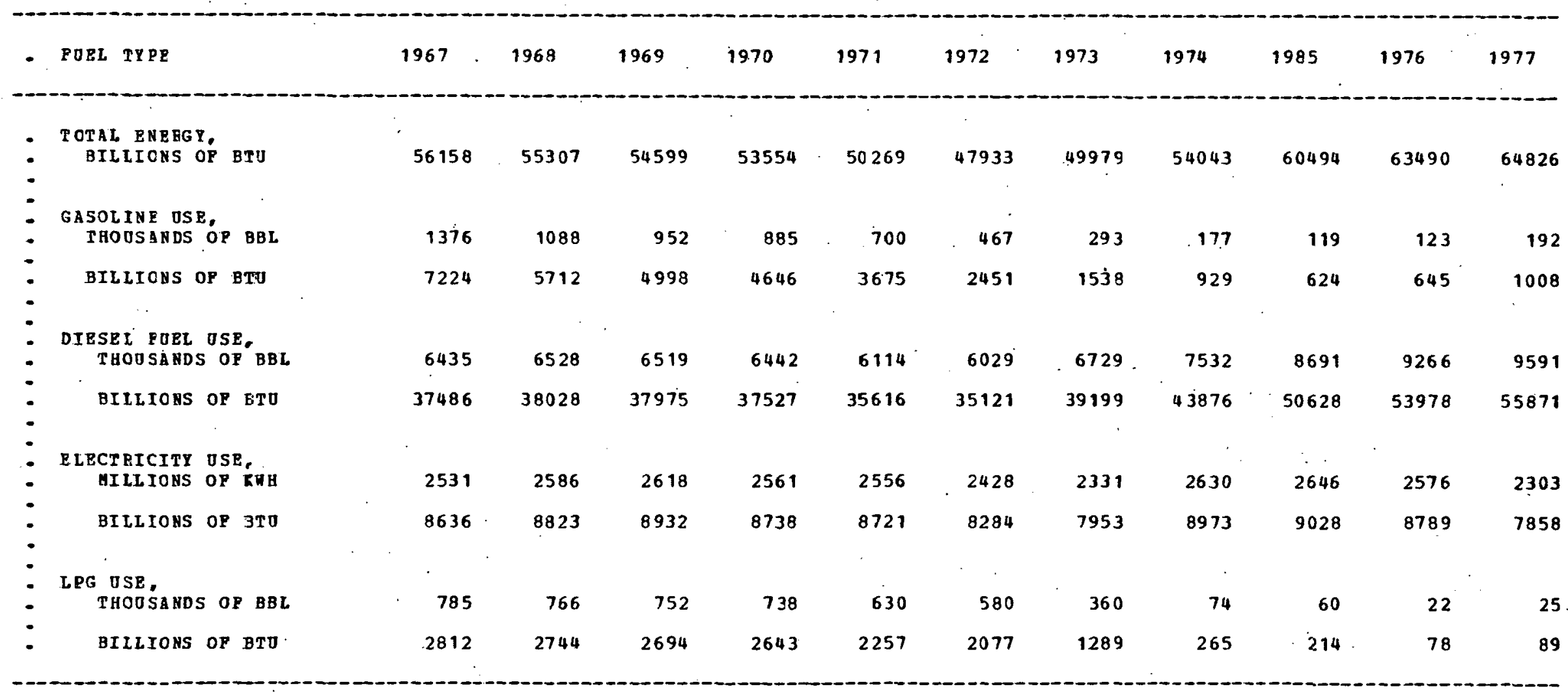

SOOHCE: AMERICAL PUBLEC TRANSIT ASSOCTATIOH (SEE METHOD 323)

CATA QUALITY: 2

HOTE: ORNI HAS IEDEPENDENTIF ESTIGATED 1976 TRANSIT CONSUMPTION OP DIESEL PUEI.

NOTE THAT THE RESOLT. IN TABLE 6.6, DOES NOT AGREE EXACTLY MITE THE APTA ESTIMATE 
TABLE 6.6A - TRANSIT BUS DIESEL POEL OSE, BY ST ITE, 1976 (PIRST I A SERIBS OP FIVE TABLES)

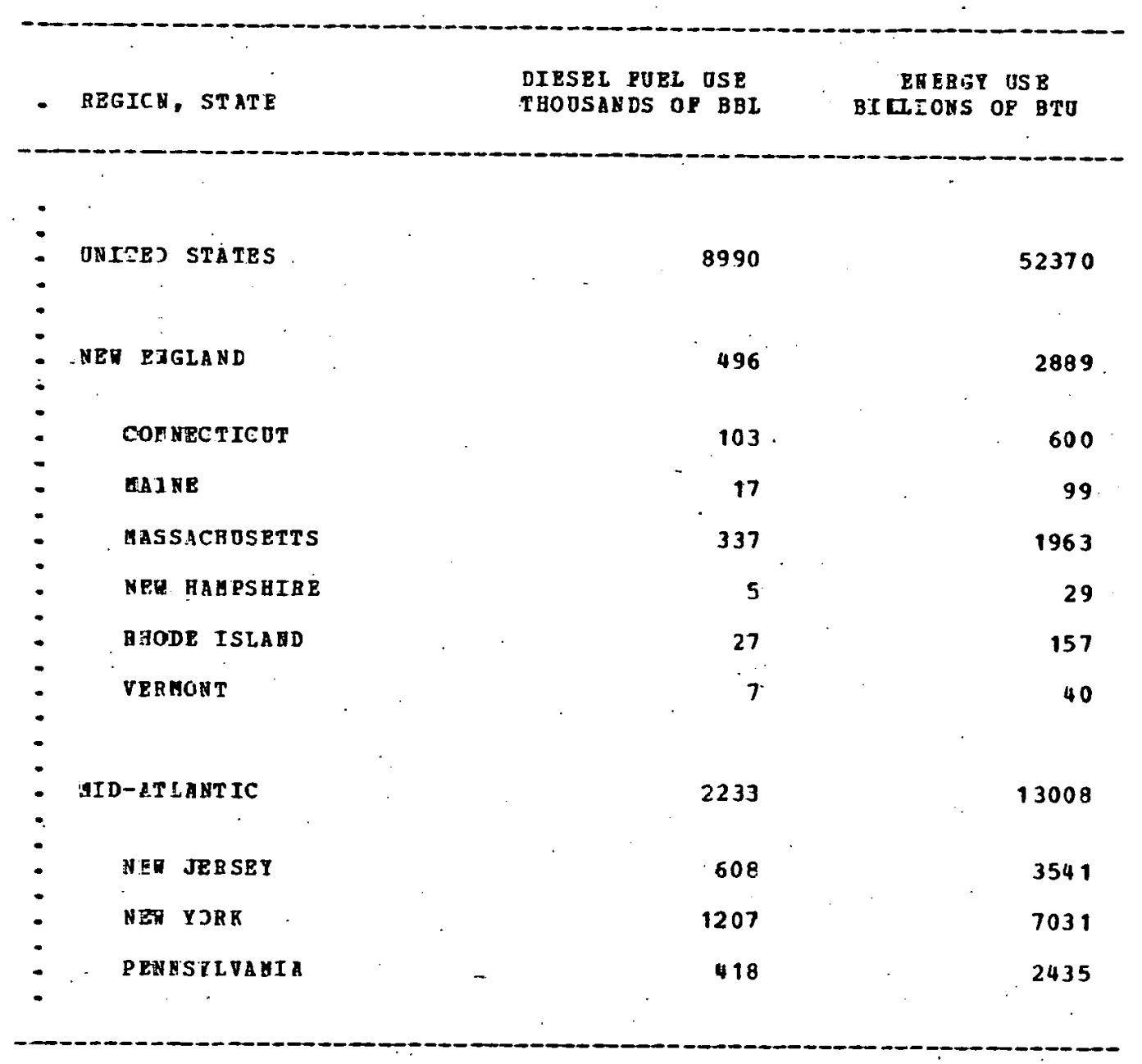


TABLE 6.6B - TRABSIT BOS DIESEL POEL USE, BY ST ATE, 1976 (SBCOND IH A SERIES OF PIVE TABLES)

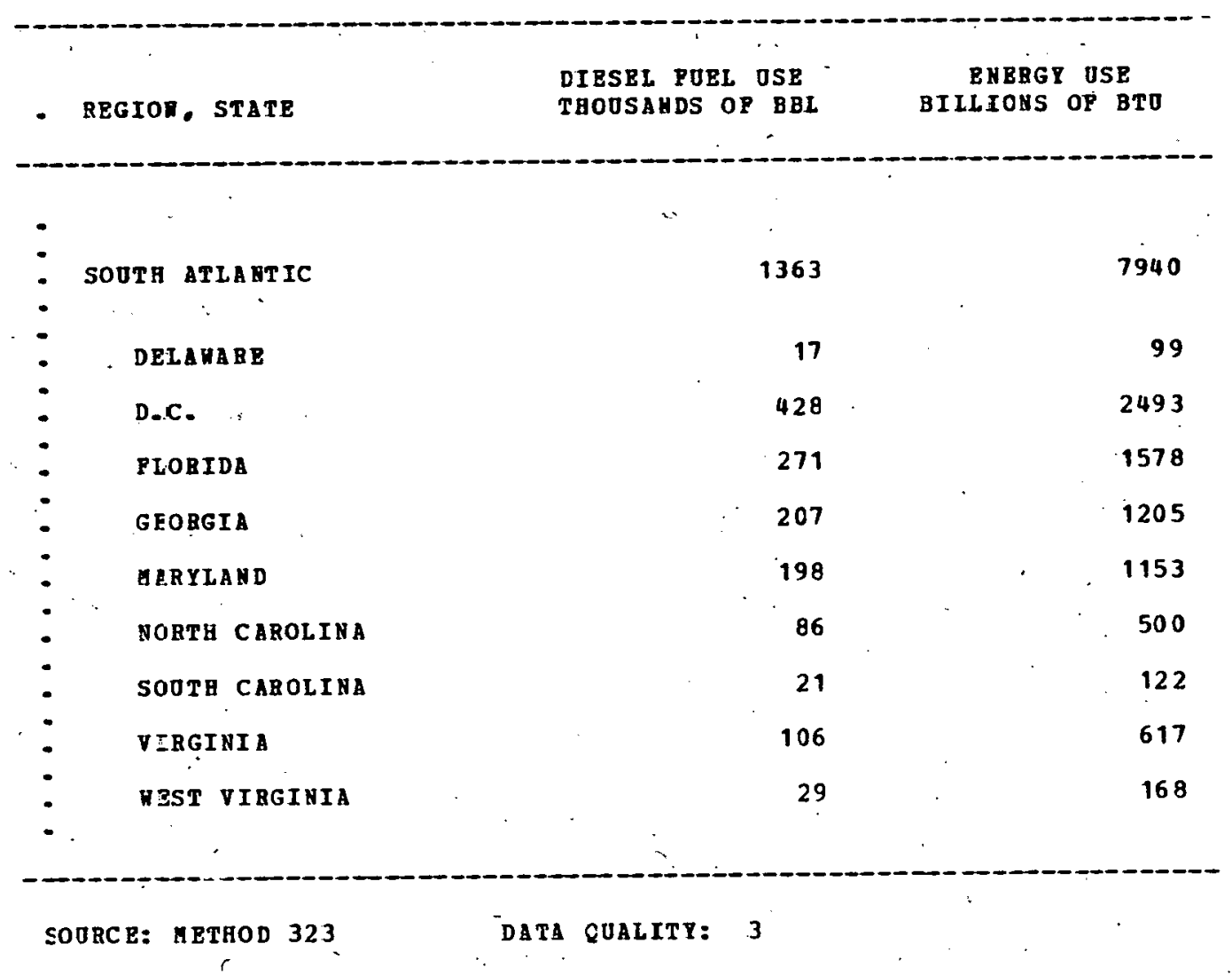


TABLE 6.6C -- TRANSIT BUS DIESEL PUEL USE, BI STATE, 1376 (THIRD IN A SERIES OF PIVE TABLES)

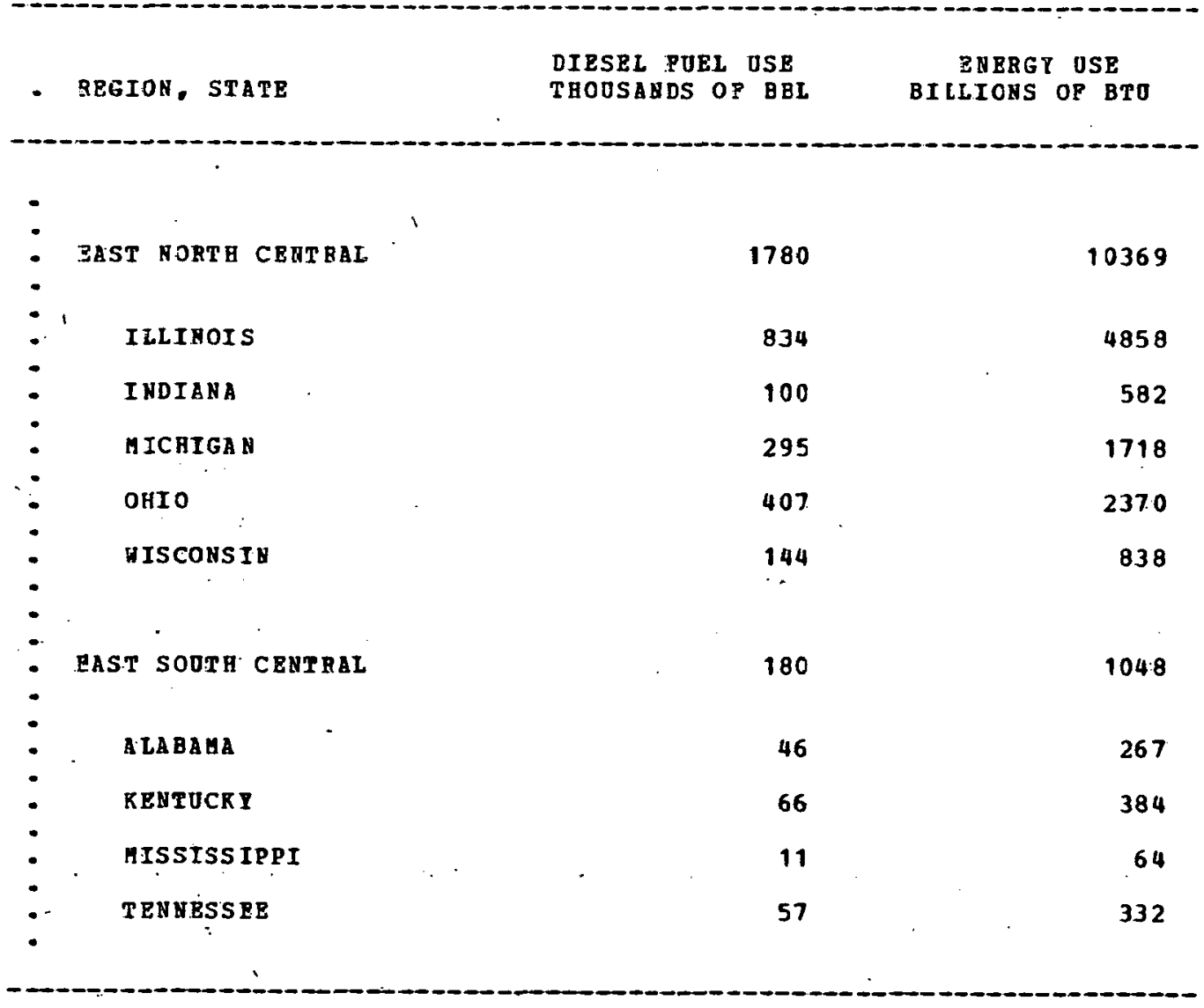


TABLB 6.6D -- TRAASIT BUS DIBSEL FOBL USE, BY ST $2 T E, 1976$ (POOBTH IN A SBRIES OP PIVE TABLES)

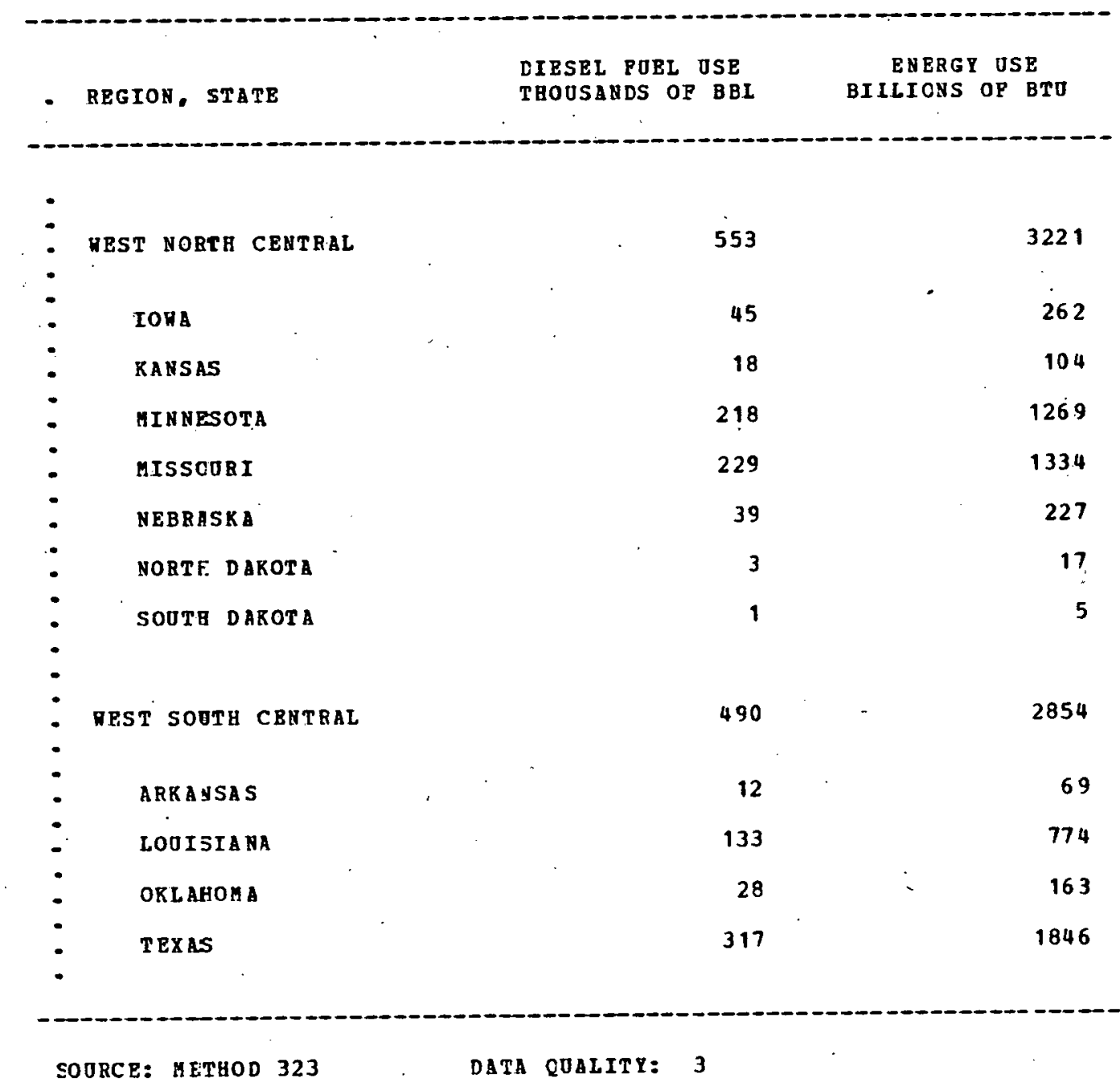


TABLE 6.6E -- TRAYSIT BOS DIESEL FOEL OSE, BY ST 1TE, 1976 (LAST IN A SBBIES OP FIVB TABLBS)

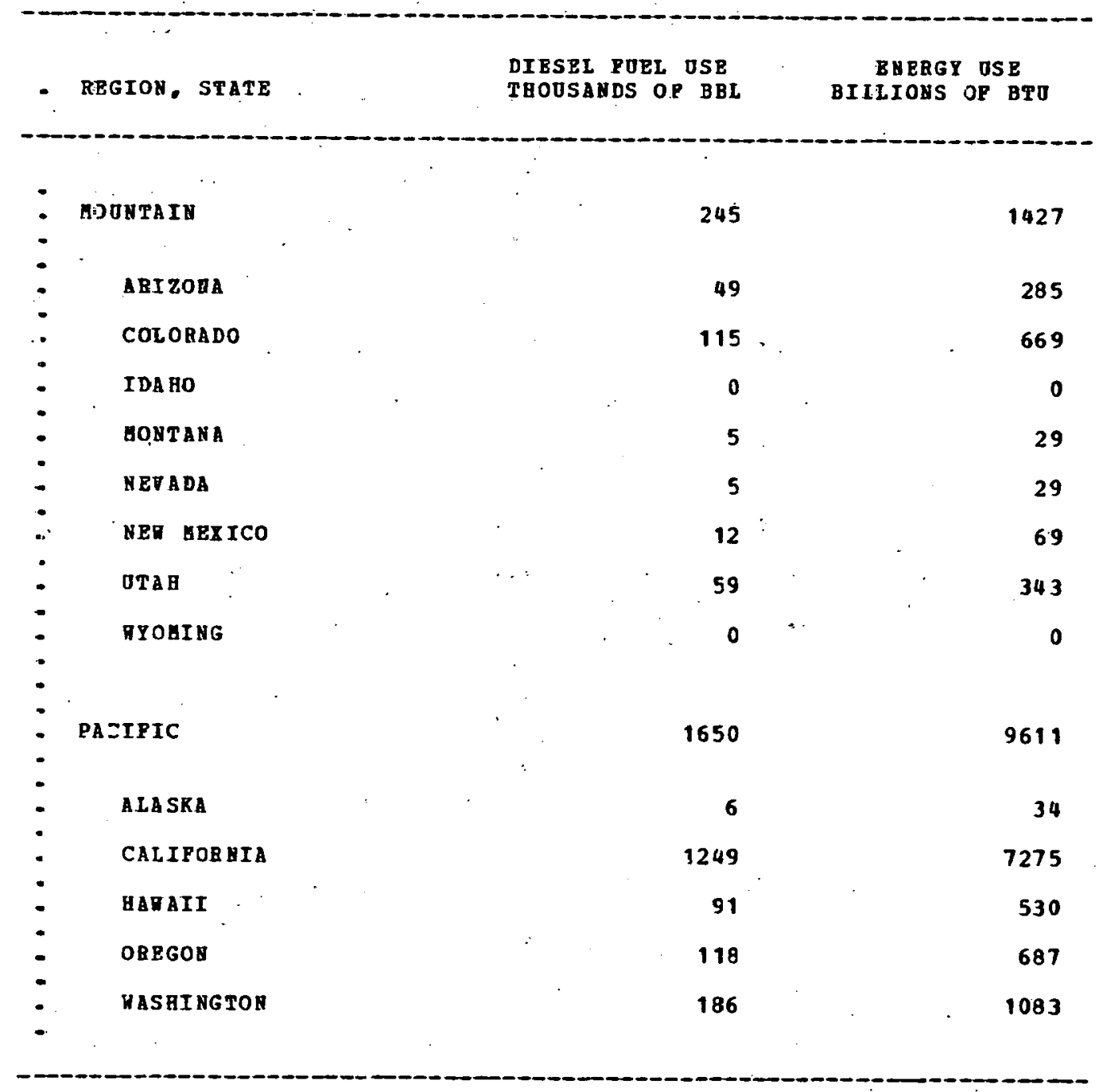


TABLE 7.1 -- TOTAL TRUCK FUEL ARD ENERGY USB, BY SBCTOR BY FOEL, 1967-76

PORL USE IN THODSANDS OF BBL, FNERGY USE IN BILLICAS OP BTU

\begin{tabular}{|c|c|c|c|c|c|c|c|c|c|c|c|}
\hline & SECTOB, FUEL & 1967 & 1968 & 1969 & 1970 & 1971. & 1972 & 1973 & 1974 & 1975 & 1976 \\
\hline & TOT IL BNEBGI & 2631341 & 2809213 & 29.85356 & 3096947 & 3291362 & 3547042 & 3783193 & 3629022 & 3624957 & 3822760 \\
\hline & $\begin{array}{l}\text { HOE SEHOLD SECTOR } \\
\text { GASOLIHE } \\
\text { DIESEL PUEL } \\
\text { IPG }\end{array}$ & $\begin{array}{r}90132 \\
13 \\
0\end{array}$ & $\begin{array}{r}100296 \\
21 \\
22\end{array}$ & $\begin{array}{r}110949 \\
32 \\
55\end{array}$ & $\begin{array}{r}121065 \\
44 \\
98\end{array}$ & $\begin{array}{r}132492 \\
61 \\
158\end{array}$ & $\begin{array}{r}147754 \\
80 \\
239\end{array}$ & $\begin{array}{r}159865 \\
108 \\
356\end{array}$ & $\begin{array}{r}158903 \\
122 \\
.443\end{array}$ & $\begin{array}{r}169364 \\
135 \\
526\end{array}$ & $\begin{array}{r}185048 \\
162 \\
678\end{array}$ \\
\hline & TOTAL ENERGY & 473295 & 526790 & 582899 & 636218 & 696538 & 777076 & 841221 & 836564 & 891856 & 974914 \\
\hline & $\begin{array}{l}\text { COAHERCIAL SECTOR } \\
\text { GASOLINE } \\
\text { DIESEL FUEL } \\
\text { LPG }\end{array}$ & $\begin{array}{r}288114 \\
104708 \\
3068\end{array}$ & $\begin{array}{r}295110 \\
119424 \\
\therefore \quad 3607\end{array}$ & $\begin{array}{r}300668 \\
134658 \\
4135\end{array}$ & $\begin{array}{r}302257 \\
-143868 \\
4480\end{array}$ & $\begin{array}{r}304757 \\
163803 \\
5077\end{array}$ & $\begin{array}{r}313034 \\
185578 \\
5689\end{array}$ & $\begin{array}{r}311779 \\
215549 \\
6473\end{array}$ & $\begin{array}{r}285051 \\
214215 \\
6280\end{array}$ & $\begin{array}{r}279126 \\
209642 \\
5936\end{array}$ & $\begin{array}{r}279777 \\
228548 \\
6118\end{array}$ \\
\hline & . TOTAL ENEBGY & 2133592 & 2257991 & 237.7862 & 2441032 & 2572429 & 2744915 & 29.15742 & 2766932 & 2707958 & 2822152 \\
\hline & $\begin{array}{l}\text { PEDERBL GOVERFGENT } \\
\text { ALL ROBLS }\end{array}$ & 4529 & 4527 & 4558 & 3679 & 4136 & 4637 & 4858 & 4720 & 4652 & 4745 \\
\hline & TOTAL ENERGT & 24454 & 24432 & 24595 & 19697 & 22395 & 25051 & 26230 & 25526 & 25143 & 25694 \\
\hline
\end{tabular}

SOURCE:- HETHOD 330

DATA QUALITY: SEE TABLES 7.2-7.12

InPORTANT NOTE: IN THIS AND SOBSEQIBNT TABL ES (EXCBPT 7.11; 7.12), THE SHABRS OP THE NATION'S HIGARAY GASOLINE AND DIESEL/LPG OSE ALLOTTED TO EACE CATRGORY OP TRUCK EOEL USE ARE BASED OH. DATA POB THE YEARS 1967 A 1972 ONLY. EACH STATE'S REPORTED TOTAL HIGHWY GASOLINE OSE ARD TOTAL TROCK DIESEL POEL USE POR THE YEARS 1967-76 ARE BASED ON ANNOAL DATA, BUT THE DISAGGREGATED TROCR FUEL USE ESTIMETES FOR YEABS OTRER THAN 1967 ABD 1972 ARE BASBD ON INTERPOLATION OB EXTRAPOLATION AND SHOULD BE OSED UTTH CAOTION.

NOTE: HOOSEHOLD TROCR FUEL CONSUHPTION IS Y ERE DEFINED TO BE THE TOTAL POEL COBSUAETION OP TFOCKS THOSE PBIHBRT OSE IS INDICATED BY THEIR OHYERS TO BE PERSONAL TAANSORTATIOH. CONSECUERTL IP A PICKOP TRUCK IS USED PARTLY FOR HAULISG PREIGHT BUT MOSTLI POR PERSONAL TRANSPORTATIOA, ALL THE FUEL IT JSES IS COONTED AS CONSOHET ION IN THE HOUSEHOLD SECTOR:

NOTE: THE SHALL AMOUET OF PUEL OSED BY STATE AND LOCAL GOVBRNMENT TRUCKS IS OMTTTED ABOVE. IT COMPRISES A NBGLIGIBLE FRACTION OP THE HOOSEHOLD AOTO FUEL USE BRPJ RTBE IN TABLE 5.5 . 
TABLE 7.2A - IRUCK POEL AND ENERGY OSE, BY PUEL BY SECTOR BY UBIGET, 1967-76 (PIBST IA A SERIES OF 3 TABLES)

ENERGT USE IN BILLIONS OF BTO

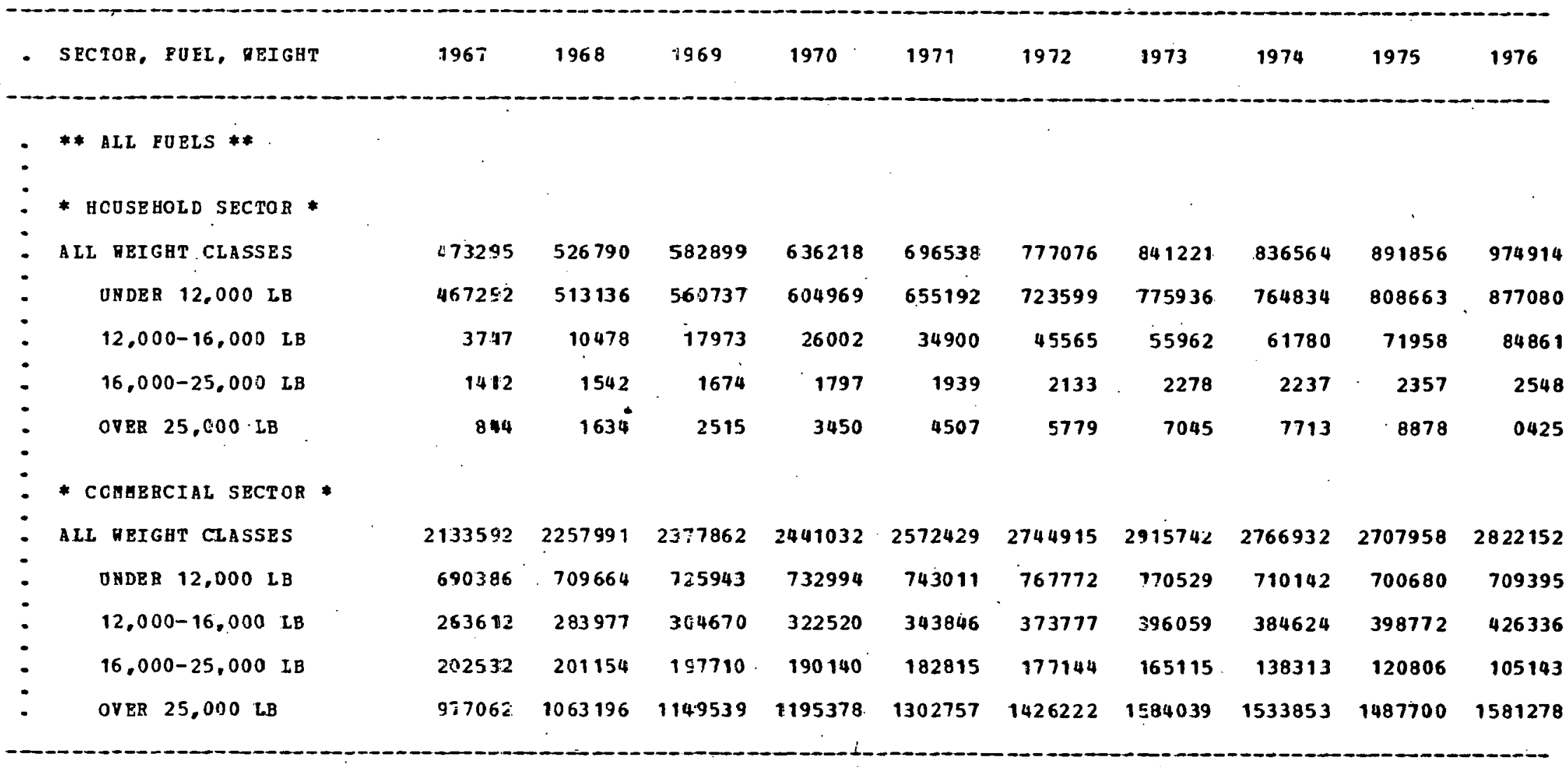

SODRCE: HETHOD 331

DATA QUALITY (DISAGgREgate DATA): 2 (1567,72), 3 (JTHEB YEABS) (AGGQEATE DATA): 1 (1967.72); 2 (OTHEB YEABS) 
TAELE 7.2B - TRUCK PUEL AND ENERGY USE, BY PURL EY SECTOR BY WEIGHT, 1967-76 (SECOND IN A SRRIES OF 4 TABLES)

POEL OSE IN THOUSANDS OF BARRELS, POLLOMED BY ENRRGY USE IN BILLIONS OF BTO

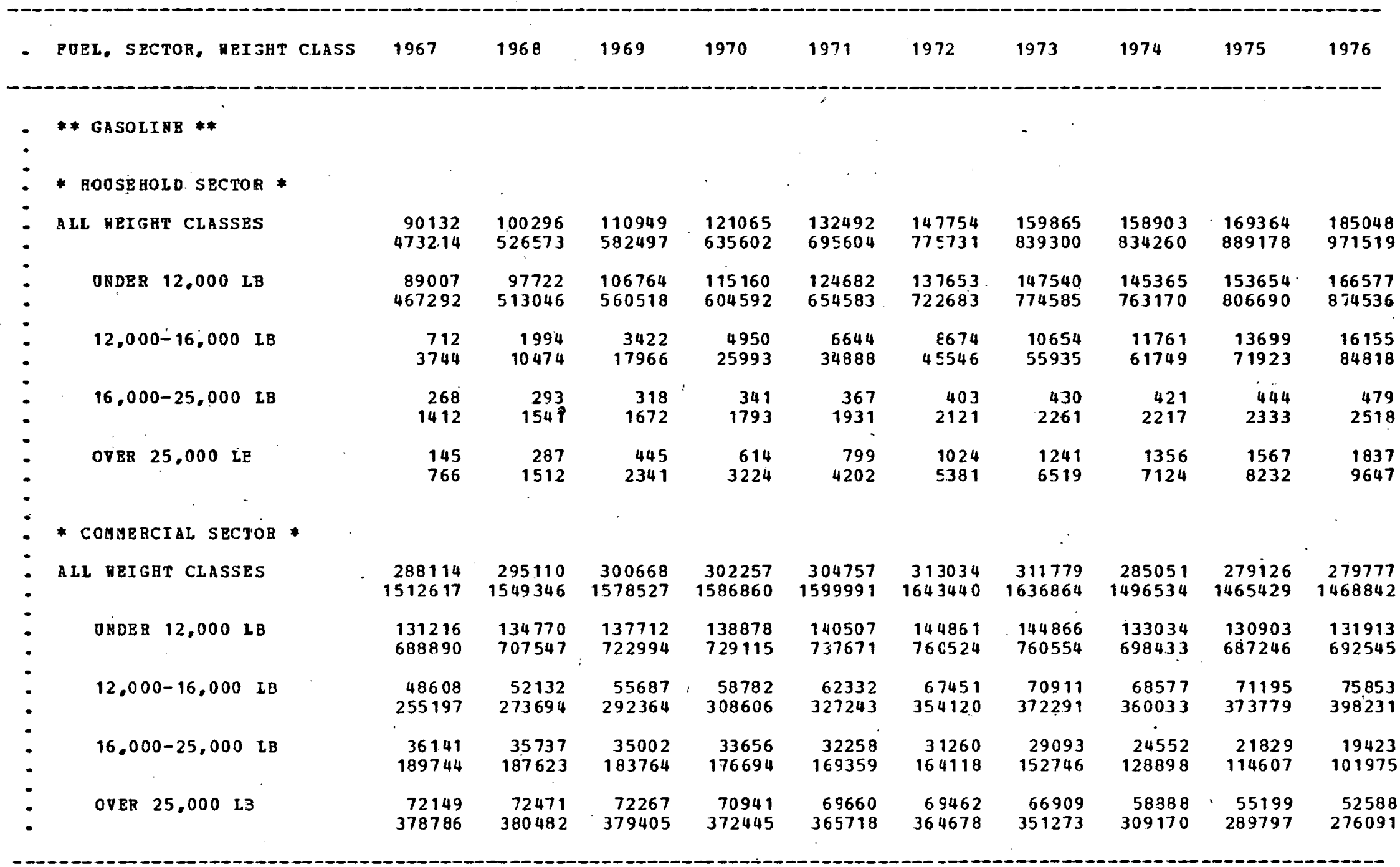

SOUBCE: $\angle E T H O D 331$

DATA QOALITY (DISAGSREGTE DATA): 2 (1967,72), 3 (OTHBB YBaRS)

(AGGREATE DATA): $1(1967,72), 2$ (OTHER YEARS) 
TAELE 7.2C -- TRUCK FOEL AND EN3RGY USE, BY ROBL BY SBCTOR BI YBIGRT, 1967-76 (THIRD IH A SERISS OP 4 TABLES)

FOEL DJE IY THOUSARDS OP BARZELS, POLLONED BY ENERGI USE IA BILLIJHS OP BTO

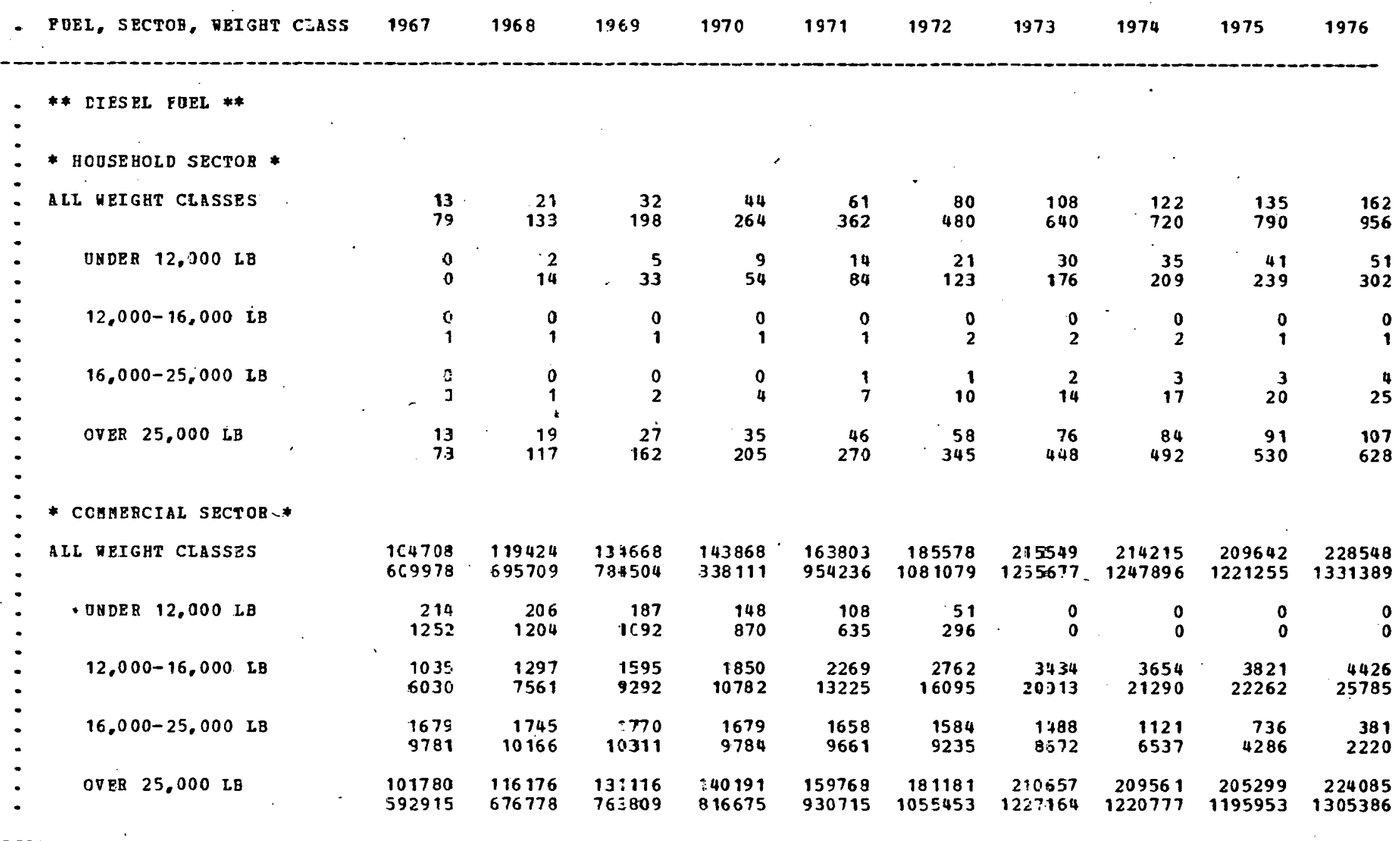

SODRCE: METHOD 331

DATA QUALITY (DISAGGREGATE DATA) : $2(1967,72), 3$ (OTIER YEARS)

(AGGREGATR DATA): $1(1967,72), 2$ (OTHER IEARS) 
TABLE 7.3A -- NONGOVERNHENT TBUCK ENERGY USR, BY POEL TYPE BT RANGE

BY BODY TYPE, 1967-76

(PIRST IN A SERIES OP 6 TABLES)

ENERGY OSE IN BILLIONS OF BTO

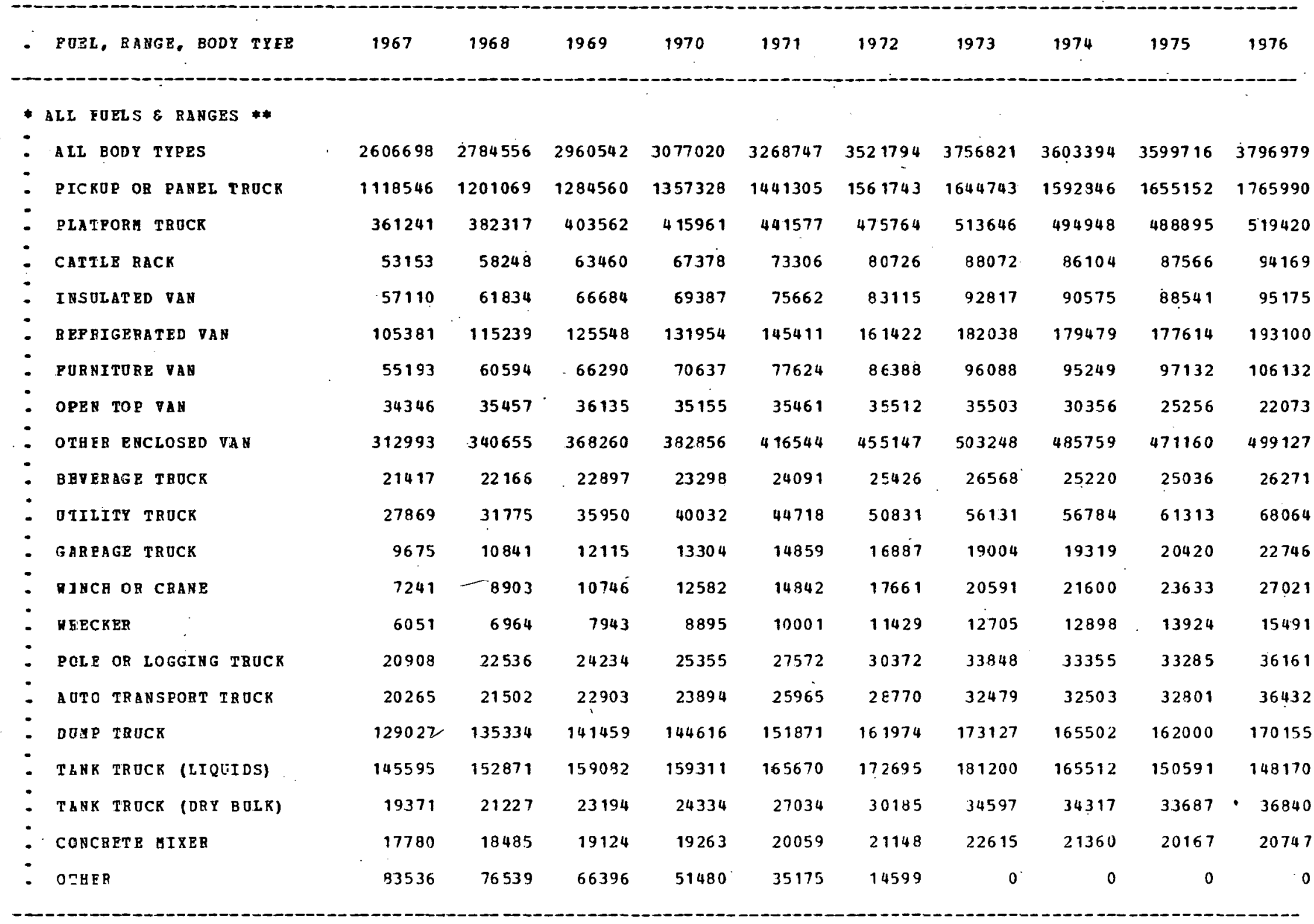




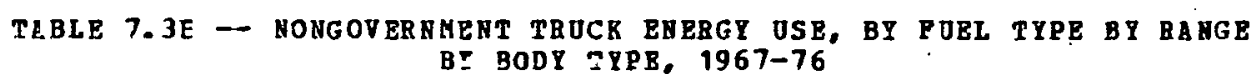

(SECOKB IN A SERIES OP 6 TABLES)

ENERGT OSE IT BILLIONS OP BTU

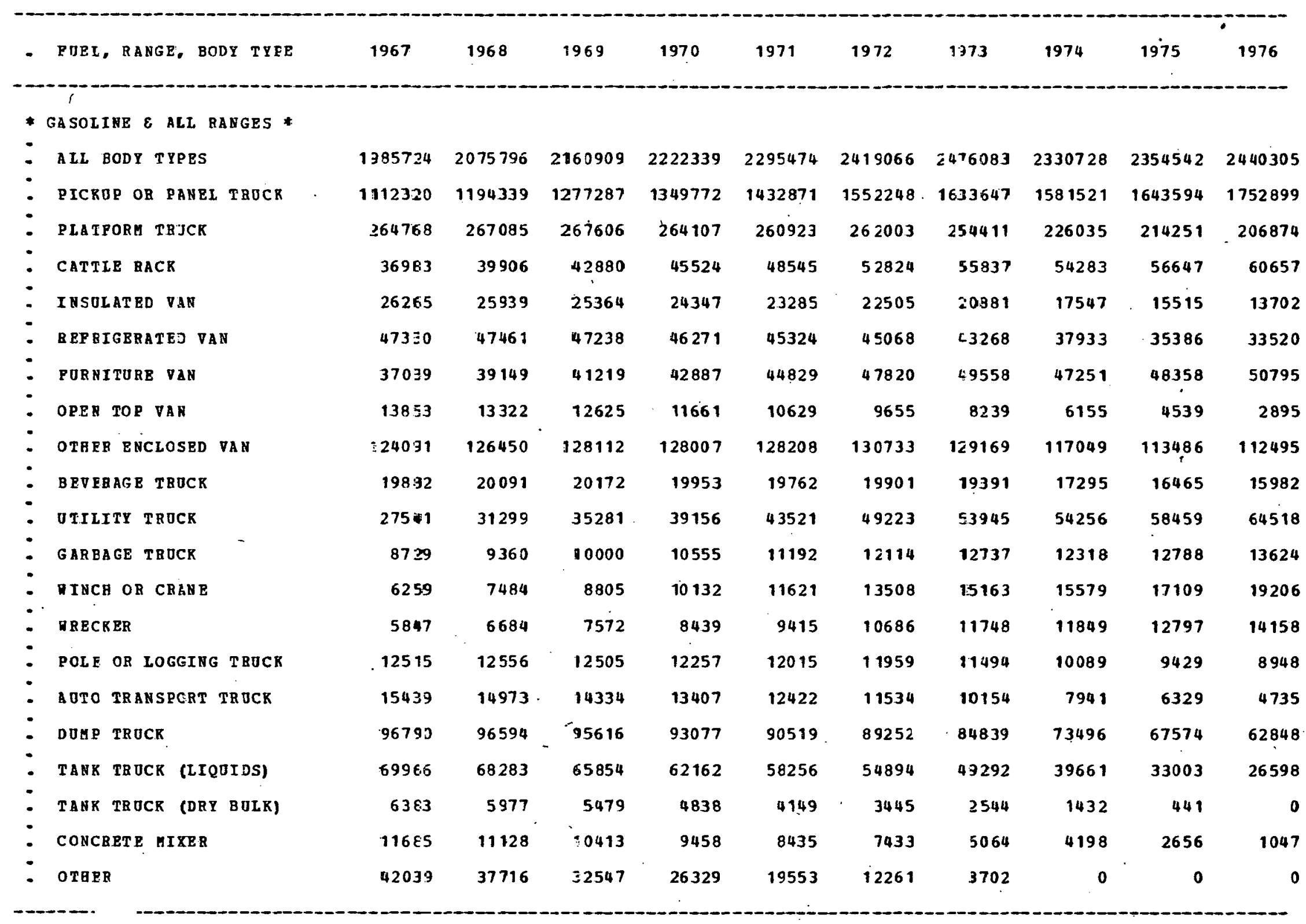

SOURCE: _. ETHOD 331

L.ATA 2UALITY: SAME AS TEBLBS 7.2A-7.2C 
TABLE 7.3C -- NONGOVERNAENT TROCK BNERGY USE, BY PUEL TYPE BY RANGE BY BODY TYPE, 1967-76

(TRIRD IN A SERIES OP 6 TABLES)

BHEBGY DSE IN BILLIONS OP BTO

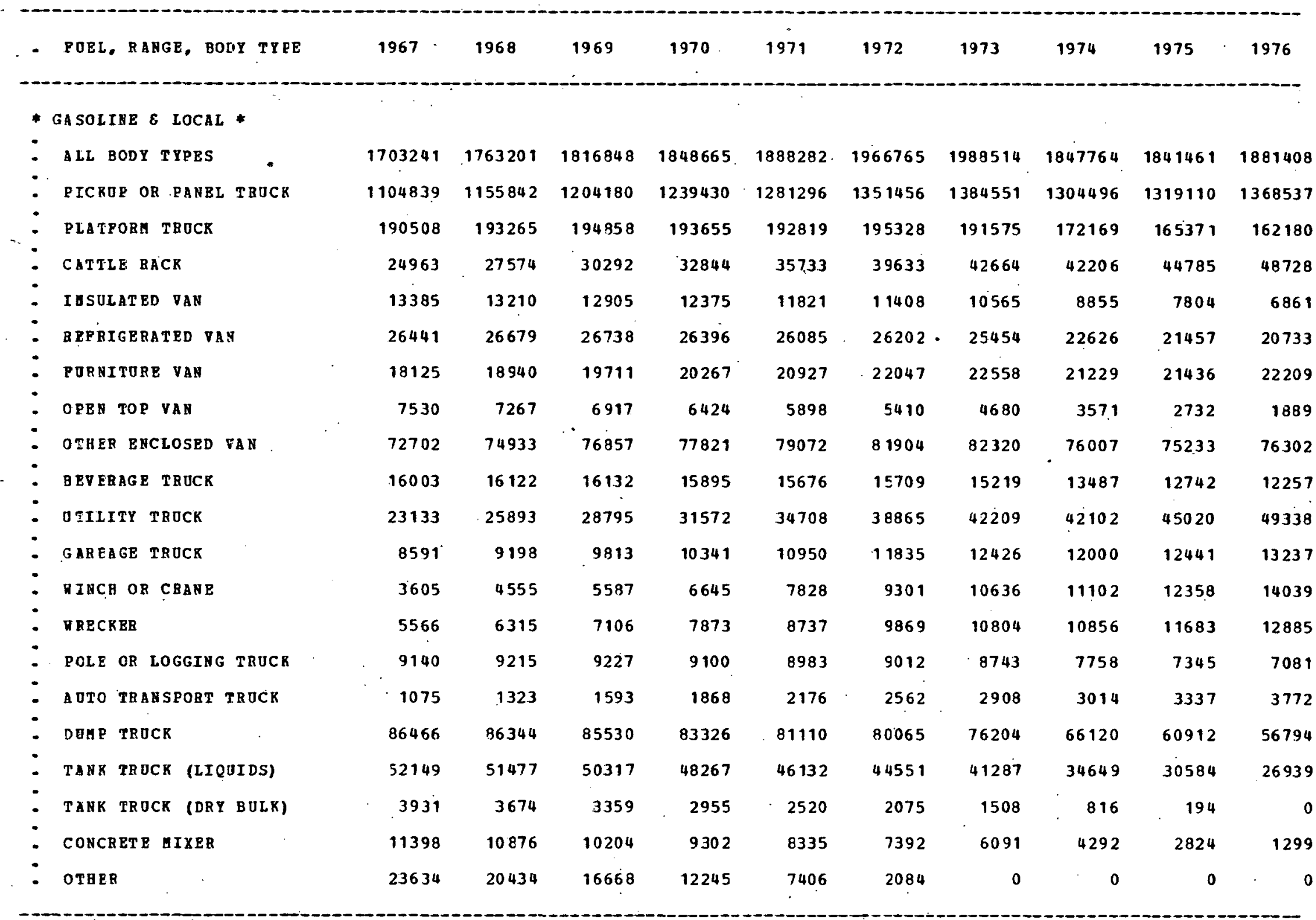


TABLE T.3D - NONGOVERAENT TROCK ENERGY USE, BY POEL TYPE BI AAMGE EY BODY TIPE, 1967-76

(FOERTE IN SERIES OP 6 TAELES)

BNERGY OSE IH BILLIOHS OP ETO

\begin{tabular}{|c|c|c|c|c|c|c|c|c|c|c|}
\hline - POEL, RANGE, BODY TYEE & 1967 & 1968 & 1969 & 1970 & 1971 & 1972 & 1973 & 1974 & 1975 & 1976 \\
\hline * Gasolthe $\varepsilon$ InTERCITt ** & & & & & & & & . & & \\
\hline - ALL BODY TYPES & 282590 & 312718 & 34417.6 & 373797 & 407313 & 452406 & 887650 & 483030 & 513146 & 558953 \\
\hline - PICKOP OR PANEL TRUCK & 7481 & 38497 & 73107 & 110342 & 151575 & 200792 & 249096 & 277025 & 324484 & 384362 \\
\hline - PLATPORA TRICK & 74260 & 73820 & 72748 & 70452 & 68104 & 66675 & 62836 & 53866 & 48880 & 44694 \\
\hline - Cattle Rack & 12020 & 12332 & 12588 & 12680 & 12812 & 13191 & 13173 & 12077 & 11862 & 11929 \\
\hline - IRSULATED VAH & 12860 & 12729 & 12459 & 11972 & 11469. & 11097 & .0 .316 & 8692 & 7711 & 6841 \\
\hline - REFBIGERATES VAN & 208E:9 & 20782 & 20500 & 19875 & 19239 & 18866 & i7814 & 15307 & 13929 & 12787 \\
\hline - PURATURE VAN & 18914 & 20209 & 21508 & 22620 & 23902 & $25773^{\circ}$ & 27000 & 26022 & 26922 & 28586 \\
\hline - OPE TOP VAY & $63 \div 3$ & 6055 & 5708 & 5237 & 4731 & 4245 & 3559 & 2584 & 1807 & 1006 \\
\hline - OTHER ENCLOSED VA & $513 E 9$ & 51517 & 51255 & 50186 & 49136 & 48829 & 66849 & 41042 & 38253 & 36193 \\
\hline - BEVEBAGE TROCK & 3879 & 3969. & 4040 & 4058 & 4086 & 4192 & 4172 & 3808 & 3723 & 3725 \\
\hline - OTILITY TROCR & 4438 & 5406 & 6486 & 7584 & 8813 & 10358 & 11736 & 12154 & 13439. & 15180 \\
\hline - GAREAGE TRUCK & 138 & 162 & 187 & 214 & 242 & 279 & 311 & . 318 & 347 & 387 \\
\hline - MINCH OR CRARB & 2654 & 2929 & 3218 & 3487 & 3793 & 4207 & 4527 & 4477 & 4751 & 5167 \\
\hline - YRECKER & $2 \geq 1$ & 369 & 466 & 566 & 678 & 817 & 944. & 993 & 1114 & 1273 \\
\hline - POLE OR LOGGING TROCR & 3375 & 3341 & 3278 & 3157 & 3032 & 2947 & 2751 & 2331 & 2084 & 1867 \\
\hline - AUTO TRANSPOBT TBOCR - & 14354 & 13650 & 12741 & 11539 & 10246 & 8972 & 7246 & 4927 & 2992 & 963 \\
\hline - DOMP TROCK & 10324 & 10250 & 10086 & 9751 & 9409 & 9187 & 8535 & 7376 & 6662 & 6054 \\
\hline$\because$ TANR TROCK (IIQUIDS) & 17817 & 16806 & 15537 & 13895 & 12124 & 10343 & 8005 & 5012 & 2419 & 0 \\
\hline - TANK TRUCK (DRY BULR) & 2452 & 2303 & 2120 & 1883 & 1629 & 1370 & 1736 & 616 & 247 & 0 \\
\hline - CONCRETE MIEER & $2: 37$ & 252 & 209 & 156 & 100 & 41 & 0 & 0 & 0 & 0 \\
\hline - OTHER & $184: 15$ & 17282 & 15879 & 14084 & 12147 & 10177 & 7535 & 4469 & 1664 & 0 \\
\hline
\end{tabular}


TABLE 7.3E - MONGOVERNEEYT TROCK ENERGY OSE, BY POEL TYPE BY RAHGE BY BODY TYPE, 1967-76

(SECOQD IB A SERIES OP 6 TABLES)

BNERGY OSE IN BILLIOYS OF BTO

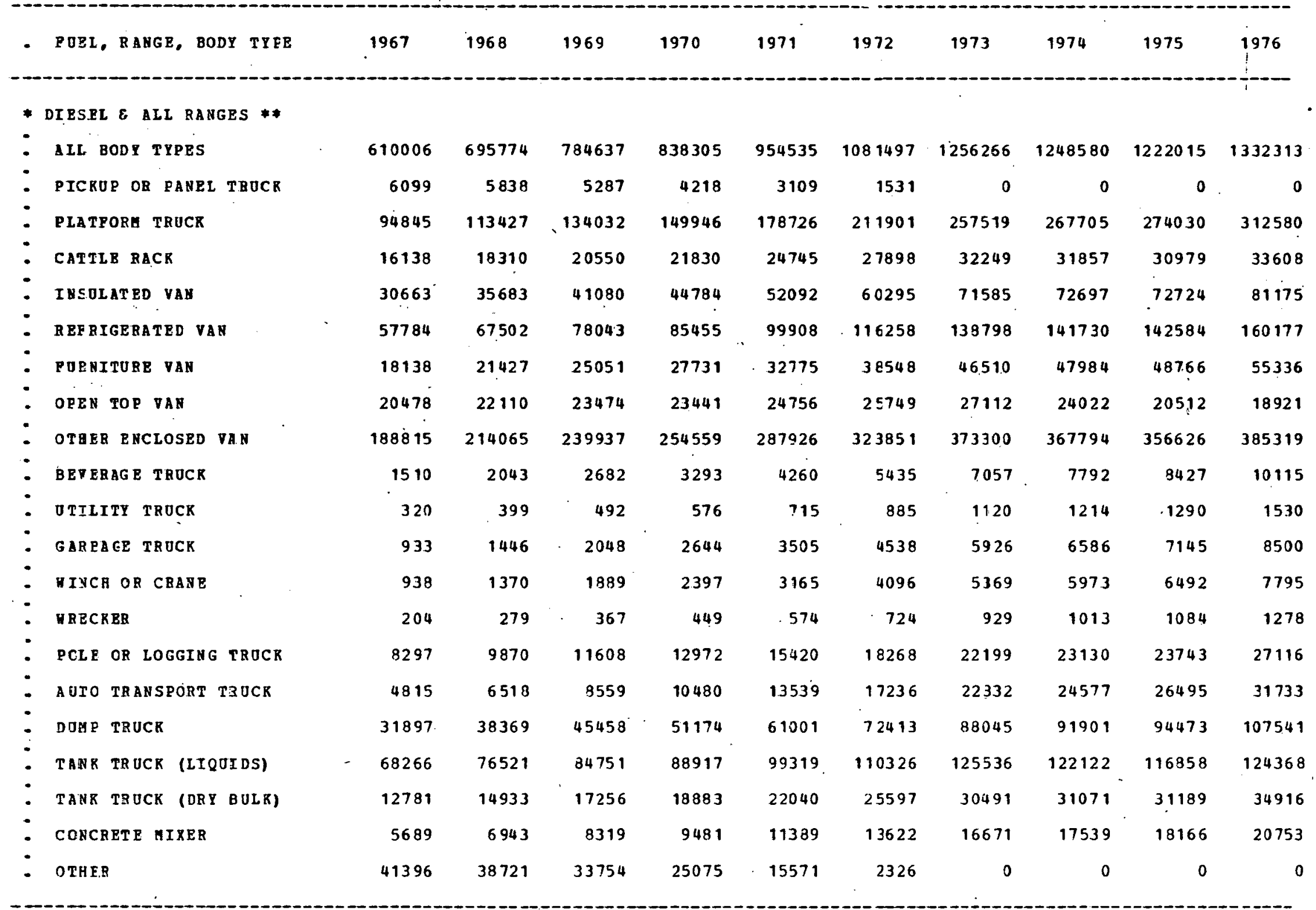




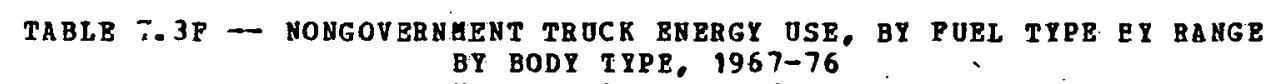

(FIPTH IN A SEBIES OF 6 TABLES)

RHERGT USE IN BILLIOHS OP BTO

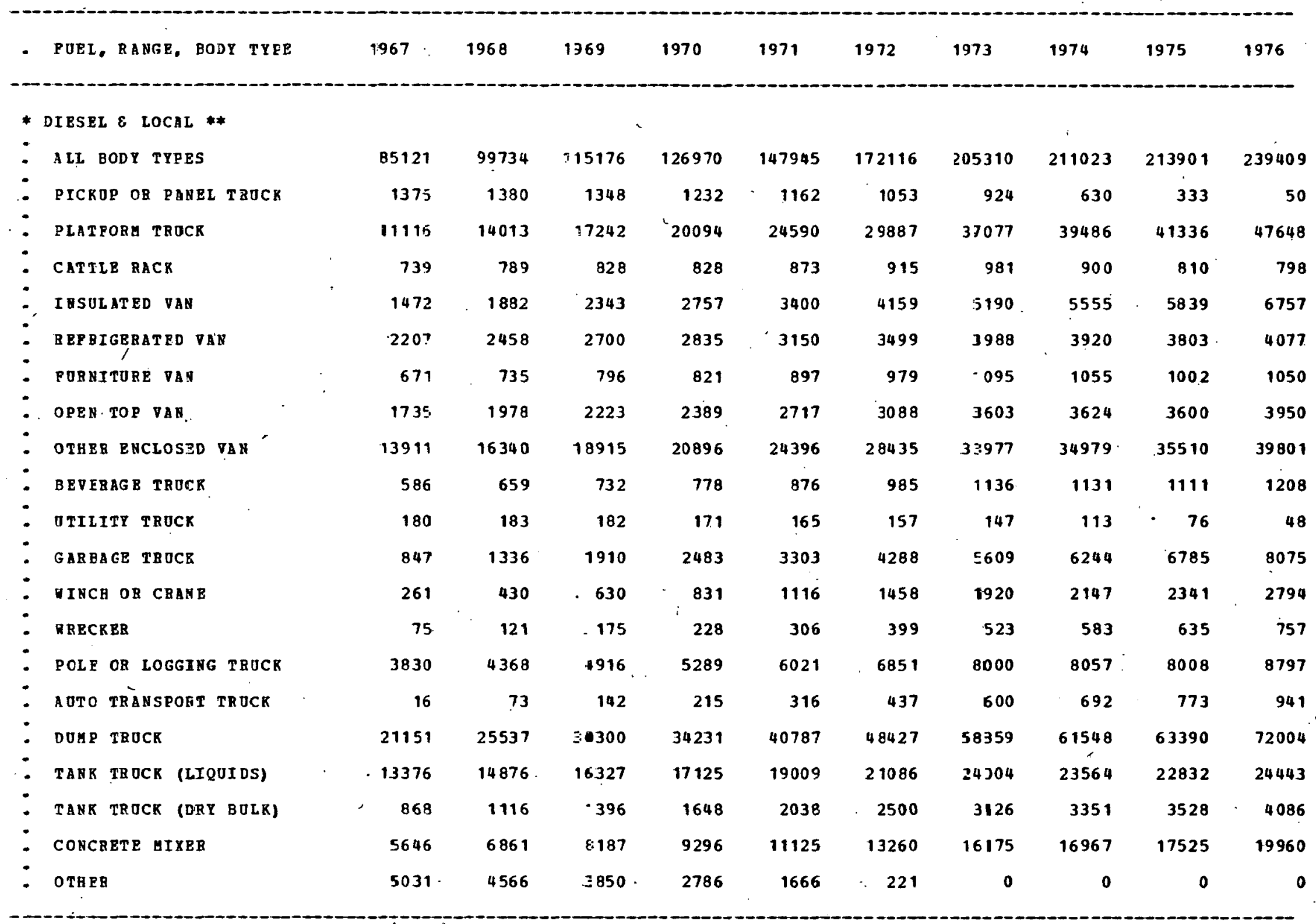

SOURCE: RTHOD 331

DATA QTALITI: SABE AS TARLBS 7.2A-7.2C 
TABLE 7. 3G - NOHGOVERYGENT TROCK ERERGY USE, BY PUBL TYPE BY RABGB BY BODY TYPE, 1967-76

(IAST IB A SERIES OF 6 TABLES)

ENERG OSE IA BILLIONS OP BTD

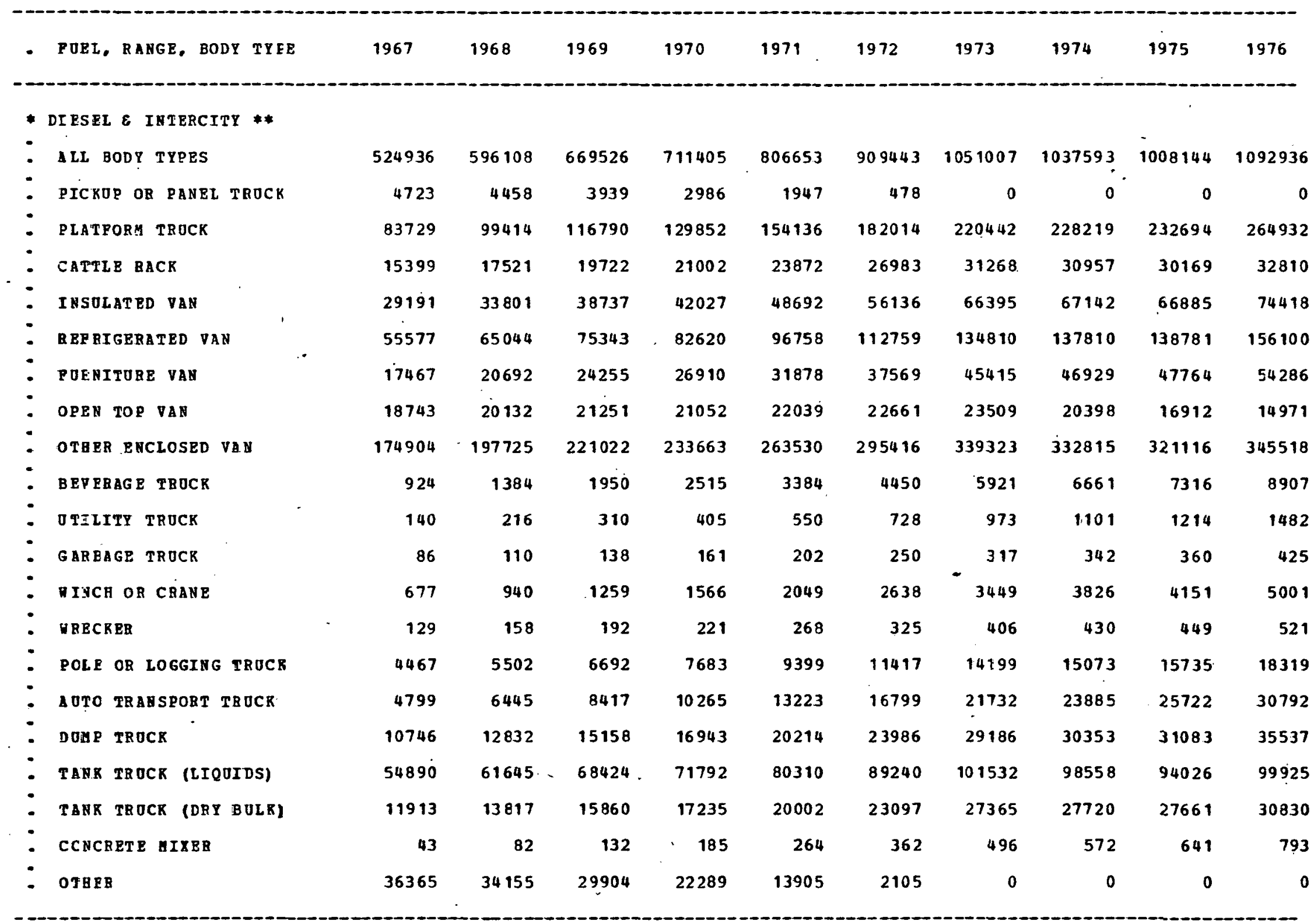


TABLE 7.4A - LOCAL HCTSBBOLD TROCK BHERGY OSR, BY STATE, 1967-76 (PIEST IB A SEBIES OP 5 TABLES)

BABEGT CO\&SOMPTICA IN BILLIOAS OF BTO

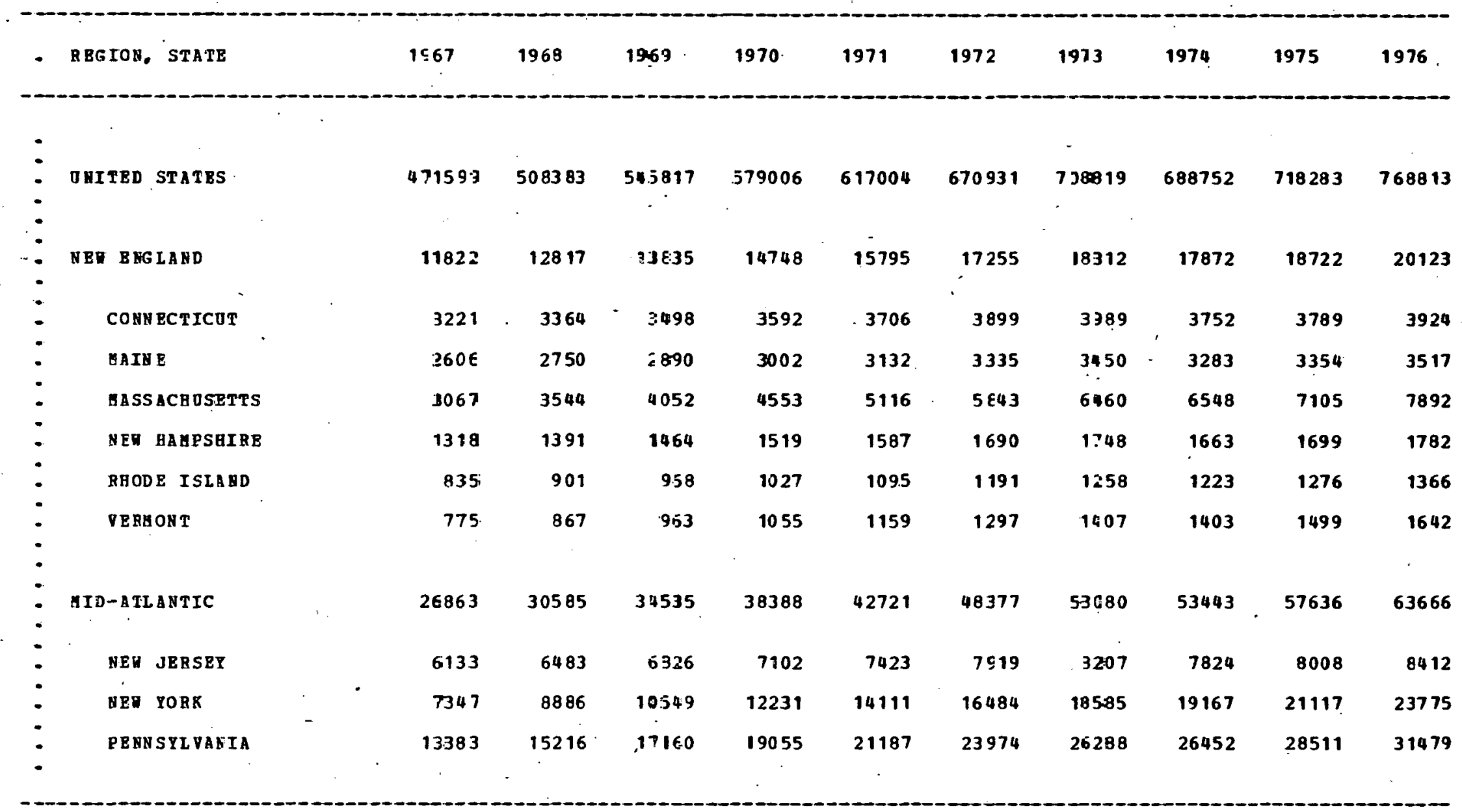

SOORCE: AETEOD 332

DATA QDALITY: 2 (1967-68,71-73).? (CEHER YEARS) 
TABLE 7.4R -- LOCAL HOUSEBOLD TROCK EHEBGI OSE, BI STATE, 1967-76

(SECOND IN A SERIES OF 5 TABLES)

ENERGY CONSUAPTION IN BILLIONS OF BTO

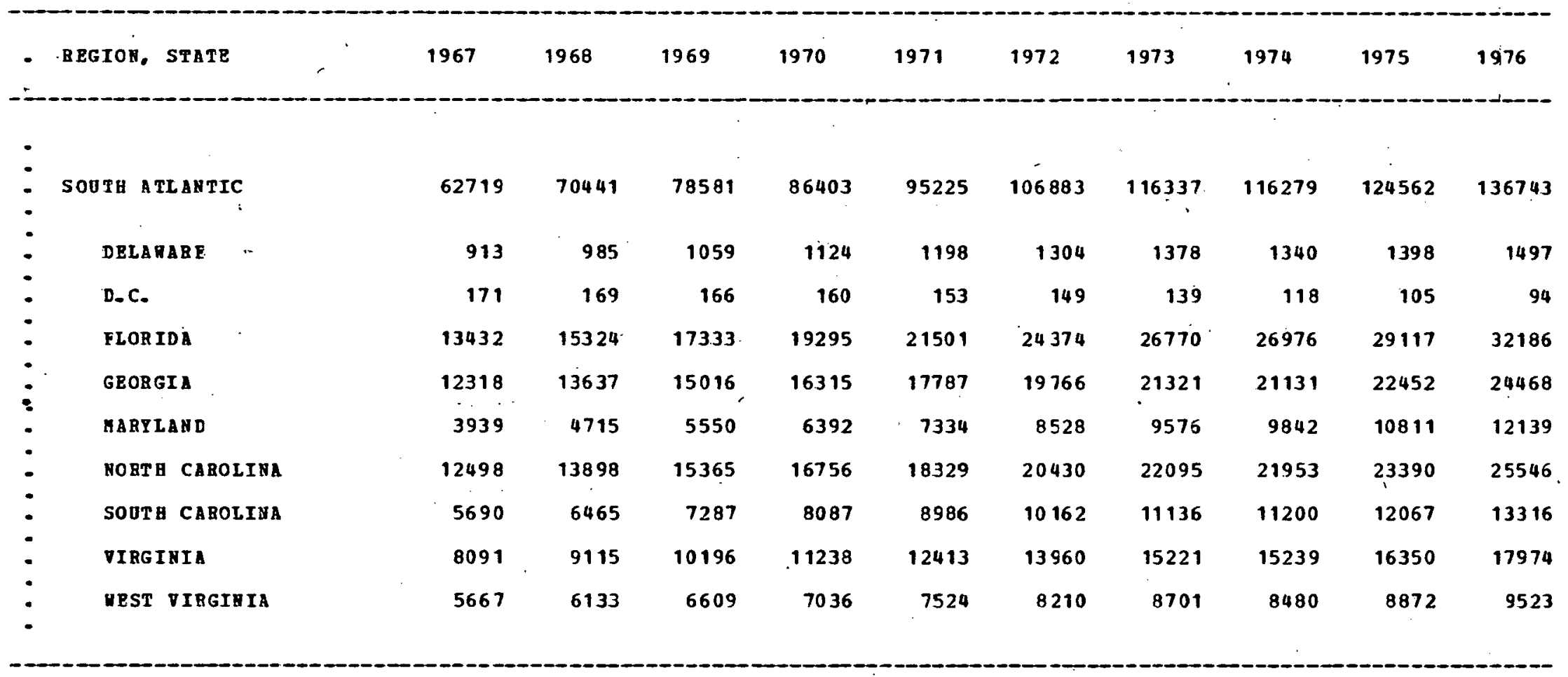

SOURCE: GETHOD 332

DATA QUALTTY: 2 (1967-68,71-73), 3 (OTRER YEARS) 
TABLE 7.4C - LOCAL HOUSEHOLD TBUCK BNERGY USE, BY STATE, 1957-76 (THIRD EN A SBRIBS OF 5 TABLES)

ENE EGT CONSOHPTION IN BILLIOUS OF BTU

\begin{tabular}{|c|c|c|c|c|c|c|c|c|c|c|c|}
\hline & REGION, STATE & 1967 & 1968. & 1969 & 1970 & 1971 & 1972 & 1975 & 1974 & 1975 & 1976 \\
\hline & & . & & & & & & & & & \\
\hline & EAST NORTH CENTRAL & 53566 & 60121 & 67029 & 73663 & 81149 & 91047 & 99070 & 98988 & 105998 & 116336 \\
\hline & ILLINOIS & 12025 & 13147 & $1+306$ & 15373 & 16585 & 18249 & .13497 & 19151 & 20185 & 21823 \\
\hline 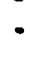 & INDI ANA & 13405 & 13733 & 13996 & 14076 & 14203 & 14601 & $1+567$ & 13338 & 13066 & 13118 \\
\hline & DICHIGAN & 15408 & 17921 & 20509 & 23273 & 26262 & 30104 & 33389 & 33945 & 36930 & 41117 \\
\hline & OH IO & 9989 & 11720 & 13590 & 15663 & 17873 & 20686 & 23137 & 23696 & 25949 & 29060 \\
\hline & M I SCONSIN & 2339 & 3600 & $4 \div 28$ & 5278 & 6226 & 7407 & 8490 & 8858 & 9868 & 11218 \\
\hline & EAST SOOTA CENTRAL & 35260 & 39222 & 43378 & 47326 & 51790 & 57757 & 62534 & 62140 & 66230 & 72381 \\
\hline & ALABAKA & 13961 & 14649 & 15309 & 15808 & 16395 & 17352 & 17839 & 16868 & 17121 & 17830 \\
\hline & KERT UCKY. & 5659 & 6959. & 8368 & 9801. & 11402 & 13412 & $15: 210$ & 15764 & 17442 & 19712 \\
\hline & AISS ISSIPPI & 8: 18 & 9162 & 9592 & 9927 & 10324 & 10960 & $11 \geq 17$ & 10747 & 10945 & 11457 \\
\hline & TENR ESSEE & 6922 & 8452 . & 10109 & 11790 & 13669 & 16033 & 18138 & 18761 & 20722 & 23382 \\
\hline
\end{tabular}

SOUBCE: HETHOD 332

DATA QUALITI: 2 (1967-68,71-73), J (OTHER IBARS) 
TABLE 7.4D -- LOCAL HOOSEBOLD TB OCK ENERGY OSE, BY STATE, 1967-76 (POORTH IN A SEBIES OP 5 TABLSS)

ZNEBGY CONSUGPTION IN BILLIONS OF BTO.

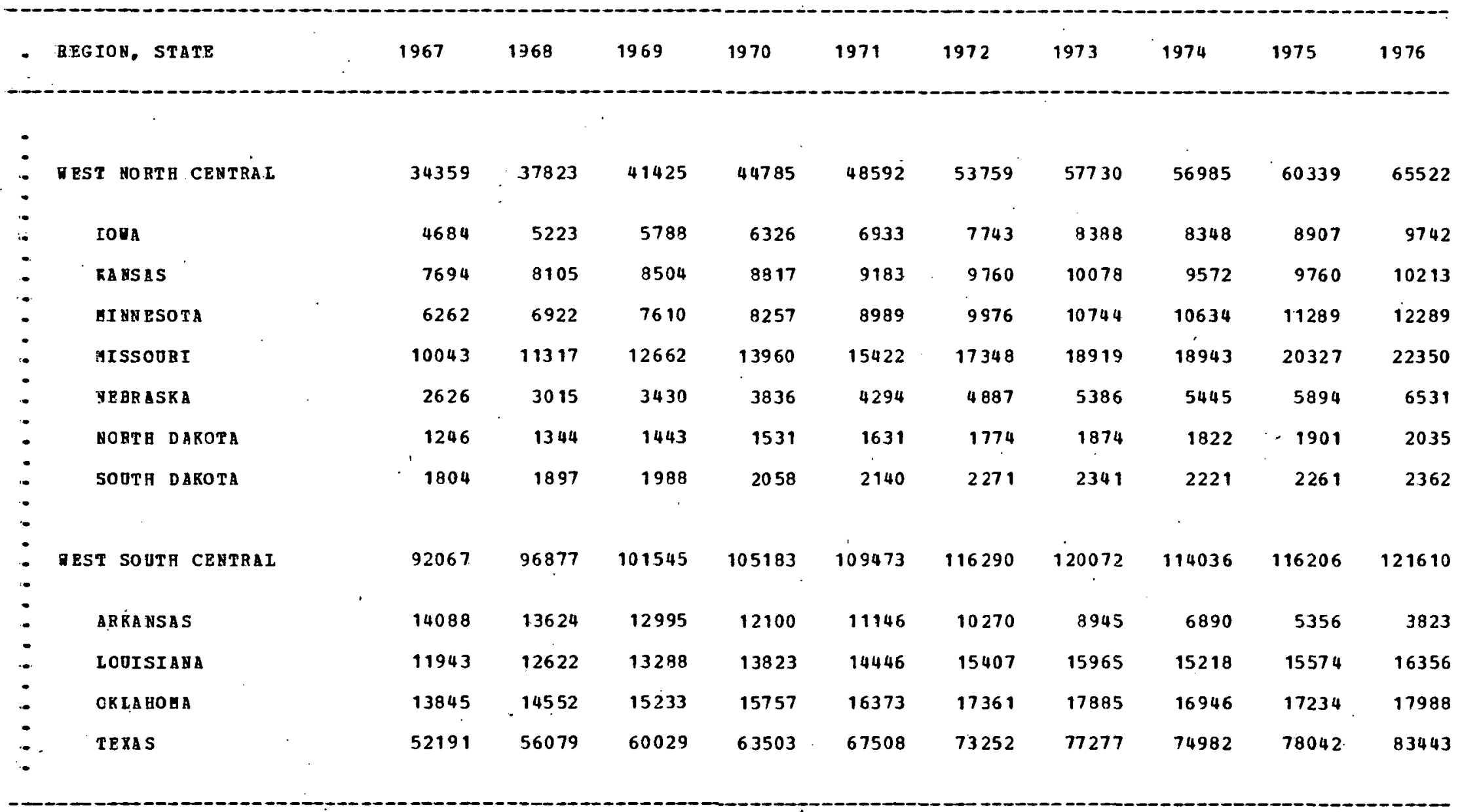

SOERCE: METHOD 332

DATA QUALITY: 2 (1967-63,71-73), 3 (OTHER YFARS) 
TABLE 7.4E - LOCAL BOUSEBOLD TRUCK BHEBGY USB, BY STATE, 1967-76

(LAST IN A SBEIES OP 5 TABLES)

BHERGY CONSOHPTIOA IX BILLTOAS OP BTU

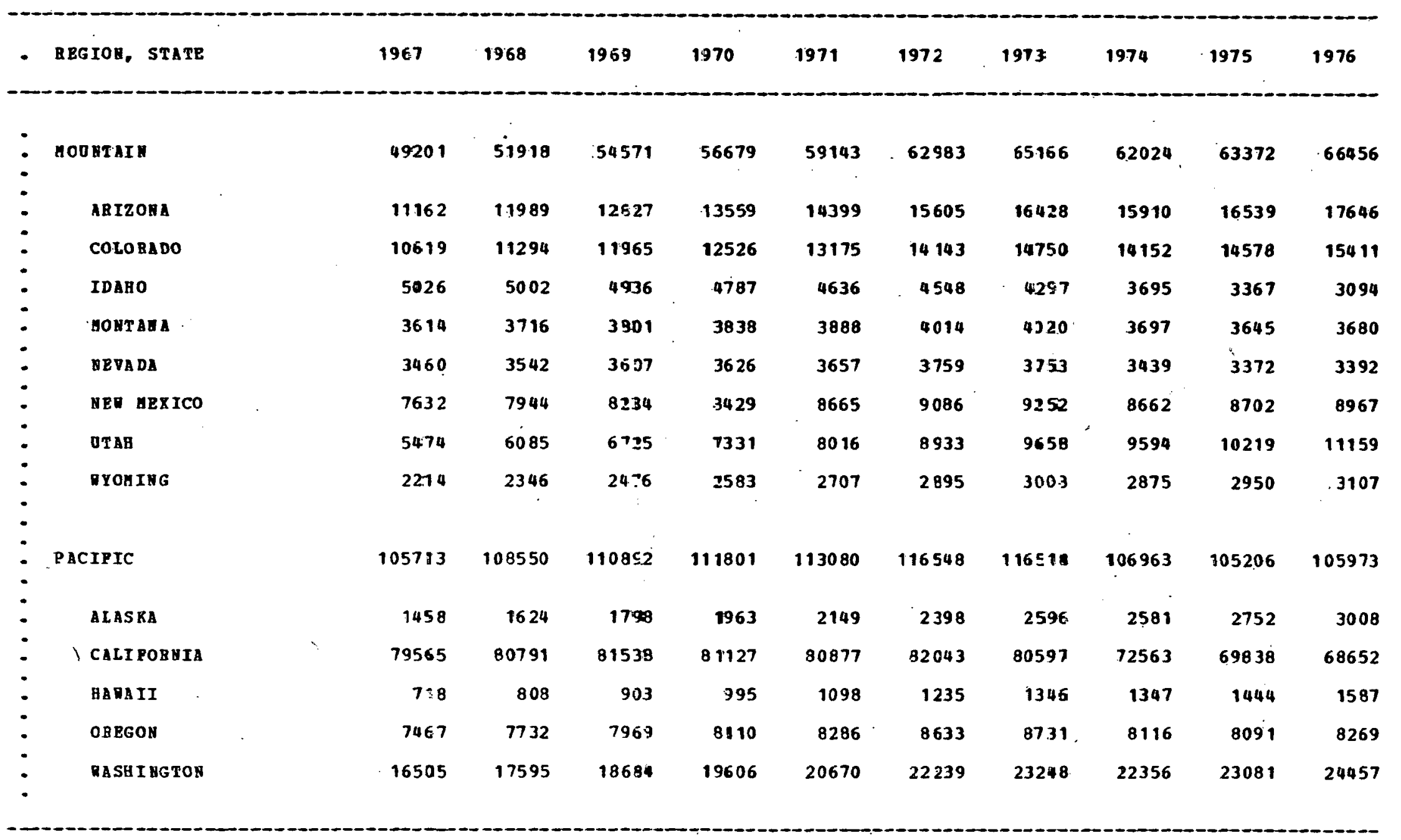

SOORCE: HETHOD 332

DATA QUALITY: 2 (1967-68,71-73), 3 (OTHER YBARS) 
TABLB 7.5 - LOCAL COHMERCIAL TRUCK ENERGY OSE, BY STATE, 1967-76 (FIRST I A SBRTBS OF 5 TABLBS)

ENE EGY CONSOHPTION IN BILLIONS OF BTO

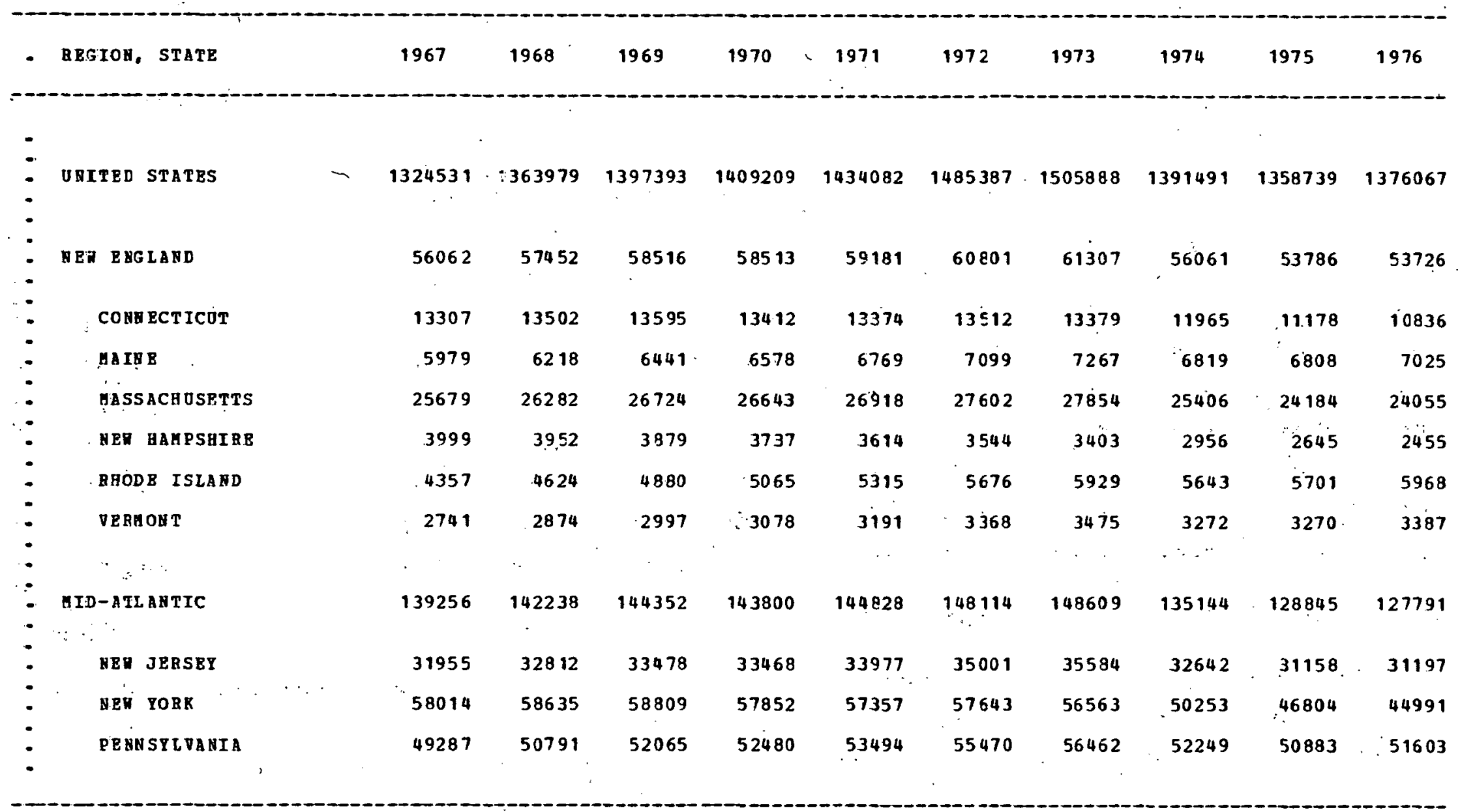

SOORCE: IETHOD 332

DATA QOALITY: 2 (1967-68,71-73), 3 (OTHER TEARS) 
TABLE 7.5B -- LOCAL COHH3RCIAL TROCK ENERGY USE, BY STATE, 1957-76

(SBCOAD IN A SERIES OP 5 TABLBS)

RNEEGT CONSUMPTION IN BILITONS OP BTO

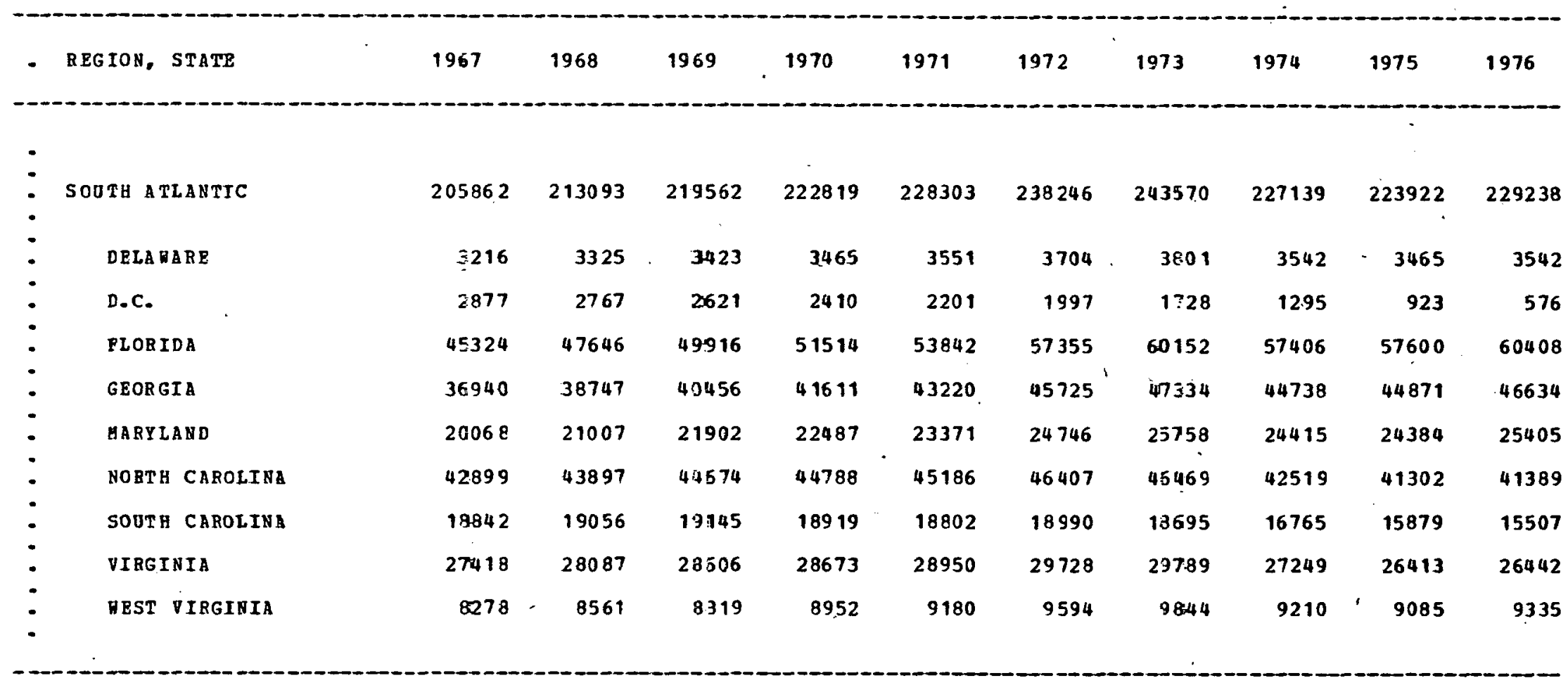

SOURCE: METHOD 332

DATA QUALITY: 2 (1967-68,T1-73), 3 (OTHER YEARS) 
TABLE 7.5C -- LOCAL COHMRRCTAL TROCK ENERGY USE, BY STATE, 1967-76 (THIBD IN A SERIES OP 5 TABLES)

BNEBGT CONSUMPTION IN BILLIONS OF BTU

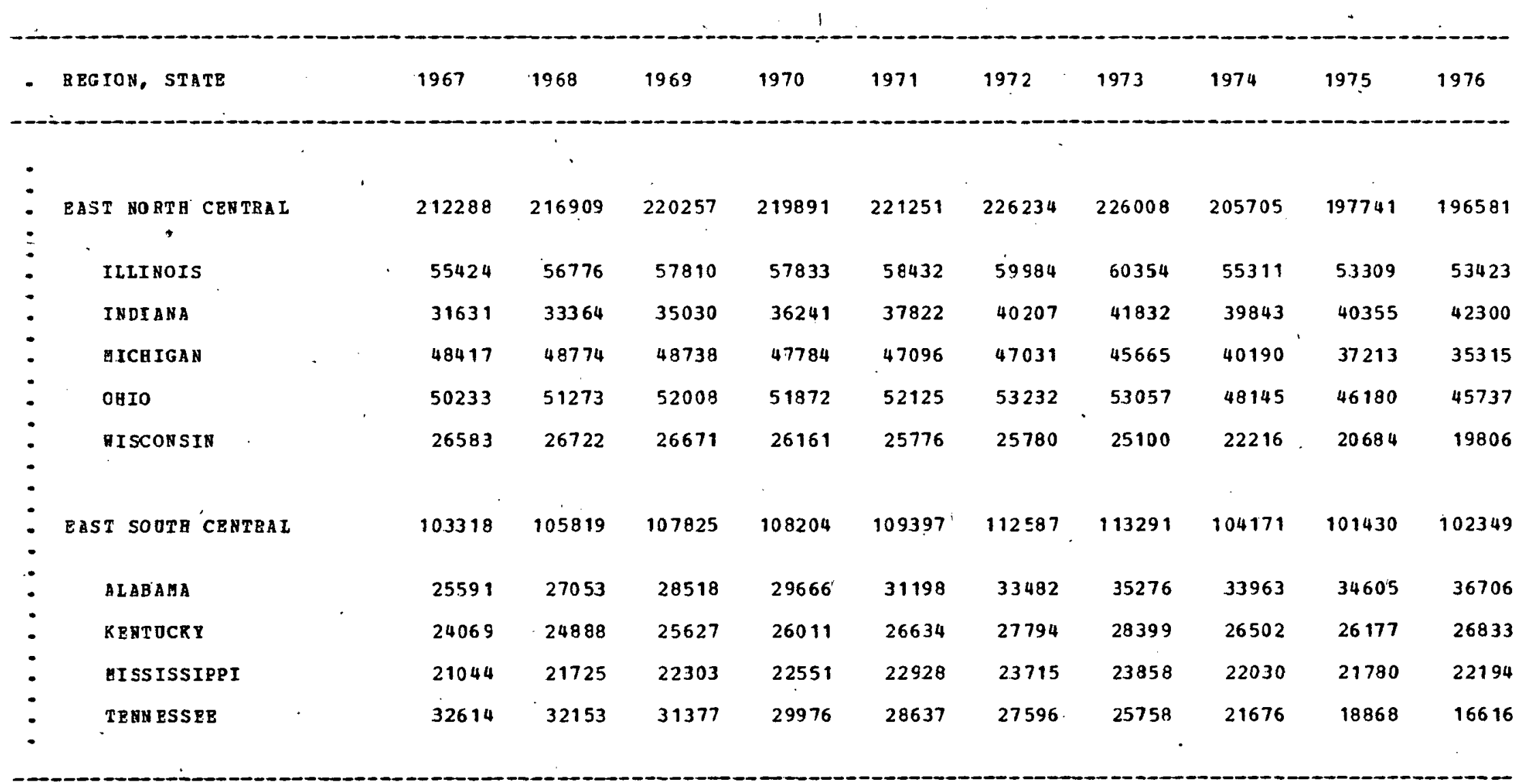

SOUBCE: $\triangle$ ETHOE 332

DATA QOALTTY 2 (1967-68,71-73), 3 (OTHER IEARS) 
TABLE 7.5L - - LOCAL COEGEBCIAL TBUCR ERERGY OSE, BP STATE, 1967-76 (POOBTH IN A SBRIES OP 5 TABLBS)

ENBRGY CONSOUPTION IN BILLIOHS OF BTO

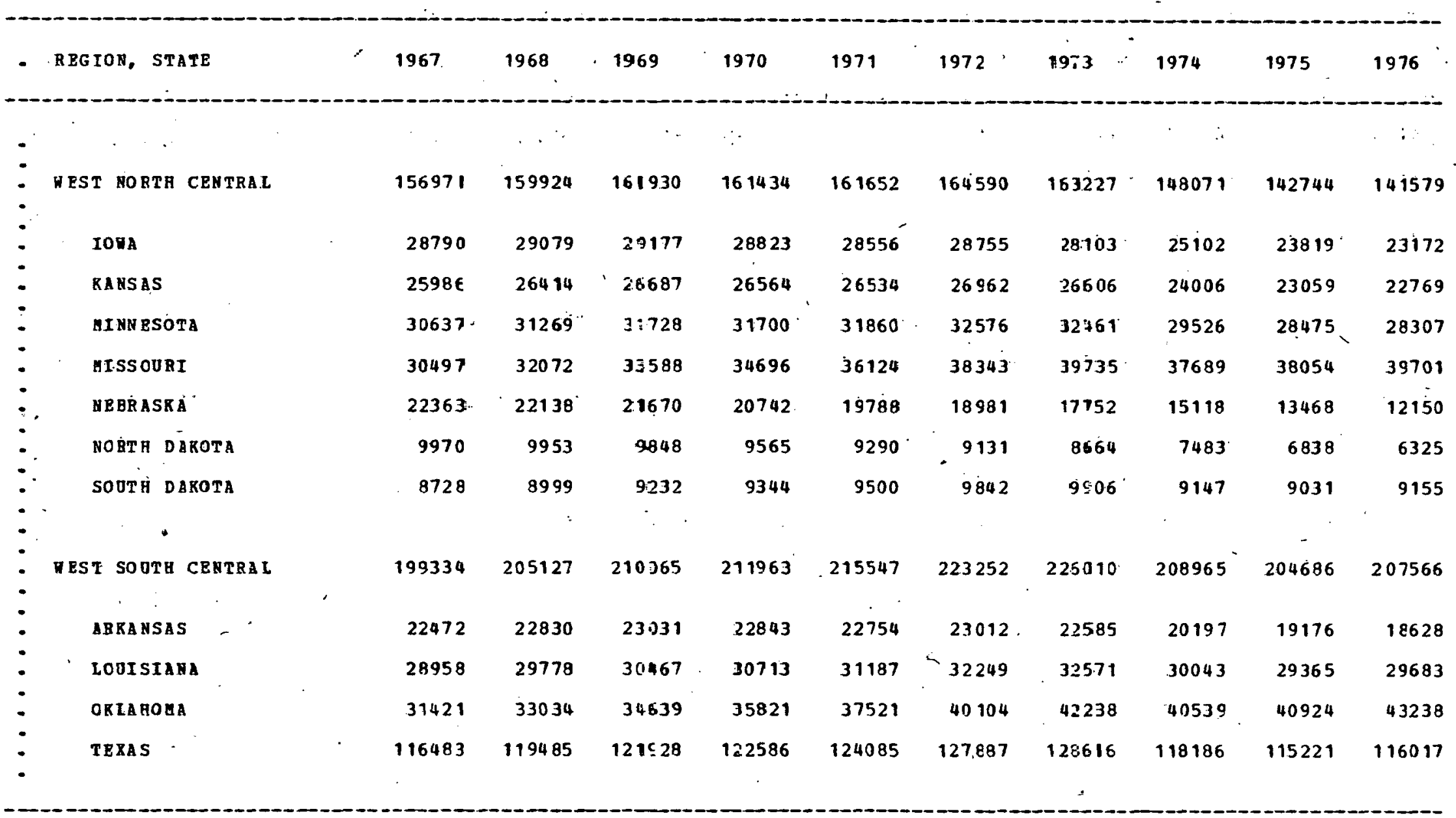

SORRCE AETHOD 332

DATA QDALITY: 2 (1967-68,71-73), 3 (OLERR YRABS) 
TABLE 7.5E - LOCAL COMHERCIAI TROCR BHBBGI USE, BY STATB, 1967-76 (LAST IE A SERIBS OP 5 , TABLBS)

EREBGY COBSUMPTION IH BILLIONS OP BTU

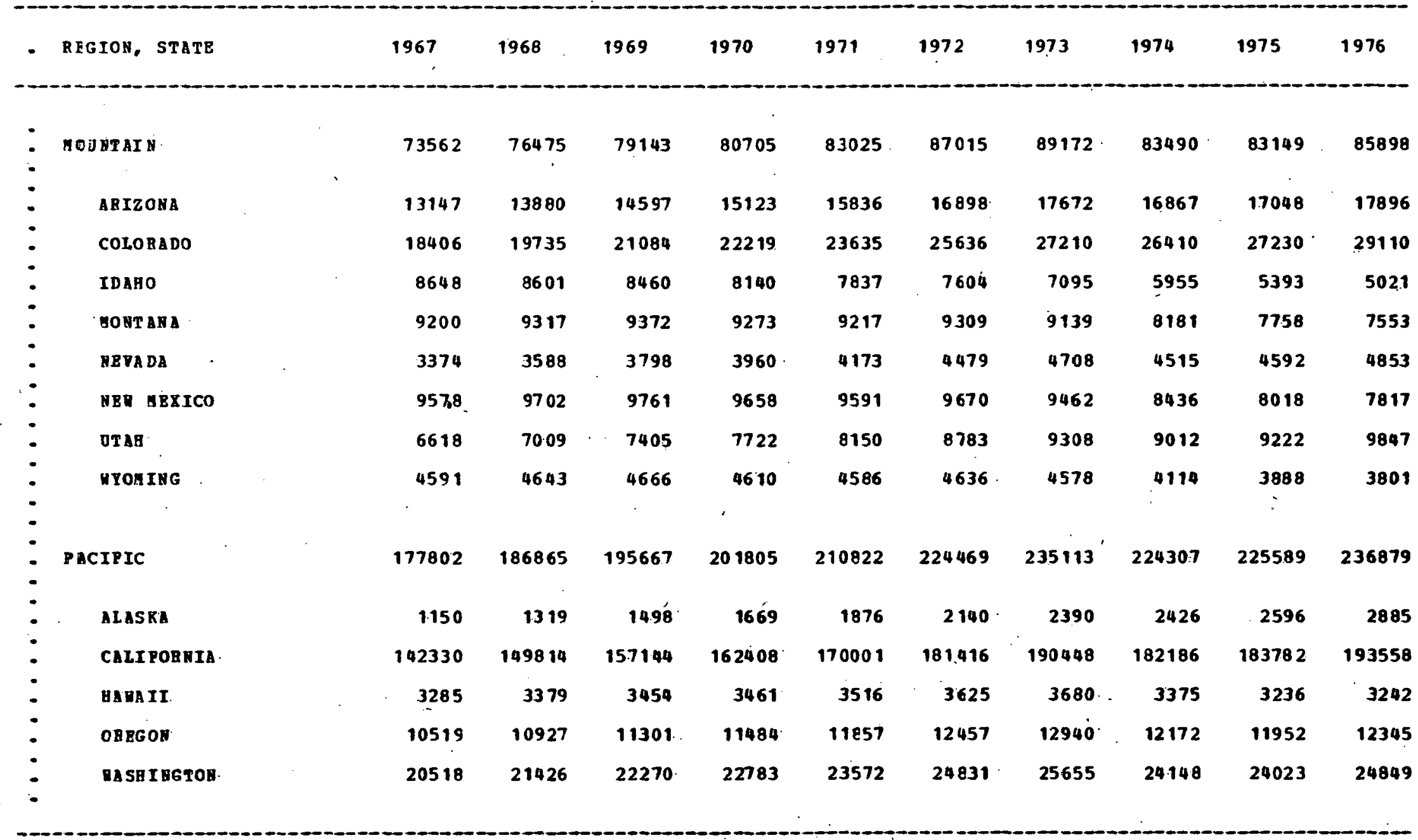

SOEBCE: ABTHOD 332

DATA QDALITI: 2 (1967-68,71-73). 3 (OTBEB IBABS) 


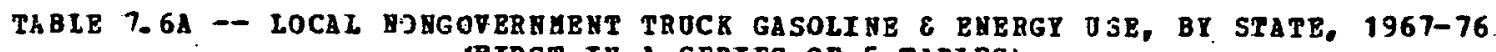

(FIRST IB A SERIBS OP 5 TABLES)

GASCLIYE USE IN THOOSANDS OP BABRELS, FOLLOWBD BY BRERGY USE IA BILLIONS OP BTO

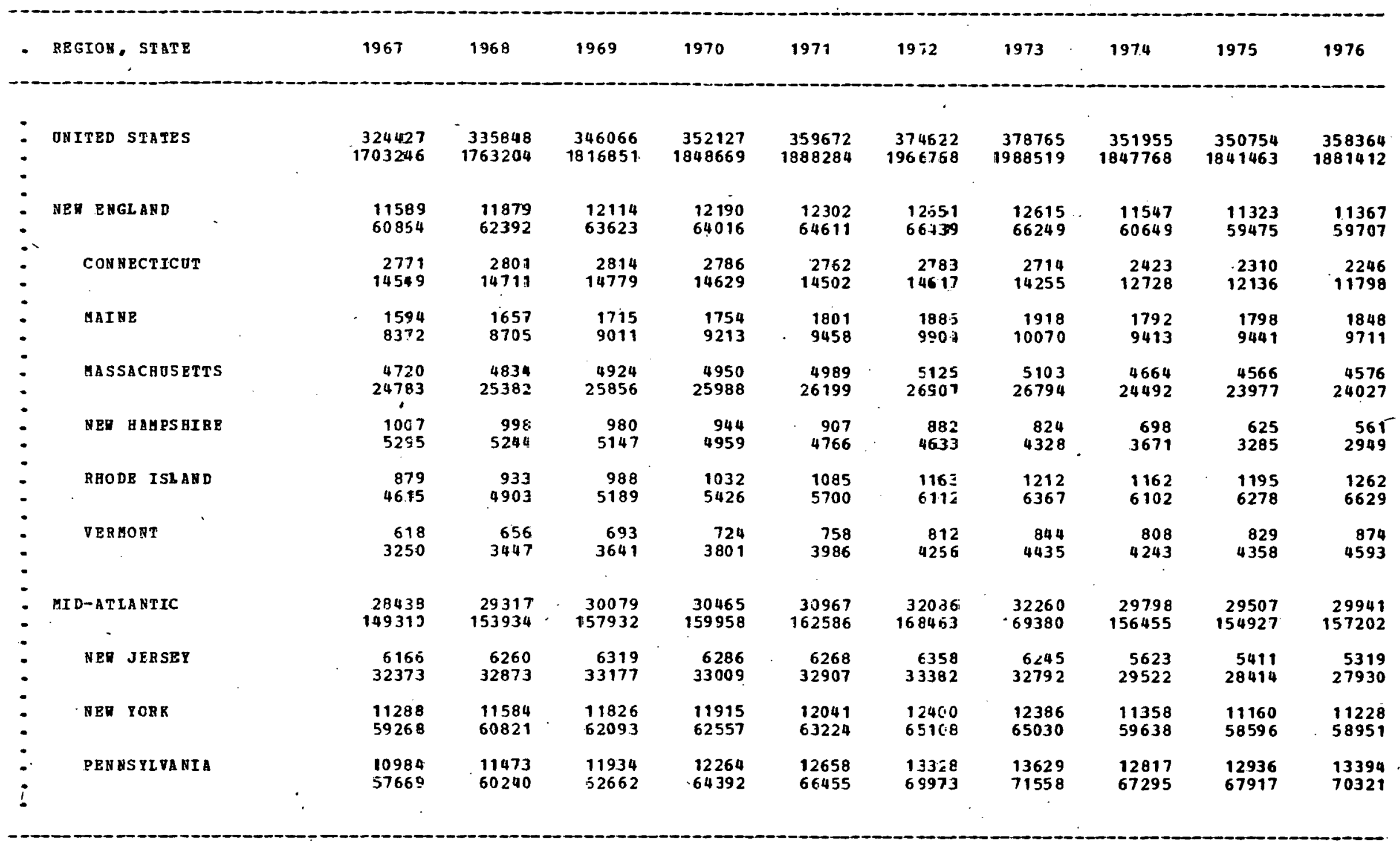


TABLE 7.6B -- LOCA NOBGOVERAEET TRUCK GASOLIRE E ENERGY OSB, BT STATE, 1967-76

(FIRST IA A SEBIBS OP 5 TABLBS)

GASOLINE USE IN THOOSA OPS BARBLS, FOILONED BY ENERGY OSE IN BILLIONS OP BTO

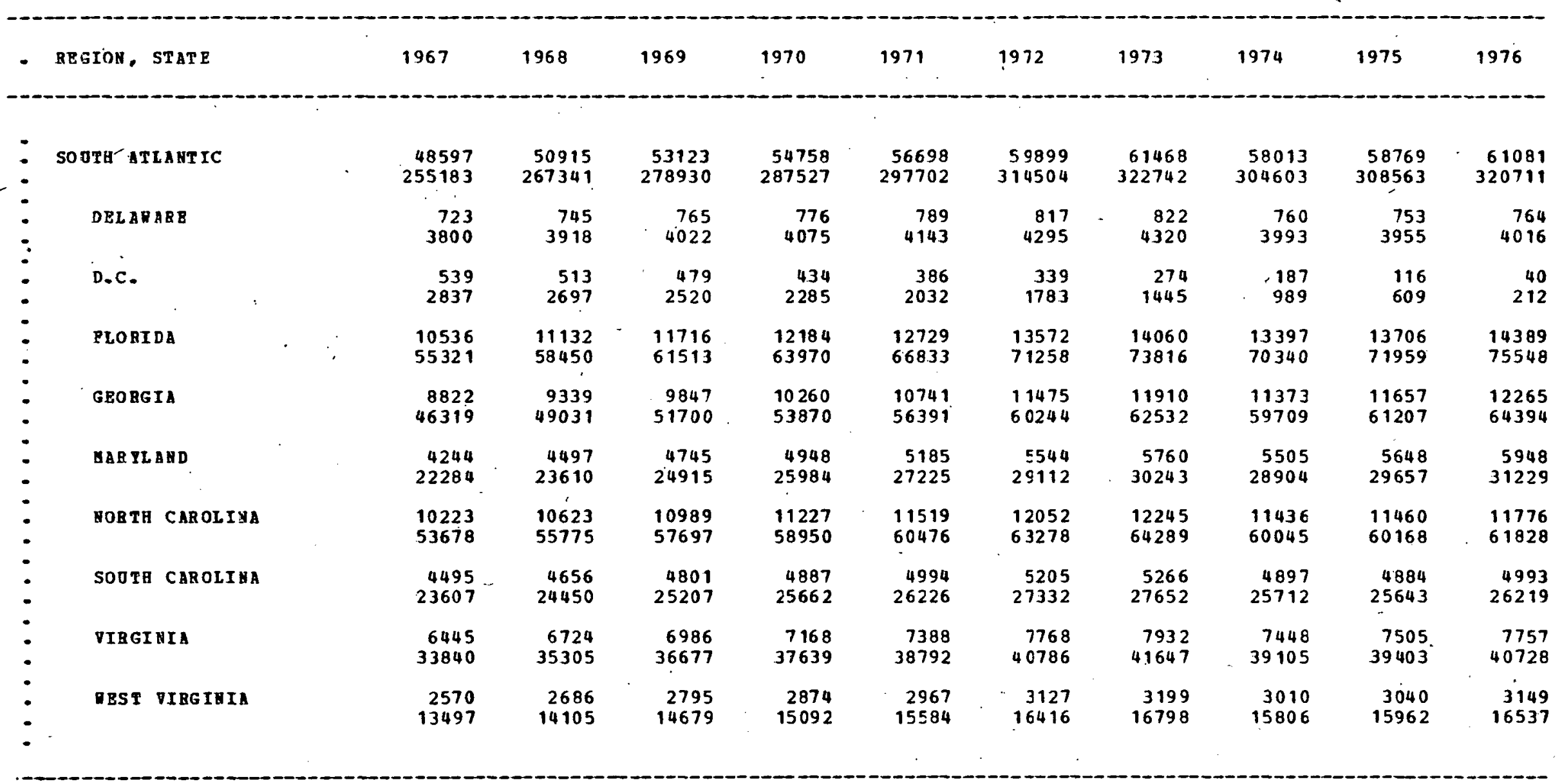




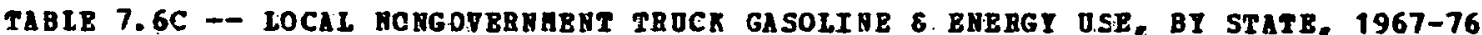

(PIBST IR A SERIBS OP 5 TABLES)

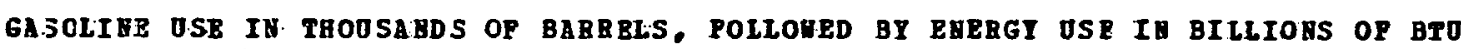

\begin{tabular}{|c|c|c|c|c|c|c|c|c|c|c|c|}
\hline & REGIOR, STATE & 1967 & 1968 & 1969 & 1970 & 197.1 & 1972 & 1973 & 1974 & 1975 & 1976 \\
\hline & $\begin{array}{l}\text { EAST HORTA CBHTBAL } \\
\text { Y }\end{array}$ & $\begin{array}{r}47499 \\
249398\end{array}$ & $\begin{array}{r}49224 \\
258446\end{array}$ & $\begin{array}{r}50777 \\
266600\end{array}$ & $\begin{array}{r}51726 \\
271580\end{array}$ & $\begin{array}{r}52899 \\
277737\end{array}$ & $\begin{array}{r}5517.3 \\
28965\end{array}$ & $\begin{array}{r}55854 \\
293257\end{array}$ & $\begin{array}{r}51975 \\
272894\end{array}$ & $\begin{array}{r}51877 \\
272382\end{array}$ & $\begin{array}{r}53090 \\
278752\end{array}$ \\
\hline & ILLINOIS & $\begin{array}{l}11818 \\
62049\end{array}$ & $\begin{array}{l}12135 \\
63710\end{array}$ & $\begin{array}{l}12396 \\
65078\end{array}$ & $\begin{array}{l}12496 \\
65606\end{array}$ & $\begin{array}{l}12638 \\
66350\end{array}$ & $\begin{array}{l}13024 \\
6 E 377\end{array}$ & $\begin{array}{l}13018 \\
68348\end{array}$ & $\begin{array}{l}11948 \\
62734\end{array}$ & $\begin{array}{l}11750 \\
61696\end{array}$ & $\begin{array}{l}11834 \\
62135\end{array}$ \\
\hline & IRDIARA & $\begin{array}{r}8167 \\
42878\end{array}$ & $\begin{array}{r}849 i \\
4461 \vdots\end{array}$ & $\begin{array}{r}8801 \\
46214\end{array}$ & $\begin{array}{r}9006 \\
47286\end{array}$ & $\begin{array}{r}9253 \\
48583\end{array}$ & $\begin{array}{r}9698 \\
50915\end{array}$ & $\begin{array}{r}9868 \\
51814\end{array}$ & $\begin{array}{r}9233 \\
48480\end{array}$ & $\begin{array}{r}9269 \\
48667\end{array}$ & $\begin{array}{r}9544 \\
50109\end{array}$ \\
\hline 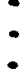 & MICHIGAN & $\begin{array}{l}11378 \\
59742\end{array}$ & $\begin{array}{l}11865 \\
62297\end{array}$ & $\begin{array}{l}12320 \\
64684\end{array}$ & $\begin{array}{l}12637 \\
66345\end{array}$ & $\begin{array}{l}13016 \\
68338\end{array}$ & $\begin{array}{l}136.77 \\
7180 \subseteq\end{array}$ & $\begin{array}{l}13957 \\
73280\end{array}$ & $\begin{array}{l}13097 \\
68763\end{array}$ & $\begin{array}{l}13188 \\
69239\end{array}$ & $\begin{array}{l}13621 \\
71519\end{array}$ \\
\hline & OHIO & $\begin{array}{l}10737 \\
56376\end{array}$ & $\begin{array}{l}11201 \\
58809\end{array}$ & $\begin{array}{l}11635 \\
61087\end{array}$ & $\begin{array}{l}11.938 \\
62680\end{array}$ & $\begin{array}{l}12302 \\
64590\end{array}$ & $\begin{array}{l}12933 \\
67931\end{array}$ & $\begin{array}{l}13204 \\
69324\end{array}$ & $\begin{array}{l}12395 \\
65080\end{array}$ & $\begin{array}{l}12487 \\
65564\end{array}$ & $\begin{array}{l}12905 \\
67756\end{array}$ \\
\hline & HISCOBSIN & $\begin{array}{r}5399 \\
28353\end{array}$ & $\begin{array}{r}5526 \\
29017\end{array}$ & $\begin{array}{r}5625 \\
29537\end{array}$ & $\begin{array}{r}5649 \\
29663\end{array}$ & $\begin{array}{r}5690 \\
29876\end{array}$ & $\begin{array}{r}5838 \\
30652\end{array}$ & $\begin{array}{r}5807 \\
30491\end{array}$ & $\begin{array}{r}5302 \\
27837\end{array}$ & $\begin{array}{r}5183 \\
27216\end{array}$ & $\begin{array}{r}5186 \\
27233\end{array}$ \\
\hline & EAST SOOTA CENTRAL & $\begin{array}{r}25553 \\
134170\end{array}$ & $\begin{array}{r}26559 \\
139452\end{array}$ & $\begin{array}{r}27483 \\
144305\end{array}$ & $\begin{array}{r}28090 \\
147487\end{array}$ & $\begin{array}{r}28826 \\
151356\end{array}$ & $\begin{array}{r}30174 \\
158430\end{array}$ & $\begin{array}{r}30668 \\
161023\end{array}$ & $\begin{array}{r}28656 \\
150456\end{array}$ & $\begin{array}{r}28727 \\
150824\end{array}$ & $\begin{array}{r}29531 \\
155059\end{array}$ \\
\hline & ALABAHA & $\begin{array}{r}7299 \\
38322\end{array}$ & $\begin{array}{r}7626 \\
40041\end{array}$ & $\begin{array}{r}7935 \\
41663\end{array}$ & $\begin{array}{r}8157 \\
42826\end{array}$ & $\begin{array}{r}8421 \\
44212\end{array}$ & $\begin{array}{r}88=0 \\
4656.8\end{array}$ & $\begin{array}{r}9073 \\
47639\end{array}$ & $\begin{array}{r}8536 \\
44816\end{array}$ & $\begin{array}{r}8618 \\
45247\end{array}$ & $\begin{array}{r}8926 \\
46865\end{array}$ \\
\hline & KBETUCKY & $\begin{array}{r}5462 \\
28678\end{array}$ & $\begin{array}{r}5806 \\
30486\end{array}$ & $\begin{array}{r}6148 \\
32283\end{array}$ & $\begin{array}{r}6433 \\
33782\end{array}$ & $\begin{array}{r}6764 \\
35516\end{array}$ & $\begin{array}{r}7257 \\
38107\end{array}$ & $\begin{array}{r}7566 \\
.39726\end{array}$ & $\begin{array}{r}7256 \\
38098\end{array}$ & $\begin{array}{r}7471 \\
39225\end{array}$ & $\begin{array}{r}7894 \\
41449\end{array}$ \\
\hline & MISSI SSIP ?I & $\begin{array}{r}5517 \\
28969\end{array}$ & $\begin{array}{r}5703 \\
29945\end{array}$ & $\begin{array}{r}5867 \\
30807\end{array}$ & $\begin{array}{r}5961 \\
31295\end{array}$ & $\begin{array}{r}6077 \\
31910\end{array}$ & $\begin{array}{r}6329 \\
33174\end{array}$ & $\begin{array}{r}6375 \\
33475\end{array}$ & $\begin{array}{r}5912 \\
31040\end{array}$ & $\begin{array}{r}5879 \\
30864\end{array}$ & $\begin{array}{r}5991 \\
31458\end{array}$ \\
\hline 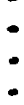 & TEN NBSSEB & $\begin{array}{r}7275 \\
38201\end{array}$ & $\begin{array}{r}7424 \\
38980\end{array}$ & $\begin{array}{r}7533 \\
39552\end{array}$ & $\begin{array}{r}7539 \\
39584\end{array}$ & $\begin{array}{r}7564 \\
39718\end{array}$ & $\begin{array}{r}7728 \\
40581\end{array}$ & $\begin{array}{r}7654 \\
90183\end{array}$ & $\begin{array}{r}6952 \\
.36502\end{array}$ & $\begin{array}{r}6759 \\
35488\end{array}$ & $\begin{array}{r}6720 \\
35287\end{array}$ \\
\hline
\end{tabular}

SOURCE: AETROD 332

DAT. QEALITY: $2(1967,72)$. 3. (OTHER TEARS) )** 


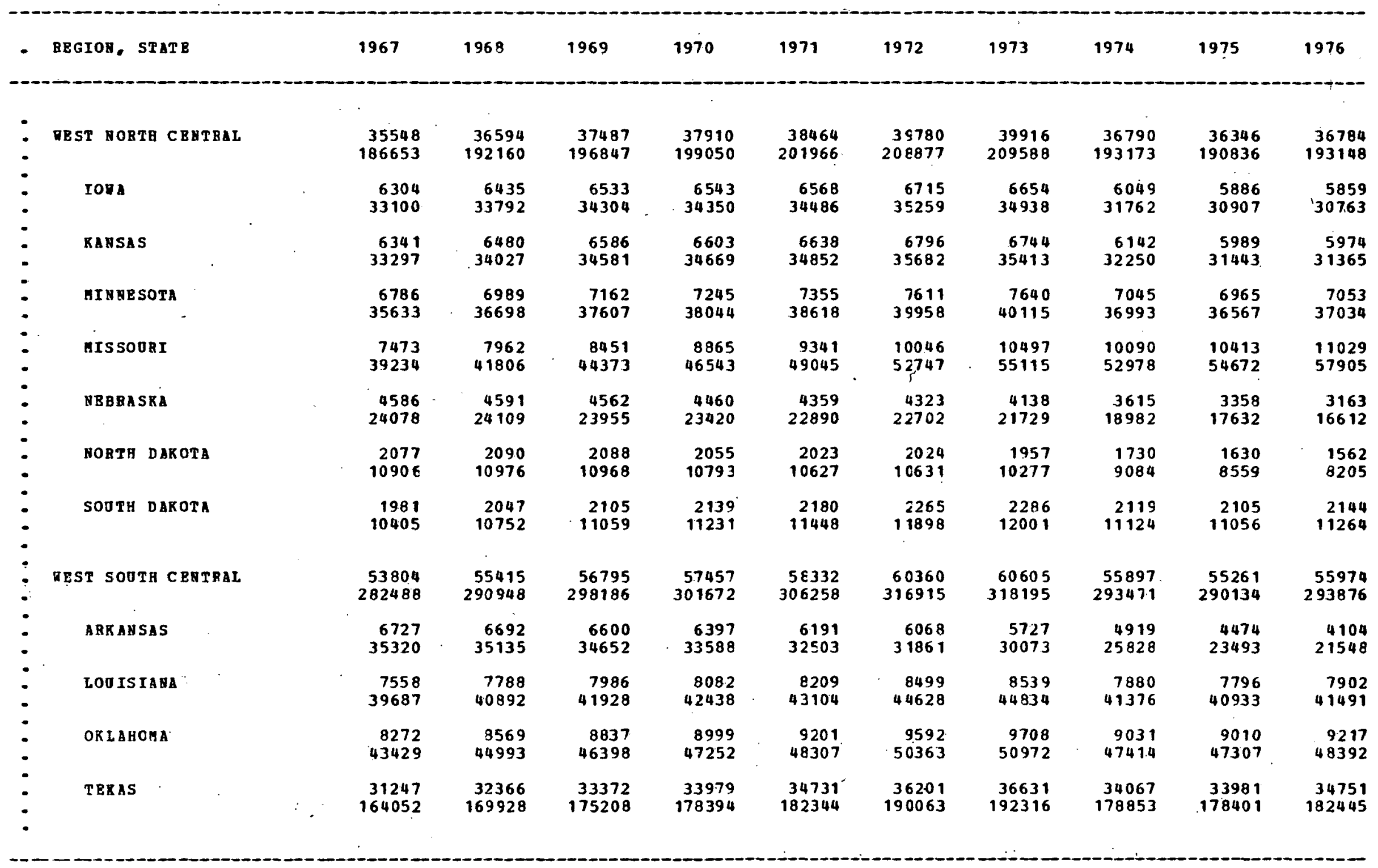




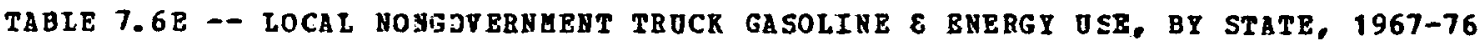

(FIBST IN A SERIES OP 5 TABLES)

GASOLINE USE IN THOUSA HD. OP BABRELS, FOLLORED BY ENERGY OSE IA BELLIOAS OF BTU

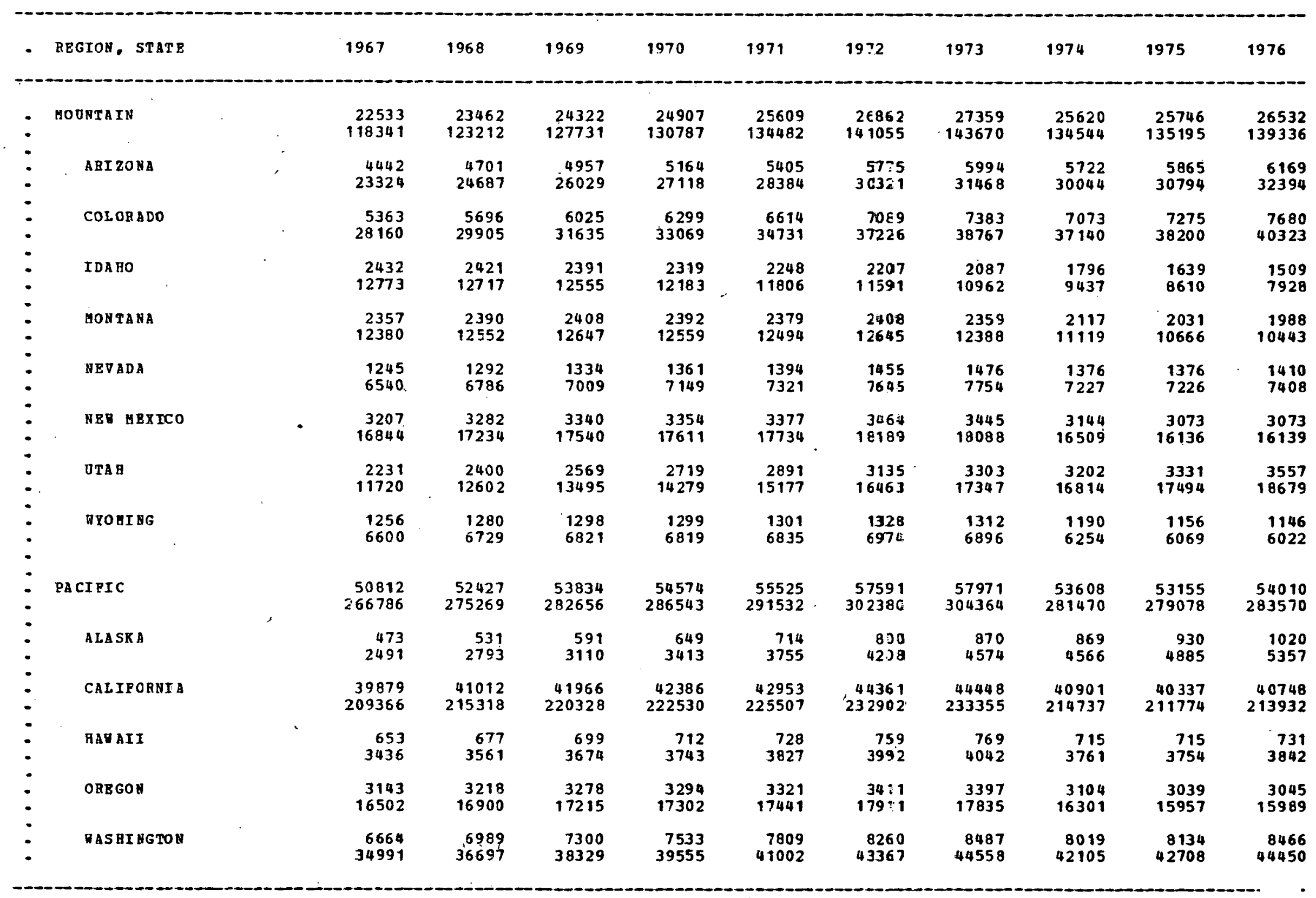

I SCORCE THOD 332 DATR GOALITY: 2 (1967.72). 3. (OTRBR YBABS) )** 
TABLB 7.7A -- LOCAL NOHGOVEANAEAT TBUCR DIESEL 8 BAERGY USE, BY STATE, 1967-76 (PIRST IB A SBRIBS OP 5 TABLES)

POEL OSE IA THOUSABDS OP BARRELS, POLLORED BY EQERGY USE IA BILLIONS OP BTU

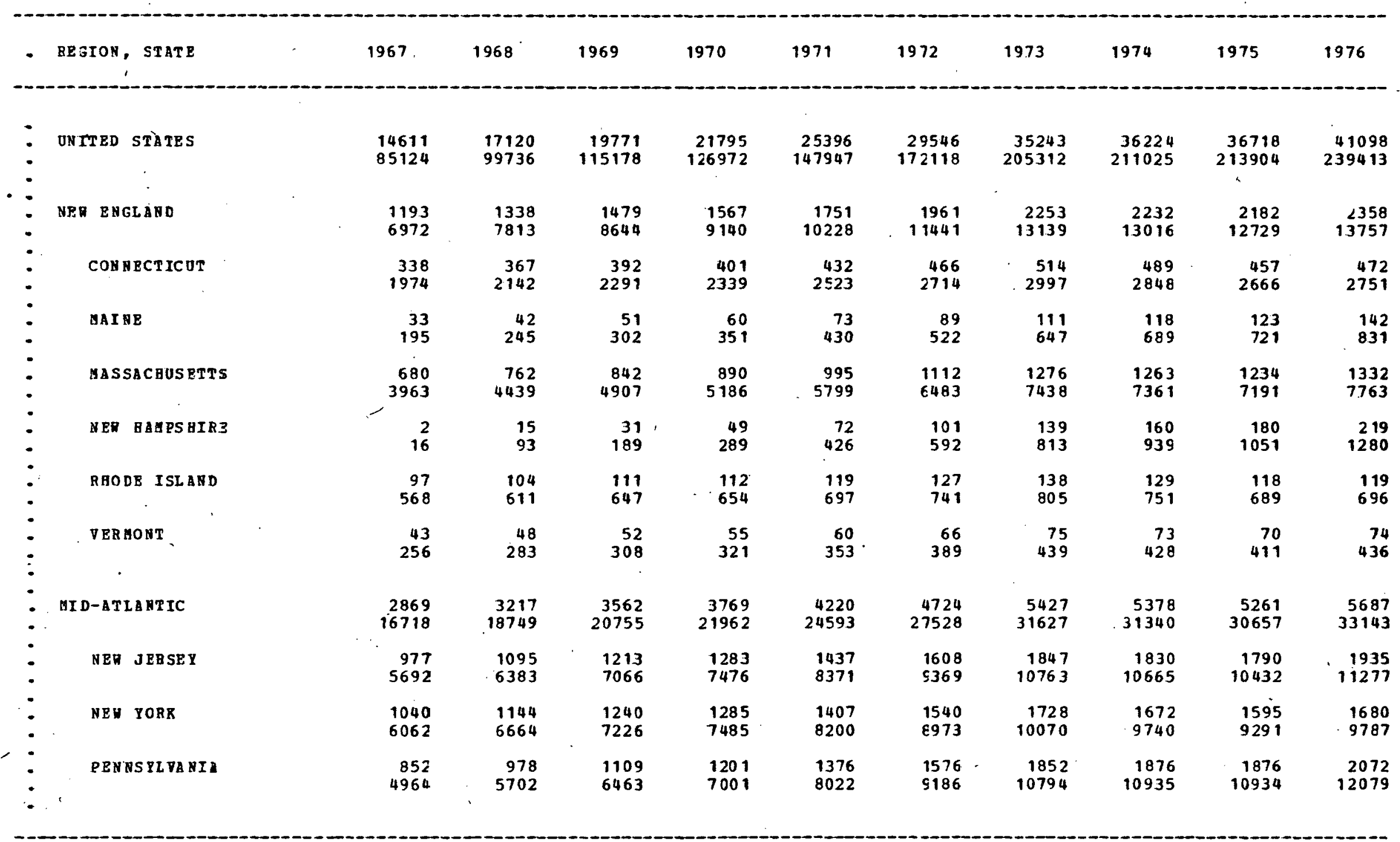


TABL 7.7B - LOCAL NONGOVERNAENT TROCK DIBSEL E EAERGI OSF, BY STATB, 1967-76 (FIRST IN A SBRIES OP 5 TABLES)

POEL USE IY THOUSA CPS CP BARBLS, POILORED BY EYERG USE IA BILLIOHS OP BTO

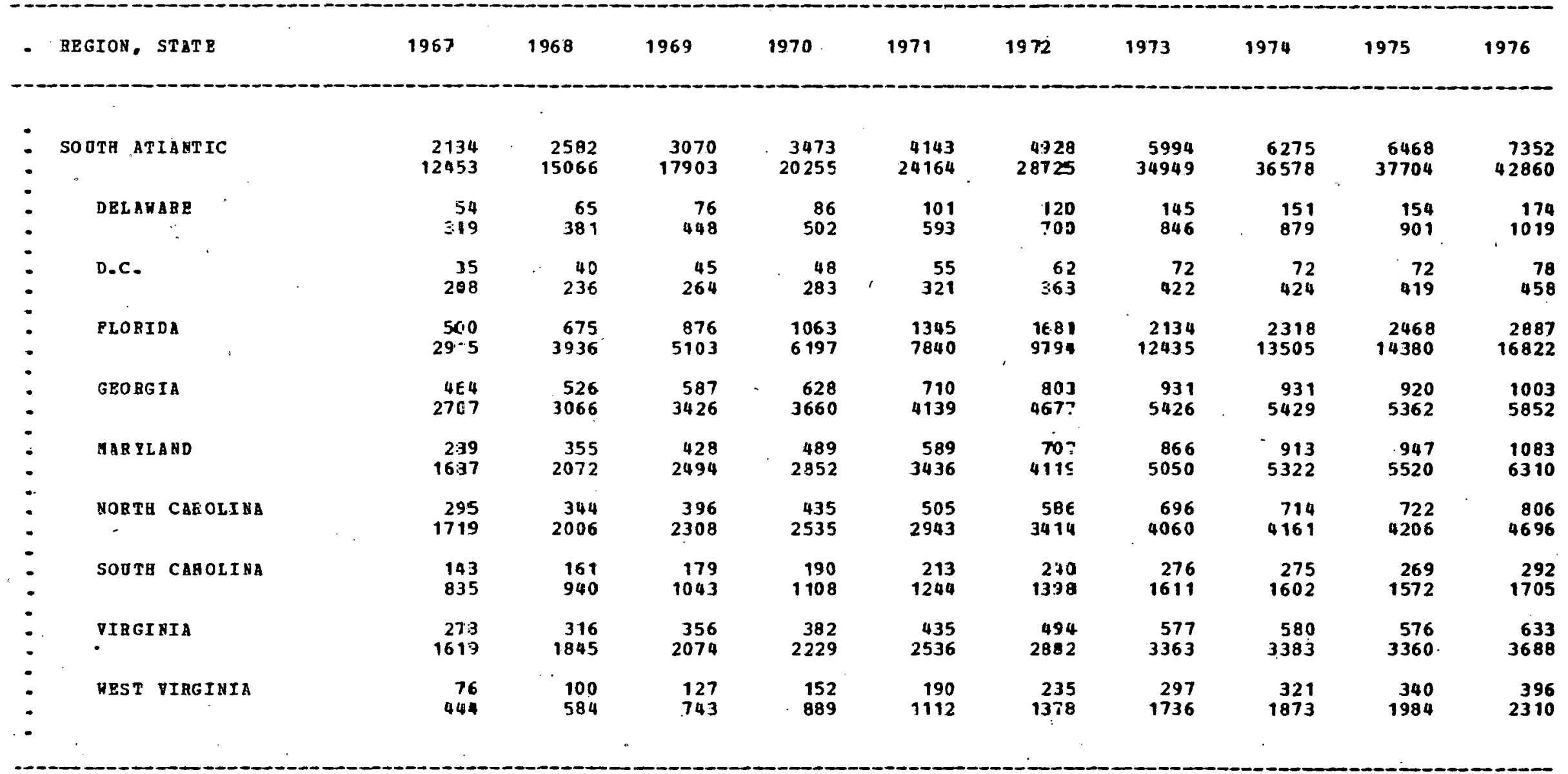


TABZE 7.7C - LOCAL MOBGOVERHERAT TBOCR DIESEL \& EUERGY.USE, BY STATE, 1967-76 (PIRST IBA SBRIES OP 5 TABLBS)

FOBL OSE IB THOOSARDS OP BARBBLS, FOLLOEBD BY BBERG OSE IA BILLIOHS OF BTO

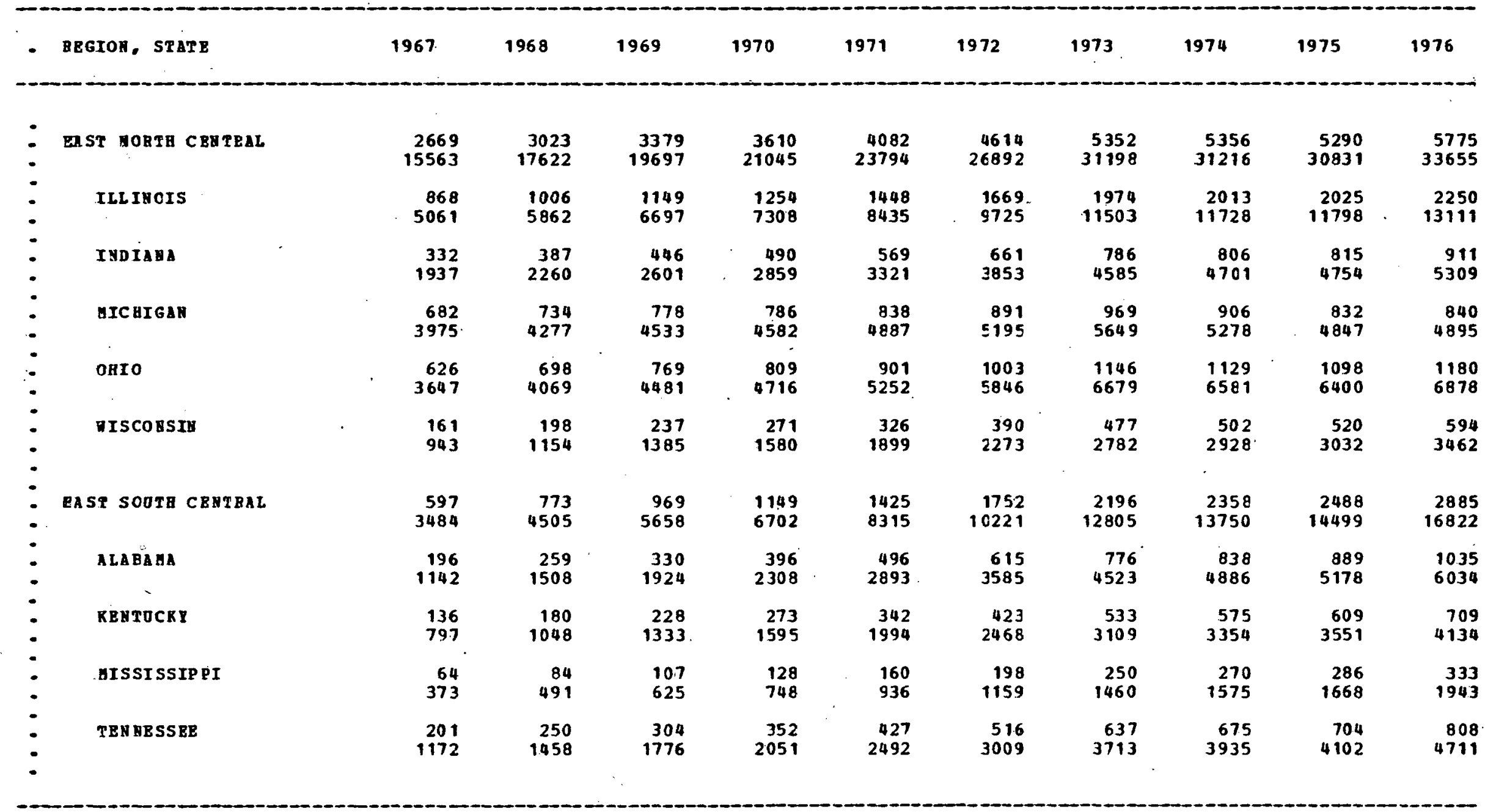


TABLE: 7.7D - LOCAL MOAGOVERHAETT TROCK DIESEL E ENERGY OSE, EY STATE, 1967-76 (PIRST IN A SEFIBS OP 5 TABLES)

POEL USE IN THOOSANDS GP BARRLS, FOILONGD BY ERERGY USE ER EILLIONS OF BTO

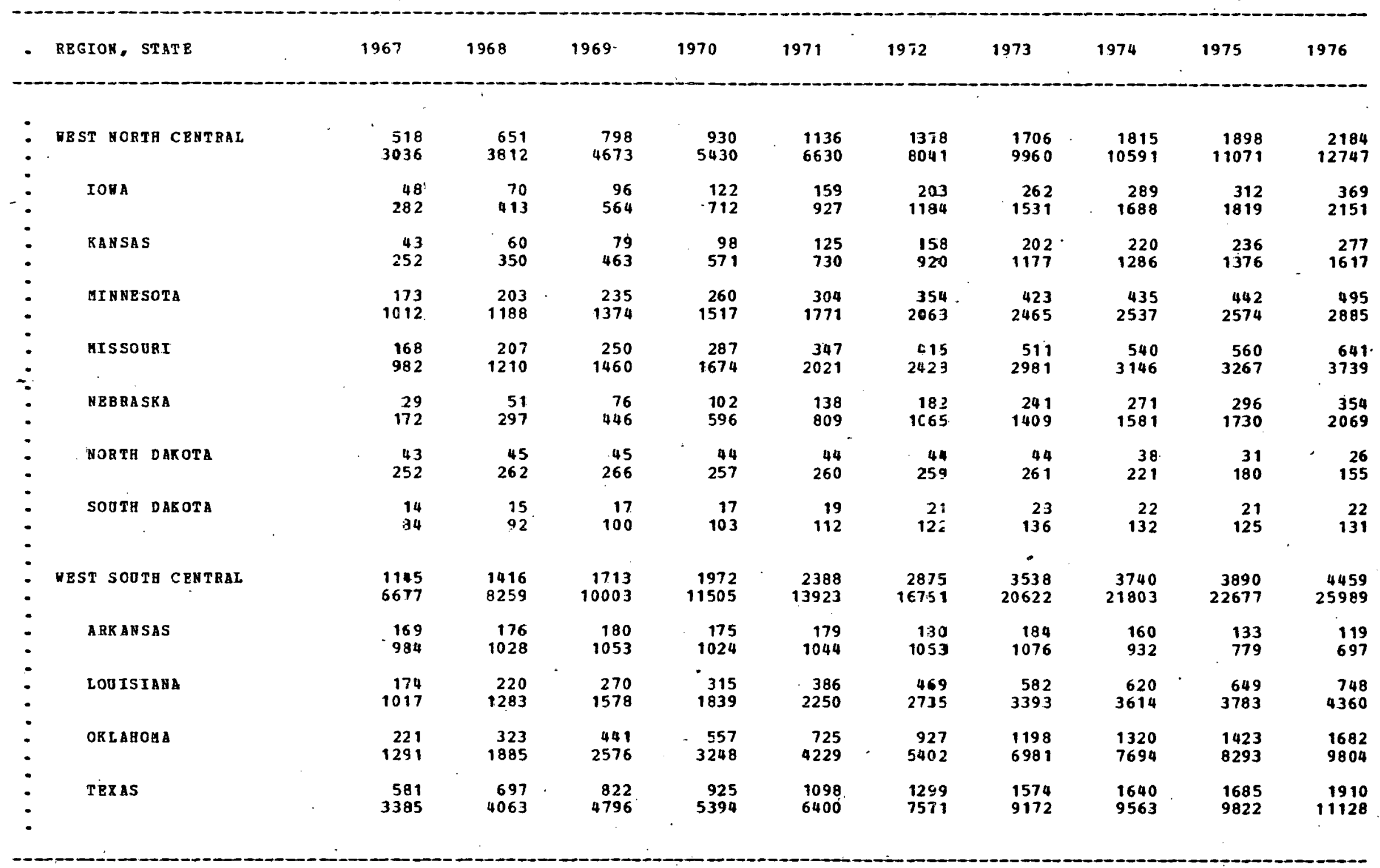


TABLE 7.7E -- EOCAL NONGOVBRHEERT TBUCK D.IESEL E ENEBGY USR, BY STATE. 1967-76

(PIRST IH A SBRIES OP 5 TABLES)

POEL OSE IB TAOUSANDS OF BABRELS, POILORED BY BEERG USE IN . BILLIOHS OP BTO

\begin{tabular}{|c|c|c|c|c|c|c|c|c|c|c|c|}
\hline - & REGIOH STATE & 1967 & 1968 & 1969 & 1970 & 1971 & 1972 & 1973 & 1974 & 1975 & 1976 \\
\hline : & DOENTAIN & $\begin{array}{r}700 \\
409.3\end{array}$ & $\begin{array}{r}814 \\
4767\end{array}$ & $\begin{array}{r}938 \\
5475\end{array}$ & $\begin{array}{l}1025 \\
6002\end{array}$ & $\begin{array}{l}1192 \\
6959\end{array}$ & $\begin{array}{l}1380 \\
8059\end{array}$ & $\begin{array}{l}1640 \\
9570\end{array}$ & $\begin{array}{l}1678 \\
9797\end{array}$ & $\begin{array}{r}1720 \\
10042\end{array}$ & $\begin{array}{r}1960 \\
11446\end{array}$ \\
\hline$\therefore$ & ARIZONA & $\begin{array}{l}152 \\
890\end{array}$ & $\begin{array}{r}183 \\
1070\end{array}$ & $\begin{array}{r}217 \\
1266\end{array}$ & $\begin{array}{r}244 \\
1425\end{array}$ & $\begin{array}{r}290 \\
1693\end{array}$ & $\begin{array}{r}344 \\
2005\end{array}$ & $\begin{array}{r}417 \\
2431\end{array}$ & $\begin{array}{r}435 \\
2537\end{array}$ & $\begin{array}{r}447 \\
2608\end{array}$ & $\begin{array}{r}507 \\
2957\end{array}$ \\
\hline 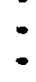 & COLORADO & $\begin{array}{l}141 \\
822\end{array}$ & $\begin{array}{r}184 \\
1077\end{array}$ & $\begin{array}{r}234 \\
1366\end{array}$ & $\begin{array}{r}279 \\
1630\end{array}$ & $\begin{array}{r}349 \\
2035\end{array}$ & $\begin{array}{r}431 \\
2515\end{array}$ & $\begin{array}{r}543 \\
3164\end{array}$ & $\begin{array}{r}585 \\
3411\end{array}$ & $\begin{array}{r}619 \\
3608\end{array}$ & $\begin{array}{r}720 \\
4198\end{array}$ \\
\hline . & IDA คО & $\begin{array}{l}152 \\
887\end{array}$ & $\begin{array}{l}148 \\
864\end{array}$ & $\begin{array}{l}139 \\
809\end{array}$ & $\begin{array}{l}120 \\
700\end{array}$ & $\begin{array}{l}104 \\
606\end{array}$ & $\begin{array}{r}82 \\
478\end{array}$ & $\begin{array}{r}54 \\
317\end{array}$ & $\begin{array}{l}13 \\
81\end{array}$ & $\begin{array}{l}0 \\
0\end{array}$ & $\begin{array}{l}0 \\
0\end{array}$ \\
\hline 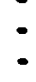 & MONTABA & $\begin{array}{r}69 \\
406\end{array}$ & $\begin{array}{r}76 \\
444\end{array}$ & $\begin{array}{r}82 \\
479\end{array}$ & $\begin{array}{r}84 \\
494\end{array}$ & $\begin{array}{r}92 \\
538\end{array}$ & $\begin{array}{l}100 \\
585\end{array}$ & $\begin{array}{l}112 \\
652\end{array}$ & $\begin{array}{l}107 \\
627\end{array}$ & $\begin{array}{l}101 \\
594\end{array}$ & $\begin{array}{l}106 \\
620\end{array}$ \\
\hline 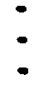 & NEVADA & $\begin{array}{r}47 \\
275\end{array}$ & $\begin{array}{r}54 \\
320\end{array}$ & $\begin{array}{r}63 \\
367\end{array}$ & $\begin{array}{r}68 \\
401\end{array}$ & $\begin{array}{r}79 \\
465\end{array}$ & $\begin{array}{r}92 \\
538\end{array}$ & $\begin{array}{l}109 \\
638\end{array}$ & $\begin{array}{l}112 \\
652\end{array}$ & $\begin{array}{l}112 \\
658\end{array}$ & $\begin{array}{l}125 \\
733\end{array}$ \\
\hline 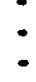 & NED MEXICO & $\begin{array}{r}46 \\
270\end{array}$ & $\begin{array}{r}53 \\
309\end{array}$ & $\begin{array}{r}60 \\
350\end{array}$ & $\begin{array}{r}64 \\
378\end{array}$ & $\begin{array}{r}74 \\
432\end{array}$ & $\begin{array}{r}84 \\
494\end{array}$ & $\begin{array}{r}99 \\
-579\end{array}$ & $\begin{array}{l}100 \\
585\end{array}$ & $\begin{array}{l}100 \\
584\end{array}$ & $\begin{array}{l}110 \\
645\end{array}$ \\
\hline . & UTA & $\begin{array}{r}63 \\
367\end{array}$ & $\begin{array}{r}78 \\
459\end{array}$ & $\begin{array}{r}96 \\
561\end{array}$ & $\begin{array}{l}111 \\
650\end{array}$ & $\begin{array}{l}136 \\
792\end{array}$ & $\begin{array}{l}164 \\
959\end{array}$ & $\begin{array}{r}203 \\
1186\end{array}$ & $\begin{array}{r}216 \\
1260\end{array}$ & $\begin{array}{r}225 \\
1315\end{array}$ & $\begin{array}{r}259 \\
1513\end{array}$ \\
\hline 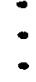 & VYOUI NG & $\begin{array}{r}30 \\
176\end{array}$ & $\begin{array}{r}38 \\
224\end{array}$ & $\begin{array}{r}47 \\
277\end{array}$ & $\begin{array}{r}55 \\
324\end{array}$ & $\begin{array}{r}68 \\
398\end{array}$ & $\begin{array}{r}83 \\
485\end{array}$ & $\begin{array}{l}103 \\
603\end{array}$ & $\begin{array}{l}110 \\
644\end{array}$ & $\begin{array}{l}116 \\
675\end{array}$ & $\begin{array}{l}133 \\
780\end{array}$ \\
\hline : & DACIPIC & $\begin{array}{r}2762 \\
16102\end{array}$ & $\begin{array}{r}3279 \\
19113\end{array}$ & $\begin{array}{r}3832 \\
22339\end{array}$ & $\begin{array}{r}4272 \\
24899\end{array}$ & $\begin{array}{r}5028 \\
29309\end{array}$ & $\begin{array}{r}5906 \\
34419\end{array}$ & $\begin{array}{r}7106 \\
41416\end{array}$ & $\begin{array}{r}7363 \\
42915\end{array}$ & $\begin{array}{r}7521 \\
43828\end{array}$ & $\begin{array}{r}8478 \\
49403\end{array}$ \\
\hline : & ALASKA & $\begin{array}{r}20 \\
117\end{array}$ & $\begin{array}{r}25 \\
149\end{array}$ & $\begin{array}{r}31 \\
185\end{array}$ & $\begin{array}{r}37 \\
217\end{array}$ & $\begin{array}{r}45 \\
267\end{array}$ & $\begin{array}{r}56 \\
326\end{array}$ & $\begin{array}{r}69 \\
406\end{array}$ & $\begin{array}{r}74 \\
434\end{array}$ & $\begin{array}{r}78 \\
455\end{array}$ & $\begin{array}{r}90 \\
526\end{array}$ \\
\hline$:$ & CALIPORNIA & $\begin{array}{r}2051 \\
11952\end{array}$ & $\begin{array}{r}2460 \\
14334\end{array}$ & $\begin{array}{r}2902 \\
16907\end{array}$ & $\begin{array}{r}3261 \\
19001\end{array}$ & $\begin{array}{r}3868 \\
22533\end{array}$ & $\begin{array}{r}4573 \\
26641\end{array}$ & $\begin{array}{r}5537 \\
32256\end{array}$ & $\begin{array}{r}5770 \\
33614\end{array}$ & $\begin{array}{r}5924 \\
34510\end{array}$ & $\begin{array}{r}6709 \\
39088\end{array}$ \\
\hline : & GARAII & $\begin{array}{r}96 \\
563\end{array}$ & $\begin{array}{l}106 \\
620\end{array}$ & $\begin{array}{l}115 \\
674\end{array}$ & $\begin{array}{l}120 \\
700\end{array}$ & $\begin{array}{l}131 \\
770\end{array}$ & $\begin{array}{l}144 \\
845\end{array}$ & $\begin{array}{l}162 \\
952\end{array}$ & $\begin{array}{l}157 \\
924\end{array}$ & $\begin{array}{l}150 \\
884\end{array}$ & $\begin{array}{l}160^{\prime} \\
935\end{array}$ \\
\hline : & OREGON & $\begin{array}{r}253 \\
147 \%\end{array}$ & $\begin{array}{r}299 \\
1741\end{array}$ & $\begin{array}{r}347 \\
2022\end{array}$ & $\begin{array}{r}384 \\
2241\end{array}$ & $\begin{array}{r}450 \\
2624\end{array}$ & $\begin{array}{r}526 \\
3067\end{array}$ & $\begin{array}{r}630 \\
3674\end{array}$ & $\begin{array}{r}650 \\
3791\end{array}$ & $\begin{array}{r}662 \\
3857\end{array}$ & $\begin{array}{r}743 \\
4332\end{array}$ \\
\hline : & RAS HINGTON & $\begin{array}{r}342 \\
1993\end{array}$ & $\begin{array}{r}389 \\
2269\end{array}$ & $\begin{array}{r}437 \\
2551\end{array}$ & $\begin{array}{r}470 \\
2740\end{array}$ & $\begin{array}{r}534 \\
3115\end{array}$ & $\begin{array}{r}607 \\
3540\end{array}$ & $\begin{array}{r}708 \\
4128\end{array}$ & $\begin{array}{r}712 \\
4152\end{array}$ & $\begin{array}{r}707 \\
4122\end{array}$ & $\begin{array}{r}776 \\
4522\end{array}$ \\
\hline
\end{tabular}


TABLE 7.8A -- INTERCITY MUNGOVERYGENT TROCK DIESEL PUEL AND ENEBGY USE. BY STATE, 1967-76

(FIRST IN A SZRIES OP PIVE TA3LES)

FOEL OSE IN THOOSANAS OP BARRELS, POLLONED BY ENERGI USE IN BIILIONS OP BTO

\begin{tabular}{|c|c|c|c|c|c|c|c|c|c|c|c|}
\hline - & BEGION, STATE & $\because 967$ & 1968 & 1969 & 1970 & 1971 & 1972 & 1973 & 1974 & 1975 & 1976 \\
\hline & $\cdot$ & 7 & & & & & & & & & \\
\hline$\dot{-}$ & UNITED STATES & $\begin{array}{r}90112 \\
524939\end{array}$ & $\begin{array}{l}102329 \\
596111\end{array}$ & $\begin{array}{l}114932 \\
669529\end{array}$ & $\begin{array}{l}122121 \\
711408\end{array}$ & $\begin{array}{l}138472 \\
806657\end{array}$ & $\begin{array}{l}156117 \\
909445\end{array}$ & $\begin{array}{r}180418 \\
10 \leq 1008\end{array}$ & $\begin{array}{r}178115 \\
1037595\end{array}$ & $\begin{array}{r}173060 \\
10081.45\end{array}$ & $\begin{array}{r}187615 \\
1092938\end{array}$ \\
\hline$\dot{-}$ & NER E BGLAND & $\begin{array}{r}2718 \\
15847\end{array}$ & $\begin{array}{r}3077 \\
17943\end{array}$ & $\begin{array}{r}3442 \\
20059\end{array}$ & $\begin{array}{r}3601 \\
20990\end{array}$ & $\begin{array}{r}3950 \\
23019\end{array}$ & $\begin{array}{r}4158 \\
24243\end{array}$ & $\begin{array}{r}4648 \\
27087\end{array}$ & $\begin{array}{r}4736 \\
27606\end{array}$ & $\begin{array}{r}4416 \\
25740\end{array}$ & $\begin{array}{r}3829 \\
22308\end{array}$ \\
\hline 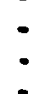 & CONN BCT ICUT & $\begin{array}{r}931 \\
5427\end{array}$ & $\begin{array}{l}1025 \\
5975\end{array}$ & $\begin{array}{l}1181 \\
6882\end{array}$ & $\begin{array}{l}1196 \\
6968\end{array}$ & $\begin{array}{l}1231 \\
7171\end{array}$ & $\begin{array}{l}1278 \\
7446\end{array}$ & $\begin{array}{l}1395 \\
8128\end{array}$ & $\begin{array}{l}1390 \\
8098\end{array}$ & $\begin{array}{l}1237 \\
7208\end{array}$ & $\begin{array}{l}1330 \\
7748\end{array}$ \\
\hline - & HAINE & $\begin{array}{r}396 \\
2308\end{array}$ & $\begin{array}{r}437 \\
2548\end{array}$ & $\begin{array}{r}481 \\
2802\end{array}$ & $\begin{array}{r}562 \\
3277\end{array}$ & $\begin{array}{r}623 \\
3629\end{array}$ & $\begin{array}{r}739 \\
4309\end{array}$ & $\begin{array}{r}343 \\
4916\end{array}$ & $\begin{array}{r}870 \\
5073\end{array}$ & $\begin{array}{r}868 \\
5059\end{array}$ & $\begin{array}{r}903 \\
5261\end{array}$ \\
\hline 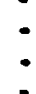 & MASSACHUSETTS & $\begin{array}{r}955 \\
5567\end{array}$ & $\begin{array}{l}1078 \\
6282\end{array}$ & $\begin{array}{l}1217 \\
7.094\end{array}$ & $\begin{array}{l}1143 \\
6662\end{array}$ & $\begin{array}{l}1258 \\
7332\end{array}$ & $\begin{array}{l}1228 \\
7159\end{array}$ & $\begin{array}{l}1394 \\
3122\end{array}$ & $\begin{array}{l}1441 \\
8399\end{array}$ & $\begin{array}{l}1370 \\
7980\end{array}$ & $\begin{array}{l}1131 \\
659.1\end{array}$ \\
\hline & . NEN BANPSHIRE & $\begin{array}{r}175 \\
1020\end{array}$ & $\begin{array}{r}197 \\
1152\end{array}$ & $\begin{array}{r}215 \\
1252\end{array}$ & $\begin{array}{r}219 \\
1281\end{array}$ & $\begin{array}{r}254 \\
1484\end{array}$ & $\begin{array}{r}257 \\
1500\end{array}$ & $\begin{array}{r}259 \\
1509\end{array}$ & $\begin{array}{r}255 \\
1488\end{array}$ & $\begin{array}{r}207 \\
1209\end{array}$ & $\begin{array}{r}227 \\
1326\end{array}$ \\
\hline - & RHODE ISLAND & $\begin{array}{r}200 \\
1167\end{array}$ & $\begin{array}{r}267 \\
1559\end{array}$ & $\begin{array}{r}270 \\
1575\end{array}$ & $\begin{array}{r}268 \\
1561\end{array}$ & $\begin{array}{r}320 \\
1865\end{array}$ & $\begin{array}{r}380 \\
2217\end{array}$ & $\begin{array}{r}401 \\
2337\end{array}$ & $\begin{array}{r}389 \\
2269\end{array}$ & $\begin{array}{r}314 \\
1833\end{array}$ & $\begin{array}{r}321 \\
1870\end{array}$ \\
\hline • & VERHONT & $\begin{array}{r}61 \\
358 \\
:\end{array}$ & $\begin{array}{r}73 \\
427\end{array}$ & $\begin{array}{r}78 \\
454\end{array}$ & $\begin{array}{r}213 \\
1241\end{array}$ & $\begin{array}{r}264 \\
1538\end{array}$ & $\begin{array}{r}276 \\
1612 \\
\end{array}$ & $\begin{array}{r}356 \\
2075\end{array}$ & $\begin{array}{r}391 \\
2279\end{array}$ & $\begin{array}{r}420 \\
2451\end{array}$ & $\begin{array}{l}0 \\
0\end{array}$ \\
\hline - & DID-ATLAYTIC & $\begin{array}{r}9624 \\
56072\end{array}$ & $\begin{array}{l}10910 \\
63561\end{array}$ & $\begin{array}{l}12775 \\
74428\end{array}$ & $\begin{array}{l}14129 \\
82311\end{array}$ & $\begin{array}{l}15121 \\
88092\end{array}$ & $\begin{array}{r}17302 \\
100800\end{array}$ & $\begin{array}{r}15237 \\
116066\end{array}$ & $\begin{array}{r}19500 \\
113602\end{array}$ & $\begin{array}{r}17278 \\
100658\end{array}$ & $\begin{array}{r}19179 \\
111732\end{array}$ \\
\hline$\dot{-}$ & NED JERSEY & $\begin{array}{r}2754 \\
16047\end{array}$ & $\begin{array}{r}3090 \\
18003\end{array}$ & $\begin{array}{r}3304 \\
19250\end{array}$ & $\begin{array}{r}3573 \\
20816\end{array}$ & $\begin{array}{r}3787 \\
22062\end{array}$ & $\begin{array}{r}4106 \\
23919\end{array}$ & $\begin{array}{r}4497 \\
26197\end{array}$ & $\begin{array}{r}4458 \\
25971\end{array}$ & $\begin{array}{r}3945 \\
22981\end{array}$ & $\begin{array}{r}4434 \\
25830\end{array}$ \\
\hline$\bullet$ & NE: YORK & $\begin{array}{l}1153 \\
5719\end{array}$ & $\begin{array}{l}1321 \\
7698\end{array}$ & $\begin{array}{r}2131 \\
12415\end{array}$ & $\begin{array}{r}2712 \\
15798\end{array}$ & $\begin{array}{r}2809 \\
16366\end{array}$ & $\begin{array}{r}3022 \\
17608\end{array}$ & $\begin{array}{r}3579 \\
23850\end{array}$ & $\begin{array}{r}3213 \\
18720\end{array}$ & $\begin{array}{r}2764 \\
16106\end{array}$ & $\begin{array}{r}3005 \\
17508\end{array}$ \\
\hline$\vdots$ & PERN SYLVANIA & $\begin{array}{r}5717 \\
33306\end{array}$ & $\begin{array}{r}6499 \\
37860\end{array}$ & $\begin{array}{r}7340 \\
42763\end{array}$ & $\begin{array}{r}7844 \\
45697\end{array}$ & $\begin{array}{r}8525 \\
49664\end{array}$ & $\begin{array}{l}10174 \\
59273\end{array}$ & $\begin{array}{l}1161 \\
65019\end{array}$ & $\begin{array}{l}11829 \\
68911\end{array}$ & $\begin{array}{l}10569 \\
61571\end{array}$ & $\begin{array}{l}11740 \\
68394\end{array}$ \\
\hline
\end{tabular}


TABLE 7.8B - IRT RRCITY NONGOVBRAENT TBOCR DIESBL PUBL AND BHBGY USB

BY STATE, $1967-76$
(SBCOND IA A SBRIES OP PIVE TABLBS)

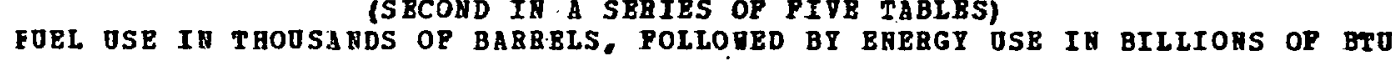

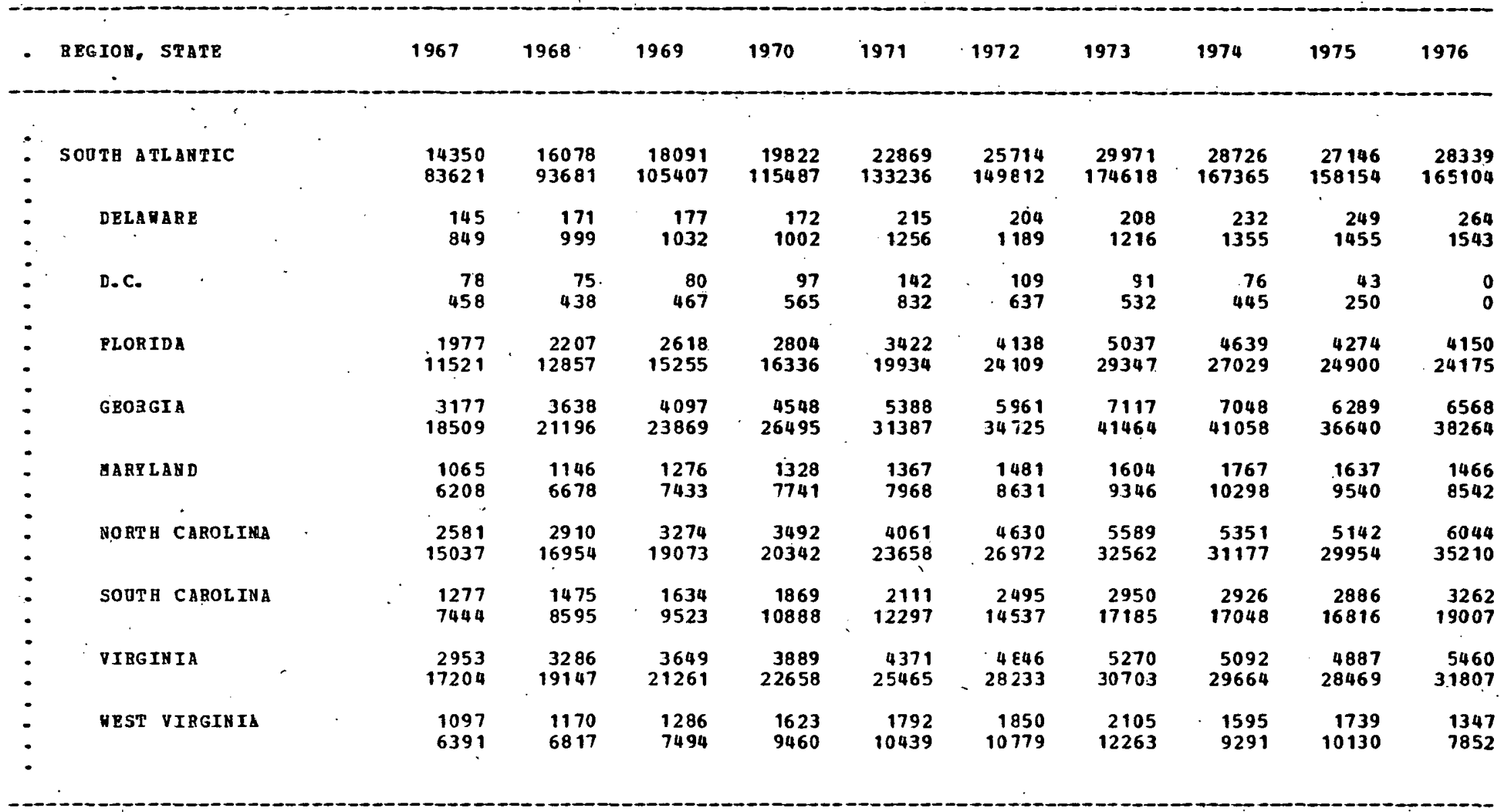


TABIE 7.8C -- INTEBCITY NONGOVERAHENT TROCR DIESEL 8 BNERGI USB,

THIRD IN 3 SBIBS OP PIVE TABLES)

FUEL USE IN THOOSA NDS OF BARREL, POLLOUED BY ENBRGY OSE IQ BILLIOUS OP BTE

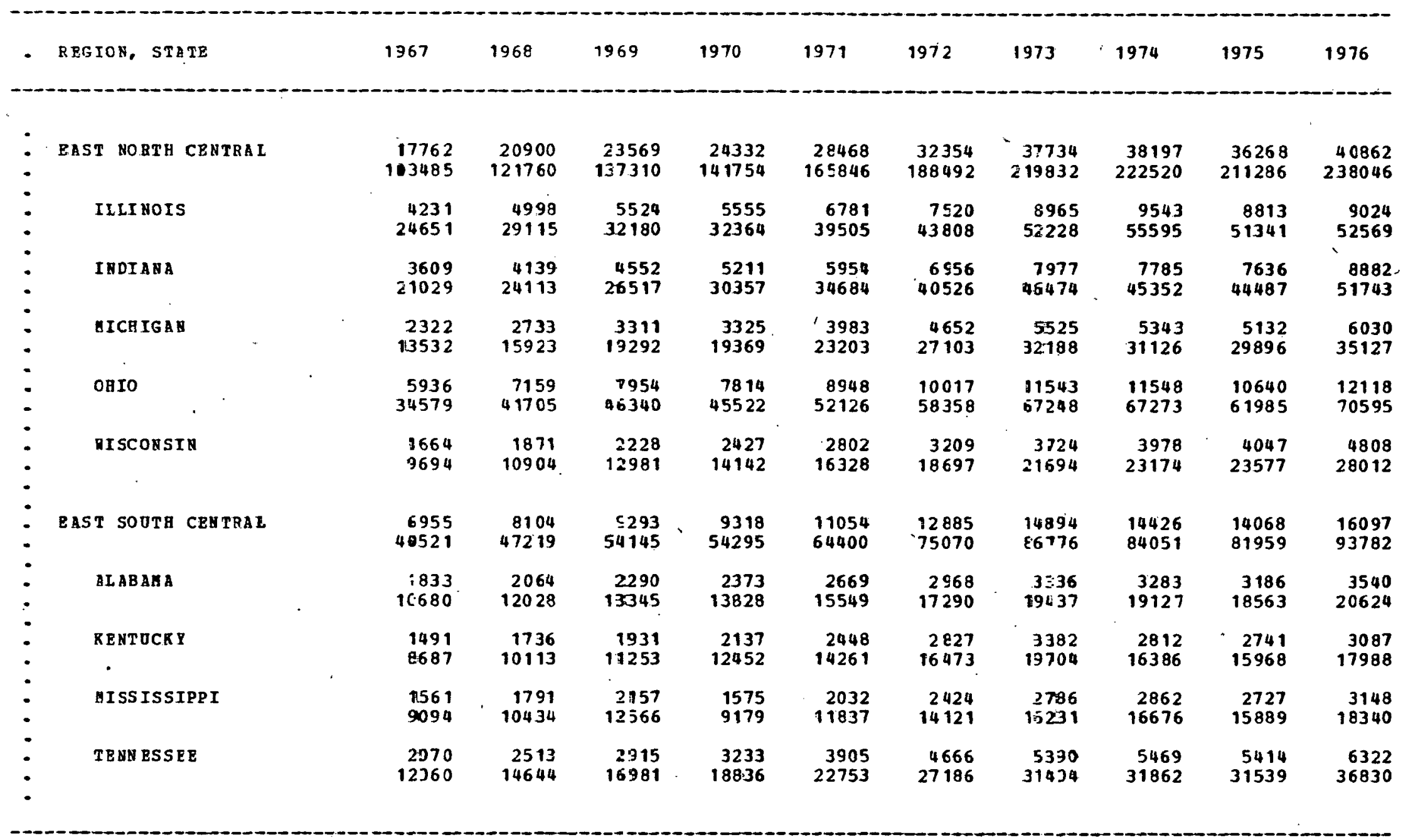


TABLE 7.80 -- INTERCITY NONGOVBRNAENT TRUCK DIESEL E BNEBGY JSE, BY STATE, $1967-76$

(FOURTH IN A SRRIBS OF PIVE TABLES)

FUEL USE IN THOOSA NDS OP BARBELS, POLLOHED BY ENERG OSE IN BILİIONS OP. BTÚ

\begin{tabular}{|c|c|c|c|c|c|c|c|c|c|c|c|}
\hline & REGION, STATE & 1967 & 1968 & 1969 & 1970 & 1971 & 1972 & 1973 & 1974 & 1975 & 1976 \\
\hline & TEST NORTH CENTRAL & $\begin{array}{l}10232 \\
59613\end{array}$ & $\begin{array}{l}11730 \\
68344\end{array}$ & $\begin{array}{l}12884 \\
75081\end{array}$ & $\begin{array}{l}14102 \\
82171\end{array}$ & $\begin{array}{l}16188 \\
94312\end{array}$ & $\begin{array}{r}18294 \\
106594\end{array}$ & $\begin{array}{r}22028 \\
128341\end{array}$ & $\begin{array}{r}21526 \\
125412\end{array}$ & $\begin{array}{r}21349 \\
124380\end{array}$ & $\begin{array}{r}23798 \\
138661\end{array}$ \\
\hline & IORA & $\begin{array}{r}2176 \\
12678\end{array}$ & $\begin{array}{r}2328 \\
13561\end{array}$ & $\begin{array}{r}2580 \\
15034\end{array}$ & $\begin{array}{r}2866 \\
16697\end{array}$ & $\begin{array}{r}3349 \\
19509\end{array}$ & $\begin{array}{r}3898 \\
22711\end{array}$ & $\begin{array}{r}4641 \\
27039\end{array}$ & $\begin{array}{r}4636 \\
27007\end{array}$ & $\begin{array}{r}4561 \\
26570\end{array}$ & $\begin{array}{r}5029 \\
29301\end{array}$ \\
\hline & RAYSAS & $\begin{array}{r}1494 \\
8703\end{array}$ & $\begin{array}{r}1737 \\
10121\end{array}$ & $\begin{array}{r}1897 \\
11055\end{array}$ & $\begin{array}{r}2048 \\
11935\end{array}$ & $\begin{array}{r}2348 \\
13683\end{array}$ & $\begin{array}{r}2785 \\
16228\end{array}$ & $\begin{array}{r}3195 \\
18613\end{array}$ & $\begin{array}{r}3130 \\
1823 \varepsilon\end{array}$ & $\begin{array}{r}3105 \\
18092\end{array}$ & $\begin{array}{r}3293 \\
1 \subseteq 187\end{array}$ \\
\hline & MINNESOTA & $\begin{array}{r}1742 \\
10147\end{array}$ & $\begin{array}{r}1971 \\
11486\end{array}$ & $\begin{array}{r}2165 \\
12617\end{array}$ & $\begin{array}{r}2352 \\
13704\end{array}$ & $\begin{array}{r}2768 \\
16124\end{array}$ & $\begin{array}{r}2913 \\
16 \subseteq 73\end{array}$ & $\begin{array}{r}3662 \\
21337\end{array}$ & $\begin{array}{r}3519 \\
20502\end{array}$ & $\begin{array}{r}3554 \\
20705\end{array}$ & $\begin{array}{r}3935 \\
22927\end{array}$ \\
\hline & UISSOORI & $\begin{array}{r}2875 \\
16750\end{array}$ & $\begin{array}{r}3542 \\
20633\end{array}$ & $\begin{array}{r}3847 \\
22410\end{array}$ & $\begin{array}{r}4013 \\
23380\end{array}$ & $\begin{array}{r}4527 \\
26374\end{array}$ & $\begin{array}{r}4942 \\
28794\end{array}$ & $\begin{array}{r}5834 \\
33989\end{array}$ & $\begin{array}{r}5620 \\
32741\end{array}$ & $\begin{array}{r}5327 \\
31035\end{array}$ & $\begin{array}{r}5999 \\
34951\end{array}$ \\
\hline & NEBRASKA & $\begin{array}{r}957 \\
5578\end{array}$ & $\begin{array}{l}1063 \\
6194\end{array}$ & $\begin{array}{l}1197 \\
6978\end{array}$ & $\begin{array}{l}1377 \\
8026\end{array}$ & $\begin{array}{l}1668 \\
9718\end{array}$ & $\begin{array}{r}2085 \\
12147\end{array}$ & $\begin{array}{r}2538^{\circ} \\
14789\end{array}$ & $\begin{array}{r}2649 \\
15436\end{array}$ & $\begin{array}{r}2664 \\
15521\end{array}$ & $\begin{array}{r}3076 \\
17923\end{array}$ \\
\hline & NOBT E DAROTA & $\begin{array}{r}527 \\
3070\end{array}$ & $\begin{array}{r}588 \\
3429\end{array}$ & $\begin{array}{r}607 \\
3540\end{array}$ & $\begin{array}{r}786 \\
4583\end{array}$ & $\begin{array}{r}787 \\
4587\end{array}$ & $\begin{array}{r}853 \\
4972\end{array}$ & $\begin{array}{l}1081 \\
6300\end{array}$ & $\begin{array}{r}943 \\
5494\end{array}$ & $\begin{array}{l}1128 \\
6572\end{array}$ & $\begin{array}{l}1352 \\
7879\end{array}$ \\
\hline & SOOTH DAROTA & $\begin{array}{r}461 \\
2687\end{array}$ & $\begin{array}{r}501 \\
2920\end{array}$ & $\begin{array}{r}591 \\
3447\end{array}$ & $\begin{array}{r}660 \\
3846\end{array}$ & $\begin{array}{r}741 \\
4317\end{array}$ & $\begin{array}{r}818 \\
4769\end{array}$ & $\begin{array}{l}1077 \\
6274\end{array}$ & $\begin{array}{l}1029 \\
5994\end{array}$ & $\begin{array}{l}1010 \\
5885\end{array}$ & $\begin{array}{l}1114 \\
6493\end{array}$ \\
\hline & 1 & & & & & & & & & & \\
\hline & MEST SOOTH CENTRAL & $\begin{array}{l}11.39 .3 \\
66384\end{array}$ & $\begin{array}{l}12693 \\
73956\end{array}$ & $\begin{array}{l}13372 \\
77911\end{array}$ & $\begin{array}{l}14342 \\
83556\end{array}$ & $\begin{array}{l}16530 \\
96300\end{array}$ & $\begin{array}{r}18911 \\
110174\end{array}$ & $\begin{array}{r}22096 \\
128724\end{array}$ & $\begin{array}{r}21989 \\
128095\end{array}$ & $\begin{array}{r}22638 \\
131885\end{array}$ & $\begin{array}{r}25162 \\
146588\end{array}$ \\
\hline & ABRANSAS & $\begin{array}{l}1295 \\
7548\end{array}$ & $\begin{array}{l}1516 \\
8835\end{array}$ & $\begin{array}{r}1759 \\
10251\end{array}$ & $\begin{array}{r}1915 \\
11157\end{array}$ & $\begin{array}{r}2337 \\
13614\end{array}$ & $\begin{array}{r}2787 \\
16236\end{array}$ & $\begin{array}{r}3349 \\
19512\end{array}$ & $\begin{array}{r}3292 \\
19177\end{array}$ & $\begin{array}{r}3207 \\
.18682\end{array}$ & $\begin{array}{r}3811 \\
22205\end{array}$ \\
\hline & LOOISIANA & $\begin{array}{l}1433 \\
8352\end{array}$ & $\begin{array}{l}1616 \\
9418\end{array}$ & $\begin{array}{l}1698 \\
9895\end{array}$ & $\begin{array}{r}1823 \\
10623\end{array}$ & $\begin{array}{r}2099 \\
12231\end{array}$ & $\begin{array}{r}2463 \\
14353\end{array}$ & $\begin{array}{r}2815 \\
16399\end{array}$ & $\begin{array}{r}3068 \\
17872\end{array}$ & $\begin{array}{r}3125 \\
18207\end{array}$ & $\begin{array}{r}3633 \\
21164\end{array}$ \\
\hline & ORLABOHA & $\begin{array}{r}1719 \\
10017\end{array}$ & $\begin{array}{r}1809 \\
10541\end{array}$ & $\begin{array}{r}1846 \\
10756\end{array}$ & $\begin{array}{r}1893 \\
11031\end{array}$ & $\begin{array}{r}1977 \\
11519\end{array}$ & $\begin{array}{r}2169 \\
12637\end{array}$ & $\begin{array}{r}2255 \\
13137\end{array}$ & $\begin{array}{r}2178 \\
12689\end{array}$ & $\begin{array}{r}2084 \\
12143\end{array}$ & $\begin{array}{r}2263 \\
13184\end{array}$ \\
\hline & TE ZAS & $\begin{array}{r}6946 \\
40467\end{array}$ & $\begin{array}{r}7752 \\
45162\end{array}$ & $\begin{array}{r}8069 \\
47009\end{array}$ & $\begin{array}{r}8711 \\
50745\end{array}$ & $\begin{array}{l}10117 \\
58936\end{array}$ & $\begin{array}{l}11492 \\
66 \subseteq 48\end{array}$ & $\begin{array}{l}13677 \\
79676\end{array}$ & $\begin{array}{l}13451 \\
78357\end{array}$ & $\begin{array}{l}14222 \\
82853\end{array}$ & $\begin{array}{l}i 5455 \\
90035\end{array}$ \\
\hline
\end{tabular}


TABLZ 7. 3E - INTEBCITY YONGOYRRMHEYT TROCK DIESEL E EHERGP OSE, (LAST IN A SEBIES OF PIVB TABLES)

FOEL USE IN THOOSANDS OP BAREELS, POLLOTED BY ENERGY OSE IN BIELZONS OF BTO

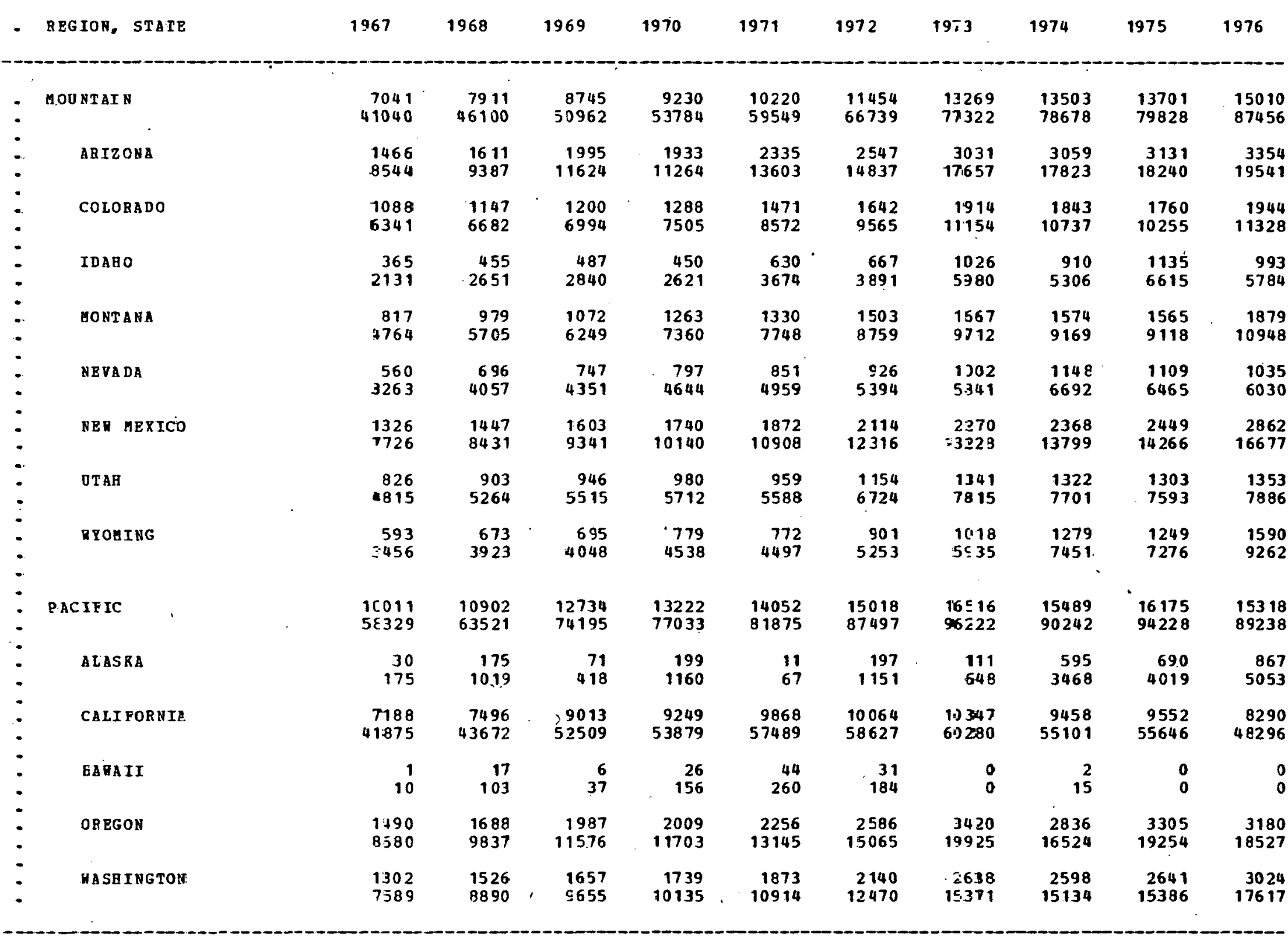


TABLE 7.9A - INTERCITY YOBGOVBRHEE TRUCR GASOLINE E ENERGY OSE, BY STATE, 1967-76

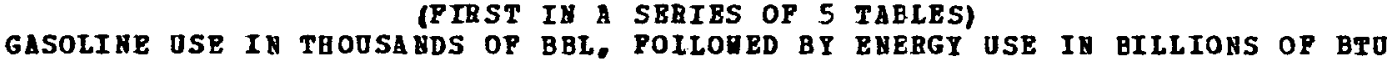

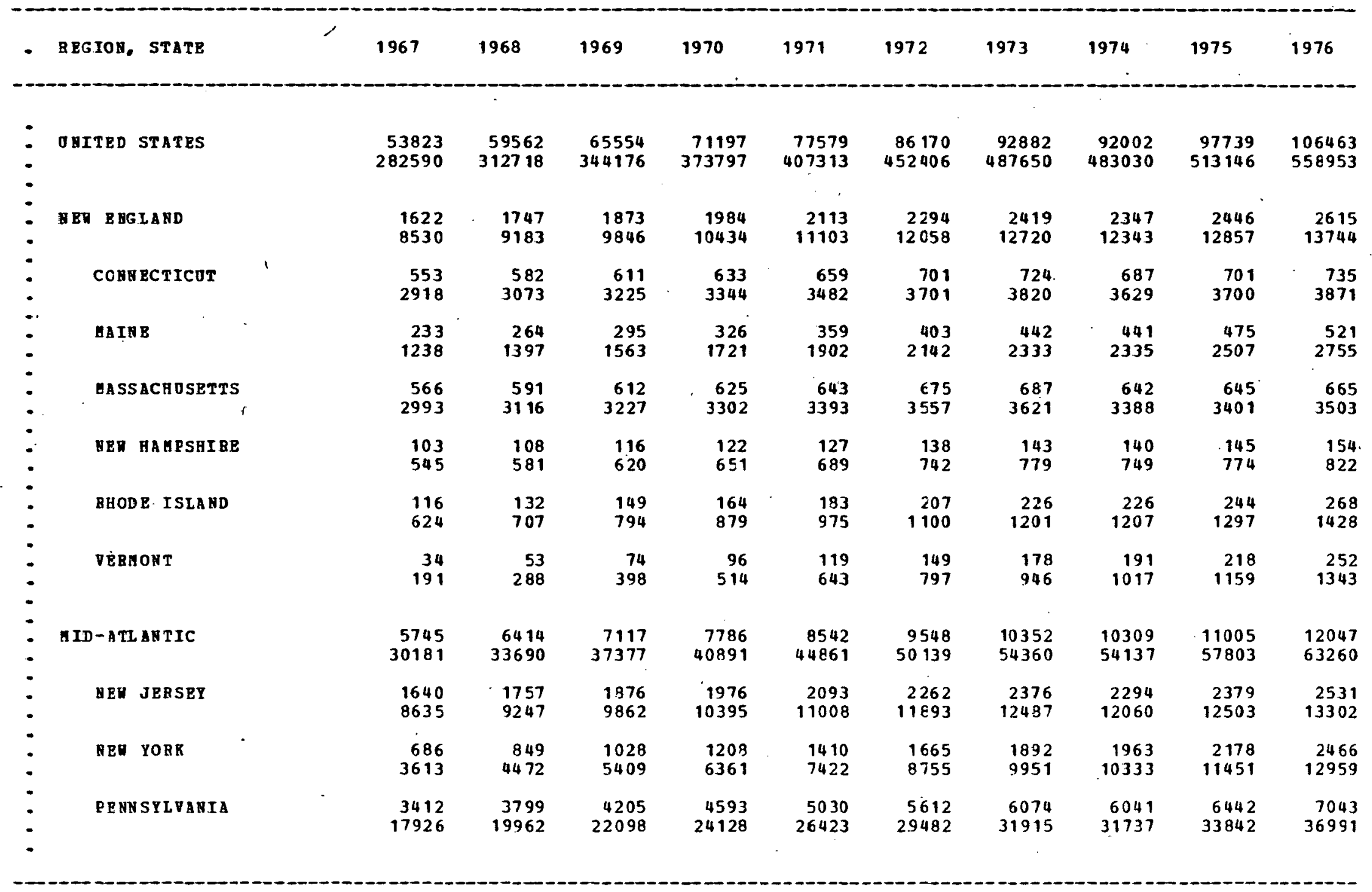


TABLE 7.9B - IHTBRCITY NONGOVE3NBBHT TROCR GASOLIHE E BNERGI OSE.

$$
\begin{aligned}
& \text { BY STATE, 1967-76. } \\
& \text { (SECOAD IN A SERIES OP } 5 \text { TABIBS) }
\end{aligned}
$$

GASOLINE OSB IN THOOSA

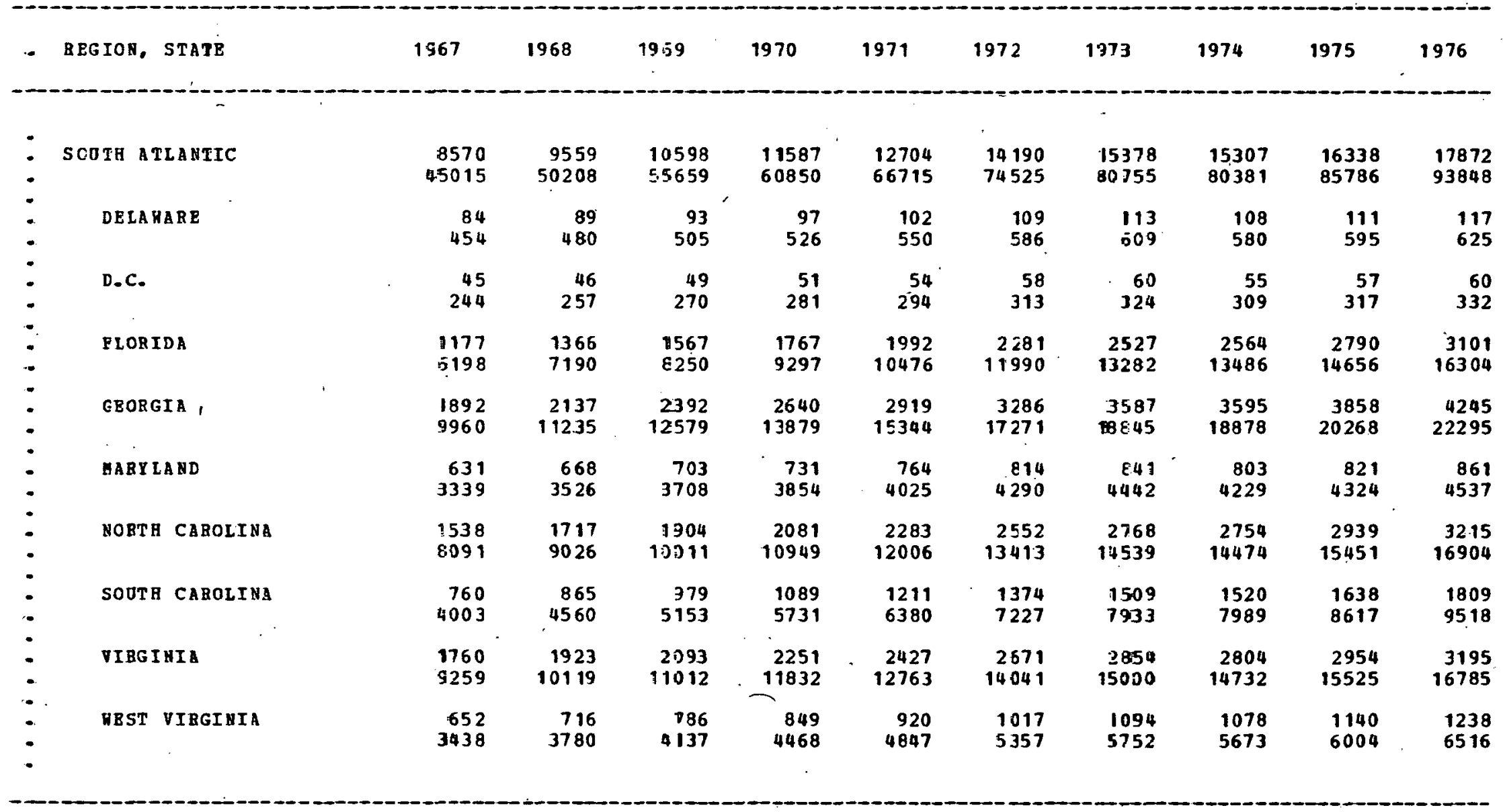


TABLE 7.9C - I ITEBCITY NOHGOVERHAENT TRUCR GASOLINE 6 ENERGY OSE, (THIRD IY SBRIES OP 5 TABLBS)

GASOLINE USE IN THOUSANDS OP BBL, POILORED BY ENERGY OSE IA BILLIONS OP BTO

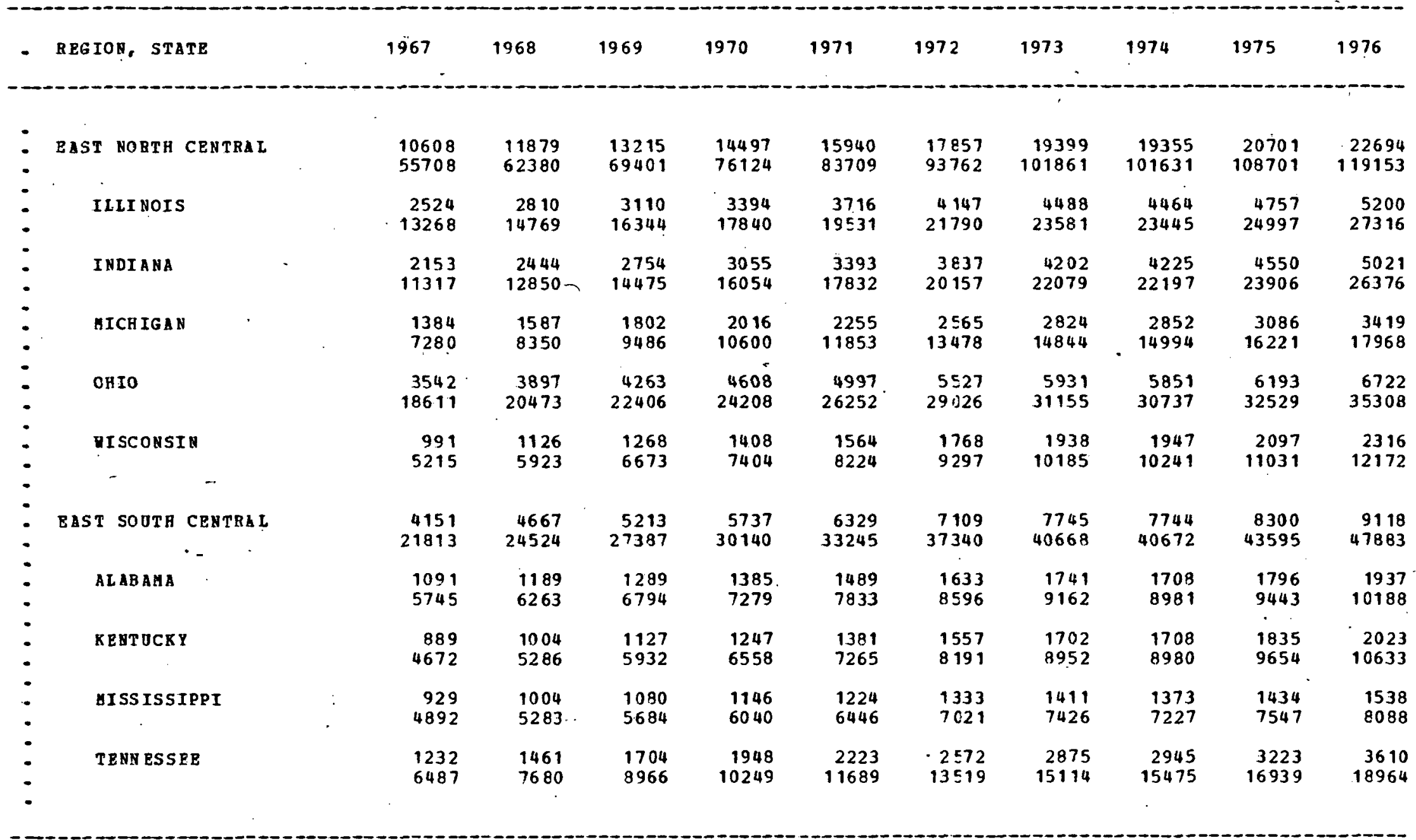


TABLE 7.90 -- IBTBRCITY NOYGOVRRBGEHT TBUCK GASOLIBE 5 EABEG: OSE. BY STATE, 1967-76

(FOORTB IN A SERIES OP 5 TABLES

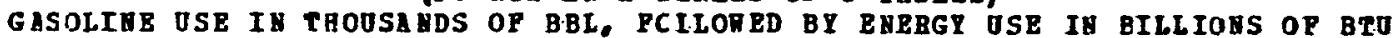

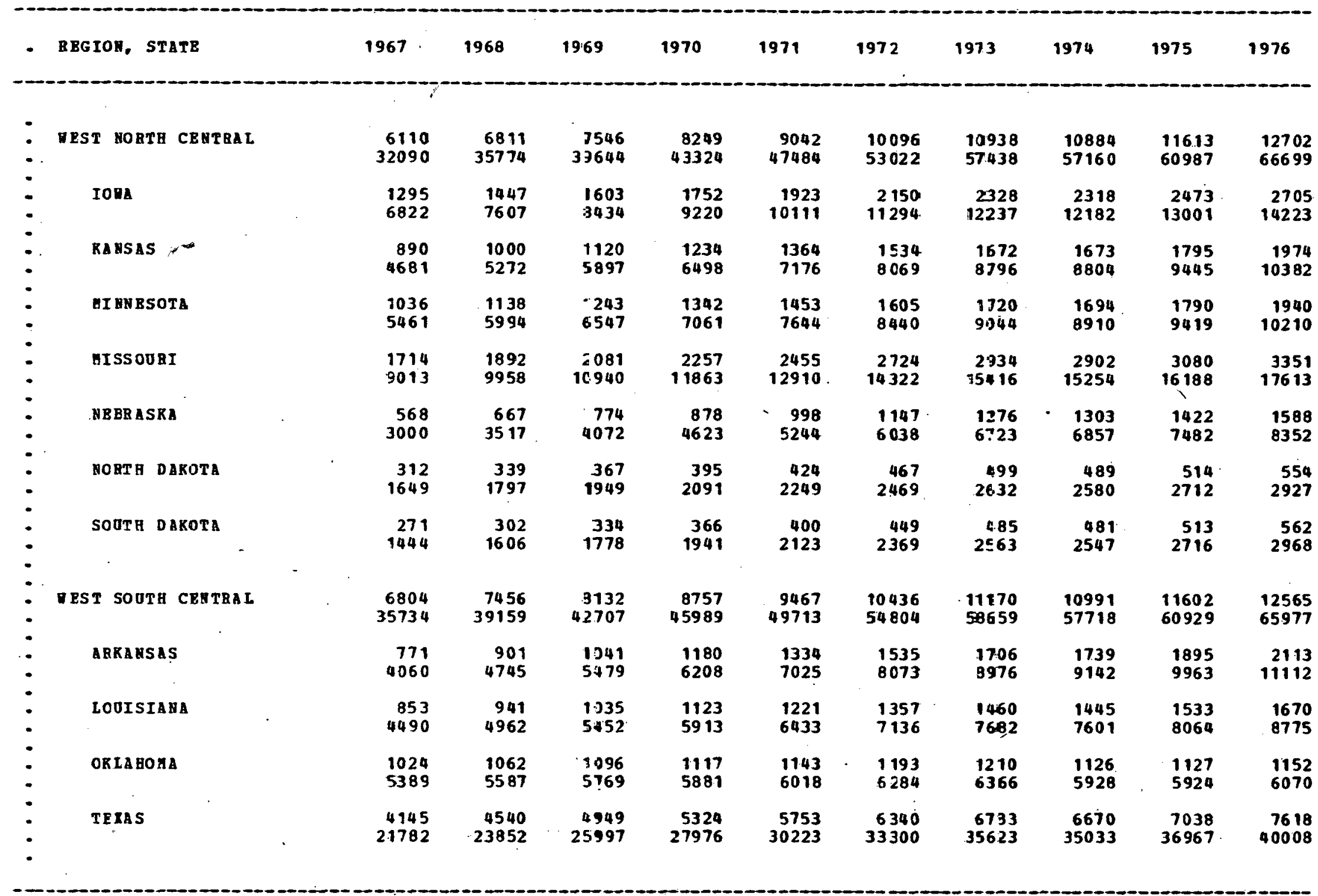


TABLB 7.9E -- INTBRCITY NOHGOVRRALERT TROCR GASOLINE E ENBBGY DSE.

BY STATE, 1967-76
(LAST IY A SBRIBS OP 5 TABLES)

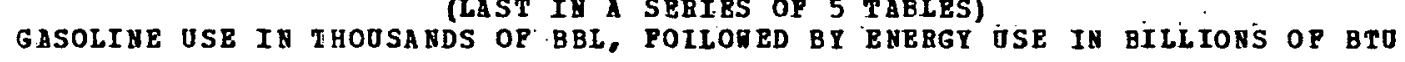

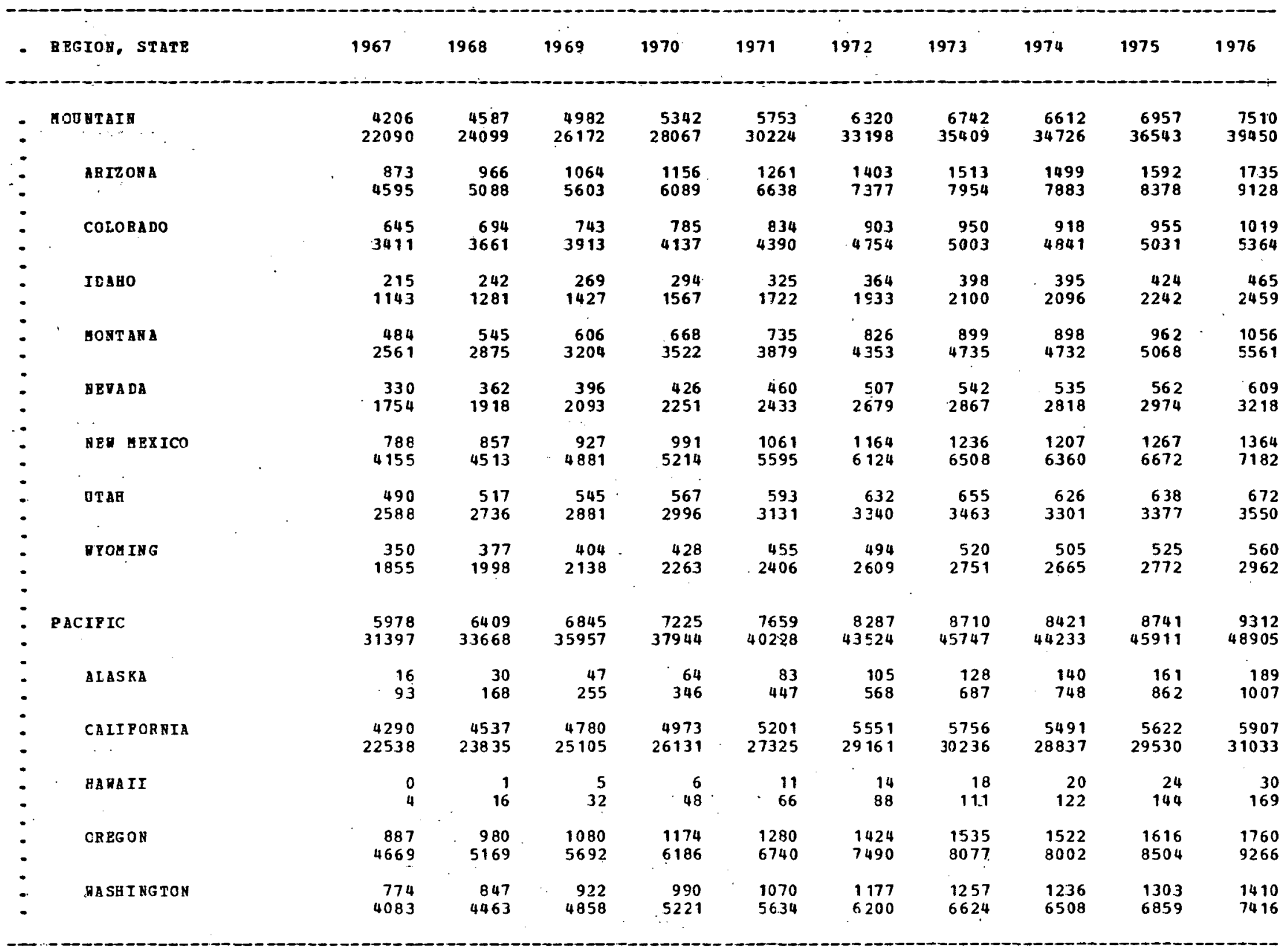


TABLE 7. 10A -- IHEERCITY NONGOVERNEENT TBOCK ENERGY CONSUHPTION,

BY YEIGHT CLASS BY SECSOR BY USE, 1967-76

ENEBGY CONSOMPTION IN BILLIONS OF BTU

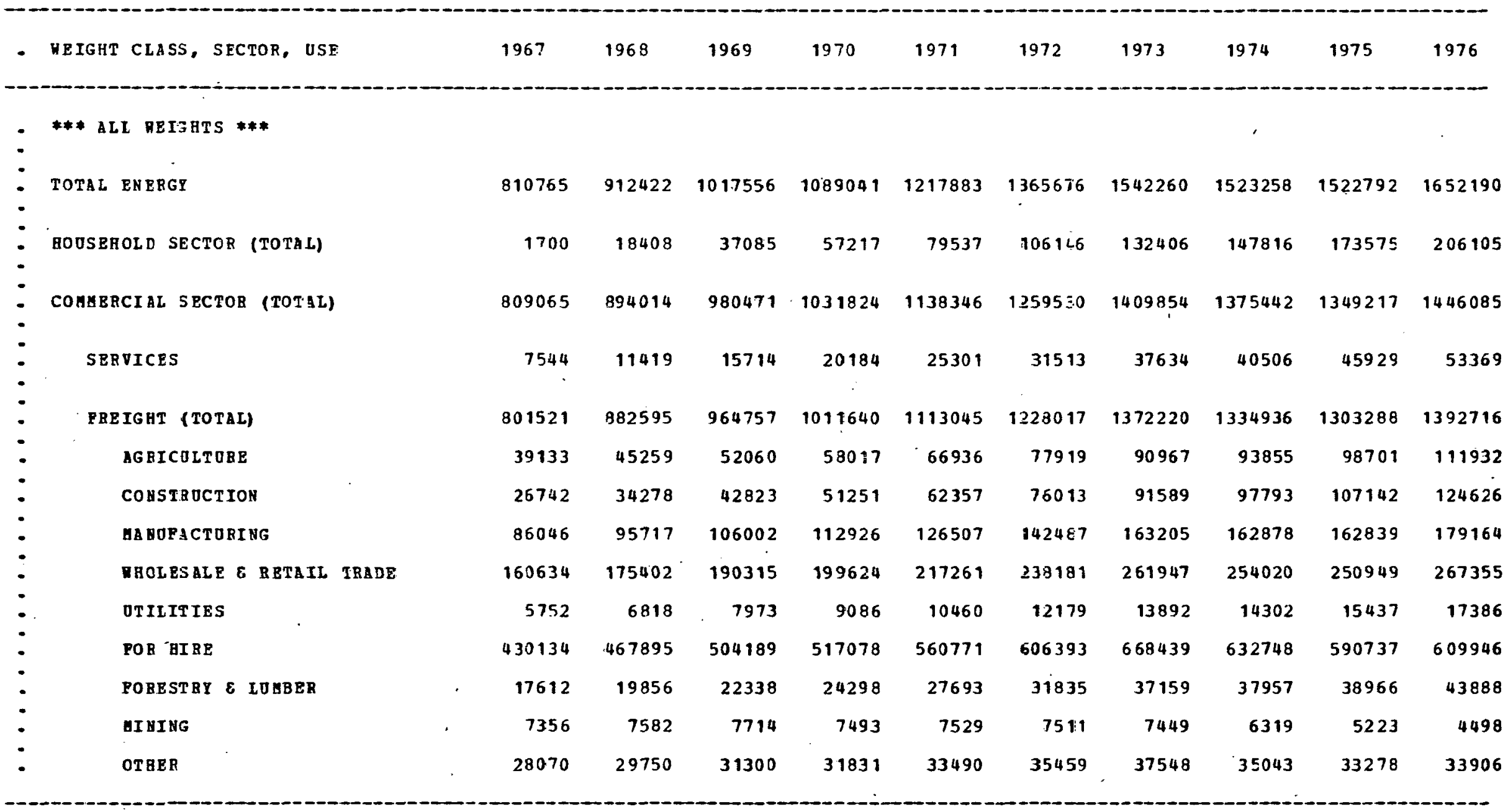

SCURCE: HETHOD 335

DATA QUALITI: 2 (1967, 72), 3 (OTHRB YEARS)

NCTE: ENERGY USE IN BACH USE CATEGOBY REPRESEUTS THE TOTAL BNRRGY OSED BY TRUCES DBOSE OW

IP PICKOP, POR IESTANCE, IS USED MOSTLY FOR PBRSONAL TRA ISPORT

AND PARTLY FOR OTHER PORPOSES, ITS PUEL USE IS COUKTED BATIRELY

AS OSE IN THE HOOSEROLD SECTOB. 
TABLE 7.10B -- I NTERCITY NONGOVEBNAENT TROCK ENERGY CONSUA PTION,

BY VEIGHT CLASS BY SECTOB BY USE, 1967-76

ENERGY CONSUMPTION IN BILLIONS OP BTU

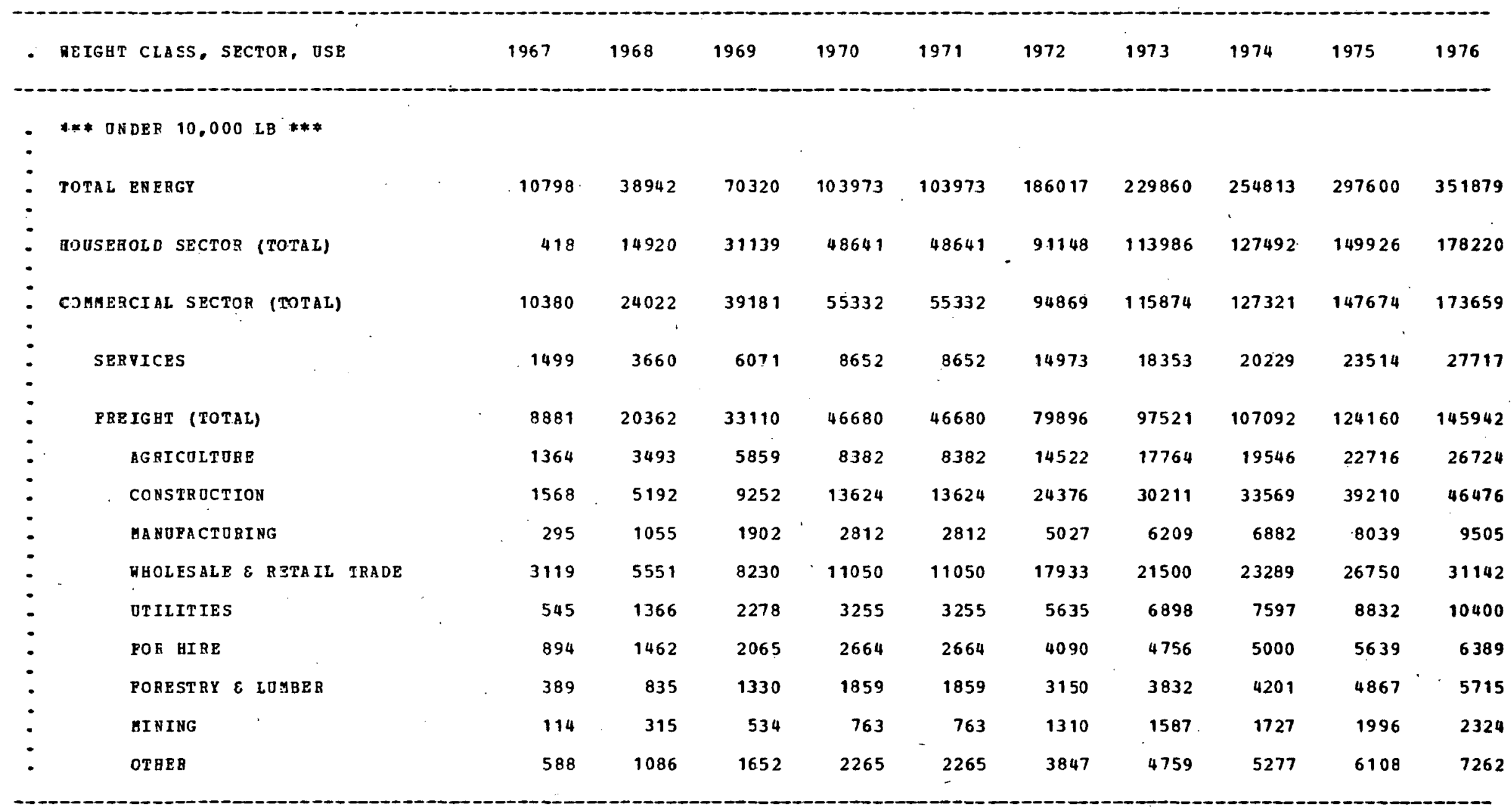

SCURCB: "

DATA QUALITY: 2 (1967. 72), 3 (OTHER YEARS)

HCTE: ENERG USE IN EACH USE CATEGORT REPRESENTS THE TOTAL RNERGY OSZD BT TROCKS REOSE ORNERS JUDGE TJEA TO SERVE PRIMARIIY THAT OSE.

IF A PICRUP. PCB INSTANCE, IS JSBD MOSTLY POR PERSONAL TRANSPORT AND PABTLY POR OTHBB PURPOSES, ITS POEL USE IS COONTED ENTIRBLY AS DSE IN THE HOUSEHOLD SECTOR. 
TABLE 7.10C -- IATBRCITY SONGOTBENHENT TRUCR ENERGY CONSOAPTION,

BY VEIGET CLASS BY SBCTOB BY USE, 1967-76

ENZBGI CONSOHPTION IN BILLIONS OF BTO

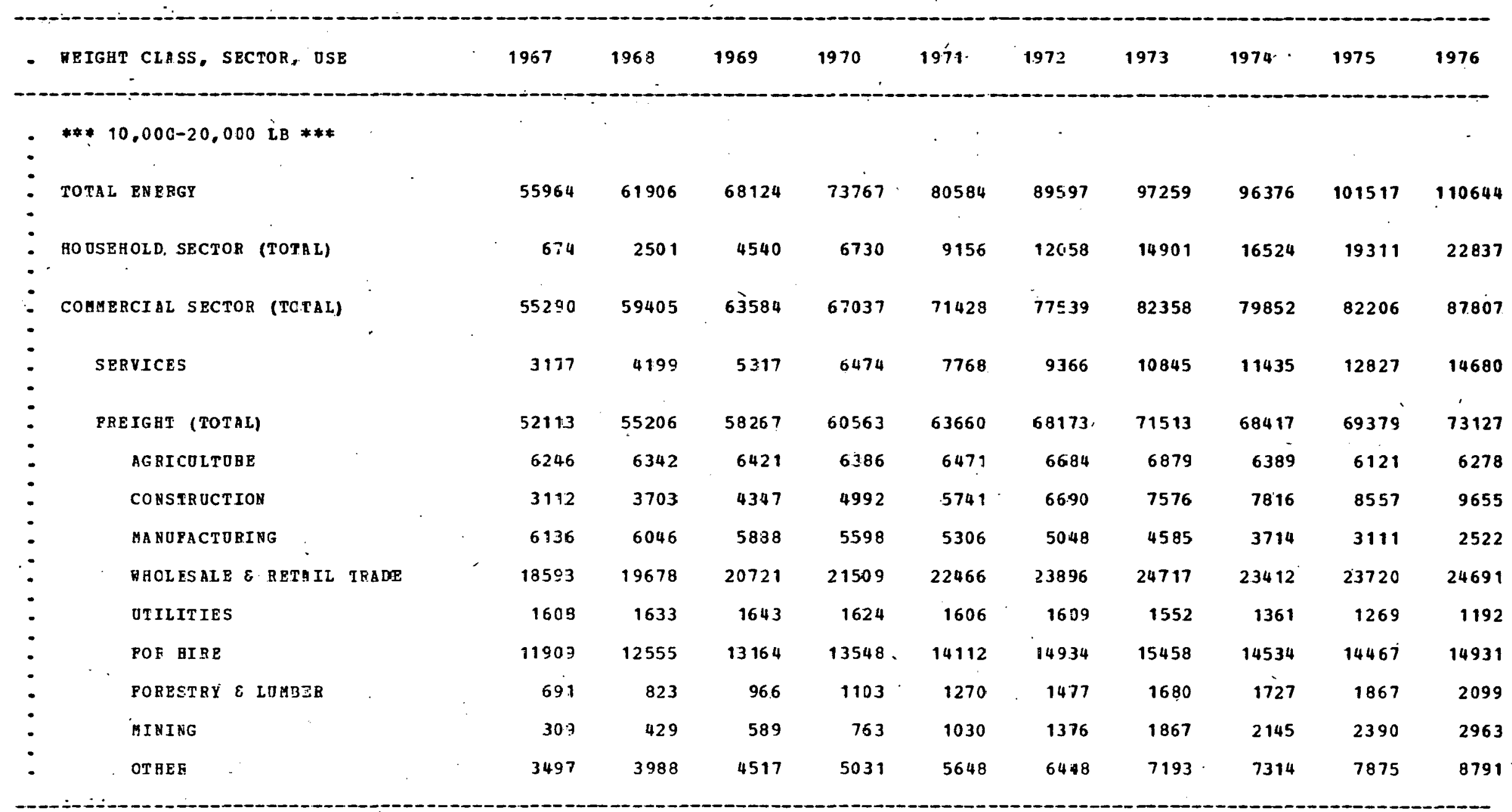

SCORCE: $\triangle E T B O D 335$

DATA QUALITY: 2 (1967, 72), 3 (OTHER YEARS)

NOTE: EYERGY OSE IM EACE USE CAORGCRY BEPRESENTS THE TOTAL BNBRGY USED BY TRUCKS WHOSE OHYESS JOMGE SHEM TO SERFE FRIMARIIT THAT OSE.

IP A PICKUP, POR INSTANCE, IS OSED MOSTLY FCR PERSONAL TRANSPORT IP A PICKUP, POR INSTANCE, IS OSED MOSTLY FCR PERSONAL TRANSPORT
$A$ W PARTLY POR OTHER PUIPASES, ITS FOEL CSE IS COUYTED BUTIBELY D PARTLY FOR OTHER PUIPASES.
USE IN THE HOUSEHOID SECTOB. 


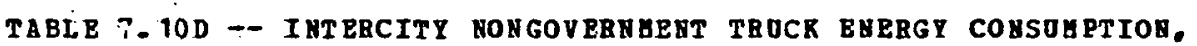

BY DEIGHT CLASS BY SBCTOR BY USE, 1967-76

RNERGI CONSUMPTION IN BILLIONS OF BTO

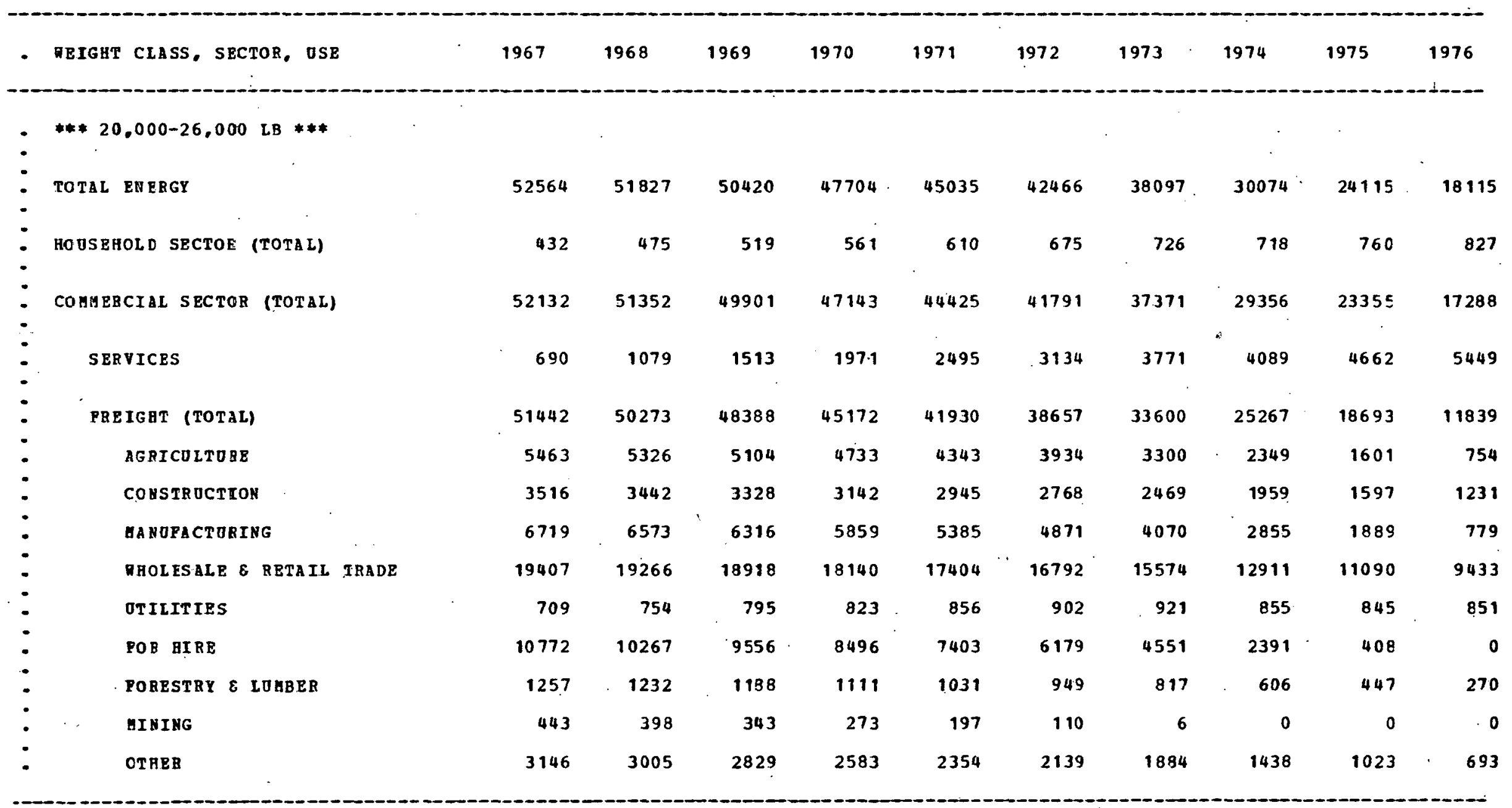

SCUBCE: VITEOD 335

DATA QUALITY: 2 (1967, 72). 3 (OTHER IEARS)

MOTE: ENERGY USE IN EACH OSE CATEGORY BEPRESENTS THE TOTAL RARRGY USED BY TRUCKS YHOSE ORHERS JUDGE THEM TO SERVE PRIMARILY THAT USE. IP A PICRUP, FOR INSTANCE, IS USED MOSTLY POB PERSONAL TBAHSPORT AYD PABTIY FOR OTHER POBPOSES, ITS POEL OSE-IS COUNTED EATIRELY AS USE IN THE HOUSBHOLD SRCTOR. 


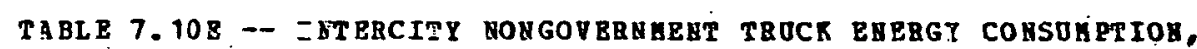

BY HEIGAT CLASS BI SECTOR BY OSE, 1967-76

EHE EGI CONSUGPTION IH BILLIOAS OF BTO

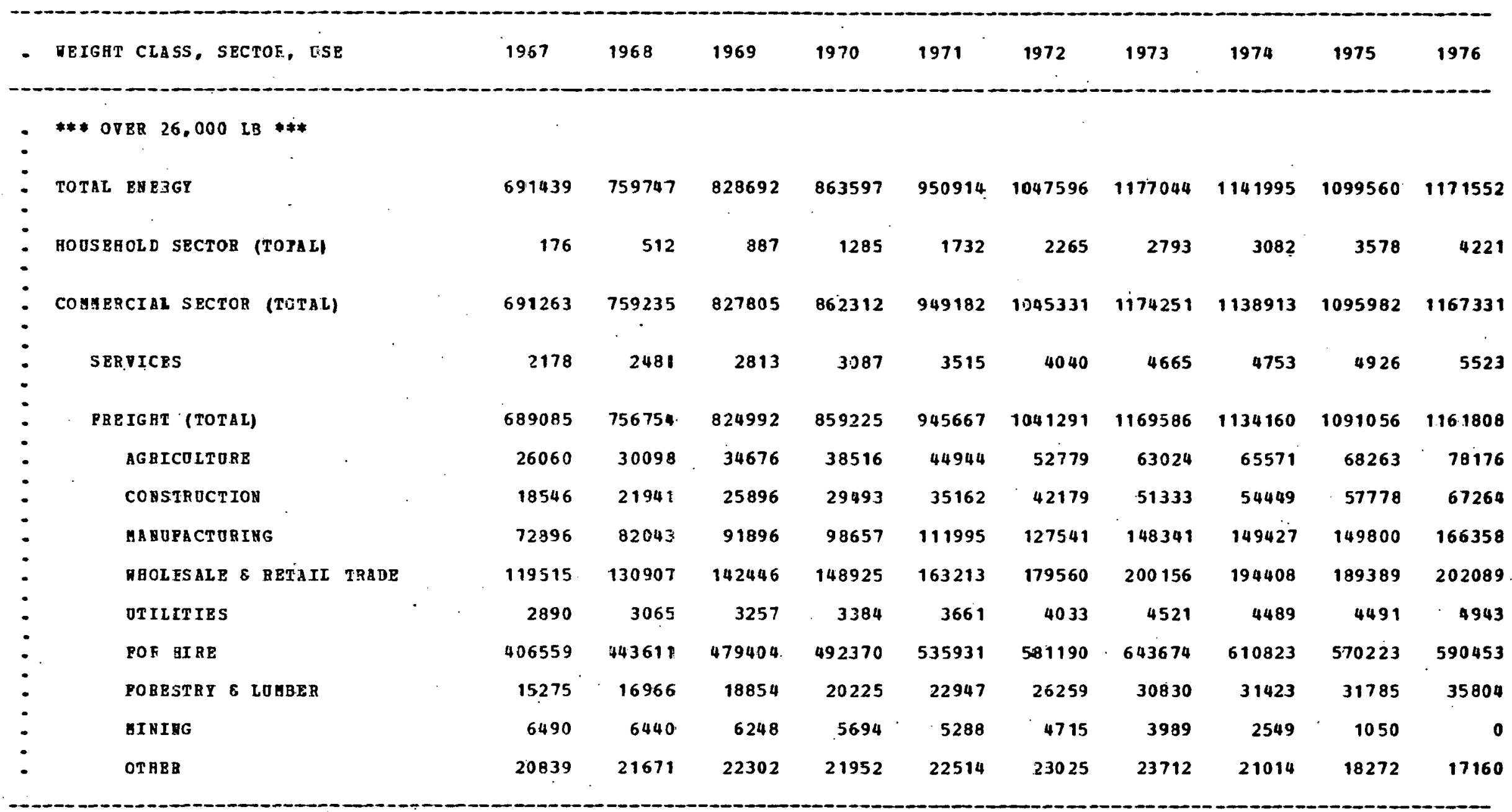

SOURCE: HETHOD 335

DATA QUALITY: $2(1967, T 2), 3$ (OTEER YEARS)

NCTE: EYRRGY OSE IR BACA OSE CAFEGCRY REPRESENTS THE TOTAL EMERGY USED BY TRUCKS RAOSB ONERS JUDGE THEA TO SEBVE PBIAABILY THAT USE.

IP A PICKDP, POR INSTANCE, IS OSED MOSTLY FOB PERSORAL TRARSPORT

AND PARTIY POB OTHEB POZPOSES, ITS PUEL OSE IS COUETED BRTIRELY

AS USB IH TBE HODSEHOLD SBCTOR. 
TABLE 7.10 -- PEDERAL TBUCK POEL AND BAERGY USE, BY YEIGHT CLASS, 1967-76

FOEL TSE (ALL PUELS) IN THOUSA OAS OP BABRELS

FOLLORED BY ENERGY USE IN BILLICNS OP BTO

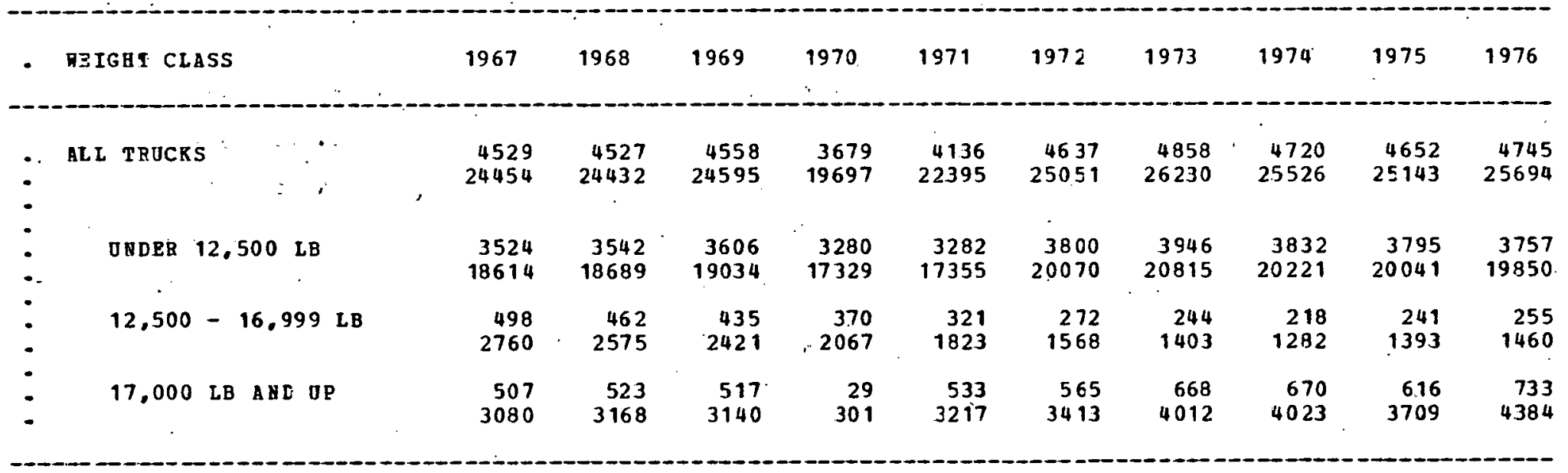

SOOECE= HETHOD 316

DAT QOALITY: 1 (FOBL FIGURES) \& 2 (ENERGY FIGORES) 
TABLE 7. 1.2A - PEDERAL TBOCE FOEL ABD ERERGY USE, BY STATE, 196:-76 (FIRST IN A. SEBIES OF 5 TABLES)

FOEL USE IN THDOSANDS OP BARBELS, POLLORED BY ENERGI OSE IN BILLIONS DF BTO

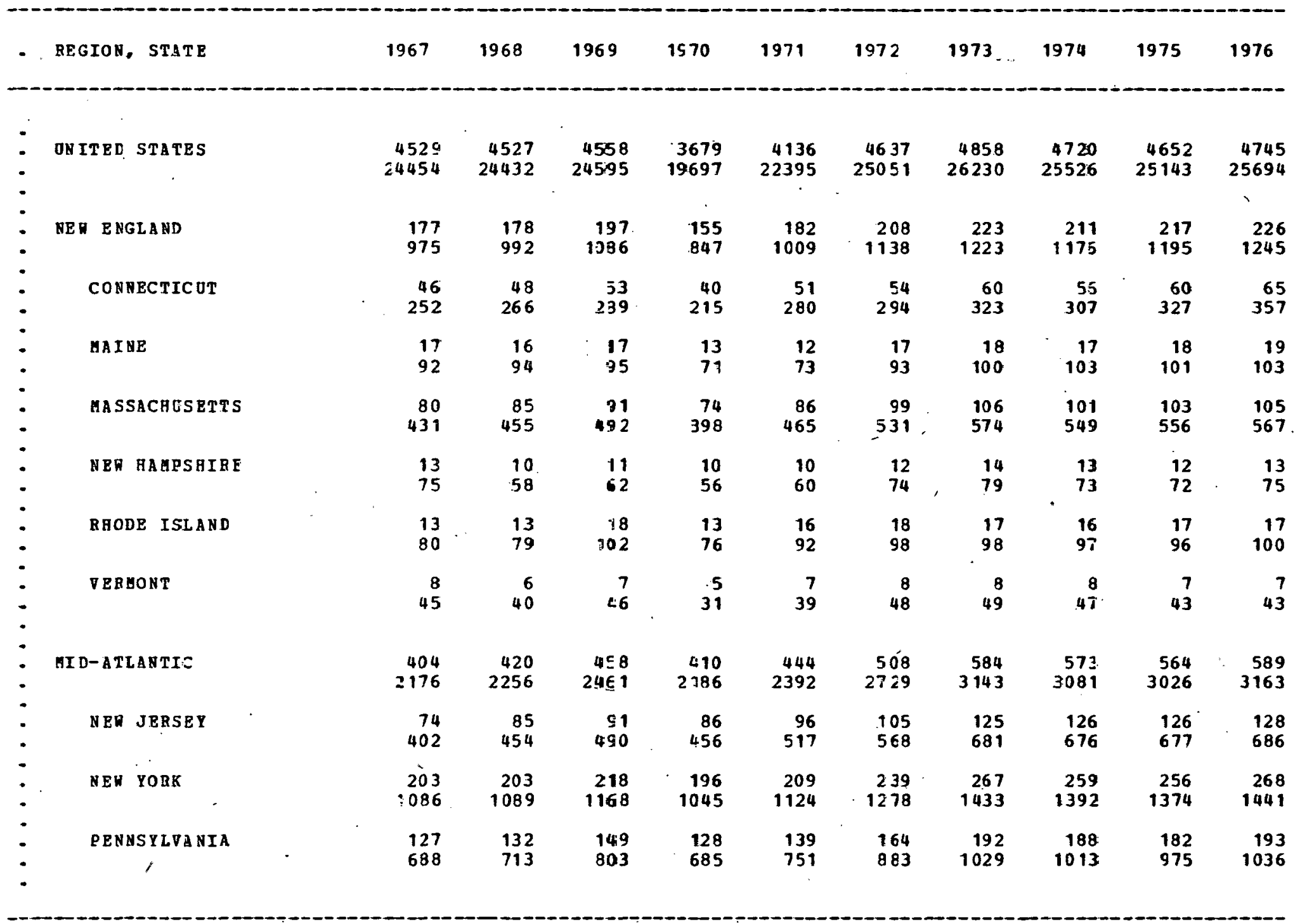


TABLE 7.12B - FEDERAL TRUCR POEL ABD ENERGY OSE, BY STATE, 1967-76

(SBCOND I\$ A SERIES OR 5 TABLBS) ?

FOEL USE IA THOOSA ADS OP BARRELS, FOLLOHBD BY BHERGY USE IN BILLIONS OP BYO

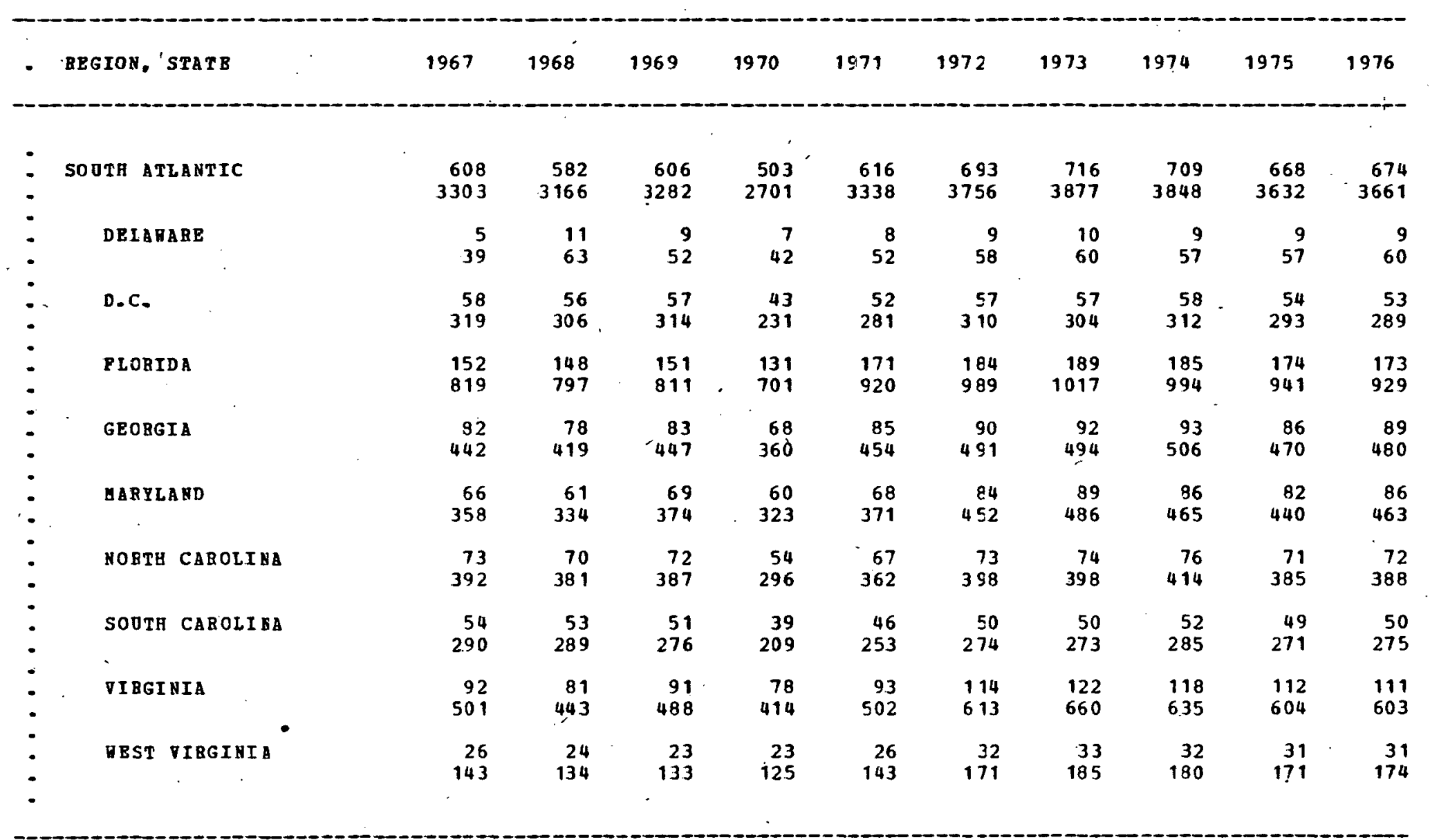


TABLE 7.12C - PEDEBAL TBOCK POBL AKD EAERGY OSE, BY STATB, 1967-76 (THIRD IN A SBRIBS: OP 5 TABLES)

POEL OSE IN TROJSANDS OF BABRELS, FOLLONBD BY BAEBgY USE IA BILLIOAS OP BTO

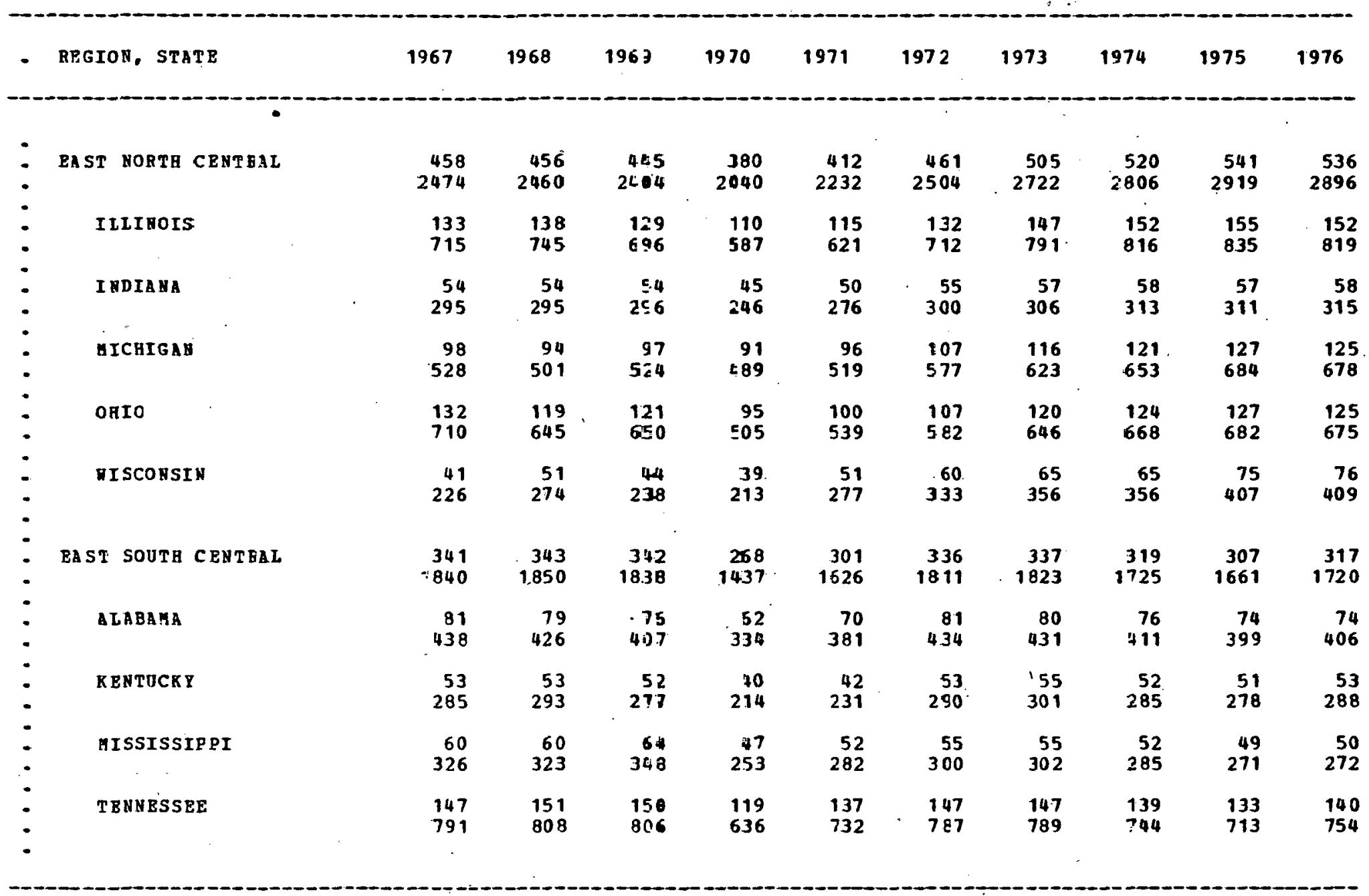


TABLE 7.12D - PEDERAL TRUCR FOEL AND BHEBGY OSE, BY STATE, 1967-76

(POURTA IN A SERIES OP 5 TABLES)

PORL USE IN TBOUSANDS OP BARBBIS, POILORBD BY ENRRG USE IU BILLIONS OF BTU

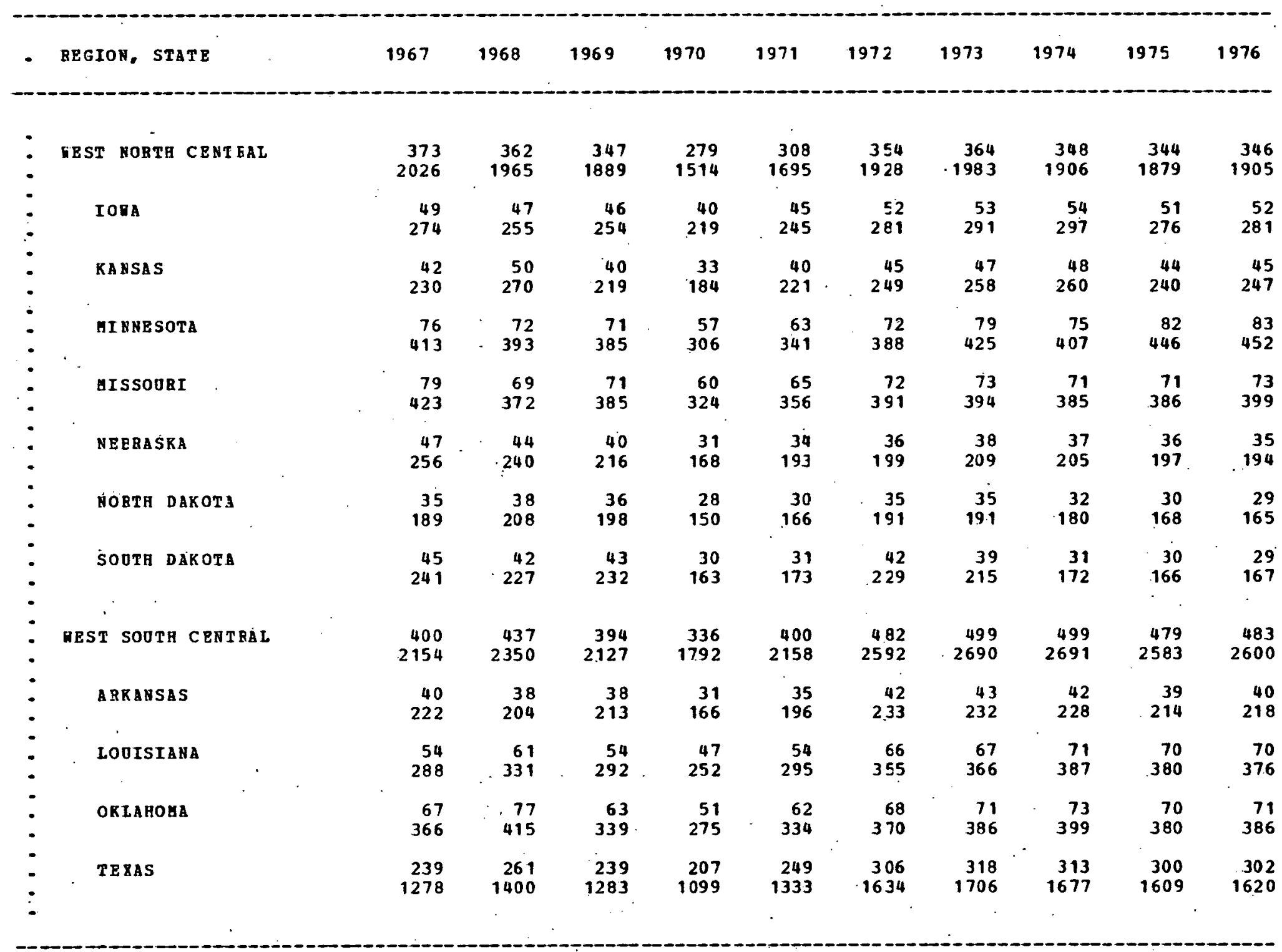


TABLE 7.12E - PEDERAL TRUCR. FUEL ABD EQEBGY USB, BY STATE, 1967-76 (LAST IN A SERIES OF 5 TABLBS)

EOEL OSE IE THOUSA MDS OP BARRELS, FOIIONED BI EBREG USB IN BILLIOHS OP BTJ

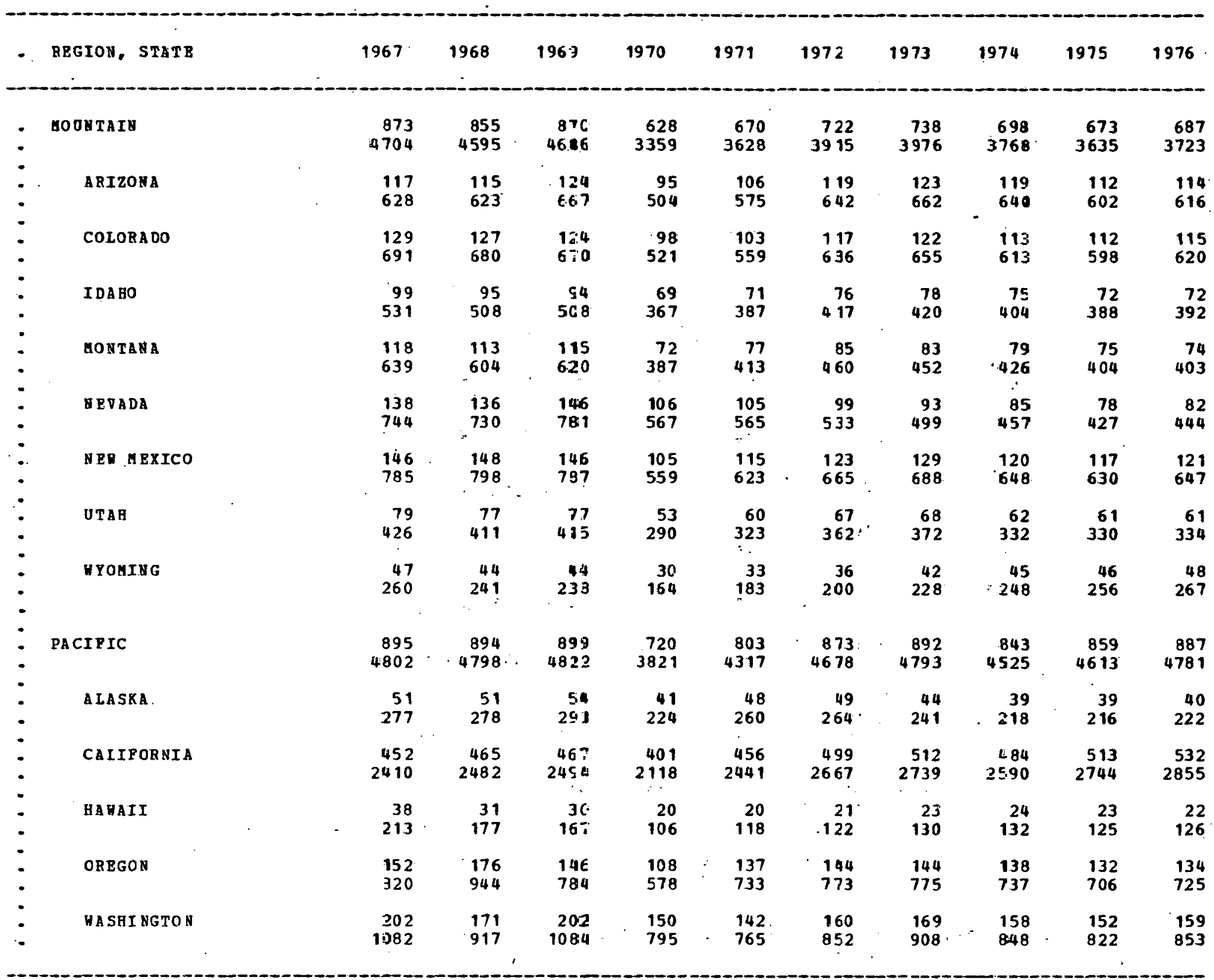


GASOLI DE CONSUAPTIOH IN THOUSANDS OP BARRELS

POLLORPD BI BNBRG COHSOHPTION IN BILLIONS OF BTO

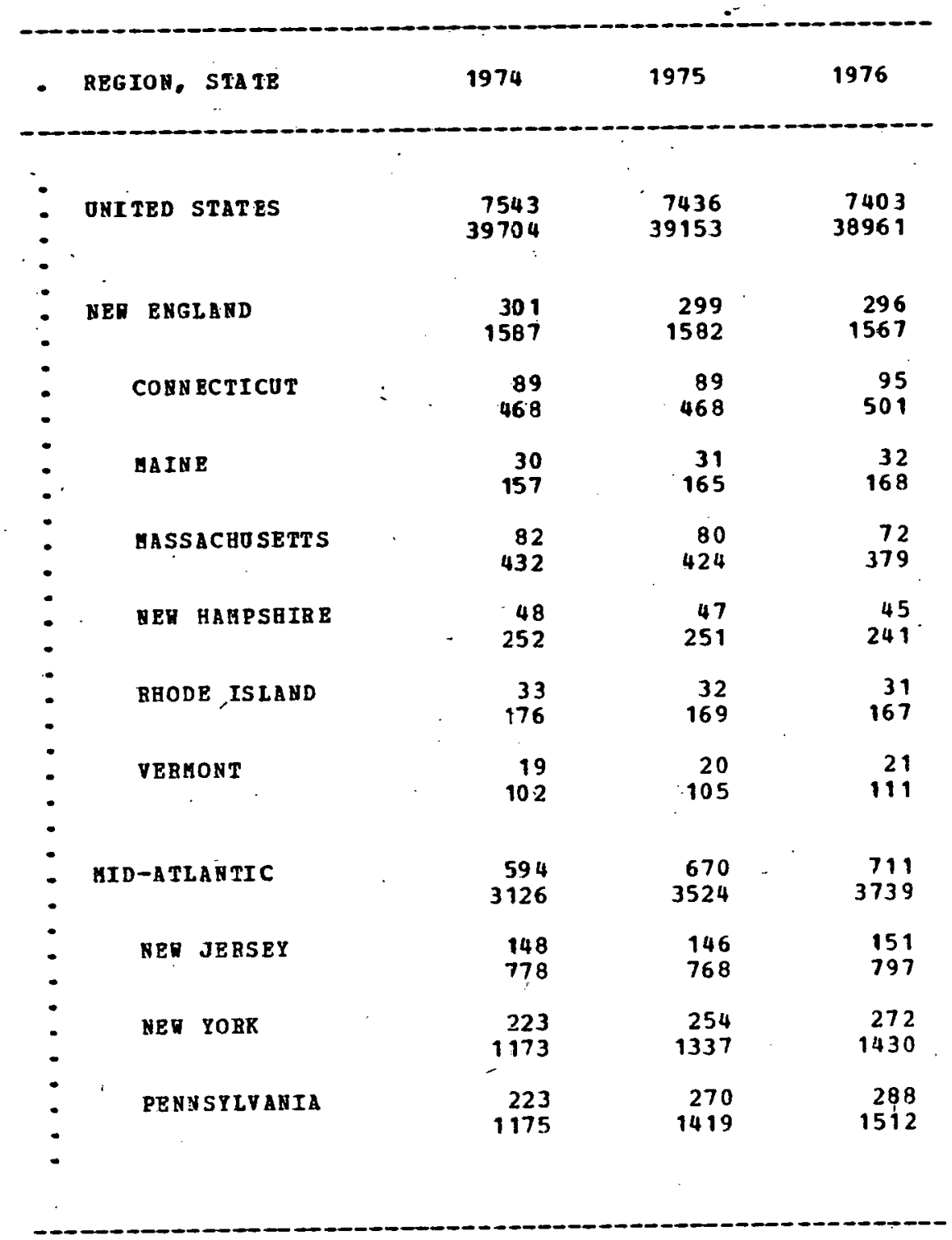

SOOBLE: HETHOD 314 DATA QOALITY: 2 (NAT'L E REGIONAL), 3 (STATES) 
TABLB 3.18 -- MOTCECYCLE GASOLINE AND ENERGY CONSJHETION, BY STATE, 1974-76 (SECOND IN A SERIBS OP 5 PAGES)

GASOLI UE CONSUAPTION IA THOUSANDS OP BARRELS

FOLLONED BT ENERGY COBSOGETION IN BILLIONS OF BTD

\begin{tabular}{|c|c|c|c|c|}
\hline & REGION, STATE & 1974 & 1975 & 1976 \\
\hline . & SOOTH ATLANTI= & $\begin{array}{l}1466 \\
7718\end{array}$ & $\begin{array}{l}1359 \\
7160\end{array}$ & $\begin{array}{l}1328 \\
6980\end{array}$ \\
\hline : & DELADABE & $\begin{array}{r}21 \\
111\end{array}$ & $\begin{array}{r}21 \\
114\end{array}$ & $\begin{array}{r}20 \\
106\end{array}$ \\
\hline 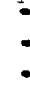 & D. C. & $\begin{array}{r}7 \\
41\end{array}$ & $\begin{array}{r}6 \\
36\end{array}$ & i \\
\hline . & PLORIDA & $\begin{array}{r}431 \\
2264\end{array}$ & $\begin{array}{r}379 \\
1991\end{array}$ & $\begin{array}{r}416 \\
2185\end{array}$ \\
\hline . & GEORGIA & $\begin{array}{l}169 \\
892\end{array}$ & $\begin{array}{l}159 \\
836\end{array}$ & $\begin{array}{l}152 \\
798\end{array}$ \\
\hline . & GARYLAND & $\begin{array}{l}141 \\
743\end{array}$ & $\begin{array}{l}140 \\
739\end{array}$ & $\begin{array}{l}144 \\
757\end{array}$ \\
\hline . & NORTH CABOLI HA & $\begin{array}{r}252 \\
1326\end{array}$ & $\begin{array}{r}239 \\
1259\end{array}$ & $\begin{array}{r}227 \\
1192\end{array}$ \\
\hline : & SOUTH CAROLJ WA & $\begin{array}{r}113 \\
594\end{array}$ & $\begin{array}{r}81 \\
428\end{array}$ & $\begin{array}{r}91 \\
+79\end{array}$ \\
\hline ? & DIRGIHIA & $\begin{array}{r}270 \\
1417\end{array}$ & $\begin{array}{r}273 \\
1436\end{array}$ & $\begin{array}{r}217 \\
1139\end{array}$ \\
\hline & HEST VIRGINIA & $\begin{array}{r}62 \\
330\end{array}$ & $\begin{array}{r}61 \\
321\end{array}$ & $\begin{array}{r}54 \\
287\end{array}$ \\
\hline
\end{tabular}

SODECE: METHOD 341 DATA QOALTT: 2 (REGIOHAL). 3 (STATES) P. 
TABLE-8.1C -- MOTORCYCLE GASOLIRE AND ENEGG CONSUGETON. BY STATE, 1974-76 (THIRD IA A SBRIES OF 5 PAGES)

GASOLI BE CONSUgPTION I THOUSABES OF BARBELS

PCLLONED AY ENERGI CORSOETION IN BILLIOUS OP BTO

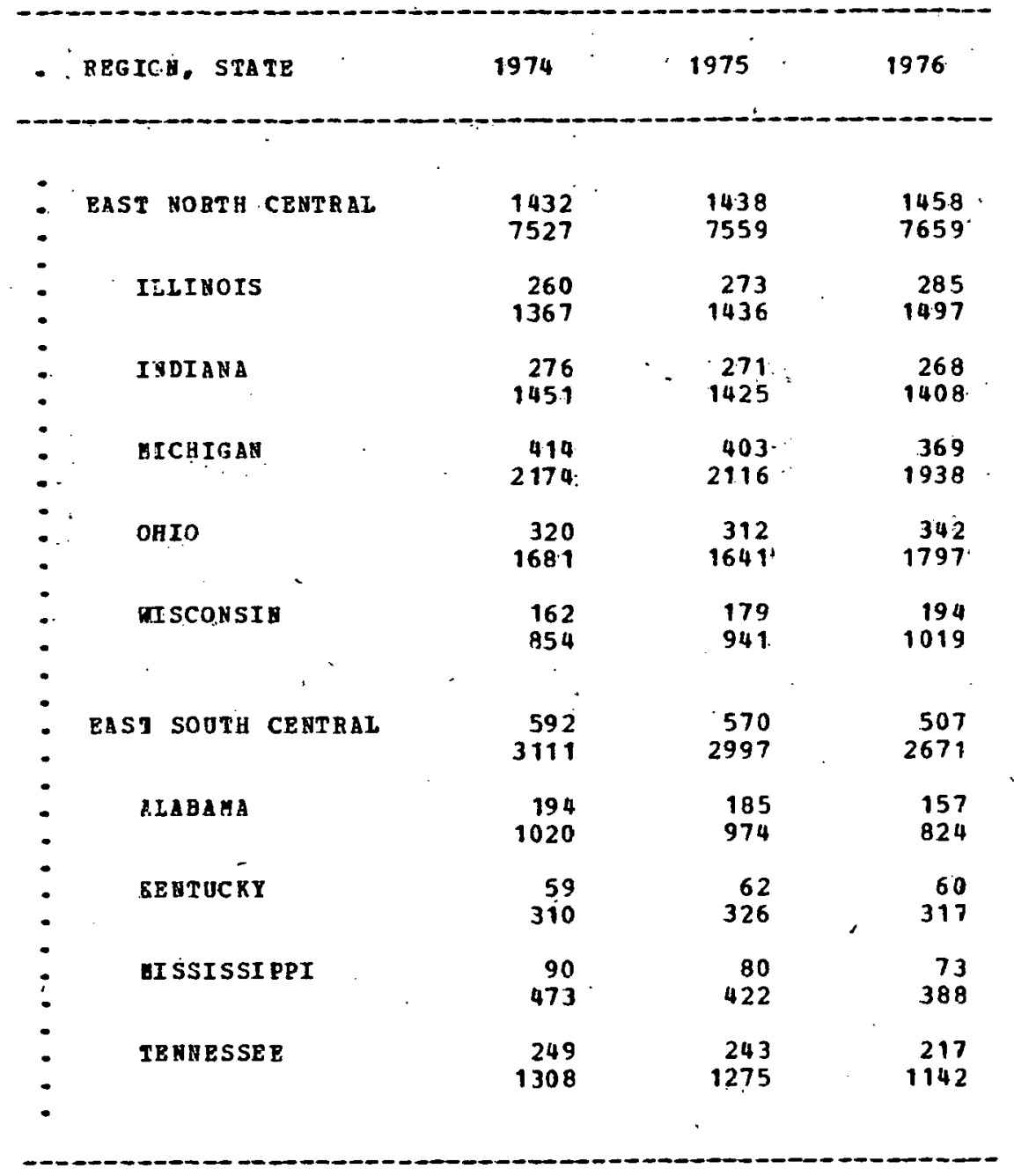



(ZODRTH TH A SERIES OF 5 PAGBS)

GASOLIME CONSUAPTIOA IA THOOSAYDS OF BARBE-S

POLLONED BE ENERGI CONSOHPTIOH IR BILLIONS OP BTO

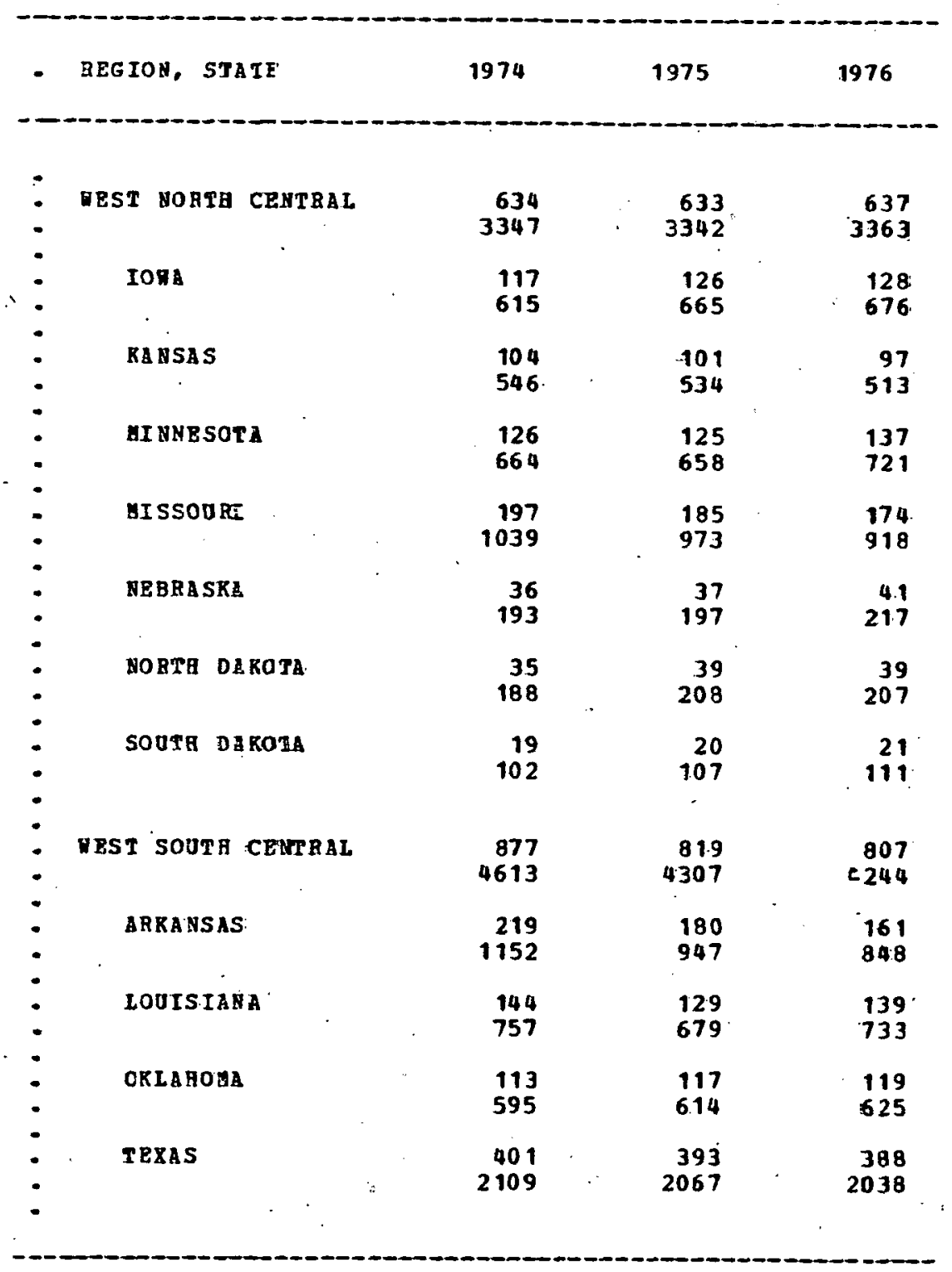


TABLE 8.1P - MOTORCYCLE GASOLIHE AND ERERGY CONSOHPTION, BY STATE, 1974-76 (FIPTH IN A SERIES OF 5 PAGES)

GASOLI BE CONSUATTON I THOOSANDS OP B.ARELS POLLOHED BY ENERGY CONSUHPTION IN BILLIONS OP BTO

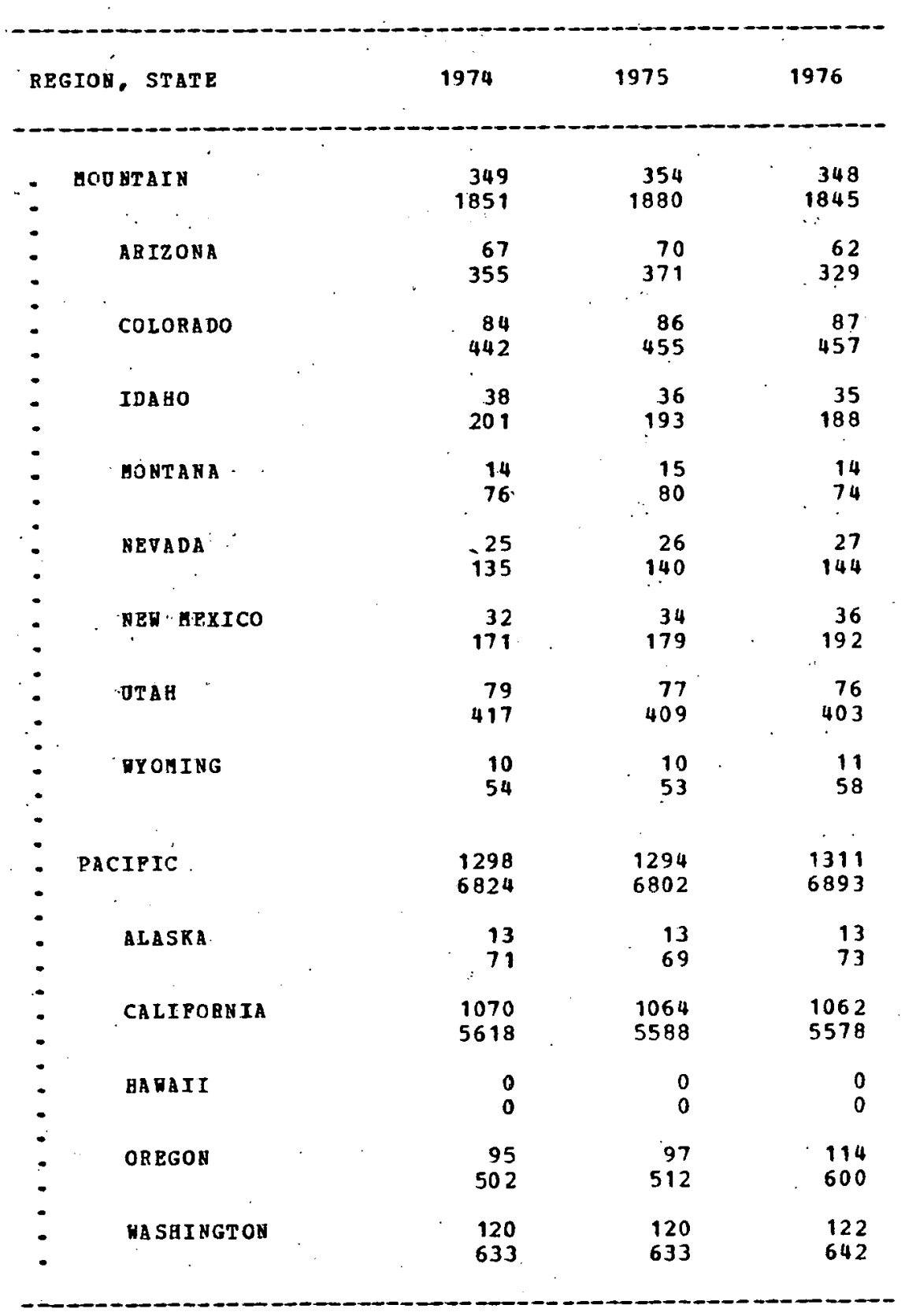


TABLE B.2 - - MOTORC YCLB POEL AAD BNERGT CONSOUPTION NATIONETDB; 1957-73

REGISTBRED EOTORCTCLBS ORLY

\begin{tabular}{|c|c|c|c|c|c|c|c|}
\hline & 1967 & 1968 & 1969 & 1970 & 1971 & 1972 & 1973 \\
\hline & & . & & & & & \\
\hline $\begin{array}{l}\text { POBL OSE, } \\
1000 \cdot 5 \text { OF BBL }\end{array}$ & 1942 & 2088 & 2302 & 2798 & 3325 & 3781 & 4332 \\
\hline $\begin{array}{l}\text { EMERGP. OSE, } \\
\text { BILLIONS OF BTO }\end{array}$ & 10195 & 10965 & 12090 & 14694 & 17456 & 19854 & 22743 \\
\hline
\end{tabular}

SOORCE: AETHOD 341

DATA QJALTTY: 2 IWERE IT IS UHDERSTOOD SHAT REGISTEBED CYCLES OHLY ARB ACCCUNTED PORJ 
TABLE 8.3 -- MOTORC YCLE PUBL AND EHERGY CONSOAPTION, BY OSE, 1974-76 GASOLI NE CONSUAPTION IY THOOSAUDS OP BABRELS FOLLOUED BY ENERGY CONSUAPTION IN BILLIONS OF BTU

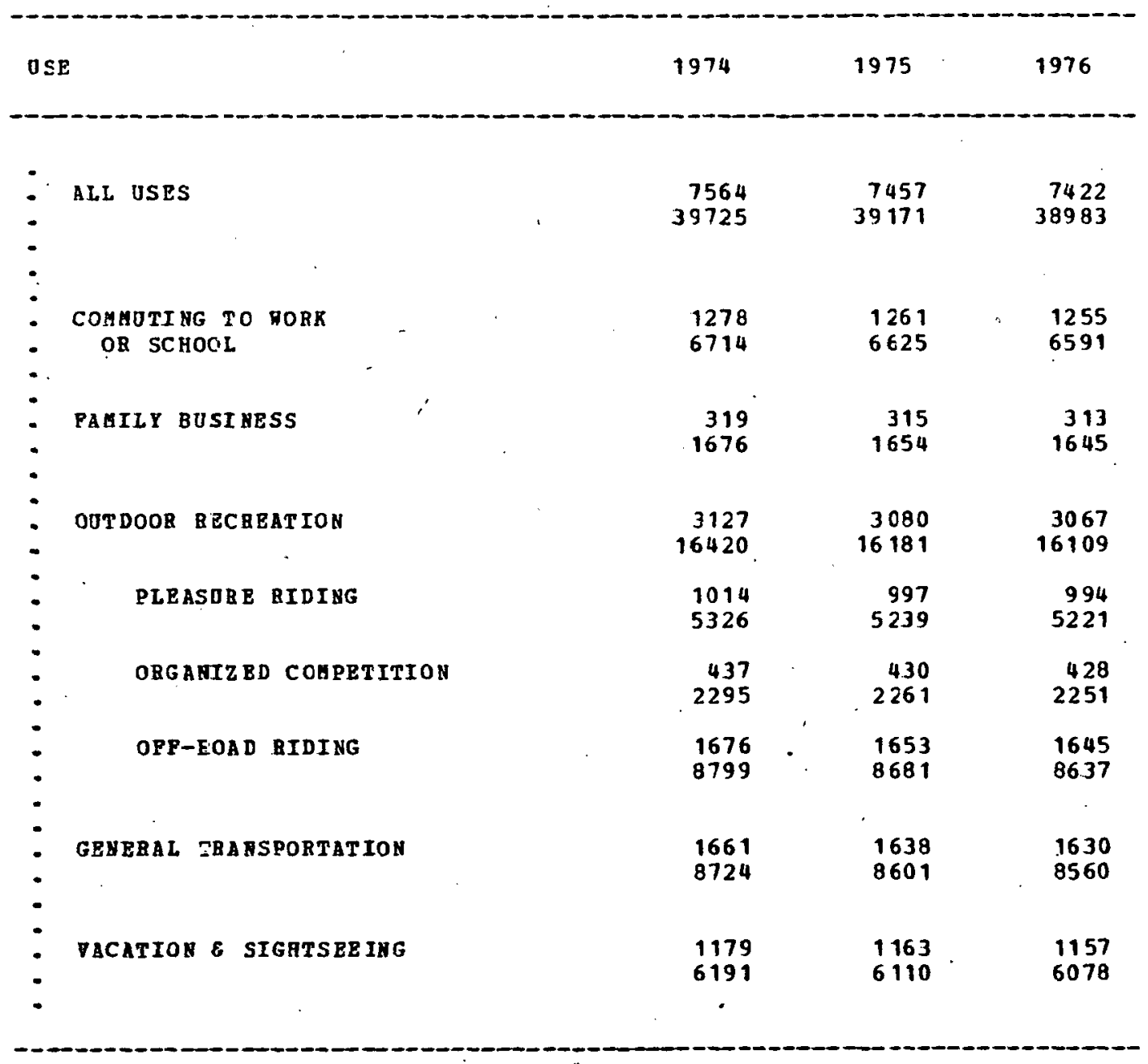

SCORCE: HETHOD 341 DATA QUALTTY: 2

HCTE: TOTALS FOB ALI OSES DO ROT AGREE PBBCISEIY IITH NATIOLAL TOTALS IN TABLE 8.2A BRCAUSE OP ACCOAULATED ROUBDOFP ERBOE TAAT OCCURS IN TABLE 8. 2A BECAUSE OF ACCU LOLATED ROUSDOFP EREOE T HAT OCCUAS 


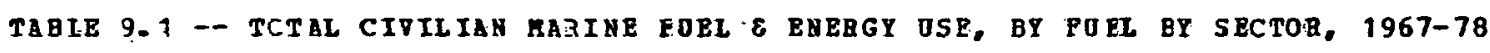

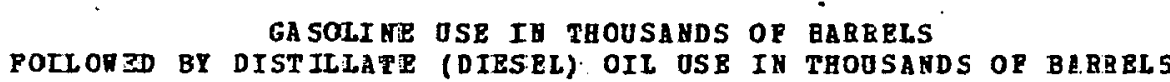

FOLLORED BY RESTDOAL OIL OSE IN THOOSANDS OF EAREAS

POLLORED BY TJEAI BQRBGI OSE IV BILLIOHS OF BTO

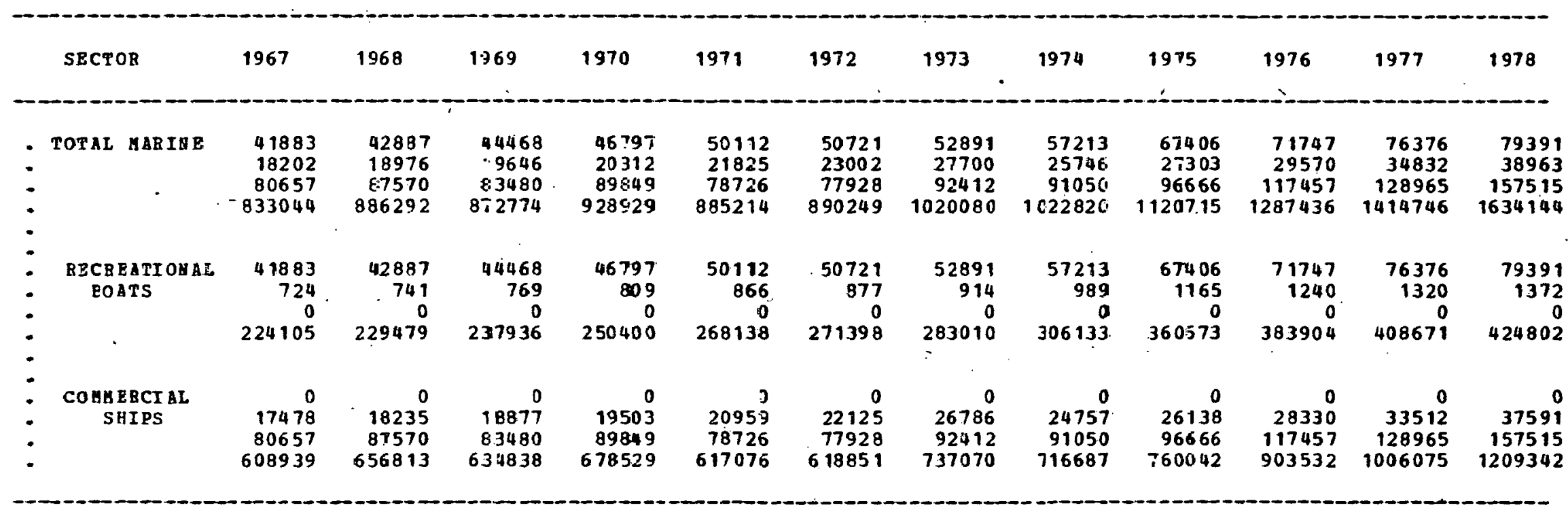

SOURCE: METHOD 400 DATA COALITY: CENEMALIY 2 
TABLE 9.2A -- REEREATIONA BOAT GASOLINE AND BUERG USE, BY STATE, 1967-78 (PIRST IR A SBRIES OP 5 TABLES)

GASOLIHE USE IN THOUSA NDS OP BB., ROLLONED BY EYERGY USE IN BILLIONS OP BTU

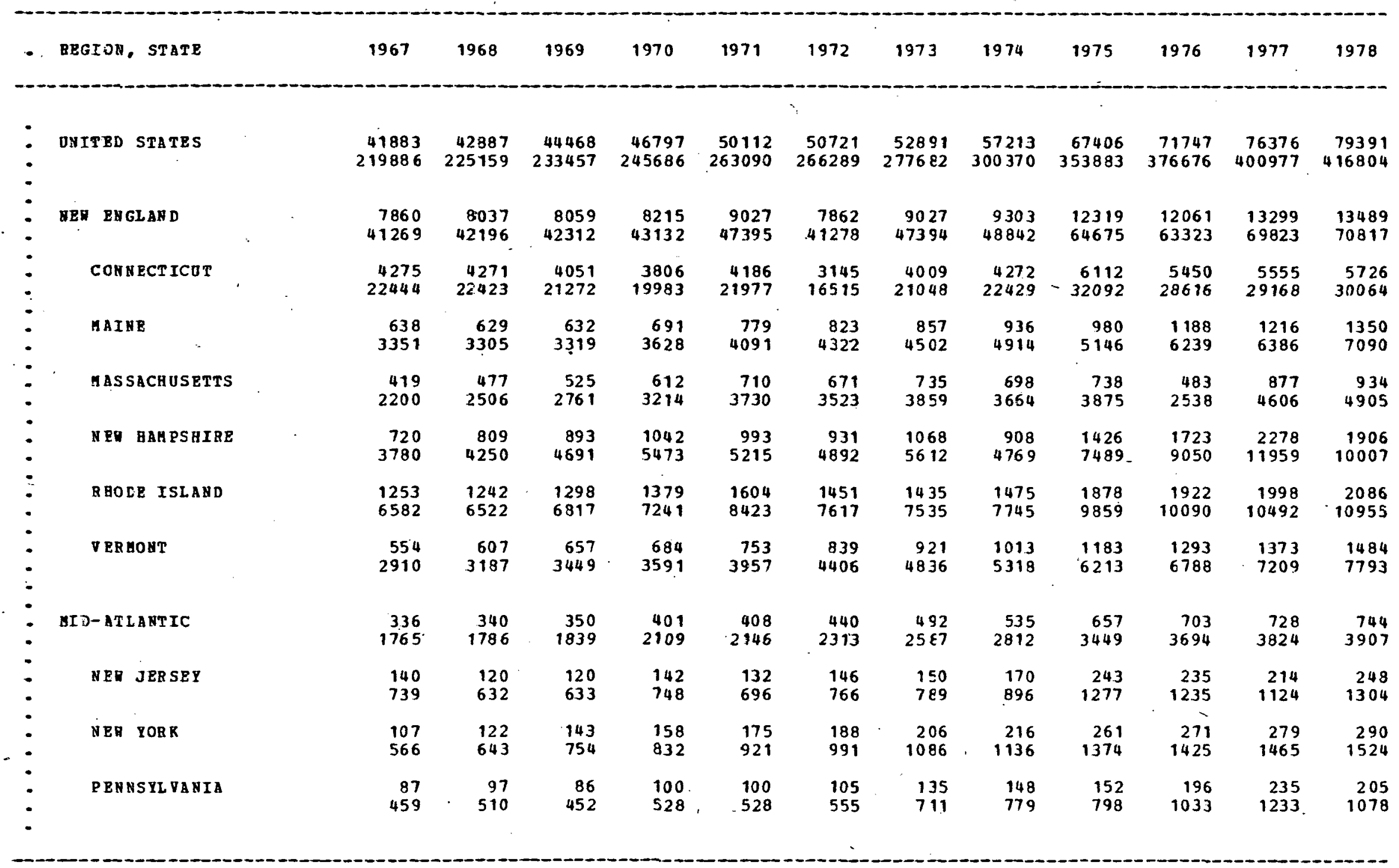


TABLE 9.2B -- RECREATIOYS L BOAT GASOLIUE AND ENERGY USE, BY STATE, 1967-78

(SZZOND IN A SERIES OP 5 TABLES)

GasOLINE GASOLINE OSE IN TgOOSAHDS OR BBL, POLLONED BT RERRG ISB IN BILLIONS OP BTU

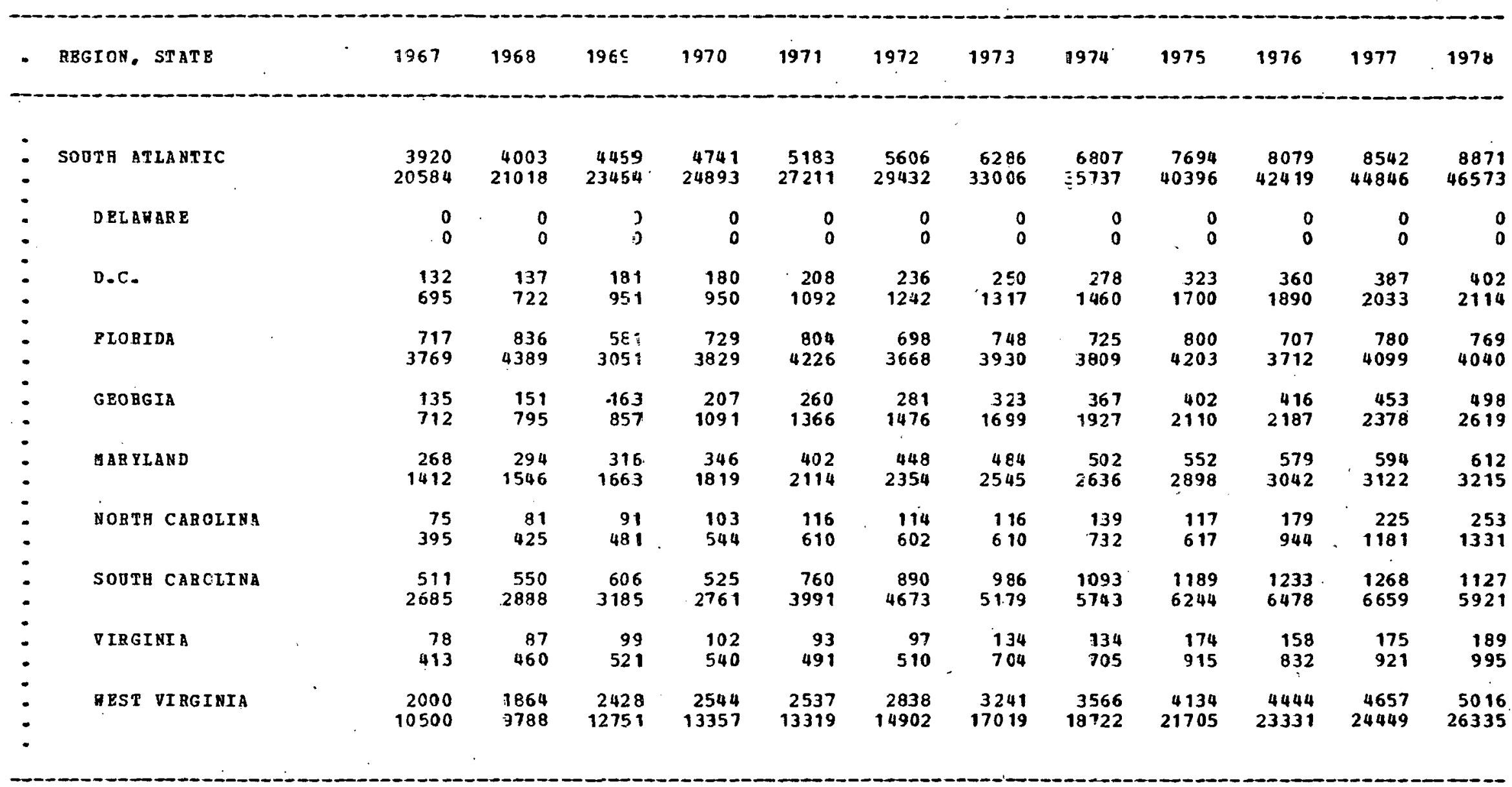


TABLE 9.2C -- RECREATIONAL BOAT GASOLIHE AND ERERGY USE, BY STATE, 1967-78 (THIBD IH A SERIBS OP 5 TABLBS)

GaSOLINE GASOLINB OSE IA THOOSANDS OP BBL, POLLONBD BI ENERG OSE IN BILLIONS OF BTU

\begin{tabular}{|c|c|c|c|c|c|c|c|c|c|c|c|c|c|c|}
\hline & BEGION, STATE & & 1967 & 1968 & 1969. & 1970 & 1971 & 1972 & 1973 & 1974 & 1975 & 1976 & 1977 & 1978 \\
\hline & $\cdot$ & & & & & & & & & & & . & & \\
\hline & BAST NORTR CENTRAL & & $\begin{array}{r}2077 \\
10907\end{array}$ & $\begin{array}{r}2169 \\
11391\end{array}$ & $\begin{array}{r}2413 \\
12672\end{array}$ & $\begin{array}{r}2516 \\
13211\end{array}$ & $\begin{array}{r}2799 \\
14695\end{array}$ & $\begin{array}{r}2877 \\
15108\end{array}$ & $\begin{array}{r}2383 \\
12515\end{array}$ & $\begin{array}{r}2995 \\
15726\end{array}$ & $\begin{array}{r}3501 \\
18385\end{array}$ & $\begin{array}{r}4180 \\
21948\end{array}$ & $\begin{array}{r}4562 \\
23955\end{array}$ & $\begin{array}{r}4821 \\
25310\end{array}$ \\
\hline- & ILINOTS & & $\begin{array}{r}800 \\
4200\end{array}$ & $\begin{array}{r}819 \\
4303\end{array}$ & $\begin{array}{r}963 \\
5055\end{array}$ & $\begin{array}{l}1003 \\
5269\end{array}$ & $\begin{array}{l}1122 \\
5893\end{array}$ & $\begin{array}{l}1137 \\
5.973\end{array}$ & $\begin{array}{r}605 \\
3177\end{array}$ & $\begin{array}{r}942 \\
4947\end{array}$ & $\begin{array}{l}1273 \\
6688\end{array}$ & $\begin{array}{l}1244 \\
6532\end{array}$ & $\begin{array}{l}1354 \\
7110\end{array}$ & $\begin{array}{l}1437 \\
7549\end{array}$ \\
\hline & I YDIANA & & $\begin{array}{l}0 \\
0\end{array}$ & $\begin{array}{l}0 \\
0\end{array}$ & $\begin{array}{l}0 \\
0\end{array}$ & $\begin{array}{l}0 \\
0\end{array}$ & $\begin{array}{l}0 \\
0 .\end{array}$ & $\begin{array}{l}0 \\
0\end{array}$ & $\begin{array}{l}0 \\
0\end{array}$ & $\begin{array}{l}0 \\
0\end{array}$ & $\begin{array}{l}0 \\
0\end{array}$ & $\begin{array}{l}0 \\
0\end{array}$ & $\begin{array}{l}0 \\
0\end{array}$ & $\begin{array}{l}0 \\
0\end{array}$ \\
\hline & GICBIGA & $\cdot$ & $\begin{array}{l}1028 \\
5398\end{array}$ & $\begin{array}{l}1089 \\
5720\end{array}$ & $\begin{array}{l}1.156 \\
6073\end{array}$ & $\begin{array}{l}1218 \\
6397\end{array}$ & $\begin{array}{l}1343 \\
7054\end{array}$ & $\begin{array}{l}1360 \\
7142\end{array}$ & $\begin{array}{l}1379 . \\
7241\end{array}$ & $\begin{array}{l}1611 \\
8462\end{array}$ & $\begin{array}{l}1734 \\
9105\end{array}$ & $\begin{array}{r}2264 \\
11886\end{array}$ & $\begin{array}{r}2492 \\
13085\end{array}$ & $\begin{array}{r}2591 \\
13606\end{array}$ \\
\hline & OHIO & & $\begin{array}{r}94 \\
493\end{array}$ & $\begin{array}{l}102 \\
536\end{array}$ & $\begin{array}{l}117 \\
616\end{array}$ & $\begin{array}{l}134 \\
708\end{array}$ & $\begin{array}{l}151 \\
794\end{array}$ & $\begin{array}{l}172 \\
903\end{array}$ & $\begin{array}{l}190 \\
998\end{array}$ & $\begin{array}{r}207 \\
1090\end{array}$ & $\begin{array}{r}244 \\
1283\end{array}$ & $\begin{array}{r}276 \\
1451\end{array}$ & $\begin{array}{r}295 \\
1552\end{array}$ & $\begin{array}{r}313 \\
1647\end{array}$ \\
\hline & NISCONSIN & & $\begin{array}{l}155 \\
814\end{array}$ & $\begin{array}{l}158 \\
831\end{array}$ & $\begin{array}{l}176 \\
926\end{array}$ & $\begin{array}{l}159 \\
837\end{array}$ & $\begin{array}{l}181 \\
952\end{array}$ & $\begin{array}{r}207 \\
1088\end{array}$ & $\begin{array}{r}209 \\
1097\end{array}$ & $\begin{array}{r}233 \\
1226\end{array}$ & $\begin{array}{r}249 \\
1309\end{array}$ & $\begin{array}{r}395 \\
2078\end{array}$ & $\begin{array}{r}420 \\
2207\end{array}$ & $\begin{array}{r}477 \\
2507\end{array}$ \\
\hline & BAST SOOTH CEHTRAL & & $\begin{array}{r}4015 \\
21080\end{array}$ & $\begin{array}{r}4251 \\
22319\end{array}$ & $\begin{array}{r}4434 \\
23280\end{array}$ & $\begin{array}{r}4393 \\
23064\end{array}$ & $\begin{array}{r}4609 \\
24197\end{array}$ & $\begin{array}{r}4847 \\
25446\end{array}$ & $\begin{array}{r}5261 \\
27623\end{array}$ & $\begin{array}{r}5757 \\
30229\end{array}$ & $\begin{array}{r}6406 \\
33636\end{array}$ & $\begin{array}{r}6709 \\
35222\end{array}$ & $\begin{array}{r}7263 \\
38135\end{array}$ & $\begin{array}{r}7390 \\
38801\end{array}$ \\
\hline & ALAEAEA & & $\begin{array}{r}844 \\
4433\end{array}$ & $\begin{array}{r}957 \\
5028\end{array}$ & $\begin{array}{l}1008 \\
5294\end{array}$ & $\begin{array}{l}1062 \\
5579\end{array}$ & $\begin{array}{l}1015 \\
5329\end{array}$ & $\begin{array}{l}1034 \\
5432\end{array}$ & $\begin{array}{l}1229 \\
6453\end{array}$ & $\begin{array}{l}1368 \\
7182\end{array}$ & $\begin{array}{l}1508 \\
7917\end{array}$ & $\begin{array}{l}1508 \\
7921\end{array}$ & $\begin{array}{l}1568 \\
8232\end{array}$ & $\begin{array}{l}1608 \\
8445\end{array}$ \\
\hline & KERTOCKY & . & $\begin{array}{l}1202 \\
631.2\end{array}$ & $\begin{array}{l}1440 \\
7563\end{array}$ & $\begin{array}{l}1516 \\
7961\end{array}$ & $\begin{array}{l}1339 \\
7030\end{array}$ & $\begin{array}{l}1442 \\
7572\end{array}$ & $\begin{array}{r}1549 \\
8135\end{array}$ & $\begin{array}{l}1674 \\
8788\end{array}$ & $\begin{array}{l}1776 \\
9326\end{array}$ & $\begin{array}{r}2007 \\
10538\end{array}$ & $\begin{array}{r}2133 \\
11201\end{array}$ & $\begin{array}{r}2247 \\
11800\end{array}$ & $\begin{array}{r}2356 \\
12370\end{array}$ \\
\hline & MISSISSIPPI & & $\begin{array}{l}1208 \\
6346\end{array}$ & $\begin{array}{l}1210 \\
6356\end{array}$ & $\begin{array}{l}1199 \\
6296\end{array}$ & $\begin{array}{l}1252 \\
6575\end{array}$ & $\begin{array}{l}1329 \\
6980\end{array}$ & $\begin{array}{l}1397 \\
7335\end{array}$ & $\begin{array}{l}1427 \\
7494\end{array}$ & $\begin{array}{l}1649 \\
8617\end{array}$ & $\begin{array}{l}1781 \\
9353\end{array}$ & $\begin{array}{l}1869 \\
9816\end{array}$ & $\begin{array}{r}2195 \\
11526\end{array}$ & $\begin{array}{r}2173 \\
11413\end{array}$ \\
\hline & TEN NESSEE & & $\begin{array}{r}759 \\
3988\end{array}$ & $\begin{array}{r}641 \\
3370\end{array}$ & $\begin{array}{r}710 \\
3727\end{array}$ & $\begin{array}{r}738 \\
3879\end{array}$ & $\begin{array}{r}821 \\
4314\end{array}$ & $\begin{array}{r}865 \\
4542 \\
\end{array}$ & $\begin{array}{r}930 \\
4886\end{array}$ & $\begin{array}{r}972 \\
5103\end{array}$ & $\begin{array}{l}1110 \\
5828\end{array}$ & $\begin{array}{l}1196 \\
6283\end{array}$ & $\begin{array}{l}1252 \\
6575\end{array}$ & $\begin{array}{l}1251 \\
6571\end{array}$ \\
\hline
\end{tabular}


IABLE 9.2D -- RBCBEATIONAL BOAT GASOLIBE AND BHBBG DSE, BI STATE, 1967-78

(FCORTH IN A SERIES OP 5 TABLBS)

GASOLINE GASOLZRE USE IB TBOJSANDS OP BBL, POLLOUED BY ENERGY USE IN BILLIONS OP BTU

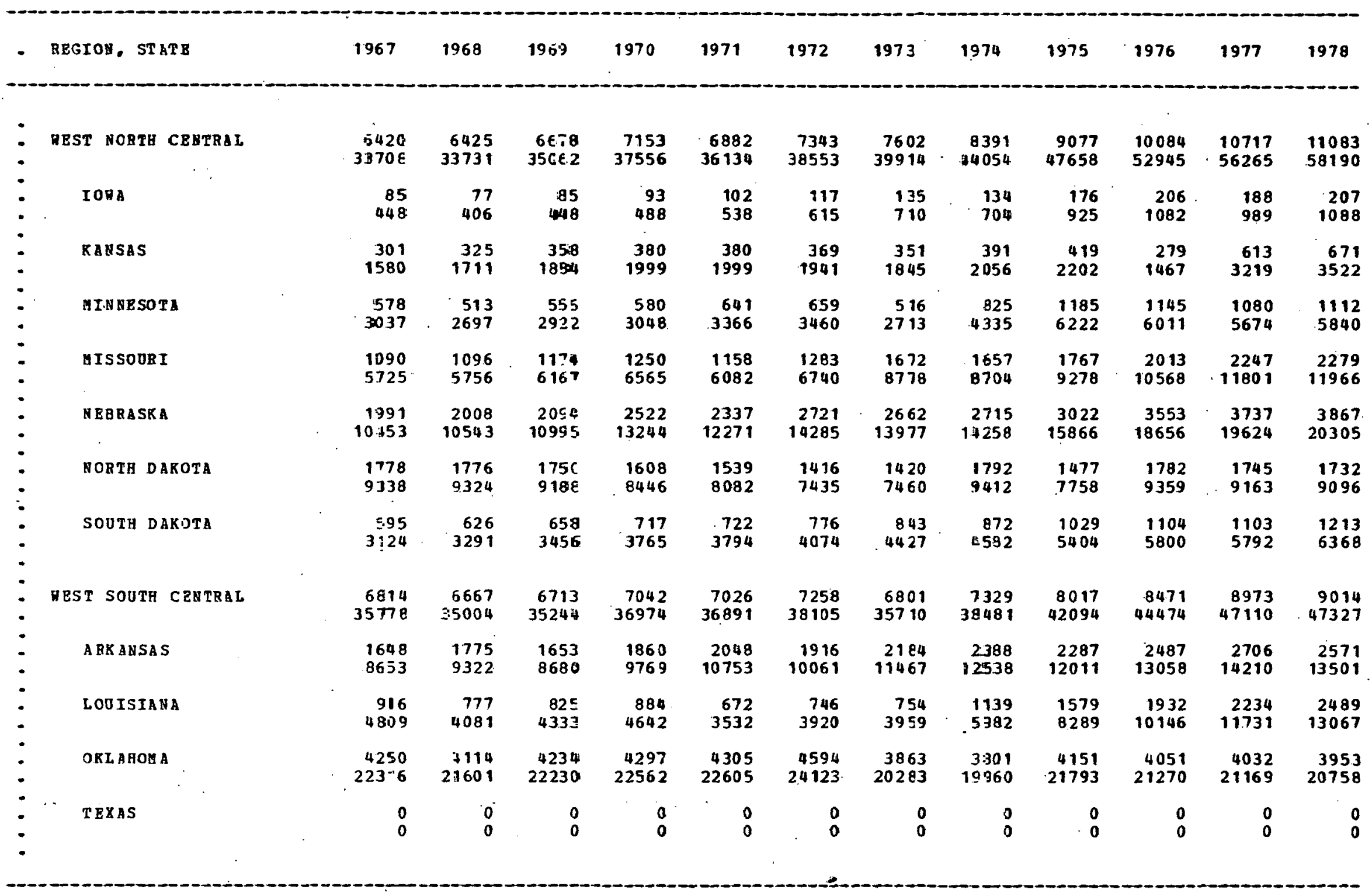


TABLE 9.2E -- RECREATIONAL BOAT GASOLINE AND ENERG USE, BY STATE, 1967-78 (LAST IN A SBBIES OF 5 TABLES)

GaSCliNe GASOLINB OSE IN THOUSANDS OR BBL, POLLORED BY RNERGP USE IN BILLIONS OF BTU

\begin{tabular}{|c|c|c|c|c|c|c|c|c|c|c|c|c|c|c|c|}
\hline - & AEGICH, STATE & & & 1967 & 1968 & 1969 & 1970 & .1971 & 1972 & 1973 & 1974 & 1975 & 1976 & 1977 & 1978 \\
\hline : & MOONTAIM & & & $\begin{array}{r}6085 \\
31946\end{array}$ & $\begin{array}{r}6550 \\
34 \equiv 92\end{array}$ & $\begin{array}{r}6496 \\
34107\end{array}$ & $\begin{array}{r}7296 \\
38305\end{array}$ & $\begin{array}{r}9076 \\
47651\end{array}$ & $\begin{array}{r}9120 \\
47880\end{array}$ & $\begin{array}{r}9073 \\
47636\end{array}$ & $\begin{array}{r}9598 \\
50391\end{array}$ & $\begin{array}{l}12029 \\
63157\end{array}$ & $\begin{array}{l}13445 \\
70586\end{array}$ & $\begin{array}{l}13706 \\
71960\end{array}$ & $\begin{array}{l}13678 \\
71812\end{array}$ \\
\hline & ARI ZOYA & & & $\begin{array}{l}103 \\
541\end{array}$ & $\begin{array}{l}101 \\
533\end{array}$ & $\begin{array}{r}107 \\
566\end{array}$ & $\begin{array}{l}112 \\
588\end{array}$ & $\begin{array}{l}113 \\
597\end{array}$ & $\begin{array}{l}116 \\
611\end{array}$ & $\begin{array}{l}119 \\
628\end{array}$ & $\begin{array}{l}144 \\
760\end{array}$ & $\begin{array}{l}169 \\
887\end{array}$ & $\begin{array}{l}173 \\
908\end{array}$ & $\begin{array}{r}220 \\
1156\end{array}$ & $\begin{array}{r}241 \\
1266\end{array}$ \\
\hline$\bullet$ & COLOBADO & & & $\begin{array}{r}288 \\
1516\end{array}$ & $\begin{array}{r}316 \\
1662\end{array}$ & $\begin{array}{r}373 \\
1959\end{array}$ & $\begin{array}{r}442 \\
2322\end{array}$ & $\begin{array}{r}532 \\
2794\end{array}$ & $\begin{array}{r}636 \\
3340\end{array}$ & $\begin{array}{r}631 \\
3315\end{array}$ & $\begin{array}{r}775 \\
4073\end{array}$ & $\begin{array}{l}1049 \\
5508\end{array}$ & $\begin{array}{l}1238 \\
6500\end{array}$ & $\begin{array}{l}1372 \\
7203\end{array}$ & $\begin{array}{l}1511 \\
7934\end{array}$ \\
\hline : & IDABO & & & $\begin{array}{r}2305 \\
12105\end{array}$ & $\begin{array}{r}2465 \\
12942\end{array}$ & $\begin{array}{r}2693 \\
14138\end{array}$ & $\begin{array}{r}2883 \\
15137\end{array}$ & $\begin{array}{r}3141 \\
16494\end{array}$ & $\begin{array}{r}3456 \\
18147\end{array}$ & $\begin{array}{r}3158 \\
165 \varepsilon 1\end{array}$ & $\begin{array}{r}3565 \\
18718\end{array}$ & $\begin{array}{r}4770 \\
25047\end{array}$ & $\begin{array}{r}5594 \\
29369\end{array}$ & $\begin{array}{r}5884 \\
30891\end{array}$ & $\begin{array}{r}6234 \\
32729\end{array}$ \\
\hline 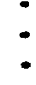 & MONTANA & & & $\begin{array}{r}2788 \\
14637\end{array}$ & $\begin{array}{r}2759 \\
15537\end{array}$ & $\begin{array}{r}2536 \\
13318\end{array}$ & $\begin{array}{r}3062 \\
16079\end{array}$ & $\begin{array}{r}4348 \\
22831\end{array}$ & $\begin{array}{r}3785 \\
19873\end{array}$ & $\begin{array}{r}4219 \\
22153\end{array}$ & $\begin{array}{r}3954 \\
20761\end{array}$ & $\begin{array}{r}4669 \\
24513\end{array}$ & $\begin{array}{r}4930 \\
25883\end{array}$ & $\begin{array}{r}4757 \\
24978\end{array}$ & $\begin{array}{r}3899 \\
20474\end{array}$ \\
\hline 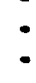 & NEVADA & & & $\begin{array}{r}197 \\
1035\end{array}$ & $\begin{array}{r}265 \\
1392\end{array}$ & $\begin{array}{r}319 \\
1679\end{array}$ & $\begin{array}{r}320 \\
1680\end{array}$ & $\begin{array}{r}424 \\
2228\end{array}$ & $\begin{array}{r}530 \\
2783\end{array}$ & $\begin{array}{r}418 \\
2196\end{array}$ & $\begin{array}{r}532 \\
2798\end{array}$ & $\begin{array}{r}639 \\
3.358\end{array}$ & $\begin{array}{r}680 \\
3570\end{array}$ & $\begin{array}{r}586 \\
3077\end{array}$ & $\begin{array}{r}789 \\
4146\end{array}$ \\
\hline 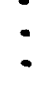 & NEM MEXICO & & & $\begin{array}{l}142 \\
746\end{array}$ & $\begin{array}{l}146 \\
771\end{array}$ & $\begin{array}{l}161 \\
847\end{array}$ & $\begin{array}{l}166 \\
87.3\end{array}$ & $\begin{array}{l}186 \\
980\end{array}$ & $\begin{array}{r}207 \\
1088\end{array}$ & $\begin{array}{r}231 \\
1213\end{array}$ & $\begin{array}{r}255 \\
1343\end{array}$ & $\begin{array}{r}292 \\
1536\end{array}$ & $\begin{array}{r}326 \\
1711\end{array}$ & $\begin{array}{r}343 \\
1802\end{array}$ & $\begin{array}{r}404 \\
2121\end{array}$ \\
\hline$\bullet$ & OTAB & & & $\begin{array}{l}142 \\
747\end{array}$ & $\begin{array}{l}174 \\
918\end{array}$ & $\begin{array}{l}176 \\
926\end{array}$ & $\begin{array}{l}178 \\
937\end{array}$ & $\begin{array}{r}194 \\
1020\end{array}$ & $\begin{array}{r}247 \\
1299\end{array}$ & $\begin{array}{l}155 \\
816\end{array}$ & $\begin{array}{r}216 \\
1134\end{array}$ & $\begin{array}{r}272 \\
1432\end{array}$ & $\begin{array}{r}326 \\
1716\end{array}$ & $\begin{array}{r}363 \\
1907\end{array}$ & $\begin{array}{r}409 \\
2151\end{array}$ \\
\hline ? & TYOING & & & $\begin{array}{l}117 \\
616\end{array}$ & $\begin{array}{l}120 \\
633\end{array}$ & $\begin{array}{l}127 \\
671\end{array}$ & $\begin{array}{l}130 \\
684\end{array}$ & $\begin{array}{l}134 \\
703\end{array}$ & $\begin{array}{l}140 \\
735\end{array}$ & $\begin{array}{l}139 \\
730\end{array}$ & $\begin{array}{l}152 \\
800\end{array}$ & $\begin{array}{l}166 \\
873\end{array}$ & $\begin{array}{l}176 \\
926\end{array}$ & $\begin{array}{l}179 \\
943\end{array}$ & $\begin{array}{l}188 \\
988\end{array}$ \\
\hline - & & . & & & & & & & & & & & & & \\
\hline • & PACIFIC & - & $\cdot$ & $\begin{array}{r}2475 \\
12994\end{array}$ & $\begin{array}{r}2651 \\
13917\end{array}$ & $\begin{array}{r}2868 \\
15061\end{array}$ & $\begin{array}{r}2918 \\
15321\end{array}$ & $\begin{array}{r}2995 \\
15727\end{array}$ & $\begin{array}{r}3247 \\
17051\end{array}$ & $\begin{array}{r}3597 \\
18885\end{array}$ & $\begin{array}{r}3843 \\
20179\end{array}$ & $\begin{array}{r}4424 \\
23226\end{array}$ & $\begin{array}{r}4651 \\
24421\end{array}$ & $\begin{array}{r}4808 \\
25243\end{array}$ & $\begin{array}{r}5442 \\
28573\end{array}$ \\
\hline - & AIASKA & $r$ & & $\begin{array}{r}598 \\
\quad 3139\end{array}$ & $\begin{array}{r}645 \\
3391\end{array}$ & $\begin{array}{r}697 \\
3661\end{array}$ & $\begin{array}{r}752 \\
3951\end{array}$ & $\begin{array}{r}829 \\
4355\end{array}$ & $\begin{array}{r}887 \\
4659\end{array}$ & $\begin{array}{r}955 \\
5017\end{array}$ & $\begin{array}{r}994 \\
5166\end{array}$ & $\begin{array}{l}1131 \\
5938\end{array}$ & $\begin{array}{l}1206 \\
6335\end{array}$ & $\begin{array}{l}1303 \\
6845\end{array}$ & $\begin{array}{l}1362 \\
7151\end{array}$ \\
\hline • & CAL IFOBNIA & $\cdot$ & & $\begin{array}{r}61 \\
321\end{array}$ & $\begin{array}{r}62 \\
325\end{array}$ & $\begin{array}{r}62 \\
329\end{array}$ & $\begin{array}{r}64 \\
340\end{array}$ & $\begin{array}{r}65 \\
345\end{array}$ & $\begin{array}{r}74 \\
391\end{array}$ & $\begin{array}{r}81 \\
428\end{array}$ & $\begin{array}{r}88 \\
466\end{array}$ & $\begin{array}{l}105 \\
553\end{array}$ & $\begin{array}{l}125 \\
661\end{array}$ & $\begin{array}{l}137 \\
722\end{array}$ & $\begin{array}{l}164 \\
863\end{array}$ \\
\hline - & HARAII & & & $\begin{array}{r}68 \\
358\end{array}$ & $\begin{array}{r}64 \\
341\end{array}$ & $\begin{array}{r}73 \\
386\end{array}$ & $\begin{array}{r}76 \\
401\end{array}$ & $\begin{array}{r}84 \\
442\end{array}$ & $\begin{array}{r}76 \\
402\end{array}$ & $\begin{array}{r}85 \\
449\end{array}$ & $\begin{array}{r}95 \\
502\end{array}$ & $\begin{array}{l}128 \\
676\end{array}$ & $\begin{array}{l}134 \\
708\end{array}$ & $\begin{array}{r}59 \\
310\end{array}$ & $\begin{array}{r}95 \\
498\end{array}$ \\
\hline • & ORECON & & $\therefore$ & $\begin{array}{r}867 \\
4552\end{array}$ & $\begin{array}{r}931 \\
4888\end{array}$ & $\begin{array}{l}1047 \\
5500\end{array}$ & $\begin{array}{l}1100 \\
5779\end{array}$ & $\begin{array}{r}921 \\
4838\end{array}$ & $\begin{array}{l}1039 \\
5455\end{array}$ & $\begin{array}{l}1188 \\
6240\end{array}$ & $\begin{array}{l}1299 \\
6821\end{array}$ & $\begin{array}{l}1332 \\
6996\end{array}$ & $\begin{array}{l}1598 \\
8390\end{array}$ & $\begin{array}{l}1768 \\
9287\end{array}$ & $\begin{array}{r}1926 \\
10114\end{array}$ \\
\hline . & MASHINGTON' & . & & $\begin{array}{r}880 \\
4622\end{array}$ & $\begin{array}{r}946 \\
4970\end{array}$ & $\begin{array}{r}987 \\
5183\end{array}$ & $\begin{array}{r}923 \\
4848\end{array}$ & $\begin{array}{l}1094 \\
5744\end{array}$ & $\begin{array}{l}1170 \\
6143\end{array}$ & $\begin{array}{l}1285 \\
6749\end{array}$ & $\begin{array}{l}1375 \\
7222\end{array}$ & $\begin{array}{l}1726 \\
9061\end{array}$ & $\begin{array}{l}1585 \\
8326\end{array}$ & $\begin{array}{l}1538 \\
8077\end{array}$ & $\begin{array}{l}1894 \\
9944\end{array}$ \\
\hline
\end{tabular}


TAEIE 9.3A -- COMHEBCIAL MABINE PUEL AND ENERGY OSE, BY PUEL BY STATE, 1967-78

(FIRST IH A SERIES OP HINB TABLES)

DIESEL TUEL OSE IN THOUSANDS OP BARBRLS

POLIOUED BY PESIDUAL OII OSE IN THOUSANDS OE EARBRLS

FOLLONBD BY TOTAL BNERGY USE IA BILLIONS O? BTO

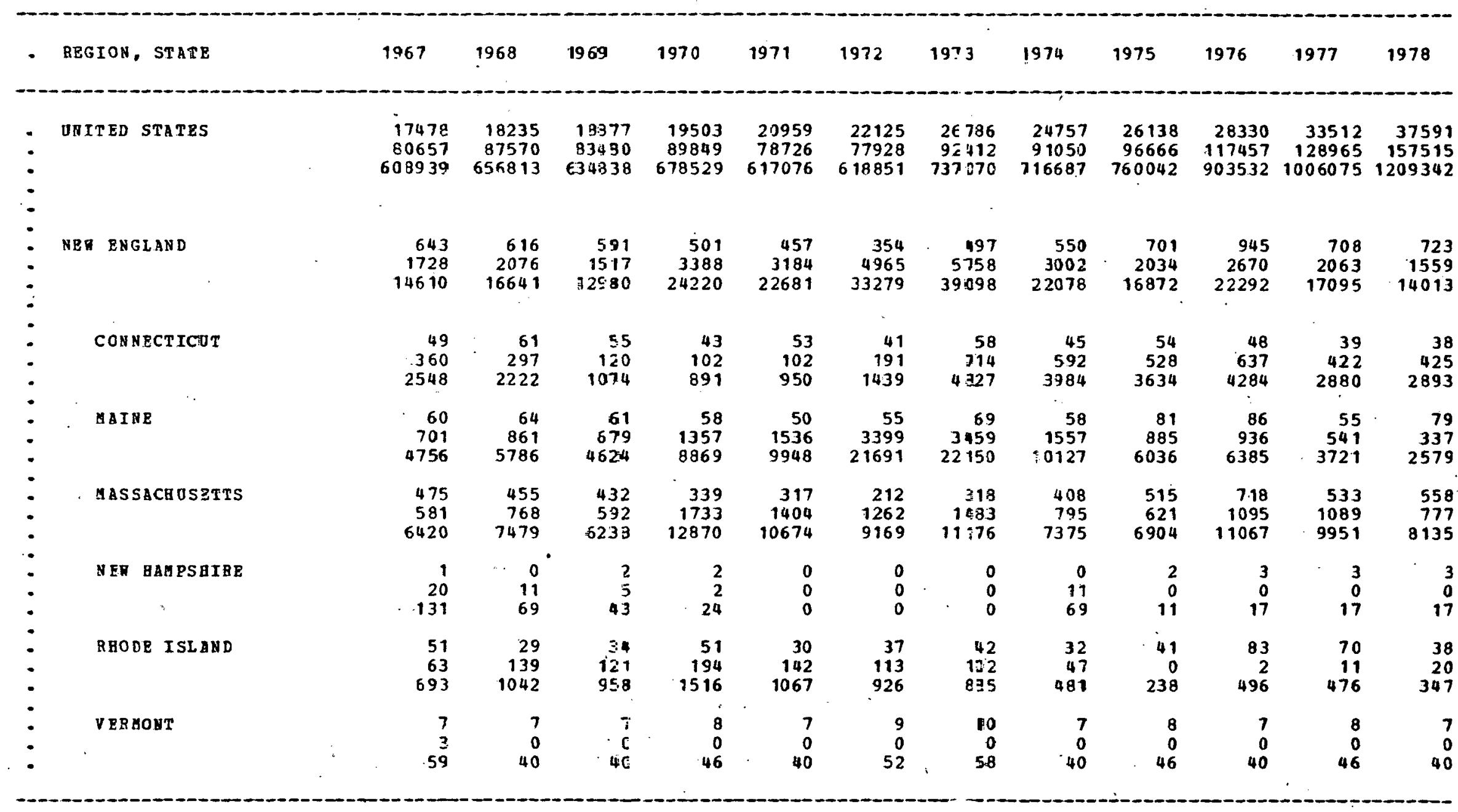


TAELB 9.38. - COBHERCIAL GARINE POEL AMD ENERGY USE. BY PUEL BY STATE. 1967-78 (SBCOND IN A SEBIES OF I I TABLES)

DIESEL FUEL OSE IN THOUSANDS OF BARRELS

POLLOTED BY RESIDUAL OIL USE IH THODSANDS OP EABBELS

POLLONED BT TOTAL ENBBGY USE IN BILLIOAS OF BTO

\begin{tabular}{|c|c|c|c|c|c|c|c|c|c|c|c|c|c|}
\hline & REGION, STATE & 1967 & 9968 & 1969 & 1970 & 1971 & 1972 & 1973 & $1974^{\circ}$ & 1975 & 1976 & 1977 & 1978 \\
\hline & MID-ATLAUTIC & $\begin{array}{r}2225 \\
24428 \\
166550\end{array}$ & $\begin{array}{r}3078 \\
26043 \\
181673\end{array}$ & $\begin{array}{r}3362 \\
23509 \\
167395\end{array}$ & $\begin{array}{r}3006 \\
26698 \\
185372\end{array}$ & $\begin{array}{r}2930 \\
27117 \\
187563\end{array}$ & $\begin{array}{r}2683 \\
25409 \\
175386\end{array}$ & $\begin{array}{r}3142 \\
25390 \\
177940\end{array}$ & $\begin{array}{r}3103 \\
18741 \\
135908\end{array}$ & $\begin{array}{r}2998 \\
14429 \\
108185\end{array}$ & $\begin{array}{r}3197 \\
17701 \\
129917\end{array}$ & $\begin{array}{r}2995 \\
17916 \\
130092\end{array}$ & $\begin{array}{r}3340 \\
17153 \\
127304\end{array}$ \\
\hline & NED JEBSEY & $\begin{array}{r}994 \\
4696 \\
35316\end{array}$ & $\begin{array}{r}1429 \\
5000 \\
39761\end{array}$ & $\begin{array}{r}1627 \\
4865 \\
40066\end{array}$ & $\begin{array}{r}1691 \\
6051 \\
47895\end{array}$ & $\begin{array}{r}1762 \\
6627 \\
51930\end{array}$ & $\begin{array}{r}1722 \\
8603 \\
64121\end{array}$ & $\begin{array}{r}1633 \\
6789 \\
52198\end{array}$ & $\begin{array}{r}1754 \\
4044 \\
35643\end{array}$ & $\begin{array}{r}1752 \\
3058 \\
29432\end{array}$ & $\begin{array}{r}1748 \\
5818 \\
46762\end{array}$ & $\begin{array}{r}1686 \\
6480 \\
50563\end{array}$ & $\begin{array}{r}2145 \\
7089 \\
57066\end{array}$ \\
\hline & NER YOR K & $\begin{array}{r}995 \\
15495 \\
103219\end{array}$ & $\begin{array}{r}1370 \\
\cdot 16478 \\
111584\end{array}$ & $\begin{array}{r}1413 \\
15071 \\
102988\end{array}$ & $\begin{array}{r}1066 \\
16632 \\
110781\end{array}$ & $\begin{array}{r}966 \\
16796 \\
111230\end{array}$ & $\begin{array}{r}636 \\
13687 \\
89760\end{array}$ & $\begin{array}{r}1137 \\
14999 \\
100928\end{array}$ & $\begin{array}{r}1005 \\
11176 \\
76122\end{array}$ & $\begin{array}{r}917 \\
7772 \\
54207\end{array}$ & $\begin{array}{r}1048 \\
7889 \\
55706\end{array}$ & $\begin{array}{r}933 \\
6631 \\
47126\end{array}$ & $\begin{array}{r}817 \\
6024 \\
42634\end{array}$ \\
\hline & PEENSTLVARIA & $\begin{array}{r}236 \\
4237 \\
28014\end{array}$ & $\begin{array}{r}279 \\
4565 \\
30327\end{array}$ & $\begin{array}{r}322 \\
3573 \\
24340\end{array}$ & $\begin{array}{r}249 \\
4015 \\
26694\end{array}$ & $\begin{array}{r}202 \\
3694 \\
24402\end{array}$ & $\begin{array}{r}325 \\
3119 \\
21503\end{array}$ & $\begin{array}{r}372 \\
3602 \\
-\quad 24814\end{array}$ & $\begin{array}{r}344 \\
3521 \\
24141\end{array}$ & $\begin{array}{r}329 \\
3599 \\
24544\end{array}$ & $\begin{array}{r}401 \\
3994 \\
27447\end{array}$ & $\begin{array}{r}376 \\
4805 \\
32401\end{array}$ & $\begin{array}{r}378 \\
4040 \\
27603\end{array}$ \\
\hline
\end{tabular}


TAELE 9.3C -- COMAERCIAL EABINE PJEL AND BNEBGY OSE, BY FOEL BY STATE, 1967-78

(TE=RS IN A SEBIES OP NINE TABLES)

DIESEL TOEL USE IN THOOSANDS OP BARBELS

FOLLONED BY EESIDOAL OIL USE IN THODSANDS OP EARRELS

FOLLONED BY TOTAL ENERGY OSE IN BILLIONS OF BTU

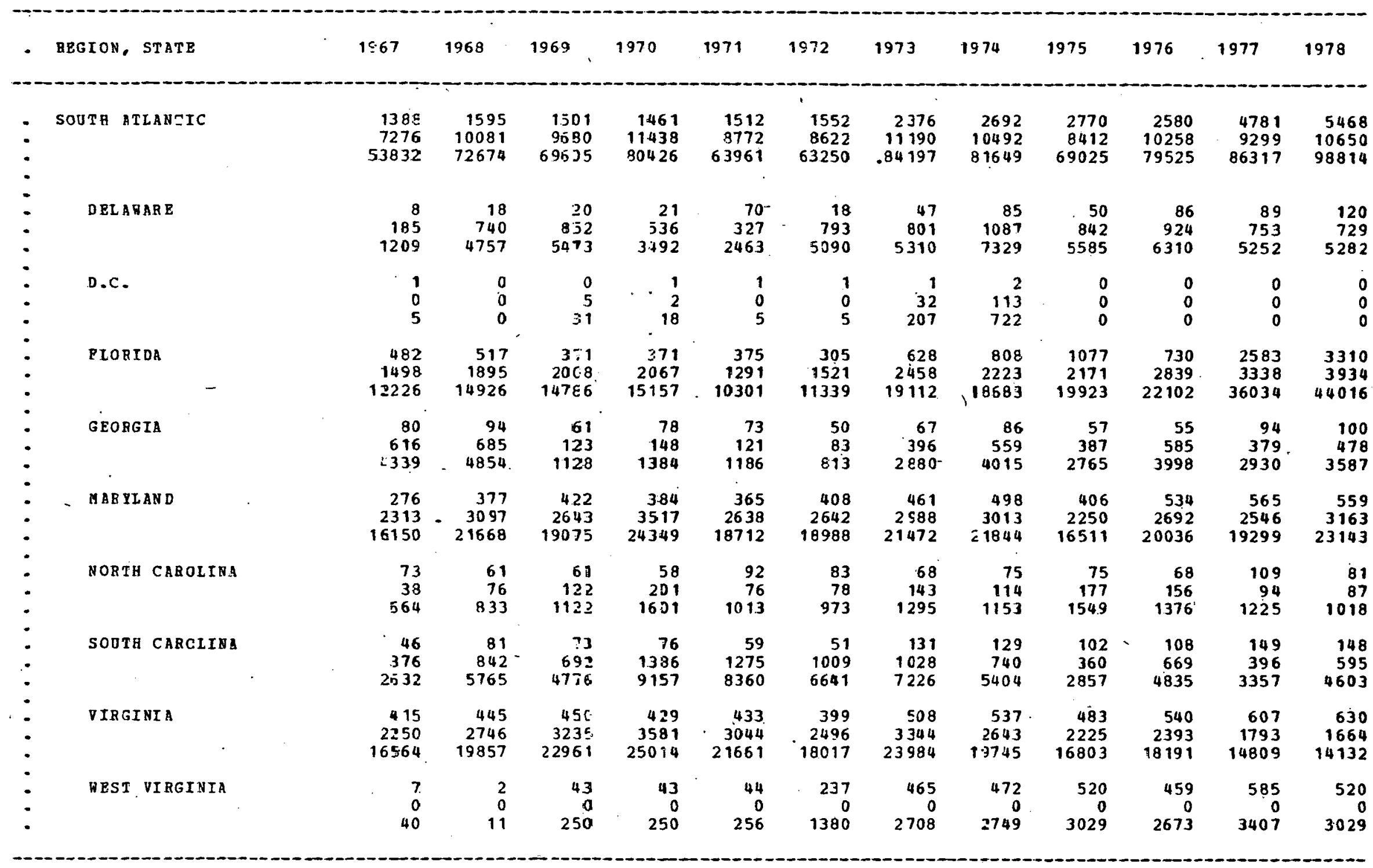


TABLE 9.3D -- COHGRRCIAL MARINE PUEL AHD EHERGY USE, BY PUEL BY STATE, 1967-78

(F OURTH IN A SERIES OP NINE TABLES)

DIESEL PUEL USE IN THOUSANDS OF BABRELS

POLLORED BY RESIOUAL OIL USE IN THOOSANDS OP EARRBLS

FOLLORED BY TOTAL ENERGY USE IN BILLIONS OP BTO

\begin{tabular}{|c|c|c|c|c|c|c|c|c|c|c|c|c|c|}
\hline & REGION, STATE & 1967 & 1968 & 1969 & 1970 & 1971 & 1972 & 1973 & 1974 & 1975 & 1976 & 1977 & 1978 \\
\hline - & $\begin{array}{c}\text { EAST NOBTH CBNTREL } \\
\text { - }\end{array}$ & $\begin{array}{r}1003 \\
1331 \\
14211\end{array}$ & $\begin{array}{r}974 \\
1173 \\
13049\end{array}$ & $\begin{array}{r}972 \\
1407 \\
14508\end{array}$ & $\begin{array}{r}886 \\
1045 \\
1.1731\end{array}$ & $\begin{array}{r}1032 \\
511 \\
9224\end{array}$ & $\begin{array}{r}1864 \\
646 \\
14920\end{array}$ & $\begin{array}{r}1908 \\
497 \\
14239\end{array}$ & $\begin{array}{r}1437 \\
973 \\
14488\end{array}$ & $\begin{array}{r}1194 \\
1492 \\
16336\end{array}$ & $\begin{array}{r}1297 \\
1948 \\
19803\end{array}$ & $\begin{array}{r}896 \\
1510 \\
14713\end{array}$ & $\begin{array}{r}1055 \\
1549 \\
15884\end{array}$ \\
\hline$\bullet$ & ILL IMors & $\begin{array}{r}482 \\
73 \\
.3266\end{array}$ & $\begin{array}{r}624 \\
61 \\
4018\end{array}$ & $\begin{array}{r}669 \\
188 \\
5079\end{array}$ & $\begin{array}{r}571 \\
84 \\
3854\end{array}$ & $\begin{array}{r}731 \\
123 \\
5031\end{array}$ & $\begin{array}{r}1221 \\
92 \\
769.1\end{array}$ & $\begin{array}{r}1265 \\
83 \\
7890\end{array}$ & $\begin{array}{r}868 \\
96 \\
5660\end{array}$ & $\begin{array}{r}606 \\
35 \\
3750\end{array}$ & $\begin{array}{r}626 \\
91 \\
4218\end{array}$ & $\begin{array}{r}438 \\
4 \\
2576\end{array}$ & $\begin{array}{r}515 \\
30 \\
3188\end{array}$ \\
\hline- & INDIANA & $\begin{array}{r}130 \\
239 \\
2259\end{array}$ & $\begin{array}{r}89 \\
161 \\
1530\end{array}$ & $\begin{array}{r}69 \\
223 \\
1804\end{array}$ & $\begin{array}{r}97 \\
192 \\
.1772\end{array}$ & $\begin{array}{r}115 \\
165 \\
1707\end{array}$ & $\begin{array}{r}197 \\
166 \\
2191\end{array}$ & $\begin{array}{r}224 \\
103 \\
1952\end{array}$ & $\begin{array}{r}218 \\
261 \\
2910\end{array}$ & $\begin{array}{r}140 \\
285 \\
2607\end{array}$ & $\begin{array}{r}118 \\
284 \\
2473\end{array}$ & $\begin{array}{r}73 \\
275 \\
2154\end{array}$ & $\begin{array}{r}68 \\
169 \\
1458\end{array}$ \\
\hline - & M ICBIGA & $\begin{array}{r}68 \\
236 \\
1879\end{array}$ & $\begin{array}{r}105 \\
449 \\
3434\end{array}$ & $\begin{array}{r}97 \\
415 \\
3174\end{array}$ & $\begin{array}{r}78 \\
352 \\
2667\end{array}$ & $\begin{array}{r}78 \\
33 \\
661\end{array}$ & $\begin{array}{r}112 \\
189 \\
1840\end{array}$ & $\begin{array}{r}78 \\
211 \\
1781\end{array}$ & $\begin{array}{r}71 \\
242 \\
1935\end{array}$ & $\begin{array}{r}107 \\
307 \\
2553\end{array}$ & $\begin{array}{r}155 \\
273 \\
2619\end{array}$ & $\begin{array}{r}58 \\
271 \\
2041\end{array}$ & $\begin{array}{r}49 \\
228 \\
1718\end{array}$ \\
\hline & OHIO & $\begin{array}{r}252 \\
527 \\
4781\end{array}$ & $\begin{array}{r}132 \\
502 \\
3925\end{array}$ & $\begin{array}{r}85 \\
576 \\
4116\end{array}$ & $\begin{array}{r}89 \\
414 \\
3121\end{array}$ & $\begin{array}{r}93 \\
187 \\
1717\end{array}$ & $\begin{array}{r}319 \\
196 \\
3090\end{array}$ & $\begin{array}{r}320 \\
89 \\
2423\end{array}$ & $\begin{array}{r}266 \\
318 \\
3548\end{array}$ & $\begin{array}{r}289 \\
582 \\
5342\end{array}$ & $\begin{array}{r}330 \\
922 \\
7719\end{array}$ & $\begin{array}{r}242 \\
638 \\
5421\end{array}$ & $\begin{array}{r}240 \\
645 \\
5453\end{array}$ \\
\hline & ISCONS IN & $\begin{array}{r}71 \\
256 \\
2023\end{array}$ & $\begin{array}{r}24 \\
0 \\
139\end{array}$ & $\begin{array}{r}52 \\
5 \\
334\end{array}$ & $\begin{array}{r}51 \\
3 \\
315\end{array}$ & $\begin{array}{r}15 \\
3 \\
106\end{array}$ & $\begin{array}{r}15 \\
3 \\
106\end{array}$ & $\begin{array}{r}21 \\
11 \\
191\end{array}$ & $\begin{array}{r}14 \\
56 \\
433\end{array}$ & $\begin{array}{r}52 \\
28.3 \\
2082\end{array}$ & $\begin{array}{r}68 \\
378 \\
2772\end{array}$ & $\begin{array}{r}85 \\
322 \\
2519\end{array}$ & $\begin{array}{r}183 \\
477 \\
4065\end{array}$ \\
\hline
\end{tabular}

SOORCE: $\triangle E T$ HOD 402

DATA QUALITY: 2 
TABLE 9.38 -- CONMERCIAL GARINE FCEL AND ENERGY OSE. BY PUEL BY STATE, 1967-78

(FIFTH IN A SBBIES OP HINE TABLES)

DIESBL FOEL USE IA THOUSANDS OF BARBELS

POLLOHED BY RESIDUAL OIL OSE IN THOUSANDS OF EAREELS

FOLLORED BY TOTAL ENEBGY USE IR BIILIOHS OF BTL

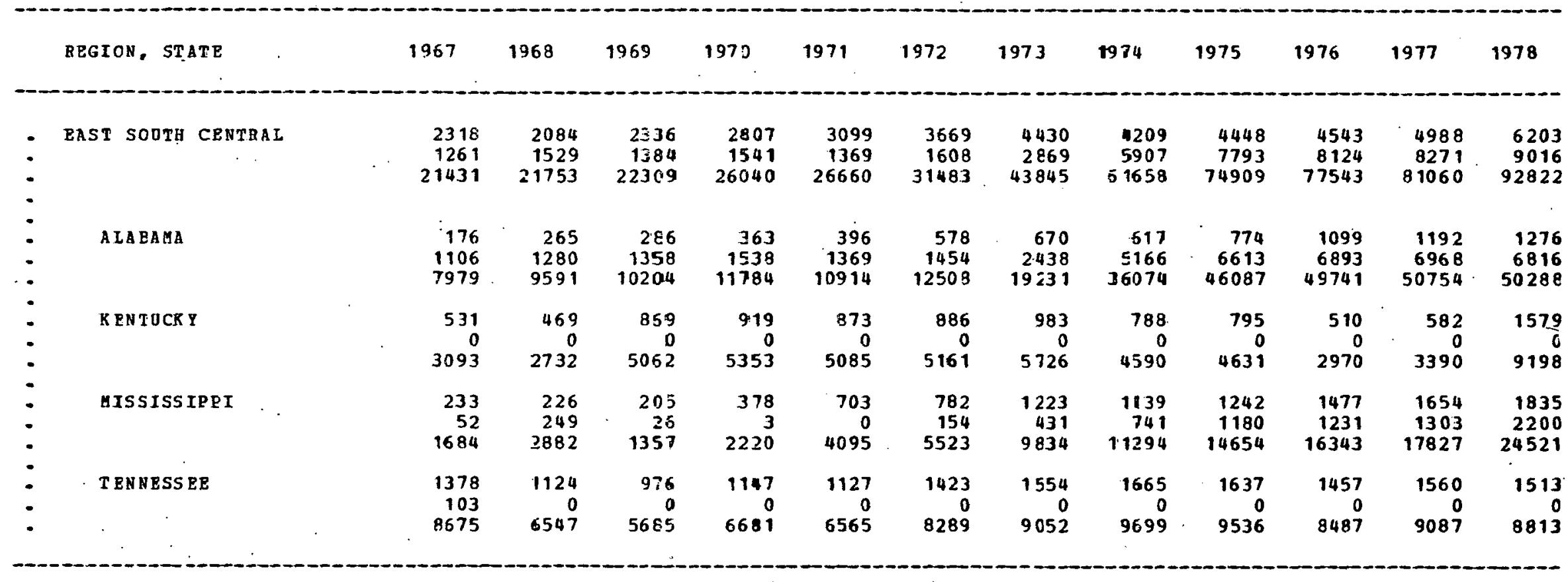

SOU RCE: NFTHOD 402

DATA QUALITY: $\tilde{z}$ 
TABLE 9.3P - COMHERCIAL MARINE POEI AND ENERGY OSE, BY PUEL BY STATE, 1967-78

(SIXTH IN A SERIES OF NINE TABLES)

DIESEL FUEL USE IN THOJSAHDS OF BARRELS

POLLOHED BY BESIDUAL OIL OSE IN THOUSANDS OP EARRELS

FOLLOHED BY TOTAL ENBGGY OSE IN BILLIONS OF BTU

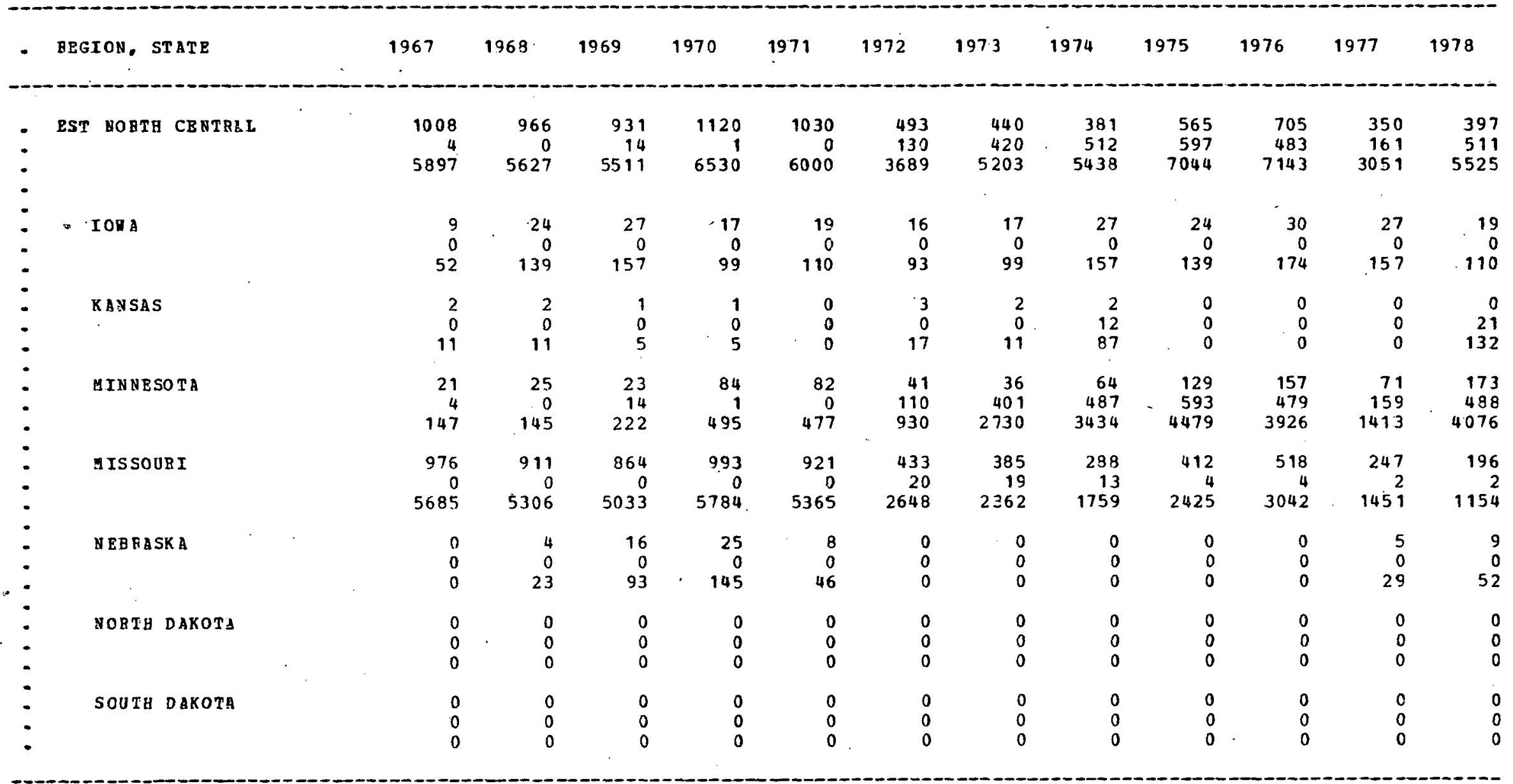

SOD RCE: METHOD 402

DATA QUALITY 2 
TAELE 9.3G - CCMHEBCIAL AAEINE FOEL AND ENERGY OSE, BY FUEL BY STATE, 1967-78

(SEVENTH IN A SBRIES OF NINE TABLES)

DIESEL PTEL USE IN THOUSANDS OP BARRELS

FOLLOHED BT BESIDUAL OIL OSE IN THODSANDS OF FAR3ELS

FOLLOWED BP TOTAI ENBRGY OSE IN BILLIONS OF BTI

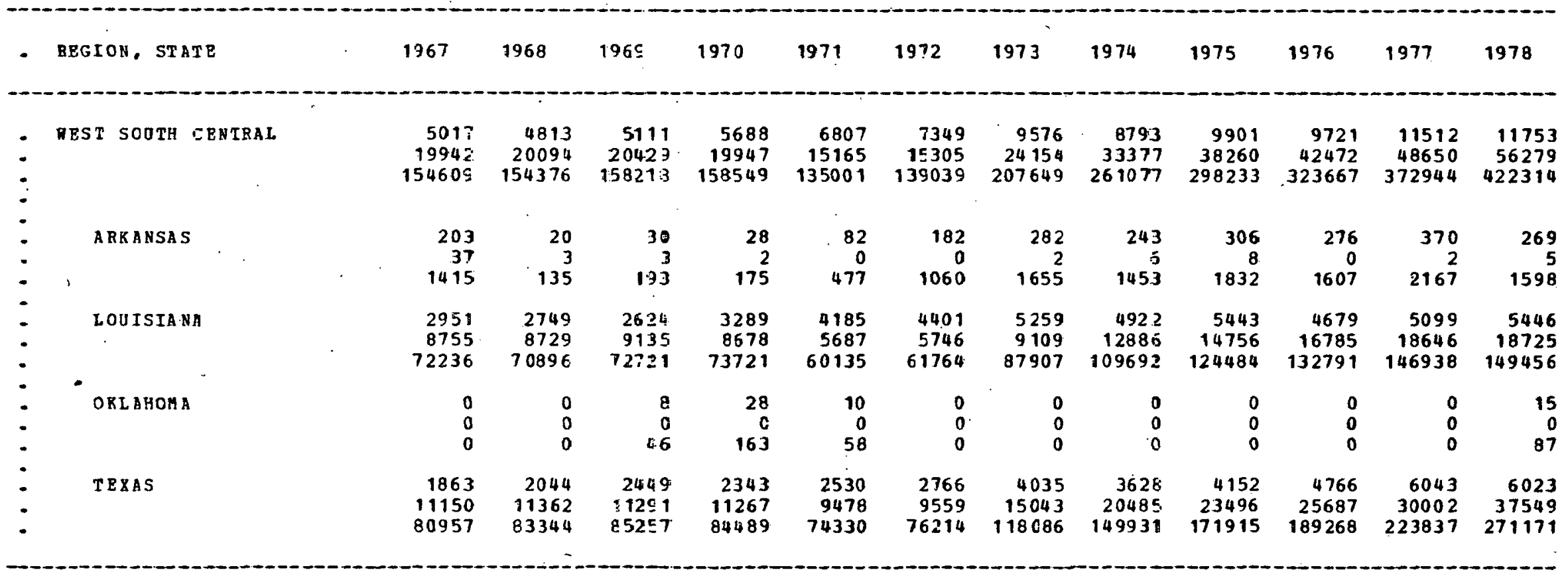

SOURCE: BETHOD 402

DATA QUALITY $=2$. 
TARLE 9.38 -- COMAERCIAL AABINE FUEL AND ENERGY USE, BY FUFL BY STATE, 1967-78 (EIGRTH IN A SBRIES OF MIIE TABLES)

DIESEL RUEL OSE IH TBOUSAHDS OF BARBELS

FOLLOHED BY RESIDUAL OIL OSB IN THODSANDS OF EARRELS

FOLLONED BY TOTAL BHBBGY USE IN BILLIONS OP BTO

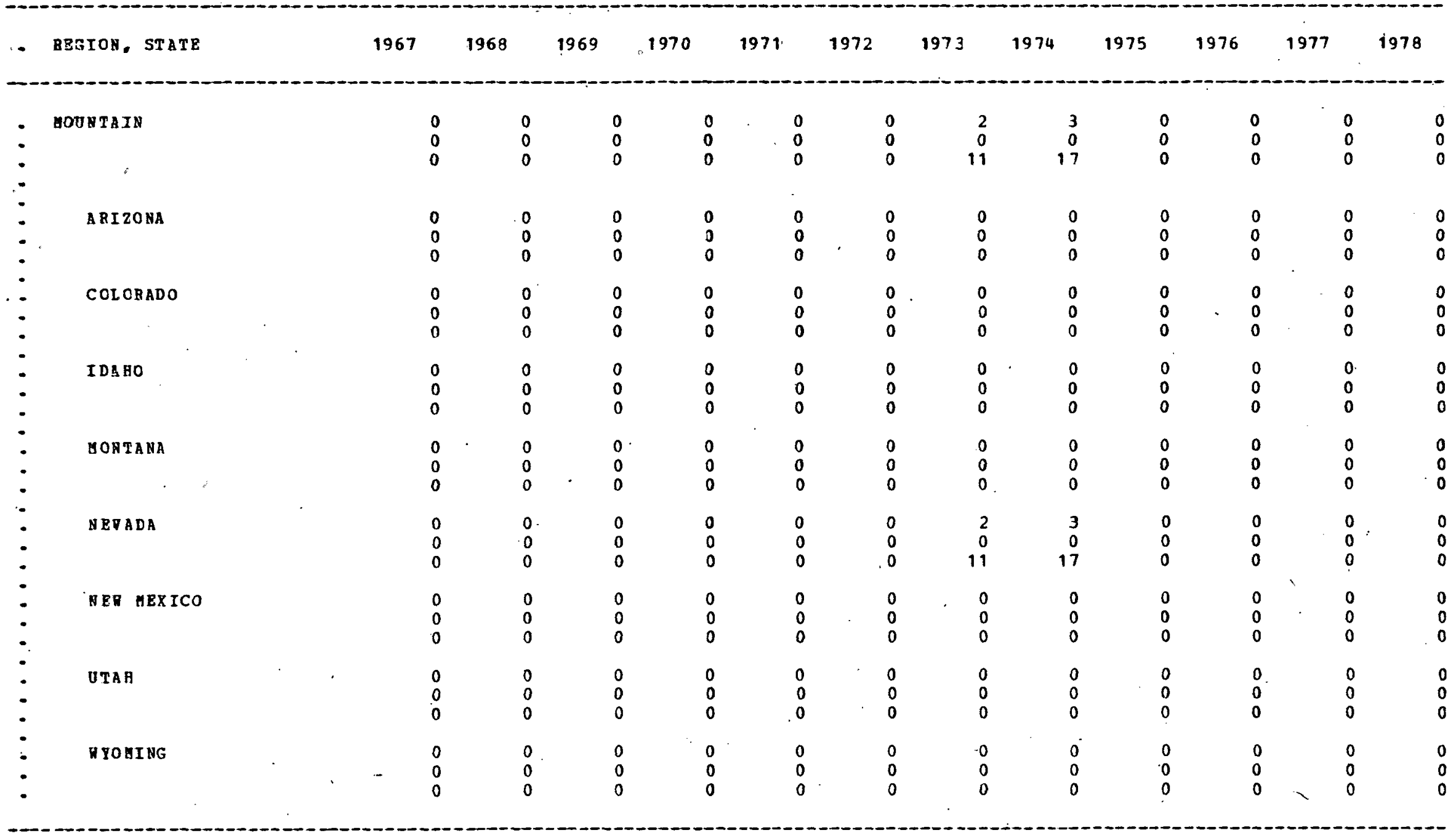


TAELE 9.3I -- COMGERCIAL KARINE FUBL AND ENERGY OSE, BY FUEL EY STATE, 1967-78 (IAST IN A SERIES OF NINE TABLES)

DIESEL FOEL OSE IN THOOSANDS OP BARRELS

FOLLONED BY RESTDUAL OIL USE IN THOUSANDS OF EARBELS

FOLLORED BI TOTAL RNERGY USE IN BILLIONS OE BTI

\begin{tabular}{|c|c|c|c|c|c|c|c|c|c|c|c|c|c|}
\hline & REGION, STETE & 1967 & 1968 & 1969 & 1970 & 1971 & 1972 & 1973 & 1974 & 1975 & 1976 & 1977 & 1978 \\
\hline & PACIPIC & $\begin{array}{r}3875 \\
24687 \\
177795\end{array}$ & $\begin{array}{r}.4109 \\
26574 \\
191017\end{array}$ & $\begin{array}{r}0073 \\
25540 \\
184307\end{array}$ & $\begin{array}{r}4034 \\
25791 \\
195657\end{array}$ & $\begin{array}{r}4092 \\
22608 \\
165983\end{array}$ & $\begin{array}{r}4161 \\
21243 \\
157802\end{array}$ & $\begin{array}{r}4415 \\
22134 \\
164884\end{array}$ & $\begin{array}{r}3589 \\
18046 \\
134369\end{array}$ & $\begin{array}{r}3561 \\
23649 \\
169434\end{array}$ & $\begin{array}{r}5342 \\
33801 \\
243639\end{array}$ & $\begin{array}{r}7282 \\
41095 \\
300801\end{array}$ & $\begin{array}{r}8652 \\
60798 \\
432662\end{array}$ \\
\hline & A LASKA & $\begin{array}{r}274 \\
24 \\
1747\end{array}$ & $\begin{array}{r}312 \\
33 \\
2025\end{array}$ & $\begin{array}{r}\vdots 13 \\
112 \\
2 \leq 27\end{array}$ & $\begin{array}{r}483 \\
124 \\
3593\end{array}$ & $\begin{array}{r}533 \\
220 \\
4488\end{array}$ & $\begin{array}{r}1244 \\
226 \\
8667\end{array}$ & $\begin{array}{r}697 \\
313 \\
6 C 28\end{array}$ & $\begin{array}{r}679 \\
326 \\
6005\end{array}$ & $\begin{array}{r}590 \\
487 \\
6498\end{array}$ & $\begin{array}{r}762 \\
850 \\
9783\end{array}$ & $\begin{array}{r}1048 \\
1150 \\
13335\end{array}$ & $\begin{array}{r}1120 \\
1963 \\
18866\end{array}$ \\
\hline & CALIFORNIA & $\begin{array}{r}2392 \\
20928 \\
14551 ?\end{array}$ & $\begin{array}{r}2432 \\
21611 \\
150044\end{array}$ & $\begin{array}{r}2512 \\
20777 \\
145266\end{array}$ & $\begin{array}{r}2323 \\
21611 \\
149409\end{array}$ & $\begin{array}{r}2226 \\
19708 \\
136879\end{array}$ & $\begin{array}{r}1457 \\
18897 \\
127300\end{array}$ & $\begin{array}{r}2210 \\
19356 \\
134573\end{array}$ & $\begin{array}{r}1355 \\
15712 \\
106914\end{array}$ & $\begin{array}{r}1415 \\
19851 \\
133054\end{array}$ & $\begin{array}{r}2364 \\
29119 \\
196854\end{array}$ & $\begin{array}{r}3563 \\
35893 \\
246429\end{array}$ & $\begin{array}{r}4543 \\
50125 \\
341620\end{array}$ \\
\hline & HAWAII & $\begin{array}{r}314 \\
147 \pm \\
11090\end{array}$ & $\begin{array}{r}348 \\
2274 \\
16324\end{array}$ & $\begin{array}{r}252 \\
2336 \\
16155\end{array}$ & $\begin{array}{r}334 \\
1738 \\
12873\end{array}$ & $\begin{array}{r}394 \\
1755 \\
13329\end{array}$ & $\begin{array}{r}336 \\
1289 \\
10061\end{array}$ & $\begin{array}{r}315 \\
1380 \\
10511\end{array}$ & $\begin{array}{r}3117 \\
786 \\
6788\end{array}$ & $\begin{array}{r}315 \\
1040 \\
8373\end{array}$ & $\begin{array}{r}671 \\
1191 \\
11397\end{array}$ & $\begin{array}{r}1018 \\
1077 \\
12701\end{array}$ & $\begin{array}{r}1227 \\
1323 \\
15465\end{array}$ \\
\hline & OREGON & $\begin{array}{r}353 \\
813 \\
7168\end{array}$ & $\begin{array}{r}363 \\
836 \\
7370\end{array}$ & $\begin{array}{r}326 \\
791 \\
6372\end{array}$ & $\begin{array}{r}300 \\
868 \\
7205\end{array}$ & $\begin{array}{r}309 \\
229 \\
3239\end{array}$ & $\begin{array}{r}308 \\
137 \\
2655\end{array}$ & $\begin{array}{r}347 \\
166 \\
3065\end{array}$ & $\begin{array}{r}346 \\
194 \\
3235\end{array}$ & $\begin{array}{r}360 \\
316 \\
4083\end{array}$ & $\begin{array}{r}419 \\
357 \\
4685\end{array}$ & $\begin{array}{r}444 \\
399 \\
5095\end{array}$ & $\begin{array}{r}456 \\
1833 \\
14181\end{array}$ \\
\hline & ИASHINGTO\& & $\begin{array}{r}543 \\
1449 \\
12273\end{array}$ & $\begin{array}{r}654 \\
1820 \\
15252\end{array}$ & $\begin{array}{r}570 \\
1524 \\
13435\end{array}$ & $\begin{array}{r}594 \\
1450 \\
-\quad 12577\end{array}$ & $\begin{array}{r}630 \\
696 \\
8046\end{array}$ & $\begin{array}{r}816 \\
694 \\
9116\end{array}$ & $\begin{array}{r}846 \\
919 \\
10706\end{array}$ & $\begin{array}{r}852 \\
1028 \\
13425\end{array}$ & $\begin{array}{r}881 \\
1955 \\
17424\end{array}$ & $\begin{array}{r}1126 \\
2284 \\
20919\end{array}$ & $\begin{array}{r}1209 \\
2576 \\
23239\end{array}$ & $\begin{array}{r}1306 \\
5554 \\
42528\end{array}$ \\
\hline
\end{tabular}




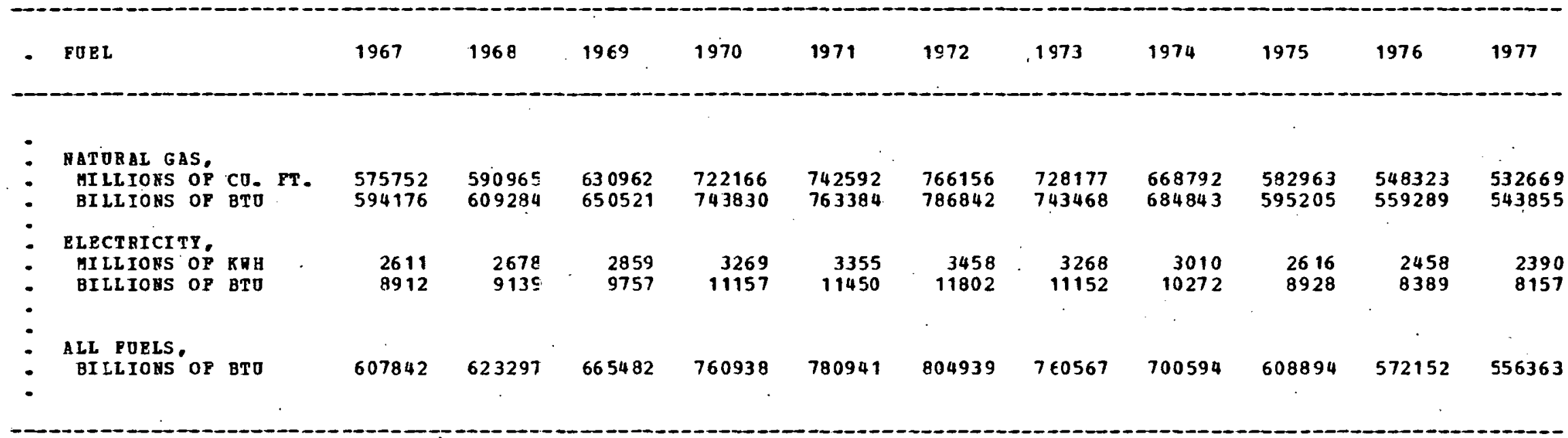

SOORCE: $\triangle \mathrm{ET}$ BOD 510

DATA QUALITI: 1 (MATORAL GAS \& ALL POELS), 3 (ELECTRICITY) 
TABLE 10.2A - NATURAL GAS PIPELIKE ENBAGY CONSOHPTIOH, BY STATB, 1967-77

(PIAST IH A SERIBS OP 5 PAGBS)

BIfLIOBS OP BTJ

\begin{tabular}{|c|c|c|c|c|c|c|c|c|c|c|c|c|}
\hline - & QEGION, STATE & 1967 & 1968 & 1969 & 1970 & 197.1 & 1972 & 1973 & 1974 & 1975 & 1976 & 1977 \\
\hline • & 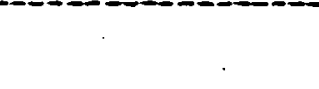 & & $:$ & & & . & & 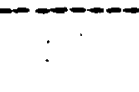 & & - & & \\
\hline 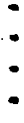 & ONITED. ST ATES & 607842 & 623297 & 665482 & 760938 & 780941 & 804939 & 760567 & 700594 & 608894 & 572152 & 556363 \\
\hline 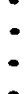 & MER ENGLAND & 2436 & 1775 & 1084 & 1202 & 749 & .738 & 646 & 764 & 587 & 687 & 530 \\
\hline . & CONNECTI $\cong 0 T$ & 320 & 58 & 62 & 51 & 45 & 40 & 25 & 45 & 43 & 27 & 14 \\
\hline . & GA IRE & 0 & 0 & 0 & 0 & 0 & 0 & 0 & 0 & 0 & 0 & 0 \\
\hline . & MASSACHUSETTS & 2052 & 1706 & 998 & 1118 & 677 & 679 & 599 & 695 & 519 & 645 & 500 \\
\hline : & BEW BABPSHIRE & o & 0 & 0 & 0 & 0 & 0 & $\mathbf{0}$ & 0 & 0 & 0 & 0 \\
\hline . & RHODE - ISLAND & 34 & 3 & 18 & 27 & 24 & 16 & 19 & 22 & 22 & 12 & 15 \\
\hline : & VERTON T & 0 & 0 & 0 & 0 & 0 & 0 & 0 & 0 & 0 & . 0 & . $\quad 0$ \\
\hline : & MID-ATLANTIC & 32782 & 28761 & 30094 & 32410 & 33881 & 33321 & 27544 & 25643 & 21957 & 26196 & 27662 \\
\hline • & NER JBRSEY & 757 & 587 & 659 & 995 & 917 & 764 & 714 & 571 & 409 & 530 & 593 \\
\hline - & NER YORK & 7040 & 3471 & 2817 & 3321 & 3568 & 3551 & 3187 & 3155 & 3028 & 3091 & 2761 \\
\hline • & PENASTLVANIA & 24975 & $2+846$ & 26673 & 28173 & 29481 & 29318 & 23723 & 21913 & 18556 & 22621 & 24364 \\
\hline
\end{tabular}

SOOBCE: METHOD 510

DATA QUALITY: 1 
TABLE 10.2B - - NATORAL GAS PIPELINE ENBRGY CORSUUPTION, BY STATE, 1967-77 (SECOND IN A SERIES OF 5 PAGES)

BILLIOHS OP BTO

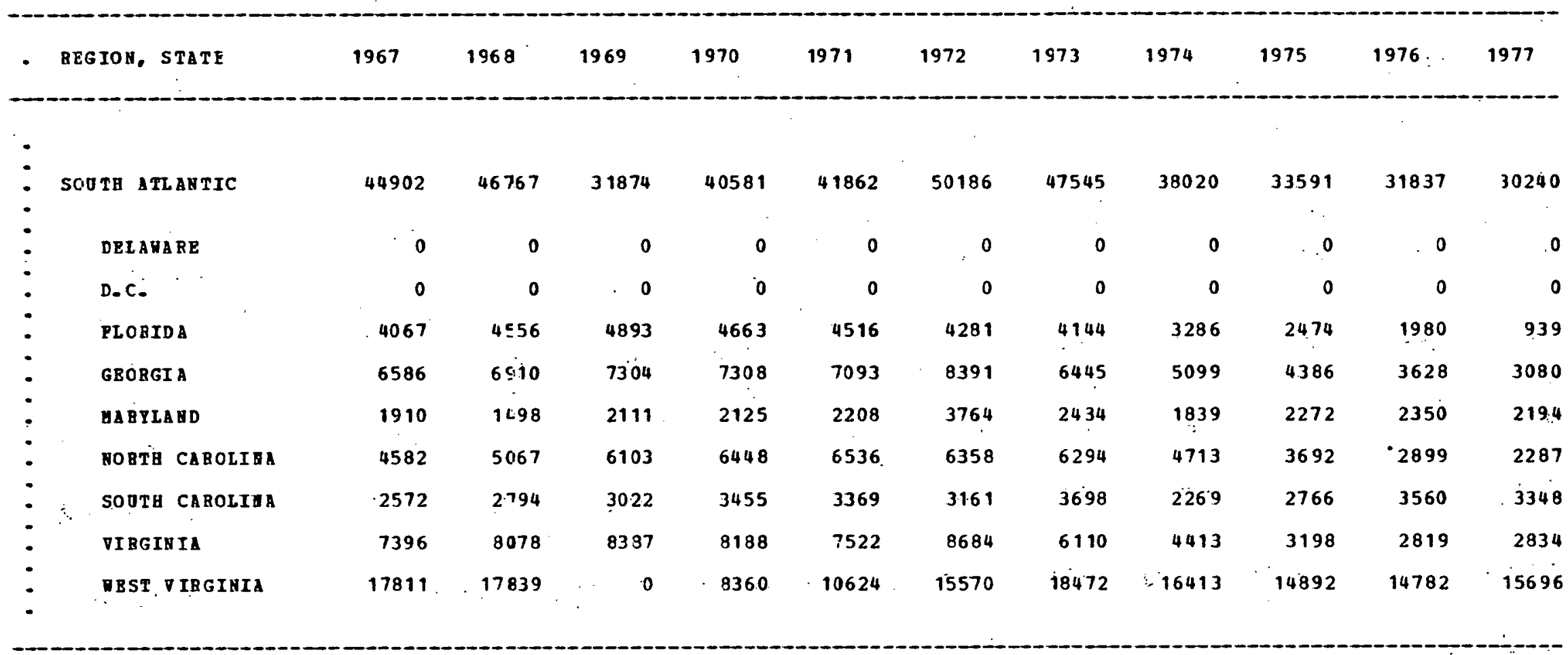

SO URCB : ABTH OD 510

DATA QOALITY: 1 
TABLE' 10.2C - NATURAL GAS P IPELINE EMERGY CONSOUPTION, BY STATE, 1967-77 (THIED IN A SERIES OP 5 PAGES)

BILLIONS OP BTO

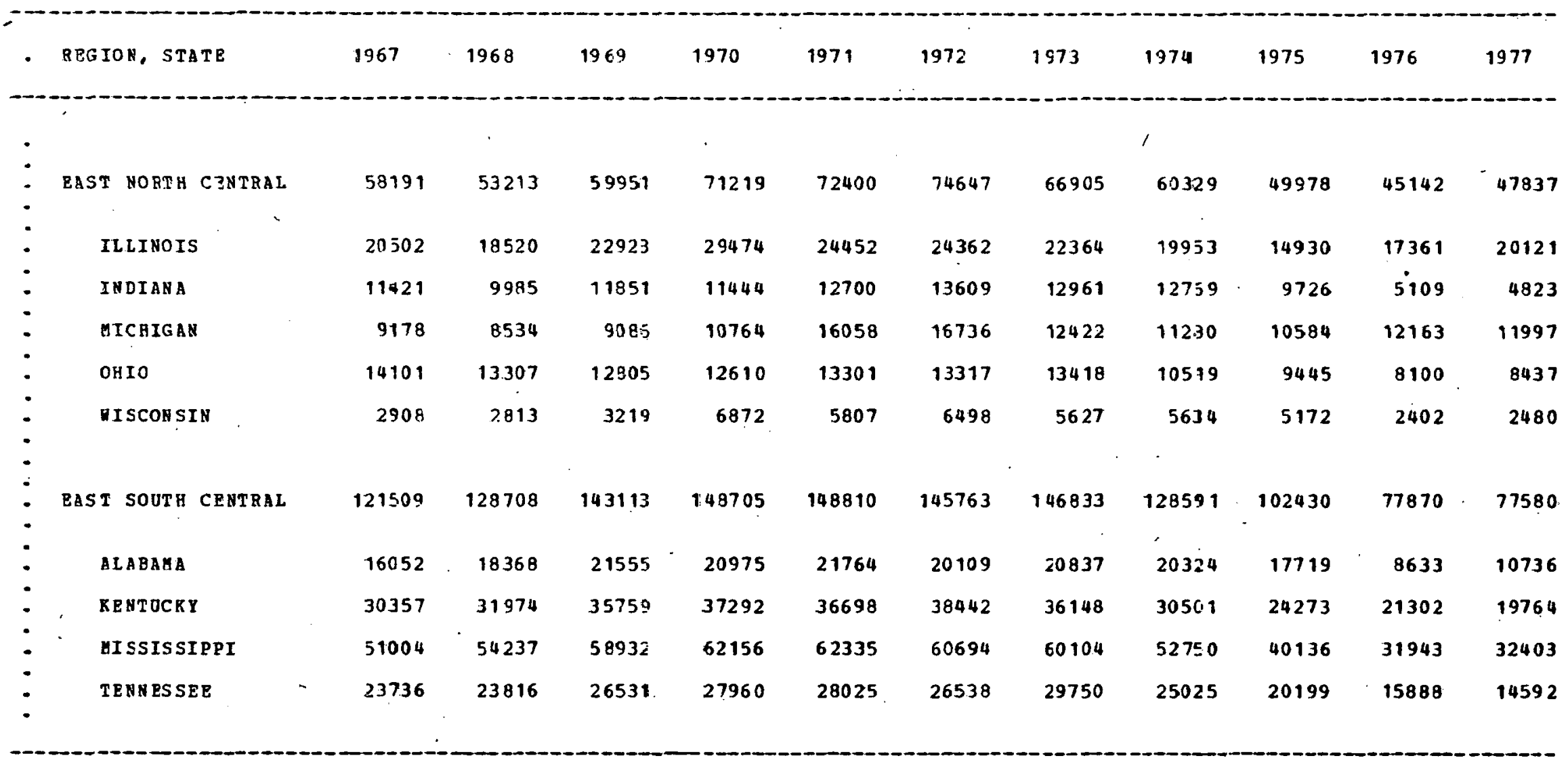


TABLE 10.20 -- NATURAL GAS PIPELINE BNERGY CONSOHPTION, BY STATE, 1967-77

(POUBTH IB A SERIES OP 5 PAGES)

BILLIONS Ò? BTU

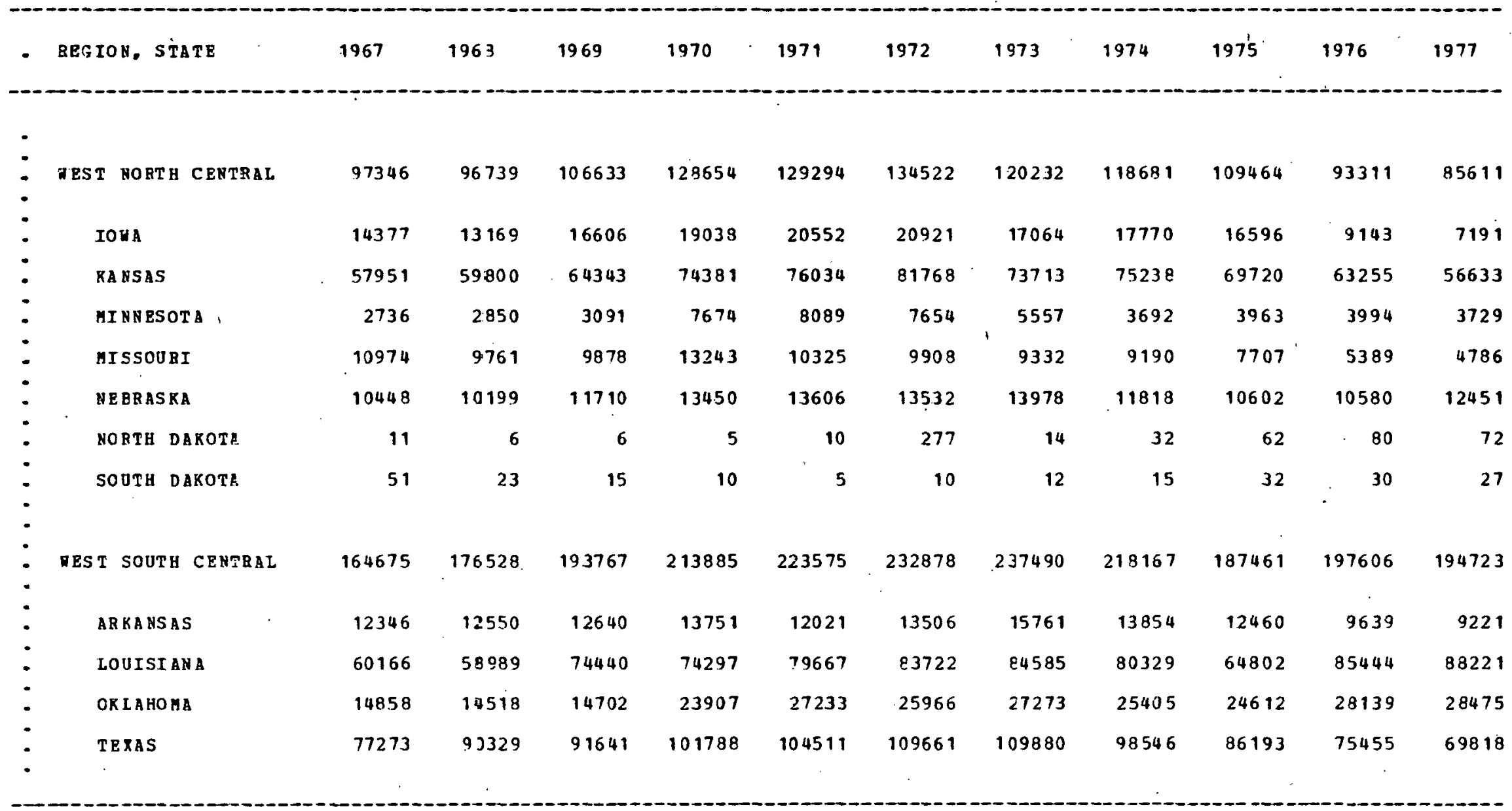

SOURCE: BETHOD 510

DATA QOALITY: 1 
TABLE $0.2 \mathrm{~F}$ - NATORAL 3AS PIPELIER BNEBGI CONSOHPTION, BY STATB, 1967-77 (FIPTH IN A SERIBS OP 5 PAGES)

BILLIONS OF BTU

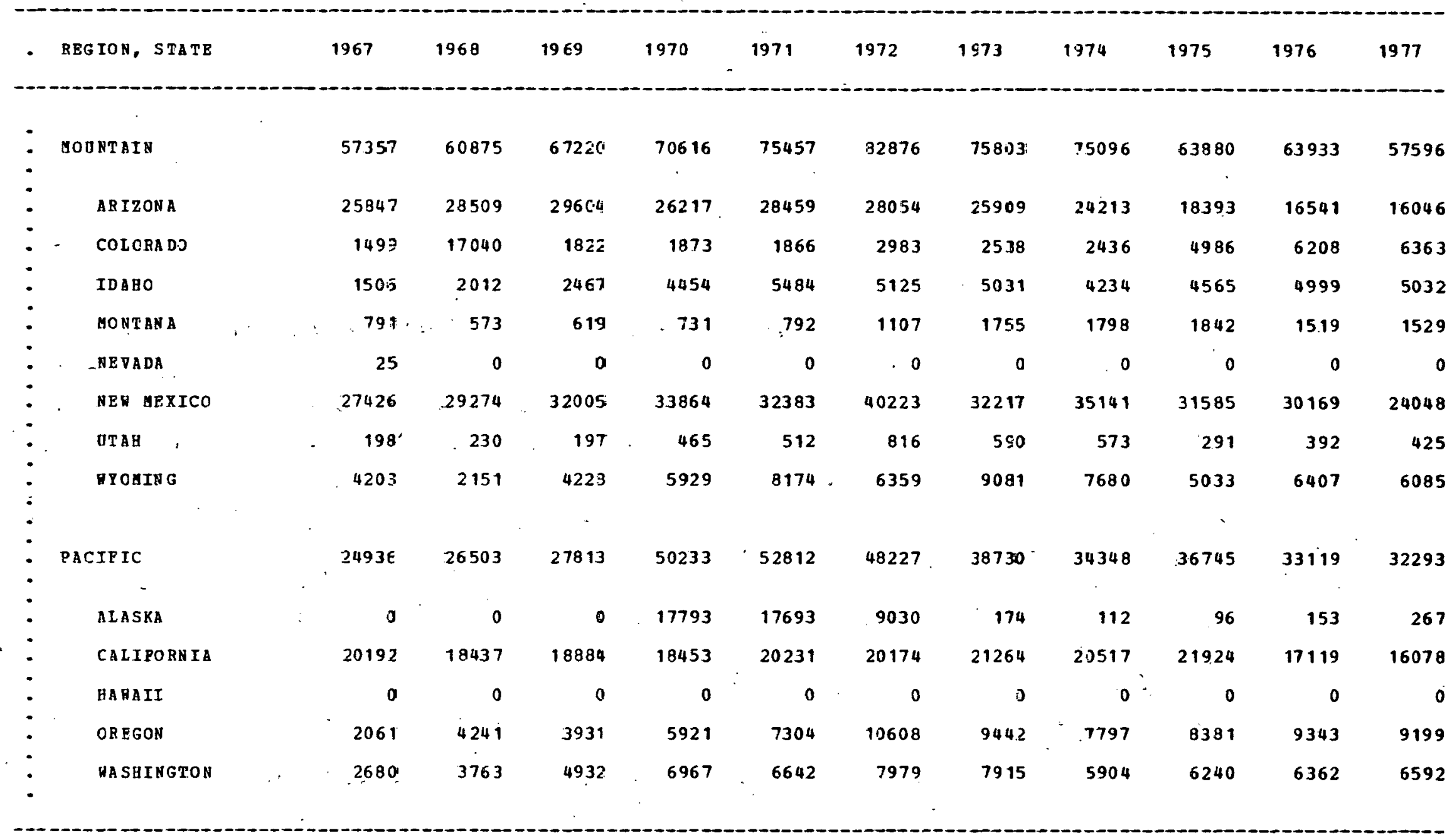


TABLE 10.3 -- LIQOIDS PIPELINE EIRCTRICITY AND EVERGY CONSUMPMION, BY OSE (SAPE ORDER-OP-MAGNITUDE ESTIMATES FOR EACH OF. THE YEARS 1967-76)

\begin{tabular}{|c|c|c|c|c|c|}
\hline & TOTAL & $\begin{array}{l}\text { CRODE OII } \\
\text { PIPELINES }\end{array}$ & $\begin{array}{l}\text { OII. PRCLUCT } \\
\text { PIPET.INES }\end{array}$ & $\begin{array}{c}\text { मATER } \\
\text { DISTRIBDIION }\end{array}$ & $\begin{array}{l}\text { CCAI SIURRY } \\
\text { DIPILINR }\end{array}$ \\
\hline $\begin{array}{l}\text { ELECTRICTY CONSUMPTICN, } \\
\text { MILLIONS OP KWH }\end{array}$ & 12708 & 4520 & 4350 & 3490 & 348 \\
\hline $\begin{array}{l}\text { FNERGY CONSUMPTION, } \\
\text { BILIIONS OF BTO }\end{array}$ & 43360 & 15420 & 14840 & 11910 & 1190 \\
\hline
\end{tabular}

NOTP: THE COAL SLOKRY ESTIMATE IS POB 1971-T6 ONLY.

SONZCE: METHOD 520

DATA QTALITY: 4 (OIL 8 WATER PIPELINES), 3 (COAI SIJJRY PIPELINE) 
TABLE 11.1 -- UILITARY PUEL AND ESBRGY OSE BY HIGḦAY MODES, 1967-77

FUEL CONSUYPTIOY IA THOOSA ADS OP BARRLS

ZOLLONED BY APPBOXI LATB EHERG COASOMPTIOA IA BILLICHS OP BTO

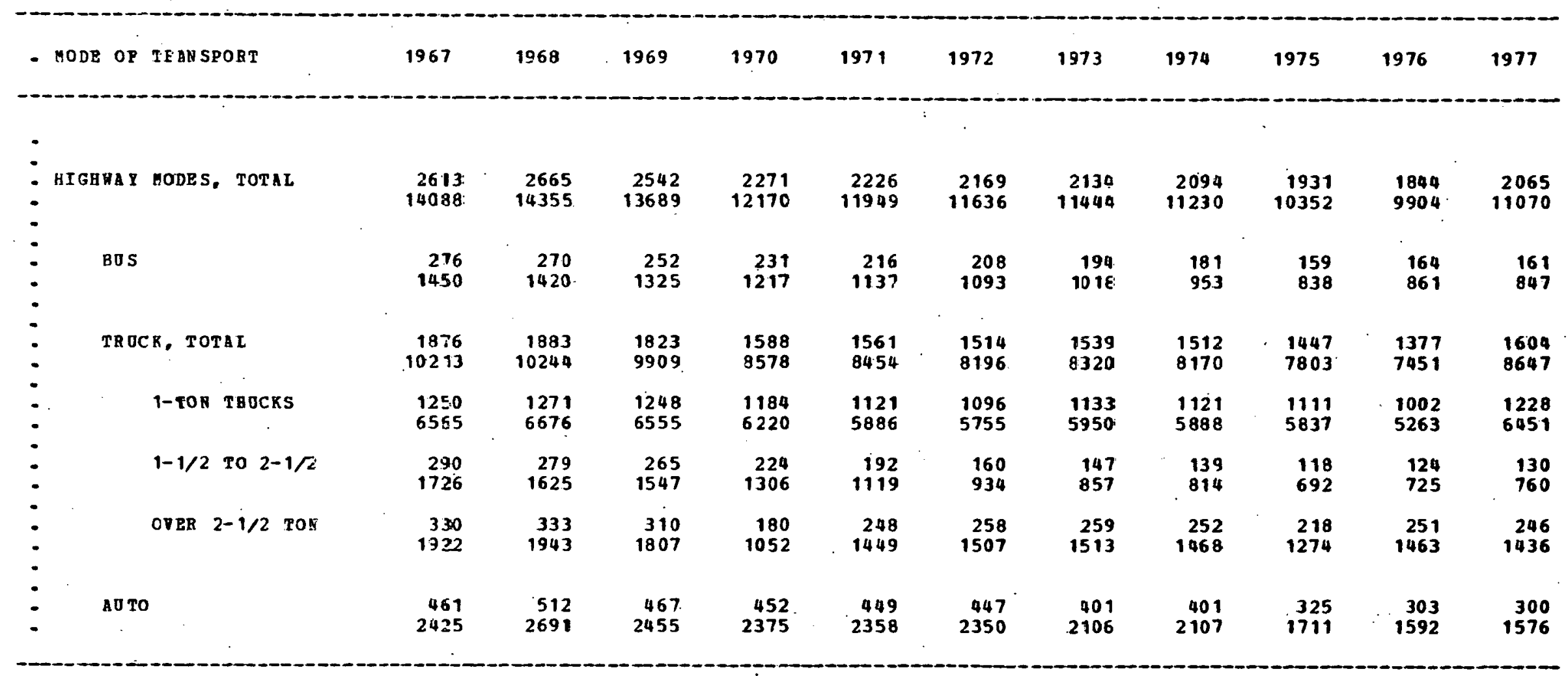

SOURCB: UETHOD 600

DATA QOALIT: 2 
TAELB 11.2A -- UILITARY POEL AND ENERGY CONSOUPTION, BY POEL BY STATE, 1975-77

(AIBCRAPT FUEL EXCLUDED) (PIBST IB A SERIES OP 5 TABLES)

POEL OSB IN THOUSANDS OF BARRELS, POLLOHED BY ENERGY USE IN BILLIONS OP BTO

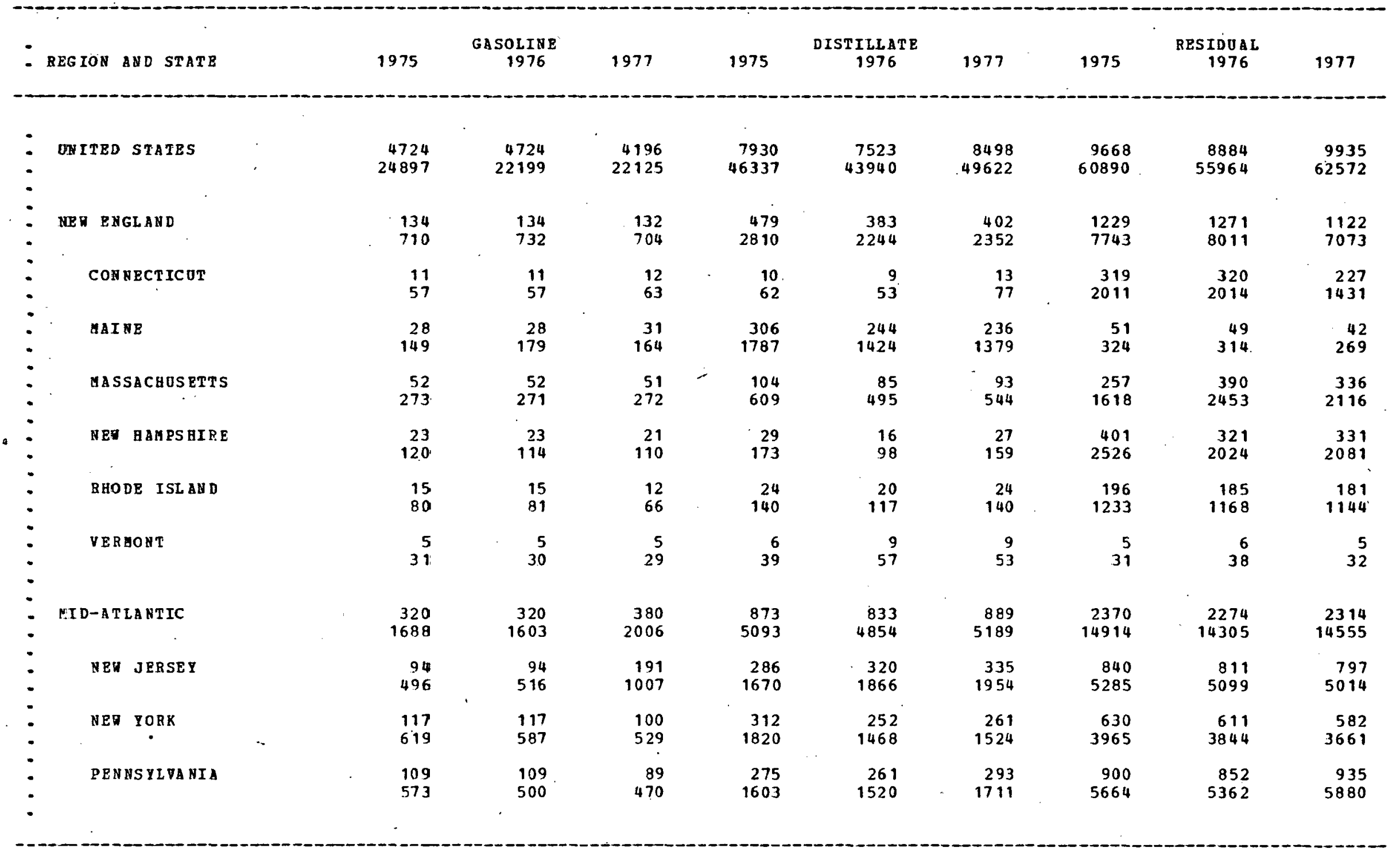




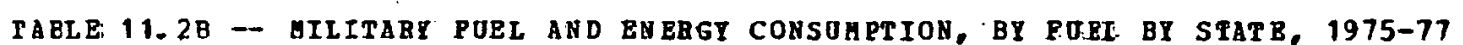

(AIRCRAPT POBL. ERCLUDED) (SBCOND IN A SERIES O.F 5 TABLES)

FUEL USE I THODSA ADS OP BABRLS, FOLLOED BY ENBRGY OSE IY BILLIOAS OP BTU

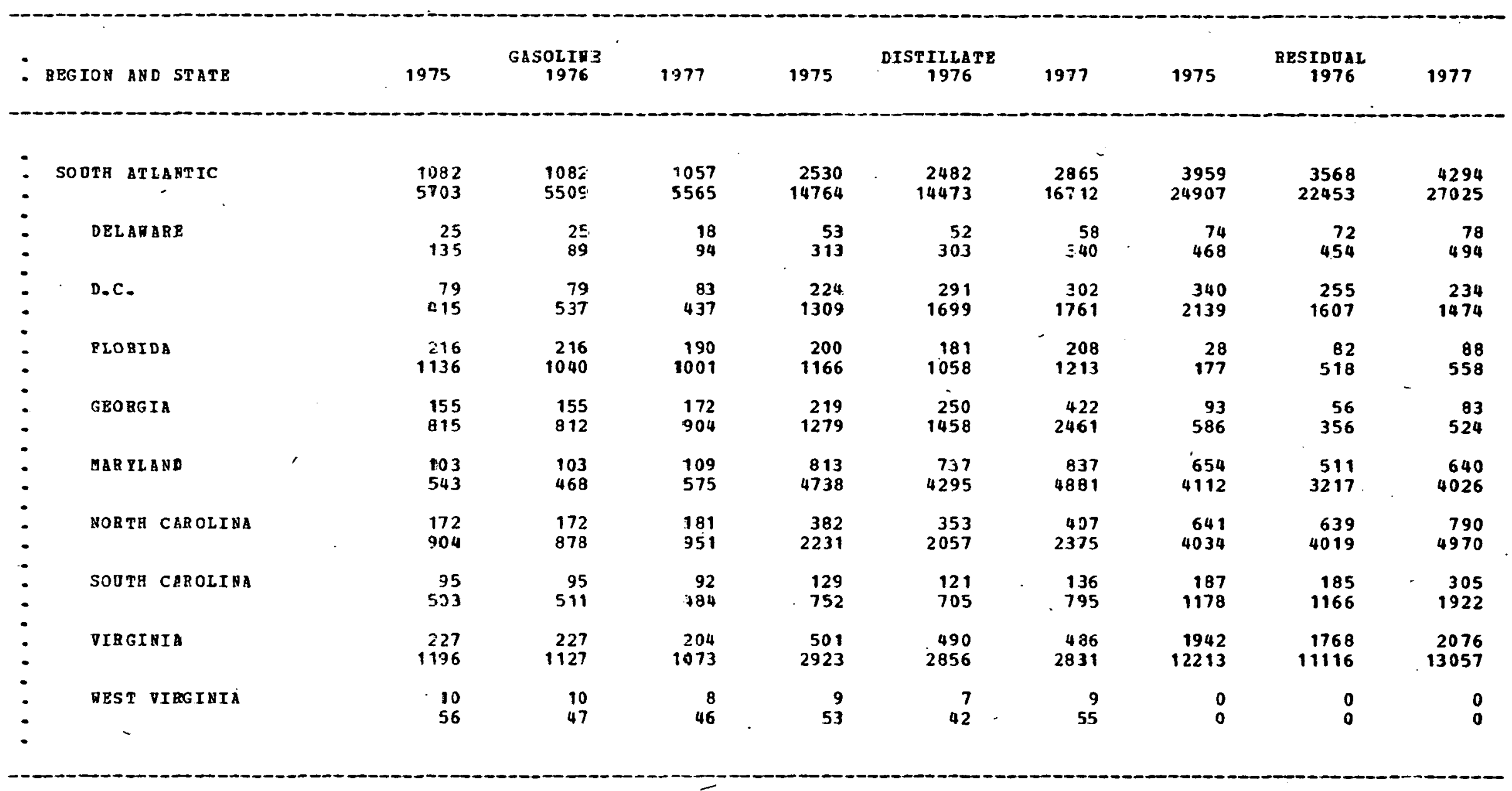


TABLE 11.2C -- MIITABY FUEL AND BNERGY CONSUEFTION, BY PURL BY STATE, 1975-77

(AIRCBAPT PUEL EXCLUDED) (TAIRD IN A SBRIES OP 5 TABLES)

POEL OSE IN THOOSANDS OF BARRELS, POLLORED BY EHERGY TSE IN BILLIONS O.F BTO

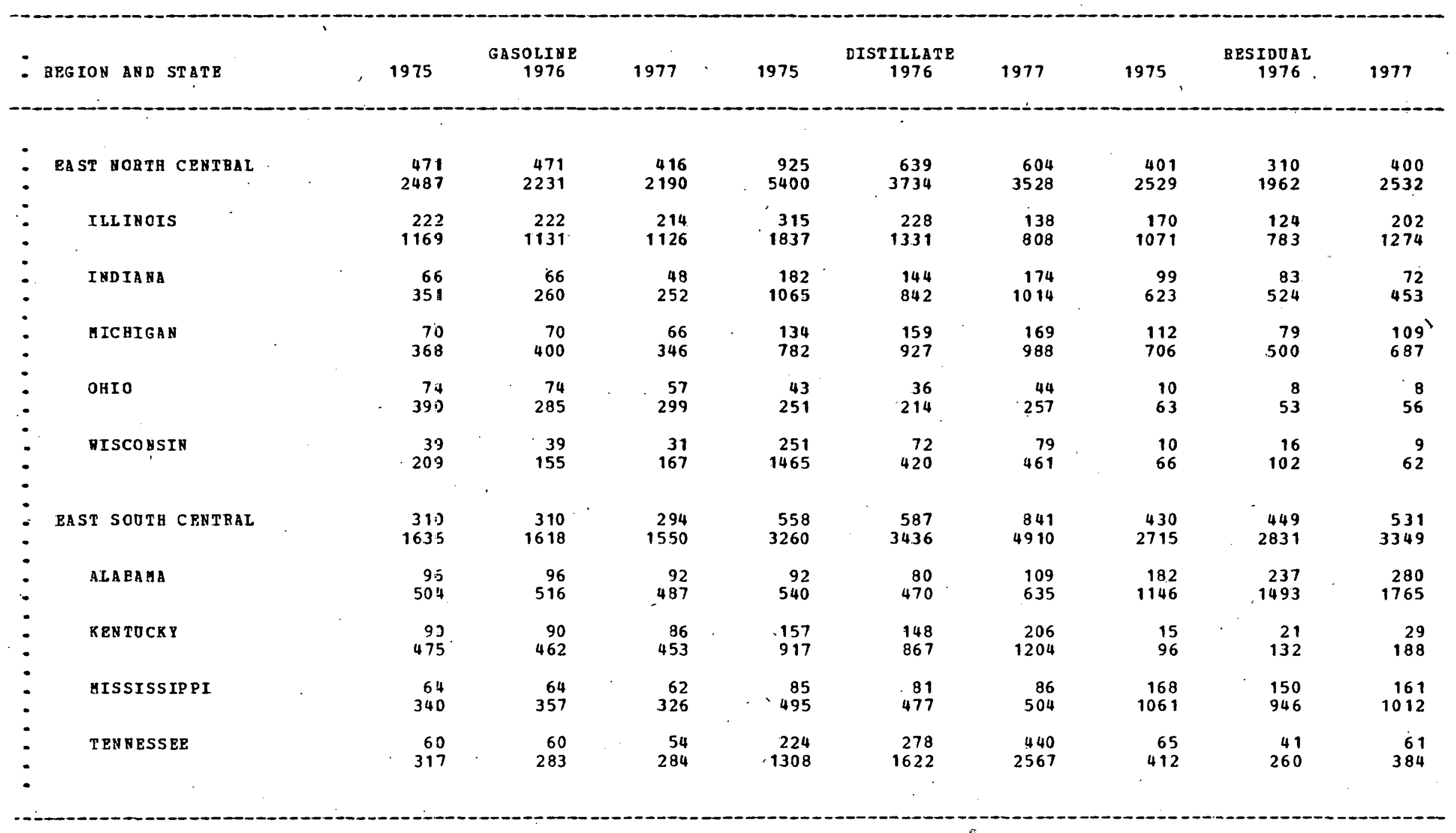


TABLB 11.2D -- UILITARY PJEL AND BUERG CONSOGPTON, BY FOEL BY STATE, 1975-77

(AIRCRAFT PUEL EXCLUDED) (FOURTH IV A SERTBS OE 5 TABLES)

FOEL OSE IQ THOUSANDS CP BARREL, ROLLOMBD BI ENERGY OSE ]N EILLTONS OF BTO

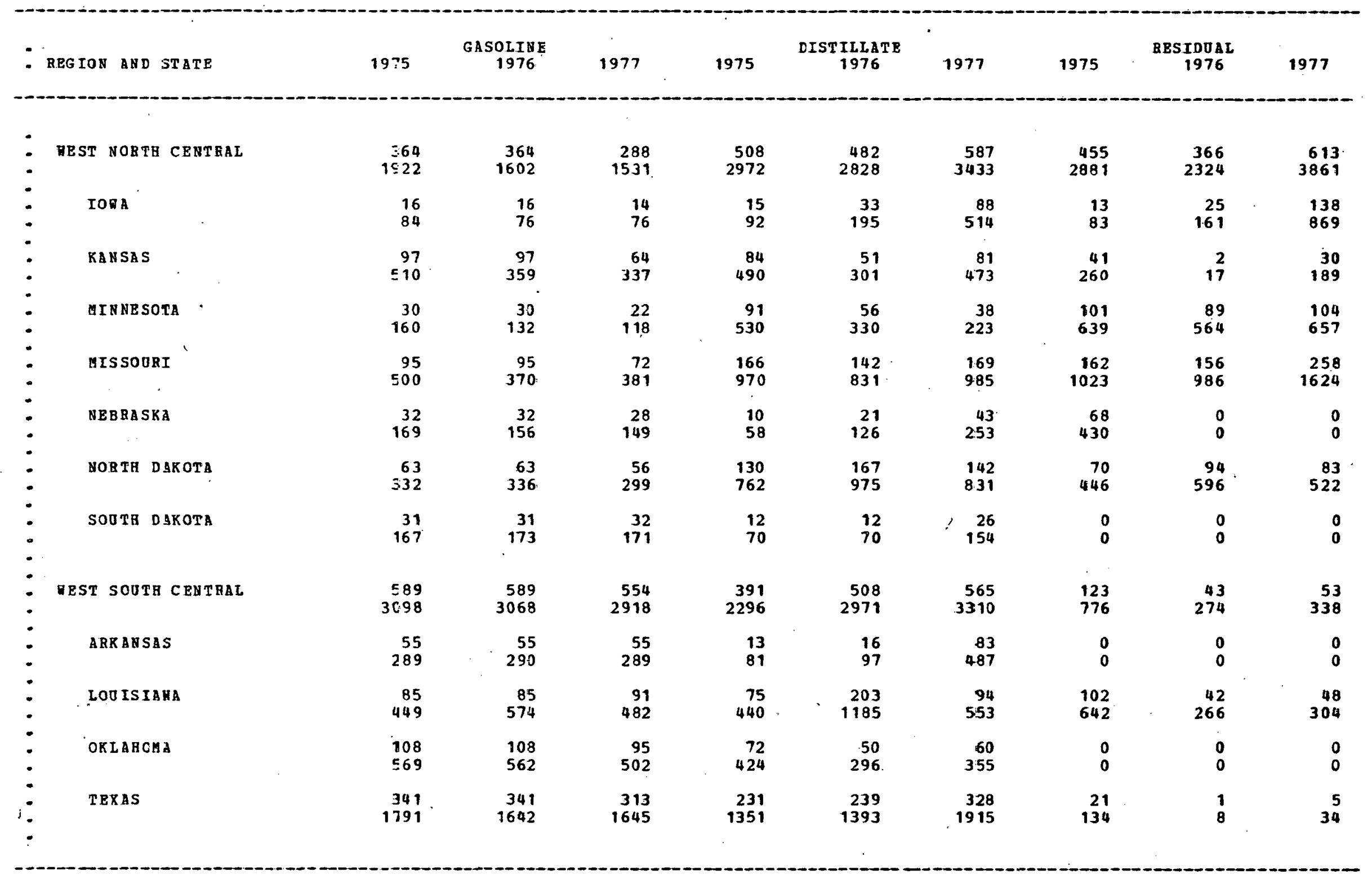


TAELE 11. 2E - GILITARY POEL A ND ENERGY CONSUHFTIOH, BY POEL BY STATE, 1975-77 (AIRCBAPT POBL BXCLODED) (IAST IN A SERIES OP 5 TABLES)

PUEL OSE IE THOOSANDS OP BARRELS, POLLONED BY ENRBGT USB IA BILL IOHS OP BTD

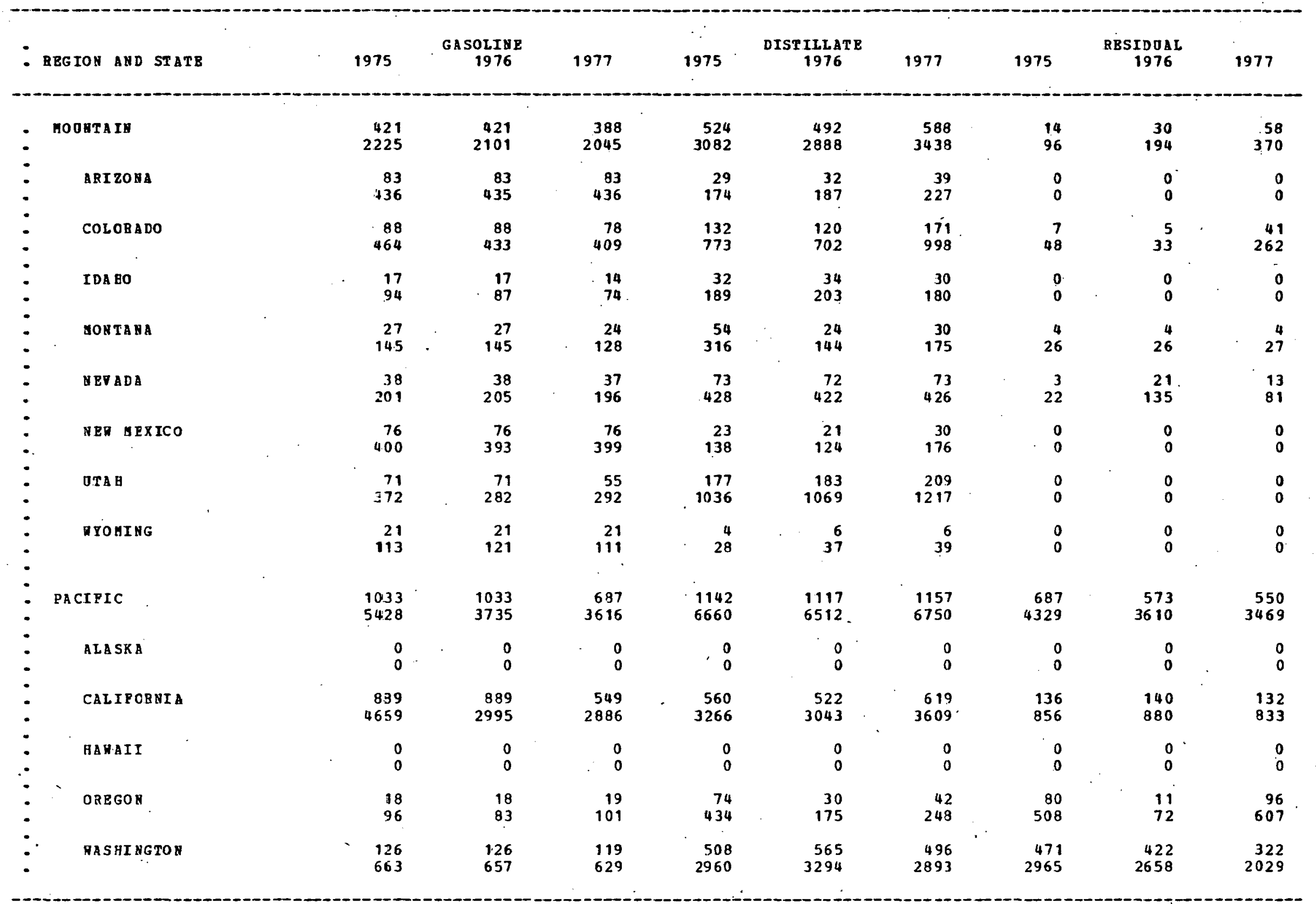


TLBLE 11.3 -- BILITAB CONSOAPTION OP JET POBL, BY TYPE JP PERL, 1975-77

POEL CONSUAPTIOA IA THOUSAHDS OP BARBELS FOLLONEL EY ENEBGY COASUHETION IN BILLIONS OE ETU

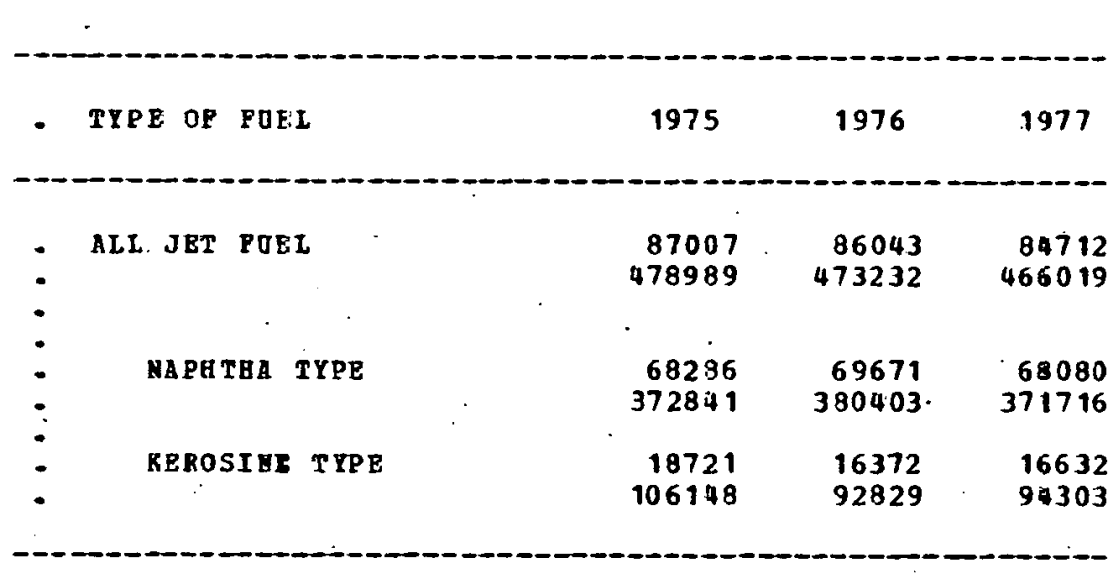

SOURCE: EETHOD 600

DATA. QUALITY: - 2 
(For use in ordering EIA Publications only - Read Ordering Information Section before cornpleting forın.) SEND ORDER FORM TO: Superintendent of Documents, U.S. Government Printing Office, Washington, D.C., 20402

Enclosed is $\$ \square \square$ Check

$\square$ Money order, or clarge to my Deposit Account No.

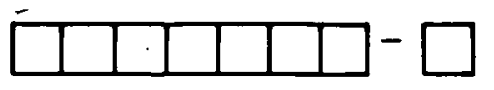

Order No.

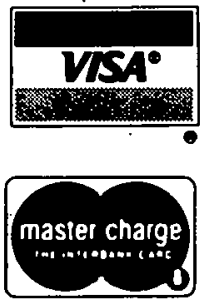

NAME AND ADDRESS

\section{PLEASE PRINT OR TYPE}

$\cdot$

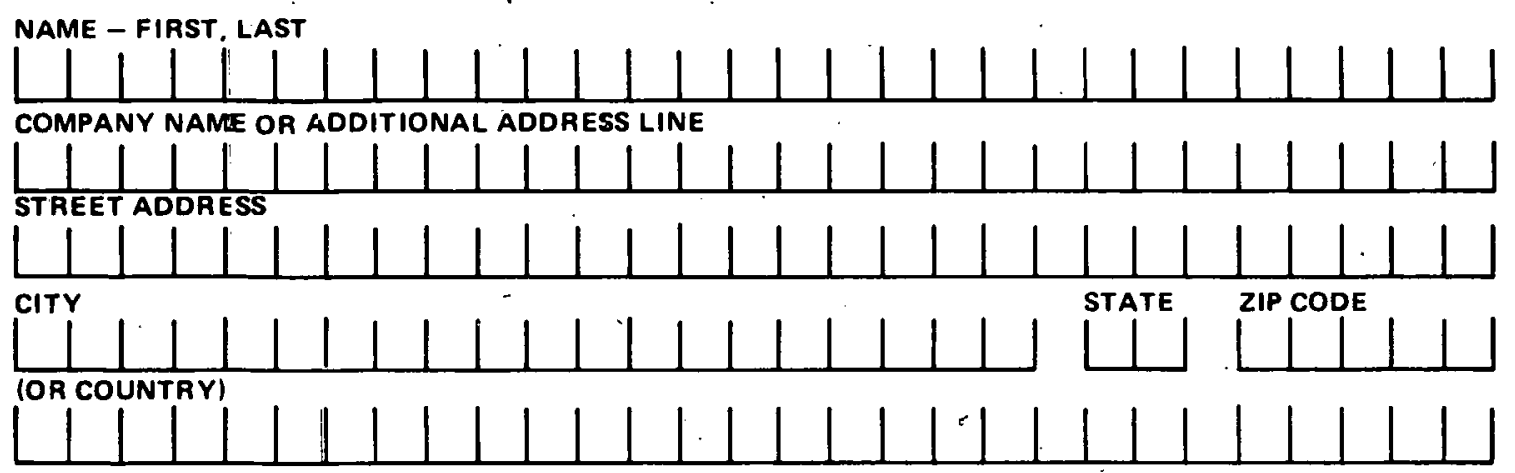

PLEASE PRINT OR TYPE THE GPO STOCK NO. OF SINGLE ISSUES OR ANNUALS YOU WISH TO RECEIVE:

\section{Credit Card Orders Only}

Total charges $\$$ Fill in the boxes below

Credit Card No.

Expiration Date Month/Year

\begin{tabular}{l|l|l|l|l|l}
\hline & & & $\square$ \\
\end{tabular} VISA $\square$ Master Charge

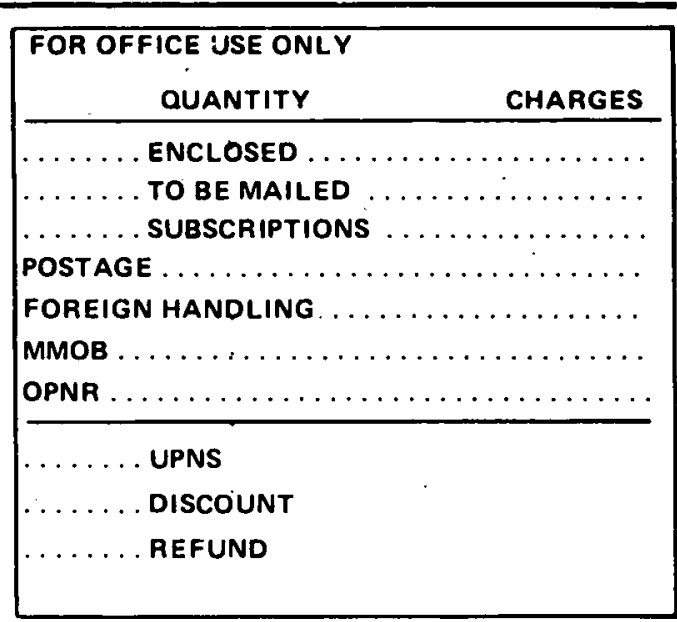

